March 2003 - NREL/TP-510-33123

\title{
Biopower Technical Assessment: State of the Industry and Technology
}

R.L. Bain and W.A. Amos

National Renewable Energy Laboratory

M. Downing and R.L. Perlack

Oak Ridge National Laboratory

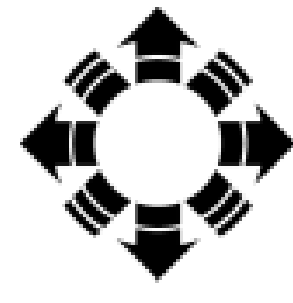

NPEI

National Renewable Energy Laboratory

1617 Cole Boulevard

Golden, Colorado 80401-3393

NREL is a U.S. Department of Energy Laboratory

Operated by Midwest Research Institute • Battelle • Bechtel

Contract No. DE-AC36-99-G010337 


\section{BIOPOWER TECHNICAL ASSESSMENT State of the Industry and the Technology}

March 2003

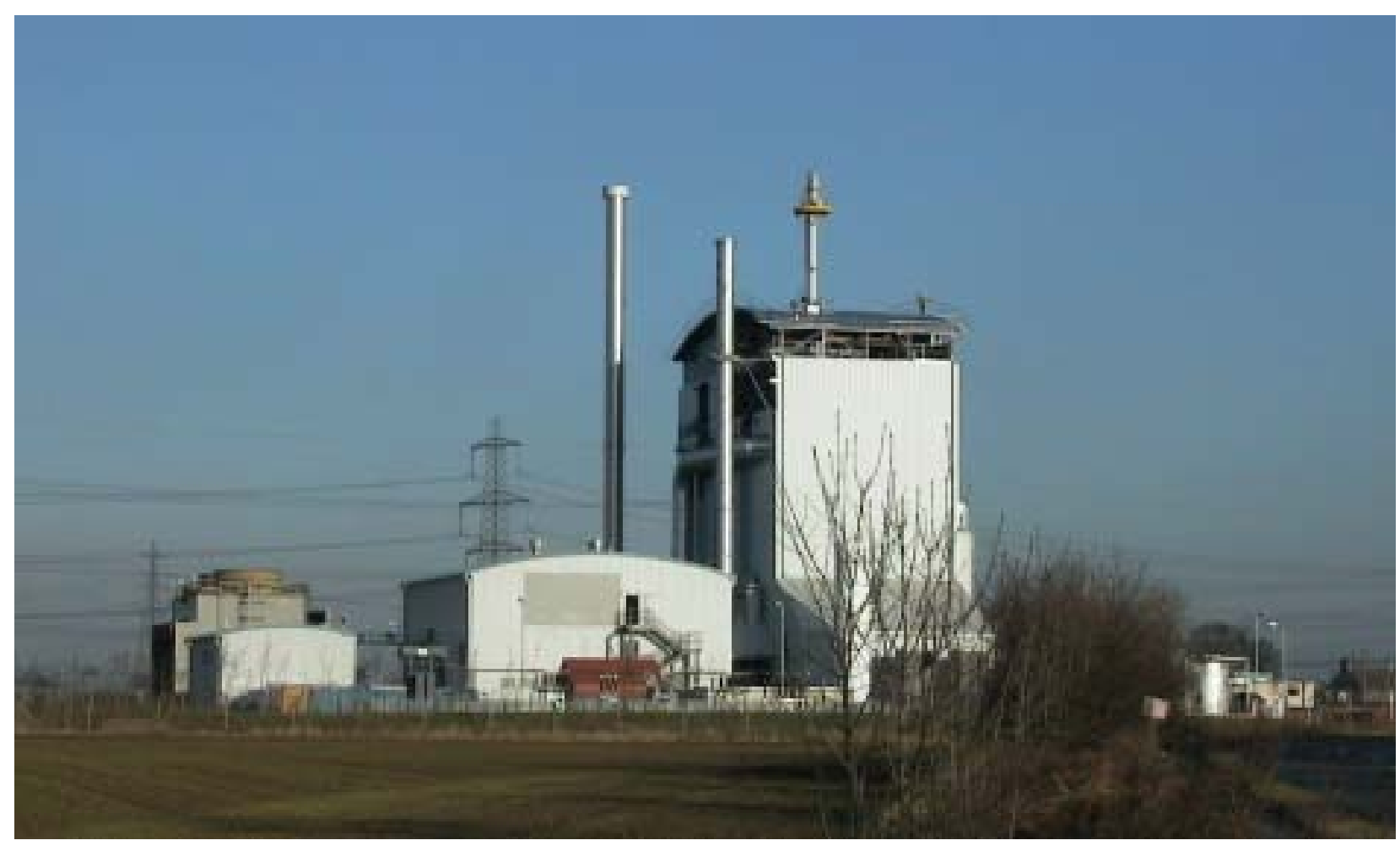

Richard L. Bain and Wade A. Amos

National Renewable Energy Laboratory, Golden, Colorado

Mark Downing and Robert L. Perlack

Oak Ridge National Laboratory, Oak Ridge, Tennessee

Prepared under Task No. BBB3.6110
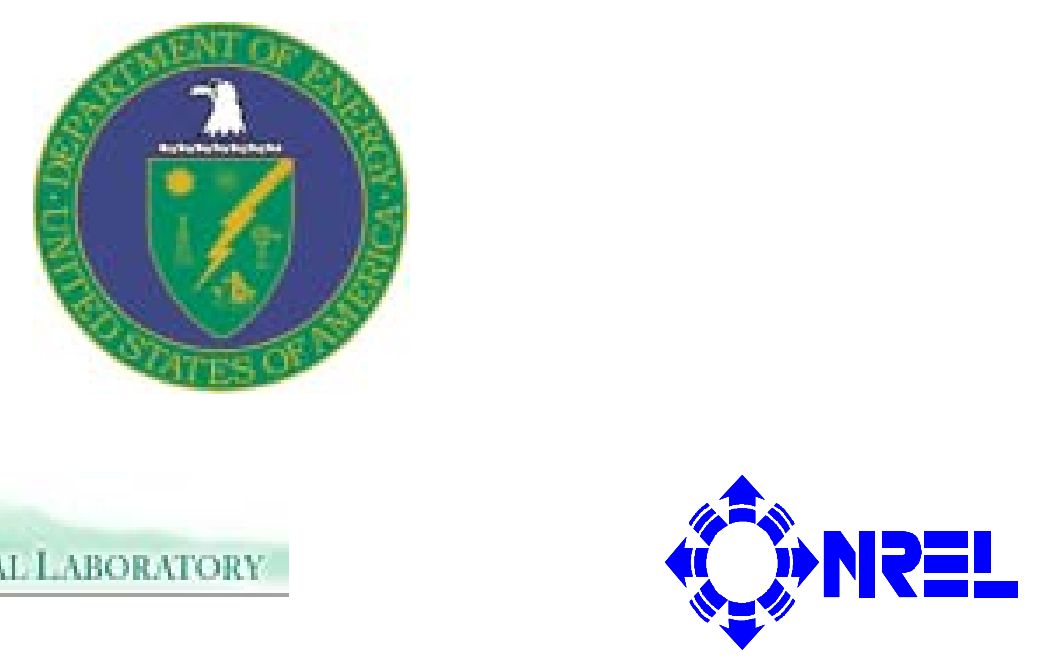


\section{NOTICE}

This report was prepared as an account of work sponsored by an agency of the United States government. Neither the United States government nor any agency thereof, nor any of their employees, makes any warranty, express or implied, or assumes any legal liability or responsibility for the accuracy, completeness, or usefulness of any information, apparatus, product, or process disclosed, or represents that its use would not infringe privately owned rights. Reference herein to any specific commercial product, process, or service by trade name, trademark, manufacturer, or otherwise does not necessarily constitute or imply its endorsement, recommendation, or favoring by the United States government or any agency thereof. The views and opinions of authors expressed herein do not necessarily state or reflect those of the United States government or any agency thereof.

Available electronically at http://www.osti.gov/bridge

Available for a processing fee to U.S. Department of Energy and its contractors, in paper, from:

U.S. Department of Energy

Office of Scientific and Technical Information

P.O. Box 62

Oak Ridge, TN 37831-0062

phone: 865.576 .8401

fax: 865.576.5728

email: reports@adonis.osti.gov

Available for sale to the public, in paper, from:

U.S. Department of Commerce

National Technical Information Service

5285 Port Royal Road

Springfield, VA 22161

phone: 800.553.6847

fax: 703.605.6900

email: orders@ntis.fedworld.gov

online ordering: http://www.ntis.gov/ordering.htm 


\section{Acknowledgments}

A significant portion of this study is excerpted from studies previously funded by the Department of Energy. The authors wish acknowledge the efforts of the authors of these studies in performing background research and preparing the reports that are so useful in this technical assessment.
Chapter
Source
Authors

2: Barriers

“2001 EERE Strategic Program Review”

Raymond Costello, DOE

Paul Grabowski, DOE

Other?

4: Lessons Learned

"Biomass Energy Production in California: The Case for a Biomass Policy Initiative"

Gregory Morris, Future Resources Associates, Inc.

4: Lessons Learned

"Lessons Learned from Existing Biomass Power Plants"

George Wiltsee, Appel Consultants, Inc.

5: Technology

"Renewable Energy Technology

Kevin Craig, NREL

Characterizations

Characterizations"

Kevin Comer, Antares Group

6: Environmental

"Green Power Fact Sheets"

Ask MM

Performance

6: Environmental

"A Comparison of the Environmental

Margaret Mann, NREL

Performance

Consequences of Power from Biomass, Coal, and Natural Gas"

7: Policy

"Biomass and Bioenergy in the United States"

7: Policy

"Incentives, Mandates, and Government

Programs for Promoting Renewable Energy"

Helena Chum, NREL Ralph P. Overend, NREL

Mark Gielecki, DOE-EIA

Fred Mayes, DOE-EIA

Lawrence Prete, DOE-EIA 


\section{CONTENTS}

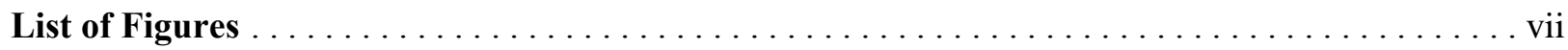

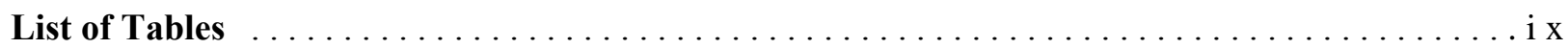

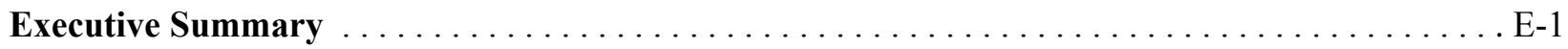

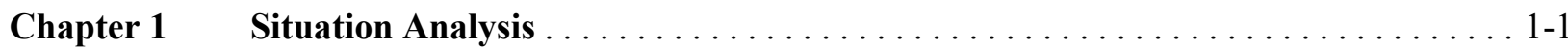

\section{Chapter 2 Barriers}

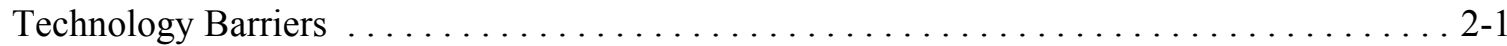

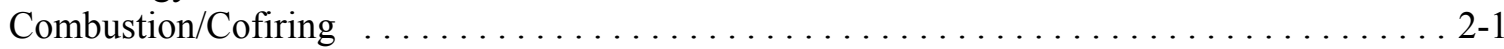

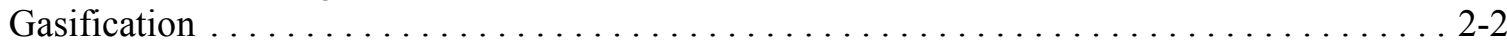

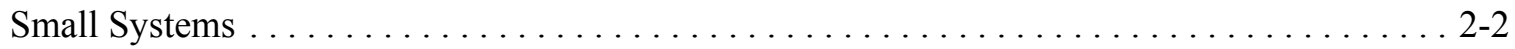

Feedstock Production Harvest and Preparation $\ldots \ldots \ldots \ldots \ldots \ldots \ldots \ldots \ldots \ldots \ldots .2$

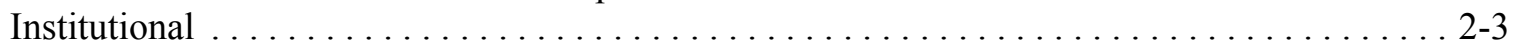

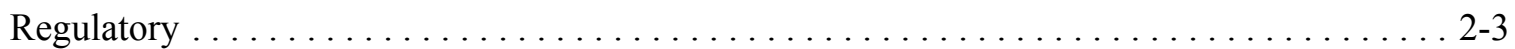

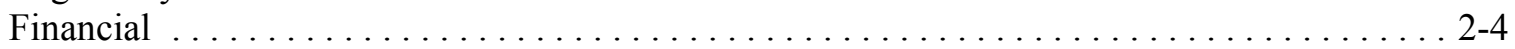

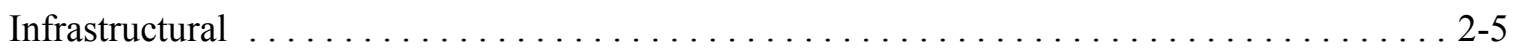

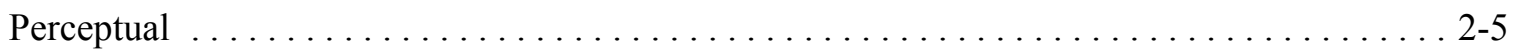

\section{Chapter 3 Feedstock Supply}

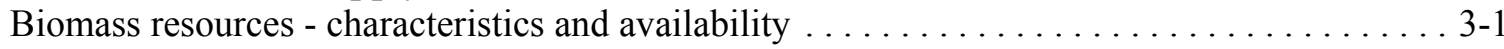

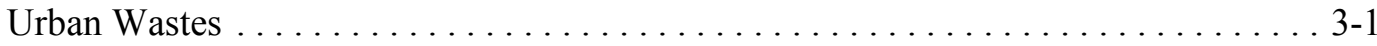

Mill residues . . . . . . . . . . . . . . . . . . . . . . . .

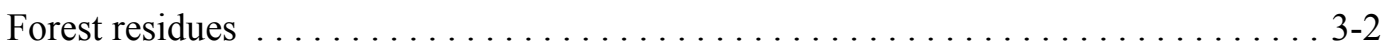

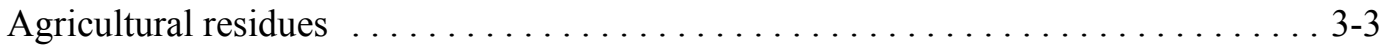

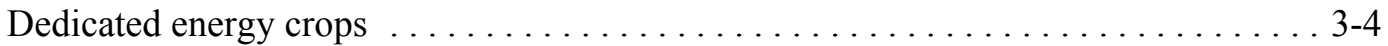

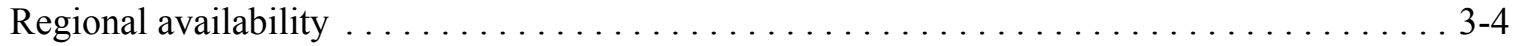

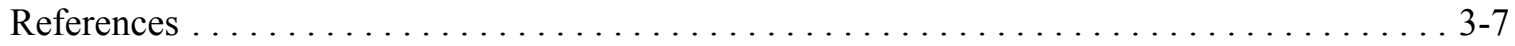

\section{Chapter 4 Lessons Learned}

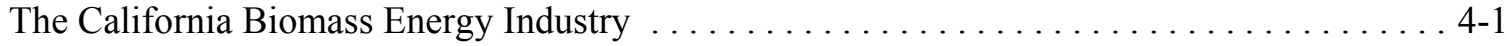

Development of the California Biomass Energy Industry $\ldots \ldots \ldots \ldots \ldots \ldots \ldots .4-1$

The 1980s: Decade of Growth . . . . . . . . . . . . . . . . . . . . . . 4-1

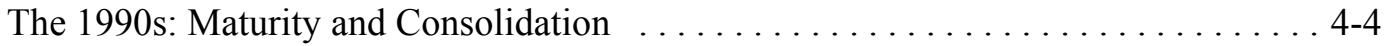

Characteristics of California's Biomass Power Plants . . . . . . . . . . . . . 4-9

Fuel Use and Alternative Disposal Options For Biomass Residues in California . . . . 4-9

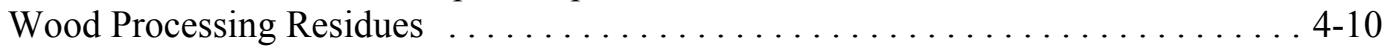

In-Forest Residues . . . . . . . . . . . . . . . . . . . . . . . . 4-11

Agricultural Residues . . . . . . . . . . . . . . . . . . . . . . 4-12

Urban Wood Residues ....... . . . . . . . . . . . . . . . . . . . . . . . 4-13

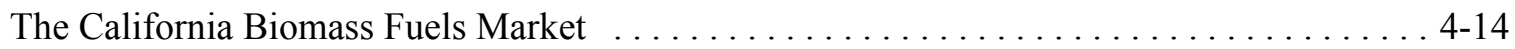

Biomass Fuel Market Price Trends . . . . . . . . . . . . . . . . 4-16

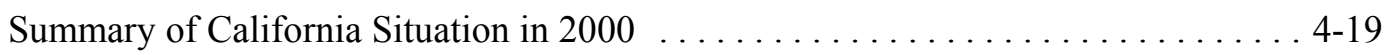

2002 Update on California Biomass Power Industry . . . . . . . . . . . . . 4-20

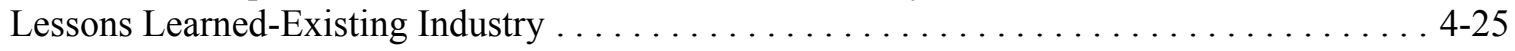

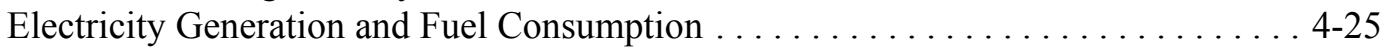

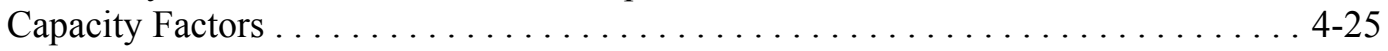




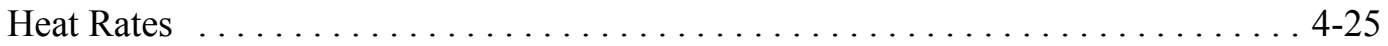

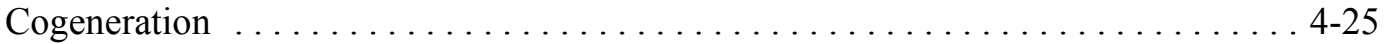

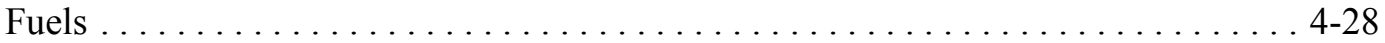

Lessons Learned ............................... 4-28

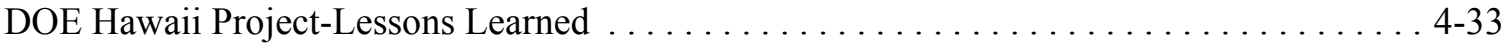

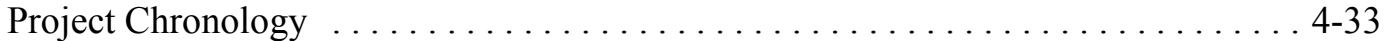

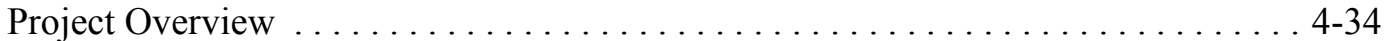

PICHTR - Phase I . . . . . . . . . . . . . . . . . . . . . 45

Westinghouse Electric Corporation Technology Validation Phase . . . . . . . . . . 4-37

Status ................................... 4-41

Summary of Lessons Learned $\ldots \ldots \ldots \ldots \ldots \ldots \ldots \ldots \ldots \ldots \ldots \ldots \ldots \ldots . \ldots \ldots \ldots \ldots$

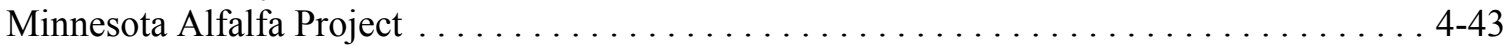

Summary of Lessons Learned : Minnesota Agri-Power Project . . . . . . . . . . . . . . 4-44

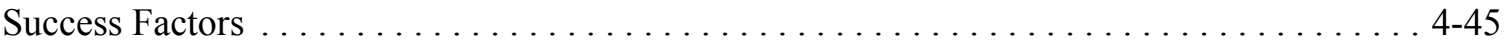

References ..................................... 4-50

\section{Chapter 5 Technology Case Studies}

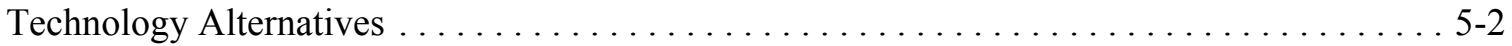

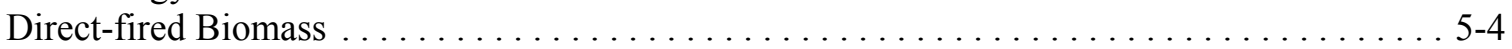

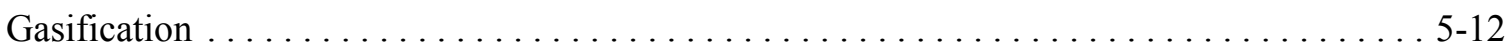

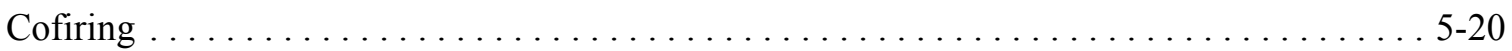

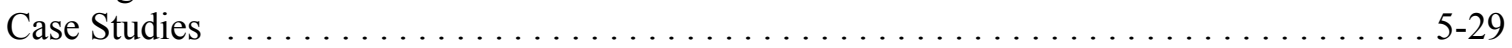

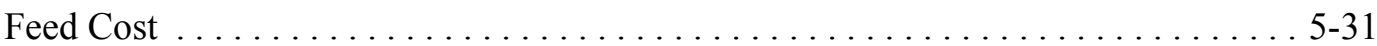

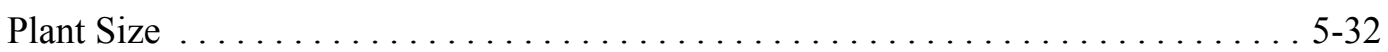

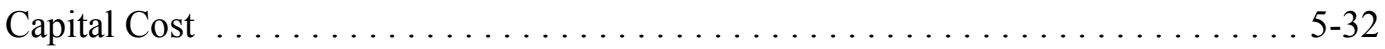

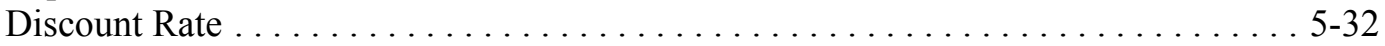

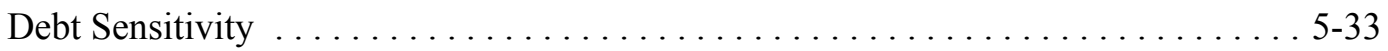

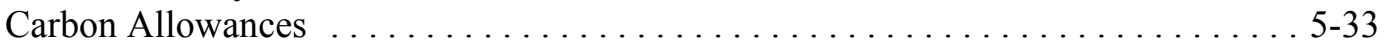

Tax Credits ........................... 5-33

Steam Only ........................... 5-34

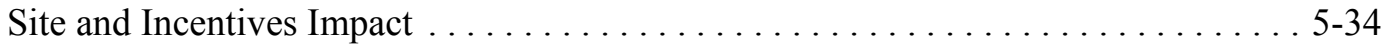

Capital Requirements and Required Cash Flow ................... . 5-34

Recommendations for Further Work . . . . . . . . . . . . . . . . . . 5-34

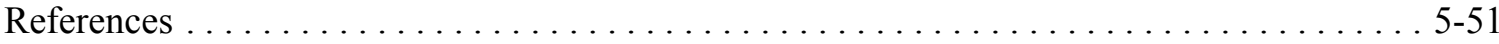

\section{Chapter 6 Environmental Performance}

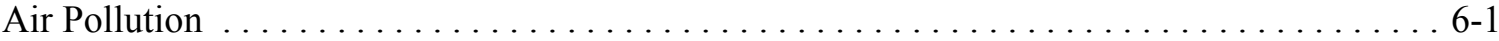

Life Cycle Analysis . . . . . . . . . . . . . . . . . . . . . . .

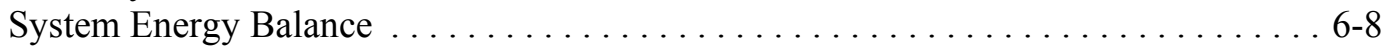

Global Warming Potential ............................6-11

Air Emissions . . . . . . . . . . . . . . . . . . . . . . . . . . . . 6-12

Resource Consumption ............................ 6-12

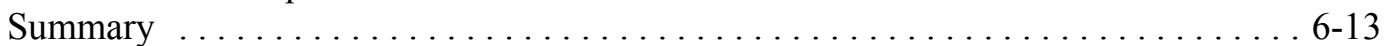

\section{Chapter 7 Policy}

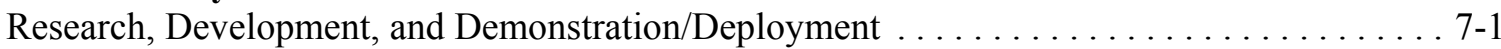

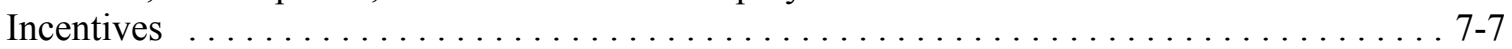

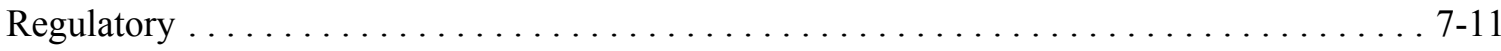




\section{Appendices}

1. Biomass Feedstock Availability in the United States. . . . . . . . . . . . . . A1

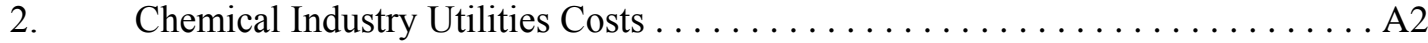

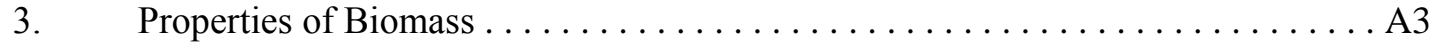

4. Wood Residue Combustion in Boilers ..................... A4 


\section{List of Figures}

\section{Chapter 1 Situation Analysis}

1. 1999 Renewable Electricity Generation Energy $\ldots \ldots \ldots \ldots \ldots \ldots \ldots \ldots \ldots \ldots \ldots \ldots 1-1$

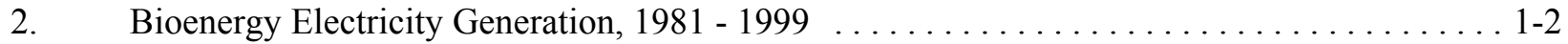

\section{Chapter 3 Feedstock Supply}

1. Total U.S. Biomass Resources at Selected Prices $\ldots \ldots \ldots \ldots \ldots \ldots \ldots \ldots \ldots \ldots \ldots$

\section{Chapter 4 Lessons Learned}

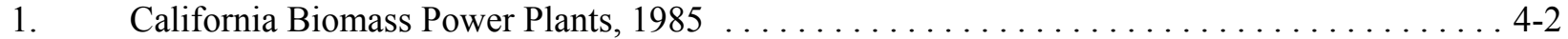

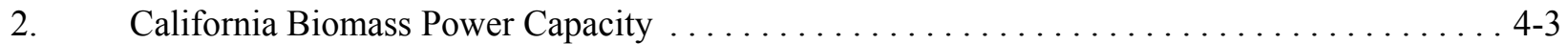

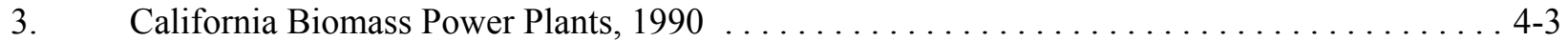

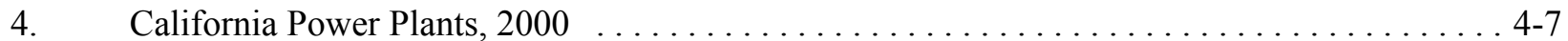

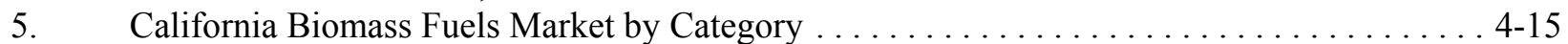

6. California Biomass Fuels Market . . . . . . . . . . . . . . . . . . . . . . . . . . . 4-17

7. California Biomass Fuel Supply Curve, 1986 - 2000 . . . . . . . . . . . . . . . . . . . . . . . 4-18

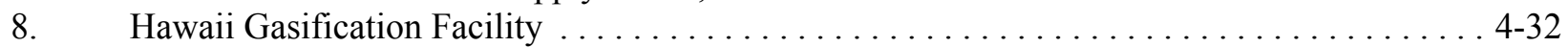

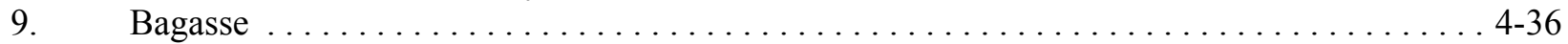

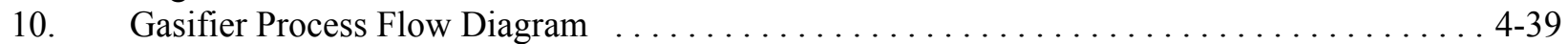

11. Hot Gas Filter Unit . . . . . . . . . . . . . . . . . . . . . . . . . . . . . . . . . . . . . 4 4-41

\section{Chapter 5 Technology Case Studies}

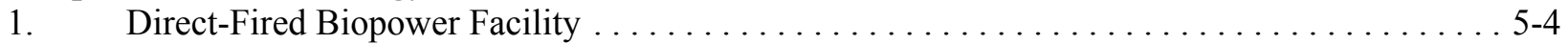

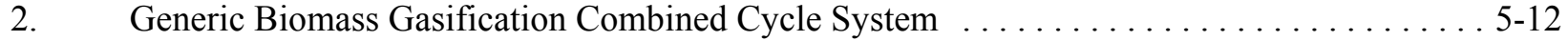

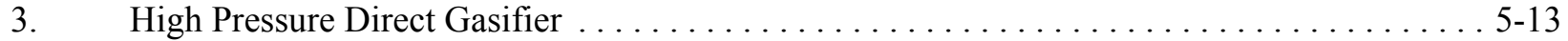

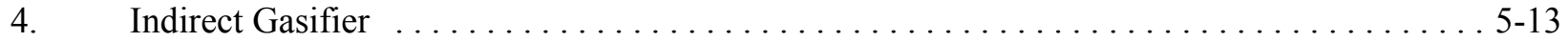

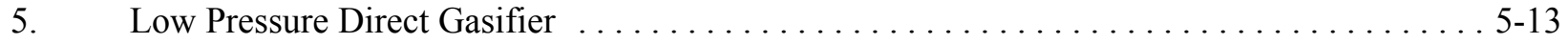

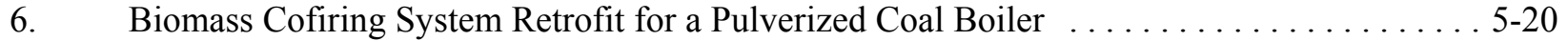

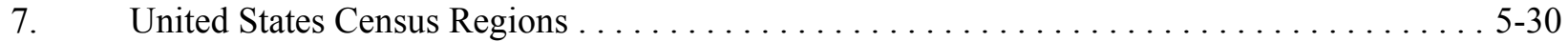

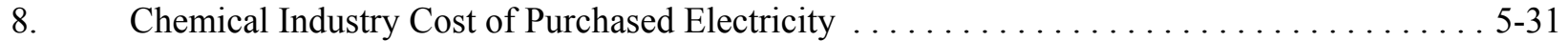

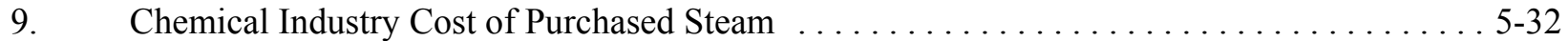

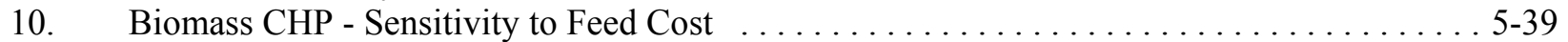

11. Biomass CHP - Effect of Plant Size on Cost of Electricity and Steam . . . . . . . . . . . . 5-40

12. Biomass CHP - Sensitivity to Capital Cost . . . . . . . . . . . . . . . . . . . . . . . . . 5-41

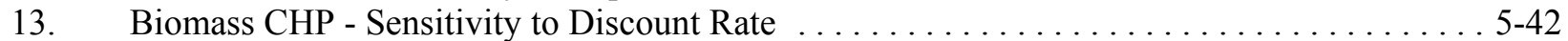

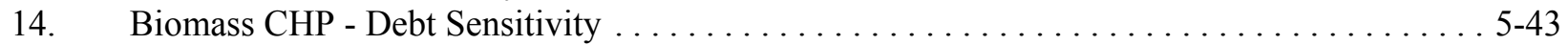

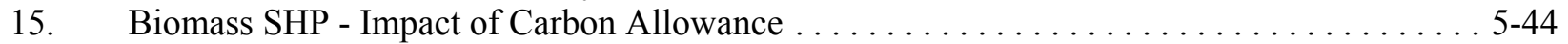

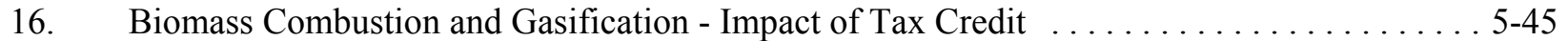

17. Biomass Cofiring CHP Incremental Costs, Impact of Tax Credit . . . . . . . . . . . . . . 5-46

18. Biomass Cofiring CHP - Effect of Tax Credit on Return on Investment, Corporate Basis . . 5-47

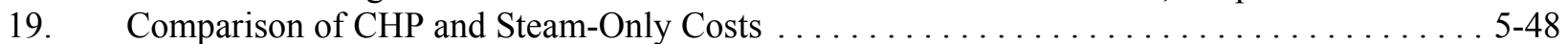

20. Gasification CHP - Site Impact with Incentives . . . . . . . . . . . . . . . . . . . . . 5-49

\section{Chapter 6 Environmental Performance}

1. $\quad \mathrm{NO}_{\mathrm{x}}$ Emissions - Life Cycle Total and Plant Operating Emissions $\ldots \ldots \ldots \ldots \ldots \ldots .6 .6$

2. Biomass Combustion - Comparison of $\mathrm{NO}_{\mathrm{x}}$ Emissions to 2001 Texas DG Standard ..... 6-5

3. Biomass Combustion - Potential for $\mathrm{NO}_{x}$ Reduction $\ldots \ldots \ldots \ldots \ldots \ldots \ldots \ldots \ldots \ldots$

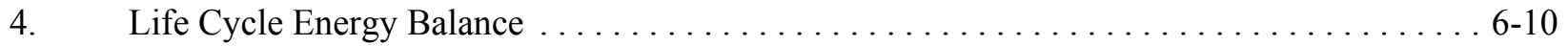

5. Net Life Cycle Greenhouse Gas Emissions $\ldots \ldots \ldots \ldots \ldots \ldots \ldots \ldots \ldots \ldots \ldots \ldots \ldots \ldots \ldots$ 


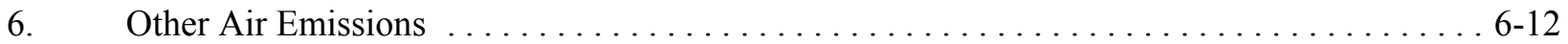

7. Resource Consumption ............................... 6-13

\section{Chapter 7 Policy}

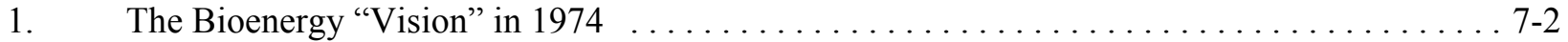

2. United States Appropriations for Energy R\&D $1978-1998 \ldots \ldots \ldots \ldots \ldots \ldots \ldots \ldots \ldots \ldots$. . . . . . . .

3. United States Appropriations for Renewable Energy R\&D $1978-1998 \ldots \ldots \ldots \ldots \ldots \ldots \ldots$. . . . . .

4. United States Appropriations for Energy Efficiency R\&D 1978 - $1998 \ldots \ldots \ldots \ldots \ldots \ldots$. . . . . .

5. United States Appropriations for Fossil Energy R\&D $1978-1998 \ldots \ldots \ldots \ldots \ldots \ldots \ldots \ldots$. . . . . .

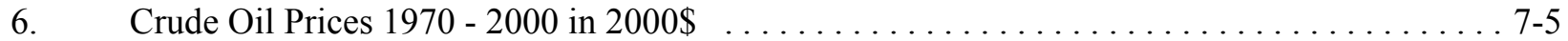




\section{List of Tables}

\section{Chapter 3 Feedstock Supply}

1. Estimated Biomass Resources Available by State and Price $\ldots \ldots \ldots \ldots \ldots \ldots \ldots \ldots$. . . . . . . . . . .

\section{Chapter 4 Lessons Learned}

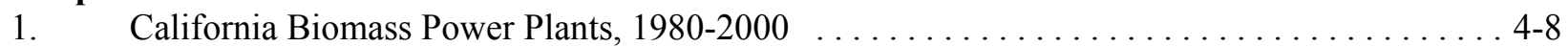

2. Idle California Biomass Facilities that Began Re-Start Investigations in $2000 \ldots \ldots \ldots \ldots$. . . . 21

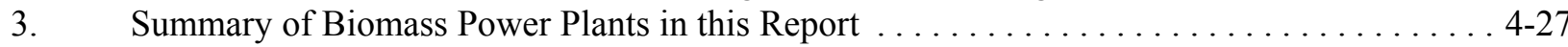

4. Plant Electricity Generation and Biomass Feed Consumption Estimates . . . . . . . . . . 4-27

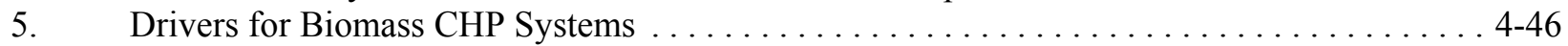

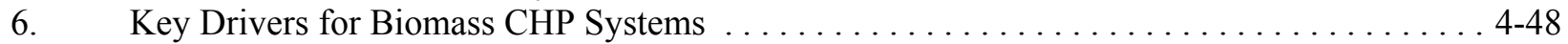

7. Key Success Factors, Relative to Coal and Natural Gas . . . . . . . . . . . . . . . . . . . 4-49

\section{Chapter 5 Technology Case Studies}

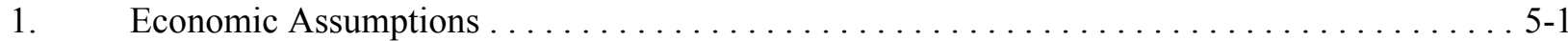

2. Feedstock composition for direct combustion and gasification $\ldots \ldots \ldots \ldots \ldots \ldots \ldots .7$

3. Biomass Direct Combustion Plant Capital and Operating Costs (excluding feed) . . . . . . . 5-8

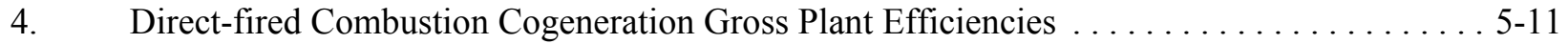

5. Biomass Gasification Capital and Operating Costs, Excluding Feed . . . . . . . . . . . 5-16

6. Gasification Cogeneration Gross Steam Turbine Efficiencies . . . . . . . . . . . . . . . . 5-19

7. Existing or Planned Biomass Cofiring Applications $\ldots \ldots \ldots \ldots \ldots \ldots \ldots \ldots \ldots \ldots \ldots$. $\ldots \ldots \ldots$

8. Ongoing DOE Cofiring Feasibility/Demonstration Projects $\ldots \ldots \ldots \ldots \ldots \ldots \ldots \ldots .24$

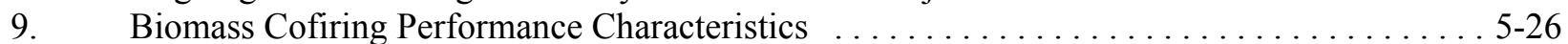

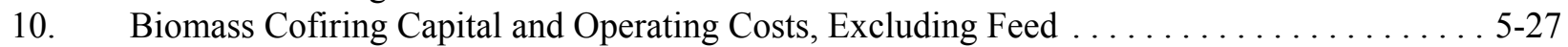

11. Cofiring Cogeneration Gross Steam Turbine Efficiencies, $100 \mathrm{MW}_{\text {eq }}$ Plant . . . . . . . . 5-28

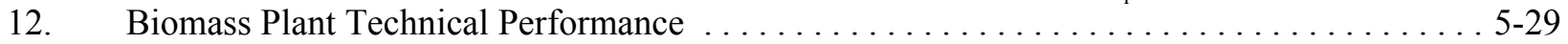

13. Cash Flow Analysis Input Data, $75 \mathrm{MW}_{\mathrm{eq}}$ Gasification CHP Plant $\ldots \ldots \ldots \ldots \ldots \ldots$. . . . . . .

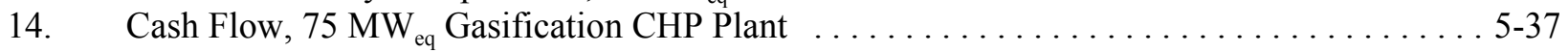

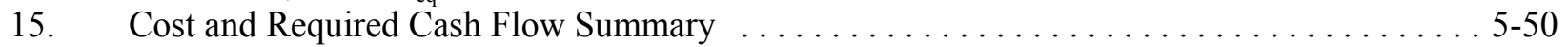

\section{Chapter 6 Environmental Performance}

Direct Air Emissions from Wood Residues Facilities by Boiler Type $\ldots \ldots \ldots \ldots \ldots \ldots \ldots \ldots \ldots 6-2$

1. Pollutant Emissions Limits for Biomass Plants $(\mathrm{lb} / \mathrm{MWh}) \ldots \ldots \ldots \ldots \ldots \ldots \ldots \ldots \ldots 6$

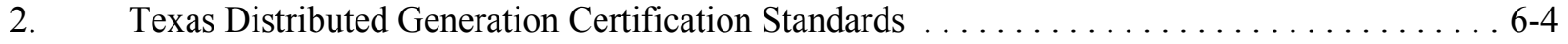

3. Proposed California Distributed Generation Certification Standards . . . . . . . . . . 6-4

4. Air Emission Rates from Landfill Gas Combustion and Electric Generation .......... . 6-7

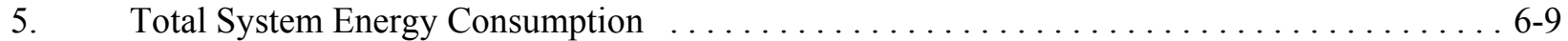

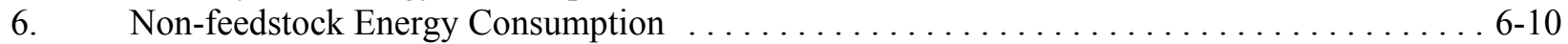

\section{Chapter $7 \quad$ Policy}

1. Time Line - Major Tax Provisions Affecting Renewable Energy . . . . . . . . . . . . . . 7-8

2. Time Line - Major Tax Provisions Affecting Renewable Transportation Fuels . . . . . . . . . 7-10

3. Nonutility Qualifying Facilities Using Renewable

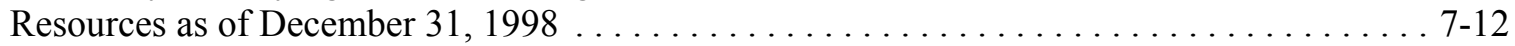

4. U.S. Electric Power Sector Net Summer Capability, 1989-1998 . . . . . . . . . . . . . . 7-13

5. California Non-utility Power Plants Installed Capacity, $1980-1996$. . . . . . . . . . . . . 7-14 


\section{EXECUTIVE SUMMARY}

Biopower (biomass-to-electricity generation), a proven electricity generating option in the United States and with about $11 \mathrm{GW}$ of installed capacity, is the single largest source of non-hydro renewable electricity. This $11 \mathrm{GW}$ of capacity encompasses about $7.5 \mathrm{GW}$ of forest product industry and agricultural industry residues, about $3.0 \mathrm{GW}$ of municipal solid waste-based generating capacity and 0.5 $\mathrm{GW}$ of other capacity such as landfill gas based production. The electricity production from biomass is being used and is expected to continue to be used as base load power in the existing electrical distribution system.

An overview of sector barriers to biopower technology development is examined in Chapter 2. The discussion begins with an analysis of technology barriers that must be overcome to achieve successful technology pathways leading to the commercialization of biomass conversion and feedstock technologies. Next, an examination of institutional barriers is presented which encompasses the underlying policies, regulations, market development, and education needed to ensure the success of biopower.

Chapter 3 summarizes biomass feedstock resources, characteristics, availability, delivered prices, requirements for processing, and the impediments and barriers to procurement.

A discussion of lessons learned includes information on the California biomass energy industry, lessons from commercial biopower plants, lessons from selected DOE demonstration projects, and a short summary of the issues considered most critical for commercial success is presented in Chapter 4.

A series of case studies, Chapter 5, have been performed on the three conversion routes for Combined Heat and Power (CHP) applications of biomass - direct combustion, gasification, and cofiring. The studies are based on technology characterizations developed by NREL and EPRI. Variables investigated include plant size and feed cost, and both cost of electricity and cost of steam are estimated using a discounted cash flow analysis. The economic basis for cost estimates is given.

Environmental considerations are discussed in Chapter 6. Two primary issues that could create a tremendous opportunity for biomass are global warming and the implementation of Phase II of Title IV of the Clean Air Act Amendment of 1990 (CAAA). The environmental benefits of biomass technologies are among its greatest assets. Global warming is gaining greater salience in the scientific community and among the general population. Biomass use can play an essential role in reducing greenhouse gases, thus reducing the impact on the atmosphere. Cofiring biomass and fossil fuels and the use of integrated biomass gasification combined cycle systems can be an effective strategy for electric utilities to reduce their emissions of greenhouse gases.

The final chapter reviews pertinent Federal government policies. U.S. government policies are used to advance energy strategies such as energy security and environmental quality. Many of the benefits of renewable energy are not captured in the traditional marketplace economics. Government policies are a means of converting non-economic benefits to an economic basis, often referred to as "internalizing" of "externalities." This may be accomplished by supporting the research, development, and demonstration of new technologies that are not funded by industry because of projected high costs or long development time lines. 


\section{SITUATION ANALYSIS}

Biopower (biomass-to-electricity power generation) is a proven electricity generating option in the United States, and with about $11 \mathrm{GW}$ of installed capacity, is the single largest source of non-hydro renewable electricity, as shown in Figure 1.1. This $11 \mathrm{GW}$ of capacity encompasses about $7.5 \mathrm{GW}$ of forest product and agricultural industry residues, about $3.0 \mathrm{GW}$ of MSW-based generating capacity, and $0.5 \mathrm{GW}$ of other capacity such as landfill gas based production. The electricity production from biomass is being used and is expected to continue to be used as base load power in the existing electrical distribution system.

\section{Figure 1.1: 1999 Renewable Electricity Generation} (Billion Kilowatthours)
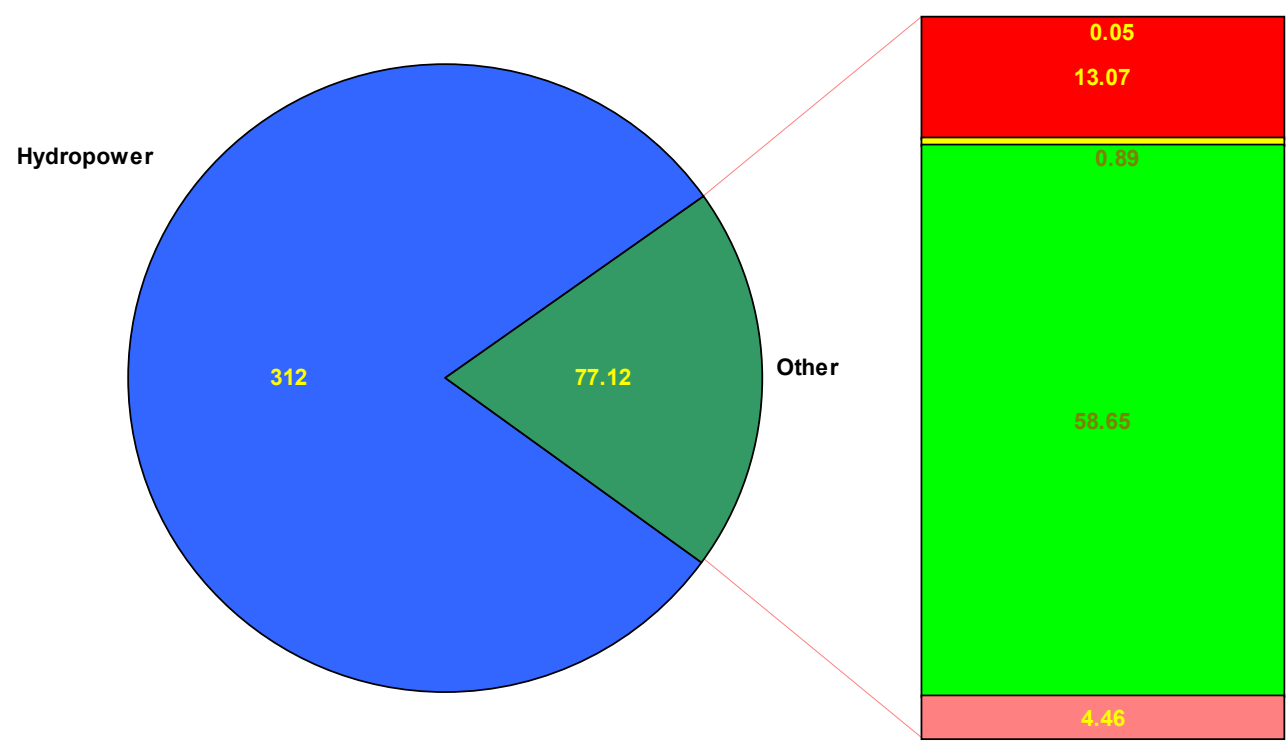

PV

Geothermal

Solar Thermal

Biomass

Wind

Source: DOE EIA Annual Energy Outlook 2001

In the United States, biopower experienced dramatic growth after the Public Utilities Regulatory Policy Act (PURPA) of 1978 guaranteed small electricity producers (less than $80 \mathrm{MW}$ ) that utilities would purchase their surplus electricity at a price equal to the utilities' avoided cost of producing electricity. The passage of PURPA as well as various state incentives resulted in a factor-of-three increase in gridconnected biopower generating capacity in the period from 1980-1990 (See Figure 1.2). The certainty of these contracts propelled industry investment to $\$ 15$ billion dollars and created 66,000 jobs. The PURPA legislation had no energy efficiency criterion and no incentives to add capacity at higher efficiency. In addition, the time needed to recover the investment was less than 10 years, so most investments were made on state-of-the-art technology at the time (combustion/steam). As a consequence, these plants, as a whole, had fairly low efficiency (industry average of $20 \%$ with notable exception at individual plants). 
Since "conventional" biopower was apparently well on its way in the commercial marketplace, research during subsequent periods focused on more advanced combustion technologies and gasification.

\section{Figure 1.2: Bioenergy Electricity Generation, 1981 - 1999}

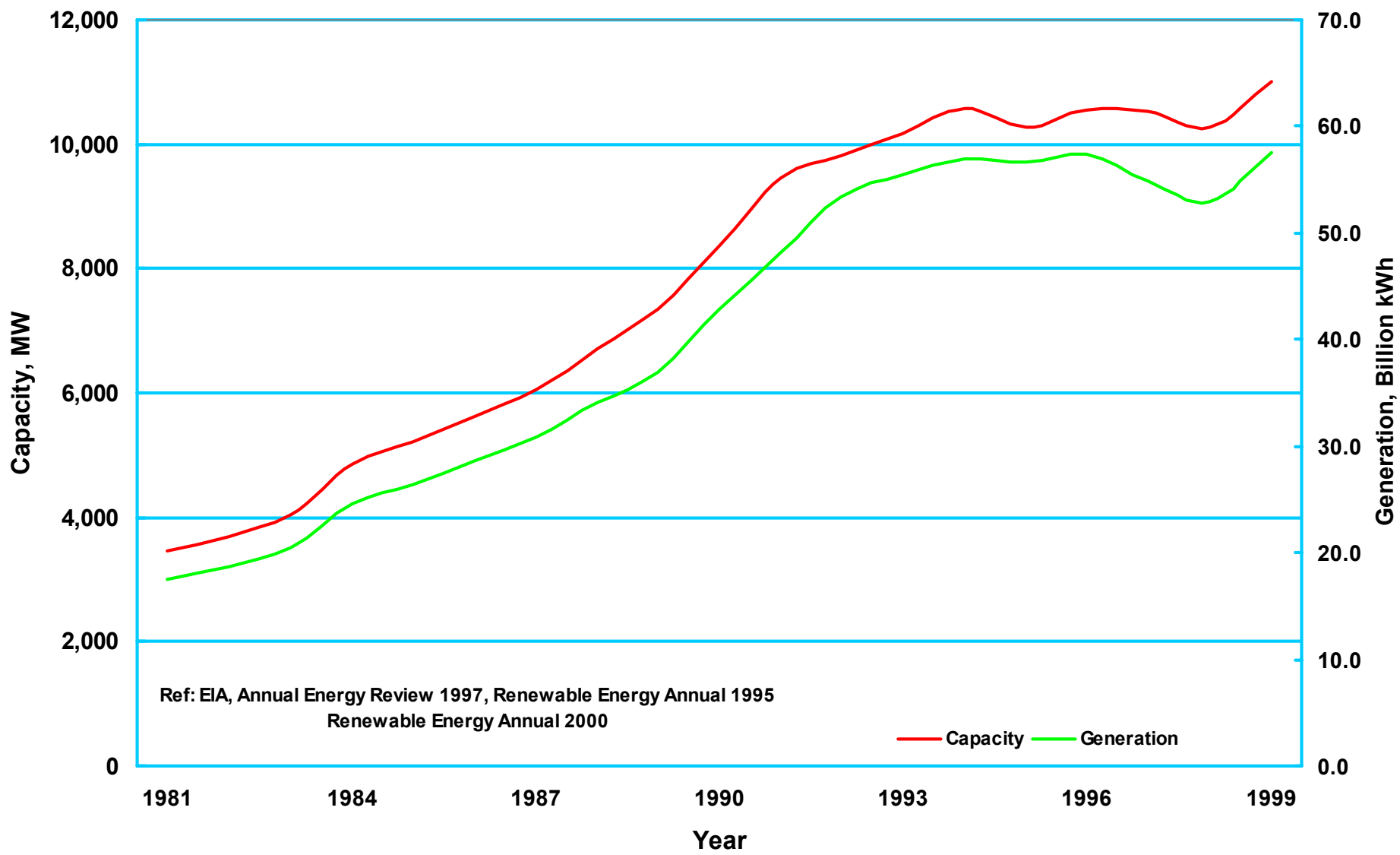

By the early 1990s, the biopower industry was beginning to stall for many reasons including higher feedstock costs, caused by inadequate infrastructure and no explicit accounting for the environmental benefits in utility regulation or market costing, and much lower new generation costs compared to natural gas CC. In addition, avoided cost contracts signed under PURPA were expiring and the utilities were unsuccessful in petitioning to buy back the contracts. More recently, the biopower industry has experienced uncertainty surrounding impending utility restructuring in a number of states. This situation has had detrimental effects on the industry that are still being felt today.

The $7.5 \mathrm{GW}$ of traditional biomass capacity represents about $1 \%$ of total electricity generating capacity and about $8 \%$ of all non-utility generating capacity. More than 500 facilities around the country are currently using wood or wood waste to generate electricity. Fewer than 20 of these facilities are owned and operated by investor- or municipally- owned electric utilities. The majority of the capacity is operated in combined heat and power (CHP) facilities in the industrial sector, primarily in pulp and paper mills and paperboard manufacturers. Some of these facilities have buy-back agreements with local utilities to purchase net excess generation. Additionally, a moderate percentage of biomass power facilities are owned and operated by non-utility generators, such as independent power producers that have power purchase 
agreements with local utilities. The number of such facilities is decreasing somewhat as utilities buy back existing contracts. The stand-alone power production facilities largely use non-captive residues, including wood waste purchased from forest products industries and from urban wood waste streams, agricultural residues from harvesting and processing, used wood pallets, and some waste wood from construction and demolition, to generate electricity. In most instances, the generation of biomass power by these facilities also facilitates a reduction in local and regional waste streams.

All of today's capacity is based on mature, direct combustion boiler/steam turbine technology. The average size of existing biopower plants is $20 \mathrm{MW}$ (the largest approaches $75 \mathrm{MW}$ ) and the average biomass- to-electricity efficiency of the industry is $20 \%$. These small plant sizes (which lead to higher capital cost per kilowatt-hour of power produced) and low efficiencies (which increase sensitivity to fluctuation in feedstock price) have led to electricity costs in the $8-12 \phi / \mathrm{kWh}$ range.

The near term domestic opportunity for gasification combined cycle technology is in the forest products industry, where a majority of whose power boilers will reach the end of their useful life in the next 10-15 years. This industry is familiar with use of its low-cost residues ("hog" fuel and a waste product called "black liquor") for generation of electric and heat for its processing needs. The higher efficiency of gasification based systems would bolster this self-generation (offsetting increasing electricity imports from the grid) and perhaps allow export of electricity to the grid. The industry is also investigating the use of black liquor gasification in combined cycles to replace the aging fleet of kraft recovery boilers.

An even nearer-term and lower-cost option for the use of biomass is cofiring with coal in existing boilers. Cofiring biomass with coal has the potential to produce $7.5 \mathrm{GW}$ by 2010 and $26 \mathrm{GW}$ by 2020 . Though the current substitution rate is negligible, a rapid expansion is possible based on wood residues (urban wood, pallets, secondary manufacturing products) and dedicated feedstock supply systems (DFSS) such as willow, poplar and switchgrass. The carbon replacement rate in 2010 would be $14.5 \mathrm{Tg}$.

The next generation of stand-alone biopower production will substantially mitigate the high costs and efficiency disadvantages of today's industry. The industry is expected to dramatically improve process efficiency through the use of cofiring of biomass in existing coal-fired power stations, through the introduction of high-efficiency gasification combined cycle systems, and through efficiency improvements in direct combustion systems made possible by the addition of dryers and more rigorous steam cycles at larger scales of operation. Technologies presently at the research and development stage, such as Whole Tree Energy ${ }^{\mathrm{TM}}$, integrated gasification fuel cell systems, and modular systems are expected to be competitive in the future. 


\section{BARRIERS}

An overview of sector barriers to biopower technology development is examined below. The discussion begins with an analysis of technology barriers that must be overcome to achieve successful technology pathways leading to the commercialization of biomass conversion and feedstock technologies. Next, an examination of institutional barriers is presented which encompasses the underlying policies, regulations, market development, and education needed to ensure the success of biopower. This document draws upon recent insights contained in The Biopower Roadmap (to be published), which was developed through a series of three industry-led stakeholder workshops facilitated by the U.S. Department of Energy during the past year. $^{2}$

\section{Technology Barriers}

Biomass is a very desirable fuel and feedstock because it is renewable, sustainable, and clean (generally does not contain many pollutant-forming species such as sulfur, nitrogen and heavy metals.) Biomass is also widely available throughout the world and amenable to conversion to a wide variety of useful forms. However, biomass, more so than virtually any other fuels or energy source, varies considerably in its elemental composition, energy content, and physical characteristics. It also contains species, such as alkali metals, that, while not considered pollutants, often cause mechanical problems, such as deposition and corrosion of heat transfer surfaces, in conversion systems. As such, it presents considerable technical challenges at virtually all phases of conversion to useful energy forms and products.

\section{Combustion/Cofiring}

Combustion has been, for the entire history of the human species, the most common method of extracting energy from biomass (other than food) either directly, in the form of heat and light from a fire, or indirectly through use of this heat to produce steam that turns electricity-generating turbines. Direct combustion of biomass to raise steam is used in all of the existing $7 \mathrm{GW}$ of biomass generation plants in operation in the U.S. today.

Many types of biomass used for fuel contain alkali metal species such as sodium, potassium, and calcium. In a combustion environment, the combustion products of these species, chlorides, silicates, etc., can form deposits on heat transfer surfaces reducing heat transfer, and thus, overall plant efficiency. They can also accelerate the corrosion or erosion of the heat transfer surfaces. Both of these mechanisms increase the maintenance requirements of the power plant. When biomass is cofired with coal (even in small percentages), the biomass containing these alkali species can change the properties of the resulting mixed ash, which can have a significant impact on the coal plant's O\&M costs or even operability.

In 1996, the Biopower Program funded a collaboration between Sandia, NREL, University of California at Davis, Foster Wheeler Development Corp., Thomas R. Miles Consulting Design Engineers, and the U.S. Bureau of Mines to conduct an integrated study that elucidated the mechanisms of alkali species formation and deposition and developed guidelines for use by plant operators to avoid deposition problems. An ongoing collaboration between Sandia, NREL and, later, NETL continued the investigation of the formation and deposition mechanisms. Results of these studies have been of great use in ongoing experiments being carried out by industry.

\footnotetext{
${ }^{1}$ Excerpted from 2001 EERE STRATEGIC PROGRAM REVIEW Biopower, DOE

${ }^{2}$ The Biopower Roadmap, Office of Power Technologies, May 2001 (draft)
} 
For cofiring to see widespread use, a number of technology-related issues must be resolved. Some, but not all cofiring tests have resulted in significant $\mathrm{NO}_{\mathrm{x}}$ reductions. The mechanisms responsible for these reductions need to be identified and taken advantage of. It must be demonstrated that a variety of biomass feedstocks can be effectively burned in the full range of coal boiler types. This demonstration will allow these plants the fuel flexibility that the existing industry has demonstrated is necessary for economic viability. There is some concern that components of some biomass feedstocks may reduce the efficiency and effectiveness of systems for the selective catalytic reduction of $\mathrm{NO}_{\mathrm{x}}(\mathrm{SCR}$ systems). This could be a significant technical barrier to market penetration of cofiring. The existence of this problem must be confirmed or refuted and, if valid, guidelines must be developed for biomass feedstock compositions as well as possible cost-effective methods for eliminating the harmful components.

\section{Gasification}

In the longer term, gasification technologies hold the most promise for next-generation power generation efficiency improvements from combined cycles and fuel cells, as well as for production of high value coproducts along with power generation. DOE has had a notable success with the FERCO Vermont gasifier project by successfully operating its commercial scale demonstration plant. This gasifier has since proven to be even more efficient than it was first thought to be in that the gasifier throughput has been in excess of 175 percent of the original design.

For this technology class to flourish, however, a number of technical barriers must be overcome. These include scale-up of the technology, replication of successful demonstrations and technologies that will aid in the integration of gasification systems with gas turbines and fuel cells. Existing technologies such as scrubbing can accomplish gas cleanup, but to achieve maximal efficiencies with minimal environmental impact, other options such as tar cracking must be developed to enhance the removal of tars and condensable organics. Some of the technical issues with conversion devices (turbines and fuel cells) have been at least partially addressed by efforts such as the DOE Clean Coal Program; however, these must be adapted for use with biomass.

\section{Small Systems}

A significant number of the world's 2 billion people who lack access to electricity have available substantial quantities of biomass resources but lack the means to convert this resource into electricity in a clean, reliable, and efficient manner. In addition, in the developed world, distributed generation is receiving increased attention as a way of increasing energy reliability as well as the efficiency of the transmission and distribution system. To be economically competitive and environmentally acceptable, a new generation of small biopower systems is being developed. These will couple biomass conversion devices (combustors and gasifiers) to conventional and advanced electricity generators such as microturbines, Stirling engines, and eventually fuel cells. These systems must overcome a number of technical issues including reliable and automated feeding and operation, reliable small-scale combustor and gasifier system development, small-scale gas cleaning systems and emission reduction methodologies. As an example, research at NREL has shown that $\mathrm{CO}$ and $\mathrm{NO}_{\mathrm{x}}$ emissions from a gasifier/internal combustion engine system (a very common system in the developing world) can be substantially reduced below equivalent emissions on natural gas by carefully tuning engine operating parameters and using a medium heat content gas. 


\section{Feedstock Production, Harvest, Transport, and Preparation}

All biomass energy systems have the economic and energy cost of producing, transporting, and preparing the biomass feedstock as technical barriers. Significant progress has been made in this area, but to be truly economically competitive, new feedstocks and methods for their harvesting and preparation must be developed. In addition, harvesting, preparation, transportation, and feeding of a variety of biomass feedstocks that are suitable for power production must be demonstrated and new methods developed for reducing costs and energy requirements must be verified. This will reduce the delivered cost of feedstock to the energy facility to a level more competitive with fossil fuels as well as increase the return to the farmer producing the biomass.

\section{Institutional}

The commercial development of renewable energy technologies can be impeded by barriers that do not involve technical aspects of a given technology. Technological progress that improves performance or increases system efficiencies can open doors to deployment; however, market issues ultimately depend on overcoming the institutional challenges that these technologies will face. It can be far more difficult to put into place the necessary institutional mechanisms that will drive these commercial efforts. The keys to the successful implementation of energy technologies, and in particular, biopower technologies, are overcoming issues that can be categorized as the following:

-Regulatory

-Financial

-Infrastructural

-Perceptual

These categories were first developed in The Potential of Renewable Energy: An Interlaboratory White Paper, by INEEL et al, prepared for the Department of Energy, March 1990.

\section{Regulatory}

Through the regulatory process, governments direct activities in the broader societal interest. Regulations usually pertain to two broad issues: (1) markets and (2) health, safety, and environmental protection. Regulatory factors can create technology development opportunities that would not exist in unregulated environments. Within the United States, for example, the passage of the Public Utilities Regulatory Policy Act (PURPA) in 1978 required electric utilities to buy power from independent power producers and was designed to encourage small-scale electric power production from renewables, cogeneration, and energy conservation. This law has been considered by some analysts to be "the single most important spur to creation of a commercial renewable power market...". During the 1980 s, biomass power capacity rapidly expanded as a result of laws mandating that utilities purchase power from suppliers under contracts based on avoided power generation costs (as specified under PURPA). These contractual prices were substantially higher than current wholesale power prices, and permitted biomass projects to be financed and operated at a profit.

\footnotetext{
${ }^{3}$ Silverman, Murray and Susan Worthman, The Future of Renewable Energy Industries, The Electricity Journal, March 1995)
} 
In the 1990s, changes in the electric power industry due to massive restructuring resulted in lower avoided costs and as present contracts are concluded, this biomass generation could be at risk. The closing of high cost power plants and the introduction of high-efficiency natural gas facilities are also putting considerable downward pressure on electricity prices. In the United States and some other countries, utilities are breaking into multiple companies that compete for the power generation, transmission, distribution, and on-site elements of the power market. The eventual impacts of these and other trends on individual power producers are not yet clear. However present trends suggest that profit margins will be even tighter in the future. This atmosphere of heightened competition has already had the effect of reducing the willingness of power companies to take risks with new technology and to use renewable energy resources.

Although this situation presents challenges, the restructuring of the power industry is also providing new opportunities for biopower. Markets are developing for "green power," where electricity from selected generation sources can be sold at high prices (typically 1-2 cents per kilowatt-hour). Through consumer choice, green markets offer opportunities to expand the use and future development of renewable technologies. Increased biopower is also being encouraged through Renewable Portfolio Standards (RPS) established by state regulatory agencies. These standards require utilities to provide certain percentages of power, typically 5-10 percent, from renewable sources. Recognizing that these market-driven forces are currently undergoing clarification, the Biopower Program participates with environmental groups (such as Green-e) to resolve issues such as defining "green power" and understanding the public perception of biomass conversion technologies. Despite this progress, state and market incentives for biopower only exist in certain states. In addition, Federal, state and municipal policies and definitions with regard to green power and qualifying biopower technologies (e.g. some states and municipalities only include landfill gas) need to be harmonized to create a robust portfolio standard. This could lead to increased acceptance of biopower and resultant grassroots demand for increased deployment.

In the United States today, the regulations that control the release of oxides of sulfur $\left(\mathrm{SO}_{2}\right)$ and nitrogen $\left(\mathrm{NO}_{\mathrm{x}}\right)$ are rapidly tightening under a variety of cap and trading schemes now being proposed for pollutants, particularly for $\mathrm{NO}_{x}$. These regulations may work as a potential boon to biopower because biopower technologies such as cofiring improve utilities' emissions profiles in $\mathrm{SO}_{\mathrm{x}}$ and $\mathrm{NO}_{\mathrm{x}}$. However, in some instances, EPA regulations and policies discourage existing coal plants from cofiring by opening them up to New Source Reviews if they modify their existing plants to accept biomass. The Biopower Program is currently collaborating with environmental regulatory bodies such as the EPA to reduce regulatory uncertainty related to NSR and emissions. This is a critical issue because there are more than 200 companies outside the wood products and food industries that generate biopower in the U.S. Where power producers have access to very low cost biomass supplies, cofiring is an attractive option for power companies to save fuel costs and earn emissions credits.

In the future, the potential regulation of greenhouse gas emissions will likely result in a particular advantage for the carbon dioxide-neutral biopower technology.

\section{Financial}

Financial constraints pertain to the availability and cost of a project and to the overall financial attractiveness of renewable energy technologies. Capital markets generally perceive the deployment of emerging technologies as involving more risk than established technologies. The higher the risk, the higher the rate of return demanded on capital thus impacting the rate of investment in these new, emerging technologies. Although the Biopower Program has worked to respond to these constraints through collaborative cost-sharing arrangements with developers, more needs to be done such as accelerating capital depreciation to facilitate investments in new technologies. 
Tax incentives for renewable energy technologies have been passed by Congress to offset their higher tax burden and the hidden costs of fossil fuels. Under the Energy Policy Act of 1992 (EPACT), electricity production from wind and biomass grown from energy crops became eligible for a 1.5 cents $/ \mathrm{kWh}$ production incentive, available for 10 years. Yet this production incentive is overly restrictive as EPACT provisions only allow for "closed loop biomass" (crops grown exclusively for power generation). The Program is hopeful that pending legislation will expand to include open loop biomass with a broader definition of qualifying feedstocks. To date, in the biomass area, ethanol is the main beneficiary of tax policy. While that may change under the President's National Energy Plan with the revisiting of Section 29 tax credits for landfill gas, tax credits need to be expanded to open loop firing and cofiring.

\section{Infrastructural}

Infrastructure is a general term for the entire energy service production and delivery system. It involves decisions made by a broad range of players including consumers, energy service providers such as utilities, fuel suppliers, and others. The nature of the biomass technology requires the need for infrastructure for the supply of feedstocks and for distributing products. Unlike fossil fuels such as coal and natural gas, which have a highly developed and sophisticated infrastructure in the U.S via railroad transportation and pipelines, a similar infrastructure does not currently exist for biofuels.

At this time, the biomass supplies are dominated by low-cost residues streams. The residue stream consists of materials self-generated by industries that process biomass for fiber or food uses (such as paper mills, lumber mills, sugar mills, etc.) or other economic activities (agriculture, urban construction and demolition, rate of waste generation, etc.). The quality, quantity, and cost of these resources continually vary in response to economic growth rates, discount factors, and regulation, e.g., the regulation of landfill activity and policies towards recycling.

In the future, a dedicated feedstock supply system based on short-rotation woody crops and herbaceous perennial crops could dramatically expand the assured availability of biomass for energy applications. The Biopower Program is working with Oak Ridge National Laboratory through the Bioenergy Feedstock Development Program to help expand the supply of these energy crops. Furthermore, establishing a Biomass Reserve Program (BRP) of perennial tree and grass crops that are particularly suitable for lowquality cropland, like that currently enrolled in the Conservation Reserve Program (CRP), could help to remove some infrastructural barriers related to the cost and supply of feedstocks. DOE will collaborate with USDA to assess the potential for using CRP-like programs to produce both energy and environmental benefits from investments in agricultural programs.

Another problem associated with the technology infrastructure concerns the 50-mile supply radius for the economic collection and transportation of fuel. In the future, the development of new technology (FischerTropsch) that allows for the conversion of biomass into a liquid may allow for the feedstock to be transported more cost-effectively at greater distances. In the meantime, small modular systems are being looked at for distributed applications. These systems are less than $5 \mathrm{MW}$ and can be transported directly to the feedstock production site.

\section{Perceptual}

The Biopower Program has a number of activities related to outreach, technology transfer, education and communication, as there is a lack of familiarity with biomass power technologies by the public and government and industry decision makers. Many people still do not know what the term "biomass" means, let alone understand the benefits and new technology developments associated with biomass. In addition, some environmental groups do not view biomass as a "green" technology. Awareness of biomass tends to be associated with wood stoves and concerns over emissions from the combustion of wood than with 
biomass as an alternative energy technology. Less is known by the public and others about the low emissions, high efficiency, and environmental benefits offered with state-of-the-art biomass power systems. There are also concerns related to harvesting of trees as well as the need for sustainable supply. These unfavorable perceptions translate into financial costs and risks to any biomass project. Only with considerable education efforts and demonstration that environmental concerns are being accounted for can the risks of nonacceptance be overcome. In terms of these perceptual barriers, the program is examining a number of activities to educate and disseminate better information on the benefits of biopower to industry, regulators, environmental organizations, and the public to gain appreciation for bioenergy and, in turn, harness support for biopower-friendly policies. 


\section{FEEDSTOCK SUPPLY}

This section summarizes biomass feedstock resources, characteristics and availability, delivered prices and requirements for processing, and the impediments and barriers to procurement.

\section{Biomass resources - characteristics and availability}

Biomass resources are generally classified into five major categories - urban wood wastes, mill residues, forest residues, agricultural residues, and dedicated energy crops. The availability, characteristics, and costs of acquisition of each of these resources are very different. Availability and price estimates for urban wood wastes and forest residues are highly uncertain and depend on local conditions. Availability of mill residues and agricultural residues can be estimated more precisely; however, prices depend on local market conditions and, in the case of agricultural residues, cropping patterns and environmental restrictions. Energy crops are not currently grown as a fuel feedstock. Availability and price is therefore more speculative. More detailed discussion on each of these feedstocks is summarized below. Discussion of the specific resource methodologies and data sources can be found in Walsh et al., 2000. ${ }^{1}$ In addition, there are numerous other useful studies that have estimated biomass feedstock availability, including Wiltsee (1998), Rooney (1998), Fehrs (1999), Antares (1999), and Goldstein (2000).

\section{Urban wastes.}

Urban waste is a generic category that encompasses a variety of woody materials, such as yard and tree trimmings, site clearing wastes, pallets, and packaging materials, that can be diverted from municipal solid waste (MSW) landfills and possibly composting facilities. Urban wood wastes also include construction and demolition debris that is typically disposed of in construction and demolition (C/D) landfills. The physical characteristics of these materials varies widely. Yard and tree trimmings are a relatively clean woody fuel that have a moisture content of $35 \%-60 \%$ depending on the vegetation type and season (Badger, 2002). Site clearing wastes are similar to tree trimmings except they may contain rocks and dirt, if stumps are not separated. Yard trimmings and site clearing wastes are often processed with drum chippers that can blow the chips directly into a chip van for transport. Processing requirements are therefore minimal once the material has been separated from the MSW stream. Pallets and packaging materials are also relatively high quality resources with moisture content tending to be rather low $(<15 \%)$. C/D debris contains many different wastes including chemically treated wood and non-woody materials, such as metal, concrete, wallboard, and shingles. These non-woody materials must be source separated or taken to a recycling center for separation and recovery. Pallets and C/D debris are usually processed with hammermills to break apart. Magnets and non-ferrous metal detectors, screens, and hogs may also be required for processing.

Estimating quantities and delivered prices of urban wood wastes is confounded by a general lack of data. For the most part, regional and state-level surveys, per capita waste generation coefficients, and compositional analysis data are used to estimate availability. Walsh et al. (2000) estimated total annual urban wood wastes at about 36 million dry tons. This estimate is based on surveys of the wood waste deposited in MSW landfills, C/D landfills, and compost facilities. These data indicate that $6 \%-8 \%$ of material taken to MSW landfills is wood, $20-50 \%$ deposited at C/D landfills is

${ }^{1}$ Walsh et al. (2000) is currently being updated. The updated report will include the state-level biomass resource database and a selected county-level database. 
wood, and $80 \%-90 \%$ taken to compost facilities is wood. The product of these composition fractions and total waste deposited, corrected for moisture content, provides an estimate of total availability.

The delivered prices at which urban wood waste is available are highly location specific. Delivered prices can be estimated as a function of an average processing cost (e.g., hammermills and separation), an average transport cost including loading and unloading, less some fraction of the landfill disposal or tipping fee. Local and state regulatory policies (e.g., recycling requirements and certification), the extent of competing uses, such as mulch and compost, as well as other factors can affect costs. Given the uncertainties about availability, location-specific factors affecting delivered prices, and anecdotal evidence, Walsh et al. assume that $60 \%$ of the resource could be available at delivered prices of $\$ 25 /$ dry ton or less and the remainder at delivered prices of less than $\$ 35 /$ dry ton. In some cases, delivered prices could be negative due to the presence of high offsetting tipping fees. For example, Goldstein (2000) reports state landfill tip fees ranging from $\$ 13$ to $\$ 70 /$ ton and Wiltsee (1998) shows supply curves for urban wastes ranging from a low of $-\$ 80 /$ ton to over $\$ 20 /$ ton. The approximate breakdown of the delivered prices for urban wood wastes is summarized below.

\begin{tabular}{lcccc}
\hline & $\begin{array}{c}\text { Avoided } \\
\text { landfill tipping } \\
\text { fee }\end{array}$ & $\begin{array}{c}\text { Collection \& } \\
\text { processing }\end{array}$ & Transport & Total \\
\cline { 2 - 5 } Urban wood wastes & $(\$ 0-\$ 100)$ & $\sim \$ 20-\$ 25$ & $\$ 5-\$ 10$ & $<\$ 25-\$ 35$ \\
\hline
\end{tabular}

\section{Mill residues.}

Primary mill residues are classified into three types-bark stripped from logs, coarse residues (chunks and slabs), and fine residues (shavings and sawdust). These residues are generated in the processing of lumber, pulp, veneers, and composite wood fiber materials. Moisture content of this material is about $20 \%$. These residues are advantageous because they tend to be clean, uniform, and concentrated at a single source. However, nearly all of these residues are currently used as fuel or as inputs in the manufacture of products. Very little of this resource is currently unused. For bark, about $80 \%$ is used for fuel with $18 \%$ used in low-value products (e.g., mulch). For coarse residues, about $85 \%$ is used in the manufacture of fiber products with about $13 \%$ used for fuel. About $55 \%$ of the fine residues are used as fuel with $42 \%$ used in products.

Although most mill residues are used, payments to mill operators greater than the residue's value in their current use could make them available as a fuel feedstock. This is especially true of the mill residues used on-site in relatively low efficiency boiler systems to produce heat and steam (Walsh et al., 2000). Walsh et al. (2000) report anecdotal evidence suggesting that residues used on-site for low-value energy purposes could be purchased for $\$ 15-25 /$ dry ton and residues used to produce higher-valued wood fiber products could be purchased for about \$30-40/dry ton. Payments to mill operators to make these residues available could thus range from $\$ 0$ to $\$ 40 /$ dry ton. Some minimal processing of the residues could also be required. In total, most of the unused residues could be obtained at prices below $\$ 25 /$ dry ton and residues in current use could be had for $\$ 15-\$ 40 /$ dry ton.

\begin{tabular}{ccccc}
\hline & Mill payments & $\begin{array}{c}\text { Collection \& } \\
\text { processing }\end{array}$ & Transport & Total \\
\cline { 2 - 5 } Mill residues & $\$ 0-\$ 40$ & $\$ 0-\$ 5$ & $\$ 5-\$ 10$ & $<\$ 25-\$ 55$ \\
\hline
\end{tabular}

\section{Forest residues.}

Forest wood residues include two sources-logging residues and the rough, rotten, and salvable dead wood (RRSD). Logging residues are the unused portion of the growing stock that are cut or killed by harvest 
operations and left behind. These materials include small branches, limbs, tops, and leaves. According to Smith and Sheffield (2000), logging residues account for about $6 \%$ of softwood growing stock removals and about $11 \%$ of hardwood removals. The total amount of logging residue produced annually is about 11 million dry tons. The RRSD resource is considerably larger than the logging residues resource. Rough trees are those that do not contain a sawlog (i.e., 50 percent or more of live cull volume) or are a nonmerchantable species. Rotten trees are trees that do not contain a sawlog because of rot (i.e., 50 percent or more of the live cull volume). Salvable dead wood includes downed or standing trees that are not considered merchantable. The size of this resource is vast and easily exceeds 1 billion dry tons. However, most of this RRSD material is inaccessible due to the absence of roads or access, is not economically retrievable with current technology, or is located in environmentally sensitive areas. About $10 \%$ of the RRSD resource might be considered available after accounting for access, material retrieval efficiency, and environmental restrictions (Walsh et al., 2000).

Recovery of the RRSD material (i.e., whole-trees) is done most cost-effectively with conventional fellerbunchers, skidders, and whole-tree chippers. Recovery of logging residues from the commercial harvest of timber and fiber operations at landings requires a whole-tree chipper or tub grinder. In both cases, chipping converts low-quality material into easily handled wood chips, which can be blown directly into a tractor trailer and chip van for transport. Quality of the material is generally high since much of the dirt debris is removed by differences in particle density when the chips are blown into the transport trailer (Badger, 2002). Although the chips may be relatively uniform in size they are often mixed with long slivers and splinters from small branches and limbs. For this reason, screening may be required before they are introduced into a wood energy handling system. The moisture content for both sources ranges from about $40-60 \%$.

Delivered prices for forest residues could include a stumpage fee for gaining access to the material, collection costs (felling, skidding, and chipping), and hauling (including loading/unloading). Collection costs will depend on the scale of operation, utilization of the equipment, and the size and density of the available material. Logging residue collection costs also depend on whether the material is collected concurrently with the commercial timber or pulp operation or whether removal is done after the commercial operation. Hauling costs for forest residues are generally higher than the other biomass resources because roads may be unpaved, curvy, and otherwise limit truck size and travel speeds.

\begin{tabular}{lcccc}
\hline & Stumpage & Collection & Transport & Total \\
\cline { 2 - 5 } Logging residues & $<\$ 5$ & $\$ 10-\$ 30$ & $\$ 5-\$ 20$ & $<\$ 25-\$ 55$ \\
\hline
\end{tabular}

\section{Agricultural residues.}

Corn stover and wheat straw are the two primary sources of agricultural residues. Other grain crops are either limited in acreage or else the amount of residue is small. The quantity of corn stover and wheat straw available depends on grain yield (bu/acre), total grain production or acreage, and the amount of residue that must be left to maintain soil quality (i.e., nutrients and organic matter) and limit erosion. These environmental sustainability restrictions differ by crop and rotation, soil type, field slope, weather conditions, and tillage system. Under average conditions, about 30 to 40 percent of corn stover and wheat straw residues may be removed. Currently, most of these agricultural residues are left on the ground and plowed under. A major limitation of agricultural residues is the limited collection season-usually a couple of months following grain harvest. Year-round utilization of these resources may require storage of up to ten months.

The costs of gathering these materials include mowing, raking, baling, loading and unloading, storage, and hauling. Collection costs using conventional baling equipment range from about $\$ 20-\$ 25 /$ dry ton. Uncovered storage of the bales for year-round use adds another $\$ 5 /$ dry ton. As reported by Walsh et al. 
(2000), typical payments to farmers to compensate for lost nutrients and environmental benefits can vary between $\$ 10-\$ 15 /$ dry ton. Haul costs depend on distance and numerous logistical factors, such as crop acreage density, proportion of farmers selling residues, etc.

\begin{tabular}{lccccc}
\hline & Collection & $\begin{array}{c}\text { Farmer } \\
\text { payments }\end{array}$ & Storage & Transport & Total \\
\cline { 2 - 5 } $\begin{array}{l}\text { Agricultural } \\
\text { residues }\end{array}$ & $\$ 20-\$ 25$ & $\$ 10-\$ 15$ & $\$ 5$ & $\$ 5-\$ 10$ & $<\$ 35-\$ 55$ \\
\hline
\end{tabular}

\section{Dedicated energy crops.}

Dedicated energy crops include short rotation woody crops (SRWC) such as hybrid poplar and hybrid willow, and herbaceous crops such as switchgrass. Management practices for each crop are regionally dependent. For hybrid poplars, trees are planted at a density of about 500-600 trees/acre and are harvested after 6 to 10 years of growth depending on the region of country and growth rates. Although these trees will re-sprout, current management guidelines suggest replanting with improved clones following harvest. Hybrid willow is relegated to the northern states. It is planted at much higher densities (about 6200 trees/acre) and harvested after 4 years of growth. Hybrid willow stands are regenerated by coppicing with as many as 7 succeeding coppice stands expected from the initial establishment. Hybrid poplars are harvested with conventional forestry equipment (feller-bunchers, skidders, and whole-tree chippers) and willow with some form of combine machine. Both woody crops are delivered as whole-tree chips. The establishment of switchgrass is similar to that of a conventional hay crop. Once established it can produce for about 10 years before replanting is required. Switchgrass is harvested with conventional baling equipment and is delivered to conversion facilities as large round or rectangular bales. The ability to use existing on-farm equipment is a major advantage of switchgrass over tree crops.

Energy crops are not currently grown as fuel feedstocks, but research indicates that energy crops would be produced provided farmers could earn a risk-adjusted return equal to that from traditional agricultural crops. Walsh et al. (2000) used an agricultural sector model to estimate the quantities of energy crops that would be grown at various energy prices and assuming given agricultural policies, such as Conservation Reserve Program acreage. Analysis results indicate that these crops could be produced at delivered prices starting about $\$ 35 /$ dry ton.

\begin{tabular}{lccc}
\hline & Production/harvesting & Hauling & Total \\
\cline { 2 - 4 } Poplars & $\$ 50-\$ 60$ & $\$ 5-\$ 10$ & $<\$ 55-\$ 70$ \\
Willows & $\$ 60-\$ 65$ & $"$ & $<\$ 65-\$ 75$ \\
Switchgrass & $\$ 30-\$ 45$ & $"$ & $<\$ 35-\$ 55$ \\
\hline
\end{tabular}

\section{Regional availability}

It is estimated that about 24 million dry tons of biomass resources might be available nationally to conversion facilities at delivered prices of about $\$ 25 /$ dry ton or less $(\$ 1.60 / \mathrm{MMBtu})$. The amount of biomass resources available increases more than fourfold at prices under $\$ 35 /$ dry ton $(\$ 2.20 / \mathrm{MMBtu})$. At prices under $\$ 55 /$ dry ton $(\$ 3.40 / \mathrm{MMBtu})$, over 510 million dry tons might be available annually. Figure 3.1 summarizes national biomass feedstock availability at delivered prices ranging from under $\$ 25$ to under $\$ 55 /$ dry ton. State-level estimates are provided in Table 3.1. No assumptions about the spatial distribution of resources within a state are made. As such, proposed conversion facilities may not be within an economically feasible transport distance. Feasibility studies of proposed conversion facilities must therefore conduct detailed local analyses to verify feedstock availability, prices, and reliability. 
Generally, urban wood wastes are the least expensive followed by mill residues, forest residues, agricultural residues, and energy crops. This ordering reflects more or less the costs of acquisition (offsetting landfill tipping fees) and the significance of collection (or production and harvesting) and processing costs. Urban wood wastes, mill residues, agricultural residues, and forest residues are often available in small and dispersed amounts, creating high transaction costs. Supply reliability and quality requirements may also be difficult to meet consistently. Further, prices do not include any processing of the wastes at the conversion facility. For example, bales would need to be broken and ground, whole-tree chips may need to be screened, and urban wastes may require more specialized processing to remove noncombustible materials. Finally, it should be reiterated that the uncertainty surrounding these estimates is high. Site-specific analyses are required to determine specific estimates of available quantities at given delivered feedstock prices. Bio-resource procurement is complex, costly, and a significant barrier to potential use.

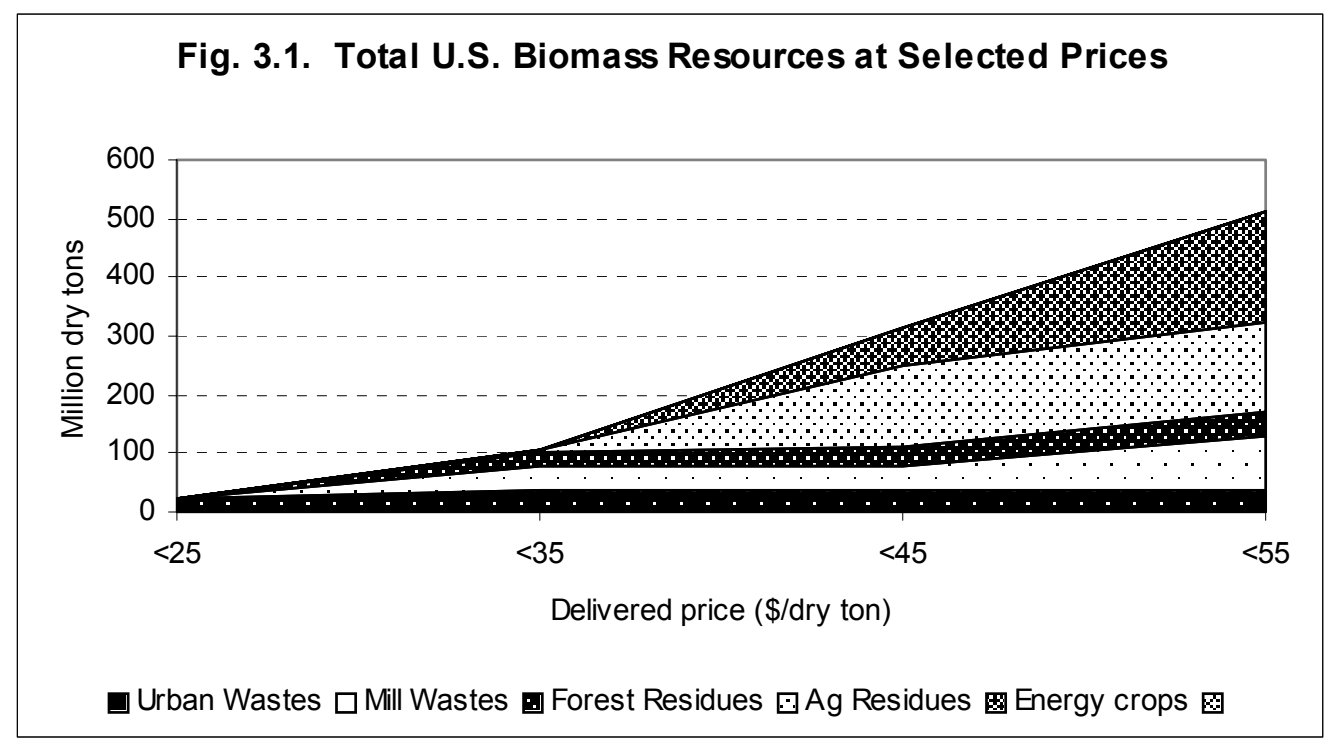


Table 3.1: Estimated Biomass Resources Available by State and Price

\begin{tabular}{|c|c|c|c|c|}
\hline \multirow[t]{3}{*}{ State } & \multicolumn{4}{|c|}{ Delivered price ( $\$$ dry ton) } \\
\hline & $<25$ & $<35$ & $<45$ & $<55$ \\
\hline & \multicolumn{4}{|c|}{ thousand dry tons } \\
\hline Alabama & 841 & 6,963 & 10,712 & 17,682 \\
\hline Arizona & 220 & 575 & 863 & 1,100 \\
\hline Arkansas & 402 & 4,092 & 7,086 & 13,604 \\
\hline California & 1,588 & 6,158 & 8,224 & 11,299 \\
\hline Colorado & 181 & 652 & 3,357 & 3,582 \\
\hline Connecticut & 247 & 561 & 611 & 906 \\
\hline Delaware & 39 & 95 & 194 & 462 \\
\hline Florida & 2,762 & 6,524 & 6,778 & 9,533 \\
\hline Georgia & 934 & 6,391 & 8,541 & 16,112 \\
\hline Idaho & 204 & 2,572 & 4,117 & 7,166 \\
\hline Illinois & 435 & 1,038 & 26,839 & 33,359 \\
\hline Indiana & 348 & 994 & 13,410 & 18,607 \\
\hline Iowa & 174 & 404 & 24,583 & 32,786 \\
\hline Kansas & 737 & 1,283 & 12,733 & 21,344 \\
\hline Kentucky & 455 & 1,472 & 5,758 & 10,809 \\
\hline Louisiana & 516 & 3,569 & 7,977 & 11,834 \\
\hline Maine & 151 & 1,196 & 1,572 & 2,214 \\
\hline Maryland & 205 & 543 & 900 & 1,959 \\
\hline Massachusetts & 419 & 939 & 1,027 & 1,436 \\
\hline Michigan & 506 & 2,468 & 4,627 & 12,163 \\
\hline Minnesota & 991 & 2,917 & 15,494 & 21,247 \\
\hline Mississippi & 599 & 4,909 & 10,673 & 17,931 \\
\hline Missouri & 478 & 1,346 & 8,030 & 19,523 \\
\hline Montana & 69 & 1,422 & 2,159 & 6,761 \\
\hline Nebraska & 114 & 210 & 18,467 & 21,773 \\
\hline Nevada & 184 & 315 & 333 & 337 \\
\hline New Hampshire & 134 & 922 & 1,061 & 2,016 \\
\hline New Jersey & 389 & 726 & 791 & 976 \\
\hline New Mexico & 168 & 424 & 961 & 1,082 \\
\hline New York & 1,168 & 3,328 & 3,885 & 8,438 \\
\hline North Carolina & 669 & 4,188 & 5,790 & 10,856 \\
\hline North Dakota & 327 & 558 & 2,507 & 21,043 \\
\hline Ohio & 745 & 1,473 & 13,018 & 18,963 \\
\hline Oklahoma & 111 & 3,874 & 7,816 & 12,700 \\
\hline Oregon & 193 & 3,341 & 4,126 & 9,810 \\
\hline Pennsylvania & 572 & 2,206 & 2,832 & 7,427 \\
\hline Rhode Island & 30 & 81 & 88 & 116 \\
\hline South Carolina & 1,294 & 4,469 & 6,332 & 9,368 \\
\hline South Dakota & 132 & 286 & 9,602 & 16,005 \\
\hline Tennessee & 878 & 3,382 & 10,720 & 15,233 \\
\hline Texas & 1,227 & 4,222 & 13,526 & 20,747 \\
\hline Utah & 159 & 388 & 648 & 723 \\
\hline Vermont & 41 & 392 & 513 & 1,023 \\
\hline Virginia & 599 & 3,059 & 5,055 & 8,715 \\
\hline Washington & 297 & 3,979 & 5,939 & 9,920 \\
\hline West Virginia & 241 & 1,361 & 1,972 & 3,736 \\
\hline Wisconsin & 425 & 2,450 & 11,502 & 14,963 \\
\hline Wyoming & 224 & 552 & 787 & 1,466 \\
\hline Total & 23,820 & 105,267 & 314,535 & 510,855 \\
\hline
\end{tabular}




\section{References}

Antares Group Inc., Biomass Residue Supply Curves for the United States, prepared for DOE Biomass Power Program and the National Renewable Energy Laboratory, unpublished report, Landover, MD, June 1999.

Badger, P., Processing Cost Analysis for Biomass Feedstocks, Draft Report Prepared for Oak Ridge National Laboratory, Oak Ridge, TN, April 2002.

Fehrs, J., Secondary Mill Residues and Urban Wood Waste Quantities in the United States, prepared for Northeast Regional Biomass Program, Washington, December 1999.

Goldstein, N., "The State of Garbage," Biocycle, April 2000.

McKeever, D., “Wood Residual Quantities in the United States,” Biocycle, January 1998.

Rooney, T., Lignocellulosic Feedstock Resource Assessment, NEOS Corporation, published by the National Renewable Energy Laboratory, NREL/TP-580-24189, Golden, CO, September 1998.

Smith, W. and R. Sheffield, A Brief Overview of the Forest Resources of the United States, 1997, USDA Forest Service, Washington, July 2000.

Walsh, M., R. Perlack, A. Turhollow, D. de la Torre Ugarte, D. Becker, R. Graham, S. Slinsky, and D. Ray, Biomass Feedstock Availability in the United States: 1999 State Level Analysis, Bioenergy Feedstock Development Program, Oak Ridge National Laboratory, January 2000, (http://bioenergy.ornl.gov/resourcedata/).

Wiltsee, G., Urban Wood Waste Assessment, published by the National Renewable Energy Laboratory, NREL/SR-570-25918, Golden, CO, November 1998. 


\section{LESSONS LEARNED}

This discussion includes information on lessons learned the California biomass energy industry and reported on in 2000, a brief update on the California situation, lessons from commercial biopower plants, lessons from selected DOE demonstration projects, and a short summary of the issues considered most critical for commercial success.

\section{The California Biomass Energy Industry ${ }^{1}$}

California has one of the largest and most diverse biomass energy industries in the world. At its peak, the California biomass energy industry produced almost 4.5 billion kilowatt hours per year of electricity and provided a beneficial use outlet for more than 10 million tons per year of the state's solid wastes. The peak, however, occurred during the early 1990s. Since that time, a quarter of the biomass energy facilities have agreed to buyouts of their power sales contracts and terminated operations, while others have reduced their operations. This has occurred because of concerns about the long-term viability of these facilities in a competitive, deregulated electricity market. This uncertainty casts an ominous cloud over the future viability of biomass energy generation in California.

\section{Development of the California Biomass Energy Industry}

California's diversity and extent of agriculture and forestry industries are unrivaled in the world. Both activities produce large quantities of solid wastes, many of which are biomass residues that can be used as fuel. Before the federal Public Utilities Regulatory Policy Act (PURPA) was passed in 1978 only a few biomass-fired boilers were operating in California, and little electricity was being generated from biomass. Most of the state's biomass wastes were being disposed of, mainly by open burning and landfill burial. PURPA changed all that by requiring that electric utility companies buy privately produced power at their "avoided cost" of generation. PURPA created the market context that allowed for the development of the independent power industry in the United States. High avoided cost rates in many areas of the country, and favorable federal tax treatment for investments in renewable energy projects, provided the motivation for its development.

California was a leader in the development of renewable energy generating facilities. A combination of circumstances, including a high growth rate in electricity demand, oil dependence, and rising concerns about environmental deterioration, led to the implementation of state energy policies that were highly conducive to the development of renewable energy sources. These policies and opportunities stimulated a major development of biomass energy generating capacity in the state. During a period of less than 15 years (roughly 1980-1993), nearly 1,000 MW of biomass generating capacity were placed into service. The biomass energy sector expanded from an outlet for a small quantity of the state's wood processing residues to an essential component of the state's solid-waste disposal infrastructure. Today the California biomass energy industry provides a beneficial use for almost 6.5 million tons of the state's solid wastes. However, it has a highly uncertain future. The expiration of fixed-price power sales provisions for many facilities, combined with the deregulation of the electric utility industry and the current availability of cheap natural gas, threaten its long-term economic viability.

\section{The 1980s: Decade of Growth}

The early 1980s mark the nascent period for the California biomass energy industry. During this period, several pioneering biomass energy generating facilities were built and placed into service. The early

\footnotetext{
${ }^{1}$ Excerpted from: Morris, G. (2000) "Biomass Energy Production in California: The Case for a Biomass Policy Initiative,” NREL/SR-570-28805, National Renewable Energy Laboratory, Golden, CO, November.
} 
facilities tended to be small, generally 2-10 MW, and most were associated with sawmills or food processing operations that were looking for beneficial use outlets for their wastes. Figure 4.1 shows a map of the state's operating biomass energy facilities at the end of 1985.

Figure 4.1: California Biomass Power Plants, 1985

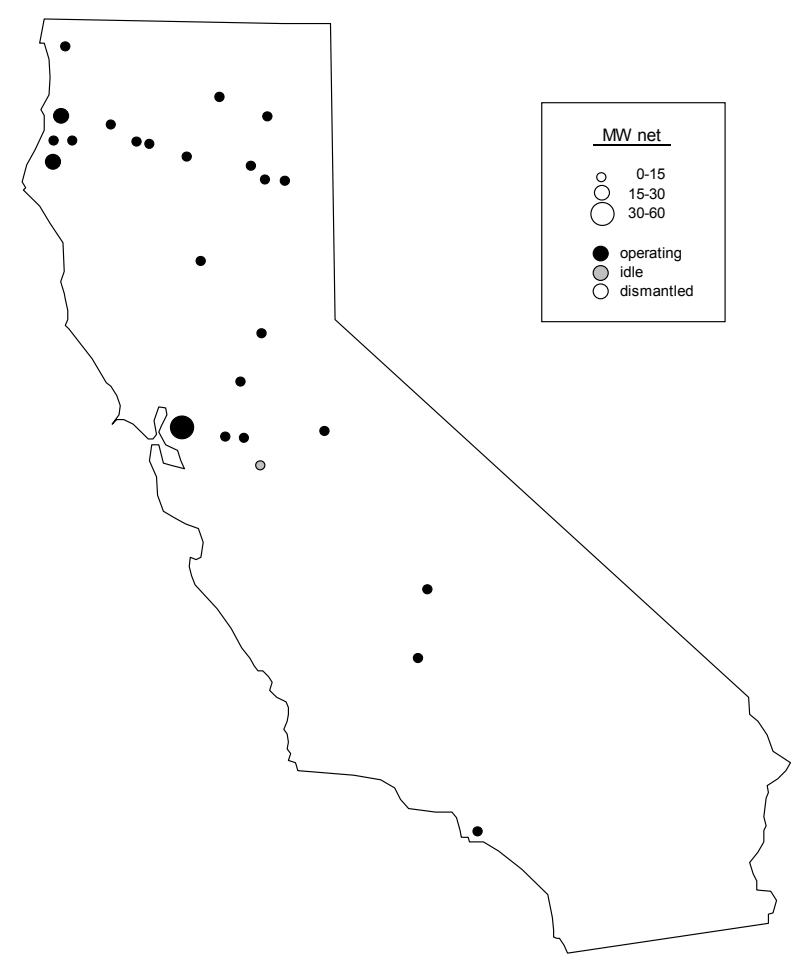

Also during the early 1980s, the California electric utility companies developed standard offer contracts for power purchases from independent generators. These contracts had particularly favorable provisions for renewable energy projects. A great deal of biomass project development activity was initiated during this period, which led to an explosion of new facility openings during the second half of the decade.

The California biomass energy industry became an important part of the state's electricity supply infrastructure and its waste disposal infrastructures during the second half of the 1980s. The incentives for renewable energy development that were offered during the first half of the decade led to the opening of 33 new biomass generating facilities between 1985 and 1990. A few of the pioneering facilities were shut down during this period, but the state's total operating biomass energy capacity grew by more than $650 \mathrm{MW}$. The average size of the facilities brought on line during this period was about $17.5 \mathrm{MW}$; the largest facilities were $50 \mathrm{MW}$. The explosive growth of biomass generating capacity culminated in 1990, when 11 new facilities were commissioned in a single year, adding $232 \mathrm{MW}$ of biomass generating capacity to the state's electricity supply. Figure 4.2 graphically illustrates the development of the biomass energy generating industry in California from 1980 to the present. Figure 4.3 shows a map of the state's installed biomass power infrastructure as of the end of 1990. 
Figure 4.2

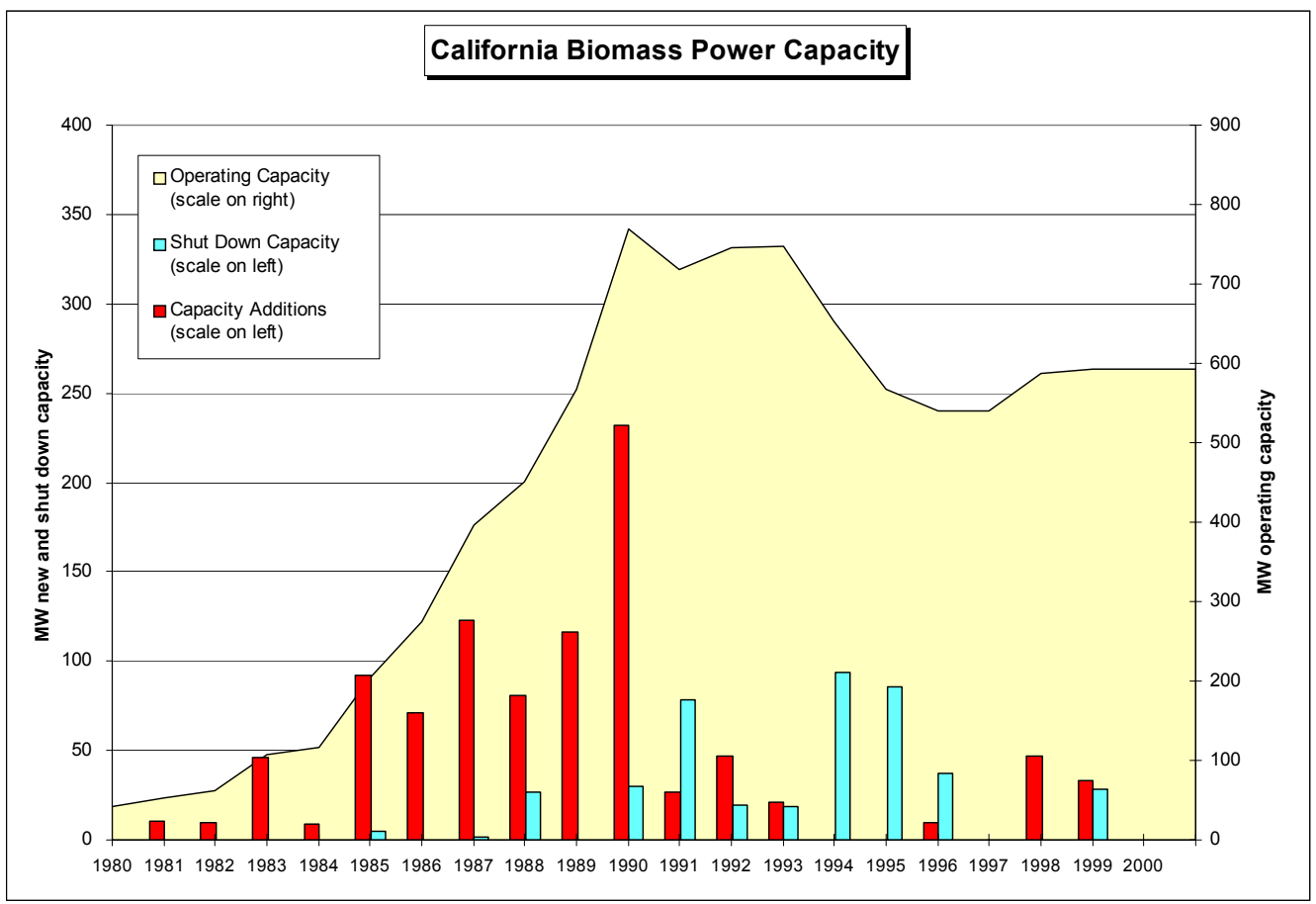

Figure 4.3: California Biomass Power Plants, 1990

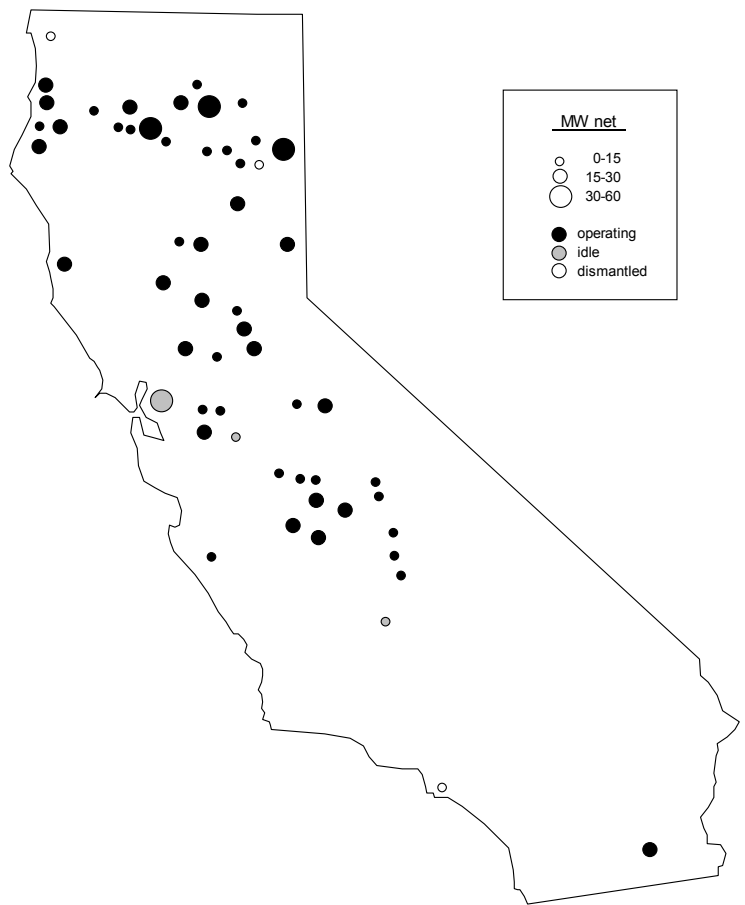


Many of the facilities that entered service during the late 1980s had Interim Standard Offer No. 4 (SO\#4) power purchase agreements (PPAs) with the state's two major electric utility companies, Pacific Gas and Electric Co. (PG\&E) and Southern California Edison (SCE) Co. The SO\#4s were the most favorable contracts available to independent project developers in California. These contracts were available for signing only during 1984 and 1985, and contract holders were given 5 years to bring their facilities into operation. The most significant feature of the SO\#4s was an option for energy sales from electricity generated from renewable resources to be based on a forecasted schedule of energy prices for the first 10 years of facility operations, rather than being subject to fluctuating, short-term prices. These schedules were based on the high avoided cost rates then in effect $(5 \phi-6 \phi / \mathrm{kWh})$, and an expectation that rates would remain high throughout the terms of the agreements. At the completion of the 10-year fixed price period generators are compensated based on the then current market price, which is called the short-run avoided cost (SRAC).

The SO\#4 power purchase provisions for biomass energy facilities were designed to encourage the development of base-load generators that would provide the power grid with dependable generating capacity during peak demand periods, which are summer weekday afternoons. Most of the contracts were written with 30-year firm capacity terms of performance, which obligate biomass facilities to generate at their contract capacity at least $80 \%$ of the time during defined peak hours of the year, for the entire term of the agreement. Payments to generators for providing firm capacity are levelized over the contract term, and confer a significant liability on generators that do not operate for the entirety of the agreements.

The second half of the 1980s was also significant for a reversal in world oil markets. World oil prices, which had remained high since the price explosions of the 1970s, collapsed during the period 1985-1986. SRACs in California fell by $50 \%$ over an 18 - month period. Most biomass power plants, however, were immune to the decline in SRAC rates during this period, because they received fixed-schedule rates under their contracts, based on early 1980s energy prices.

The attention of the biomass generating facilities focused instead on a looming crisis in the biomass fuels market. As the state's installed biomass generating capacity grew rapidly during the later half of the 1980 s, the demand for fuel soon overwhelmed the readily available supply. Virtually all sawmill and food processing residues that did not have higher valued uses were being sold into the fuel market, and still there was a significant deficit between biomass supply and demand. Numerous efforts were under way to develop technologies to produce biomass fuels from new sources of supply, such as agricultural prunings, agricultural field residues, forestry residues, and urban waste wood, with rising fuel prices providing the incentive. The state's biomass fuels crisis peaked in 1990 with average prices topping $\$ 40 / \mathrm{bdt}^{2}$ of fuel, and spot prices reaching $\$ 60 / \mathrm{bdt}$ or higher. Moreover, several major new facilities were approaching the completion of construction, and there was a fear that biomass fuel prices might continue to rise.

\section{The 1990s: Maturity and Consolidation}

At the end of 1990, more than 770 MW of biomass energy generating capacity were operating in California, and an additional $100 \mathrm{MW}$ of capacity were in advanced stages of construction. The early years of the 1990s saw the state's biomass energy industry stabilize at a level of about $750 \mathrm{MW}$ of operating capacity. During this period, the startup of the last of the SO\#4 facilities was balanced by the retirement of several pre-SO\#4 facilities, many of which had serious design flaws or operational problems. 1993 also saw the first retirement and dismantling of a facility with an SO\#4 contract. This

\footnotetext{
${ }^{2} \mathrm{bdt}=$ bone-dry ton equivalent, a unit of measure used for biomass fuels. A bdt refers to an amount of material that contains a ton of moisture-free biomass fiber. Generally, 1 bdt is equivalent to 1.2-2.4 actual, or green tons of biomass. In this discussion on California the term ton used alone refers to green tons of biomass, and bdt refers to bone-dry ton equivalents of biomass.
} 
was a facility that had been beset with technical and operational problems that prevented its profitable operation.

The California biomass fuels market also stabilized during the early 1990s, with average market prices settling at a level of about $\$ 37.50 / \mathrm{bdt}$, at an average consumption level of approximately 9 million tons per year. This stability was reached despite the beginning, in 1990, of a long-term decline in the state's wood products industry, which was caused by a combination of environmental restrictions and economic conditions. This is significant because wood processing residues are the lowest-cost biomass fuels in the state. By the end of 1993, the biomass energy industry appeared to have attained a level of maturity, and a workable equilibrium between fuel supply and fuel demand had been established. Although there were winners and losers, the California biomass energy industry as a whole successfully weathered the storm of the fuel crisis that marked the beginning of the decade.

The stability, however, was short lived. In April 1994 the California Pubic Utilities Commission (CPUC) issued its landmark Blue Book proposal for restructuring the state's regulated electric utility industry (CPUC 1994). The Blue Book proposal provided for competition among generating sources on the basis of price alone, without regard to non-market factors such as resource diversity and environmental impact. This represented a major threat to biomass energy generation. Because of the low density of biomass fuels and the resultant high handling and transportation costs, the relatively small size of biomass generating facilities, and the low cost of natural gas, the cost of power production from biomass was inherently higher than the cost of power generation using natural gas. Competition based on price factors alone would not favor biomass energy generation.

The most immediate effect of the Blue Book restructuring proposal for the biomass energy industry was that it provided an incentive for the state's regulated electric utility companies to buy out the SO\#4 PPAs held by the biomass generators in their service territories. Many biomass generators were receptive to these offers because of their concern about their own long-term liabilities to the utility companies in connection with the firm-capacity obligations in their contracts. Over the next 3 years 17 biomass facilities, rated collectively at more than $215 \mathrm{MW}$, accepted buyout offers and shut down operations. ${ }^{3}$ Unlike in earlier years, when only marginal facilities were closed, most of the facilities that shut down following the issuing of the Blue Book proposal were first-rate facilities that had been operating efficiently and profitably until the buyouts of their PPAs.

Annual biomass fuel use in the state shrank by $37 \%$ during the 2 years following the appearance of the Blue Book proposal. More than 3 million tons/year of biomass residues that were being used for energy production in the early 1990s were returned to open burning and landfilling for disposal. In addition, at its peak the state's biomass industry was supporting forest treatment operations on approximately 60,000 acres/year of forest land that was not otherwise being commercially harvested or treated. These treatments reduce the risk of destructive wildfires and improve the health and productivity of the thinned forest. With the retraction in the demand for biomass fuels the amount of this type of forest treatment activity has declined dramatically.

The CPUC's original restructuring proposal underwent a process of refinement that lasted for more than two years. By the summer of 1996 the CPUC had acknowledged the desirability of incorporating environmental factors into the choice of energy sources, and embraced the concept of a minimum purchase requirement for renewable energy sources. A working group made up of the utility companies,

\footnotetext{
${ }^{3}$ One of the 17 facilities was sold and restarted during this period. This facility was purchased by a buyer who intended to operate it at about one-half of its rated capacity, supplying steam and electricity to an over-the-fence industrial customer. Two other shut-down facilities, which only sold out the remaining fixed-price period of their PPAs, have since restarted. The other 14 facilities that were shut down during this period remain shut down today.
} 
independent power generators, and public interest groups worked on formulating a consensus proposal to the CPUC to implement a minimum renewables purchase requirement for California's regulated electric utility sector (Morris et al. 1996). The biomass industry, which pioneered the concept of a renewables portfolio standard (RPS), played a key role in this process.

In late August 1996, just before the end of the state legislative session, the California legislature formulated its own electric utility restructuring program, superseding the efforts of the CPUC. The legislation that emerged, $\mathrm{AB} 1890$, included a program of short-term support for renewable energy during the 4-year transition period (1998-2001) to full implementation of restructuring. However, no long-term support program for renewables was included. AB 1890 explicitly recognized the special waste disposal benefits associated with biomass energy in California. The legislation directed the California Environmental Protection Agency (Cal/EPA) to study policies that would shift some costs of biomass energy production away from the electric ratepayer, and onto the beneficiaries of the waste disposal services it provides. Cal/EPA was directed to report to the legislature on biomass cost-shifting measures by April 1997.

Cal/EPA had difficulty coming to grips with this political football. Two of the principal agencies under the Cal/EPA umbrella, the California Air Resources Board and the California Integrated Waste Management Board (CIWMB), had obvious interests in the outcome of the process. In addition, agencies outside Cal/EPA, such as the California Department of Forestry and Fire Prevention and the California Energy Commission, also have a strong interest in policies affecting biomass energy production. Rather than take the lead itself, Cal/EPA assigned the task to the Waste Board. CIWMB convened a series of public workshops, during which they solicited research and information about the public benefits of biomass energy production, and policy proposals to support continued biomass energy production. A great deal of public input was received, which the agency tried to distill into a report to the legislature within a very tight time frame. At some point a decision seemed to have been made that any information that caused interagency disagreements would be removed from the report. The result was a watereddown report that provided the legislature with no basis for enacting the kinds of cost-shifting policies for biomass envisioned in AB 1890.

The legislature made one more attempt to develop the background necessary for the developing biomass support policies in California. In 1998, AB 2273 was passed and signed into law. AB 2273 directs $\mathrm{Cal} / \mathrm{EPA}$ to report annually to the legislature on progress in developing biomass cost-shifting policies in the state. CIWMB was assigned the lead role in developing the first report under this legislation. Although a report was prepared in early 1999 and sent to the Cal/EPA Board for approval, it was never released and sent to the legislature.

Despite the cloud of uncertainty over the future viability of biomass energy production in California, the state's biomass energy industry has operated with relatively stability during the latter half of the 1990s. Following the shutdowns of 1994-1996, 27 biomass facilities, representing 540 MW of generating capacity, remained in operation. Twenty operated under intact SO\#4s. The other seven had special circumstances, such as a captive fuel supply or an ability to earn retail-offset for most or all of their electricity output, that allowed them to continue operating. The fixed-price periods in the SO\#4 PPAs came to an end at the end of the 1990s, but the renewables transition fund created by AB 1890 offered biomass generators a supplement of $1.5 \notin / \mathrm{kWh}$ for facilities that did not receive $\mathrm{SO} \# 4$ fixed-scheduled prices for their sales of electricity.

The operating biomass energy generating capacity in California actually increased slightly at the end of the 1990s, to almost $600 \mathrm{MW}$. This was mainly because two 25-MW facilities that had accepted contract buyouts and shut down operations in 1994 had special provisions in their buyouts that provided for restarting the facilities at the end of their fixed-price periods. These facilities resumed operations in 1998 
and 1999, respectively. Biomass fuel use increased by 15\% over its low point following the 1994-1996 shutdowns, but was still more than 30\% lower than the peak level achieved during the early part of the decade. Table 4.1 shows a list of all the biomass energy generation facilities that have operated in California since 1980. Figure 4.4 shows a current map of the California biomass energy facilities, keyed to the list of facilities in Table 4.1.

Figure 4.4: California Power Plants, 2000

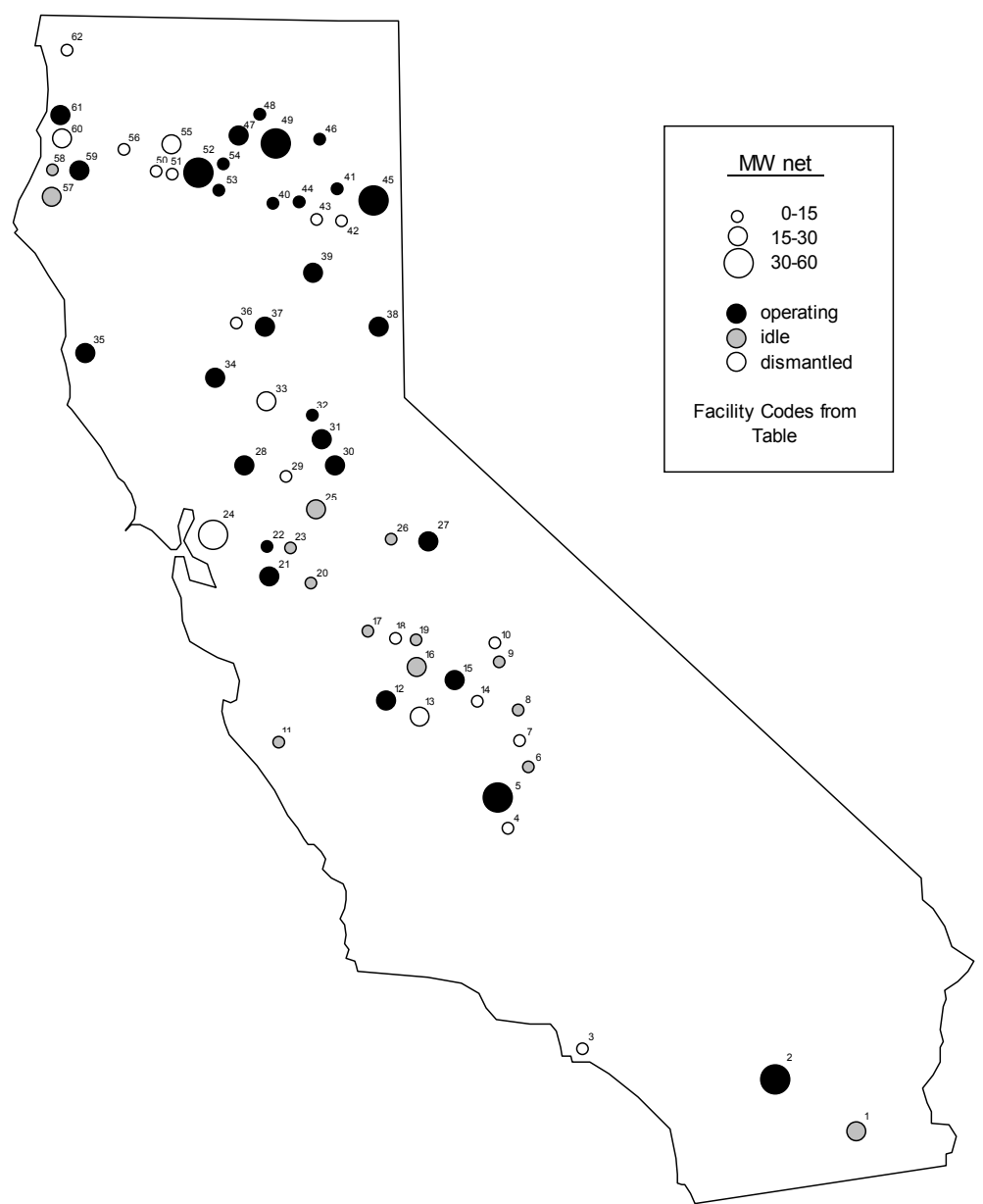


TABLE 4.1:CALIFORNIA BIOMASS POWER PLANTS, 1980-2000

\begin{tabular}{|c|c|c|c|c|c|c|c|c|c|c|c|c|c|}
\hline & Project & County & $\begin{array}{l}\text { Net } \\
\text { MW }\end{array}$ & $\mathrm{mBDT} / \mathrm{y}$ & Cogen & $\begin{array}{l}\text { Own } \\
\text { Fuel }\end{array}$ & $\begin{array}{l}\text { Boiler } \\
\text { Type }\end{array}$ & $\underline{\text { Status }}$ & Utility & PPA & $\begin{array}{l}\text { Start } \\
\underline{\text { Up }}\end{array}$ & $\begin{array}{l}\text { Shut } \\
\text { Down }\end{array}$ & $\begin{array}{l}\text { Re- } \\
\text { Start }\end{array}$ \\
\hline 1 & $\overline{\text { Western Power }}$ & $\overline{\text { Imperial }}$ & $1 \overline{15.0}$ & 122 & & & $\overline{\text { grate }}$ & $\overline{\text { Idle }}$ & $\overrightarrow{\mathrm{SCE}}$ & so $\overline{\# 4}$ bo & $1 \overline{990}$ & $\overline{1996}$ & \\
\hline 2 & Colmac Energy & Riverside & 47.0 & 330 & & & $\mathrm{cfb}$ & Operating & SCE & SO\#4 & 1992 & & \\
\hline 3 & Proctor \& Gamble & Los Angeles & 13.5 & 98 & $x$ & & grate & Dismantled & SCE & Pre so & 1985 & 1988 & \\
\hline 4 & Apex Orchard & Kern & 5.5 & 48 & $x$ & & grate & Dismantled & PG\&E & Pre SO & 1983 & 1988 & \\
\hline 5 & Thermo Ecotek Delano & Tulare & 48.0 & 375 & & & $\mathrm{bfb}$ & Operating & SCE & SO\#4 & 1991 & & \\
\hline 6 & Sierra Forest Products & Tulare & 9.3 & 75 & $x$ & $x$ & grate & Idle & SCE & $\mathrm{SO} \# 4$ bo & 1986 & 1994 & \\
\hline 7 & Lindsay Olive & Tulare & 2.2 & 20 & $x$ & $x$ & grate & Dismantled & SCE & & 1980 & 1993 & \\
\hline 8 & Dinuba Energy & Tulare & 11.5 & 97 & $x$ & $x$ & $\mathrm{bfb}$ & Idle & PG\&E & SO \#4 bo & 1986 & 1995 & \\
\hline 9 & Auberry & Fresno & 7.5 & 70 & $x$ & $x$ & $\mathrm{bfb}$ & Idle & PG\&E & so \#4 bo & 1986 & 1994 & \\
\hline 10 & North Fork & Madera & 8.0 & 68 & $x$ & $x$ & $\mathrm{bfb}$ & Dismantled & PG\&E & SO \#4 bo & 1988 & 1994 & \\
\hline 11 & Soledad Energy & Monterey & 13.5 & 98 & & & $\mathrm{bfb}$ & Idle & PG\&E & $\mathrm{SO} \# 4$ bo & 1990 & 1994 & \\
\hline 12 & Thermo Ecotek Mendota & Fresno & 25.0 & 185 & & & $c f b$ & Operating & PG\&E & SO\#4 & 1990 & & \\
\hline 13 & Agrico Cogen & Fresno & 25.0 & 198 & $\mathrm{x}$ & & grate & Conv. to gas & PG\&E & So\#2 & 1990 & 1991 & \\
\hline 14 & Sanger (biomass $\rightarrow$ feed) & Fresno & 0.0 & 50 & $x$ & & - & Dismantled & NA & NA & 1991 & 1991 & \\
\hline 15 & Rio Bravo Fresno & Fresno & 25.0 & 180 & & & $\mathrm{cfb}$ & Operating & PG\&E & SO\#4 & 1989 & 1994 & 1998 \\
\hline 16 & SJVEP--Madera & Madera & 25.0 & 182 & & & $\mathrm{bfb}$ & Idle & PG\&E & SO \#4 bo & 1990 & 1995 & \\
\hline 17 & SJVEP--EI Nido & Merced & 10.2 & 88 & & & $\mathrm{bfb}$ & Idle & PG\&E & $\mathrm{SO} \# 4$ bo & 1989 & 1995 & \\
\hline 18 & SJVEP--Chowchilla I & Madera & 9.9 & 99 & & & grate & Dismantled & PG\&E & $\mathrm{SO} \# 4$ bo & 1988 & 1995 & \\
\hline 19 & SJVEP--Chowchilla II & Madera & 10.8 & 90 & & & $\mathrm{bfb}$ & Idle & PG\&E & SO \#4 bo & 1990 & 1995 & \\
\hline 20 & Redwood Food Pkg & Stanislaus & 4.5 & 36 & $x$ & $x$ & grate & Idle & PG\&E & SO\#1 & 1980 & 1985 & \\
\hline 21 & Tracy Biomass & San Joaquin & 19.5 & 150 & & & grate & Operating & PG\&E & SO\#4 & 1990 & & \\
\hline 22 & Diamond Walnut & San Joaquin & 4.5 & 35 & $\mathrm{x}$ & $x$ & grate & Operating & PG\&E & Pre SO & 1981 & & \\
\hline 23 & California Cedar Products & San Joaquin & 0.8 & 11 & $x$ & $x$ & grate & Idle & PG\&E & SO\#1 & 1984 & 1991 & \\
\hline 24 & Gaylord Antioch & Contra Costa & 30.0 & 225 & $x$ & & grate & Conv. to gas & PG\&E & Pre SO & 1983 & 1990 & \\
\hline 25 & Jackson Valley, lone & Amador & 18.0 & 140 & & & & Idle & PG\&E & negotiated & 1998 & 1999 & \\
\hline 26 & Fiberboard, Standard & Tuolumne & 3.0 & 27 & $\mathrm{x}$ & $x$ & grate & Idle & PG\&E & Pre SO & 1983 & 1996 & \\
\hline 27 & Chinese Station & Tuolumne & 22.0 & 174 & & & bfb & Operating & PG\&E & $\mathrm{SO} \# 4$ & 1987 & & \\
\hline 28 & Thermo Ecotek Woodland & Yolo & 25.0 & 200 & & & $\mathrm{cfb}$ & Operating & PG\&E & SO\#4 & 1990 & & \\
\hline 29 & Blue Diamond Growers & Sacramento & 9.5 & 68 & $x$ & $x$ & grate & Dismantled & PG\&E & Pre SO & 1982 & 1996 & \\
\hline 30 & Wheelabrator Martell & Amador & 18.0 & 135 & $x$ & $x$ & grate & Operating & \multicolumn{2}{|c|}{ Industrial Cust. } & 1987 & & \\
\hline 31 & Rio Bravo Rocklin & Placer & 25.0 & 180 & & & $\mathrm{cfb}$ & Operating & PG\&E & SO \#4 & 1990 & 1994 & 1999 \\
\hline 32 & Sierra Pacific Lincoln & Placer & 8.0 & 70 & $x$ & $x$ & grate & Operating & PG\&E & SO\#4 & 1985 & & \\
\hline 33 & EF Feather River & Yuba & 16.5 & 150 & & & $\mathrm{cfb}$ & Dismantled & PG\&E & $\mathrm{SO} \# 4$ bo & 1987 & 1993 & \\
\hline 34 & Wadham Energy & Colusa & 26.5 & 209 & & & $\mathrm{cfb}$ & Operating & PG\&E & So\#4 & 1989 & & \\
\hline 35 & Georgia Pacific & Mendocino & 15.0 & 119 & $\mathrm{x}$ & $x$ & grate & Operating & PG\&E & SO\#1 & 1987 & & \\
\hline 36 & Koppers & Butte & 5.5 & 110 & $x$ & $x$ & grate & Dismantled & PG\&E & So \#2 & 1984 & 1994 & \\
\hline 37 & Ogden Pacific Oroville & Butte & 18.0 & 142 & & & grate & Operating & PG\&E & SO\#4 & 1986 & & \\
\hline 38 & Sierra Pac. Loyalton & Sierra & 17.0 & 134 & $x$ & $x$ & grate & Operating & \multicolumn{2}{|c|}{ Sierra Pacific } & 1990 & & \\
\hline 39 & Sierra Pacific Quincy & Plumas & 25.0 & 200 & $x$ & $x$ & grate & Operating & PG\&E & SO\#4 & 1987 & & \\
\hline 40 & Collins Pine & Plumas & 12.0 & 90 & $x$ & $x$ & grate & Operating & PG\&E & So\#2 & 1986 & & \\
\hline 41 & Sierra Pac. Susanville & Lassen & 13.0 & 105 & $x$ & $x$ & grate & Operating & PG\&E & SO\#4 & 1986 & & \\
\hline 42 & Lassen College & Lassen & 1.5 & 12 & $x$ & & grate & Dismantled & PG\&E & SO\#1 & 1985 & 1987 & \\
\hline 43 & Jeld Wen Industries & Lassen & 2.5 & 20 & $x$ & $x$ & grate & Conv. to gas & PG\&E & Pre SO & 1984 & 1992 & \\
\hline 44 & Ogden Westwood & Lassen & 11.4 & 90 & & & grate & Operating & PG\&E & SO\#4 & 1985 & & \\
\hline 45 & Honey Lake Power & Lassen & 30.0 & 225 & & & grate & Operating & PG\&E & SO \#4 & 1989 & & \\
\hline 46 & Big Valley Lumber & Lassen & 7.5 & 59 & $x$ & $x$ & grate & Operating & PG\&E & Pre So & 1983 & & \\
\hline 47 & Sierra Pacific Burney & Shasta & 17.0 & 145 & $x$ & $x$ & grate & Operating & PG\&E & SO\#4 & 1987 & & \\
\hline 48 & Ogden Burney & Shasta & 10.0 & 77 & & & grate & Operating & PG\&E & $\mathrm{SO} \# 4$ & 1985 & & \\
\hline 49 & Burney Forest Products & Shasta & 31.0 & 245 & $x$ & $x$ & grate & Operating & PG\&E & SO\#4 & 1990 & & \\
\hline 50 & Roseburg Lumber & Shasta & 4.0 & 32 & $x$ & $x$ & grate & Dismantled & PG\&E & Pre SO & 1980 & 1992 & \\
\hline 51 & Paul Bunyan & Shasta & 3.0 & 24 & $x$ & $x$ & grate & Dismantled & PG\&E & Pre SO & 1980 & 1992 & \\
\hline
\end{tabular}

The year 1999 saw a renewal of interest in PPA buyouts. One small facility, which was already operating past its fixed-price period, accepted a buyout agreement for its remaining capacity obligation and shut down. One of the state's largest facilities accepted a buyout of its contract, and remains in operation as a merchant power facility, although its future viability is in doubt. Other possible buyouts were in various stages of discussion, and future shutdowns are possible as the new century begins. The cap on the renewable transition supplement paid to biomass generators decreased to $1.0 \notin / \mathrm{kWh}$ on January 1,2000 , and more than $100 \mathrm{MW}$ of capacity will see their fixed-schedule energy provisions expire during 2000. No biomass support measures have yet been enacted. The industry's future remains very much in doubt. 


\section{Characteristics of California's Biomass Power Plants}

Gregory Morris of the Green Power Institute has developed and maintained an extensive database on the California biomass energy industry (Morris 1997), which has been brought up to date as part of this project. The California biomass energy database contains information about every solid fuel biomass energy generating facility that has operated in California since 1980. The database includes information about biomass fuel use and price on an annual basis, and annual electricity production, for the 20 -year period covered, 1980-1999, as well as projections for the current year (2000). This database is the source of much the data used in the environmental and economic analyses in this report.

Sixty-two biomass energy generating facilities have operated in California during the past 15 years. Twenty-nine still operate. Eighteen have been dismantled or otherwise modified to render them no longer available for service as biomass energy facilities. Most of the remaining 15 facilities are currently idle and available for future operations. They are located throughout the state, as shown in Figure 4.4. Half obtain at least some of their fuel from captive sources, although only a few obtain all their fuel from captive sources. Thus, most have participated in the state's biomass fuels marketplace. California biomass facilities range from 1-50 MW, with annual fuel requirements of 10,000-750,000 tons/year.

All biomass energy generation facilities in California employ conventional steam-turbine technology for converting biomass fuels to electricity. This technology has been in use for almost 100 years, and has been used extensively with a wide variety of fuels, including biomass and fossil fuels. Nevertheless, the technology continues to evolve, and has shown significant improvement as the modern biomass energy industry in California has developed. Much of the development since 1980 has been in the area of environmental performance, which includes improvements in combustion technology and in emissionscontrol technology.

Most of California's biomass power plants employ conventional biomass combustion technology with fixed or traveling grate furnaces. Seventeen of the facilities were built with fluidized-bed boilers, including bubbling bed and circulating bed configurations. Fluidized-bed boilers provide for lower emissions and higher efficiency than conventional boilers, but have higher capital and operating costs. The major deployment of fluidized-bed biomass boilers has contributed valuable learning experience to the continuing technological refinement and commercial development of this promising technology.

The industry is poised to continue to contribute to technological innovation in the biomass energy arena as the twenty-first century begins. The newest biomass generating facility in the state, taking advantage of the IRS Section 29 gasification tax credit, employs a close-coupled gasifier as part of its combustion system, achieving high efficiency and low emissions. Several biomass facilities are considering the development of associated ethanol production operations as an enhancement to the overall energy production enterprise. It is hoped that synergies between the electricity production enterprise and the ethanol production enterprise, such as shared biomass procurement and handling facilities, and segregation of the resource into higher and lower valued outlets, will provide benefits to both. The California biomass energy industry can contribute to future biomass technology innovation only if it continues to be viable in the near-term.

Fuel Use and Alternative Disposal Options for Biomass Residues in California

The biomass energy industry in California can be thought of as much as a solid waste disposal service provider as an electricity generating enterprise. It provides for the disposal of 6.4 million tons/year of the state's solid wastes. The biomass residues used as fuel come from a variety of sources, and would be subject to a variety of alternative fates, such as open burning or landfill burial, if the biomass industry were not a disposal option. The major categories of biomass fuels used in California include:

- Wood processing residues

- In-forest residues 
- $\quad$ Agricultural residues

- Urban wood residues

Most biomass generating facilities in California were built with an expectation of using either wood processing residues or agriculture residues as their major fuel source. The facilities designed to burn primarily agricultural residues are concentrated in the Central Valley. Those designed to burn primarily residues from the forest products industry are concentrated in the northern and eastern mountain regions. Three biomass facilities were designed to burn primarily urban wood waste. These were located close to the Los Angeles and San Francisco Bay Areas. Urban wood waste fuels, which were largely ignored during the industry's development, have become far more important than anyone originally anticipated. They are second only to sawmill residues in terms of their contribution to the California biomass fuels market.

Several California biomass facilities burn supplemental fuels in addition to solid biomass residues. Biomass energy facilities that are qualifying facilities (QFs) are allowed to obtain as much as $25 \%$ of their input heat from conventional fossil fuels. In addition, they can burn unlimited quantities of other renewable fuels or approved waste materials, such as petroleum coke and old tires. Landfill gas, ${ }^{4}$ tires, and petroleum coke are the major supplemental fuels used by the state's biomass generators. One facility uses geothermal heat to preheat boiler water.

\section{Wood Processing Residues}

Wood processing residues are the waste materials produced during the processing and conversion of lumber into wood products. Those residues are the most important biomass fuel source in California, consistently accounting for more than one-third of the total biomass fuel supply used. Almost half the biomass content of a typical sawlog becomes residue at a primary sawmill. A variety of secondary forestry industries have been developed to use some of this material. Active markets for wood processing residues include pulp chips, wood fiber for fiberboard and composites, animal bedding, and garden products such as decorative bark. Sawmills are used to segregating their residues into the highest-value markets available, but a substantial quantity of the residues, typically $15 \%-20 \%$ of the total biomass in a sawlog, has no useful application and must be disposed of. Wood-processing residues are produced in a variety of forms, including:

\begin{tabular}{ll} 
- & Bark \\
- & Round-offs \\
- & End cuts \\
- & Trimmings \\
- & Sawdust \\
- & Shavings \\
\hline & Reject lumber
\end{tabular}

The traditional method of disposing of sawmill residues in California before the biomass energy industry was developed was incineration in teepee burners, a technology that produces large quantities of smoke and air pollution. Beginning in the early 1970s, air pollution control efforts applied increasing pressure on sawmills to close down their teepee burners, leading them to look for new disposal alternatives. This was one important factor that led to the early development of the biomass industry in California. Virtually all the readily available wood processing residues generated that have no higher valued application are now used as power-plant fuel.

\footnotetext{
${ }^{4}$ California has 30 power generation installations powered exclusively by landfill gas. This report is focused on the solid fuels biomass power industry, and does not cover the landfill gas facilities.
} 
Teepee burners are no longer used to dispose of wood processing residues in California. The only readily available option for disposing of these materials, if fuel use were not a possibility, would be landfill burial - a highly undesirable alternative. Waste wood has a slower decay rate than other forms of biomass in the landfill environment, and thus is slower to stabilize. Moreover, state solid waste policy is strongly oriented to reducing the amount of material being buried in landfills, and introducing a sizable new waste stream would make compliance with recycling regulations almost impossible.

If there were no biomass energy industry in California today, some sawmill residues currently used for fuel would be used for energy production in sawmill kiln burners, an old disposal option for some of a sawmill's residues. This application would probably use one-third or more of the residues currently used for power production. A small quantity would be composted and/or spread; the rest would be landfilled.

Wood processing residues are the cheapest of the four categories of biomass fuels to produce and deliver to the power plants. They form the backbone of the state's biomass fuel supply, and would probably be the last type of fuel to exit the system if the demand for biomass fuels state declined. The major factor that determines the quantity of mill residues used as fuel in California is the level of activity in the forest products industry. Economic factors and environmental restrictions on timber supplies have led many sawmills to shut down. This has led to a decline in the amount of wood processing residues used as power plant fuels, which began during the early 1990 s.

\section{In-Forest Residues}

In-forest biomass residues include two major categories: residues generated in the forest when timber is harvested for wood products, generally called slash, and material naturally occurring in forests whose removal would provide environmental benefits to the remaining forest. Harvesting residues include the tops and limbs of harvested trees, bark when debarking takes place in the forest, and cull $\operatorname{logs}^{5}$ that are cut and removed during harvesting operations. The cheapest way to manage this material is to leave it in the forest as it is generated, but that is also the worst management practice from a forestry perspective, as leaving harvesting residues in the field retards regrowth of the forest and represents a substantial fire hazard. Virtually all timber harvesting contracts in California require loggers to manage the slash they generate. Slash that is generated close enough to an operating biomass energy plant can be collected and converted to fuel. The alternative is to collect the slash and burn it in piles. Open burning leads to high levels of emissions of smoke, particulates, and other air pollutants.

The other category of in-forest residue is overstocked material in vast areas of California's forests. Poor forestry practices and aggressive fire-fighting efforts during most of the past century have resulted in vast areas of the state's forests becoming overstocked with biomass. This material represents an enhanced risk of destructive wildfires, and generally degrades the functioning of the forest ecosystem. Overstocked forests benefit greatly from thinning operations. The quantity of in-forest biomass whose removal would benefit California's forests is far greater than the total amount of biomass fuel demand in the state. However, this fuel source is generally more expensive to produce than other types of biomass fuels, so less is used.

Two basic alternatives can be used to reduce the biomass overloading in standing forests: prescribed burning and mechanical thinning. The primary goal of reducing fire risks in standing forests is to protect mature trees. Most of the tonnage of forest overgrowth biomass is material on and near the forest floor, called ground fuel. Periodic fires in undisturbed California forests tended to be primarily ground fires, and control the buildup of these materials. When ground fuels are left uncontrolled for prolonged periods, such as in areas where fires have been excluded for 75 years or more, some of the undergrowth

\footnotetext{
${ }^{5} \mathrm{Cull} \operatorname{logs}$ are trees that are diseased, damaged, misshapen, or otherwise unsuitable for use in producing commercial wood products.
} 
begins to grow into taller poles, which become "ladder fuels." Ladder fuels provide a mechanism to transfer ground fires to the crowns of mature trees in the forest, thus greatly increasing the damage caused by the fires, in the worst cases turning benign ground fires into out-of-control, destructive wildfires. Traditional commercial harvesting operations do not affect the fuel overloading problem in the forest, because neither ground nor ladder fuels are removed. In fact, if slash is left untreated, the fire risk can be increased. Mechanical thinning and prescribed burning remove ladder and ground-based fuels.

Forestry officials would like to see large areas of California's forests thinned. An official of the U.S. Forest Service, which manages approximately one-half the state's forest land, has asserted that at least 250,000 acres per year of the land under their jurisdiction needs to be thinned to fully realize the desirable fire suppression, forest health, and watershed improvement benefits (Morris 1998a). During the peak of the California biomass fuels market in the early 1990s only about 60,000 acres per year were being thinned statewide for fuel production. With the decline in biomass fuels demand that occurred in the middle of the decade, the level of thinning for fuels production has been cut by more than half.

The alternative to biomass fuels production for reducing overstocking in the state's forests is prescribed burning. However, environmental and safety concerns may limit the amount of prescribed burning that will be allowed in California. Prescription burning produces more pollution per ton of material consumed than open burning of biomass in piles (EPA 1995). In addition, prescribed burning in densely overstocked forest stands entails a significant risk of residual stand damage and may initiate of offsite, uncontrolled wildfires. The recent massive wildfire in Los Alamos, New Mexico, has already become a notorious example of a prescribed burn running amok, but northern California has experienced this phenomenon on a smaller scale repeatedly during the past decade. Mechanical thinning and residue removal before prescription burning reduces the pollution and risk factors associated with the treatment, and in some cases can eliminate the need to burn. Mechanical thinning, however, is expensive, and rarely performed in the absence of fuel applications for the thinned material.

\section{Agricultural Residues}

Agriculture is a multibillion-dollar enterprise in California, producing large quantities of biomass residues in the process. Approximately one-third of California's biomass energy plants were built in the state's agricultural regions in order to use these residues as fuel. Many receive emissions offsets for pollutants that are avoided when biomass residues that would otherwise be open burned are used for energy production. Agricultural fuels provide about $20 \%$ of the state's biomass fuel supply. Agricultural residues come in a wide variety of forms, some which are unsuitable for use as power plant fuel. Agricultural residues suitable for fuel use in solid-fuel biomass energy plants include materials in the following categories:

- $\quad$ Food processing residues such as pits, shells, and hulls

- $\quad$ Orchard and vineyard removals

- $\quad$ Orchard and vineyard prunings

- $\quad$ Field straws and stalks

Food processing residues are generated in concentrated quantities and require some form of disposal. Like wood products manufacturers, food processors have worked diligently to develop high-valued uses for these materials, such as in feed products. Nevertheless, a surplus of food processing residues is available for use as biomass fuel. In the absence of fuel markets, these materials would otherwise be buried in a landfill or open burned. Some wastes that have been used as fuels in California, such as nut hulls, shells, pits, and rice hulls, present special combustion problems that limit their application to facilities able to deal with these materials. Several pioneering biomass generating facilities were built at food processing facilities specifically to dispose of the processing residues. Although some experienced 
operating problems when first starting up, most were able to adapt and adjust their equipment to handle the specific fuels.

California's agriculture includes extensive plantings of orchards and vineyards, permanent woody crops that require annual pruning operations and produce large quantities of residues. Conventional agricultural practice for the disposal of these prunings is to pull them to the sides of the rows, where they are piled and burned. It has long been recognized that agricultural burning is a major contributor to the air pollution problems in California's major agricultural regions. During the early development of the biomass energy industry there was a great deal of interest in using orchard and vineyard prunings as fuels. Combustion of this material in a power plant greatly reduces the resulting emissions of smoke and air pollutants compared with open burning. In addition to the environmental benefits anticipated, many farmers were under the impression that fuel sales would offset the cost of pruning, and even create a new profit center for their operations.

Orchard and vineyard prunings are more expensive and difficult to use as fuels than was originally anticipated. This is a consequence of two factors. First, the density of the resource (tons per acre) is less than originally projected. The result of this miscalculation is that more area needs to be covered to produce a given amount of fuel, which results in concomitant increase in fuel production cost. Second, compared with other sources of biomass boiler fuels, prunings are very stick-like, which makes them more difficult to process into fuel form and creates a special hazard for fuel handling and delivery equipment at the power plant. These considerations have limited the amount of fuel produced from orchard prunings in California. It is estimated that less than $7.5 \%$ of the state's agricultural prunings are being converted to fuel in the current market environment. The remainder continues to be open burned.

In contrast to the experience with prunings, orchard and vineyard removals constitute very desirable source of biomass fuel. Orchards and vineyards are cleared periodically for purposes of replanting, and in response to changing land use decisions. Orchard clearing, in particular, provides a high density of material (tons per acre) that can be processed into conventional whole tree chips. In addition, this material is generally felled in the mid to late summer from plantations that have not been irrigated, the wood is often very dry compared with other sources of recently cut biomass fuels. Fuels derived from orchard clearings, and to a more limited extent from vineyard clearings, are the major agricultural residue fuels used in California.

California agriculture also produces large quantities of field residues in the forms of straws and stalks that are disposed of either by open burning, or by plowing under in the fields. These residues can be collected and processed into power plant fuels. Straw and stalk-based fuels tend to be expensive to produce, and their low bulk density $\left(\mathrm{lb} / \mathrm{ft}^{3}\right)$ presents materials handling problems and combustion difficulties. As a result, very little of this material contributes to the fuel supply, even though these materials qualify as agricultural offset fuels.

Most agricultural residues used as fuels in California are woody residues derived from extensive orchard crops. Whole-tree chips produced from orchard removals constitute a particularly successful source of biomass fuel. Even with the present level of agricultural biomass fuel use, an enormous amount of agricultural residues suitable for use as power plant fuels continues to be open burned. The alternative fate for most agricultural residues used for fuel is open burning, although a small percentage of these materials would likely be landfilled or plowed under in the absence of fuel applications.

\section{Urban Wood Residues}

Fifteen to twenty percent of the material traditionally disposed in municipal landfills is clean, separable waste wood. This material comes from a variety of sources, including: 
- Waste wood from construction contractors

- $\quad$ Old and damaged pallets

- Waste wood from land clearing

- Waste wood from public and private tree trimmers and landscapers

- Waste wood from industrial manufacturers, including packing materials and trimmings

Urban wood residues are brought to landfills in a variety of forms, including loads of chipped wood and brush from public and private tree trimmers and land clearers, debris boxes from manufacturers of wood products and construction contractors, and mixed loads of yard debris. Some amount of demolition wood waste is also used as a biomass fuel, although many facilities have permit restrictions that prohibit the use of painted wood and/or treated wood because of emissions concerns. Transfer station and landfill operators can segregate loads containing fuel-usable materials as they enter the gate, and process the material to produce a high-quality fuel product. Urban wood residues contribute much more to California's biomass fuels mix than anyone anticipated during the early development of the industry.

Landfill-diverted waste wood supplied about 1.5 million tons of fuel annually to the biomass energy industry during the 1990s, hitting a peak of 1.9 million tons in 1993. As the overall biomass fuels market declined through the decade, the percentage of landfill-diverted fuels in the state's biomass fuel mix has increased, from approximately $20 \%$ at the beginning of the decade, to $30 \%$ today. Landfill-diverted waste wood is the second cheapest source of biomass fuel to produce after sawmill residues, in large part because of the pressure to divert wastes away from landfill disposal.

The traditional disposal option for urban wood waste is burial in landfills. However, the alternative disposal options that might be available for this material in the future, should the fuels market disappear, are more complicated to project. California's solid waste diversion law, AB 939, mandates that by the end of 2000 all counties must achieve a diversion rate of $50 \%$ of their total solid waste, compared to their performance during 1990. An intermediate target of $25 \%$ diversion by 1995 was met statewide, but compliance with the year 2000 standards will be significantly more difficult to achieve. Peak urban biomass fuel use of 1.9 million tons/year represents $6.6 \%$ of the amount of solid waste that must be diverted statewide by the end of 2000 .

Solid waste managers are under pressure to develop diversion applications of all kinds. The alternatives, however, are limited, and most of the obvious markets that can accept waste wood, such as spreading as mulch or composting, are already being flooded with material. Most of the urban biomass fuels would otherwise probably be landfilled; some would be spread as mulch or composted.

\section{The California Biomass Fuels Market}

During the early development of the biomass energy industry in California, wood processing and agricultural residues provided virtually all the fuel used by the various biomass power producers. As the industry grew the use of these sources of fuel grew in step, and two new sources of fuel were introduced: in-forest residues and urban wood residues. Figure 4.5 shows the time course of the use of the four categories of biomass fuels as a function of fuel type. Wood processing residues have continued to be the primary source of supply for the biomass energy industry throughout the period covered by this study. The use of wood processing residues as fuel increased rapidly during the 1980 s, peaking in 1990 at more than 5.5 million tons/year. At that point all but the most remote wood processing residues were being used as biomass fuels. 


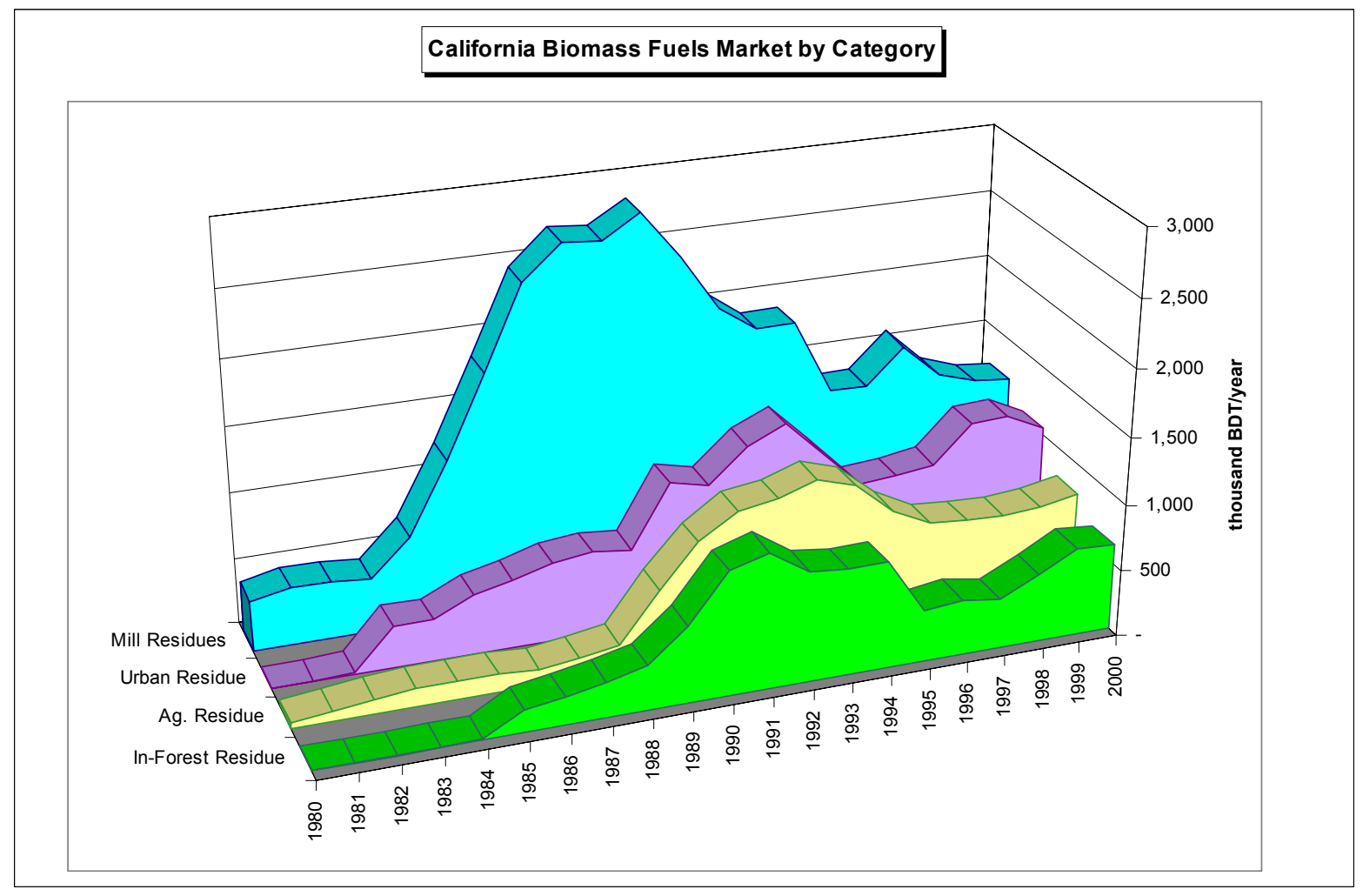

Figure 4.5

Although the demand for biomass fuels remained relatively stable during the early 1990s, the use of mill residues dropped dramatically during this period. This was a result of the fact that sawmilling activity in the state declined in response to poor economic conditions and increasing environmental restrictions on the supply of round wood. At the same time supplies of the other types of biomass fuels became more available as high biomass fuel prices and long-term fuel supply contracts required by the financial institutions that funded the power plants stimulated a variety of new ventures in the fuel supply business. As the lowest-cost-to-produce fuel source, mill residues are used to the full extent they are available. The state's biomass energy industry would have to shrink to less than half its current size before significant quantities of mill residues would start to be disposed of using alternative disposal options.

The other category of biomass fuels that has been in use since the beginning of the development of the biomass energy industry is agricultural residue fuels. The first agricultural fuels to be used were food processing residues such as nut hulls and pits. Several pioneering biomass energy facilities were built at food processing facilities to provide for the disposal of these materials. Expansion of the use of agricultural fuels has been more gradual than many industry observers originally predicted, because converting of orchard and vineyard prunings to fuels was more difficult and expensive than originally projected. Agricultural fuel use increased significantly between 1988 and 1990, as the statewide biomass fuel crisis hit, and many new facilities entered operation with permit requirements to burn agricultural wastes to offset their air pollutant emissions. With the closure of many agricultural fuels-based facilities during the mid-1990s, agricultural residue fuel use declined by about $33 \%$ from its peak in the early part of the decade.

Urban waste wood began to contribute to the state's biomass fuel mix in 1983, when Gaylord Paper Corp. started up its pioneering facility in the San Francisco Bay area. This facility was designed to burn 
primarily urban waste wood fuel, and was a very successful venture. In 1985 a second facility designed to burn urban wood fuel, Procter \& Gamble, began operations in the Long Beach (Los Angeles) area. These two facilities, located in the two largest metropolitan areas, stimulated the development of a market for producing fuel from material that was traditionally buried in landfills.

As the technical viability of using urban waste wood fuels was proven, biomass energy facilities designed to burn primarily sawmill and agricultural residue fuels began purchasing fuels derived from urban waste wood, and the use of urban biomass fuels in California increased gradually during the mid-1980s. When the statewide biomass fuel crisis hit at the end of the decade, urban biomass fuel use doubled, reaching approximately 1.5 million tons/year in 1990. This fuel source continued to grow over the next several years, as statewide fuel demand remained stable and the availability of wood processing residues decreased. Urban biomass fuel use peaked at almost 1.9 million tons in 1993. Urban biomass fuel use contracted to below 1.2 million tons/year as overall biomass fuel demand declined with the shutdowns of the middle of the decade, then began to pick up again as the 1990s came to a close. With increasing pressure to divert material from landfill disposal to comply with AB 939, urban biomass fuel use currently exceeds 1.5 million tons/year.

In-forest residues are the most expensive of the four types of biomass fuel sources used in California. Significant in-forest fuel production did not begin until 1985, and grew gradually until the end of the decade, when the statewide fuel crisis forced fuel prices above $\$ 40 / \mathrm{bdt}$. In-forest biomass fuel use peaked in 1990-1991 at about 1.8 million tons/year, then began to fall as the market reached equilibrium, sawmilling activity recovered slightly, and cheaper urban and agricultural fuels out competed in-forest fuels. When the buyouts and closures hit the biomass energy industry in 1994-1995, in-forest biomass fuel use took the greatest hit, dropping to less than 700,000 tons/year in 1997. Since then in-forest residue fuel use has rebounded to more than 1 million tons/year.

\section{Biomass Fuel Market Price Trends}

Before the development of the modern biomass energy industry in California most agricultural and woodprocessing residues, as well as a significant quantity of the forest harvesting residues, were being open burned, while urban wood residues were being buried in landfills. In addition, the amount of overstocking of fuel in the state's forests was increasing relentlessly, a process that has spanned the entire twentieth century. These disposal alternatives have economic costs as well as adverse environmental consequences. The early development of the state's biomass energy industry was spurred as much by sawmills and food processors looking for improved disposal options for their residues, as by the incentives provided by the energy sector.

During the early development of the biomass fuels market in California, a surplus of residue material was available for conversion to fuel, and fuel prices were based primarily on the cost of processing the residues and transporting them to the power plants. During the early 1980s, biomass fuel prices were stable, about $\$ 15-20$ per bdt. Some sawmill residues were sold to nearby generating facilities for less than $\$ 10 /$ bdt. Figure 4.6 shows the average price of biomass fuels as a function of time. 
Figure 4.6

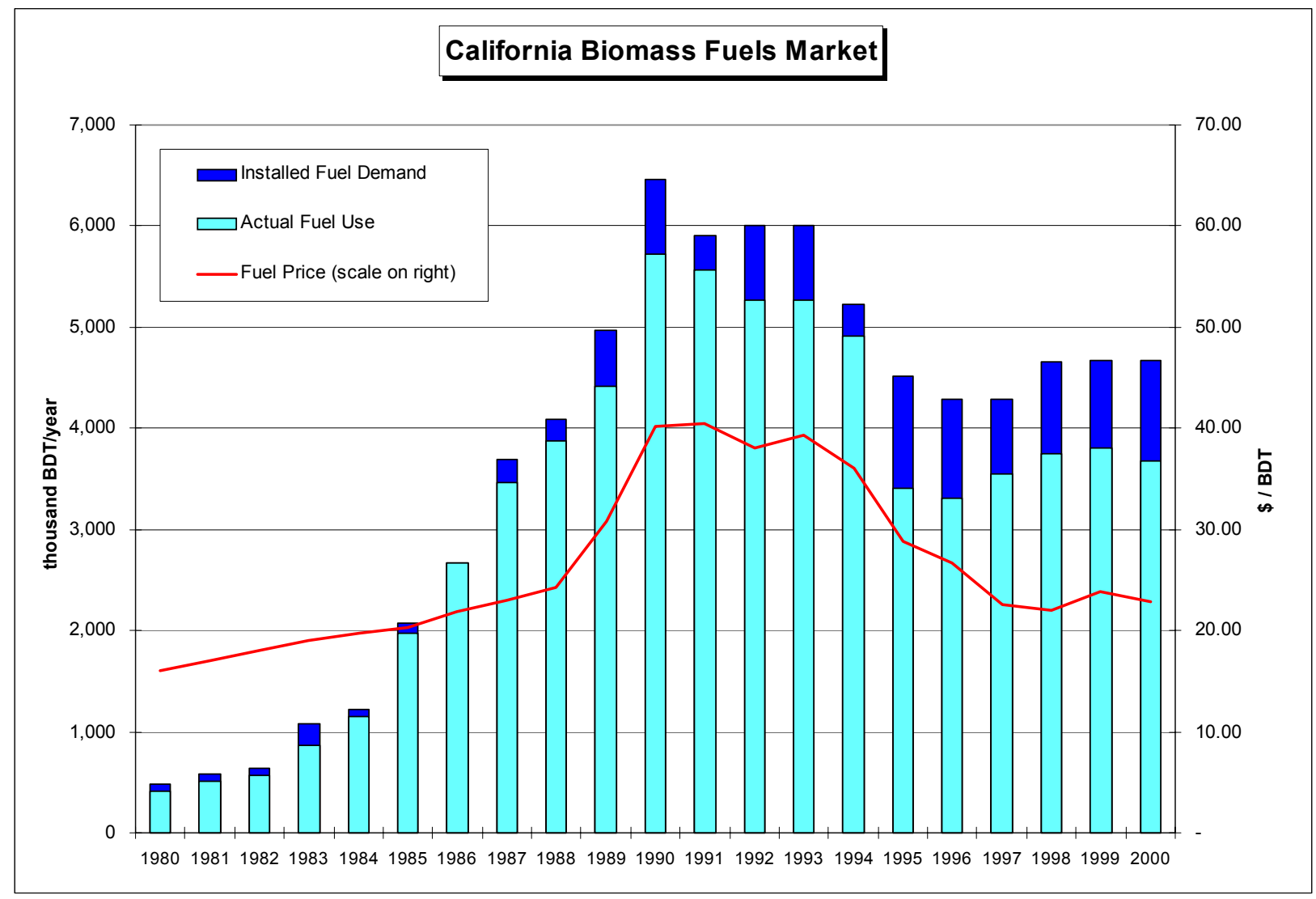

As biomass fuel demand increased during the mid to late 1980s, the average statewide price of biomass fuels began to climb upward, reaching an average value of almost $\$ 25 /$ bdt by 1988 . From 1980 to 1988 , fuel demand grew at a greater rate than the rate of increase in fuel prices. The inflation-corrected price of biomass fuel was virtually unchanged during this period. From that point forward, however, fuel demand reached a critical level, and prices shot up, reaching more than $\$ 40 /$ bdt during the early 1990s, with spot prices reportedly tipping $\$ 60 / \mathrm{bdt}$. The industry appeared to be in a full-blown fuel crisis, which was precipitated by the extremely rapid increase in generating capacity, and the requirements for long-term fuel supply contracts imposed by the banks on the power plants as a condition of funding.

By 1988, statewide biomass fuel demand had grown to the point that it exceeded the capacity to provide biomass fuels. The cheapest source of biomass fuels, mill residues, was completely committed to the fuels market, and additional mill residues were no longer available to satisfy new fuel demand. New sources of biomass fuels were required, and significant investments had to be made to develop the new fuel supplies. In general, the new supplies of fuel were more expensive than the fuel sources that had already been developed. These were all factors in the rapid increase in biomass fuels prices that occurred between 1988 and 1990, during which statewide average biomass fuel prices increased by approximately $60 \%$.

By the end of 1990 the demand for biomass fuels stabilized, as did the price, which averaged about $\$ 40 /$ bdt. The fuel-supply infrastructure had a chance to catch up with the demand, and a great deal of experience was accumulating with respect to the technologies necessary to produce power plant fuels from new sources of biomass, such as urban wood residues and various types of agricultural and in-forest residues. Fuel prices might have decreased somewhat during the early 1990s as a better balance was 
achieved between supply and demand, except that the supply of mill residues decreased significantly because of a cutback in lumber production (see Figure 4.5). Thus, the pressure for fuel price decreases due to an improved supply-demand balance was countered by the loss from the market of a fraction of the wood processing residues. The loss of wood processing residues had to be made up for by sources of supply that were more expensive to produce.

Beginning in 1994, the regulated California electric utility companies, in response to the deregulation process at the CPUC, initiated a series of buyout negotiations with many biomass generating facilities. Owners of approximately 200 MW of capacity accepted buyouts during 1994 and 1995, shutting down $25 \%$ of the state's operating capacity, and decreasing the demand for biomass fuels by more than onethird. Supply and demand were again out of balance, and fuel prices began a fall that brought them back to pre-1988 levels. Figure 4.7 shows a plot of the supply curve for biomass fuels in California. The data points represent the period 1986 to the present, showing, for each year in the range, the quantity of biomass fuel used and the average price.

Figure 4.7

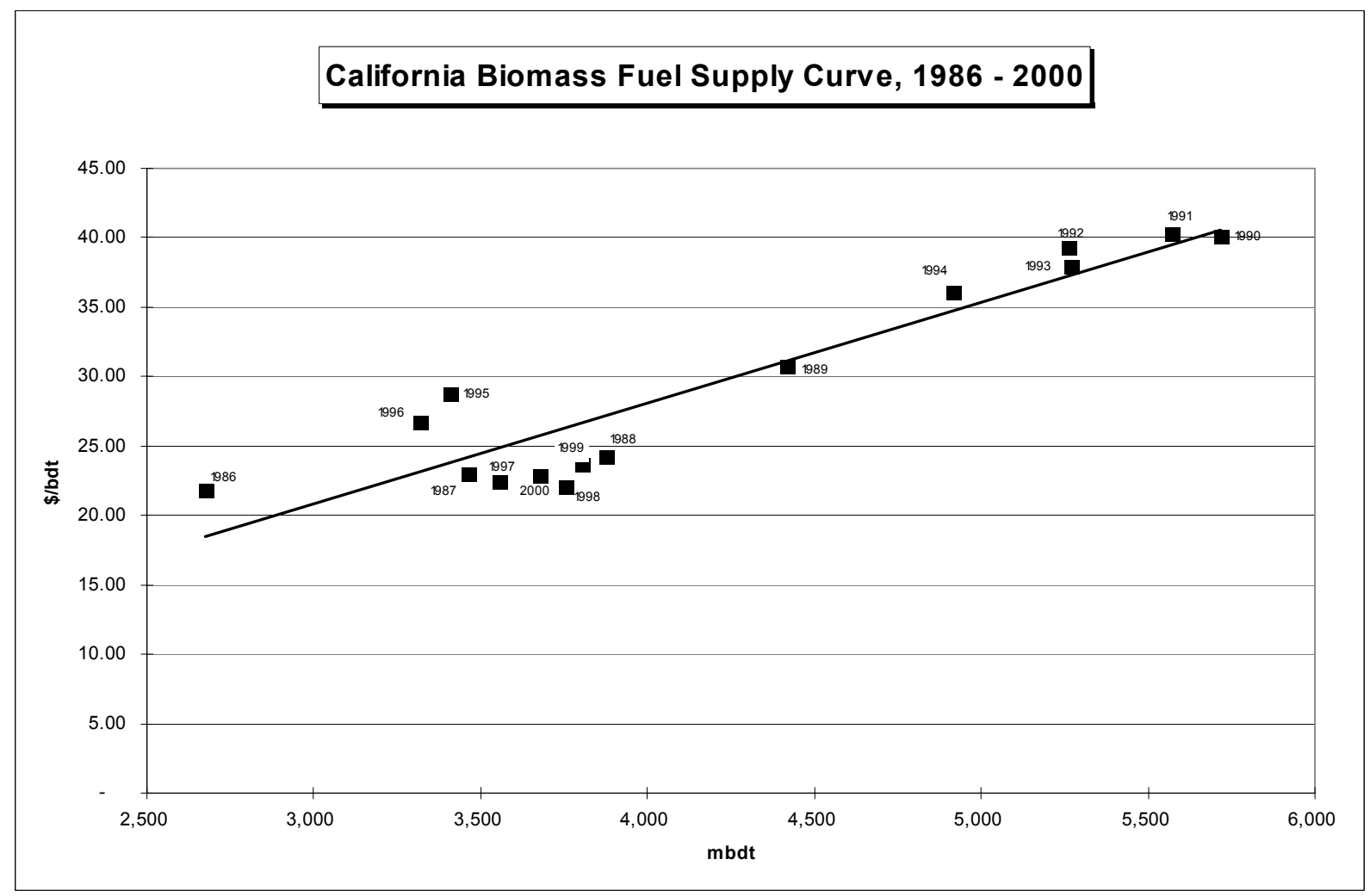

The future for biomass fuel prices in California is difficult to predict. The renewable transition fund payments to biomass generators over the past 2 years have provided sufficient incentive for generators earning SRAC rates to increase their production during off-peak hours, compared with what they were doing before the transition funds were available. This, combined with the restart of two twenty-five MW facilities, has increased total fuel use, with a concomitant rise in fuel prices. As fixed-price periods expire for more facilities, and the renewable transition fund payments are ramped down and disappear by the end 
of 2001, this upturn in statewide fuel demand might very well be short lived. Power plant operating economics will ultimately determine the marginal price of fuel that producers will be willing to pay.

\section{Summary of California Situation in 2000}

The biomass energy industry in California reached its peak level of production during the early 1990s, and has since declined by more than one-third. This decline has a variety of causes, but the underlying reality is that biomass energy is expensive to produce compared with the lowest cost alternatives available on the grid. The high cost of biomass energy production, an inevitable result of the small facilities and the high cost of collecting and transporting low-density residue materials, is a considerable liability in a marketplace that is being deregulated and that increasingly emphasizes cost. As a result, unless biomass energy generators are compensated for the environmental benefits they provide, the viability of the enterprise is in serious doubt.

Loss of a significant fraction of the present level of biomass energy production in California would present serious social and environmental consequences. Almost 3 million tons/year of residues currently used as fuel would be added to the burden of material entering sanitary landfills, making compliance with AB 939 virtually impossible for many counties. Moreover, burying this material will burden the country with future greenhouse gas emissions that will not be avoidable when the Kyoto greenhouse gas emissions reductions must be achieved in 2012 .

Disappearance of the industry would mean that more than 1.75 million tons of residues currently being used as fuels will return to open burning piles, where they will add measurably to the air pollution problems in agricultural and forested regions, many of which are already out of compliance with state and federal air-quality standards. Moreover, an additional 500,000 tons/year of residues will be allowed to accumulate in overstocked or otherwise unhealthy forests and watersheds. These residues will exacerbate the risks of destructive wildfires and ecosystem degradation that plague California's forests, and depress the productivity of many key watersheds.

The loss of the biomass energy industry would represent a loss of almost 3,000 rural employment positions, with serious negative impacts. Many rural communities would also lose their largest source of property taxes, and would suffer other economic multiplier effects as well. Energy diversity and security values would be lost.

The loss of the California biomass energy industry would exacerbate a number of important environmental problems, and leave affected rural regions with virtually irreplaceable losses of quality employment opportunities and tax base. In fact, increasing the capacity utilization of the infrastructure and encouraging the development of new biomass installations using ever-advancing technology, should be important goals of state and federal policy. The ancillary benefits of biomass energy production are worth far more than the above-market costs of operations. A modest level of compensation for these benefits will achieve a several-fold return in social and environmental benefits. The California experience with providing of biomass production credits $1.5 \mathrm{\phi} / \mathrm{kWh}$ demonstrates that this level of support can stabilize and increased the use of facilities. A higher level of support would be needed to encourage idle facilities to reopen, or the development of new biomass energy production capacity.

The California biomass energy industry provides a valuable, environmentally preferred waste disposal service for more than 6.4 million tons of the annual solid-waste stream. These services have been provided without compensation, as the electricity market was able to underwrite them fully. They will be lost to competitive electric market unless means are developed to compensate generators for their environmental services. 
The total cost of support to maintain biomass energy production in California at its present level of activity is approximately $\$ 50$ million/year, based on conditions that are expected at the beginning of 2002 , the end of the transition period to full competition and the end of the RTF program. Most of the required amount could be provided by modifying the federal renewable energy tax credit, or extending public purpose funding for renewables in California beyond the end of the transition period. The remainder could be provided by targeted policy measures, such as appropriations of funds for wildfire risk reduction activities on state and federal forest lands, and for diverting agricultural prunings from open burning to energy production. Expanding the use of particular forms of residues through targeted policy measures will be well worth the cost in terms of the value of the benefits produced.

\section{Update on California Biomass Power Industry ${ }^{6}$}

Natural gas prices in California, which had been stable throughout the 1990s, abruptly shot upwards during the winter of 2000. This was in no small part a result of pipeline capacity bottlenecks that were related more to business issues than to physical capacity constraints. Whatever the cause, this staggering increase in gas prices, combined with rapidly growing electricity demand fueled by the booming high tech industries in California, and a drought-caused decrease in hydroelectric production in the Pacific Northwest, led to electricity supply shortages in California.

Wholesale electricity prices, which had remained within a penny of three cents per kWh for more than 15 years, broke through the four-cent barrier in May of 2000. In June, they hit double digits. By August prices at the state power exchange were averaging more than $15 \mathrm{c} / \mathrm{kWh}$. California was engulfed in a fullfledged energy crisis. The Governor resolved to hold the line on consumer electricity prices, and the utilities found their cash reserves evaporating rapidly.

Biomass power generators in the state responded quickly to what was a considerable opportunity. Each of the operating biomass facilities looked to expand its fuel purchasing, and pushed its facility to maximize output around the clock. All of the facilities that were eligible opted to convert to power exchange pricing in order to take advantage of the higher prices available there. Ten of the biomass facilities in California that had been shut down during the 1990s, representing $130 \mathrm{MW}$ of generating capacity, began investigations to see whether they could profitably resume operations. The ten facilities, many of which are located near the state's Central Valley region, are shown in Table 4.2. The state support payments to the biomass generators were suspended because market prices exceed the target level. By the end of the year biomass fuel prices were on the rise, but few of the generators were complaining.

The complaints started promptly in December of 2000, when the utility companies stopped paying power producers for energy. Six months of unprecedented wholesale energy prices had mortally wounded the utility companies, and they were teetering on the verge of bankruptcy. To put the topping on the cake, prices at the power exchange suddenly shot up again in December, averaging more than $35 \mathrm{c} / \mathrm{kWh}$ during the month. They remained at that level into January 2001, when the power exchange itself was shut down. The electricity market in California was in chaos, and the state's investor-owned electric utility companies were crippled.

\footnotetext{
${ }^{6}$ Reference: Morris, G. (2002) “Biomass Energy Production in California,” NREL Progress Report, Task Order No. KCL-0-30040-02, April
} 


\section{Table 4.2: Idle California Biomass Facilities that Began Re-Start Investigations in 2000}

\author{
Auberry Energy, Auberry \\ Blue Lake Energy, Blue Lake \\ Capitol Power, Ione \\ Chow II, Chowchilla \\ Dinuba Biomass, Dinuba \\ E1 Nido, Chowchilla \\ EPI Madera, Madera \\ Primary Power, Brawley \\ Sierra Forest Products, Terra Bella \\ Soledad Energy, Soledad
}

\author{
7.5 MW \\ 10.0 MW \\ 18.0 MW \\ 10.0 MW \\ $11.5 \mathrm{MW}$ \\ 10.0 MW \\ 25.0 MW \\ 15.0 MW \\ 9.5 MW \\ $13.5 \mathrm{MW}$
}

restart abandoned

restart abandoned

start up summer 2002

restart abandoned

started up in 2001

restart abandoned

started up in 2001

started up in 2001

started up in 2001

started up in 2001

California's biomass power producers were faced with a mind-boggling irony. At the very time that they were earning unprecedented profits, they were facing insolvency. The supposed profits, of course, were only on paper. With their revenues suspended, fuel prices elevated, and the state demanding that they produce as much power as they could, their short-term cash positions were precarious. Many biomass operators talked openly of giving up and shutting down for good.

In spite of the troubles faced by the operating biomass facilities, the efforts to restart ten of the state's idled biomass facilities were proceeding full-speed ahead. Wholesale electricity prices had never been higher, actual operations for these facilities were months away, and it seemed reasonable to assume that something would be done to get the flow of money moving again. In fact, in many ways it appeared in the beginning of 2001 that the idled facilities that were trying to restart would enjoy a couple of distinct advantages over the operating facilities. They were not hobbled by having had to endure a prolonged period of operating without any revenues, and they were not saddled by old power purchase contracts that now were paying below-market prices.

Governor Gray Davis convened an emergency session of the state legislature in January 2001 to deal with the still burgeoning energy crisis. Many commentators were predicting that a long, hot summer of brownouts and blackouts lay ahead. The governor was negotiating bailout deals with the utility companies that would have them sell their entire transmission systems to the state for prices that were well above book value. In March the CPUC, for the first time since the energy crisis hit, granted the utility companies across-the-board rate increases of ten percent. Nevertheless, negotiations with PG\&E broke down and the utility company declared bankruptcy. The negotiations with SCE eventually broke down too, although SCE avoided bankruptcy.

The state's electricity generators were desperately searching for a way to get the utility companies to pay them. A deal was struck in late March at the CPUC that allowed the utility companies to resume payments to the power generators on a going-forward basis, with the matter of payments for past due bills left unresolved. None of the thirty operating biomass facilities had been forced to shutdown, although many were severely stretched. Short-run avoided cost rates hovered in the neighborhood of $10 \notin / \mathrm{kWh}$ through the Spring of 2001, well below their unbelievable levels of December and January, but still some three times higher than historical levels.

With the collapse of the state power exchange and the crippled financial status of the utility companies, the emergency session of the state legislature passed legislation that allowed the state, through the Department of Water Resources (DWR), to begin buying electricity on behalf of the state's consumers. DWR immediately set up a trading unit and created an exchange for short-term energy purchases. In addition to purchasing energy on a short-term basis the DWR embarked on a program of negotiating 
long-term energy contracts at prices below the then prevailing rates, but above historical levels. Many of the state's generators were eager to join the negotiations, and the state began to deal.

The ten idled biomass generating facilities in the state that had initiated startup preparations during late 2000 and early 2001 looked at long-term contracts with the state as the obvious way to go. At first they were rebuffed. DWR's initial request for proposals specified a minimum generating unit size of $50 \mathrm{MW}$. This excluded all of the candidate biomass facilities. One of the potential biomass startups, the $13.5 \mathrm{MW}$ Soledad facility, applied to DWR in spite of not meeting the size qualification. They explained on their application that they understood they were undersized, but hoped that DWR would consider them for what they were, which included the possibility of starting up before the crucial summer season just ahead. The remaining biomass restarts waited to enter into negotiations with DWR until after the first wave of applications from the large producers had entered into negotiations.

In parallel with the state's efforts to negotiate long-term contracts with large generators, the CPUC developed a program to allow biomass facilities operating under old standard offer PPAs to select a fiveyear fixed price payment of $5.37 \mathrm{c} / \mathrm{kWh}$, instead of being paid at variable short-term market rates. Many, but not all, of the biomass facilities operating under standard offer contracts accepted this offer, and began receiving the fixed price payments beginning in July 2001.

At this point the biomass power plants in California could be divided into two functional groups based on their power sales arrangements. The first group, which included most of the facilities operating under the old standard offer PPAs, had fixed price agreements that would cover the next five years, with prices that were high enough to ensure their continued ability to operate throughout this period. The second group, which included a few of the facilities that had operated continuously during the 1990s, and most of the facilities that were in various stages of restarting, were stuck without long-term PPAs. The already operating facilities in this group were selling their output on the short-term market, where prices were in the neighborhood of $10 \notin / \mathrm{kWh}$ during the spring of 2001. Many of the facilities in this group were actively negotiating long-term contracts (five years or more) with the DWR. A few were content to remain players in the short-term market.

Available power supplies for the California grid remained at very low levels during the spring of 2001, as unusually large numbers of the state's fossil fuel-fired power plants seemed to be out of operation for servicing, many for prolonged periods of time. A couple of rolling blackouts of two or three hours duration each were imposed on many PG\&E customers, despite the fact that spring is traditionally a period of low electrical demand in the state. Rumors and charges began to surface that some of the state's largest generators were manipulating their production units to game the market. The state was petitioning the FERC to impose price controls on the wholesale market, but the FERC was resistant. The situation was rapidly coming to a boiling point.

By the beginning of the summer of 2001, the DWR had signed some forty long-term contracts with generators for more than 10,000 MW of power. Although the contracts were not made public, prices were rumored to be in the range of $7-10 \notin / \mathrm{kWh}$, with terms ranging from $2-10$ years. Soledad's gamble had paid off. Their biomass power plant was among the recipients of the first set of DWR contracts, and was already firing fuel. Seven of the biomass restarts were now actively engaged in negotiations with DWR. The other two attempted restarts, twin $10 \mathrm{MW}$ facilities near Chowchilla (Chow II and El Nido), suspended their efforts to restart.

The newspapers continued to be full of dire warnings of looming summer blackouts. The crisis was beginning to spread to the entire Western U.S., and electricity supplies were reportedly strained in the Northeast. The Governor pushed hard for conservation in California, and for FERC price caps to be 
imposed in Washington. Finally FERC acted and imposed price caps on the wholesale electric market in the western U.S.

Then something totally unexpected happened. The long-dreaded summer of 2001 had arrived. But wholesale energy prices fell from May to June by more than a third, despite the fact that it was the beginning of the peak demand season. By the middle of the summer prices had fallen below four cents per $\mathrm{kWh}$, which was within the range of pre-crisis levels. Not one blackout occurred during the entire summer. A combination of factors, including aggressive conservation efforts by consumers, an economic recession, an unusually cool summer, the long-term contracts signed by the DWR, the end of the drought in the Northwest, and the breaking of the bottleneck in the natural gas market, seemed to have combined to knock out the energy crisis. The FERC price caps were reached a couple of times soon after their imposition, then quickly became irrelevant. By late summer there were grumblings that the state had signed too many contracts at too high prices. There were even periods when the state was purchasing more contract electricity than it could use, and had to sell the excess into the out-of-state markets at a loss.

More than 99 percent of the long-term contracts the state signed in the spring of 2001 were for energy generated from natural-gas fired power plants, a result of the crisis atmosphere that had been in effect when the DWR began to seek long-term power supplies. Due to size and other considerations, renewables had been put on the back burner in the spring, and were just coming up for consideration at the DWR as the summer reached its peak, and the energy crisis ebbed.

Timing was distinctly against the biomass facilities. The DWR was coming under fire for the contracts they had just signed with the natural gas generators. Negotiations for additional long-term power purchase contracts suddenly ground to a halt, even in cases where there were signed letters of intent for power to be purchased from clean generating sources. Biomass project proponents complained that their questions went unanswered, and their phone calls were not returned. With the exception of Soledad, all of the other facilities attempting to restart, as well as several operating biomass power plants that did not have standard offer PPAs, found themselves relegated to selling into the short-term market at prices that were insufficient to cover their fuel and operating costs.

One of the many actions taken by the emergency session of the state legislature was the creation of the California Power Authority (CPA), which began operations in August 2001. The CPA was vested with $\$ 5$ billion in bonding authority to invest in generating assets that would give the state power grid an adequate reserve margin of generating capacity. A minimum of $\$ 1$ billion of the total was earmarked for conservation and renewables. Soon after its creation, the CPA put out a request for proposals, asking for any kind of proposal that a proposer wished to make. They were particularly interested in peakers, renewables, efficiency, and any kind of generator that would be located in known voltage-constrained regions. All of the biomass facilities that were negotiating with the DWR filed applications for their projects with the CPA.

One of the CPA's mandates was to produce, within six moths of its creation, an investment plan for its $\$ 5$ billion capital fund. The investment plan had to be submitted to the legislature by the middle of February 2002. A series of meetings were held around the state to solicit public input, and a strategic document was hashed out. The official document rejected the notion of having the CPA support the development of a new generation of natural gas-fired peaking plants in California, and enthusiastically embraced renewables. In particular, the CPA Investment Plan recognizes the importance of maintaining and enhancing the state's biomass generating infrastructure, and stated an intention to contract with the biomass generators who did not have standard-offer contracts, and had so far been unable to negotiate contracts with the DWR. 
Despite their good intentions with regards to biomass, the CPA has been thwarted in their efforts to move forward with any biomass contracts. The problem is that, due to a dispute between the state and the CPUC over regulatory jurisdictional issues, the CPA, in concert with the state Treasurer's Office, is unwilling to issue the bonds that will supply the funds they need in order to make commitments to generating facilities. At the present time the state underwriters have taken the position that the state lacks the authority to ensure that ratepayers will be held fully responsible for the costs of energy procurement. They will not issue the CPA bonds until the guarantees they are seeking are in place.

December 2001 was the sixth consecutive month in which short-run avoided cost rates were insufficient to cover all of the costs of biomass power generation. The group of facilities that did not have long-term contracts were nearing the end of their ability to hang on, a finding that was recognized and confirmed by the CPA, the DWR, and the Governor's Office. One project, Capital Power Ione, an $18 \mathrm{MW}$ facility, was able to finalize a contract with DWR during the last months of 2001. This project had obtained a signed letter of intent with DWR in the early spring, and continued to negotiate faithfully throughout the summer and fall, enlisting support wherever it could be found. They were finally able to come to terms that were substantially less favorable than those that had been granted to the natural gas industry earlier in the year. This was the second, and so far last, of the restarts that has managed to finalize a long-term power purchase agreement with the state.

Recognizing that the issues that were holding up the issuance of the CPA's bonds were not going to be resolved quickly, the DWR, in conjunction with the CPA, signed 90-day interim contracts with eleven facilities before the end of the year, with a common intention to enter into long-term contracts as soon as it became possible. The interim contracts were extended for a second 90-day period at the end of March, carrying these facilities through the end of June 2002.

The interim contracts provide for average revenues of $6.5 \phi / \mathrm{kWh}$, differentiated by time-of-use and seasonal factors. The payment level covers both energy and capacity, and as such is below the level earned by the facilities with old standard offer utilities contracts $(5.37 \phi / \mathrm{kWh}$ energy plus $2.0 \notin / \mathrm{kWh}$ capacity), and on the low side of the range of the legitimate costs of energy production from biomass (see Morris, G., Biomass Energy Production in California: The Case for a Biomass Policy Initiative, NREL Report No. NREL/SR-570-28805, November 2000).

California currently has thirty-five biomass power plants in operation, representing a total of $685 \mathrm{MW}$ of electricity generating capacity. Approximately two-thirds of the total are operating under old standardoffer power purchase agreements with fixed energy prices that will remain in effect through the middle of 2006. These facilities are well served by their contracts, and should be able to operate viably until at least that time. The other one-third of California's biomass power plants are operating under interim 90-day contracts that provide them with minimally acceptable operating revenues. The long-term fate of this group of facilities is a function of whether they are ultimately able to obtain longer-term contracts with adequate power purchase provisions. 


\section{Lessons Learned - Existing Industry ${ }^{7}$}

This discussion includes summary information on 20 biomass power plants - 18 in the United States, one in Canada, and one in Finland, which represent some of the leaders in the industry. Table 4.1 lists the 20 plants in order of on-line date, the same order in which they are presented in the report. In some cases, the on-line date means the date an older fossil-fired plant started using biomass fuel commercially (not its original on-line date). Some of the information in the table is abbreviated, but can be clarified by referring to the specific plant sections.

The on-line dates of the plants span about 18 years, from December 1979 to January 1998. The types of biomass fuels used are abbreviated: "mill" refers to mill wastes, etc. Many boiler types are represented: six traveling grate stoker boilers, four water-cooled vibrating grate boilers, four bubbling fluidized bed combustors (FBCs), one circulating fluidized bed (CFB) boiler, one fixed-grate boiler, one sloping grate boiler, and two pulverized coal (PC) boilers retrofitted to cofire solid or gasified biomass. Steam temperatures for the biomass-fired boilers are $750^{\circ}-980^{\circ} \mathrm{F}$; for the PC boilers, $1,004^{\circ}-1,005^{\circ} \mathrm{F}$. The nominal sizes of the plants range from $10 \mathrm{MW}$ to $79.5 \mathrm{MW}$.

\section{Electricity Generation and Fuel Consumption}

Table 4.2 lists the plants in order of electricity generation, in gigawatt-hours/yr (GWh/yr). For some plants, the generation numbers are actual statistics from a recent year (1996, 1997, or 1998). For plants that did not provide these statistics, the generation rates were estimated based on available information. The same is true for the annual capacity factors $(\mathrm{CFs}, \%)$ and net plant heat rates $(\mathrm{Btu} / \mathrm{kWh})$. The biomass fuel consumptions were calculated by multiplying $\mathrm{GWh} / \mathrm{yr}$ times Btu/kWh, and dividing by 8.5 million $\mathrm{Btu} / \mathrm{t}$ (4250 Btu/lb, or $8500 \mathrm{Btu} /$ dry lb with 50\% moisture content).

\section{Capacity Factors}

Annual CFs range from 19\% to 106\%. Some plants with low CFs (e.g., Multitrade and McNeil) are peaking units. The plants with very high CFs have special circumstances. Shasta and Colmac were still under the first 10 years of California Standard Offer contracts when the data were obtained. Williams Lake can operate as high as $15 \%$ over its rated capacity, and can frequently sell extra power.

\section{Heat Rates}

The Williams Lake plant also holds the distinction of having the largest single boiler (60 MW) and the lowest heat rate $(11,700 \mathrm{Btu} / \mathrm{kWh})$ of any $100 \%$ biomass-fired power plant. Biomass-cofired coal plants can achieve slightly lower heat rates, as exemplified by Greenidge Station $(11,000 \mathrm{Btu} / \mathrm{kWh}$ on the biomass portion of the fuel, compared to 9818 on coal alone). The least efficient plants in this report have heat rates of about $20,000 \mathrm{Btu} / \mathrm{kWh}$. A "typical" value is about $14,000 \mathrm{Btu} / \mathrm{kWh}(24.4 \%$ thermal efficiency, HHV).

\section{Cogeneration}

The four cogeneration plants in the report - Okeelanta, Snohomish, Lahti, and Camas - are recent plants, using the latest technology, in traditional niches for biomass power: two at pulp and paper mills (Snohomish and Camas), one at a sugar mill (Okeelanta), and one at a municipal district heating plant (Lahti). The estimates given in Table 4.2 for these plants represent only the solid fuel biomass portion of the energy input. At the two pulp and paper mills, recovery boilers produce large fractions of the total steam from waste liquor; the wood waste boilers at these facilities constitute focus of this report. At Lahti, coal and natural gas produce most of the energy; wood wastes and refuse derived fuel (RDF) are fed to a

\footnotetext{
${ }^{7}$ Excerpted from Wiltsee, G. (2000). "Lessons learned from existing biomass power plants," NREL/SR570-29-6946, National Renewable Energy Laboratory, Golden, CO.
} 
gasifier that supplies low-Btu gas to the boiler. The Okeelanta cogeneration plant burns bagasse for about 6 months of the year, and burns urban and other wood wastes at other times.

Table 4.3: Summary of Biomass Power Plants in this Report

\begin{tabular}{|c|c|c|c|c|c|c|}
\hline Plant & Location & MWe & GWh/yr & CF, \% & $\underline{\text { Btu/kWh }}$ & Tons/yr* \\
\hline Williams Lake & British Columbia & 60.0 & 558 & 106 & 11,700 & 768,000 \\
\hline Okeelanta (cogen) & Florida & 74.0 & 454 & 70 & 13,000 & 694,000 \\
\hline Shasta & California & 49.9 & 418 & 96 & 17,200 & 846,000 \\
\hline Colmac & California & 49.0 & 393 & 90 & 12,400 & 573,000 \\
\hline Stratton & Maine & 45.0 & 353 & 90 & 13,500 & 561,000 \\
\hline Kettle Falls & Washington & 46.0 & 327 & 82 & 14,100 & 542,000 \\
\hline Snohomish (cogen) & Washington & 39.0 & 205 & 60 & 17,000 & 410,000 \\
\hline Ridge & Florida & 40.0 & 200 & 57 & 16,000 & 376,000 \\
\hline Grayling & Michigan & 36.0 & 200 & 63 & 13,600 & 320,000 \\
\hline Bay Front & Wisconsin & 30.0 & 164 & 62 & 13,000 & 251,000 \\
\hline McNeil & Vermont & 50.0 & 155 & 35 & 14,000 & 255,000 \\
\hline Lahti (cogen) & Finland & 25.0 & 153 & 70 & 14,000 & 252,000 \\
\hline Multitrade & Virginia & 79.5 & 133 & 19 & 14,000 & 219,000 \\
\hline Madera & California & 25.0 & 131 & 60 & 20,000 & 308,000 \\
\hline Tracy & California & 18.5 & 130 & 80 & 14,000 & 214,000 \\
\hline Camas (cogen) & Washington & 17.0 & 97 & 65 & 17,000 & 194,000 \\
\hline Tacoma & Washington & 40.0 & 94 & 27 & 20,000 & 221,000 \\
\hline Greenidge & New York & 10.8 & 76 & 80 & 11,000 & 98,000 \\
\hline Chowchilla II & California & 10.0 & 53 & 60 & 20,000 & 125,000 \\
\hline El Nido & California & 10.0 & 53 & 60 & 20,000 & 125,000 \\
\hline
\end{tabular}

*Tons/year are calculated, assuming $4250 \mathrm{Btu} / \mathrm{lb}$. 
Table 4.4: Plant Electricity Generation and Biomass Fuel Consumption Estimates

\begin{tabular}{|c|c|c|c|c|c|c|c|}
\hline Plant & $\underline{\text { Online }}$ & Fuels & Boiler(s) & Ib/hr & Psig & $\mathbf{D F}$ & MWe \\
\hline ay Fro & Dec-79 & Mill, TDF, coal & 2 modified coal stokers & 280,000 & & & 30 \\
\hline ettle Falls & & Mill & raveling grate stoker & 415,000 & 1500 & 950 & \\
\hline McNeil & & Forest, mill, urban & 1 traveling grate stoker & 480,000 & 1275 & 950 & 50 \\
\hline hasta & ec- 87 & Mill, forest, ag, & 3 traveling grate stokers & 510,000 & 900 & 905 & 49.9 \\
\hline do (closed) & 38 & $\mathrm{Ag}$, forest, 1 & & 00 & 650 & 750 & 10 \\
\hline a (close & & $\mathrm{Ag}$, fore & & & 850 & 850 & 25 \\
\hline trat & & Mill, forest & ate stoker & & 1485 & 955 & 45 \\
\hline hilla II (closed) & eb-90 & $\mathrm{Ag}$, fore & & 130,000 & 650 & 750 & 10 \\
\hline 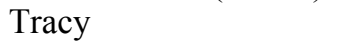 & & & $1 \mathrm{w}$ & & & & 18.5 \\
\hline (cofiring & & Wood, $\mathrm{F}$ & $2 \mathrm{bu}$ & & 400 & 750 & 12 \\
\hline & $b-92$ & Urban, & $2 \mathrm{CF}$ & 464,000 & 1255 & 925 & 49 \\
\hline & & & & & 1280 & 950 & 36.17 \\
\hline Lake & & $\mathrm{Mi}$ & & & 1575 & 950 & 60 \\
\hline Iultitrade & & Mill & & & 1500 & 950 & 79.5 \\
\hline idge & & Urban, tires, LFC & & & 1500 & 980 & 40 \\
\hline & & Inufacturing & & & 1465 & 1005 & $10.8^{*}$ \\
\hline & & & & & 600 & 750 & $38-48$ \\
\hline & & Mill, urban & & 435,000 & 825 & 850 & 43 \\
\hline Okeelanta (cogen) & Jan-97 & Bagasse, urban, & 3 water-cooled vib grate & $1,320,000$ & 1525 & 955 & 74 \\
\hline Lahti (cofiring, cogen) & Jan-98 & Urban, RDF & $1 \mathrm{CFB}$ gasifier + PC & 992,000 & 2500 & 1004 & $25^{* *}$ \\
\hline
\end{tabular}

*108 total net MW, $10 \%$ from wood and $90 \%$ from coal.

**167 total net MW, $15 \%$ from biofuels and $85 \%$ from coal.

\section{Fuels}

The cost of biomass fuel from mill wastes and urban wood wastes can range from about \$0/MBtu to about $\$ 1.40 / \mathrm{MBtu}$, depending on the distance from the fuel source to the power plant. Getting to zero fuel cost depends on locating a power plant in an urban area next to a wood waste processor, or next to a large sawmill or group of sawmills. Deregulation will make this zero fuel cost strategy more important in the future.

Agricultural residues (primarily orchard tree removals) can be processed into fuel and delivered to nearby biomass power plants for about $\$ 1 / \mathrm{MBtu}$. Only if open burning of residues is prohibited will transferring some of this cost to the orchard owners be possible.

Forest residues are much more costly $(\$ 2.40-\$ 3.50 / \mathrm{MBtu})$, because of the high costs of gathering the material in remote and difficult terrain, processing it to fuel, and transporting it to power plants. There are strong arguments for government programs to bear the costs of forest management and (in the West) fire prevention. Only if such programs are created will forest residues be as cost-competitive fuel as in the future.

Plants that have come close to zero fuel cost are Williams Lake, which is located very close to five large sawmills, and Ridge, which accepts raw urban wood wastes and whole tires, and burns landfill gas. Other plants burning primarily mill wastes include Shasta, Kettle Falls, Stratton, Snohomish, Grayling, Bay Front, Multitrade, and Camas. Other plants burning primarily urban wood wastes (and in some cases RDF) are Okeelanta, Colmac, Lahti, and Tacoma. Sawdust from furniture manufacturing is the main biomass fuel at the Greenidge plant. Plants burning agricultural residues include Okeelanta, Tracy, Madera, Chowchilla II, and El Nido. Plants burning significant amounts of forest residues include McNeil, Shasta, Stratton, and Grayling. 


\section{Lessons Learned}

The project experiences described in the following sections capture some important lessons learned that lead in the direction of an improved biomass power industry. Undoubtedly, many other problems and solutions did not surface in the interviews and in the documents and articles that served as source materials. A summary of the lessons learned from these 20 biomass plants follows; in each category an effort is made to identify plants that illustrate particular points, so the reader can go to those sections to learn more.

$\underline{\text { Fuel }}$

The highest priority at most biomass power plants is to obtain the lowest-cost fuels possible. This involves tradeoffs in fuel quality, affects the design and operation of the system, and frequently is limited by permit requirements. Some fuel-related lessons illustrated in this report are:

- $\quad$ At Bay Front, the conversion from coal and oil to biomass and other waste fuels kept an old generating station operating and provided continued employment.

- At the McNeil Station, long-term fuel contracts insisted on by financing institutions created some costly problems. As required, McNeil had 15 or 20 long- term fuel contracts when it started up. The CF dropped because of dispatch requirements, resulting in lawsuits and settlements with fuel suppliers and odors from the wood piles. The plant now runs more economically by buying wood fuel under short-term contracts.

- Maintaining adequate fuel supply in the midst of a declining regional timber industry has been the single biggest challenge for the Shasta plant. Almost from startup, Shasta has tried to diversify its fuel sources. From an initial list of permitted fuels that included only mill waste, logging/thinning residue, and cull logs, Shasta added agricultural residues, fiber farm residues, land and road clearing wood wastes, tree trimmings and yard wastes, and natural gas.

- $\quad$ The San Joaquin Valley Energy Partners plants (Chowchilla II, El Nido, and Madera) experimented in combusting low-cost, low-demand agricultural waste materials such as grape pomace, green waste, onion and garlic skins, and bedding materials not desired by competing facilities. However, the most difficult-to-burn agricultural residues were assigned to the "tertiary" fuel category and mixed in small percentages with better fuels, primarily wood.

- Experience at the Tracy plant shows that urban wood waste can be a comparatively inexpensive fuel $(\sim \$ 0.35 / \mathrm{MBtu})$ if the plant is located close to the urban area. Compared to urban wood waste, orchard wood is relatively expensive $(\sim \$ 1.00 / \mathrm{MBtu})$ because growers are used to simply pushing and burning it, and are generally not willing to pay a fee to have the wood removed.

- Tacoma found that focusing on fuel cost $(\phi / \mathrm{kWh})$ rather than fuels that provide highest efficiency (Btu/kWh) saved the plant $\$ 600,000 / y r$. Opportunity fuels (with tipping fees) can eliminate fuel costs and generate net revenues. Fuel procurement should be one of the highest priorities and a full-time job.

- $\quad$ At the Williams Lake plant, with uncertainty in the forestry industry, unknown impacts of Asian market upheaval, high provincial stumpage fees, and closure of some coastal sawmills and pulp mills, the biggest threat to an enviable operating record appears to be fuel availability.

- The Ridge Generating Station is an urban waste recycling facility, working within the local waste management infrastructure to provide a low-cost recycling service to waste generators, and to obtain a free or negative-cost fuel mix (urban wood wastes, scrap tires, and landfill gas) for energy production.

- The Snohomish Cogeneration plant design anticipated the trend toward declining quantities of sawmill residues, and the increasing use of urban wood wastes in the region. Siting the plant at a paper mill provided an excellent fit for steam use, as well as expertise in wood waste handling and combustion. 


\section{Fuel Yard and Fuel Feed System}

The area of a biomass power plant that can almost be counted on to be mentioned in response to the question "Have you had any significant problems or lessons learned?" is the fuel yard and fuel feed system. Most plants in this report spent significant time and money during the first year or two of operation, solving problems such as fuel pile odors and heating, excessive equipment wear, fuel hangups and bottlenecks in the feed system, tramp metal separation problems, wide fluctuations in fuel moisture to the boiler, etc., or making changes in the fuel yard to respond to market opportunities. Examples noted in this report include:

- $\quad$ At Bay Front Northern States Power (NSP) engineers installed and improved (over time) a system that allows feeding of $100 \%$ biomass, $100 \%$ coal, or any combination of the two. Because wood fuel quality varies more than coal quality, proper tuning of the automatic combustion controls is more important when firing wood. Operators must pay close attention and periodically adjust feeders.

- With the addition of a debarker, high-speed V-drum chipper, chip screen, and overhead bins, the Shasta plant was able to offer to custom chip logs, keeping the $35 \%$ of the log not suitable for chips. In times of low chip prices, Shasta still purchases the whole log. Shasta successfully marketed the program to some of the largest landowners in California.

- At Shasta, the operators learned to blend all the fuels into a homogeneous mixture that allowed the boilers to fire at a consistent rate and maintain maximum load under all conditions, without violating environmental standards, excessively corroding heat transfer surfaces, or slagging beyond the point where the boilers required cleaning more than twice per year.

- At Stratton, the original owners spent about $\$ 1.8$ million during the first year of operation to improve the operation of the fuel yard.

- Tacoma personnel stress the need to take extra care at the beginning of the project with design of the fuel feed system. Selecting a proven fuel feed system is important.

- The only area of the Williams Lake plant that was modified after startup was the fuel handling system. Minor modifications were made to improve performance, such as adding the ability to reverse the dragchains on the dumper hoppers, to make it easier to unplug fuel jams; and adding three more rolls to each disk screen (12 rolls were provided originally), to reduce the carryover of fine particles that tended to plug up the hog.

- The Multitrade plant's minor problems included fuel feeding problems in the early days of operation (quickly corrected); erosion and corrosion in the fuel splitter boxes and conveyor belt shrouds (corrected by relining with plastic); and occasional heating and odor problems in the fuel pile until they learned not to let any part of the pile age more than 1 year.

- $\quad$ The Greenidge Station found that the technology for preparing biomass fuel for cofiring in a PC boiler needs further economic evaluation, research, and development. Grinders do not normally produce a product that has good flow characteristics. The wood fibers are sticky, stringy, and elongated when produced from a grinding operation. The fuel product needs to processed by equipment that produces a chip.

\section{Design for Fuel Flexibility}

Many biomass plants change fuels significantly over the years, as opportunities arise or old fuel sources dry up. These changes are often not predictable. The best strategy to deal with this problem is to have a plant design and permits that allow as much fuel flexibility as possible. For example:

- $\quad$ Bay Front was a coal-fired stoker plant that converted to wood firing and cofiring capability in 1979. Experience showed that ash fouling and slagging problems were much more severe when cofiring wood and coal than when firing either fuel alone. NSP now operates in either $100 \%$ coal or $100 \%$ wood firing mode. 
- In 1989, the ability to burn natural gas was added to McNeil Station. Summer pricing for Canadian gas was more attractive than wood prices at that time. Six fossil fuel burners were installed, allowing full load capability (50 MW) on gas and $15 \mathrm{MW}$ capability on No. 2 oil. Gas prices rose during the mid-1990s, and McNeil burned almost no natural gas from 1997 to 1998.

- $\quad$ At the Shasta plant, a large hammermill was added to the fuel processing system to allow the use of a broader range of fuels. This reduced fuel costs by allowing the plant to process opportunity fuels such as railroad ties, brush, and prunings.

- $\quad$ The Tacoma plant was constrained by a limited fuel supply and permit, and worked hard to develop more options to use opportunity fuels (tipping fee fuels, some of which are not biomass)—waste oil, asphalt shingles, petroleum coke, etc.

- $\quad$ Colmac found that modifying its permit to allow the use of petroleum coke was worthwhile. At times, waste fossil fuels can be more economical than biomass.

- $\quad$ The Ridge fuel yard can handle essentially any type or size of wood waste; its only restriction is that it will not accept palm trees. The simple and reliable traveling grate stoker boiler can burn these mixed wood wastes, including yard wastes, and can burn crude tire-derived fuel (TDF) and landfill gas. The emission control system with a lime spray dryer and baghouse can remove almost any significant pollutant encountered in these wastes.

\section{Location}

As realtors say, "Location, location, location!" Biomass residues and wastes are local fuels, with very low energy densities compared to fossil fuels. Transport costs become very significant after about 20 miles, and usually prohibitive beyond 100 or 200 miles. The ability to have the waste generators deliver the fuel to the plant site at their own expense requires a location very close to the sources of waste. There are also other considerations, such as the proximity to residential neighborhoods. For example:

- $\quad$ The primary lesson learned from the McNeil plant experience in Burlington, Vermont, is the need to pay careful attention to the siting of a biomass-fueled plant. Siting the plant in a residential neighborhood of a small city has caused a number of problems and extra expenses over the years: a permit requirement to use trains for fuel supply, high taxes, high labor rates, local political involvement, and neighborhood complaints about odors and noise.

- $\quad$ The Colmac plant shows that urban wood waste can be a comparatively expensive fuel ( $\sim 1.50 / \mathrm{MBtu})$ if the plant is located far outside the urban area. The transportation cost is significant. An urban biomass plant can derive income from its fuel with a location and tipping fees that attract wood waste generators with loads to dump.

\section{Reliability and Dependability}

Several plant managers with the best long-term operating records stressed the necessity for placing a high value on reliability and dependability. This is true during plant design and equipment selection, and during operation. For example:

- $\quad$ Outside of planned outages, the Kettle Falls plant has an availability factor of about $98 \%$ over a continuous 16-year period. The superintendent has high praise for the people on the staff. The plant is always exceptionally clean and neat.

- The Shasta general manager advises: "Always place a high value on reliability and dependability, for these will allow you to be considered a 'player' and thus a participant in the development of special programs with the utility."

- At Williams Lake, which has an outstanding performance record, the chief engineer stressed that staying on top of maintenance programs at all times is essential.

\section{$\underline{\text { Partnerships }}$}

The most successful projects have developed formal or informal partnerships with their key customers and suppliers. The relationship with the utility company that buys the power is usually the most important. This may change as generators simply bid their power into a power pool. Cogeneration plants by definition must 
have close relationships with their steam users. Sometimes there are a few large fuel suppliers (such as sawmills) with whom special relationships are crucial. Examples in this report that illustrate the importance of strong partnerships include:

- In the words of the Shasta general manager: "But these new approaches must go forward on a very different basis than our past biomass developments. They must go forward in partnership with utilities. While the utility may want to participate in such systems, they will not and cannot do so unless the cost to ratepayers is very close to that of other generating options."

- Like several other biomass power plants, the Grayling Station is operated as a cycling plant. It has run at about a 70\%-80\% CF during peak demand periods, and at about a 40\%-50\% CF during offpeak periods. The McNeil, Multitrade, and Ridge plants are other examples of cycling plants.

- The arrangement between the Camas Mill and its electric utility (PacifiCorp) is mutually beneficial. The utility-financed turbine/generator provides the mill with an additional source of cash flow, without significantly changing the mill's steam generation and delivery system. The utility has added about $50 \mathrm{MW}$ of reliable generating capacity to its system for a relatively small investment, and has strengthened its relationship with a major customer.

- The Okeelanta Cogeneration Plant provides many environmental benefits, and should serve as a reliable energy source for the sugar mill and the electric utility. Unfortunately, the owners and the utility could not amicably resolve their differences over a "standard offer" contract. The ensuing lawsuits, bankruptcy, shutdown, and layoffs significantly affected the project.

\section{Cofiring}

Once the availability of low-cost biomass fuel is established, the primary issue addressed in most retrofitted cofiring projects is how to feed the fuel (and in what form to feed it) to the coal-fired boiler. There are of course many other issues, such as effects on boiler operations, plant capacity, emissions, and ash quality. Some of these are highlighted by lessons learned at four plants in this report:

- $\quad$ Bay Front could use standard wood sizing and feeding equipment because its coal-fired boilers were stokers. Cofiring was possible at any ratio of wood to coal from $0 \%$ to $100 \%$. However, slagging and fouling was very severe because of the interaction between the alkali in the wood and the sulfur in the coal.

- The bubbling FBCs at Tacoma can fire 0\%-100\% wood, 0\%-50\% coal, and 0\%-50\% RDF (permit limitation). The actual fuel mix on a heat input basis from 1993 to 1997 was $54 \%-68 \%$ waste wood, $12 \%-32 \%$ coal, and 12\%-20\% RDF. Opportunity fuels that command a tipping fee or can be obtained free became a high priority in 1997.

- The cofiring experience at Greenidge Station demonstrates that a separate fuel feed system can effectively feed wood wastes to a PC unit. The economics at this site are favorable; the difference between coal and wood prices is $\$ 0.45-\$ 0.79 / \mathrm{MBtu}$. The plant has continued to cofire wood and invest in system improvements since the testing began more than 4 years ago.

- The Lahti cofiring project at a PC- and natural gas-fired district heating and electric generation plant in Finland uses a CFB gasifier to convert wood wastes and RDF to low-Btu gas that is burned in the boiler. The operation has been technically successful for 1 year, and gives utilities in the United States another option to consider when examining the feasibility of cofiring biomass and waste fuels in coal-fired boilers.

\section{Benefits}

The 20 biomass projects in this report provide many concrete illustrations of environmental and economic benefits. The Kettle Falls, Williams Lake, and Multitrade plants provide air quality benefits in rural settings where sawmills used to pollute the air with teepee burners. The Ridge, Tacoma, and Lahti plants serve urban areas by burning urban waste fuels cleanly; Lahti provides district heat as well. The Okeelanta, Tracy, and San Joaquin plants burn agricultural residues cleanly, which formerly were burned with no emission controls. The Shasta, McNeil, and Grayling plants serve the forest management operations in their areas by cleanly burning unmerchantable wood, brush, and limbs. For example: 
- The Bay Front plant was being considered for phase out as larger, more efficient units came on line in the NSP system. Adding the ability to use biomass fuel kept the plant operating, saved jobs, and improved waste management.

- $\quad$ Long-term residents in the Kettle Falls area reported major reductions in haze after the plant went into operation. The plant improved air quality by eliminating numerous wigwam burners formerly used to dispose of mill wastes.

- In the forests near the Shasta plant: "The result is a healthier, faster growing forest that has a dramatically lowered potential to be destroyed by fire. There are now adequate moisture, nutrients and sunlight for the remaining trees and net growth often triples. The remaining trees regain their traditional resistance to insect and disease attack."

- $\quad$ The Grayling and Ridge projects were planned and the plants were designed with waste management roles in mind - one in a rural setting and the other in an urban setting. Efforts were made to fit constructively into the local economic and environmental landscapes, with clearly positive results.

\section{Subsidy Programs Do Not Last}

As a final note, the Shasta general manager's list of lessons learned includes this one: "Beware of entering a regulatory system in which the utility commission or legislature has determined that it is acceptable for ratepayers to pay the full cost of your technology. Such things do not last." 


\section{DOE Hawaii Project Lessons Learned}

This section discusses the "Hawaii Gasification Facility" project. The pilot facility is shown in Figure 4.8. The purpose is to review the chronology of major milestones for the project, and to discuss lessons learned from the project.

Figure 4.8: Hawaii Gasification Facility

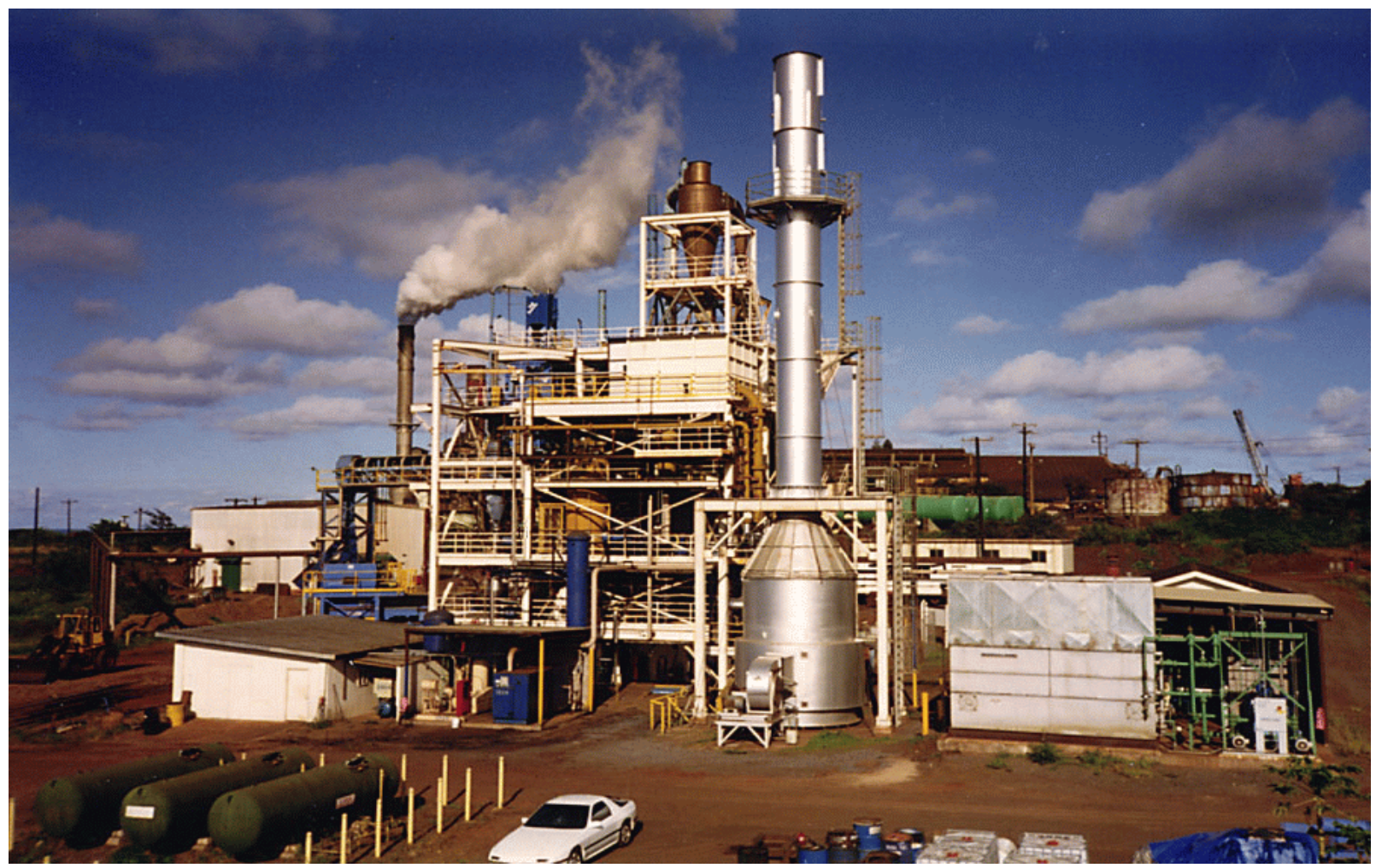

\section{Project Chronology}

- $\quad$ DOE Request for Proposal Issued

- DOE Reorganization

- Cooperative Agreement, DOE and PICHTR

1994: Phase 1 Plant Completion

1995: Phase 1 Experimental Completion

1996: Cooperative Agreement, DOE and Westinghouse

1997: Plant Modifications Complete

1997: Initial Westinghouse Experiments Performed

1997: Westinghouse Experimental Work Stopped

1998: Project Stopped 


\section{Project Overview}

The solicitation for the project "Federal Assistance Solicitation for Cooperative Agreement Proposals DEPS02-89CH10407 for a Biomass Gasifier Scale-up Facility" was issued by the DOE SERI Area Office July 31, 1989, (DOE 1989) with a proposal due date of November 28, 1989. The solicitation was a reissue of a solicitation issued in 1986 by the DOE Richlands Office, in which the proposals were withdrawn during the final negotiation stage.

The abstract of the solicitation stated that DOE desired to share with a U.S. citizen, U.S. corporation, or a state or local government the cost of a project to design, construct, start-up, test and evaluate an experimental scale-up facility to produce a medium-BTU gas (300-500 BTU/scf) from the thermochemical conversion of biofuel feedstocks. DOE intended that the facility provide industry with the engineering data necessary for the commercialization of the technology and that the facility serve as a centerpiece from which DOE and industry could develop additional capabilities such as the conversion of medium-BTU gas to methanol. It was stated that a majority of the medium-BTU gas produced by the facility be available for sale or used to provide data on gas utilization and to support facility operations; however a portion of the gas was to be made available for experimental purposes such as gas cleanup, compression, water-gas shift reactions, and/or synthesis gas reactions.

Other requirements were:

1. The gasification system was to be capable of processing 50 to 200 tons of feedstock per day.

2. Although not required, it was desirable that the facility be capable of handling a variety of biomass feedstocks. Fossil fuels were not allowed, except for start up.

3. The system was to allow for the later addition of process development units (PDUs) necessary to cool, shift, clean up, and compress the gas so that it was suitable for the production of liquid fuels such as methanol. The funding of such future PDUs was dependent on future negotiations and the availability of DOE funds.

4. The medium-BTU product gas was to be applied to a process to (a) provide an example of its usefulness as an energy product; (b) provide financial support to gasifier operations; and (c) provide for a complete technoeconomic evaluation of the process from feedstock preparation to gas utilization.

5. The project was to be constructed and operated within the 50 United States or the U.S. territorial possessions.

6. The DOE funding was to be limited to a maximum of 50\% cost share with an upper limit of $\$ 5$ million.

The Pacific International Center for High Technology Research (PICHTR), Honolulu, Hawaii proposed a project at Paia, Maui, Hawaii to scale-up the Institute of Gas Technology (IGT) RENUGAS ${ }^{\circledR}$ biomass gasification technology. The total proposal cost was $\$ 11.8$ million, with a DOE cost share of $\$ 5$ million (PICHTR 1989). PICHTR was selected by DOE for negotiation, and on September 30, 1991 a cooperative agreement was awarded to PICHTR for $\$ 9,156,904$. DOE's share was $\$ 5,000,000$; the State of Hawaii, with contributions from the Ralph M. Parsons Company and Hawaii Commercial and Sugar Company (HC\&S), was $\$ 4,156,904$. The following purpose for the project was given:

"The purpose of this cooperative agreement is: To design, construct and operate a biomass gasification facility to produce medium-Btu gas. The gas will be suitable for use as a gaseous fuel or for upgrading to a synthesis gas for conversion to liquid transportation fuels or utilization in a gas turbine for electrical energy production. This effort will also provide scale-up and operating engineering data from which the commercial feasibility of the gasification technology employed can be assessed. Upon completion of the initial program, an ongoing two-part Phase 2 


\section{Program is anticipated. Part 1 would be primarily oriented toward electrical production; Part 2 toward biomass fuels or methanol production."}

In addition, although the stated purpose of the project was to produce a medium-Btu gas, initial design and operation would be as an air-blown gasifier to produce a low-Btu gas (150 Btu/scf), with limited testing using bottled oxygen to produce a medium-Btu gas (Kearns, 1991). This change was instituted to reduce project costs.

\section{PICHTR - Phase I}

Between 1991 and 1996 PICHTR directed the Phase 1 cooperative agreement. PICHTR was assisted by a Project Oversight Board consisting of representatives of PICHTR, DOE, and the State of Hawaii. A technical advisory committee with members from DOE, PICHTR, NREL, IGT, and HNEI advised PICHTR on technical issues. During Phase 1 the basic unit was permitted, designed, constructed, and tested. A total of three test runs were conducted in 1995. These initial tests operated the Biomass Gasification Facility (BGF) over a range of 20 to 50 tons per day of bagasse. Operating pressures ranged from 28 to $100 \mathrm{psi}$, and operating temperatures were from $1,000^{\circ} \mathrm{F}$ to $1,650^{\circ} \mathrm{F}$. The range of product gas higher heating value was 81.5 - $155.5 \mathrm{BTU} / \mathrm{scf}$, and carbon conversion efficiencies of $95.4 \%-98.7 \%$ were obtained. Total running time for the tests was 108 hours, during which time 165 tons of wet bagasse were gasified. The Phase 1 effort was summarized in a final summary report (Trenka, et al 1997).

A number of system limitation and problems were identified, primarily with components of the bagasse feeding system, including:

- $\quad$ Feed rate out of the walking floor was non-uniform due to batch feed from a front end loader and minimal leveling using a leveling bar. PICHTR recommended the use of doffing rolls in future tests.

- $\quad$ Problems were encountered in maintaining dryer throughput because of choking of the inlet rotary valve and buildup of bagasse in the dryer. The buildup of bagasse in the dryer was believed to be caused by the high degree of variability in bagasse moisture content. Later analysis by the vendor during the Westinghouse operations would show that the solids buildup was caused by improper operation, and that when air flows were properly set that the dryer operation was not a problem.

- Blow over of stones and plastic drip tubing to the downstream feed system caused excessive wear and plugged blower screens.

- $\quad$ The metering feeder to feed the weigh belt was grossly oversized for the feed rates used in Phase 1 and, in fact, did not meter feed. Therefore, feed fluctuations caused by the walking floor were not evened out, and uneven feed was delivered to the plug-screw feeder.

- $\quad$ The weigh belt performed well mechanically. However, variations in belt weight (splices, etc.) gave varying tare weights and masked variations in bagasse feed rate. Therefore, actual flow rate was only known within 10-15\%.

- The original concept was to use two plug-screw feeders in series, because the vendor believed that a maximum pressure seal of 150 psi per feeder was all that could be obtained. Therefore, a vertical space was left between the weigh belt and the plug-screw feeder to accommodate installation of a second feeder when higher-pressure operations were attempted. A tapered downcomer chute was installed between the weigh belt and plug-screw feeder. This chute, in combination with other system limitations, caused the majority of problems with the plug-screw feeder. Bagasse, shown below in Figure 4.9, has a bimodal particle size distribution. 


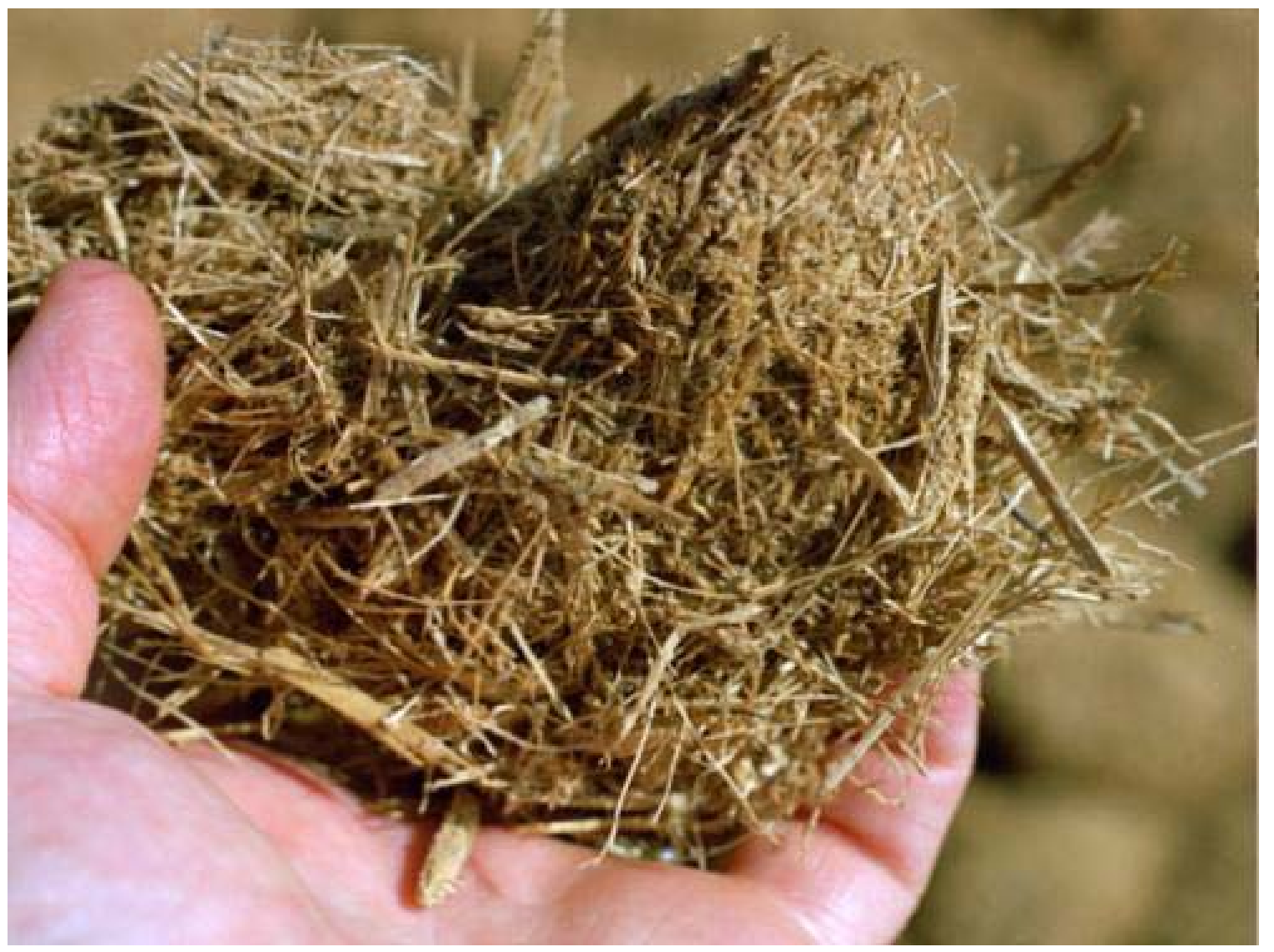

Figure 4.9: Bagasse

The majority of the bagasse consists of very fibrous material. A certain fraction is the 'pith' of the original sugar cane and is non-fibrous in nature. During unit start up, bagasse feed was recycled back to the walking floor. During this operation, pith dust built up in the chute leading to the metering feeder. When the metering feeder started, this pocket of pith dust moved as a unit through the weigh belt to the chute and on to the plug-screw feeder. The plug screw feeder is designed to use the fibrous nature of biomass to mechanically move the material through the feeder. When a pocket of non-fibrous material was encountered a center plug would break free and the feeder would no longer work. This made start up very difficult. Small pockets of pith dust normally caused no problem, but in some instances the plugscrew feeder chute would tend to segregate pith causing non-fibrous pockets to reach the feeder. The variable fiber content also caused the density of the plug to vary, causing blow-backs under pressure, leading to unit shut-down.

- Other problems encountered with the plug-screw feeder included speed mismatches with the upstream feed delivery system. If the speed of the feeder was too fast, the plug was lost, causing blow-backs. If the speed of the screw was too slow, feed built up in the inlet chute and plugged. In addition, if the feed was too dry, excessive friction led to high current draws on the feeder motor and feeder shutdown. The feeder design could have been modified to fix the majority of the mechanical problems. The addition of a barrel lubricator would have lessened the friction and barrel wear and permitted operation with dry feed. The installation of a two-piece barrel would have greatly lessened the time to correct plug problems. 
- The shredder conveyor was used to feed bagasse from the plug-screw feeder to the gasifier. This conveyor worked fine, but seal design made it difficult to hold pressure.

- The gasifier air-spargers tended to plug during periods of pressure variations. A design change was indicated.

- $\quad$ The back pressure valve tended to plug, and system pressure was controlled with the backpressure bypass valve. It was not clear whether the basic design of the valve was incorrect, or whether the fluctuations in system operation was causing excessive blow-out of fluid-bed media.

The Phase 1 effort was contractually completed with the operation of the gasifier for 100 hours.

\section{Westinghouse Electric Corporation Technology Validation Phase}

Westinghouse Electric Corporation (WEC) was chosen by DOE as the lead organization for the second phase of the Hawaii project, called the Technology Validation Phase (TVP). WEC was chosen because of their interest in commercially developing the gasification technology and their interest in moving ahead with a commercial demonstration in the Hawaiian islands. WEC was supported in the TVP by PICHTR, the Institute of Gas Technology, the Hawaii Natural Energy Institute, and the Hawaii Commercial and Sugar Company. Funding was supplied by DOE, the State of Hawaii, and WEC. The State of Hawaii funding included $\$ 2$ million for the TVP, plus \$2 million conditional on establishing a commercial project in the islands. The Project Oversight Board and Technical Advisory Committee were disbanded.

The objective the Technology Validation Phase of the Hawaii Project was

1. To operate the gasifier for a total of 1500 hours at $100 \mathrm{tpd}, 300 \mathrm{psi}$, and with a slip-stream hot-gas filter unit in operation,

2. To demonstrate sustained mechanical reliability of the overall core system (including the feed system and gasifier and their support systems) and the hot-gas filter system,

3. To determine plant performance, including

- $\quad$ gas quality/variability

- $\quad$ focusing on gas turbine needs

- permitting baseline

- up-load response time

- $\quad$ turndown limits $(3: 1)$

- $\quad$ hot-gas filter system performance

- $\quad$ operating temperature

- cleanability

- $\quad$ pressure drop across filter.

In addition to performing extended testing, WEC proposed extensive modifications to the BGF, including

- $\quad$ The plug-screw feeder was replaced. WEC stated "The current plug-screw feeder must be replaced with a commercially viable system. After reviewing several alternate feed system designs, a lock-hopper feed system was selected for the program because of its commercial viability and operating experience on a wide range of fuels" (Bartol 1996).

- An inert gas delivery system was added, to provide purge nitrogen for the lock-hopper system, and to provide additional purge gas for instruments and the gasifier.

- $\quad$ The air delivery system was upgraded to supply sufficient air for operation at 300 psi and 100 tpd.

- $\quad$ The front end of the feed system was modified to provide a cleaner, more uniform feed to the lock-hopper. Modifications included a new discharge assembly on the walking floor bin, a vibrating screen for oversize material removal, a destoner to remove small rocks, a chopper to 
reduce the particle size to about minus 1 inch, a day-bin for intermediate dry feed storage, and a weigh bin to measure the amount of bagasse fed.

- A lock-hopper, designed by Thomas R. Miles Engineers, was installed to replace the plug-screw feeder.

- $\quad$ A pressurized metering bin was installed below the lock-hopper to convert the batch feed mode of the lock-hopper to a continuous mode.

- A collector screw was installed to transfer bagasse from the metering bin to the existing shredder conveyor.

- $\quad$ A hot-gas filter unit, sized for a 10 tpd equivalent slipstream, was installed downstream of the gasifier. This unit had been constructed and successfully operated by WEC at the IGT test facility in Chicago under subcontract to NREL. The unit was moved to Hawaii to perform longterm testing, since the pilot unit in Chicago was not designed for such operation.

- The system back-pressure valves were replaced with a design used by IGT in the Chicago pilot plant. 


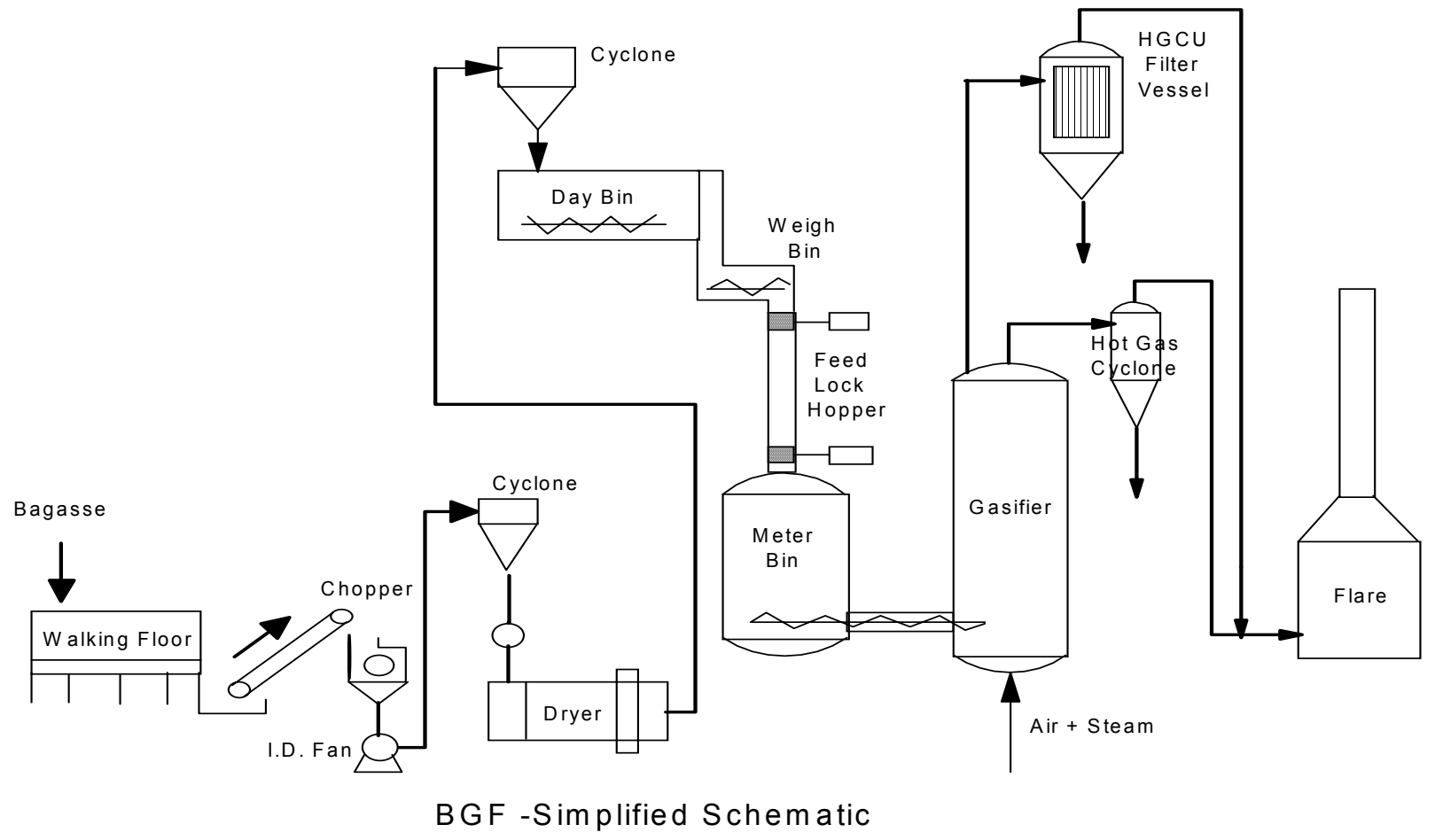

Figure 4.10: Gasifier Process Flow Diagram

The TVP Phase started in the summer of 1996, with a WEC estimated completion date of September 1997. A number of problems, briefly discussed below, were encountered and the TVP Phase was not completed by November 1997, at which time WEC determined that there were insufficient funds to complete the project.

A significant number of problems were encountered during the TVP. Given below is a summary of the problems.

- $\quad$ The schedule proposed by WEC was extremely ambitious, with no allowance for any major problems or delays. Insufficient funds were estimated to cover major delays.

- $\quad$ As a general statement, the majority of the equipment designed and installed during the TVP was undersized for operation at full capacity. Although the vendor had extensive experience in wood and straw handling systems, the direct applicability of items such as required horsepower was not correct. Based on the experience obtained during the TVP a rule of thumb would be to double the size of all motors if not based on previous operation with bagasse.

- $\quad$ Although doffing rolls were installed at the end of the walking floor to even out feed rate, the feed was still non-uniform. The basic problem was the walking floor.

- The vibratory conveyor was not long enough to permit good segregation of impurities. Modifications were made in the finger design to permit better flow, but very little separation of rock and plastic tubing occurred. The bagasse tended to make a mat which prevented bagasse from dropping through the fingers. When the fingers were enlarged almost everything dropped though. 
- The destoner did a good job of separating stones out of the feed. The only problem was some blockage of the vacuum system.

- The primary problem with the chopper was that the original motor was undersized. A new motor was installed. Because of other problems with the feed system, screen size and shape was not optimized. Because of limited continuous operating time, a reliable estimate of required blade sharpening interval was not completed. Some capacity tests were performed at the completion of the TVP experimental program.

- $\quad$ The primary problems with the day bin were an incorrect screw rotation direction for the live bottom, motors incorrectly sized for bagasse, and the use of belt drives, instead of chain drives. All of these problems were corrected during the TVP. The day bin then worked correctly for traditional bagasse with a bulk density of $7 \mathrm{lb} / \mathrm{ft}^{3}$. HC\&S processed a new variety of sugar cane in 1997 which caused large problems with the sugar mill operation, including excess sugar in the bagasse and a higher bulk density of the bagasse. At times the bulk density of bagasse reached 11 $\mathrm{lb} / \mathrm{ft}^{3}$. Because all of the bins were designed for volumetric control of flow, the higher bulk density caused additional problems. These problems were overcome by reducing the solids inventory permitted in the bin.

- $\quad$ There were a number of problems with the lockhopper. The liner for the lockhopper was incorrectly fabricated. It did not extend to the bottom of the lockhopper. A sleeve was fabricated, but the welds seemed to cause some hangup of material. As a consequence, the lockhopper could not be filled to capacity, resulting in rapid cycling of the lockhopper to obtain throughput, and increased inert gas usage. A major reliability problem was encountered with the lock hopper valves. As bagasse built up on the rails, the valves would not move far enough for the limit switches to indicate that the valves were open or closed. The distributed control system interlocks would then stop operations. Many minor adjustments were tried during the tests, but were unsuccessful in giving reliable valve operation. The proposed solution involved modifying the connector between the valve and actuator with a universal joint with more tolerance, and the use of a hydraulic actuator instead of an air actuator. These changes would also require that the valve bonnet (a pressure vessel) be modified. These recommended changes were not made and tested during TVP operations.

- The metering bin had a basic design problem. The bin liner had a converging wall. It was not obvious from process schematics that this was the case. The converging wall caused plugging of the metering bin. The problem was solved by field installation of a straight wall. In addition, the level sensors in the bin did not work reliably, and a lot of time was involved in testing to obtain believable readings. This was critical since metering bin inventory was a key control variable for the feed system.

- The collector screw bearings caused problems throughout the TVP, although not bad enough to stop operations. At the end of the TVP a decision had been made to redesign the bearings. It was felt that the existing design would not permit operation for extended periods of time.

- $\quad$ Problems were encountered in plugging of the air sparge ring in the gasifier. Analysis showed degradation of the fluid-bed media was causing the problems. Because of supply problems a different media was used for the TVP than for Phase 1. The solution would seem to be to use the original media.

- $\quad$ Extreme problems were encountered on the back pressure control valve. The valve was a ceramic gate valve. On two occasions loss of pressure control was observed. When the valve was disassembled the ceramic gate was gone. Small pieces of ceramic were later found downstream in the flare. Speculation is that during start-up and non-steady-state operations that some of the attemperator water was not vaporized and that liquid water impacted the valve gate causing thermal shocks that destroyed the gate. The valve was eventually replaced by the valve used in Phase 1. 

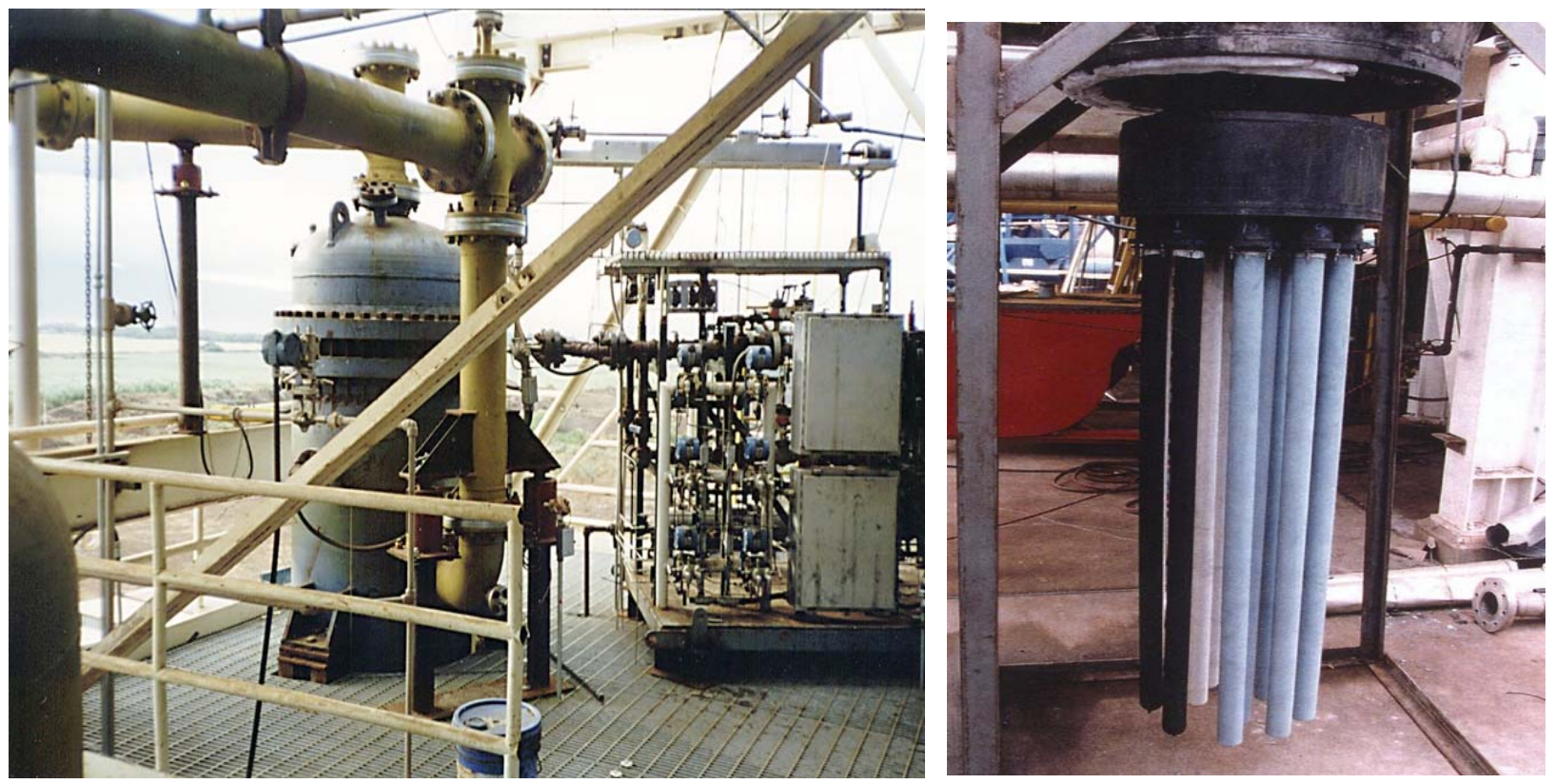

Figure 4-11: Hot Gas Filter Unit

Approximately 130 hours of gasification were achieved during the TVP. None of the operation was steady-state and only very limited gasification data were obtained. Filters were removed from the HGCU at the end of the test period and sent to WEC in Pittsburgh for analysis. Analytical results were presented in the WEC final report. Operations were stopped in November 1997 when WEC determined that there were insufficient funds to make needed modifications to the lock-hopper and continue operations.

\section{Status}

The TVP Phase of the Hawaii project was completed without reaching any of the major goals. In 1998 DOE completed an evaluation of future options and decided to discontinue participation in the project.

\section{Summary of Lessons Learned}

A brief summary of lessons learned for the Hawaii project is given below.

Non-technical

- Impact of Initial Cost Increase:

Major experimental programs of this nature must have the leadership of a commercial E\&C firm during the design and construction phase.

- Environmental Assessment:

The most important lesson coming out of the environmental permitting process is that solicitations should require substantial environmental reviews before committing to the decision to proceed with a project. Given the time and expense to perform such reviews the time and cost impacts of environmental assessments should be included in project plans. To a large extent the 
Biomass Power Program has learned from the Hawaii Project in this area. The Vermont Project was able to structure a project involving feeding the product gas to an existing boiler, without requiring a complete evaluation of the existing power plant permits, and using the using the existing boiler emission permits.

Impact of the Energy Policy Act of 1992

DOE was required to evaluate the project under the rules of EPACT92. Given the requirement by the State of Hawaii for commercial application for funding, a DOE determination was made that the project was a commercial, not an experimental, project. The conversion into a commercial project placed expectations on the project that could not be met.

Commercialization required a number of conditions to be met. HS\&S, the host company, needed to agree to assume ownership of the facility. They did not. Since the completion of the Hawaii project, HC\&S has closed the Paia mill. Second, the facility was an experimental unit at a small scale. The capital cost of an experimental facility and the associated labor-intensive design (needed for experimental data gathering/analysis but not commercial operation) made the commercial cost of electricity uneconomic.

Although the stated experimental goals were not reached in the proposed time, much valuable technical experience was gained in material handling systems, and in system integration. Therefore, the project was successful in addressing issues in start-up, testing and evaluation, and scaling up of biomass gasification technology.

- TVP Project:

The advisory groups should not have been disbanded. On highly developmental projects of this nature, limiting technical input greatly increases technical risk.

\section{$\underline{\text { Technical }}$}

- Impact of Initial Cost Increase:

Bagasse is an extremely difficult feedstock. Organizations with direct operating and design experience should be involved in bagasse projects. Decisions to modify the feed system design to fit within the allowable funding did not recognize the potential for technical difficulties and led to the majority of operational difficulties through the life of the project.

- $\quad$ Phase 1 Equipment Decisions:

Uniformity of feed is critical to the successful operation of a gasifier. The use of a feeder designed for a particular feed, rather than adaptation of a system not designed as a process feed system is needed.

\section{- $\quad$ Phase 1 Equipment Decisions:}

We need to do a better job of evaluating the ability of the non-Federal partner to operate new equipment such as the plug-screw feeder. We probably would have had more success using a system closer to commercialization. 
- $\quad$ Phase 1 Equipment Decisions:

We should more carefully evaluate the details of equipment. In the case of the plug-screw feeder, the use of a lubrication system would have eliminated many of the problems with overheating and high-current draws.

\section{Minnesota Alfalfa Project}

This section discusses the "Minnesota Agri-Power" project. The alfalfa biomass pilot separation facility in Priam, Minnesota is shown below. The purpose of this section is to review the chronology of major milestones for the project, and to discuss lessons learned.

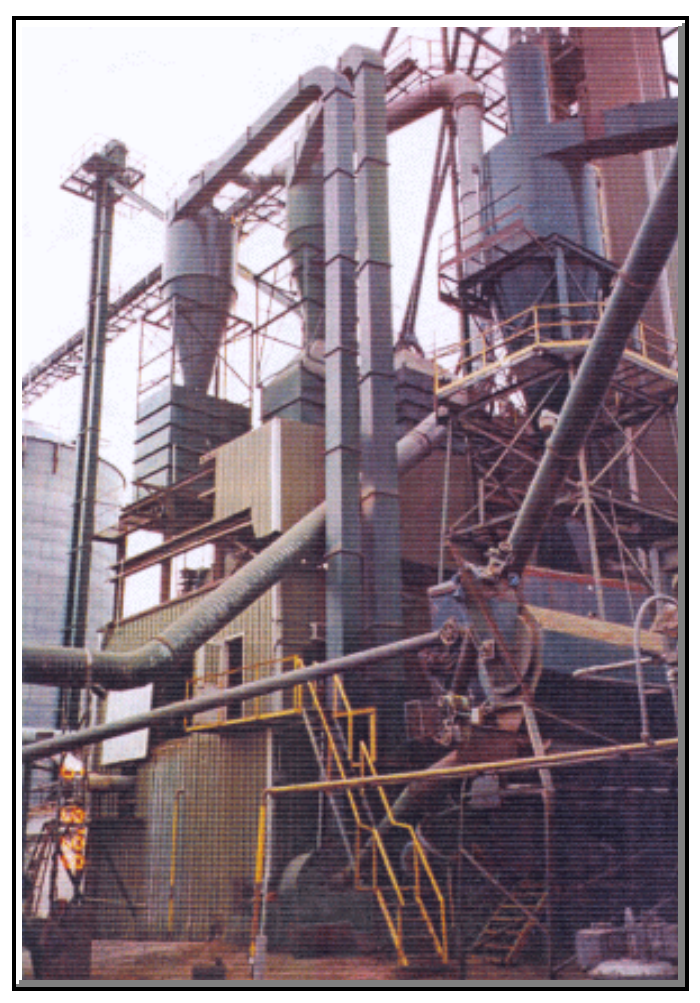

\section{Project chronology}

1994 - DOE, NSP, and U of M complete feasibility study 1994 - DOE Biomass Power for Rural Development Request for Proposal 1996 - MnVAP purchases Priam, MN processing and separation facility 1996 - DOE and MnVAP execute a cooperative agreement for development of MAP 1997 - MnVAP and UPA execute a letter of intent to provide technical services 1997 - MnVAP and NSP execute a PPA 1998 - Enron Capital and Trade Resources Corporation and MnVAP execute a joint development agreement for co-ownership of the MAP Project 1998 - FERC approves MAP Project as an exempt wholesale generator 1999 - AAPA is allowed by the MPUC to submit comments opposing the PPA 1999 - Enron terminates the joint development agreement

1999 - DOE suspends funding and withdraws from participation

\section{Project Overview}

MnVAP was incorporated as a cooperative under chapter 308A of the laws of the State of Minnesota in December 1994. MnVAP is an agricultural cooperative, currently owned by nearly 500 alfalfa farmers in western Minnesota. The company was formed in response to the interest shown by DOE, USDA, and others, in the development of biomass electric projects that use farm-grown, closed loop energy crops as primary fuels.

A 1994 feasibility study of biomass power, funded by DOE and conducted by NSP, U of M, and several other renewable energy industry organizations, determined that alfalfa would be a viable energy crop. During this feasibility study, staff of NSP and U of M sought participation of farmers in southwestern Minnesota to appraise their interest in developing an alfalfa fuel production system. NSP sealed this realistic possibility by committing to obtain $125 \mathrm{MW}$ of farm-grown closed-loop biomass power, and when DOE made a significant financial commitment to energy crop power systems with the BiomassPower for Rural Development initiative. 
MnVAP's proposal for the Minnesota Agri-Power Project was submitted to the DOE in mid-1995. The project's goal was to demonstrate the commercial viability and environmental sustainability of an integrated energy crop and "new technology" biomass electric generation system. MnVAP Project Phase I of the cooperative agreement provided funding for technology testing, feedstock supply development, preliminary design, environmental review, and other preliminary business and project development tasks. Final design and construction of the MAP project would have been accomplished in Phase II.

In early 1995, NSP requested proposals to supply biomass generation resources to satisfy the first phase of the Biomass Mandate. MnVAP and its project team submitted two proposals to NSP: one for a biomass gasification combined-cycle power plant, and another for a conventional power generation plant. Each project would use alfalfa stems as a primary fuel source. The original design of the project called for a Tampella Power gasification island and a 75-megawatt combined-cycle power plant with a Westinghouse 251B combustion turbine. At full production, the power plant would require nearly 350,000 tons of alfalfa stem material per year.

In late 1996, NSP selected MnVAP's biomass gasification combined-cycle project for negotiation of a PPA. MnVAP and NSP executed an MOU that outlined the terms to be incorporated in a power purchase agreement. By the end of 1997, MnVAP executed a long-term PPA with NSP. It was expected that this would provide long-term project viability. Execution of the PPA justified accelerated development work to prepare for financial closing and start of construction.

Phase I of the cooperative agreement provided DOE funds on a cost-shared basis to complete work in seven major project task areas. Each task area supported completion of items necessary for the MAP Project to reach financial closing and start construction; however there was insufficient time to begin commercial operations before the end of the calendar year 2001, the date by which NSP was required to bring biomass resources on line. Most tasks were completed, or were progressing well, but development work was suspended prior to financial closing de to a combination of events precipitated largely by regulatory delays.

\section{Summary of Lessons Learned: Minnesota Agri-Power Project}

1. Vendor Guarantees and Warranties: If plant configuration has not been tested, and/or if the feed has not been tested, then extended pilot testing is required ( 1000 - 2000 hours at steady state conditions) to develop vendor confidence leading to guarantees and warranties for commercial operation.

2. Pilot Plant Experience: Such testing may be doubly important when guarantees and warranties are needed from "downstream" unit operation vendors such as gas clean-up, gas turbine and stearn turbine original equipment manufacturers.

3. Project Scale-Up: A scale-up of ten times is too large to incorporate guarantees and warranties for untested processing steps or combinations of unit operations.

4. Project Financing: Developmental projects are inherently risky, requiring the development of creative approaches to investment and financing arrangements.

5. Entering New Markets: A marketing plan and study of existing markets for agriculturallybased, and other potential feedstock products must be developed. Expect resistance (political and economic) from current market suppliers. 
6. Feedstock Suitability and Flexibility: Criteria for suitability of feedstocks for electrical conversion need to be developed. If possible, the conversion system should be designed to handle multiple feedstocks.

7. Technical Readiness: DOE needs to perform in-depth reviews of the technical status of development in relation to the proposed commercial project to better estimate the technical/commercial feasibility of the project. At a minimum, the project technical development time and cost should be reviewed in detail.

8. Reviews Prior to Award: A detailed technical review is required at the solicitation technical review stage to identify technology readiness for commercialization, rather than addressing such issues after agreements have been reached and project timing and costs have been contractually set.

\section{Success Factors}

Successful commercial implementation of technology is dependent on a wide range of positive and negative drivers. A preliminary analysis was performed that identified drivers in the areas of policy, corporate policy, regulation, legal, infrastructure, and technology, which resulted in a preliminary methodology for ranking relative importance. The analysis methodology involves development of an estimate of the impact of drivers on CHP systems (high, medium, low), the relative importance of each driver, and the probability of the driver occurring by 2020. Multiplying the three factors gives a weighted probability of the impact. This weighted probability can be normalized to $100 \%$ and ordered in terms of numerical importance. An example of the rating of drivers was estimated by the authors to demonstrate the methodology. Eventually, it would be desirable to ask a group of experts in the area to provide independent estimates of factors, and then develop a group evaluation of drivers. The example positive and negative drivers are given in Table 4-5. Table 4-6 presents a summary of key drivers, ranked by weighted probability.

Seventy-five percent of the positive drivers are given by 10 factors in the categories of technology, corporate policy, regulation and finance. The top three positive factors are the technology maturity of combustion and cofiring systems, the corporate need for CHP, and Federal mandates such as PURPA. Seventy-five percent of the negative drivers are given by nine factors in the categories of finance, corporate policy, and legal. The top three negative factors are lack of feedstock infrastructure, the cost of products compared to traditional sources, a corporate resistance to new technology introduction.

A qualitative comparison of key success factors relative to coal and natural gas was made and is presented in table 4-7. In general, biomass systems compare favorably with new coal facilities, especially in the area of environmental impact. In general, biomass systems do not compare favorably with natural gas systems, except in the area of environmental impact. 


\section{DRIVERS FOR BIOMASS CHP SYSTEMS}

\begin{tabular}{|c|c|c|c|c|c|c|}
\hline $\begin{array}{c}A \\
(H, M, L)\end{array}$ & B & $\begin{array}{c}C \\
(1-100 \%)\end{array}$ & $A \times B$ & $A \times B \times C$ & & \\
\hline$(5,3$ & & & & & & \\
\hline $\begin{array}{l}\text { pact on } \\
\text { CHP } \\
\text { ystems }\end{array}$ & $\begin{array}{l}\text { Relative } \\
\text { nportance }\end{array}$ & $\begin{array}{c}\text { of } \\
\text { Occurring } \\
\text { by } 2010\end{array}$ & $\begin{array}{l}\text { Importa } \\
\times \operatorname{Imp}\end{array}$ & $\begin{array}{l}\text { Weighted } \\
\text { Probability } \\
\text { of Impact }\end{array}$ & $\begin{array}{l}\text { Weighted } \\
\text { Probability } \\
\text { \% of Total }\end{array}$ & $\begin{array}{l}\text { Cumulative } \\
\text { Probability } \\
\% \text { of Total }\end{array}$ \\
\hline
\end{tabular}

\begin{tabular}{|c|c|c|c|c|c|c|c|c|c|}
\hline Ref & Category & $\begin{array}{l}\text { DRIVERS } \\
\text { POSITIVE DRIVERS }\end{array}$ & systems & Importance & by 2010 & x Impact & of Impact & $\%$ of Total & $\%$ of Total \\
\hline A & Policy & National Security (Domestic Sourcing Rulings) & 5 & 10 & $25 \%$ & 50 & 12.5 & $2.2 \%$ & $2.2 \%$ \\
\hline B & Regulation & Air Emissions Controls (National, State) & 5 & 10 & $75 \%$ & 50 & 37.5 & $6.7 \%$ & $9.0 \%$ \\
\hline C & Policy & State Programs for RE & 5 & 15 & $25 \%$ & 75 & 18.8 & $3.4 \%$ & $12.4 \%$ \\
\hline D & Finance & Federal Tax Incentives for RE & 5 & 20 & $25 \%$ & 100 & 25.0 & $4.5 \%$ & $16.9 \%$ \\
\hline E & Regulation & Federal Mandates, e.g., PURPA, RPS & 5 & 20 & $50 \%$ & 100 & 50.0 & $9.0 \%$ & $25.8 \%$ \\
\hline $\mathbf{F}$ & Infrastructure & Transmission Bottlenecks / Disruptions & 3 & 10 & $25 \%$ & 30 & 7.5 & $1.3 \%$ & $27.2 \%$ \\
\hline G & Regulation & Distributed Energy Certification Standards & 3 & 5 & $100 \%$ & 15 & 15.0 & $2.7 \%$ & $29.9 \%$ \\
\hline H & Regulation & Electricity Wheeling & 3 & 10 & $\mathbf{5 0} \%$ & 30 & 15.0 & $2.7 \%$ & $32.6 \%$ \\
\hline I & Policy & Climate Change Policy (international) & 1 & 5 & $50 \%$ & 5 & 2.5 & $0.4 \%$ & $33.0 \%$ \\
\hline $\mathbf{J}$ & Finance & Fuel Price Volatility (coal, oil, natural gas) & 3 & 15 & $50 \%$ & 45 & 22.5 & $4.0 \%$ & $37.1 \%$ \\
\hline $\mathrm{K}$ & Finance & Fuel Supply Disruptions (Oil, Natural Gas) & 3 & 20 & $25 \%$ & 60 & 15.0 & $2.7 \%$ & $39.8 \%$ \\
\hline $\mathbf{L}$ & Corp Policy & Corporate Energy Autonomy & 3 & 5 & $50 \%$ & 15 & 7.5 & $1.3 \%$ & $41.1 \%$ \\
\hline M & Corp Policy & Corporate RE Mandate & 5 & 20 & $25 \%$ & 100 & 25.0 & $4.5 \%$ & $45.6 \%$ \\
\hline $\mathbf{N}$ & Corp Policy & Corporate Use/Need for CHP & 3 & 20 & $100 \%$ & 60 & 60.0 & $10.8 \%$ & $56.4 \%$ \\
\hline 0 & Finance & Use of Existing Residues & 5 & 10 & $100 \%$ & 50 & 50.0 & $9.0 \%$ & $65.4 \%$ \\
\hline $\mathbf{P}$ & Technology & Alternative Future Uses, e.g., SYNGAS & 3 & 5 & $100 \%$ & 15 & 15.0 & $2.7 \%$ & $68.1 \%$ \\
\hline $\mathbf{R}$ & Finance & Cost of Fuel - Stability & 3 & 10 & $75 \%$ & 30 & 22.5 & $4.0 \%$ & $72.1 \%$ \\
\hline $\mathbf{s}$ & Corp Policy & Support of Local Economy - Indigenous Feed & 1 & 5 & $100 \%$ & 5 & 5.0 & $0.9 \%$ & $73.0 \%$ \\
\hline $\mathbf{T}$ & Finance & Low Interest Rates & 5 & 5 & $10 \%$ & 25 & 2.5 & $0.4 \%$ & $73.5 \%$ \\
\hline u & Finance & Cofiring Capital Cost & 3 & 15 & $100 \%$ & 45 & 45.0 & $8.1 \%$ & $81.6 \%$ \\
\hline v & Finance & Production of Export Electricity & 3 & 10 & $50 \%$ & 30 & 15.0 & $2.7 \%$ & $84.3 \%$ \\
\hline w & Technology & Technology Maturity, Combustion and Cofiring & 5 & 15 & $100 \%$ & 75 & 75.0 & $13.5 \%$ & $97.8 \%$ \\
\hline $\mathbf{x}$ & Legal & Environmental Community Acceptance & 5 & 5 & $50 \%$ & 25 & 12.5 & $2.2 \%$ & $100.0 \%$ \\
\hline & & $\begin{array}{l}\text { Average for Positive Factors } \\
\text { Sum for Positive Factors }\end{array}$ & 3.70 & 11.52 & & 45.0 & 556.3 & $0.0 \%$ & \\
\hline
\end{tabular}




\section{Drivers for Biomass CHP Systems}

\begin{tabular}{|c|c|c|c|c|c|c|c|c|c|}
\hline & & $\begin{array}{l}\text { DRIVERS } \\
\quad \text { NEGATIVE DRIVERS }\end{array}$ & $\begin{array}{c}\text { A } \\
(H, M, L) \\
(5,3,1) \\
\text { Impact on } \\
\text { CHP } \\
\text { systems }\end{array}$ & $\begin{array}{c}\text { B } \\
\text { (1 to 20) } \\
\text { Relative } \\
\text { Importance }\end{array}$ & $\begin{array}{c}\text { C } \\
(1-100 \%) \\
\text { Probability } \\
\text { of } \\
\text { Occurring } \\
\text { by } 2010\end{array}$ & $\begin{array}{c}\text { A } \times \text { B } \\
\text { Importance } \\
\times \text { Impact }\end{array}$ & $\begin{array}{l}\text { Weighted } \\
\text { Probability } \\
\text { of Impact }\end{array}$ & $\begin{array}{l}\text { Weighted } \\
\text { Probability } \\
\% \text { of Total }\end{array}$ & $\begin{array}{c}\text { Weighted } \\
\text { Cumulative } \\
\text { Probability } \\
\% \text { of Total }\end{array}$ \\
\hline AA & Corp Policy & Resistance to Change & 5 & 20 & $80 \%$ & 100 & 80.0 & $9.1 \%$ & $9.1 \%$ \\
\hline BB & Corp Policy & Corporate Experience & 5 & 20 & $50 \%$ & 100 & 50.0 & $5.7 \%$ & $14.7 \%$ \\
\hline CC & Finance & Feedstock Infrastructure & 5 & 20 & $100 \%$ & 100 & 100.0 & $11.3 \%$ & $26.1 \%$ \\
\hline DD & Finance & Feedstock Cost & 3 & 15 & $80 \%$ & 45 & 36.0 & $4.1 \%$ & $30.1 \%$ \\
\hline EE & Finance & Feedstock Transportation & 3 & 10 & $50 \%$ & 30 & 15.0 & $1.7 \%$ & $31.8 \%$ \\
\hline FF & Finance & Competition for Feedstock & 5 & 20 & $50 \%$ & 100 & 50.0 & $5.7 \%$ & $37.5 \%$ \\
\hline GG & Technology & Process Efficiency & 3 & 10 & $95 \%$ & 30 & 28.5 & $3.2 \%$ & $40.7 \%$ \\
\hline $\mathrm{HH}$ & Finance & Capital Cost, Economy of scale & 5 & 15 & $95 \%$ & 75 & 71.3 & $8.1 \%$ & $48.8 \%$ \\
\hline II & Finance & Operating Costs & 5 & 15 & $95 \%$ & 75 & 71.3 & $8.1 \%$ & $56.9 \%$ \\
\hline JJ & Finance & Cost of Products & 5 & 20 & $95 \%$ & 100 & 95.0 & $10.8 \%$ & $67.6 \%$ \\
\hline KK & Finance & Higher Interest Rates & 3 & 10 & $90 \%$ & 30 & 27.0 & $3.1 \%$ & $70.7 \%$ \\
\hline LL & Finance & Low Coal Prices & 1 & 15 & $95 \%$ & 15 & 14.3 & $1.6 \%$ & $72.3 \%$ \\
\hline MM & Finance & Low Oil and Gas Prices & 1 & 15 & $25 \%$ & 15 & 3.8 & $0.4 \%$ & $72.7 \%$ \\
\hline NN & Regulation & Permitting / Siting Problems & 5 & 20 & $50 \%$ & 100 & 50.0 & $5.7 \%$ & $78.4 \%$ \\
\hline OO & Legal & Environmental Community Opposition & 5 & 20 & $75 \%$ & 100 & 75.0 & $8.5 \%$ & $86.9 \%$ \\
\hline PP & Corp Policy & Power Purchase Agreements & 3 & 20 & $95 \%$ & 60 & 57.0 & $6.5 \%$ & $93.4 \%$ \\
\hline $\mathbf{Q Q}$ & Regulation & Cost of Environmental Controls & 3 & 15 & $100 \%$ & 45 & 45.0 & $5.1 \%$ & $98.5 \%$ \\
\hline $\mathbf{R} \mathbf{R}$ & Technology & Technology Immaturity - Gasification & 1 & 15 & $90 \%$ & 15 & 13.5 & $1.5 \%$ & $100.0 \%$ \\
\hline & & $\begin{array}{l}\text { Average for Negative Factors } \\
\text { Sum for Negative Factors }\end{array}$ & 3.67 & 16.39 & & 63.056 & 882.5 & & \\
\hline
\end{tabular}




\section{KEY SUCCESS FACTORS FOR BIOMASS CHP SYSTEMS}

Weighted Weighted

Probability Cumulative

$\%$ of Total Probability

$\%$ of Total
Category

KEY DRIVERS

$\begin{array}{ll}\text { W } & \text { Technology } \\ \text { N } & \text { Corp Policy } \\ \text { E } & \text { Regulation } \\ \text { O } & \text { Finance } \\ \text { U } & \text { Finance } \\ \text { B } & \text { Regulation } \\ \text { D } & \text { Finance } \\ \text { M } & \text { Corp Policy } \\ \text { J } & \text { Finance } \\ \text { R } & \text { Finance } \\ \text { C } & \text { Policy } \\ \text { G } & \text { Regulation } \\ \text { H } & \text { Regulation } \\ \text { K } & \text { Finance } \\ \text { P } & \text { Technology } \\ \text { V } & \text { Finance } \\ \text { A } & \text { Policy } \\ \text { X } & \text { Legal } \\ \text { F } & \text { Infrastructure } \\ \text { L } & \text { Corp Policy } \\ \text { S } & \text { Corp Policy } \\ \text { I } & \text { Policy } \\ \text { T } & \text { Finance }\end{array}$

Ref

\section{POSITIVE FACTORS}

Technology Maturity, Combustion and Cofiring

Corporate Use/Need for CHP

Federal Mandates, e.g., PURPA, RPS

Use of Existing Residues

Cofiring Capital Cost

Air Emissions Controls (National, State)

Federal Tax Incentives for RE

Corporate RE Mandate

Fuel Price Volatility (coal, oil, natural gas)

Cost of Fuel - Stability

State Programs for RE

Distributed Energy Certification Standards

Electricity Wheeling

Fuel Supply Disruptions (Oil, Natural Gas)

Alternative Future Uses, e.g., SYNGAS

Production of Export Electricity

National Security (Domestic Sourcing Rulings)

Environmental Community Acceptance

Transmission Bottlenecks / Disruptions

Corporate Energy Autonomy

Support of Local Economy - Indigenous Feed

Climate Change Policy (international)

Low Interest Rates

\begin{tabular}{ll}
$13.5 \%$ & $13.5 \%$ \\
$10.8 \%$ & $24.3 \%$ \\
$9.0 \%$ & $33.3 \%$ \\
$9.0 \%$ & $42.2 \%$ \\
$8.1 \%$ & $50.3 \%$ \\
$6.7 \%$ & $57.1 \%$ \\
$4.5 \%$ & $61.6 \%$ \\
$4.5 \%$ & $66.1 \%$ \\
$4.0 \%$ & $70.1 \%$ \\
$4.0 \%$ & $74.2 \%$ \\
$3.4 \%$ & $77.5 \%$ \\
$2.7 \%$ & $80.2 \%$ \\
$2.7 \%$ & $82.9 \%$ \\
$2.7 \%$ & $85.6 \%$ \\
$2.7 \%$ & $88.3 \%$ \\
$2.7 \%$ & $91.0 \%$ \\
$2.2 \%$ & $93.3 \%$ \\
$2.2 \%$ & $95.5 \%$ \\
$1.3 \%$ & $96.9 \%$ \\
$1.3 \%$ & $98.2 \%$ \\
$0.9 \%$ & $99.1 \%$ \\
$0.4 \%$ & $99.6 \%$ \\
$0.4 \%$ & $100.0 \%$ \\
\hline &
\end{tabular}

\section{NEGATIVE FACTORS}

$\begin{array}{cl}\text { CC } & \text { Finance } \\ \text { JJ } & \text { Finance } \\ \text { AA } & \text { Corp Policy } \\ \text { OO } & \text { Legal } \\ \text { HH } & \text { Finance } \\ \text { II } & \text { Finance } \\ \text { PP } & \text { Corp Policy } \\ \text { BB } & \text { Corp Policy } \\ \text { FF } & \text { Finance } \\ \text { NN } & \text { Regulation } \\ \text { QQ } & \text { Regulation } \\ \text { DD } & \text { Finance } \\ \text { GG } & \text { Technology } \\ \text { KK } & \text { Finance } \\ \text { EE } & \text { Finance } \\ \text { LL } & \text { Finance } \\ \text { RR } & \text { Technology } \\ \text { MM } & \text { Finance }\end{array}$

Feedstock Infrastructure

$11.3 \% \quad 11.3 \%$

Cost of Products

$10.8 \% \quad 22.1 \%$

Resistance to Change

Environmental Community Opposition

$9.1 \%$

$31.2 \%$

Capital Cost, Economy of scale

$8.5 \%$

$39.7 \%$

Operating Costs

$47.7 \%$

$55.8 \%$

Power Purchase Agreements

$8.1 \%$

$62.3 \%$

Corporate Experience

$6.5 \%$

$67.9 \%$

Competition for Feedstock

$5.7 \%$

$73.6 \%$

Permitting / Siting Problems

$5.7 \%$

$79.3 \%$

Cost of Environmental Controls

$84.4 \%$

Feedstock Cost

$5.1 \%$

$88.4 \%$

Process Efficiency

$91.7 \%$

Higher Interest Rates

$4.1 \%$

$3.2 \%$

$94.7 \%$

Feedstock Transportation

$3.1 \%$

$96.4 \%$

Low Coal Prices

Technology Immaturity - Gasification

$1.7 \%$

$98.0 \%$

Low Oil and Gas Prices

$1.6 \%$

$99.6 \%$

$1.5 \%$

$100.0 \%$ 


\section{KEY SUCCESS FACTORS}

Construction/Installation

Relative to Coal Relative to N. Gas

Experience

Capital Cost

Predictability of Schedule

Space/Footprint, including acreage

Operating

Labor Costs

Maintenance Costs

System Reliability

Feedstock

Price

Residues

Dedicated Feeds

Availability

Reliability of Supply

Quality

Environmental

Air Emissions

Green House Gases

Solid Wastes

Liquid Wastes

Permitting

Waste Reduction

$+/ 0 \quad 0 /-$

NA NA

$+$

NA NA

O --

$0 \quad++$

0 -

$-$

-

onomic

Financing

Power Purchase Agreement

Tax Incentives

Regulatory Policy 


\section{References}

Bartol, D.A. (1996). "Proposal for: Hawaii Biomass Gasification Program,” Westinghouse Electric Corporation, Orlando, FL (March).

DOE, Chicago Operations Office, SERI Area Office (1989). "Federal Assistance Solicitation for Cooperative Agreements Proposals, DE-PS02-89CH10407, For a Biomass Gasifier Scale-up Facility," July.

Hays, R.J. (1989) "Research Proposal Submitted to the Department of Energy in Response to FASCAP No. DE-PS02-89CH10407," Pacific International Center for High Technology Research, Honolulu, HI, November.

House of Representatives (1992). "Energy Policy Act of 1992: Conference Report to Accompany H.R. 776," October 5.

Kearns, P.K. (1991) Letter to A. R. Cox, PICHTR, DOE -SERI Area Office, Golden, CO, May 21.

Trenka, A. R., M. Onischak, J. Gissy, R. Knight, C. Kinoshita, S. Turn, J. Arcate, J. Loux, and G. Smith (1997) "Biomass Gasification Facility (BGF) - Proof of Scale-Up Operation and Test Results," Pacific International Center for High Technology Research, Honolulu, HI, May. 


\section{TECHNOLOGY CASE STUDIES}

A series of case studies have been performed on the three conversion routes for combined heat and power (CHP) applications of biomass - direct combustion, gasification, and cofiring. The studies are based on technology characterizations developed by NREL and EPRI ${ }^{1}$, and the technology descriptions are excerpted from that study. Variables investigated include plant size and feed cost, and both cost of electricity and cost of steam are estimated using a discounted cash flow analysis. The economic basis for cost estimates is given below.

Table 5.1: Economic Assumptions

\begin{tabular}{|c|c|c|}
\hline Parameter & Value & Discussion \\
\hline Basis Year & $3^{\text {rd }} \mathrm{Qtr}, 2001$ & \\
\hline Cost Index & Marshall \& Swift & \\
\hline Scale Factor & 0.7 & \\
\hline Debt & $50 \%$ & \\
\hline Inflation & None & \\
\hline Capital & $7 \%$ for 20 years & \\
\hline Discount Rate & $20 \%$ & \\
\hline Salvage Value & 0 & \\
\hline \multicolumn{3}{|l|}{ Taxes } \\
\hline Federal & $35 \%$ & \\
\hline State & $5 \%$ & \\
\hline State Wholesale Excise & 0 & \\
\hline Federal Alt. Min. Tax & Not estimated & \\
\hline Industrial Electricity Purchase Price & 3.8 cents $/ \mathrm{kWh}$ & $\begin{array}{l}\text { Chemicals Industry Costs: EIA Manufacturing Consumption of } \\
\text { Energy 1998, Table N8.3, corrected to } 2001 \$\end{array}$ \\
\hline Industrial Steam Purchase Price & $\$ 3.3 / 1000 \mathrm{lb}$ & $\begin{array}{l}\text { Chemicals Industry Costs: EIA Manufacturing Consumption of } \\
\text { Energy 1998, Table N8.3, corrected to } 2001 \$\end{array}$ \\
\hline Construction Period & 2 years & Comparable to EPRI/DOE Technical Characterization \\
\hline Operating Life & 30 years & Comparable to EPRI/DOE Technical Characterization \\
\hline Stream Factor & $90 \%$ & \\
\hline \multirow[t]{3}{*}{ Depreciation } & 7-year MACRS & For biomass specific operations \\
\hline & 20-year MACRS & For generating equipment, BOP \\
\hline & 5-year MACRS & For biomass qualifying facility sensitivity case \\
\hline Tax Credit & $0.5,1,1.5,2 \notin / \mathrm{kWh}$ & Sensitivity Case \\
\hline Financial Parameter & $\mathrm{NPV}(0)$ & net present value \\
\hline Feed Costs & $-1,0,1,2,3,4 \$$ MBtu & \\
\hline Plant Size & $\begin{array}{l}25,50,75,100 \mathrm{MW} \\
75 \mathrm{MW} \\
45,105 \mathrm{MW}\end{array}$ & $\begin{array}{l}\text { Based on electricity only - direct combustion } \\
\text { Gasification } \\
\text { Cofiring (biomass contribution) }\end{array}$ \\
\hline
\end{tabular}

1 “Renewable Energy Technology Characterizations," EPRI-TR-109469, Electric Power Research Institute, Palo Alto, California, December 1997 (RETC97) 


\section{Technology Alternatives}

The nearest term low-cost option for the use of biomass is cofiring with coal in existing boilers. Cofiring refers to the practice of introducing biomass as a supplementary energy source in high efficiency boilers. Boiler technologies where cofiring has been practiced, tested, or evaluated, include wall- and tangentially-fired pulverized coal (PC) boilers, cyclone boilers, fluidized-bed boilers, and spreader stokers. The current coal-fired power generating system represents a direct system for carbon mitigation by substituting biomass-based renewable carbon for fossil carbon. Extensive demonstrations and trials have shown that effective substitutions of biomass energy can be made up to about $15 \%$ of the total energy input with little more than burner and feed intake system modifications to existing stations. Since large scale power boilers (both utility and independent operators) in the 1999345 GW (EIA 1999) capacity fleet range from $100 \mathrm{MW}$ to $1.3 \mathrm{GW}$, the biomass potential in a single boiler ranges from 15 MW to $150 \mathrm{MW}$. Preparation of biomass for cofiring involves well known and commercial technologies. After tuning the boiler's combustion output, there is little or no loss in total efficiency, implying that the biomass combustion efficiency to electricity would be about 33-37\%. Since biomass in general has significantly less sulfur than coal, there is a $\mathrm{SO}_{2}$ benefit; and early test results suggest that there is also a $\mathrm{NO}_{\mathrm{x}}$ reduction potential of up to $20 \%$ with woody biomass. Investment levels are very site specific and are affected by the available space for yarding and storing biomass, installation of size reduction and drying facilities, and the nature of the boiler burner modifications. Investments are expected to be in $\$ 100-700 / \mathrm{kW}$ of biomass capacity, with a median in the $\$ 180-200 / \mathrm{kW}$ range.

Another potentially attractive biopower option is based on gasification. Gasification for power production involves the devolatilization and conversion of biomass in an atmosphere of steam or air to produce a medium- or low- calorific gas. This biogas is used as fuel in a combined cycle power generation cycle involving a gas turbine topping cycle and a steam turbine bottoming cycle. A large number of variables influence gasifier design, including gasification medium (oxygen or no oxygen), gasifier operating pressure, and gasifier type. Advanced biomass power systems based on gasification benefit from the substantial investments made in coal-based gasification combined cycle (GCC) systems in the areas of hot gas particulate removal and synthesis gas combustion in gas turbines. They also leverage investments made in the Clean Coal Technology Program (commercial demonstration cleanup and utilization technologies) and in those made as part of DOE's Advanced Turbine Systems (ATS) Program. Biomass gasification systems will also stand ready to provide fuel to fuel cell and hybrid fuelcell/gas turbine systems, particularly in developing or rural areas without cheap fossil fuels or problematic transmission infrastructure. The first generation of biomass GCC systems would realize efficiencies nearly double that of the existing industry. In a cogeneration application efficiencies could exceed $80 \%$. This technology is very near to commercial availability with mid-size plants operating in Finland, the UK, the Netherlands, and Vermont. Costs of a first-of-a-kind biomass GCC plant are estimated to be in the $\$ 1800-2000 / \mathrm{kW}$ range with the cost dropping rapidly to the $\$ 1400 / \mathrm{kW}$ range for a mature plant in the 2010 time frame.

Direct-fired combustion technologies are another option, especially with retrofits of existing facilities to improve process efficiency. Direct combustion involves the oxidation of biomass with excess air, giving hot flue gases that produce steam in the heat exchange sections of boilers. The steam is used to produce electricity in a Rankine cycle. In an electricity-only process, all of the steam is condensed in the turbine cycle while, in CHP operation, a portion of the steam is extracted to provide process heat. Today's biomass-fired steam cycle plants typically use single pass steam turbines. However, in the past decade, efficiency and design features, found previously in large-scale steam turbine generators, have been transferred to smaller capacity units. These designs include multi-pressure, reheat and regenerative steam turbine cycles, as well as supercritical steam turbines. The two common boiler designs used for steam generation with biomass are stationary- and traveling-grate combustors (stokers) and atmospheric fluidbed combustors. The addition of dryers and incorporation of more-rigorous steam cycles is expected to 
raise the efficiency of direct combustion systems by about $10 \%$ over today's efficiency, and to lower the capital investment from the present $\$ 2,000 / \mathrm{kW}$ to about $\$ 1275 / \mathrm{kW}$.

The three technologies are all at either the commercial scale or commercial prototype scale, and have been included in this technology case study. There are additional technologies which are at the conceptual or research and development stage and do not warrant development of a technology case study at this time, but which are potentially attractive from a performance and cost perspective and merit discussion. These technologies include biomass gasification fuel cell processes, and modular systems such as biomass gasification/Stirling engines.

Gasification fuel cell systems hold the promise for high efficiency and low cost at a variety of scales. The benefits may be particularly pronounced at scales previously associated with high cost and low efficiency (i.e., from $<1 \mathrm{MW}$ to $20 \mathrm{MW}$ ). Fuel cell based power systems are likely to be particularly suitable for distributed power generation strategies in the U.S. and abroad. Extensive development of molten carbonate fuel cell (MCFC) technology has been conduced under DOE's Fossil Energy Program largely with natural gas as a test fuel. Several demonstration projects are underway in the U.S. for long-term testing of these cells. A limited amount of testing was also done with MCFC technology on synthesis gas from a DOW coal gasifier at DESTEC's facility in Plaquamine, LA. The results from this test were quite promising.

To date, little fuel cell testing has been done with biomass-derived gases despite the several advantages that biomass has over coal in this application. Biomass' primary advantage is its very low sulfur content. Sulfur-containing species is a major concern in fossil fuel-based fuel cell systems because all fuel cells are very sensitive to this contaminant. An additional biomass advantage is its high reactivity. This allows biomass gasifiers to operate at lower temperatures and pressures, while maintaining throughput levels comparable with their fossil fueled counterparts. These relatively mild operating conditions and a high throughput should permit economic construction of gasifiers of a relatively small scale that are compatible with planned fuel cell system sizes. Additionally, the operating temperature and pressure of MCFC units may allow a high degree of thermal integration over the entire gasifier/fuel cell system. Despite these obvious system advantages, it is still necessary for actual test data and market assessments to be obtained to stimulate commercial development and deployment of fuel cell systems.

The Stirling engine is designed to use any heat source, e.g., biomass, and any convenient working gas to generate energy, in this case electricity. The basic components of the Stirling engine include: a compression space and an expansion space with a heater, regenerator, and cooler in between. Heat is supplied to the working gas at a higher temperature by the heater and is rejected at a lower temperature in the cooler. The regenerator provides a means for storing heat deposited by the hot gas in one stage of the cycle and releasing it heat the cool gas in a subsequent stage. Stirling engine systems using biomass are ideal for remote applications, stand alone or cogeneration applications, or as backup power systems. A feasibility test of biomass gasification Stirling engine generation has been performed by Stirling Thermal Motors using a $25 \mathrm{~kW}$ engine connected to a small Chiptec updraft gasifier. While the results were encouraging, further demonstration of the concept is required. 
Figure 5.1: Direct-fired Biopower Facility

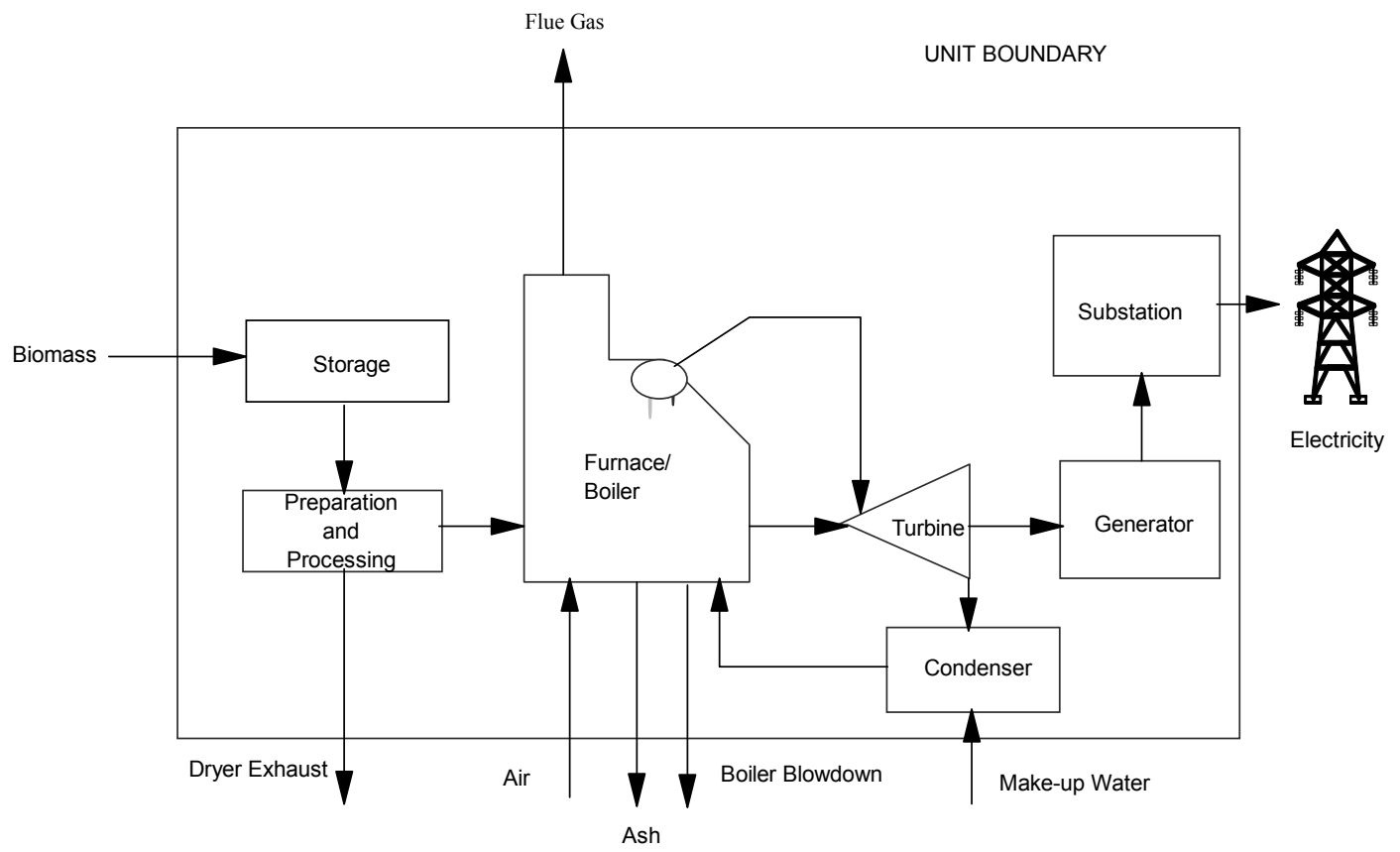

\section{Direct-Fired Biomass}

Direct combustoin, illustrated in Figure 5.1, involves the oxidation of biomass with excess air, giving hot flue gases that produce steam in the heat exchange section of boilers. The steam is used to produce electricity in a Rankine cycle; usually, only electricity is produced in a condensing steam cycle, while electricity and steam are cogenerated in an extracting steam cycle. Today's biomass-fired steam cycle plants typically use single-pass steam turbines. However, in the past decade, efficiency and design features, found previously in large scale steam turbine generators $(>200 \mathrm{MW})$, have been transferred to smaller capacity units. These designs include reheat and regenerative steam cycles as well as supercritical steam turbines. The two common boiler designs used for steam generation with biomass are stationaryand traveling-grate combustors (stokers) and atmospheric fluid-bed combustors.

All biomass combustion systems require feedstock storage and handling systems. The 50-MW Burlington, Vermont, McNeil station, which uses a spreader-stoker boiler for steam generation, has a typical feed system for wood chips (Wiltsee and Hughes 1995). Whole tree chips are delivered to the plant gate by either truck or rail. Fuel chips are stored in open piles (about a 30 day supply on about 3.25 ha of land), fed by conveyor belt through an electromagnet and disc screen, then fed to surge bins above the boiler by belt conveyors. From the surge bins the fuel is metered into the boiler's pneumatic stokers by augers.

Pile burners represent the historic industrial method (Hollenbacher 1992) of wood combustion and typically consist of a two-stage combustion chamber with a separate furnace and boiler located above the 
secondary combustion chamber. The combustion chamber is separated into a lower pile section for

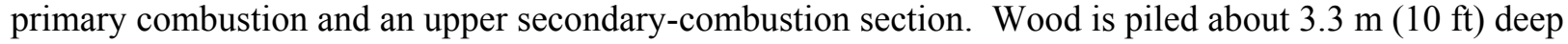
on a grate in the bottom section and combustion air is fed upwards through the grate and inwards from the walls; combustion is completed in a secondary combustion zone using overfire air. Feed is introduced either on top of the pile or through an underfeed arrangement using an auger. The underfeed arrangement gives better combustion control by introducing feed underneath the active combustion zone, but it increases system complexity and lowers its reliability. Ash is removed by isolating the combustion chamber from the furnace and manually dumping the ash from the grate after the ash is cooled. Pile burners typically have low efficiencies (50\% to 60\%), cyclic operating characteristics because of the ash removal, and combustion cycles that are erratic and difficult to control. Because of the slow response time of the system and the cyclic nature of operation, pile burners are not considered for load-following operations. The advantage of the pile burner is its simplicity and ability to handle wet, dirty fuels.

Stoker combustors (Hollenbacher 1992), improve on operation of the pile burners by providing a moving grate which permits continuous ash collection, thus eliminating the cyclic operation characteristic of traditional pile burners. In addition, the fuel is spread more evenly, normally by a pneumatic stoker, and in a thinner layer in the combustion zone, giving more efficient combustion. Stoker fired boilers were first introduced in the 1920's for coal; and in the late 1940's the Detroit Stoker Company installed the first traveling grate spreader stoker boiler for wood. In the basic stoker design the bottom of the furnace is a moving grate which is cooled by underfire air. Underfire air rate defines the maximum temperature of the grate and thus the allowable moisture content of the feed. More modern designs include the Kabliz grate, a sloping reciprocating water-cooled grate. Reciprocating grates are attractive because of simplicity and low fly ash carryover. Combustion is completed by the use of overfire air. Furnace wall configurations include straight and bull nose water walls. Vendors include Zurn, Foster Wheeler, and Babcock \& Wilcox.

In a gas-solid fluidized bed, a stream of gas passes upwards through a bed of free-flowing granular materials in which the gas velocity is large enough that the solid particles are widely separated and circulate freely throughout the bed. During overall circulation of the bed, transient streams of gas flow upwards in channels containing few solids, and clumps or masses of solids flow downwards (Perry and Chilton 1973). The fluidized bed looks like a boiling liquid and has the physical properties of a fluid. In fluidized-bed combustion of biomass, the gas is air and the bed is usually sand or limestone. The air acts as the fluidizing medium and is the oxidant for biomass combustion. A fluidized-bed combustor is a vessel with dimensions such that the superficial velocity of the gas maintains the bed in a fluidized condition at the bottom of the vessel. A change in cross-sectional area above the bed lowers the superficial gas velocity below fluidization velocity to maintain bed inventory and acts as a disengaging zone. Overfire air is normally introduced in the disengaging zone. To obtain the total desired gas-phase residence time for complete combustion and heat transfer to the boiler walls the larger cross-sectional area zone is extended and is usually referred to as the freeboard. A cyclone is used to either return fines to the bed or to removes ash-rich fines from the system. The bed is fluidized by a gas distribution manifold or series of sparge tubes (Hansen 1992).

If the air flow of a bubbling fluid bed is increased, the air bubbles become larger, forming large voids in the bed and entraining substantial amounts of solids. This type of bed is referred to as a turbulent fluid bed (Babcock and Wilcox 1992). In a circulating fluid bed the turbulent bed solids are collected, separated from the gas, and returned to the bed, forming a solids circulation loop. A circulating fluid bed can be differentiated from a bubbling fluid bed in that there is no distinct separation between the dense solids zone and the dilute solids zone. The residence time of the solids in a circulating fluid bed is determined by the solids circulation rate, the attritibility of the solids, and the collection efficiency of the solids separation device. As with bubbling fluid beds, the primary driving force for development of circulating fluid beds in the United States is emissions. The uniform, low combustion temperature gives 
low $\mathrm{NO}_{\mathrm{x}}$ emissions. In a circulating fluid bed, with its need for introduction of solids to maintain bed inventory, it is easy to introduce a sorbent solid, such as limestone or dolomite, to control $\mathrm{SO}_{2}$ emissions without the need for back-end sulfur removal equipment. Circulating fluid bed temperatures are maintained at about $870^{\circ} \mathrm{C}$, which helps to optimize the limestone-sulfur reactions (Tampella Power 1992). The major manufacturers of circulating fluid bed boilers for biomass are Combustion Engineering (CE-Lurgi), B\&W-Studsvik, Ahlstrom Pyropower (Foster Wheeler) and Gotaverken. A number of plants have been built in the $25 \mathrm{MW}$ size range, primarily in California.

The suspension burning of pulverized wood in dedicated biomass boilers is a fairly recent development and is practiced in relatively few installations. Suspension burning has also been accomplished in lime kilns (MacCallum 1992) and is being investigated by the utility industry for cofiring applications (Tillman et al 1994). For successful suspension firing, a feed moisture content of less than 15\% (Hollenbacher 1992) and a particle size less than $0.0015 \mathrm{~m}$ (MacCallum 1992) give higher boiler efficiencies, up to $80 \%$, than firing wet wood chips, $50-55 \%$ moisture, in a stoker grate or fluid bed, at $65 \%$ efficiency. The higher efficiency also results in smaller furnace size. Offsetting the higher efficiency is the cost and power consumption of drying and comminution. In addition, special burners need to be used. Burners developed for suspension firing include scroll cyclonic burners and verticalcylindrical burners (Hollenbacher 1992). Installations include the Oxford Energy, $27 \mathrm{MW}$ facility at Williams, California (Hollenbacher 1992); the ASSI Lövholmen Linerboard Mill in Piteå, Finland (Westerberg 1981); the Klabin do Parana mill in Monte Alegre, Brazil (MacCallum 1992); and the E.B. Eddy Mill in Espanola Ontario (MacCallum 1992).

The base technology is a commercially available stoker-grate biomass plant constructed in the mid-1980's (EPRI 1993b), and is representative of modern biomass plants with an efficiency of about $23 \%$. Plant efficiency of the stoker plant increased in the case study to $30 \%$ through the use of a dryer and steam cycle efficiency increases, e.g. higher pressure, higher temperature and reheat.

The feedstock used is assumed to be a mixture of pine and oak ( $40 \%$ pine - $60 \%$ oak) with $50 \%$ moisture content. This feed mixture was also used in the gasification analysis. For cofiring a mixture residues was assumed, with blending to reduce the moisture content to $21.5 \%$, thus eliminating the need for a dryer. An analysis of the two feeds is given in Table 5.2.

The starting case is based on EPRI report TR-102107, v2 (Wiltsee and Hughes 1995), for the Burlington, VT, McNeil Station. Wood heating values are about $10 \mathrm{MJ} / \mathrm{kg}$ on a wet basis and $20 \mathrm{MJ} / \mathrm{kg}$ on a dry basis; these values are about $40 \%$ and $80 \%$ of coal (24.78 MJ/kg [AEO97 1996]), respectively. The name plate efficiency of the McNeil station is 25\%, while the Biopower model (EPRI 1995) gives 23.0\%. An average of $24 \%$ was used as the starting point for the case study.

The RETC97 capital and operating costs were updated to 2001 dollars using the Marshall and Swift Index (Marshall and Swift ------), and plant costs were updated by adding a dryer (Craig and Mann 1996). Capital and operating costs for other plant sizes were scaled from the $50 \mathrm{MW}$ values using a 0.7 scaling factor. Peters and Timmerhaus (Peters and Timmerhaus 1980) state, "It is often necessary to estimate the cost of a piece of equipment when no cost data are available for the particular size of operational 
Table 5.2 Feedstock Composition for direct combustion and gasification

\begin{tabular}{|c|c|c|c|c|}
\hline \multirow{2}{*}{ Component } & \multicolumn{2}{|c|}{ Pine } & \multicolumn{2}{c|}{ Oak } \\
& $5 \% \mathrm{M}$ & $50 \% \mathrm{M}$ & $50 \% \mathrm{M}$ \\
\hline $\mathrm{C}, \mathrm{wt} \%$ & 50.45 & 26.55 & 47.65 & 25.08 \\
\hline $\mathrm{H}$ & 5.74 & 3.02 & 5.72 & 3.01 \\
\hline $\mathrm{N}$ & 0.16 & 0.09 & 0.09 & 0.05 \\
\hline $\mathrm{O}$ & 37.34 & 19.66 & 41.17 & 21.65 \\
\hline $\mathrm{S}$ & 0.02 & 0.01 & 0.01 & 0.01 \\
\hline $\mathrm{Cl}$ & 0.03 & 0.01 & 0.01 & 0.01 \\
\hline $\mathrm{Moisture}$ & 5.00 & 50.00 & 5.00 & 50.00 \\
\hline $\mathrm{Ash}$ & 1.26 & 0.67 & 0.35 & 0.19 \\
\hline $\mathrm{MJ} / \mathrm{kg}($ wet $)$ & 19.72 & 10.38 & 18.92 & 9.96 \\
\hline $\mathrm{MJ} / \mathrm{kg}$ (dry) & 20.76 & 20.76 & 19.92 & 19.92 \\
\hline
\end{tabular}

capacity involved. Good results can be obtained by using the logarithmic relationship known as the 'sixtenths-factor rule,' if the new piece of equipment is similar to one of another capacity for which cost data are available. According to this rule, if the cost of a given unit at one capacity is known, the cost of a similar unit with $\mathrm{X}$ times the capacity of the first is approximately $(\mathrm{X})^{0.6}$ times the cost of the initial unit." Valle-Riesta (Valle-Riesta 1983) states “ A logical consequence of the 'sixth-tenths-factor' rule for characterizing the relationship between equipment capacity and cost is that a similar relationship should hold for the direct fixed capital of specific plants.....In point of fact, the capacity exponent for plants, on the average, turns out to be closer to 0.7." The exception to this rule happens when plant capacity is increased by change in efficiency, not change in equipment size. In this case, capital cost in dollars remains constant, and capital cost in $\$ / \mathrm{kW}$ decreases in proportion to efficiency increase.

The electrical substation is part of the general plant facilities, and is not separated out in the factor analysis. The convention follows that used in the EPRI Technical Assessment Guide (EPRI 1993a), as follows "It also includes the high-voltage bushing of the generation step-up transformer but not the switchyard and associated transmission lines. The transmission lines are generally influenced by transmission system-specific conditions and hence are not included in the cost estimate." A summary of capital and operating costs is given in Table 5.3.

To estimate plant performance as a CHP facility the steam conditions from the Biopower model (8.72 $\mathrm{MPa}$ and $510^{\circ} \mathrm{C}$ ) were used in an $\mathrm{ASPEN}^{\mathrm{TM}}$ steam turbine simulation to estimate steam turbine performance in three modes of operation - as a condensing turbine (comparable to the RETC97 electricity case), as a backpressure turbine, and as an extraction turbine. The steam efficiency was assumed to be $80 \%$. The extraction turbine case was used in CHP performance estimates. The use of the extraction turbine gave a heat $(\mathrm{H})$ to power ratio $(\mathrm{P})$ of 1.44 , as shown in Table 5.12. A summary of turbine performance for a $50 \mathrm{MW}_{\mathrm{e}}$ equivalent facility is given in Table 5.4. To convert to net plant efficiency a parasitic load of $5 \mathrm{MW}_{\mathrm{e}}$ is subtracted from gross electricity production. 
Table 5.3: Biomass Direct Combustion Plant Capital and Operating Costs (excluding feed)

\begin{tabular}{|c|c|c|c|c|c|c|c|c|}
\hline Indicator Name & Units & M.F. & $\begin{array}{c}\text { Scale } \\
\text { Factor }\end{array}$ & Base & 2001 Base & 200125 MW & 200175 MW & $2001100 \mathrm{MW}$ \\
\hline & & & & 1996 & 2001 & 2001 & 2001 & 2001 \\
\hline$M \& S$ index & & & & 1039 & 1092 & & & \\
\hline Plant Size Net & MW & & & 50 & 50 & 25 & 75 & 100 \\
\hline Gross & MW & & & & 55 & 28 & 83 & 110 \\
\hline General Performance Indicators & & & & & & & & \\
\hline Capacity Factor & $\%$ & & & $80 \%$ & $90 \%$ & $90 \%$ & $90 \%$ & $90 \%$ \\
\hline Net Heat Rate & $\mathrm{Btu} / \mathrm{kWh}$ & & & 14,234 & 11,373 & 11,373 & 11,373 & 11,373 \\
\hline Annual Energy Delivery & $\mathrm{GWh} / \mathrm{yr}$ & & & 350 & 394 & 197 & 591 & 788 \\
\hline Capital Cost & $\$ 000$ & & & & & & & \\
\hline Fuel Preparation & & & 0.7 & 9,052 & 8,373 & 5,154 & 11,121 & 13,602 \\
\hline Dryer & & & 0.7 & - & 4,418 & 2,719 & 5,868 & 7,177 \\
\hline Boiler & & & 0.7 & 22,215 & 20,549 & 12,649 & 27,293 & 33,381 \\
\hline Baghouse and Cooling Tower & & & 0.7 & 1,456 & 1,347 & 829 & 1,789 & 2,188 \\
\hline Boiler feedwater/ deaerator & & & 0.7 & 2,784 & 2,575 & 1,585 & 3,420 & 4,183 \\
\hline Steam turbine/generator & & & 0.7 & 7,407 & 6,851 & 4,218 & 9,100 & 11,130 \\
\hline Balance of plant & & & 0.7 & 13,641 & 12,618 & 7,767 & 16,759 & 20,498 \\
\hline Subtotal $(A)$ & & & & 59,867 & 59,794 & 36,808 & 79,419 & 97,136 \\
\hline General Plant Facilities (B) & & & 0.7 & 15,498 & 14,336 & 8,825 & 19,040 & 23,288 \\
\hline Engineering Fee, $\mathrm{k}^{*}(\mathrm{~A}+\mathrm{B})$ & & 0.1 & & 7,537 & 7,413 & 4,563 & 9,846 & 12,042 \\
\hline Process/project contingency & & 0.15 & & 11,305 & 11,119 & 6,845 & 14,769 & 18,064 \\
\hline Total Plant Cost (TPC) & & & & 94,206 & 92,662 & 57,040 & 123,074 & 150,530 \\
\hline AFUDC & & & & 2,826 & 2,780 & 1,711 & 3,692 & 4,516 \\
\hline Total Plant Investment (TPI) & & & & 97,032 & 95,442 & 58,752 & 126,766 & 155,046 \\
\hline Prepaid Royalties & & & 1 & - & & & & \\
\hline Initial Cat \& Chem Inventory & & & 1 & 110 & 76 & 38 & 115 & 153 \\
\hline Startup costs & & & 1 & 2,653 & 1,842 & 921 & 2764 & 3685 \\
\hline Inventory Capital & & & 0.7 & 559 & 433 & 217 & 650 & 866 \\
\hline Land, 100 acres@\$7,250/acre & & & 1 & 725 & 725 & 725 & 725 & 725 \\
\hline Total Capital Requirement (TCR) & & & & 101,079 & 98,519 & 60,652 & 131,019 & 160,475 \\
\hline
\end{tabular}




\begin{tabular}{|c|c|c|c|c|c|c|c|}
\hline Indicator Name & M.F. & $\begin{array}{c}\text { Scale } \\
\text { Factor }\end{array}$ & Base & 2001 Base & 200125 MW & 200175 MW & 2001 100MW \\
\hline Capital & $\$ / \mathrm{kW}$ & & & & & & \\
\hline Fuel Preparation & & & 181 & 167 & 206 & 148 & 136 \\
\hline Dryer & & & - & 88 & 109 & 78 & 72 \\
\hline Boiler & & & 444 & 411 & 506 & 364 & 334 \\
\hline Baghouse and Cooling Tower & & & 29 & 27 & 33 & 24 & 22 \\
\hline Boiler feedwater/ deaerator & & & 56 & 52 & 63 & 46 & 42 \\
\hline Steam turbine/generator & & & 148 & 137 & 169 & 121 & 111 \\
\hline Balance of plant & & & 273 & 252 & 311 & 223 & 205 \\
\hline Subtotal $(A)$ & & & 1,197 & 1,196 & 1,472 & 1,059 & 971 \\
\hline General Plant Facilities (B) & & & 310 & 287 & 353 & 254 & 233 \\
\hline Engineering Fee, $\mathrm{k}^{*}(\mathrm{~A}+\mathrm{B})$ & & & 151 & 148 & 183 & 131 & 120 \\
\hline Process/project contingency & & & 226 & 222 & 274 & 197 & 181 \\
\hline Total Plant Cost (TPC) & & & 1,884 & 1,853 & 2,282 & 1,641 & 1,505 \\
\hline AFUDC & & & 57 & 56 & 68 & 49 & 45 \\
\hline Total Plant Investment (TPI) & & & 1,941 & 1,909 & 2,350 & 1,690 & 1,550 \\
\hline Initial Cat \& Chem Inventory & & & 2 & 2 & 2 & 2 & 2 \\
\hline Startup costs & & & 53 & 37 & 37 & 37 & 37 \\
\hline Inventory Capital & & & 11 & 9 & 9 & 9 & 9 \\
\hline Land, 100 acres@ $\$ 7,250 /$ acre & & & 15 & 15 & 29 & 10 & 7 \\
\hline Total Capital Requirement (TCR) & $\$ / \mathbf{k W}$ & & 2,022 & 1,970 & 2,426 & 1,747 & 1,605 \\
\hline Operating & & & & $1,1,628$ & 814 & $2,2,442$ & 3,256 \\
\hline Supervision and Clerical & & & & 408 & 408 & 408 & 408 \\
\hline Maintenance Labor and Materia & Costs@1.8\% of TPC & & & 1,668 & 834 & 2,502 & 3,336 \\
\hline Total Fixed Costs & $\mathrm{K} \$ / \mathrm{a}$ & & & 3,704 & 2,056 & 5,351 & 6,999 \\
\hline Variable Costs (without feed) & & & & & & & \\
\hline Labor & & & & 1,349 & 675 & 2,024 & 2,699 \\
\hline Maintenance Labor and Materia & Costs & & & 768 & 384 & 1,152 & 1,536 \\
\hline Total Variable Costs & $\mathrm{K} \$ / \mathrm{a}$ & & & 2,118 & 1,059 & 3,176 & 4,235 \\
\hline Consumables & & & & & & & \\
\hline Chemicals & & & & 670 & 335 & 1,006 & 1,341 \\
\hline Water & & & & 169 & 85 & 254 & 338 \\
\hline Solids/ash disposal & & & & 182 & 91 & 273 & 364 \\
\hline Feed estimates & & & & & & & \\
\hline Capacity Factor & $\%$ & & & $90 \%$ & $90 \%$ & $90 \%$ & $90 \%$ \\
\hline Feed heating value & Mbtu/ton & & & 17 & 17 & 17 & 17 \\
\hline
\end{tabular}




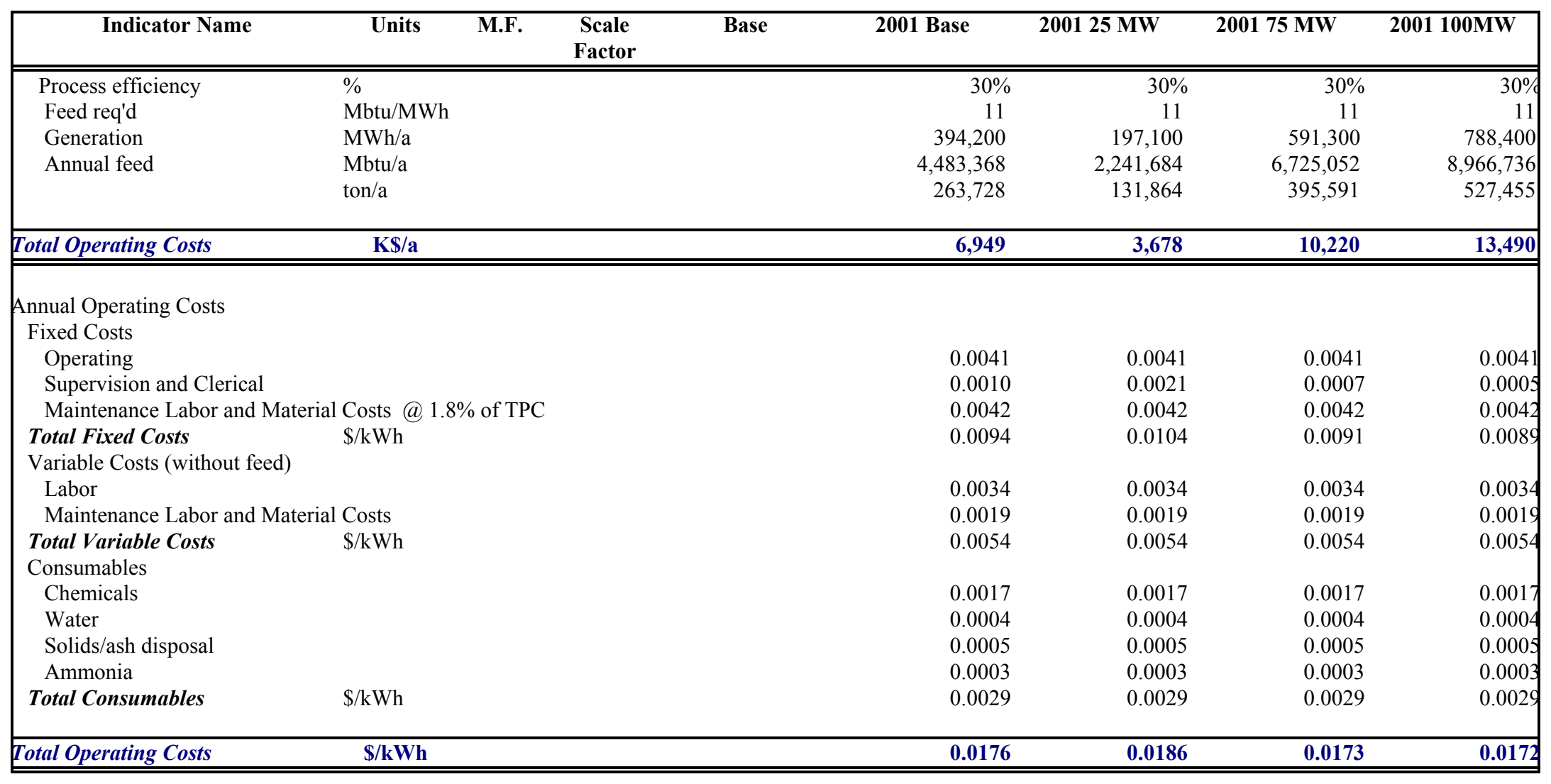


Table 5.4: Direct-fired Combustion Cogeneration Gross Plant Efficiencies

\begin{tabular}{|c|c|c|c|c|c|c|c|c|c|c|c|c|c|}
\hline & \multicolumn{2}{|c|}{ Temp } & \multicolumn{2}{|c|}{ Pressure } & \multicolumn{2}{|c|}{ Flow } & $\begin{array}{r}\text { Quality } \\
(\%)\end{array}$ & $\begin{array}{c}\text { Electricity } \\
\left(\mathrm{MW}_{\mathrm{e}}\right)\end{array}$ & $\begin{array}{l}\text { Steam } \\
\qquad\left(\mathrm{MW}_{\mathrm{t}}\right)\end{array}$ & $\begin{array}{c}\text { HP Steam } \\
\left(\mathrm{MW}_{\mathrm{t}}\right)\end{array}$ & \multicolumn{3}{|c|}{ Efficiency } \\
\hline & $\left({ }^{\circ} \mathrm{C}\right)$ & $\left({ }^{\circ} \mathrm{F}\right)$ & (MPa) & (psia) & $(\mathrm{kg} / \mathrm{s})$ & $(\mathrm{lb} / \mathrm{hr})$ & (\%) & $\left(\mathrm{MW}_{\mathrm{e}}\right)$ & $\left(\mathrm{MW}_{\mathrm{t}}\right)$ & $\left(\mathrm{MW}_{\mathrm{t}}\right)$ & $\begin{array}{c}\text { Electric } \\
(\%)\end{array}$ & $\begin{array}{c}\text { Thermal } \\
(\%)\end{array}$ & $\begin{array}{c}\text { Steam } \\
(\%)\end{array}$ \\
\hline \multicolumn{14}{|c|}{ Condensing Turbine } \\
\hline Inlet & 510 & 848 & 8.720 & 1,279 & 54.00 & 428,610 & 100 & 55 & 0 & 172.5 & 31.9 & 0 & 31.9 \\
\hline \multicolumn{14}{|l|}{ Extraction $^{(a)}$} \\
\hline Outlet & 54 & 130 & 0.0152 & 2.2 & 54.00 & 428,610 & 91 & & & & & & \\
\hline \multicolumn{14}{|c|}{ Backpressure Turbine } \\
\hline Inlet & 510 & 848 & 8.720 & 1,279 & 54.00 & 428,610 & 100 & 24.2 & 137.5 & 172.5 & 14.0 & 93.7 & 79.2 \\
\hline \multicolumn{14}{|l|}{ Extraction $^{(a)}$} \\
\hline Outlet & 266 & 510 & 1.140 & 150 & 54.00 & 428,610 & 91 & & & & & & \\
\hline \multicolumn{14}{|c|}{ Extraction Turbine } \\
\hline Inlet & 510 & 848 & 8.720 & 1,279 & 54.00 & 428,610 & 100 & 39.6 & 69.2 & 172.5 & 22.9 & 40.1 & 63.0 \\
\hline Extraction $^{(a)}$ & 266 & 510 & 1.140 & 150 & 27.00 & 214,305 & 100 & & & & & & \\
\hline Outlet & 54 & 130 & 0.0152 & 2.2 & 27.00 & 214,305 & 91 & & & & & & \\
\hline
\end{tabular}

(a) Doesn't include process use extraction 


\section{Gasification}

This discussion characterizes a biomass-based power plant that utilizes a gasification combined cycle (GCC) system as depicted in Figure 5.2. Generally speaking, the conversion of biomass to a low- or medium-heating-value gaseous fuel (biomass gasification) involves two processes. The first process, pyrolysis, releases the volatile components of the fuel at temperatures below $600^{\circ} \mathrm{C}\left(1112^{\circ} \mathrm{F}\right)$ via a set of complex reactions. Included in these volatile vapors are hydrocarbon gases, hydrogen, carbon monoxide, carbon dioxide, tars, and water vapor. Because biomass fuels tend to have more volatile components (70 - $86 \%$ on a dry basis) than coal (30\%), pyrolysis plays a proportionally larger role in biomass gasification than in coal gasification. The by-products of pyrolysis that are not vaporized are referred to as char and consist mainly of fixed carbon and ash. In the second gasification process, char conversion, the carbon remaining after pyrolysis undergoes the classic gasification reaction (i.e. steam + carbon) and/or combustion (carbon + oxygen). It is this latter, combustion, reaction that provides the heat energy required to drive the pyrolysis and char gasification reactions. Due to its high reactivity (as compared to coal and other solid fuels), all of the biomass feed, including char, is normally converted in a single pass through a gasifier system.

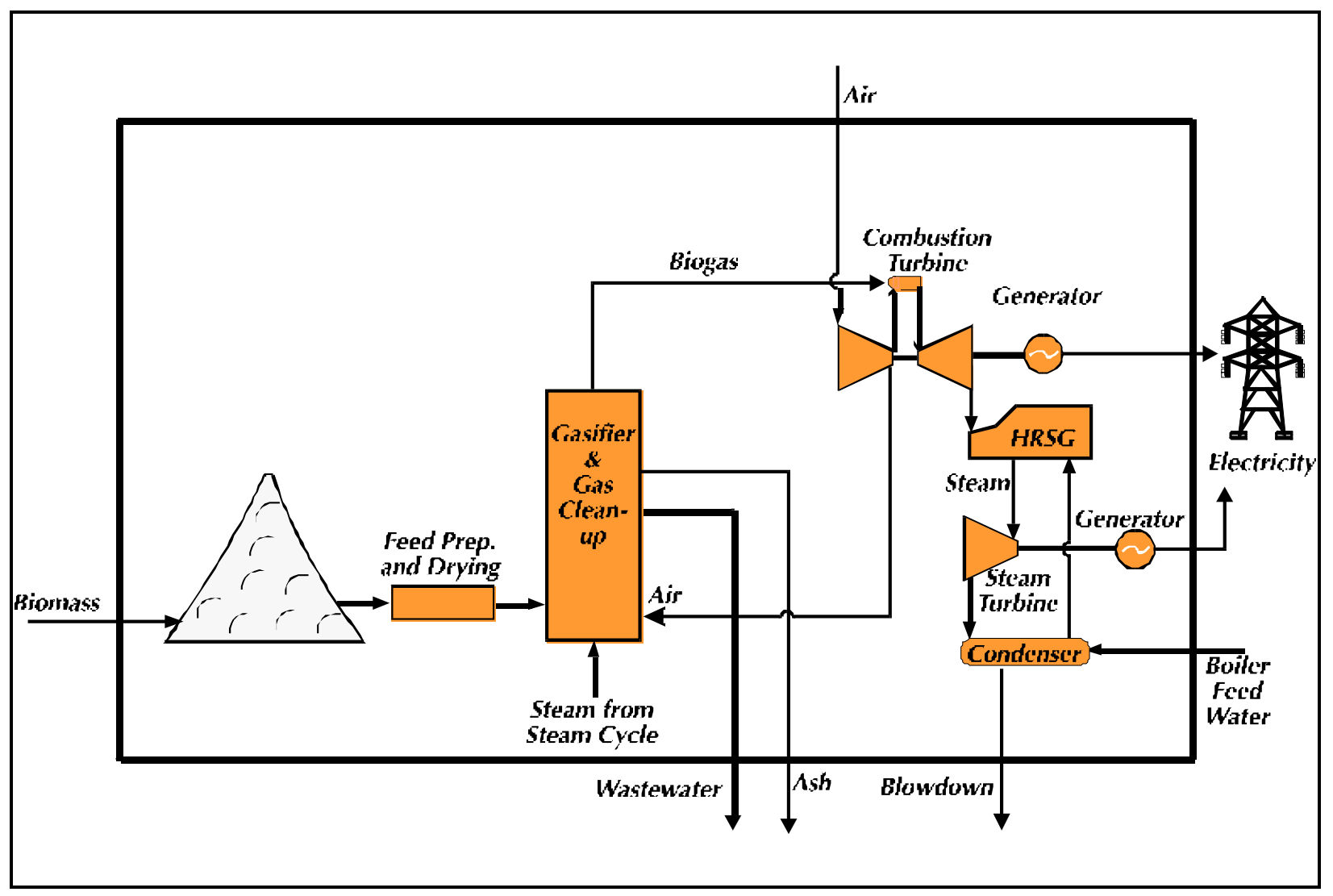

Figure 5.2: Generic Biomass Gasification Combined Cycle System

Depending on the type of gasifier used, the above reactions can take place in the same reactor vessel or separate vessels. These gasifier types are typically referred to as direct (pyrolysis, gasification, and combustion take place in one vessel) and indirect (pyrolysis and gasification in one vessel, combustion in a separate vessel). In direct gasification, air and sometimes steam are directly introduced to the single gasifier vessel (Figures 5.3 and 5.5). In indirect gasification, an inert heat transfer medium such as sand carries heat generated in the combustor to the gasifier to drive the pyrolysis and char gasification 


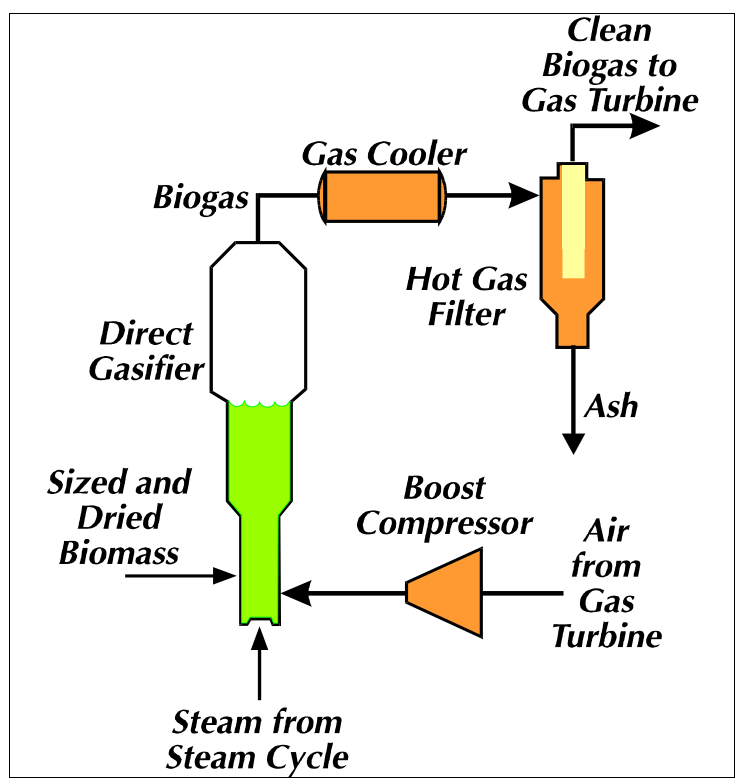

Figure 5.3: High Pressure Direct Gasifier

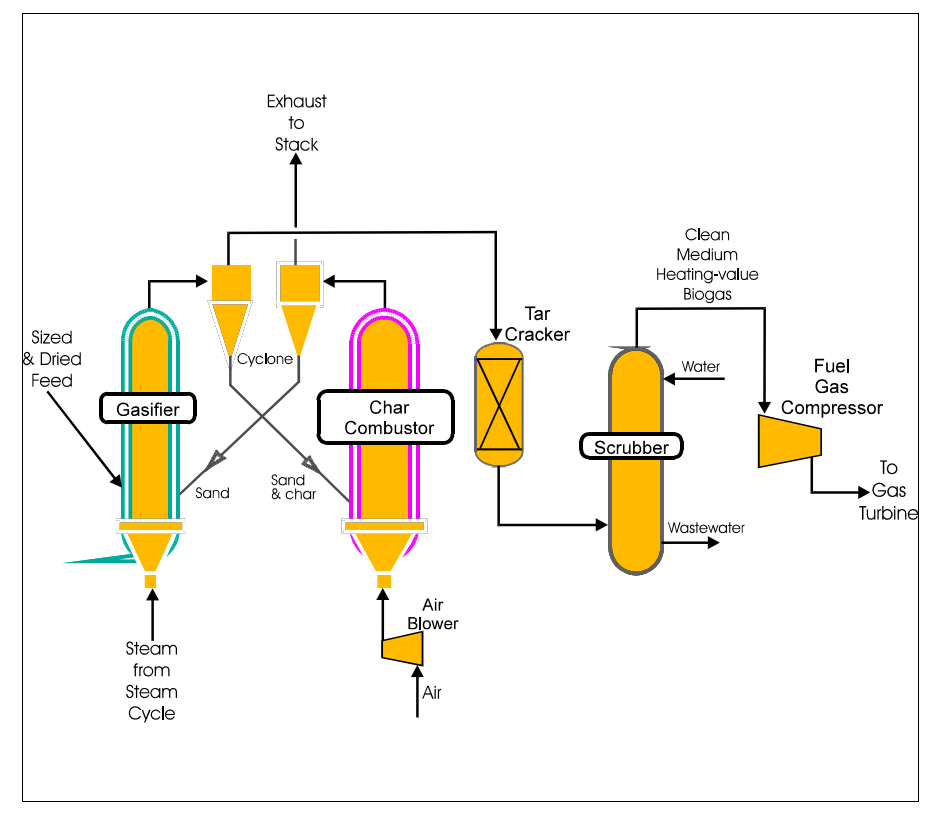

Figure 5.4: Indirect Gasifier

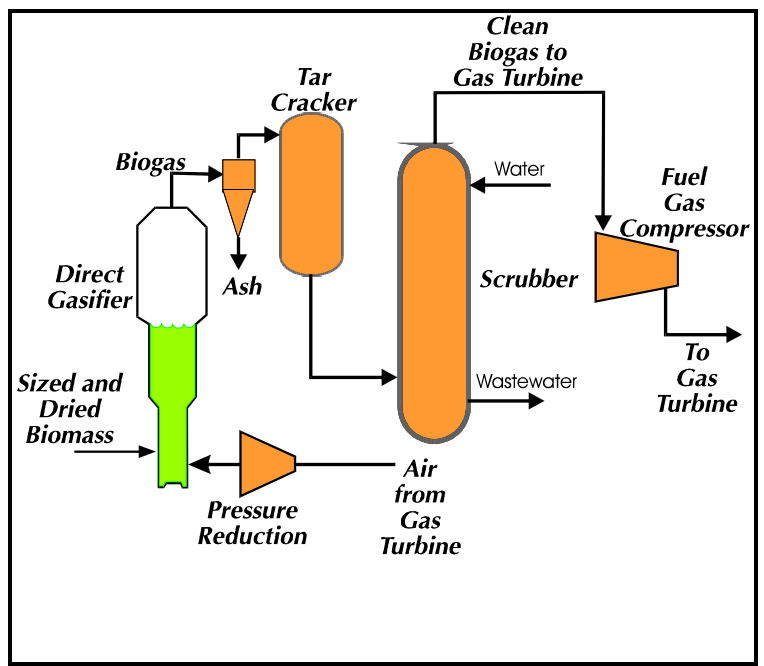

Figure 5.5: Low Pressure Direct Gasifier

reactions (Figure 5.4). Currently, indirect gasification systems operate near atmospheric pressure. Direct gasification systems have been demonstrated at both elevated (Figure 5.4) and atmospheric pressures (Figure 5.3). Any one of the gasifier systems shown in Figures 5.3 - 5.5 can be utilized in the generic gasifier block represented in the main system diagram above and have been utilized in a least one recent system design study (NSP 1995; Weyerhaeuser 1995; Craig and Mann 1996; EPRI 1995).

There are several practical implications of each gasifier type. Because of the diluent effect of nitrogen in air, fuel gas from a direct gasifier is of low heating value $\left(5.6-7.5 \mathrm{MJ} / \mathrm{Nm}^{3}\right)$. This low heat content in turn requires an increased fuel flow to the gas turbine. Consequently, to maintain the total (fuel + air) mass flow through the turbine within design limits, an air bleed is usually taken from the gas turbine compressor and used in the gasifier. This bleed air is either boosted slightly in pressure or expanded to near atmospheric pressure depending on the operating pressure of the direct gasifier. 
Because the fuel-producing reactions in an indirect gasifier take place in a separate vessel, the resulting fuel gas is free of nitrogen diluent and is of medium heating value $\left(13-18.7 \mathrm{MJ} / \mathrm{Nm}^{3}\right)$. This heat content is sufficiently close to that of natural gas (approx. $38 \mathrm{MJ} / \mathrm{Nm}^{3}$ ) that fuel gas from an indirect gasifier can be used in an unmodified gas turbine without air bleed.

Gasifier operating pressure impacts not only equipment cost and size but the interfaces to the rest of the power plant including the necessary cleanup systems. Since gas turbines operate at elevated pressures, the fuel gas generated by low pressure gasifiers must be compressed. This favors low temperature gas cleaning since the fuel gas must be cooled prior to compression in any case. Air for a low pressure gasifier can be extracted from the gas turbine and reduced in pressure (direct, low pressure gasifier) or supplied independently (indirect gasifier). High pressure gasification favors hot, pressurized cleanup of the fuel gas and supply to the gas turbine combustor at high temperature (circa $538^{\circ} \mathrm{C}$ or $1000^{\circ} \mathrm{F}$ ) and sufficiently high pressure for flow control and combustor pressure drop. Air for a high pressure, direct gasifier is extracted from the gas turbine and boosted in pressure prior to introduction to the gasifier.

Cooling, cold cleanup, and fuel gas compression add equipment to an indirect gasifier system and reduce its efficiency by up to 10\% (Craig and Mann 1996, Marrison and Larson 1995). Gasifier and gas cleanup vessels rated for high pressure operation and more elaborate feed systems, however, add cost and complexity to high pressure gasification systems despite their higher efficiency. Results from several recent studies (NSP 1995, Weyerhaeuser 1995, Craig and Mann 1996, Marrison and Larson 1995) indicate that, at the current, preliminary grade of estimates (as defined by EPRI TAG, 1993) being performed, there is little discernable difference in cost of electricity (COE) between systems employing high and low pressure gasification.

For the purposes of this analysis, a high-pressure, direct gasification system as shown in Figure 5.3 was selected. The resulting system is very similar to that evaluated in a pre-feasibility study conducted by Northern States Power under subcontract AAE-5-14456-01 for NREL and EPRI, reported in NREL/TP430-20517 (NSP 1995). This study examined a $75 \mathrm{MW}_{\mathrm{e}}$ power plant that would gasify alfalfa stems to provide electricity to the Northern States Power Company and sell the leaf co-product for animal feed. A departure from the NSP study is the use here of wood as the biomass feedstock. Wood feedstock allows for a more generic plant representation. Alfalfa separation and leaf meal processing steps in the original NSP study would have added complexity and cost to the plant and have complicated the economic analysis.

Following receipt of wood chips at the plant, they are screened and hogged to a proper size consistency, and dried in a rotary drum dryer. Dried wood is conveyed to storage silos adjacent to the gasifier building. It is then weighed and transferred to a lockhopper/screw feeder system and is fed into the fluidized bed gasifier. The gasifier vendor selected for the NSP study was Tampella Power Systems (now Carbona) who have developed a commercial version of the IGT RENUGAS ${ }^{\text {TM }}$ gasifier. A dolomite feed system is also provided to maintain the inventory of inert material in the bed. In the gasifier, the biomass is gasified at temperatures between $843^{\circ} \mathrm{C}\left(1550^{\circ} \mathrm{F}\right)$ and $954^{\circ} \mathrm{C}\left(1750^{\circ} \mathrm{F}\right)$. The fluidizing and gasifying medium is a mixture of air and steam. As shown above, air is extracted from the compressor section of the gas turbine and fed into the gasifier through a boost compressor. Gasification steam is extracted from the steam cycle. The gasifier operates as a so-called spouted bed with intensive circulation of solids from top to bottom, which guarantees rapid gasification and maximizes tar cracking.

Fuel gases exiting the gasifier are cooled in the product gas cooler to approximately $538^{\circ} \mathrm{C}\left(1000^{\circ} \mathrm{F}\right)$. In addition to protecting the fuel flow control valve, this cooling causes the vapor-phase alkali species present in the fuel gas, which could damage the gas turbine, to condense, congeal, and deposit on the fine particulate matter carried over from the gasifier. The combined particulate matter and alkali species are next removed in a Westinghouse hot ceramic candle filter unit to levels within gas turbine tolerances. Since biomass in general and wood in particular is very low in sulfur, a sulfur removal step is not 
necessary prior to combustion in the gas turbine. Hot cleanup of the fuel gas also minimizes wastewater generation from this step of gas processing.

The fuel gas is combusted in a Westinghouse "ECONOPAC" 251B12 gas turbine producing electric power and a high temperature exhaust stream. A heat recovery steam generator (HRSG) is employed to recover this heat to generate high temperature, high pressure steam that is then expanded in a steam turbine to produce additional power. Steam for the gasifier is extracted from the steam cycle. As noted above, the total net electricity output from this system is $75 \mathrm{MW}_{\mathrm{e}}$. The following cost and performance estimates, Table 5.5, were scaled to $150 \mathrm{MW}$ using the 0.7 rule. It is worth noting that rapid developments are also being made in smaller turbine sizes as well, and the industrial and cogeneration markets $\left(10-50 \mathrm{MW}_{\mathrm{e}}\right.$ output) should not be ignored.

As mentioned earlier, several gasifier configurations could have been considered. Converting solid biomass into a gaseous fuel with suitable heating value creates the opportunity to integrate biomass gasifiers with the gas turbine cycles such as the combined gas and steam cycle depicted above. Close coupling of gasification and the power system increases overall conversion efficiency by utilizing both the thermal and chemical energy of hot product gases to fuel the power cycle. Combined cycles, with their high efficiency and low emission characteristics, are a prime choice for biomass gasification systems.

To estimate plant performance as a CHP facility the steam conditions given for year 2000 technology were used in an ASPEN ${ }^{\mathrm{TM}}$ steam turbine simulation to estimate steam turbine performance in three modes of operation - as a condensing turbine (comparable to the RETC97 electricity case), as a back-pressure turbine, and as an extraction turbine. The steam efficiency was assumed to be $80 \%$. The back-pressure turbine case was used in CHP performance estimates. The back-pressure turbine was chosen to give a H/P approximately the same as the direct combustion case. The gasification $\mathrm{H} / \mathrm{P}$ was 1.60 compared to 1.44 for direct combustion. A summary of turbine performance for a $75 \mathrm{MW}_{\mathrm{e}}$ equivalent facility is given in Table 5.6. To convert to net plant efficiency a parasitic load of $6.7 \mathrm{MW}_{\mathrm{e}}$ was subtracted from gross electricity production, and the gas turbine production of $51 \mathrm{MW}_{\mathrm{e}}$ was added. 
Table 5.5: Biomass Gasification Capital and Operating Costs, Excluding Feed

\begin{tabular}{|c|c|c|c|c|c|c|c|}
\hline Indicator Name & Units & M.F. & S.F. & & & & \\
\hline & & & & 1996 & 1996 & 2001 & 2001 \\
\hline $\mathrm{M} \& \mathrm{~S}$ index & & & & 1039.1 & 1039.1 & 1092 & 1092 \\
\hline Plant Size Net & MW & & & 75 & 75 & 75 & 150 \\
\hline Gross & MW & & & & & & \\
\hline \multicolumn{8}{|l|}{ General Performance Indicators } \\
\hline Capacity Factor & $\%$ & & & $80 \%$ & $90 \%$ & $90 \%$ & $90 \%$ \\
\hline Efficiency & $\%$ & & & $36 \%$ & $36 \%$ & $36 \%$ & $36 \%$ \\
\hline Net Heat Rate & $\mathrm{Btu} / \mathrm{kWh}$ & & & 9,483 & 9,483 & 9,483 & 9,483 \\
\hline Annual Energy Delivery & $\mathrm{GWh} / \mathrm{yr}$ & & & 526 & 591 & 591 & 1,183 \\
\hline Capital Cost & $\$ 000$ & & & & & & \\
\hline Fuel Preparation & & & 0.7 & 7,575 & 7,575 & 7,961 & 12,932 \\
\hline Gasifier & & & 0.7 & 25,950 & 25,950 & 27,271 & 44,302 \\
\hline Gas Turbine & & & 0.7 & 14,850 & 14,850 & 15,606 & 25,352 \\
\hline Steam Turbine & & & 0.7 & 3,300 & 3,300 & 3,468 & 5,634 \\
\hline Balance of Plant & & & 0.7 & 11,025 & 11,025 & 11,586 & 18,822 \\
\hline Control System & & & 0.7 & 600 & 600 & 631 & 1,024 \\
\hline Hot gas Cleanup & & & 0.7 & 2,325 & 2,325 & 2,443 & 3,969 \\
\hline Installation & & & 0.7 & 9,900 & 9,900 & 10,404 & 16,901 \\
\hline Turbine Building & & & 0.7 & 450 & 450 & 473 & 768 \\
\hline Waste Pond & & & 1 & 150 & 150 & 158 & 315 \\
\hline Subtotal $(A)$ & & & & 76,125 & 76,125 & 80,000 & 130,020 \\
\hline General Plant Facilities (B) & & 0.1 & 0.7 & 7,613 & 7,613 & 8,000 & 13,002 \\
\hline Engineering Fee, $\mathrm{k}^{*}(\mathrm{~A}+\mathrm{B})$ & & 0.1 & & 8,374 & 8,374 & 8,800 & 14,302 \\
\hline Process/project contingency & & 0.15 & & 12,561 & 12,561 & 13,200 & 21,453 \\
\hline Total Plant Cost (TPC) & & & & 104,672 & 104,672 & 110,001 & 178,778 \\
\hline AFUDC & & & & & - & - & \\
\hline Total Plant Investment (TPI) & & & & 104,672 & 104,672 & 110,001 & 178,778 \\
\hline Prepaid Royalties & & & 1 & & & & \\
\hline Initial Cat \& Chem Inventory & & & 1 & & & & \\
\hline Startup costs & & & 1 & 4,200 & 4,200 & 4,414 & 8,828 \\
\hline Inventory Capital & & & 0.7 & 750 & 750 & 788 & 1,576 \\
\hline Land,100 acres@\$7,250/acre & & & & 750 & 750 & 788 & 1,576 \\
\hline & & & & 5700 & 5,700 & 5,990 & 5990 \\
\hline
\end{tabular}




\begin{tabular}{|c|c|c|c|c|c|c|c|}
\hline Indicator Name & Units & M.F. & S.F. & & & & \\
\hline Total Capital Requirement (TCR) & & & & 110,372 & 110,372 & 115,991 & 196,749 \\
\hline Capital & $\$ / \mathrm{kW}$ & & & & & & \\
\hline Fuel Preparation & & & & 101 & 101 & 106 & 86 \\
\hline Gasifier & & & & 346 & 346 & 364 & 295 \\
\hline Gas Turbine & & & & 198 & 198 & 208 & 169 \\
\hline Steam Turbine & & & & 44 & 44 & 46 & 38 \\
\hline Balance of Plant & & & & 147 & 147 & 154 & 125 \\
\hline Control System & & & & 8 & 8 & 8 & 7 \\
\hline Hot gas Cleanup & & & & 31 & 31 & 33 & 26 \\
\hline Installation & & & & 132 & 132 & 139 & 113 \\
\hline Turbine Building & & & & 6 & 6 & 6 & 5 \\
\hline Waste Pond & & & & 2 & 2 & 2 & 2 \\
\hline Subtotal $(A)$ & & & & 1,015 & 1,015 & 1,067 & 867 \\
\hline General Plant Facilities (B) & & 0.1 & & 102 & 102 & 107 & 87 \\
\hline Engineering Fee, $\mathrm{k}^{*}(\mathrm{~A}+\mathrm{B})$ & & 0.1 & & 112 & 112 & 117 & 95 \\
\hline Process/project contingency & & 0.15 & & 167 & 167 & 176 & 143 \\
\hline Total Plant Cost (TPC) & & & & 1,396 & 1,396 & 1,467 & 1,192 \\
\hline AFUDC & & & & & & - & \\
\hline Total Plant Investment (TPI) & & & & 1,396 & 1,396 & 1,467 & 1,192 \\
\hline Prepaid Royalties & & & & & & & \\
\hline Initial Cat \& Chem Inventory & & & & & & & \\
\hline Startup costs & & & & 56 & 56 & 59 & 59 \\
\hline Inventory Capital & & & & 10 & 10 & 11 & 11 \\
\hline Land, 100 acres@ $@ 7,250 /$ acre & & & & 10 & 10 & 11 & 11 \\
\hline & & & & & & 80 & 40 \\
\hline Total Capital Requirement (TCR) & $\$ / \mathbf{k W}$ & & & 1,472 & 1,472 & 1,626 & 1,312 \\
\hline Annual Operating Costs & & & & & & & \\
\hline Fixed Costs & & & & & & & \\
\hline Operating & & & & 535 & 535 & 562 & 1,124 \\
\hline Supervision and Clerical & & & & 435 & 435 & 457 & 457 \\
\hline Maintenance Labor and Mater & Costs & & 0.7 & 2,285 & 2,285 & 2,402 & 3,901 \\
\hline Total Fixed Costs & $\mathrm{K} \$ / \mathrm{a}$ & & & 3,255 & 3,255 & 3,421 & 5,482 \\
\hline Variable Costs (without feed) & & & & & & & \\
\hline Labor & & & & 1,787 & 2,010 & 2,113 & 4,021 \\
\hline Maintenance Labor and Mater & Costs & & & 315 & 355 & 373 & 710 \\
\hline Total Variable Costs & $\mathrm{K} \$ / \mathrm{a}$ & & & 2,102 & 2,365 & 2,486 & 4,730 \\
\hline
\end{tabular}




\begin{tabular}{|c|c|c|c|c|c|}
\hline Indicator Name & Units M.F. & S.F. & & & \\
\hline \multicolumn{6}{|l|}{ Consumables } \\
\hline Chemicals & & 210 & 237 & 249 & 473 \\
\hline Water & & 315 & 355 & 373 & 710 \\
\hline $\begin{array}{l}\text { Solids/ash disposal } \\
\text { Ammonia }\end{array}$ & & 158 & 177 & 186 & 355 \\
\hline Total Consumables & $\mathrm{K} \$ / \mathrm{a}$ & 683 & 769 & 808 & 1,537 \\
\hline Total Operating Costs & $\mathbf{K} \$ \mathbf{a}$ & 6,041 & 6,389 & 6,714 & 11,750 \\
\hline \multicolumn{6}{|l|}{ Annual Operating Costs } \\
\hline \multicolumn{6}{|l|}{ Fixed Costs } \\
\hline Operating & & 0.0010 & 0.0009 & 0.0010 & 0.00095 \\
\hline Supervision and Clerical & & 0.0008 & 0.0007 & 0.0008 & 0.00039 \\
\hline Maintenance Labor and M & osts $@ 1.8 \%$ of TPC & 0.0043 & 0.0039 & 0.0041 & 0.00330 \\
\hline Total Fixed Costs & $\$ / \mathrm{kWh}$ & 0.0062 & 0.0055 & 0.0058 & 0.00464 \\
\hline \multicolumn{6}{|l|}{ Variable Costs (without feed) } \\
\hline Labor & & 0.0034 & 0.0034 & 0.0036 & 0.0034 \\
\hline Maintenance Labor and M & osts & 0.0006 & 0.0006 & 0.0006 & 0.0006 \\
\hline Total Variable Costs & $\$ / \mathrm{kWh}$ & 0.004 & 0.004 & 0.0042 & 0.004 \\
\hline \multicolumn{6}{|l|}{ Consumables } \\
\hline Chemicals & & 0.0004 & 0.0004 & 0.0004 & 0.0004 \\
\hline Water & & 0.0006 & 0.0006 & 0.0006 & 0.0006 \\
\hline $\begin{array}{l}\text { Solids/ash disposal } \\
\text { Ammonia }\end{array}$ & & 0.0003 & 0.0003 & 0.0003 & 0.0003 \\
\hline Total Consumables & $\$ / \mathrm{kWh}$ & 0.0013 & 0.0013 & 0.0014 & 0.0013 \\
\hline Total Operating Costs & $\$ / \mathbf{k W h}$ & 0.0115 & 0.0108 & 0.0114 & 0.0099 \\
\hline
\end{tabular}


Table 5.6: Gasification Cogeneration Gross Steam Turbine Efficiencies

\begin{tabular}{|c|c|c|c|c|c|c|c|c|c|c|c|c|}
\hline & \multicolumn{2}{|c|}{ Temp } & \multicolumn{2}{|c|}{ Pressure } & \multicolumn{2}{|c|}{ Flow } & \multirow{2}{*}{$\begin{array}{c}\text { Quality } \\
(\%)\end{array}$} & \multirow{2}{*}{$\begin{array}{c}\text { Electricity } \\
\left(\mathrm{MW}_{\mathrm{e}}\right)\end{array}$} & \multirow{2}{*}{$\begin{array}{l}\text { Steam } \\
\left(\mathrm{MW}_{\mathrm{t}}\right)\end{array}$} & \multicolumn{3}{|c|}{ Efficiency } \\
\hline & $\left({ }^{\circ} \mathrm{C}\right)$ & $\left({ }^{\circ} \mathrm{F}\right)$ & (MPa) & (psia) & $(\mathrm{kg} / \mathrm{s})$ & $(\mathrm{lb} / \mathrm{hr})$ & & & & $\begin{array}{c}\text { Electric } \\
(\%)\end{array}$ & $\begin{array}{c}\text { Thermal } \\
\text { (\%) }\end{array}$ & $\begin{array}{c}\text { Steam } \\
(\%)\end{array}$ \\
\hline \multicolumn{13}{|c|}{ Condensing Turbine } \\
\hline Inlet & 468 & 874 & 5.860 & 865 & 32.64 & 259,045 & 100 & 31 & 0 & 30.4 & 0 & 30.4 \\
\hline \multicolumn{13}{|l|}{ Extraction $^{(a)}$} \\
\hline Outlet & 54 & 130 & 0.0152 & 2.2 & 32.64 & 259,045 & 92 & & & & & \\
\hline \multicolumn{13}{|c|}{ Backpressure Turbine } \\
\hline Inlet & 468 & 874 & 5.860 & 865 & 32.64 & 259,045 & 100 & 12 & 84 & 11.8 & 82.4 & 94.1 \\
\hline \multicolumn{13}{|l|}{ Extraction $^{(a)}$} \\
\hline Outlet & 266 & 510 & 1.140 & 165 & 32.64 & 259,045 & 92 & & & & & \\
\hline \multicolumn{13}{|c|}{ Extraction Turbine } \\
\hline Inlet & 468 & 874 & 5.860 & 865 & 32.64 & 259,045 & 100 & 21 & 42 & 20.6 & 41.2 & 61.8 \\
\hline Extraction $^{(\mathrm{a})}$ & 266 & 527 & 1.140 & 165 & 16.32 & 129,522 & 100 & & & & & \\
\hline Outlet & 54 & 130 & 0.0152 & 2.2 & 16.32 & 129,522 & 92 & & & & & \\
\hline
\end{tabular}

(a) Doesn't include process use extraction 


\section{Cofiring}

Cofiring is the co-combustion of multiple fuels in the same boiler. Many coal- and oil-fired boilers at power stations have been retrofitted to permit multi-fuel flexibility. Biomass is well-suited for cofiring with other solid fuels, primarily coal, as an acid rain and greenhouse gas emission control strategy. Cofiring is a fuel-substitution option for existing fuel capacity, and is not a capacity expansion option. Cofiring utilizing biomass has been successfully demonstrated and is currently practiced in the full range of coal boiler types, including pulverized coal boilers, stokers, cyclones, and bubbling and circulating fluidized beds (Winslow et al. 1993). The system described here is for pulverized coal-fired boilers, which represent the majority of the current fleet of utility boilers in the U.S.; however, there are also significant opportunities for cofiring with biomass in stokers, cyclones, and fluidized bed boilers. Cofiring in an existing pulverized coal (PC) boiler will generally require minor modifications or additions to fuel handling, storage, and feed systems. An automated system capable of processing and storing sufficient biomass fuel in one shift for 24-hour use is needed to allow continuous cofiring. Typical biomass fuel receiving equipment will include truck scales and hydraulic tippers; however, tippers are not required if deliveries are made with self-unloading vans. New automated reclaiming equipment may be added or existing front-end loaders may be detailed for use to manage and reclaim biomass fuel. Conveyors will be added to transport fuel to the processing facility, with magnetic separators to remove spikes, nails, and tramp metal from the feedstock. Since biomass is the "flexible" fuel at these facilities, a 5-day stockpile should be sufficient and avoids problems with longer term storage of biomass (Winslow et al. 1993).

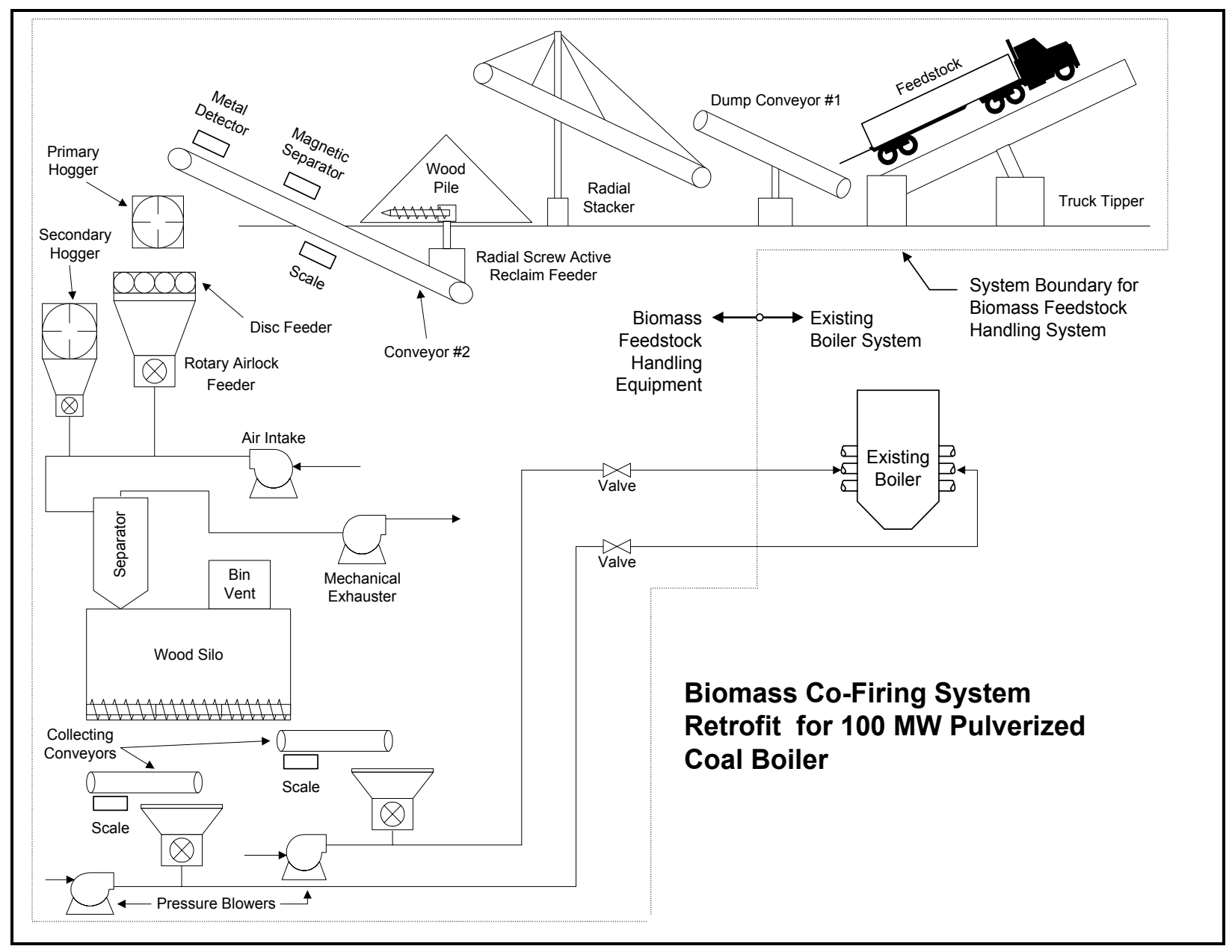

Figure 5.6: Biomass Co-firing System Retrofit for a Pulverized Coal Boiler 
Fuel processing requirements are dictated by the expected fuel sources, with incoming feedstocks varying from green whole chips up to $5 \mathrm{~cm}$ ( 2 inches) in size (or even larger tree trimmings) to fine dry sawdust requiring no additional processing. In addition to woody residues and crops, biomass fuel sources could include alfalfa stems, switchgrass, rice hulls, rice straws, stone fruit pits, and other materials (Hughes and Tillman 1996). For suspension firing in pulverized coal boilers, biomass fuel feedstocks should be reduced to a particle size of $6.4 \mathrm{~mm}(1 / 4 \mathrm{inch})$ or less with moisture levels under $25 \% \mathrm{MCW}$ (Moisture Content, Wet basis) when firing in the range of $5 \%$ to $15 \%$ biomass on a heat input basis (Antares and Parsons 1996, Ebasco 1993). Equipment such as hoggers, hammer mills, spike rolls, and disc screens are required to properly size the feedstock. Other boiler types, such as stokers and fluidized beds are better suited to handle larger fuel particles. There must also be a biomass buffer storage and a fuel feed and metering system. Biomass is pneumatically conveyed from the storage silo and introduced into the boiler through existing injection ports. Introducing the biomass at the lowest level of burners helps to ensure complete burnout due to the scavenging effect of the upper level burners and the increased residence time in the boiler.

The system described here and shown in Figure 5.6 is designed for high percentage cofiring ( $>2 \%$ on a heat input basis) and, for that reason, requires a separate feed system for biomass which acts in parallel to the coal feed systems. Existing coal injection ports are modified to allow dedicated biomass injection during the cofiring mode of operation. For low percentage cofiring ( $<2 \%$ on a heat input basis), it may be possible to use existing coal pulverizers to process the biomass. If using existing pulverizers, the biomass is processed and conveyed to the boiler with the coal supply and is introduced into the boiler through the same injection ports as the coal. Using existing pulverizers could reduce capital costs by allowing the avoided purchase of dedicated biomass processing and handling equipment, but the level of cofiring on a percentage basis will be limited by pulverizer performance, biomass type, and excess pulverizer capacity. The suitability of existing pulverizers to process biomass with coal will vary depending on pulverizer type and biomass type. Atritta mills, for example, have significant capability to process biomass fuels (Hughes and Tillman 1996).

Drying equipment has been evaluated by many designers and recommended by some. Dryers are not included here for three reasons: (1) the benefit-to-cost ratio is almost always low, (2) the industrial fuel sources that supply most cofiring operations provide a moderately dry fuel (between $28 \%$ and $6 \% \mathrm{MCW}$ ), and (3) biomass is only a modest percentage of the fuel fired. Although drying equipment is not expected to be included initially, future designs may incorporate cost effective drying techniques (using boiler waste heat) to maintain plant efficiency while firing a broader range of feedstocks with higher moisture contents.

The current fleet of low cost, coal-fired, base load electricity generators are producing over $50 \%$ of the nation's power supply (EIA 1996). With the Clean Air Act Amendments (CAAA) requiring reductions in emissions of acid rain precursors such as sulfur dioxide $\left(\mathrm{SO}_{2}\right)$ and nitrogen oxides $\left(\mathrm{NO}_{\mathrm{x}}\right)$ from utility power plants, cofiring biomass at existing coal-fired power plants is viewed as one of many possible compliance options. In addition, cofiring using biomass fuels from sustainably grown dedicated energy crops is viewed as a possible option for reducing net emissions of carbon dioxide $\left(\mathrm{CO}_{2}\right)$, a greenhouse gas that contributes to global warming. Coupled with the need of the industrial sector to dispose of biomass residues (generally clean wood byproducts or remnants), biomass cofiring offers the potential for solving multiple problems at potentially modest investment costs. These opportunities have caught the interest of power companies in recent years.

Unlike coal, most forms of biomass contain very small amounts of sulfur. Hence, substitution of biomass for coal can result in significant reductions in sulfur dioxide emissions. Cofiring biomass with coal can allow power producers to earn sulfur dioxide $\left(\mathrm{SO}_{2}\right)$ emission allowances under section 404(f) of the CAAA (U.S. House of Representatives 1990) (1 allowance $=1$ ton of reduced $\mathrm{SO}_{2}$ emissions $=0.91$ metric ton of reduced $\mathrm{SO}_{2}$ emissions). An allowance is earned for each ton of $\mathrm{SO}_{2}$ emissions reduced. This section of the CAAA includes provisions for earning credits from $\mathrm{SO}_{2}$ emissions avoided through energy 
conservation measures (i.e., demand side management or DSM) and renewable energy. In addition to any allowances which the producer saved by not emitting $\mathrm{SO}_{2}$, two allowances can be given to the utility from an allowance reserve for every gigawatt-hour $\left(\mathrm{GWh}=10^{6} \mathrm{kWh}\right)$ produced by biomass in a co-fired boiler. These allowances may then be sold or traded to others who need them to remain in compliance with the CAAA.

Potential negative impacts associated with cofiring biomass fuels include: 1) the possibility for increased slagging and fouling on boiler surfaces when firing high alkali herbaceous biomass fuels such as switchgrass, and 2) the potential for reduced fly ash marketability due to concerns that commingled biomass and coal ash will not meet existing ASTM fly ash standards for concrete admixtures, a valuable fly ash market. These two issues are the subject of on-going research and investigation efforts. Two factors indicate that biomass cofiring (using sources of biomass such energy crops or residues from untreated wood) will have a negligible effect on the physical properties of coal fly ash. First, the mass of biomass relative to coal is small for cofiring applications, since biomass provides $15 \%$ or less of the heat input in the boiler. Second, combustion of most forms of biomass results in only half as much ash when compared to coal. Despite these factors, significant efforts will be required to ensure that commingled biomass and coal ash will be accepted by ASTM standards for concrete admixture applications.

Biomass cofiring is a retrofit application, primarily for coal-fired power plants. Biomass cofiring is applicable to most coal fired boilers used for power generation. A partial list of existing or planned utility applications is shown in Table 5.7. Recent DOE feasibility/demonstration projects are given in Table 5.8. Retrofits for coal-fired stokers, cyclones, and fluidized bed boilers are potentially simpler and less expensive than for pulverized coal. However, pulverized coal boilers are the most widely used steam generating system for coal-fired power generation in the U.S., and they represent most of plants affected by 1990 Clean Air Act Amendments (CAAA) provisions for reducing the emissions of $\mathrm{SO}_{2}$ and $\mathrm{NO}_{\mathrm{x}}$ from electric generating units.

The power plants characterized are pulverized coal plants which co-fire $15 \%$ biomass on a heat input basis. System capital and operating costs are assumed to be representative of plants which receive biomass via self-unloading vans and can utilize existing front-end loaders for receiving and pile management. The facilities are assumed to be located in a region where medium- to high-sulfur coal $(0.8 \%$ by weight and greater) is used as a utility boiler fuel and where biomass residues are available for relatively low costs $(\$ 0.47 / \mathrm{GJ}$, or $\$ 0.50 / \mathrm{Mbtu})$. Areas with these characteristics include portions of the Northeast, Southeast, mid-Atlantic, and Midwest regions.

For each case, the performance of two systems is estimated. One is a pulverized coal power plant using only coal as a fuel source. These cases represent the plant operation prior to a biomass cofiring retrofit. The other case shows the performance of the same power plant operating with biomass cofiring. The tools used for this analysis were based on EPRI's BIOPOWER cofiring model (EPRI 1995). Input requirements for the model include ultimate analyses of the fuels (chemical composition of the fuels), capacity factor for the power plant, net station capacity, gross turbine heat rate, and percent excess air at which the plant operates. The technical input information used for the model were based on data from a representative Northeast power plant that intends to implement biomass cofiring. For a given biomass cofiring rate, the model calculates thermal efficiency, change in net heat rate, coal and biomass consumption, and reduced $\mathrm{SO}_{2}$ and $\mathrm{CO}_{2}$ emissions. 
Table 5.7: Existing or Planned Biomass Cofiring Applications (Winslow et al. 1996)

\begin{tabular}{|c|c|c|c|}
\hline PLANT & FUEL & SIZE & TECHNOLOGY \\
\hline $\begin{array}{l}\text { Northern States Power } \\
\text { Allen S. King Station } \\
\text { Minneapolis, Minnesota }\end{array}$ & Coal/wood residues (lumber) & $560 \mathrm{MWe}$ & Cyclone \\
\hline $\begin{array}{l}\text { Otter Tail Power Co. } \\
\text { Big Stone City, } \\
\text { South Dakota }\end{array}$ & $\begin{array}{l}\mathrm{Coal} / \mathrm{RDF} / \text { tires/ } \\
\text { waste oil/ag. refuse }\end{array}$ & $440 \mathrm{MWe}$ & Cyclone \\
\hline $\begin{array}{l}\text { Tennessee Valley Authority } \\
\text { Allen (1) \& Paradise (2) Stations } \\
\text { Memphis \& Dunmore, Tennessee }\end{array}$ & $\begin{array}{l}\text { 1) Coal/wood residues and } \\
\text { coal/wood/tires } \\
\text { 2) Coal/wood residues }\end{array}$ & $\begin{array}{l}\text { 1) } 176 \mathrm{MWe} \\
\text { 2) } 700 \mathrm{MWe}\end{array}$ & $\begin{array}{l}\text { 1) Cyclone } \\
\text { 2) Cyclone }\end{array}$ \\
\hline $\begin{array}{l}\text { Elsam } \\
\text { Grenaa Co-Generation Plant } \\
\text { Grenaa, Denmark } \\
\end{array}$ & Coal/straw & $150 \mathrm{MWe}$ & $\begin{array}{l}\text { Circulating } \\
\text { Fluidized Bed }\end{array}$ \\
\hline $\begin{array}{l}\text { Tacoma City \& Light } \\
\text { Tacoma Two Station } \\
\text { Tacoma, Washington }\end{array}$ & $\mathrm{Coal} / \mathrm{RDF} /$ wood residues & $2 \times 25 \mathrm{MWe}$ & $\begin{array}{l}\text { Bubbling } \\
\text { Fluidized Bed }\end{array}$ \\
\hline $\begin{array}{l}\text { GPU GENCO } \\
\text { Shawville Station } \\
\text { Johnstown, Pennsylvania }\end{array}$ & Coal/wood residues & $130 \mathrm{MWe}$ & Pulverized Coal \\
\hline $\begin{array}{l}\text { IES Utilities Inc. } \\
\text { Sixth Street (1) \& Ottumwa (2) Stations } \\
\text { Marshalltown, Iowa }\end{array}$ & $\begin{array}{l}\text { 1) Coal/agricultural residues } \\
\text { 2) Coal/switchgrass }\end{array}$ & $\begin{array}{l}\text { 1) } 3 \text { Units } 6-15 \mathrm{MWe} \\
\text { 2) } 714 \mathrm{MWe}\end{array}$ & $\begin{array}{l}\text { 1) Pulverized Coal } \\
\text { 2) Pulverized Coal }\end{array}$ \\
\hline $\begin{array}{l}\text { Madison Gas \& Electric } \\
\text { Blount Street Station } \\
\text { Madison, Wisconsin }\end{array}$ & Coal/switchgrass & $50 \mathrm{MWe}$ & Pulverized Coal \\
\hline $\begin{array}{l}\text { New York State Elec \& Gas } \\
\text { Greenidge Station } \\
\text { Dresden, New York }\end{array}$ & $\begin{array}{l}\text { Coal/wood residues and } \\
\text { coal/energy crops (willow) }\end{array}$ & $108 \mathrm{MWe}$ & Pulverized Coal \\
\hline $\begin{array}{l}\text { Niagara Mohawk Power Corp. } \\
\text { Dunkirk Station } \\
\text { Dunkirk, New York }\end{array}$ & $\begin{array}{l}\text { Coal/wood residues and } \\
\text { coal/energy crops (willow) }\end{array}$ & $91 \mathrm{MWe}$ & Pulverized Coal \\
\hline $\begin{array}{l}\text { Tennessee Valley Authority } \\
\text { Kingston Station } \\
\text { Oakridge, Tennessee }\end{array}$ & Coal/wood residues & $150 \mathrm{MWe}$ & Pulverized Coal \\
\hline $\begin{array}{l}\text { EPON } \\
\text { Centrale Gelderland } \\
\text { Netherlands }\end{array}$ & $\begin{array}{l}\text { Coal/wood residues } \\
\text { (demolition) }\end{array}$ & $602 \mathrm{MWe}$ & Pulverized Coal \\
\hline $\begin{array}{l}\text { I/S Midtkraft Energy Co. } \\
\text { Studstrupvaeket, Denmark }\end{array}$ & Coal/straw & $150 \mathrm{MWe}$ & Pulverized Coal \\
\hline $\begin{array}{l}\text { Uppsala Energi AB } \\
\text { Uppsala, Sweden }\end{array}$ & $\begin{array}{l}\text { Coal (peat)/ } \\
\text { wood chips }\end{array}$ & $\begin{array}{l}200 \mathrm{MWe} \& \\
320 \mathrm{MWt}\end{array}$ & Pulverized Coal \\
\hline $\begin{array}{l}\text { New York State Elec \& Gas } \\
\text { Hickling (1) \& Jennison (2) Stations } \\
\text { Big Flats \& Bainbridge, New York }\end{array}$ & $\begin{array}{l}\text { Coal/wood residues and } \\
\text { coal/tyres }\end{array}$ & $\begin{array}{l}\text { 1) } 37.5 \mathrm{MWe} \\
\text { 2) } 37.5 \mathrm{MWe}\end{array}$ & $\begin{array}{l}\text { 1) Stoker } \\
\text { 2) Stoker }\end{array}$ \\
\hline $\begin{array}{l}\text { Northern States Power } \\
\text { Bay Front Station } \\
\text { Ashland, Wisconsin }\end{array}$ & Coal/wood residues (forest) & $2 \times 17 \mathrm{MWe}$ & Stoker \\
\hline
\end{tabular}


Table 5.8: Ongoing DOE Cofiring Feasibility/Demonstration Projects

\begin{tabular}{|c|c|c|}
\hline Title & Organization & Description \\
\hline $\begin{array}{l}\text { Blending Biomass with Tire-Derived Fuel for } \\
\text { Firing at Willow Island Generating Station }\end{array}$ & $\begin{array}{l}\text { Allegeny Energy } \\
\text { Supply Company }\end{array}$ & $\begin{array}{l}\text { Researchers are demonstrating the blending of fuels for } \\
\text { cofiring at the Willow Island Generating Station in West } \\
\text { Virginia. Biomass fuels are expected to reduce harmful } \\
\text { emissions form the power generating station. }\end{array}$ \\
\hline $\begin{array}{l}\text { Development of a Validated Model for Use in } \\
\text { Minimizing NO Emissions and Maximizing } \\
\text { Carbon Utilization When Cofiring Biomass } \\
\text { With Coal }\end{array}$ & Southern Research Inst. & $\begin{array}{l}\text { This project involves developing a computer model to calculate } \\
\text { optimal energy and environmental benefits derived from } \\
\text { cofiring biomass and coal. }\end{array}$ \\
\hline $\begin{array}{l}\text { Urban Wood/Coal Cofiring in the NIOSH } \\
\text { Boiler Plant }\end{array}$ & University of Pittsburgh & $\begin{array}{l}\text { The University of Pittsburgh is conducting cofiring } \\
\text { demonstrations at the University's Bellefield boiler plant and at } \\
\text { the NIOSH stoker boiler at the Bruceton Research Center. }\end{array}$ \\
\hline Cofiring Biomass with Lignite Coal & $\begin{array}{l}\text { Energy and } \\
\text { Environmental } \\
\text { Research Center, Grand } \\
\text { Forks, ND }\end{array}$ & $\begin{array}{l}\text { Tis demonstration wis cofiring wood waste with lignite coal at } \\
\text { the North Dakota Penitentiary in Bismark. }\end{array}$ \\
\hline Gasification-Based Biomass Cofiring Project & $\begin{array}{l}\text { Northern Indiana Public } \\
\text { Service Co. }\end{array}$ & $\begin{array}{l}\text { The project is evaluating the feasibility of using wood waste, } \\
\text { switchgrass, corn stover, non-recyclable paper and other related } \\
\text { products to produce synthesis gas, and to fire the syngas in a } \\
\text { generating that ordinarily fires natural gas. }\end{array}$ \\
\hline Gasification-Based Cofiring Project & Nexant, LLC & $\begin{array}{l}\text { Nexant will study the use of poultry litter in a biomass } \\
\text { gasification cofiring demonstration at the Reid plant in } \\
\text { Henderson, KY. This project will determine the optimum size } \\
\text { at which gasifiers can be integrated, while maintaining boiler } \\
\text { operation. }\end{array}$ \\
\hline $\begin{array}{l}\text { Calla Energy Biomass Gasification Cofiring } \\
\text { Project }\end{array}$ & & $\begin{array}{l}\text { This project involves developing and Demonstrating as } \\
\text { advanced version of the Gas Technology Institute } \\
\text { RENUGAS } \\
\text { biomass at a plant being built in Estill, KY. The gas will be } \\
\text { used to produce steam and electricity in a } 600 \text {-acre industrial } \\
\text { park. }\end{array}$ \\
\hline $\begin{array}{l}\text { Feasibility Analysis for Installing a CFB Boiler } \\
\text { for Cofiring Multiple Biofuels and Other } \\
\text { Wastes with Coal }\end{array}$ & $\begin{array}{l}\text { Pennsylvania State } \\
\text { University }\end{array}$ & $\begin{array}{l}\text { PSU is analyzing the installment of a state-of -the -art } \\
\text { circulating fluidized bed boiler and ceramic emission control } \\
\text { device, and is developing a test program to evaluate cofiring } \\
\text { multiple biofuels and coal-based feedstocks. }\end{array}$ \\
\hline $\begin{array}{l}\text { Cofiring Coal: Feedlot and Litter Biomass } \\
\text { Fuels in a Pulverized Fuel and Fixed-Bed } \\
\text { Burners }\end{array}$ & Texas A\&M University & $\begin{array}{l}\text { Texas A\&M University is investigating cattle feedlot and } \\
\text { chicken litter biomass cofiring with coal to determine the } \\
\text { optimum operating parameters and maximum combustion } \\
\text { efficiency that can be achieved with the least emissions. }\end{array}$ \\
\hline $\begin{array}{l}\text { Cofiring Biomass at the University of North } \\
\text { Dakota }\end{array}$ & $\begin{array}{l}\text { University of North } \\
\text { Dakota }\end{array}$ & $\begin{array}{l}\text { This project is assessing local biomass resources available to } \\
\text { the University and designing an economical feed system for the } \\
\text { University's boiler. }\end{array}$ \\
\hline $\begin{array}{l}\text { Fuel-Lean Biomass Reburning in Coal-Fired } \\
\text { Boilers }\end{array}$ & Iowa State University & $\begin{array}{l}\text { ISU is examining the feasibility of adapting a commercially } \\
\text { successful emissions reduction technology to herbaceous } \\
\text { biomass when fired with coal. }\end{array}$ \\
\hline
\end{tabular}

The coal was assumed to contain $1.9 \%$ sulfur, compared to a $0.2 \%$ sulfur content for the biomass. Moisture contents were $7.2 \%$ for the coal and $21.5 \%$ for the biomass. The coal heating value was 31.75 $\mathrm{MJ} / \mathrm{kg}(13,680 \mathrm{Btu} / \mathrm{lb})$ (dry) and the biomass heating value was $19.10 \mathrm{MJ} / \mathrm{kg}(8,231 \mathrm{Btu} / \mathrm{lb})($ dry $)$. These values for sulfur, moisture, and HHV were taken directly from tests conducted on the fuel supplies for the representative power plant. The resulting estimated net heat rate for coal-only operation is $10.93 \mathrm{MJ} / \mathrm{kW}$ 
$(10,359 \mathrm{Btu} / \mathrm{kW})$. This value is typical of high capacity factor coal boilers in the range from $100 \mathrm{MW}$ to $400 \mathrm{MW}$, and was therefore assumed constant for all cases.

All system capital costs are due to the retrofit of an existing pulverized coal boiler to co-fire biomass. Costs shown in Table 5.9 are based on engineering specifications, including materials and sizing of major system components, from a feasibility study for a corresponding $10 \mathrm{MW}$ (biomass power) biomass cofiring retrofit at an existing plant (Antares and Parsons 1996). The unit costs for the cofiring retrofit are expressed in $\$ / \mathrm{kW}$ of biomass power capacity, not total power capacity. Capital costs include costs for new equipment (e.g., fuel handling), boiler modifications, controls, engineering fees $(10 \%$ of total process capital), civil / structural work including foundations and road ways, and a $15 \%$ contingency. Cost estimates for the example systems assume that front-end loaders and truck scales are already available at the plant for unloading and pile management. Costs also assume that live-bottom trucks are used for biomass delivery, allowing the avoidance of the purchase of a truck tipper. Land and substation (system interface) costs are zero because existing plant property and the existing substation will be utilized. Operation and maintenance costs, including fuel costs, are presented in the Table on an incremental basis. That is, each O\&M cost component listed in the table represents the difference in that cost component when comparing biomass cofiring operation to coal-only operation. Negative costs, surrounded by parentheses in the table, represent a cost savings in the cofiring operation relative to coal-only operation. Updated plant performance indicators are given in Table 5.9, and updated capital and operating costs are given Table 5.10.

To estimate plant performance as a CHP facility, the biopower steam conditions $\left(16.5 \mathrm{MPa}\right.$ and $\left.538^{\circ} \mathrm{C}\right)$ were used in an ASPEN ${ }^{\mathrm{TM}}$ steam turbine simulation to estimate steam turbine performance in three modes of operation - as a condensing turbine (comparable to the RETC97 electricity case), as a backpressure turbine, and as an extraction turbine. The steam efficiency was assumed to be $80 \%$. The extraction turbine case was used in CHP performance estimates. The use of the extraction turbine gave a heat $(\mathrm{H})$ to power ratio $(\mathrm{P})$ of 1.44, as shown in Table 5.12. A summary of turbine performance for a $100 \mathrm{MW}_{\mathrm{e}}$ equivalent facility is given in Table 5.11. To convert to net plant efficiency a parasitic load of $6 \mathrm{MW}_{\mathrm{e}}$ is subtracted from gross electricity production. 
Table 5.9: Biomass Cofiring Performance Characteristics

\begin{tabular}{|llrr|}
\hline \multicolumn{1}{|c}{ Indicator Name } & Units & \multicolumn{2}{c|}{ Value r } \\
\hline \hline Plant Size & $\mathrm{MW}$ & 300 & 700 \\
General Performance Indicators & & & \\
Capacity Factor & $\%$ & 90 & 90 \\
Total Electricity Generated & $\mathrm{GWh} / \mathrm{yr}$ & 2,365 & 5,518 \\
Coal Moisture Content & $\%$ & 7.2 & 7.2 \\
$\quad$ Biomass Moisture Content & $\%$ & 21.5 & 21.5 \\
Coal-Only Performance Factors & & & \\
Plant Thermal Efficiency & $\%$ & 32.9 & 32.9 \\
Net Plant Heat Rate & $\mathrm{KJ} / \mathrm{kWh}$ & 10,929 & 10,929 \\
& $\mathrm{Btu} / \mathrm{kWh}$ & 10,377 & 10,377 \\
Net Pow er Capacity From Coal & $\mathrm{MW}$ & 300 & 700 \\
Annual Electricity From Coal & $\mathrm{GWh} / \mathrm{yr}$ & 2,365 & 5,518 \\
Coal Consumption (w et) & tonnes/yr & 877,550 & $2,047,617$ \\
Annual Heat Input From Coal & $\mathrm{TJ} / \mathrm{yr}$ & 25,847 & 60,310 \\
Total Annual Heat Input & $\mathrm{TJ} / \mathrm{yr}$ & 25,847 & 60,310 \\
Biomass Cofiring Performance Indicators & & & \\
Cofiring Rate (Heat Input From Biomass) & $\%$ & 15 & 15 \\
Plant Thermal Efficiency & $\%$ & 32.5 & 32.5 \\
Net Plant Heat Rate & $\mathrm{kJ} / \mathrm{kWh}$ & 11,066 & 25,821 \\
Net Pow er Capacity From Coal & $\mathrm{Btu} / \mathrm{kWh}$ & 10,505 & 24,512 \\
Net Pow er Capacity From Biomass & $\mathrm{MW}$ & 255 & 595 \\
Annual Electricity From Coal & $\mathrm{MWW}$ & 45 & 105 \\
Annual Electricity From Biomass & $\mathrm{GWh} / \mathrm{yr}$ & 2,136 & 4,984 \\
Coal Consumption (w et) & $\mathrm{GWh} / \mathrm{yr}$ & 377 & 880 \\
Biomass Consumption (Dry) & tonnes/yr & 802,220 & $1,871,847$ \\
Annual Heat Input From Coal & tonnes/yr & 218,347 & 509,476 \\
Annual Heat Input From Biomass & $\mathrm{TJ} / \mathrm{yr}$ & 23,638 & 55,155 \\
Total Annual Heat Input & $\mathrm{TJ} / \mathrm{yr}$ & 4,172 & 9,735 \\
& $\mathrm{TJ} / \mathrm{yr}$ & 27,810 & 64,890 \\
\hline
\end{tabular}


Table 5.10: Biomass Cofiring Capital and Operating Costs, Excluding Feed

\begin{tabular}{|c|c|c|c|c|c|}
\hline $\begin{array}{l}\text { Capital Cost (basis: Biomass Pow er Capacity) } \\
\text { M\&S Index }\end{array}$ & $\begin{array}{r}1996 \$ \\
300 \mathrm{MW} \\
\$ / \mathrm{kW} \\
1039\end{array}$ & $\begin{array}{r}2001 \$ \\
300 \mathrm{MW} \\
\$ / \mathrm{kW} \\
1092\end{array}$ & $\begin{array}{l}300 \mathrm{MW} \\
\$\end{array}$ & $\begin{array}{r}700 \mathrm{MW} \\
\$ / \mathrm{kW}\end{array}$ & $\$$ \\
\hline \multicolumn{6}{|l|}{ Biomass Handling System Equipment } \\
\hline Conveyor & 10.3 & 10.8 & 487,097 & 8.4 & 881,452 \\
\hline Separation Equipment, Conveyor & 2.8 & 2.9 & 132,415 & 2.3 & 239,618 \\
\hline Hogging Tow er and Equipment & 17.0 & 17.9 & 803,946 & 13.9 & $1,454,824$ \\
\hline Pneumatic Conveying System (Vacuum) & 3.6 & 3.8 & 170,247 & 2.9 & 308,080 \\
\hline Wood Silo w ith Live Bottom & 4.4 & 4.6 & 208,080 & 3.6 & 376,543 \\
\hline Collecting Conveyers & 5.3 & 5.6 & 250,642 & 4.3 & 453,563 \\
\hline Rotary Airlock Feeders & 0.5 & 0.5 & 23,645 & 0.4 & 42,789 \\
\hline Pneumatic Conveying System (Pressure) & 13.6 & 14.3 & 643,157 & 11.1 & $1,163,859$ \\
\hline Controls & 8.4 & 8.8 & 397,244 & 6.8 & 718,854 \\
\hline Total Equipment & 65.9 & 69.3 & $3,116,472$ & 53.7 & $5,639,583$ \\
\hline Installation & 40.9 & 43.0 & $1,934,199$ & 33.3 & $3,500,136$ \\
\hline Total Biomass Handling & 106.8 & 112.2 & $5,050,671$ & 87.0 & $9,139,718$ \\
\hline Civil Structure Work & 29.4 & 30.9 & $1,390,353$ & 24.0 & $2,515,990$ \\
\hline Modifications at Burners & 2.4 & 2.5 & 113,498 & 2.0 & 205,387 \\
\hline Eectrical & 13.1 & 13.8 & 619,511 & 10.7 & $1,121,070$ \\
\hline Subtotal (A) & 151.7 & 159.4 & $7,174,033$ & 123.6 & $12,982,165$ \\
\hline Contingency @ 15\%, 0.15*A & 22.8 & 23.9 & $1,076,105$ & 18.5 & $1,947,325$ \\
\hline Total Direct Costs (B) & 174.5 & 183.3 & $8,250,138$ & 142.2 & $14,929,490$ \\
\hline Engineering @ 10\%, 0.1B & 17.4 & 18.3 & 825,014 & 14.2 & $1,492,949$ \\
\hline Total Capital Requirements (TCR) & 191.9 & 201.7 & $9,075,152$ & 156.4 & $16,422,439$ \\
\hline \multicolumn{6}{|l|}{$\begin{array}{l}\text { Incremental Operating and Maintenance Costs } \\
\text { Variable Costs }\end{array}$} \\
\hline Consumables & 0.00163 & 0.0016 & 614,510 & 0.0016 & $1,433,857$ \\
\hline Coal Savings & & $(0.0051)$ & $(1,916,829)$ & $(0.0051)$ & $(4,472,601)$ \\
\hline \multicolumn{6}{|l|}{ Fixed Costs } \\
\hline Labor & 0.0006 & 0.00063 & & 0.00063 & \\
\hline Maintenance & 0.0005 & 0.00053 & & 0.00053 & \\
\hline Total & 0.0011 & 0.00116 & 435,812 & 0.00116 & $1,016,895$ \\
\hline
\end{tabular}


Table 5.11: Cofiring Cogeneration Gross Steam Turbine Efficiencies, $100 \mathrm{MW}_{\mathrm{eq}}$ Plant

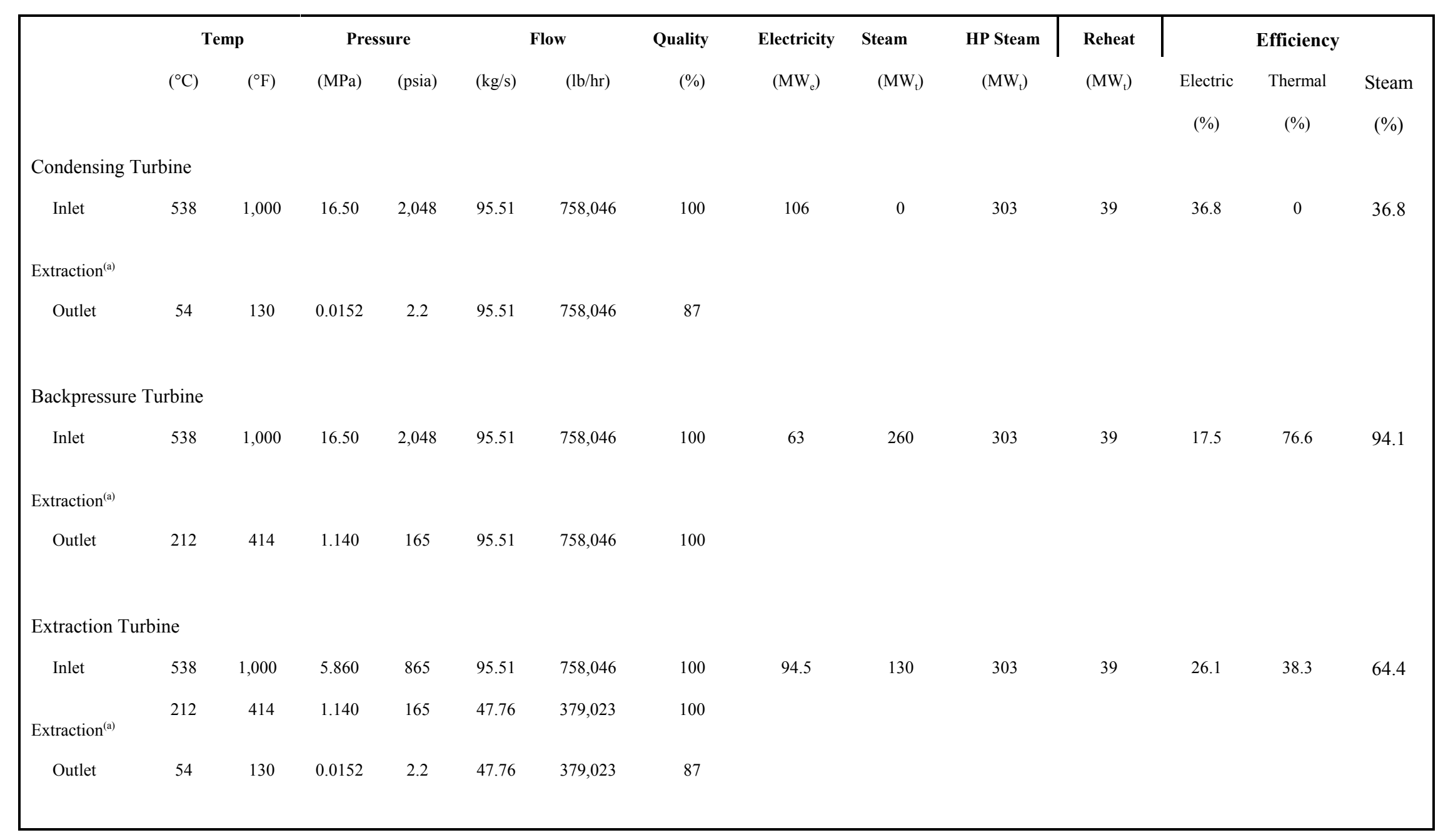

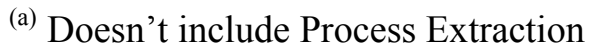




\section{Case Studies}

A technoeconomic comparison has been made the direct combustion, gasification, and cofiring systems. A listing of cases, along with technical performance is given in Table 5.12. Plants are defined in terms of electricity-only base cases. For example, the $25 \mathrm{MW}$ CHP case has a feed rate equal to the feed rate for a $25 \mathrm{MW}_{\mathrm{e}}$ electricity-only plant. The actual electric capacity for the $25 \mathrm{MW} \mathrm{CHP}$ case is $19.8 \mathrm{MW}_{\mathrm{e}}$, and the plant also produces $107,000 \mathrm{lb} / \mathrm{hr}$ of $150 \mathrm{lb}$ steam. On an energy basis, the $\mathrm{H} / \mathrm{P}$ ratio is 1.44 ; and the overall HHV efficiency is $62 \%$.

Table 5.12: Biomass Plant Technical Performance

\begin{tabular}{|c|c|c|c|c|c|}
\hline Case & $\begin{array}{c}\text { Efficiency } \\
\%\end{array}$ & $\begin{array}{c}\text { Feed Rate } \\
\text { MBtu/hr }\left(\mathrm{TPH}^{*}\right)\end{array}$ & $\begin{array}{l}\text { Electricity } \\
\text { MW }\end{array}$ & $\begin{array}{c}150 \mathrm{lb} \text { Steam } \\
1000 \mathrm{lb} / \mathrm{hr}\end{array}$ & $H / P$ \\
\hline $25 \mathrm{MW}$ Electric - Direct Comb & 30 & $284 \quad(16.73)$ & 25.0 & 0 & -- \\
\hline 25 MW CHP - Direct Comb & 62 & $284(16.73)$ & 19.8 & 107 & 1.44 \\
\hline 25 MW Steam & 75 & 284 (16.73) & -2.5 & 214 & -- \\
\hline 50 MW Electric - Direct Comb & 30 & 569 (33.45) & 50.0 & 0 & -- \\
\hline 50 MW CHP - Direct Comb & 62 & 569 (33.45) & 41.5 & 214 & 1.44 \\
\hline 50 MW Steam & 75 & $569 \quad(33.45)$ & -5.0 & 429 & -- \\
\hline 75 MW Electric - Direct Comb & 30 & $853 \quad(50.18)$ & 75.0 & 0 & -- \\
\hline 75 MW CHP - Direct Comb & 62 & 853 (50.18) & 62.2 & 321 & 1.44 \\
\hline 75 MW Steam & 75 & $853(50.18)$ & -7.5 & 643 & -- \\
\hline 100 MW Electric - Direct Comb & 30 & $1,137(66.90)$ & 100.0 & 0 & -- \\
\hline 100 MW CHP - Direct Comb & 61 & $1,137(66.90)$ & 83.0 & 428 & 1.44 \\
\hline 100 MW Steam & 75 & $1,137(66.90)$ & -10.0 & 857 & -- \\
\hline 75 MW Gasification-Electric & 36 & $711(41.80)$ & 75.0 & 0 & -- \\
\hline 75 MW Gasification - CHP & 82 & $711(41.80)$ & 59.3 & 324 & 1.60 \\
\hline 150 MW Gasification - Electric & 36 & $711(41.80)$ & 150.0 & 0 & -- \\
\hline 150 MW Gasification - CHP & 82 & $1,422(83.60)$ & 118.6 & 648 & 1.60 \\
\hline 45 MW Cofiring CHP (15\%) & 60 & $518(30.46)$ & 41.0 & 170 & 1.21 \\
\hline 45 MW Cofiring Steam & 66 & $518(30.46)$ & -2.7 & 341 & -- \\
\hline 105 MW Cofiring CHP (15\%) & 60 & $1,208(71.08)$ & 95.7 & 397 & 1.21 \\
\hline 105 MW Cofiring Steam & 66 & $1,208(71.08)$ & -6.30 & 796 & -- \\
\hline
\end{tabular}

*Dry tons@17 MBtu/ton

For each of the cases a discounted cash flow (DCF) analysis was performed, using the economic parameters presented in Table 5.1. Since CHP operations have two products, electricity and steam, a protocol for prorating values was needed. One way to do this would be to assign market value to one product and determine the required cost of the second. However, this can unduly penalize or benefit the product being calculated if the required cost differs significantly from market value. Therefore, this method was not used. A second method is to estimate the present market value of the two products, and use the ratio to determine required costs of both. An estimate of relative market values was made using EIA $^{2}$ cost of manufacturing data from 1998. Based on survey data, the EIA presented purchased electricity

${ }^{2}$ Energy Information Agency, Department of Energy, EIA Manufacturing Consumption of Energy 1998, Table N8.3, 1998. 
and steam data for the United States and census region by manufacturing sector. A complete set of cost data for chemical industry sub-sectors in given in Appendix 2. For this study, the average values for the chemical sector were used. Figure 5-7 shows census regions. Figures 5-8 and 5-9 show purchased electricity and steam costs, respectively, updated to 2001 dollars using the GDP deflator. The United States average value of industrial electricity was $\$ 0.038 / \mathrm{kWh}$ and industrial steam was $\$ 3.20 / 1,000 \mathrm{lb}$. In practice, as can be seen in the figures, the actual ratio will be site specific. When converted to a consistent set of units, the ratio of heat to power value $(\$ \mathrm{H} / \$ \mathrm{P})$ was 0.287 . The matrix of cases analyzed was relatively large. For example, for direct combustion there were four plant sizes and five feed cost levels. A graphical presentation of the results using the 0.287 ratio with electricity in $\phi / \mathrm{kWh}$ and steam in $\$ / 1,000 \mathrm{lb}$ was confusing simply because of the number of lines on each graph. In discounted cash flow analysis, if the capital and operating costs are fixed, and the discount rate is held constant, all feasible solutions give identical cash flows, e.g. identical incomes. Therefore, the absolute ratio of electricity and steam costs does not significantly impact the analysis. A $\$ \mathrm{H} / \mathrm{P}$ value was determined, 0.341 , which would simplify graphical presentation of results, and would still be realistic; this value was used for the case studies.

Figure 5.7: United States Census Regions

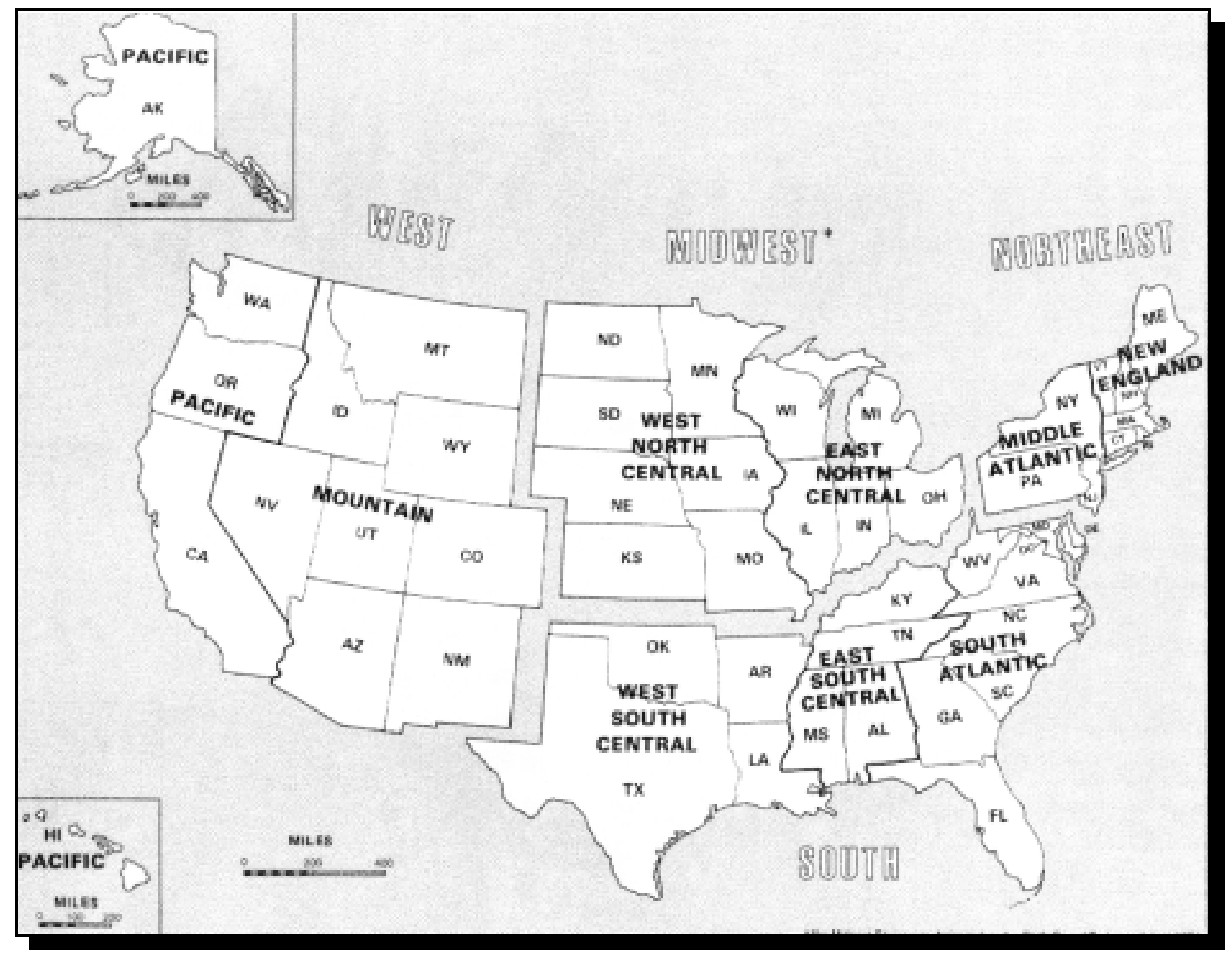


Figure 5.8: Chemical Industry Cost of Purchased Electricity

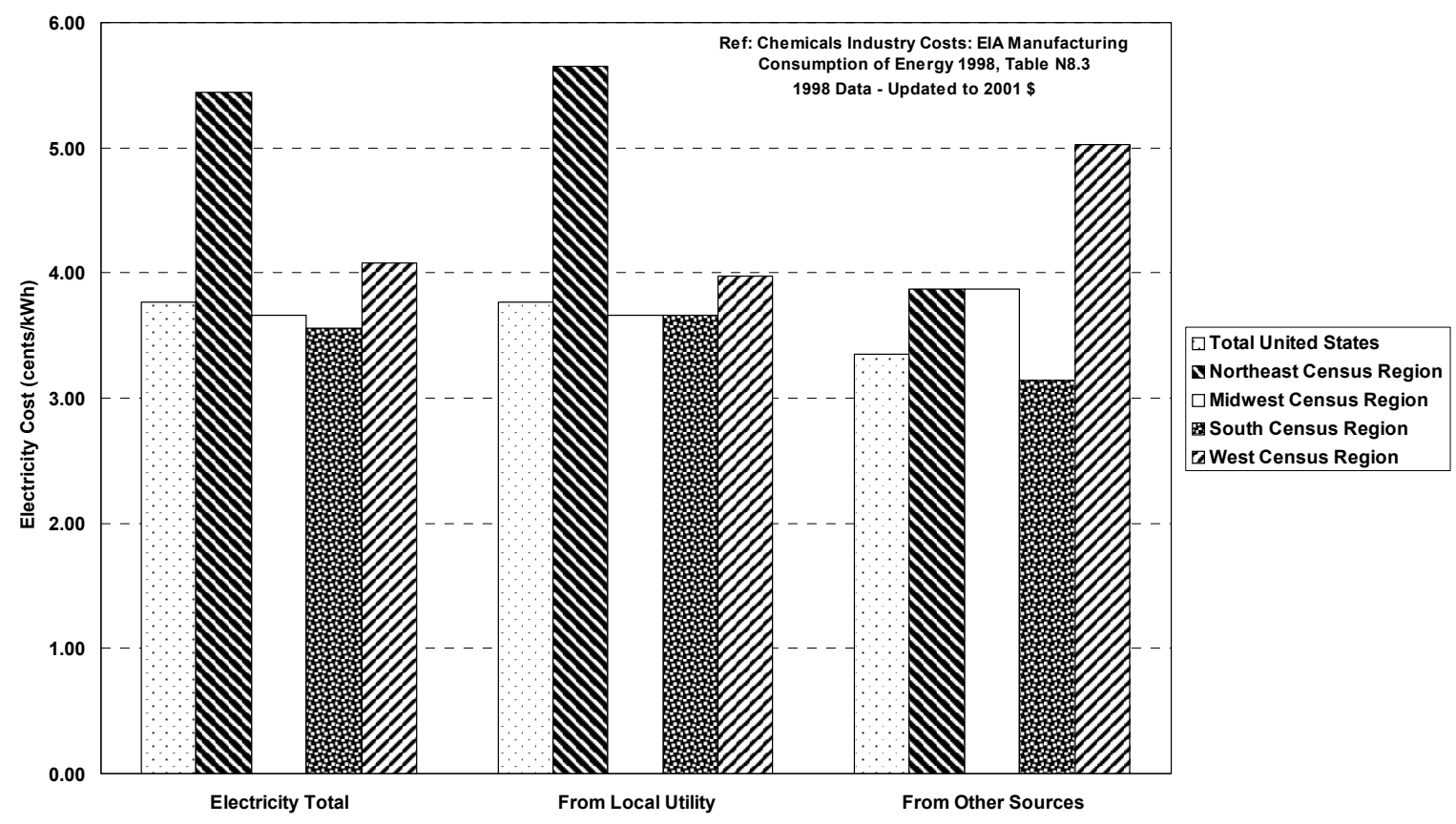

The DCF analysis was performed as a net present value (NPV) equals zero calculation in which the internal rate of return was set at the assumed discount rate, and the cost of products varied until NPV equaled zero. An example set of input values is given in Table 5.13, and the corresponding cash flow result shown in Table 5.14.

\section{Feed Cost}

In Figure 5.10, the effect of feed cost on required electricity and steam costs is shown for all systems The negative feed cost represents residue material generated in a chemical manufacturing or other industrial facility that is presently disposed of at some net cost, and where the negative cost represents a savings in disposal cost that can be represented by a negative transfer price. The $0-1 \$ /$ ton values represent residue materials presently used (see Figure 3.1 in Chapter 3), and the higher values represent marginal costs for larger supply levels. Typically, dedicated feeds will only be available at $>\$ 3 / \mathrm{MBtu}$. The results show that all combustion CHP cases give required product costs greater than existing industrial market prices. The gasification plants show a comparable trend, but with required product costs 2 to $3 \notin / \mathrm{kWh}(\$ 2-3 / 1,000$ lb steam) lower than the direct combustion cases. Gasification CHP using technology presently available, i.e., $1^{\text {st }}$ generation commercial systems, may be competitive with existing sources of industrial electricity and steam if a manufacturing facility has an internal source of waste available. For higher cost residues or dedicated crops, incentives or more advanced technologies, i.e., nth plant technology with higher efficiency, will be required to reduce product costs to a competitive level. Cofiring represents fuel substitution for existing coal feed. The coal savings offsets the required capital investment and the incremental cost of cofiring reflects the cost of biomass feed.

\section{Plant Size}

Figure 5.11 shows the effect of plant size on required product cost for the base feed cost of \$2/MBtu. Capital and operating costs were scaled using a 0.7 scaling factor. The rationale for the scaling factor was discussed earlier in the direct-fired biomass section. Since only two plant sizes were calculated for gasification and cofiring, the shape of the curve is not apparent, but would follow the same trend if more sizes were estimated. The cost of electricity (steam) for direct combustion varied from $10.6 \phi / \mathrm{kWh}$ 
$\left(\$ / 1,000 \mathrm{lb}\right.$ steam) at $25 \mathrm{MW}_{\text {eq }}$ to $8.4 \phi / \mathrm{kWh}\left(\$ / 1,000 \mathrm{lb}\right.$ steam) at $100 \mathrm{MW}_{\text {eq }}$. Gasification production costs were $6.7 \notin / \mathrm{kWh}\left(\$ / 1,000 \mathrm{lb}\right.$ steam) at $75 \mathrm{MW}_{\text {eq }}$ and $6.1 \phi / \mathrm{kWh}(\$ / 1,000 \mathrm{lb}$ steam) at $150 \mathrm{MW}$. For cofiring at $15 \%$ the incremental costs were $2.2 \notin / \mathrm{kWh}\left(\$ / 1000 \mathrm{lb}\right.$ steam) for $45 \mathrm{MW}_{\text {eq }}$ biomass and $2.1 \notin / \mathrm{kWh}$ $\left(\$ / 1,000 \mathrm{lb}\right.$ steam) for $105 \mathrm{MW}_{\mathrm{eq}}$ biomass.

\section{Capital Cost}

The sensitivity of cost of production on capital cost is shown in Figure 5.12. Because of the low capital investment required for $15 \%$ cofiring CHP the sensitivity to a $\pm 25 \%$ variation in capital cost is small, e.g., $2.1 \pm 0.08 \notin / \mathrm{kWh}\left(\$ / 1,000 \mathrm{lb}\right.$ steam) at $105 \mathrm{MW}_{\text {eq }}$ biomass. For gasification CHP, the sensitivity at 150 $\mathrm{MW}_{\text {eq }}$ is $6.10 \pm 0.73 \phi / \mathrm{kWh}$, and for direct combustion at $100 \mathrm{MW}_{\text {eq }}$ is $8.44 \pm 0.97 \phi / \mathrm{kWh}$ for the same \pm $25 \%$ variation.

\section{Discount Rate}

The base case study uses a 20 percent discount rate, but the allowable discount rate is dependent on the individual organization performing the evaluation. NREL typically uses $15 \%$ for analyses, and EPRI has used $10.8 \%$ for utility cash flow comparisons (EPRI TAG, 1993). Therefore, a set of sensitivity cases was performed to look at the sensitivity to discount rate over the range $10 \%-25 \%$. The results are given in

Figure 5.9: Chemical Industry Cost of Purchased Steam

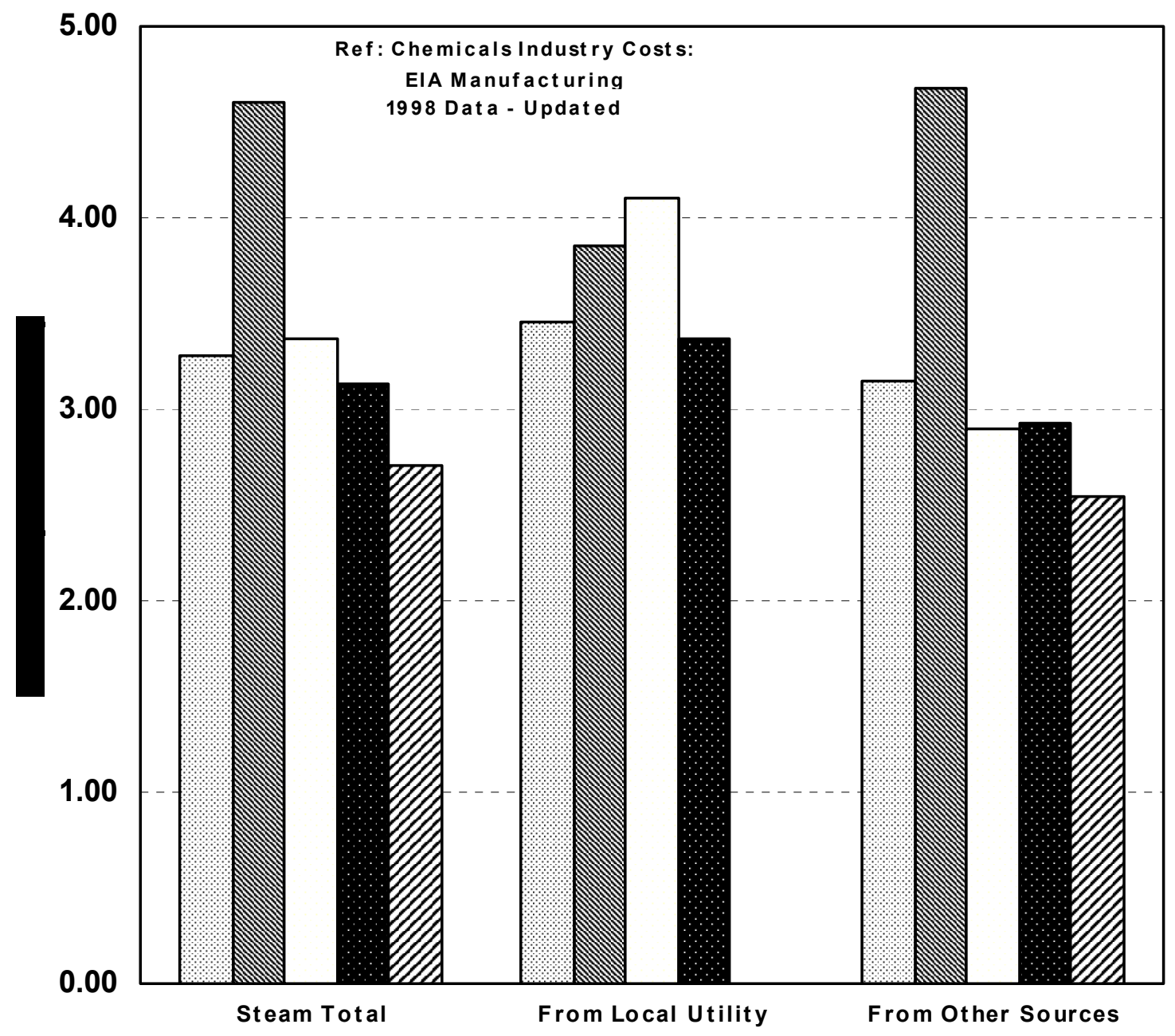

Total United States \$ Northeast Census Region 口M idwest Census Region - South Census Region $\square$ West Census Region 
Figure 5.13. Over the range of $10 \%$ to $25 \%$, the $100 \mathrm{MW}_{\text {eq }}$ direct combustion CHP system cost varies from $6.4 \phi / \mathrm{kWh}\left(\$ / 1,000 \mathrm{lb}\right.$ steam) to $9.6 \phi / \mathrm{kWh}$, the $150 \mathrm{MW}_{\text {eq }}$ gasification CHP cost from $4.5 \phi / \mathrm{kWh}$ to $7.0 \notin / \mathrm{kWh}$, and the $105 \mathrm{MW}_{\mathrm{eq}}$ cofiring $\mathrm{CHP}$ cost from $1.9 \notin / \mathrm{kWh}$ to $2.2 \phi / \mathrm{kWh}$.

\section{Debt Sensitivity}

Each organization has its own debt-equity protocol for cash flow estimation. A set of sensitivity cases was performed to estimate the required cost sensitivity to level of debt and the results are shown in Figure 5.14. For the $100 \mathrm{MW}_{\text {eq }}$ direct combustion system, the required CHP costs are $10.5 \phi / \mathrm{kWh}(\$ / 1,000 \mathrm{lb}$ steam) and $7.5 \phi$ at $100 \%$ equity and $50 \%$ equity-50\% debt, respectively. For the $150 \mathrm{MW}_{\text {eq }}$ gasification system the respective CHP costs at $100 \%$ and $50 \%$ equity are $7.6 \notin / \mathrm{kWh}$ and $5.4 \varnothing / \mathrm{kWh}$, and for cofiring CHP at 105 $\mathrm{MW}_{\mathrm{eq}}$ are 2.2 and $2.0 \phi / \mathrm{kWh}$.

\section{Carbon Allowances}

There is a significant amount of ongoing discussion about the use of carbon taxes, carbon sequestration credits, or carbon emission penalties as a way to reduce greenhouse gas emissions. An estimate of the impact of carbon allowances on biomass CHP was estimated over the range of 0-100 \$/ton carbon emissions avoided. U.S. average carbon emissions for electricity production from coal-fired utility stations were used to estimate carbon allowances (EIA AEO 2002). The estimated value is $2.75 \times 10^{-4}$ metric tons carbon $/ \mathrm{kWh}$. The carbon allowance was credited only against electricity production and was considered a before-tax income stream. The results are given in Figure 5.15. The cost of electricity (steam) for the 100 $\mathrm{MW}_{\text {eq }}$ direct combustion CHP case at 0, 25, 50, and $100 \$ /$ metric ton carbon avoided are 8.44, 8.01, 7.58, and $6.71 \phi / \mathrm{kWh}\left(\$ / 1,000 \mathrm{lb}\right.$ steam), respectively. For the $150 \mathrm{MW}_{\text {eq }}$ gasification CHP case, the respective costs are $6.10,5.65,5.21$, and $4.32 \phi / \mathrm{kWh}$; and for $15 \%$ cofiring CHP at $105 \mathrm{MW}_{\text {eq }}$ biomass the costs are $2.06,1.58,1.09$, and $0.12 ф / \mathrm{kWh}$.

\section{Tax Credits}

Various proposals are before Congress to modify and expand the definition of the IRS Section 49 "closed loop" biomass tax credit to include residues and cofiring. Therefore, estimates of the impact of such tax credits were made. The estimates were made using two assumptions-a project basis and a corporate basis. Using the project basis assumption, only project generated taxable income is used. In this case, the capital equipment depreciation in the early years of the project greatly limits taxable income, and the impact of a tax credit is small. For the corporate basis cases, the assumption is made that the corporation has other taxable income that the tax credit can be applied against so that all potential tax credit can be used. Other assumptions are that the tax credit is available for $100 \%$ of the net plant production, i.e, that the net production of electricity is sold, and that the tax credit applies for 10 years of plant operation.

Figure 5.16 shows the impact of a electricity production tax credit on the required cost of production of electricity for direct combustion CHP and for gasification CHP. For the $100 \mathrm{MW}_{\mathrm{eq}}$ direct combustion system, the impact on electricity (steam) cost of production with a $1 \notin / \mathrm{kWh}$ production credit is minus 0.36 $\notin / \mathrm{kWh}(\$ / 1,000 \mathrm{lb}$ steam) for a project basis and minus $0.77 \phi / \mathrm{kWh}$ for a corporate basis; with a $2 \notin / \mathrm{kWh}$ production credit the respective values are minus $0.57 \phi / \mathrm{kWh}$ and minus $1.51 \phi / \mathrm{kWh}$. For the $150 \mathrm{MW}_{\mathrm{eq}}$ gasification CHP system with a $1 \notin / \mathrm{kWh}$ production credit, the cost of production is lowered by 0.42 and $0.81 \varnothing / \mathrm{kWh}$ for the project and corporate cases, respectively; with a $2 \phi / \mathrm{kWh}$ credit, the respective cost of production reduction is 0.50 and $1.57 \phi / \mathrm{kWh}$.

Comparable estimates can be made for the cofiring CHP cases, but the analysis is somewhat more complicated. Figure 5.17 shows the impact of a production credit on $15 \%$ cofiring CHP incremental costs. For the project cases, the decrease in cost of production for the 45 and $105 \mathrm{MW}_{\text {eq }}$ plants reaches a maximum of about $0.07 \varnothing / \mathrm{kWh}$ at a tax credit of about $0.5 \varnothing / \mathrm{kWh}$. For the corporate analysis, the NPV calculation does not give meaningful results above a tax credit level of $0.5 \phi / \mathrm{kWh}$. At this level, the reduction is about $0.40 \notin / \mathrm{kWh}$ for both plants sizes. Above this level a NPV calculation can be made but 
to satisfy the $20 \%$ return constraint, a solution is obtained that gives negative cash flows in the years after expiration of the tax credit. This indicates that the 10 -year production tax credit has a large impact on potential project rate of return. A return on investment (ROI) estimate was made to show the impact of the production tax credit, assuming a fixed cost of production. For this example, the incremental cost of production of electricity (steam) was set at $2.0 \notin / \mathrm{kWh}(\$ 2 / 1,000 \mathrm{lb}$ steam), and the 10-year production tax credit varied from 0 to $1 \phi / \mathrm{kWh}$. For the $45 \mathrm{MW}_{\mathrm{eq}}$ plant, the ROI varies from $13.6 \%$, to $31.6 \%$, to $47.8 \%$ at a $0,0.5$, and $1 \phi / \mathrm{kWh}$ tax credit, respectively. The comparable ROIs for the $105 \mathrm{MW}_{\text {eq }}$ case are 17.0 , 38.6 , and $57.5 \%$.

\section{Steam Only}

For the direct combustion and cofiring systems based on the Rankine cycle, cases were analyzed to see if steam-only production was more economic. For the direct combustion system, the steam turbine was removed from the capital cost estimate, and for both systems the steam exiting the boiler was used as product. The results are shown in Figure 5.19. Production of steam results in an increase in the cost of production in comparison to CHP. At $50 \mathrm{MW}_{\text {eq }}$ the cost of steam is $11.90 \$ / 1,000 \mathrm{lb}$, an increase of 2.53 $\$ / 1,000 \mathrm{lb}$ over the comparable CHP case. At $100 \mathrm{MW}_{\text {eq }}$, the steam cost is $10.81 \$ / 1000 \mathrm{lb}$, an increase of $2.37 \$ / 1,000 \mathrm{lb}$. For cofiring steam-only production at $45 \mathrm{MW}_{\mathrm{eq}}$ the incremental cost of steam is 4.16 $\$ / 1000 \mathrm{lb}$, versus $2.16 \$ / 1000 \mathrm{lb}$ for CHP; at $105 \mathrm{MW}_{\text {eq }}$, the incremental cost of steam is $3.82 \$ / 1,000 \mathrm{lb}$ versus $2.06 \$ / 1,000 \mathrm{lb}$ for CHP.

\section{Site and Incentives Impact}

To see the potential impact of regional plant location, discount rate, and incentives, one set of gasification CHP cases was performed. The discount rate was assumed to be $5 \%$, and both a carbon allowance $(15 \$ /$ ton carbon equivalent $)$ and production tax incentive $(1.5 \phi / \mathrm{kWh})$ were allowed. The tax incentive was taken on a corporate basis. The results were compared to U.S. and Northeast region costs of purchased electricity and steam, and are presented in Figure 5.20. For $75 \mathrm{MW}_{\text {eq }}$ both the cost of electricity and steam are higher than the national average purchased prices, but are lower than purchase prices in the Northeast. At $150 \mathrm{MW}_{\mathrm{eq}}$ the results are comparable, but the cost of electricity is equal to the national average price.

\section{Capital Requirements and Required Cash Flow}

Although the three technologies-direct combustion, gasification, and cofiring-were evaluated at a constant discount rate to determine the required costs of electricity and steam, another important investment consideration is capital required and cumulative cash flow realized over the life of the project. A comparison of costs and cash flow is given in Table 5.15. Cofiring has the smallest capital investment and lowest operating costs, and gives the smallest cash flow. Gasification at $150 \mathrm{MW}$ has an intermediate investment requirement, and direct combustion has the highest requirements.

\section{Recommendations for Further Work}

The case studies give a good base comparison of the three technologies. Further analysis is needed to fully investigate CHP applications.

- An advanced gasification case with higher efficiency-to-electricity ratios should be analyzed to determine if costs can be reduced to purchase prices.

- Given the variation in regional prices of electricity and steam, a resource evaluation relative to chemical plant locations should be performed to determine if there are site specific cases where feasibility studies should be performed. The project should map currently available biomass feedstocks (e.g., industrial processing residues, urban wood residues, agricultural residues) against locations of industrial facilities capable of biorefinery operations. The mapping should allow for a preliminary identification and ranking of prospective opportunities based on feedstock characteristics (i.e., type and availability, processing requirements, delivered costs) and industrial facility characteristics (i.e., type, size, location). 
It should utilize a biomass feedstock database being developed by ORNL that provides quantity and delivered price information at the county level. Feedstock evaluations should include secondary residues generated by biorefineries. It should also utilize secondary data and information sources, such as EPA Sector Notebooks and U.S. Census Bureau County Business Patterns, where appropriate.

- For a few of the more promising identified facilities, we should apply the technical and economic findings of this report to determine the appropriate biomass CHP systems (e.g., gasification, co-firing) as well as syngas opportunities for chemicals, such as ethanol or mixed alcohols. This latter analysis should assess opportunities for specific facilities as well as develop a replicable methodology (including information requirements) for identifying biorefinery opportunities for industrial sites throughout the U.S. 


\section{Table 5.13: Cash Flow Analysis Input Data, $\mathbf{7 5 M W}_{\mathrm{eq}}$ Gasification CHP System}

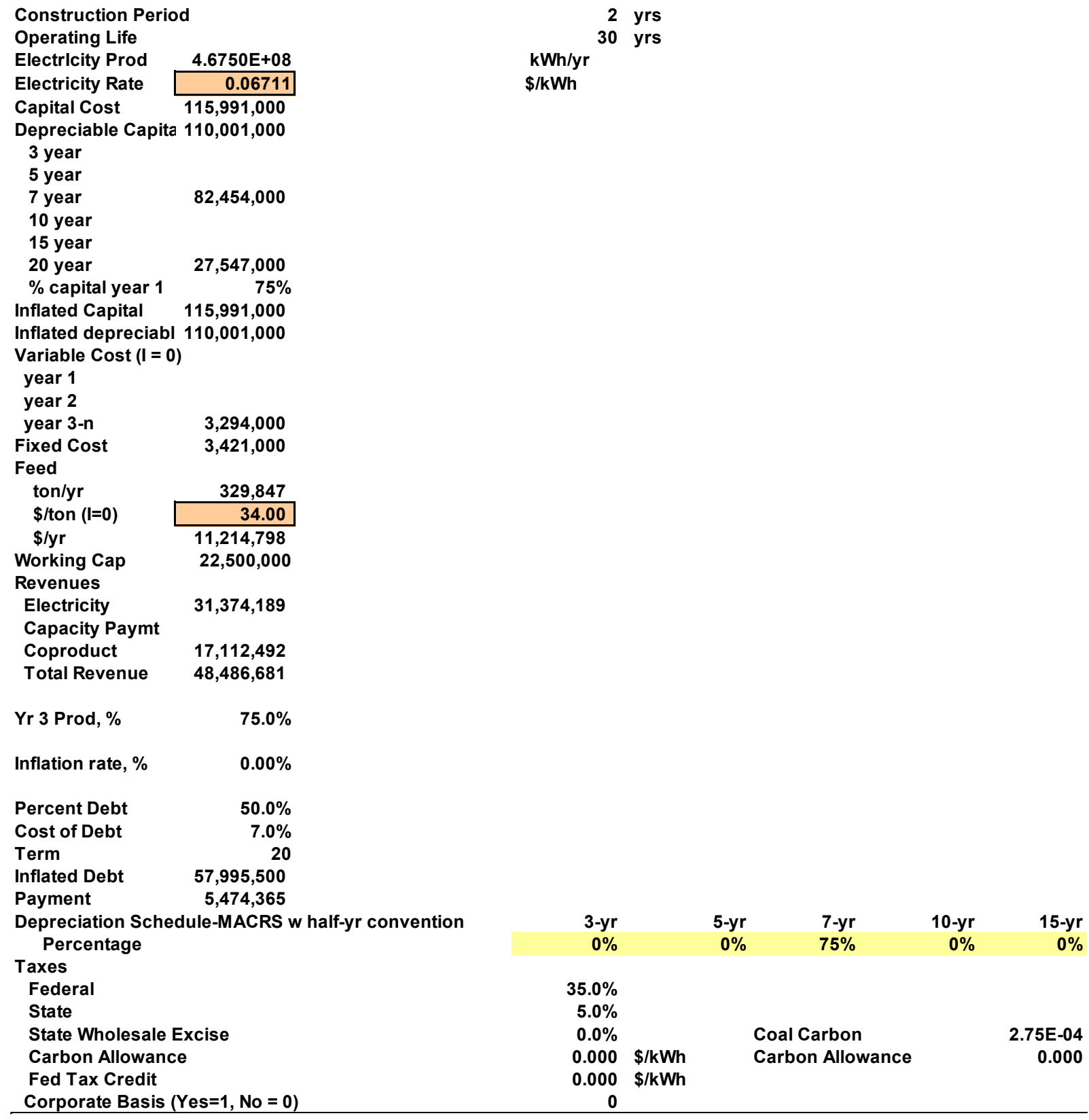


Table 5.14: Cash Flow, 75 MW $_{\text {eq }}$ Gasification CHP System

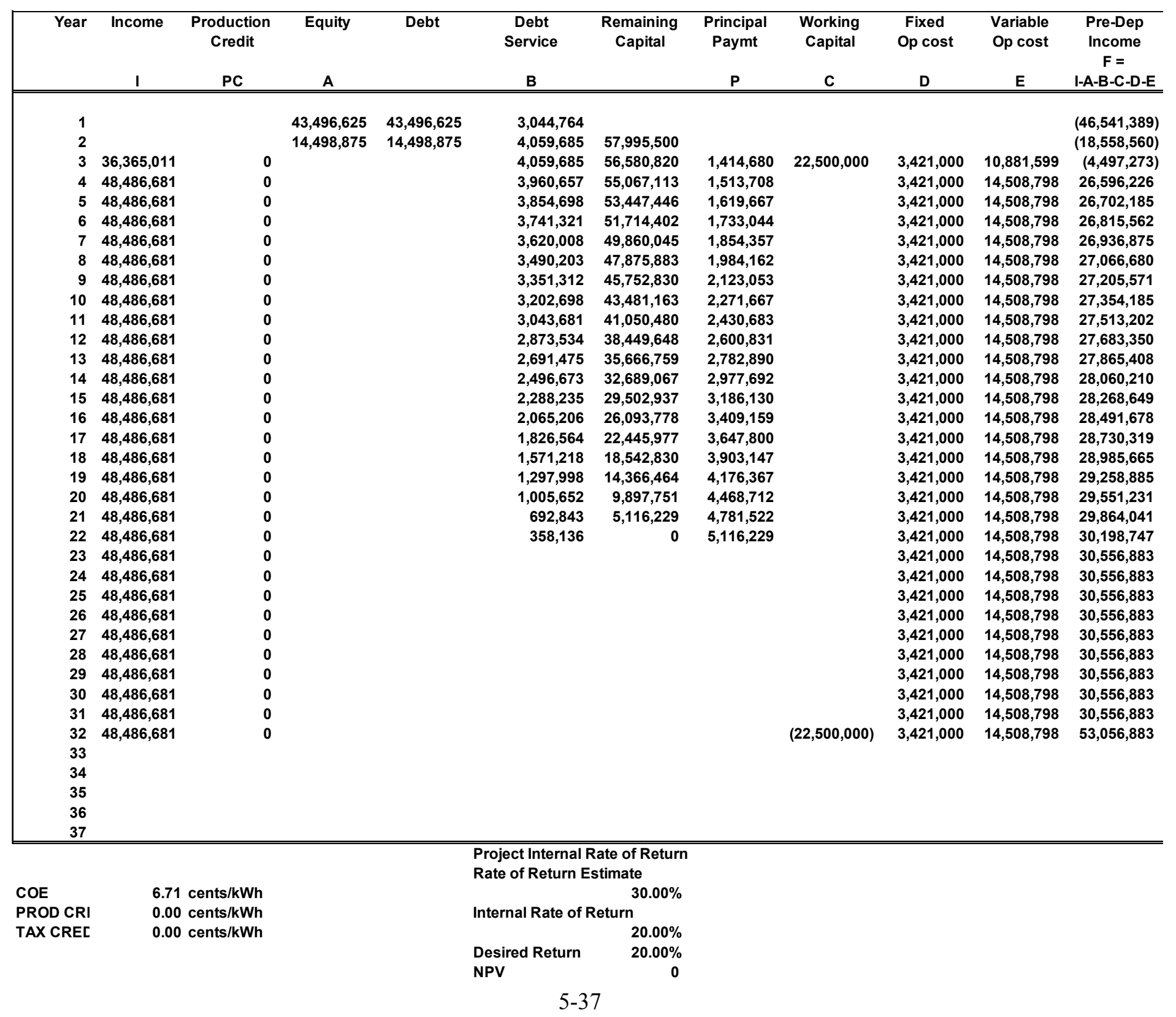


Table 5.14 (cont.)

\begin{tabular}{|c|c|c|c|c|c|c|c|}
\hline Deprec & $\begin{array}{c}\text { Pre-tax } \\
\text { Calculation } \\
\text { Income } \\
\text { F - G } \\
\end{array}$ & Tax & $\begin{array}{l}\text { Federal } \\
\text { Tax } \\
\text { Credit }\end{array}$ & $\begin{array}{l}\text { After-Tax } \\
\text { Income }\end{array}$ & $\begin{array}{l}\text { Corporate } \\
\text { Tax Credit }\end{array}$ & $\begin{array}{l}\text { Cash } \\
\text { Flow }\end{array}$ & $\begin{array}{c}\text { Cum } \\
\text { Cash Flow }\end{array}$ \\
\hline & $(46,541,389)$ & 0 & & $(46,541,389)$ & & $(46,541,389)$ & $(46,541,389)$ \\
\hline & $(18,558,560)$ & 0 & & $(18,558,560)$ & & $(18,558,560)$ & $(65,099,949)$ \\
\hline 0 & $(4,497,273)$ & 0 & 0 & $(4,497,273)$ & 0 & $(5,911,952)$ & $(71,011,901)$ \\
\hline $26,596,226$ & 0 & 0 & 0 & 0 & 0 & $25,082,518$ & $(45,929,383)$ \\
\hline $24,661,584$ & $2,040,602$ & 816,241 & 0 & $1,224,361$ & 0 & $24,266,278$ & $(21,663,105)$ \\
\hline $12,000,083$ & $14,815,479$ & $5,926,192$ & 0 & $8,889,288$ & 0 & $19,156,327$ & $(2,506,779)$ \\
\hline $8,936,902$ & $17,999,973$ & $7,199,989$ & 0 & $10,799,984$ & 0 & $17,882,529$ & $15,375,751$ \\
\hline $8,810,756$ & $18,255,924$ & $7,302,370$ & 0 & $10,953,555$ & 0 & $17,780,149$ & $33,155,899$ \\
\hline $8,709,640$ & $18,495,932$ & $7,398,373$ & 0 & $11,097,559$ & 0 & $17,684,146$ & $50,840,045$ \\
\hline $4,923,124$ & $22,431,061$ & $8,972,425$ & 0 & $13,458,637$ & 0 & $16,110,094$ & $66,950,139$ \\
\hline $1,229,147$ & $26,284,055$ & $10,513,622$ & 0 & $15,770,433$ & 0 & $14,568,896$ & $81,519,035$ \\
\hline $1,228,872$ & $26,454,478$ & $10,581,791$ & 0 & $15,872,687$ & 0 & $14,500,727$ & $96,019,762$ \\
\hline $1,229,147$ & $26,636,261$ & $10,654,504$ & & $15,981,756$ & & $14,428,014$ & $110,447,776$ \\
\hline $1,228,872$ & $26,831,339$ & $10,732,535$ & & $16,098,803$ & & $14,349,983$ & $124,797,759$ \\
\hline $1,229,147$ & $27,039,501$ & $10,815,801$ & & $16,223,701$ & & $14,266,718$ & $139,064,477$ \\
\hline $1,228,872$ & $27,262,806$ & $10,905,122$ & & $16,357,684$ & & $14,177,396$ & $153,241,873$ \\
\hline $1,229,147$ & $27,501,172$ & $11,000,469$ & & $16,500,703$ & & $14,082,050$ & $167,323,923$ \\
\hline $1,228,872$ & $27,756,793$ & $11,102,717$ & & $16,654,076$ & & $13,979,801$ & $181,303,724$ \\
\hline $1,229,147$ & $28,029,738$ & $11,211,895$ & & $16,817,843$ & & $13,870,623$ & $195,174,347$ \\
\hline $1,228,872$ & $28,322,359$ & $11,328,944$ & & $16,993,416$ & & $13,753,575$ & $208,927,922$ \\
\hline $1,229,147$ & $28,634,894$ & $11,453,957$ & & $17,180,936$ & & $13,628,561$ & $222,556,483$ \\
\hline $1,228,872$ & $28,969,876$ & $11,587,950$ & & $17,381,925$ & & $13,494,568$ & $236,051,051$ \\
\hline \multirow[t]{10}{*}{614,574} & $29,942,310$ & $11,976,924$ & & $17,965,386$ & & $18,579,959$ & $254,631,010$ \\
\hline & $30,556,883$ & $12,222,753$ & & $18,334,130$ & & $18,334,130$ & $272,965,140$ \\
\hline & $30,556,883$ & $12,222,753$ & & $18,334,130$ & & $18,334,130$ & $291,299,270$ \\
\hline & $30,556,883$ & $12,222,753$ & & $18,334,130$ & & $18,334,130$ & $309,633,400$ \\
\hline & $30,556,883$ & $12,222,753$ & & $18,334,130$ & & $18,334,130$ & $327,967,530$ \\
\hline & $30,556,883$ & $12,222,753$ & & $18,334,130$ & & $18,334,130$ & $346,301,660$ \\
\hline & $30,556,883$ & $12,222,753$ & & $18,334,130$ & & $18,334,130$ & $364,635,790$ \\
\hline & $30,556,883$ & $12,222,753$ & & $18,334,130$ & & $18,334,130$ & $382,969,920$ \\
\hline & $30,556,883$ & $12,222,753$ & & $18,334,130$ & & $18,334,130$ & $401,304,050$ \\
\hline & $53,056,883$ & $21,222,753$ & & $31,834,130$ & & $31,834,130$ & $433,138,180$ \\
\hline
\end{tabular}


Figure 5.10: Biomass CHP - Sensitivity to Feed Cost

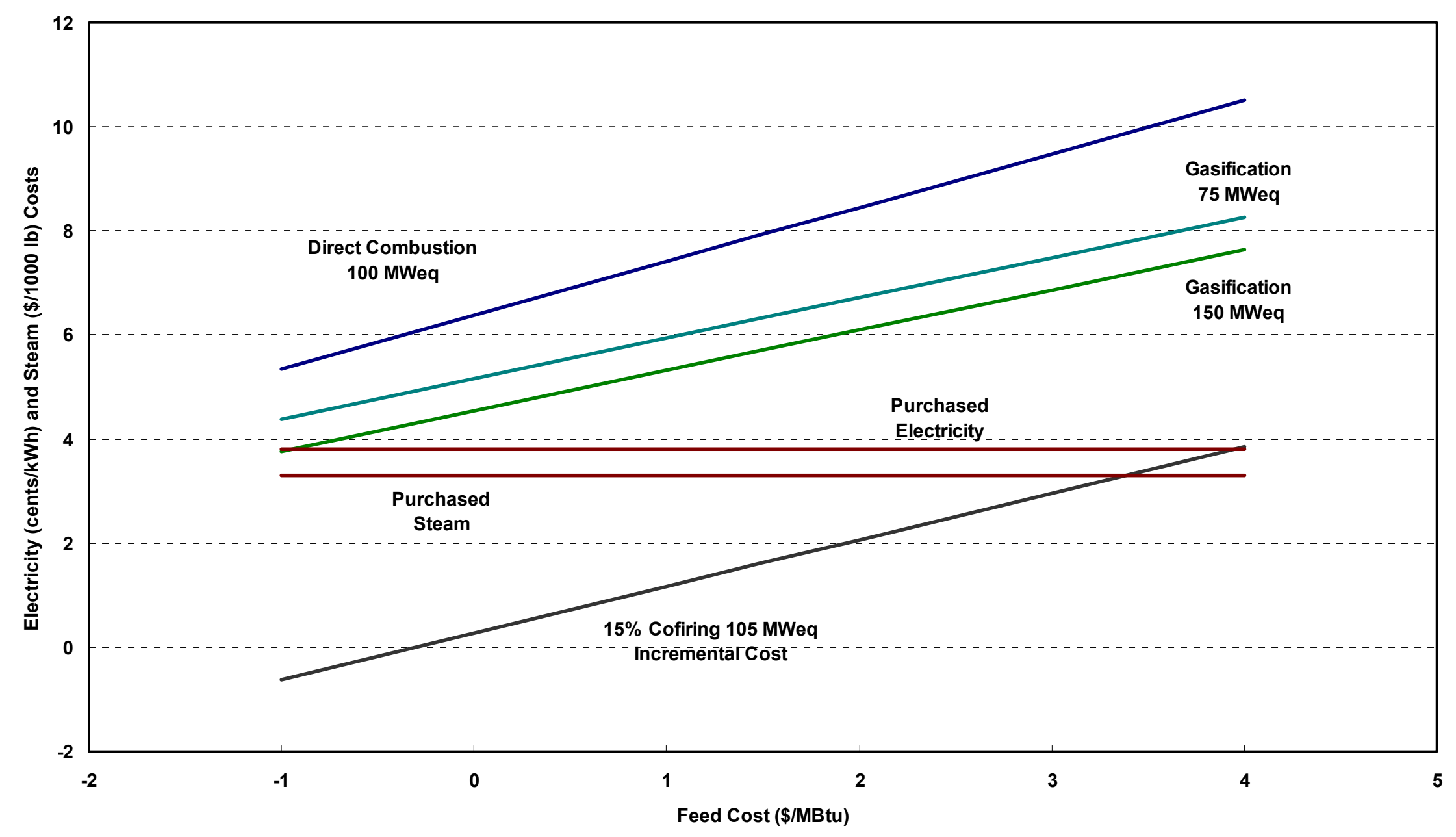


Figure 5.11: Biomass CHP - Effect of Plant Size on Cost of Electricity and Steam Feed Cost $=\$ 2 / \mathrm{MBtu}$

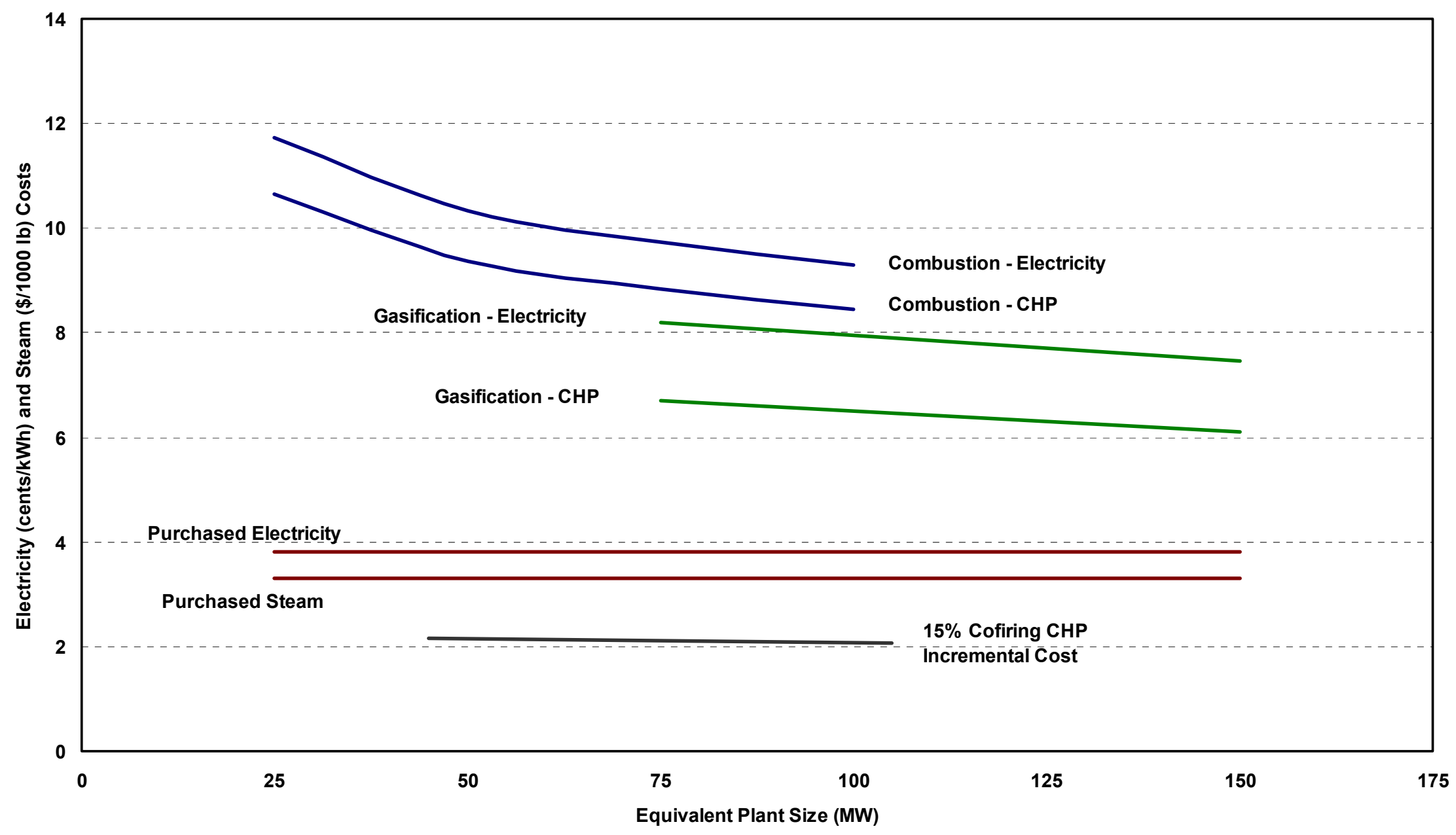


Figure 5.12: Biomass CHP - Sensitivity to Capital Cost

Feed Cost $=\$ 2 / \mathrm{MBtu}$

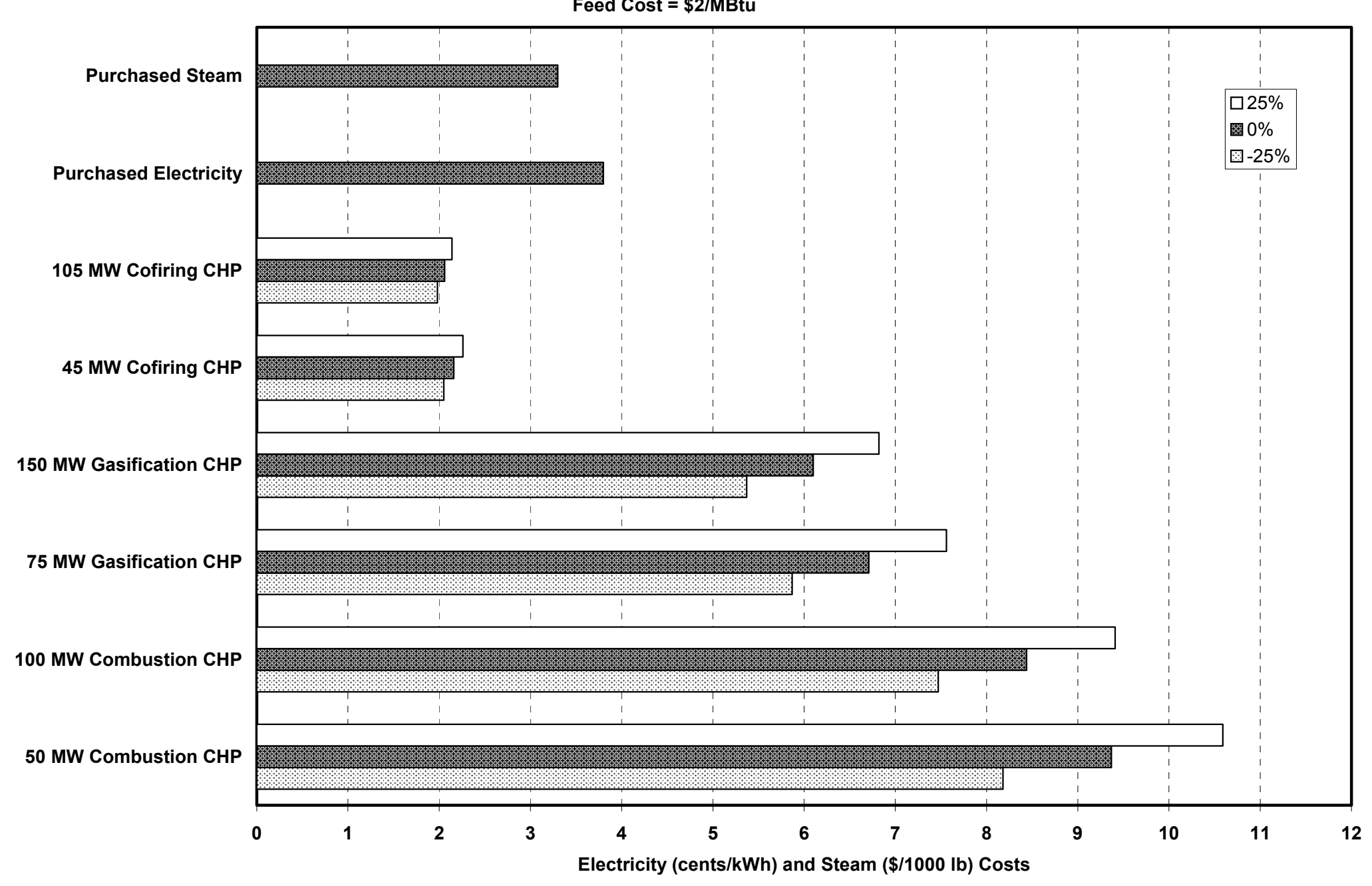


Figure 5.13: Biomass CHP - Sensitivity to Discount Rate

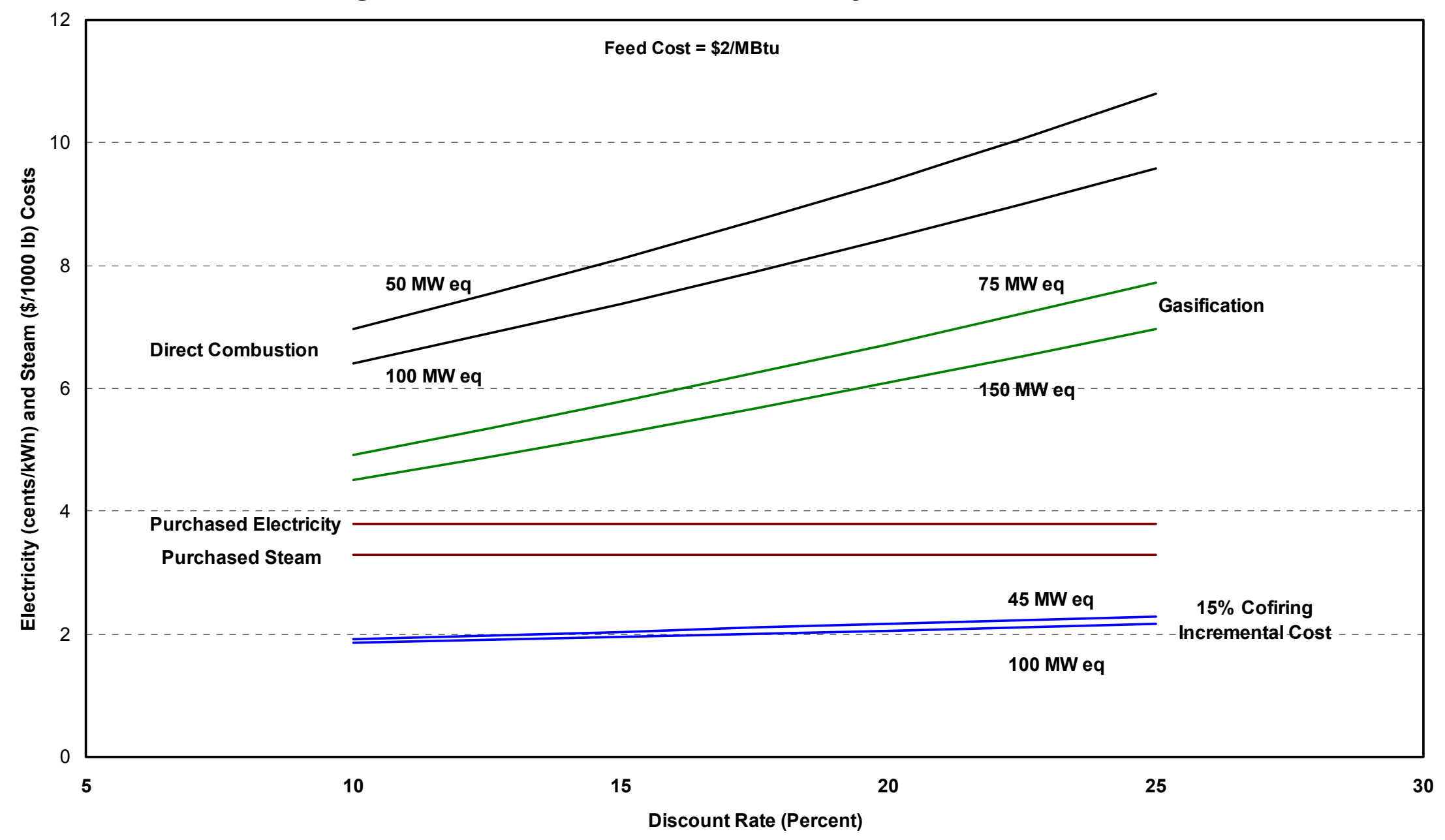




\section{Figure 5.14: Biomass CHP - Debt Sensitivity}

Feed Cost $=\$ 2 / \mathrm{MBtu}$

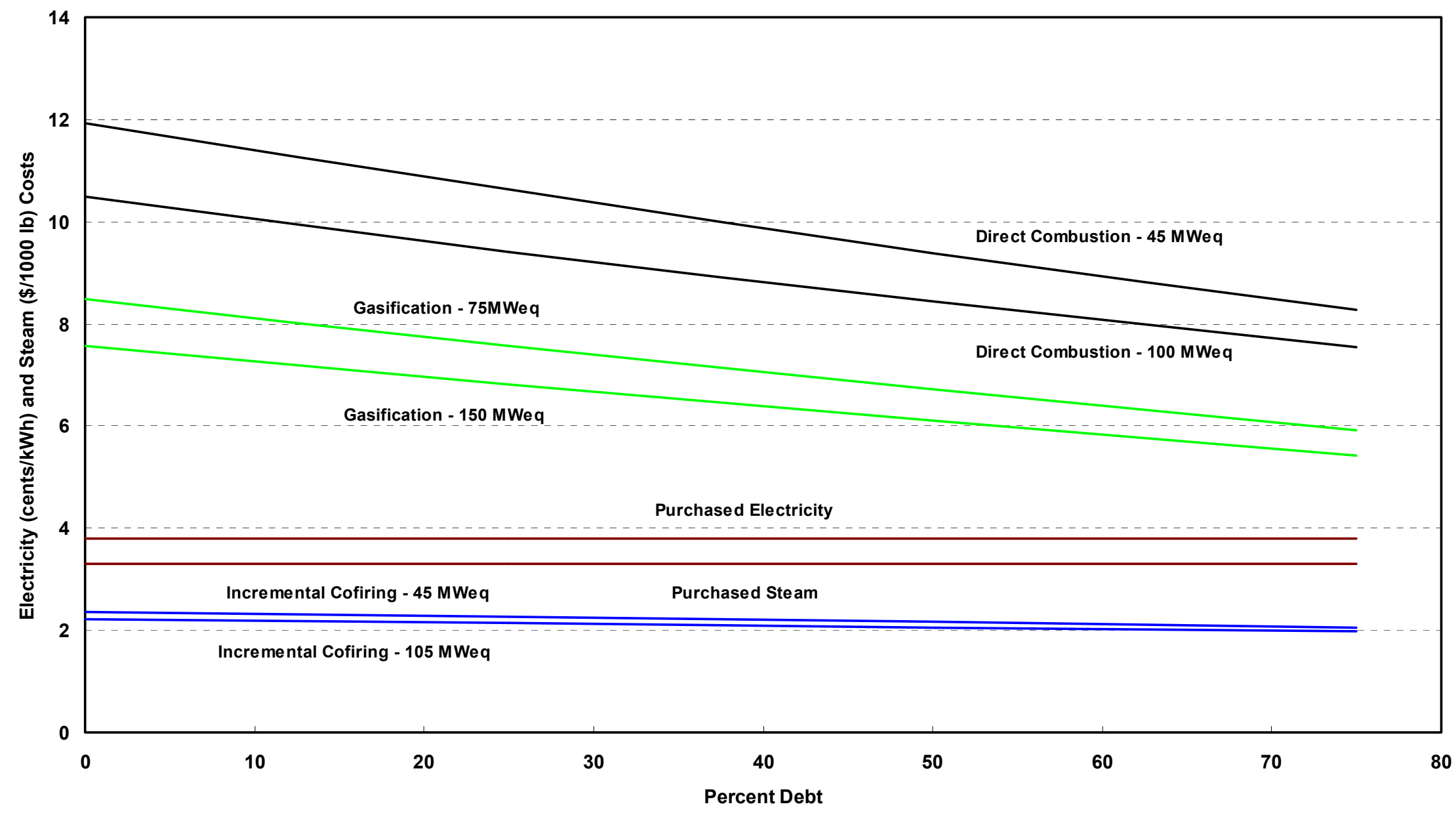


Figure 5.15: Biomass CHP - Impact of Carbon Allowances

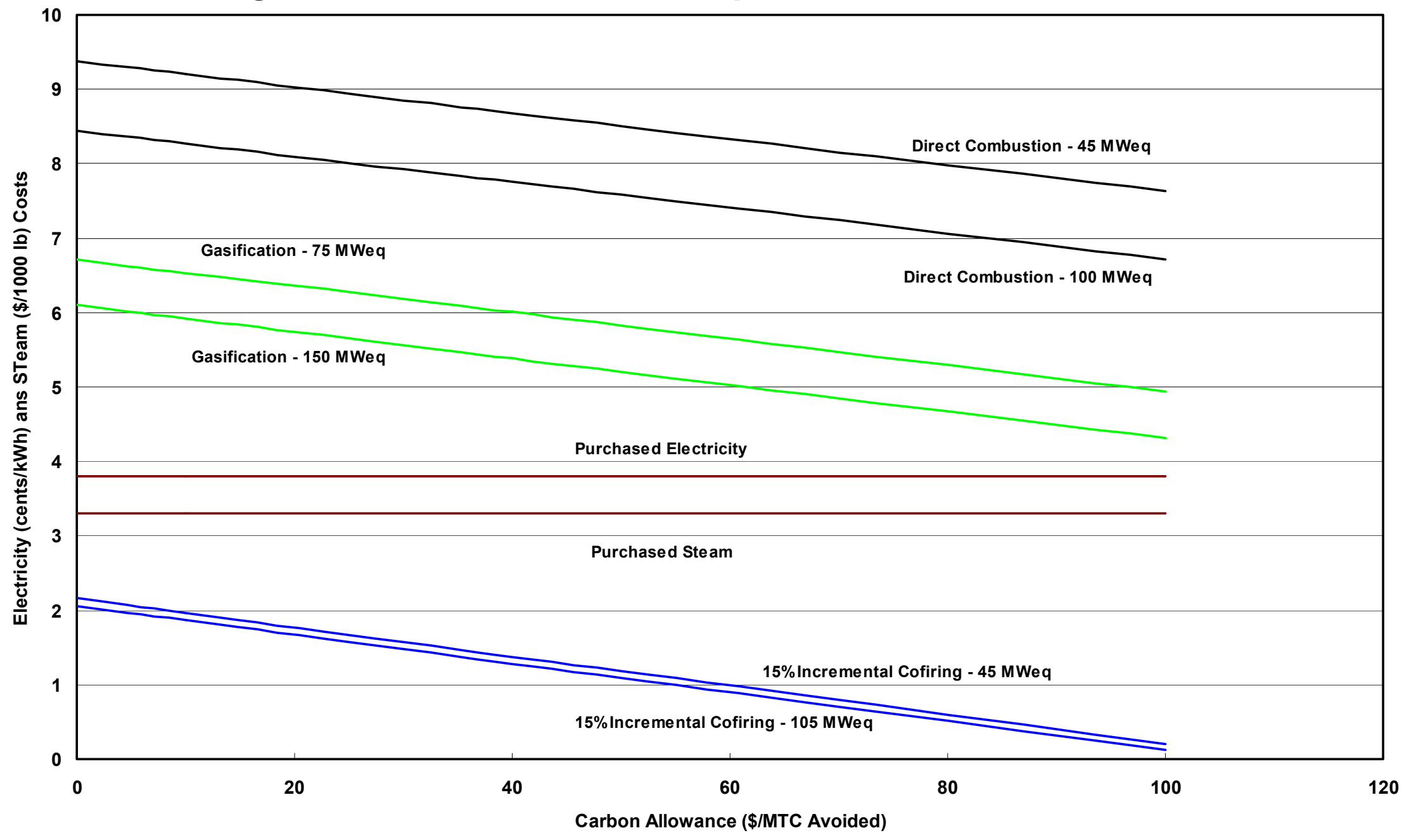


Figure 5.16: Biomass Combustion and Gasification CHP Impact of Tax Credit

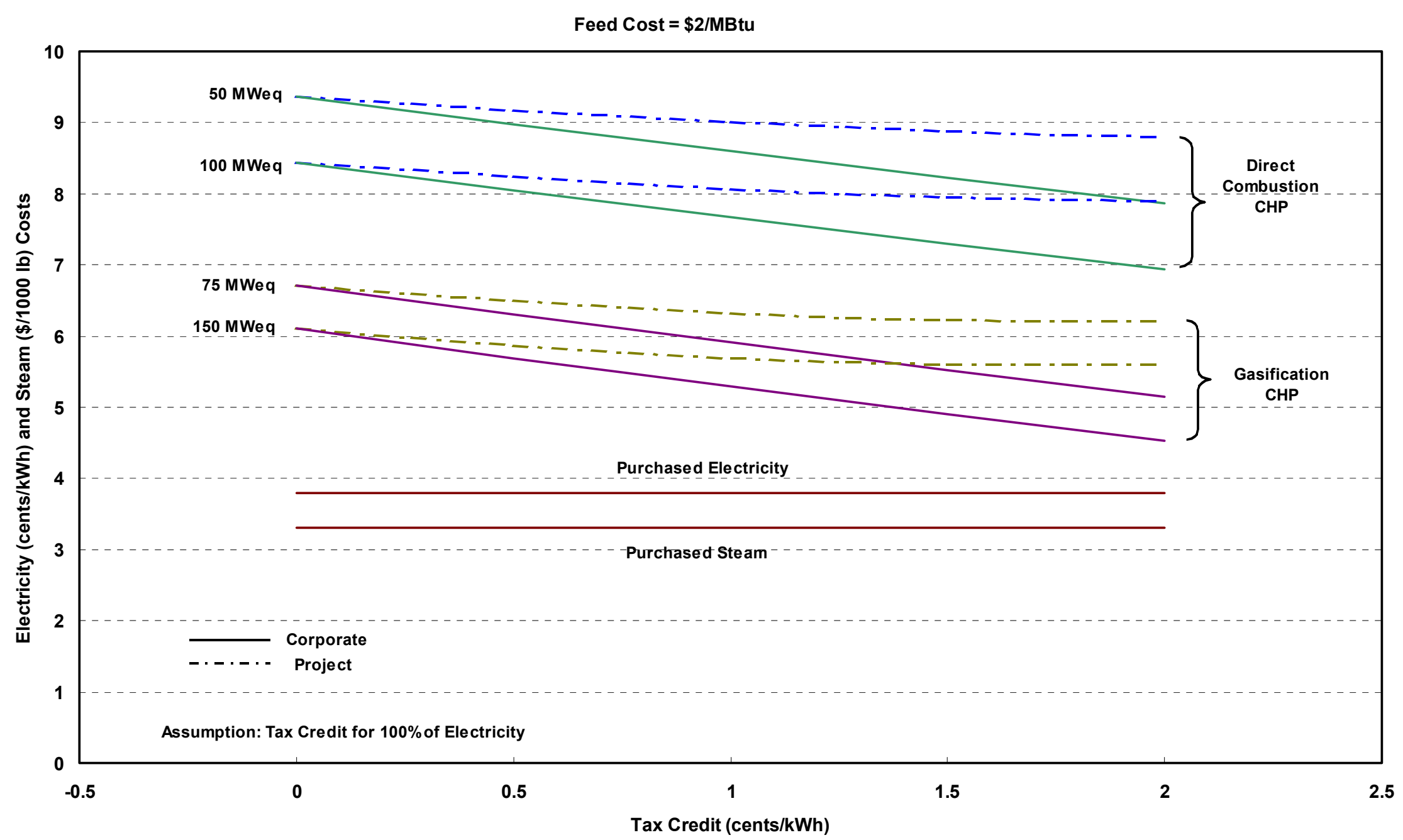


Figure 5.17: Biomass Cofiring CHP Incremental Costs, Impact of Tax Credit

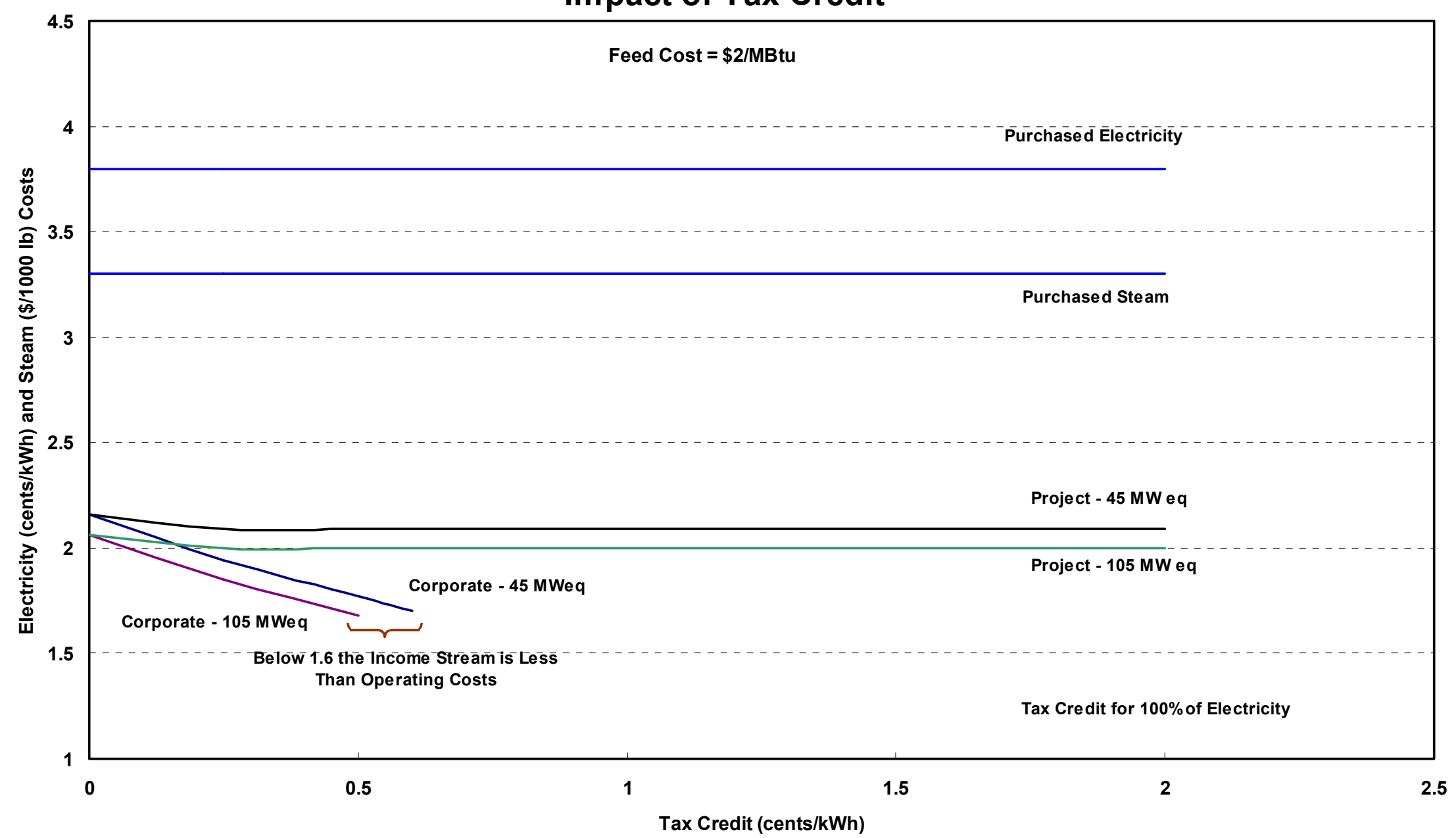


Figure 5.18: Biomass Cofiring CHP - Effect of Tax Credit on Return on Investment, Corporate Basis

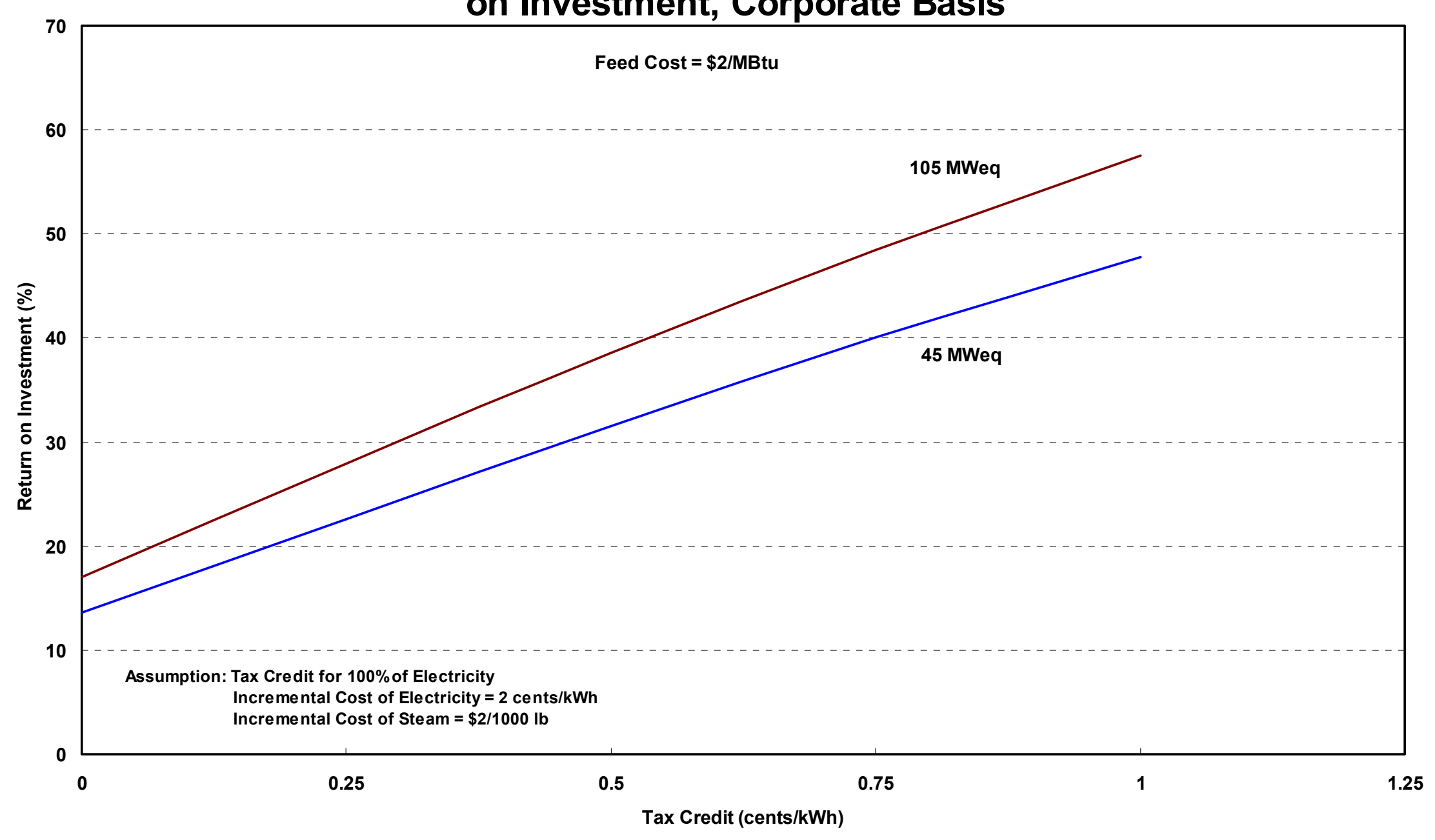


Figure 5.19: Comparison of CHP and Steam-Only Costs

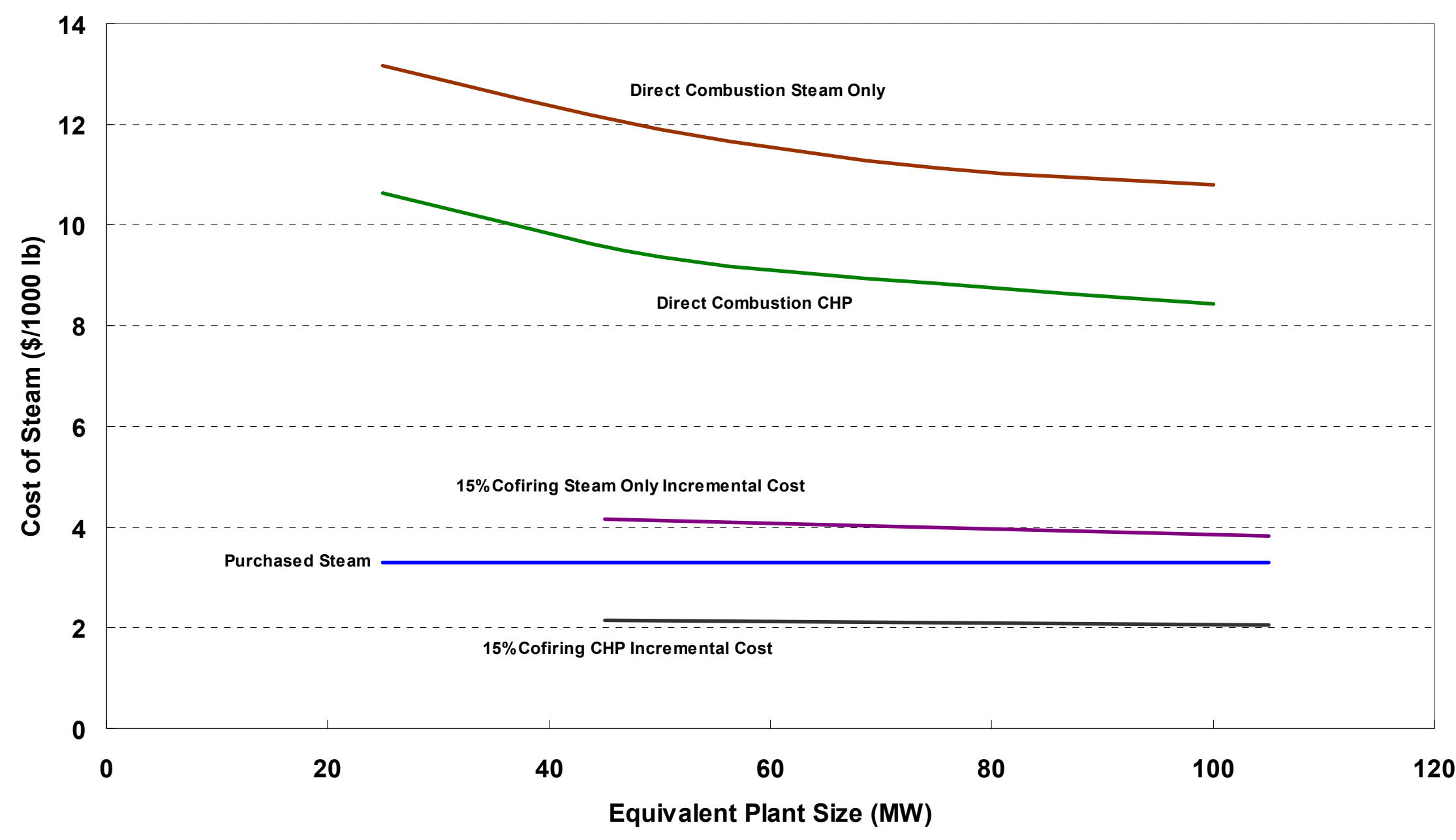


Figure 5.20: Gasification CHP - Site Impact with Incentives

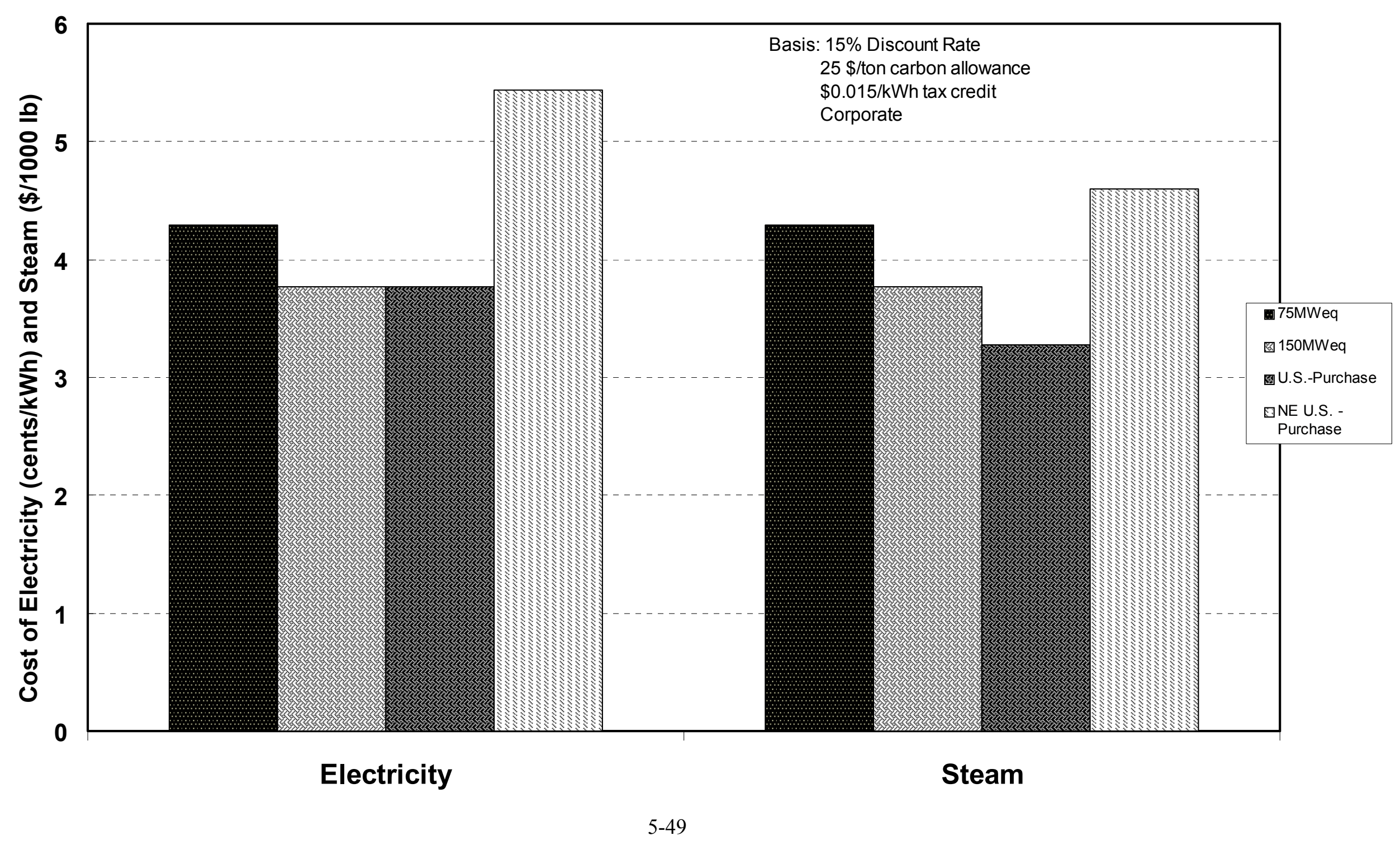


Table 5.15: Cost and Required Cash Flow Summary

\begin{tabular}{|c|c|c|c|c|c|}
\hline \multirow[t]{2}{*}{ CHP Case } & \multicolumn{2}{|c|}{ Capital Cost } & \multicolumn{2}{|c|}{ Operating Cost $\mathrm{C}^{(\mathrm{a})}$} & \multirow{2}{*}{$\begin{array}{c}\text { Cumulative } \\
\text { Required } \\
\text { Cash Flow } \\
\text { Million \$ }\end{array}$} \\
\hline & Million \$ & $\$ / \mathrm{kW}$ & Million $\$ / y r$ & $\phi / \mathrm{kWh}$ & \\
\hline Cofiring - $105 \mathrm{MW}$ & 16.4 & 156 & $(2.02)^{(b)}$ & $(0.23)^{(b)}$ & 72 \\
\hline Direct Combustion - $75 \mathrm{MW}$ & 131.0 & 1,747 & 10.22 & 1.73 & 479 \\
\hline Direct Combustion - $100 \mathrm{MW}$ & 160.5 & 1,605 & 13.49 & 1.71 & 593 \\
\hline IGCC - $75 \mathrm{MW}$ & 149.3 & 2,070 & 6.71 & 1.14 & 433 \\
\hline IGCC - $150 \mathrm{MW}$ & 196.7 & 1,312 & 11.75 & 0.99 & 767 \\
\hline
\end{tabular}
(a) incremental cost
(b)exclusive of feed 


\section{References}

(AEO97), Annual Energy Outlook 1997 (1996). Energy Information Agency, Department of Energy, Washington, D.C., DOE/EIA-0383(97).

Antares and Parsons (1996), Utility Coal-Biomass Cofiring Plant Opportunities and Conceptual Assessments, prepared by Antares Group Inc., Landover, MD and Parsons Power, Reading, PA, for the Northeast Regional Biomass Program and the U.S. Department of Energy.

Babcox and Wilcox (1992). Steam, 40th ed., Chapter 16: Atmospheric Pressure Fluidized-Bed Boilers, Babcock and Wilcox, Barberton, $\mathrm{OH}$.

Craig, K.R. and M.K. Mann, (1996). "Cost and Performance of Biomass-based Integrated Gaification Combined Cycle Systems, NREL Report No. TP-430-21657, January.

Ebasco (1993), Wood Fuel Cofiring at TVA Power Plants--Volume 1: Retrofitting Existing Boilers toCofire Wood Fuel, prepared by Ebasco Environmental for Electric Power Research Institute, Contract 3407-1, June 1993.

Energy Information Administration (EIA, 1996), Utility Annual Energy Outlook 1996 with Projections to 2015, DOE/EIA-0383(96), January 1996.

Energy Information Administration (EIA., 1996), Electric Power Annual 1995--Volume I, DOE/EA.0348(95), July 1996.

Energy Information Agency (EIA, 1999) www.eia.doe.gov/eneaf/electricity/IPP/html1/t17p01.html.

Electric Power Research Institute (1988), Guidelines for Cofiring Refuse-Derived Fuel in Electric Utility Boilers, Project 1861-1, June 1988.

Electric Power Research Institute. (June, 1993a). TAG - Technical Assessment Guide EPRI TR-102276-

V1R7 Volume 1: Rev. 7. Palo Alto, CA.

Electric Power Research Institute (1993b), Strategic Analysis of Biomass and Waste Fuels for Electric Power Generation, EPRI TR-102773, December 1993.

Electric Power Research Institute (1995), BIOPOWER: Biomass and Waste-Fired Power Plant Performance and Cost Model, EPRI TR-102774, March 1995.

Hansen, J.L. (1992). "Fluidized Bed Combustion of Biomass; an Overview," Biomass Combustion conference, Reno, Nevada, U.S. DOE Western Regional Biomass Energy Program, Jan 28-30.

Hollenbacher, R., (1992), Biomass Combustion Technologies in the United States, Biomass Combustion Conference, Reno, Nevada, sponsored by the Electric Power Research Institute, Palo Alto, California.

Hughes, E. And Tillman, D. (1996), Biomass Cofiring: Status and Prospects, Electric Power Research Institute \& Foster Wheeler Environmental Corp., November 1996.

Langr, Kenneth, A Comparison of Wood, Coal, and RDF Combustion Systems - Focus on N.S.P. Bay Front and French Island, presented at the Biomass Combustion Conference, Reno, Nevada, January 1992.

Marrison, C. I. and Larson E. D. (1995). "Cost Versus Scale for Advanced Plantation-Based Biomass Energy Systems in the U.S." U.S. EPA Symposium on Greenhouse Gas Emissions and Mitigation Research. June 27-29, 1995. Washington, D.C.

MacCallum, C. (1992). "Boiler Design Considerations with Respect to Biomass Ash Deposition," Biomass Combustion Conference, Reno, Nevada, U.S. DOE Western Regional Biomass Energy Program, Jan 28-30.

Marsahll and Swift Equipment Cost Index (1996), Chemical Engineering, July.

Perry, R.H. and C.H. Chilton (1973). Chemical Engineers' Handbook, Fifth Ed., McGraw-Hill Book Co, New York, New York.

Peters, M.S. and K.L. Timmerhaus (1980). Plant Design and Economics for Chemical Engineers, $3^{\text {rd }}$ Ed., McGraw-Hill Book Company, NY,NY, ISBN 0-07-049582-3.

Tampella Power (1992). "Circulating Fluid Bed Boilers (CFB)," USA - Finland Executive Seminar on Power Generation and the Environment, Orlando, Florida, Nov 16. 
Tillman, D., E. Stephens, E. Hughes, and B. Gold (1994). "Cofiring Biofuels Under Coal-Fired Boilers: Case Studies and Assessments," Bioenergy '94, Reno, Nevada, Hosted by the U.S. DOE Western Regional Biomass Energy Program, Oct 2-6.

U.S. House of Representatives, Clean Air Act Amendments of 1990, Report 101-952, October 1990.

U.S. Department of Energy, Electricity from Biomass: A Development Strategy, Office of Solar Energy Conversion, April 1992.

Valle-Riestra, J.F. (1983). Project Evaluation in the Chemical Products Industry, McGraw-HIll Book Company, NY,NY, ISBN 0-07-066840-X.

Westerberg, L. (1981). "Operation of a Flakt Drying System for Bark and Peat in an Existing Linerboard Mill," Fifth International Forest Products Research Society Industrial Wood Energy Forum 81, New Orleans

Weyerhauser et al. (June 1995). "New Bern Biomass to Energy Project, Phase 1 Feasibility Study." NREL/TP-421-7942. Golden, CO: National Renewable Energy Laboratory. Work performed by Weyerhauser, Inc.

Wiltsee, G.A. and E. E. Hughes (1995). "Biomass Energy: Cost of Crops and Power," EPRI Report TR102107, v2, Electric Power Research Institute, Palo Alto, CA.

Winslow, J.C.; Smouse, S.M.; Ekmann, J.M.; et. al., Cofiring of coal and waste, IEA Coal Research, London, IEACR/90, August 1996.

\section{Other Useful References (Not Cited)}

Bain. R. L. And R. P. Overend (1992). "Biomass Electric Technologies: Status and Future Development," in Advances in Solar Energy: An Annual Review of Research and Development, v 7, edited by K. W. Böer, Amercian Solar Energy Society, Boulder, CO.

Benjamin, Wallace (1996), Building Biomass into the Utility Fuel Mix at NYSEG: System Conversion and Testing Results for Greenidge Station, presented at The Seventh National Bioenergy Conference, Nashville, TN, September, 1996.

Craig, K. and Reed, M. (September, 1996). "Results and Implications of Eleven Site Specific Biomass Feasibility Studies,” BioEnergy '96, September 16-18, 1996. Nashville, TN.

Craig, K.R., Bain, R.L., Overend, R.P., (October 1995). "Biomass Power: Where Are We, Where Are We Going, and How Do We Get There? The Role of Gasification." Proceedings of EPRI Conference on New Power Generation Technology. San Francisco, CA.

C.T. Donovan Associates, Inc. (1995); Information obtained in private communication with Ed Neuhauser from Niagara Mohawk Power Corp. (NMPC). Study was performed for NMPC by C.T. Donovan Assoc., Inc.C.T. Donovan Associates, Inc. (1995); Information obtained in private communication with Ed Neuhauser from Niagara Mohawk Power Corp. (NMPC). Study was performed for NMPC by C.T. Donovan Assoc., Inc.

Dhargalkar, P.H. (1991), A Unique Approach to Municipal Waste Management in Chianti, Italy, presented at the Municipal Waste Combustion Conference sponsored by EPA and the Air and Waste Management Association, Tampa, Florida, April.

Easterly, James L. (1993), Overview of Biomass and Waste Fuel Resources for Power Production, Proceedings: Strategic Benefits of Biomass and Waste Fuels, EPRI TR-103146, December 1993.

Environmental Protection Agency (1991), The National Allowance DataBase Version 2.0 Technical Support Document, EPA/400/1-91/028, Office of Atmospheric and Indoor Air Pollution, June 1991.

Evans, R.J., R.A. Knight, M. Onishak, and S.P. Babu (1988), Development of Biomass Gasification to Produce Substitute Fuels, PNL-6518/UC-245, Chicago, Illinois, Institute of Gas Technology for Pacific Northwest Laboratory, Richland, Washington, May.

Feldmann, H.F., M.A. Paisley, H.R. Applebaum, and D.R. Tayler (1988), Conversion of Forest Residues to a Methane-Rich Gas in a High Throughput Gasifier, PNL-6570/UC-245, Columbus, Ohio, Battelle Columbus Laboratories for Pacific Northwest Laboratory, Richland, Washington, May. 
Flanigan, V.J., O.C. Sitton and W.E. Huang (1988), The Development of a 20-inch Indirect Fired Fluidized Bed Gasifier, PNL-6520/UC-245, Rolla, Missouri, University of Missouri at Rolla for Pacific Northwest Laboratory, Richland, Washington, March.

Gas Turbine World 1996 Handbook. (1996). Volume 17, Pequot Publishing Inc. Fairfield, CT.

Gilmore Sugar Manual, 1994/95 (1994). Sugar Publications, Fargo, ND

Hall, D.O., Rosillo-Calle, F., and de Groot, P. (January 1992). "Biomass Energy-Lessons from Case Studies in Developing Countries," Energy Policy, p 62-73.

Koljonen, J. (199), Peat, a Raw Material for Ammonia, presented at the International Fertilizer Industry Association Technical Conference, Venice, Italy.

Kurkela, E., P. Stäberg, P. Simell, J. Leppälahti (1989), Updraft Gasification of Peat and Biomass, Biomass, January, pp. 12-19.

Loeffler, J. and P.K. Herbert (1991), ACFB and PCFB Gasification of Biomass, Garbage and Coals for the Generation of Fuel, Synthesis Gas, and Electricity, distributed at the IEA Biomass Gasification Working Group meeting, Espoo, Finland, September 17-20.

Lundqvist, R. G. (1993). "The IGCC Demonstration Plant in Varnamo.” Bioresource Technology. Volume 46, No. 1\&2. pp 49-53.

Lyytinen, H. (1991), Biomass Gasification as a Fuel Supply for Lime Kilns; Description of Recent Installations, TAPPI Journal, July, pp. 77-80.

McGowan, F. (March 1991). "Controlling the Greenhouse Effect - the Role of Renewables," Energy Policy, p 111-118.

Meridian and Antares (1992), Economic Benefits of Biomass Power Production in the U.S., prepared by Meridian Corporation, Alexandria, Virginia, and Antares Inc., Edgewater, Maryland, for the National Renewable Energy Laboratory, Golden, Colorado.

Miles, T.R. et al. (1996), "Alkali Deposits Found in Biomass Power Plants. A Preliminary Investigation of Their Extent and Nature." NREL/TP-433-8142. February, 1996.

Moore, E.A. and G. Smith, (1990), Capital Expenditures for Electric Power in the Developing World, World Bank, New York, New York.

National Energy Strategy, 1st ed. - 1991/1992, U.S. Department of Energy, Washington, D.C.

Northern States Power et al. (May 1995). "Economic Development Through Biomass Systems Integration - Sustainable Biomass Energy Production.” NREL/TP-421-20517. Golden, CO. Work performed for the National Renewable Energy Laboratory and the Electric Power Research Institute by Northern States Power, Minneapolis, MN.

Olauson, L. (1991), Biomass Gasification at the Värö Pulp Mill, presented at the International Energy Agency (IEA) Biomass Gasification Working Group Meeting, Espoo, Finland, September 17-19.

Ostlie, L.D. (1993). "Whole Tree Energy ${ }^{\mathrm{TM}}$ Technology and Plot Test Program," Proceedings: Strategic Benefits of Biomass and Waste Fuels, Electric Power Research Institute, Palo Alto, CA, EPRI TR103146, December.

Overend, R.P. and K.R. Craig. December 1995. "Biomass Energy Resource Enhancement: The move to modern secondary energy forms." Proceedings of UNIDO Symposium on Development and Utilization of Biomass Energy Resources in Developing Countries. Vienna, Austria.

Piscitello, E.S., C.P. Demeter, ANTARES Group Inc., Biomass Cofiring Analysis Summary, May 1992. Pulp and Paper 1996 North American Fact Book (1995). Miller Freeman, San Francisco, CA, ISBN 1087930-421-9.

Raymond, D. (November, 1996). "A Window of Opportunity (Forest Products Industry). Proceedings of Advanced Turbine Systems - Annual Program Review. November 7-8, 1996. Washington, D.C.

Rural Electric Research (1992), Technical Assessment of Waste-to-Electric Energy Options--Final Report, Volume 1, Project 90-4, February 1992.

Saint John, G. (1996). "An Assessment of the Potential of Hawaii to Support the First Commercial Biomass Based IGCC, subcontact report, National Renewable Energy Laboratory, Golden, CO. 
Schiefelbein, G.F. (199), Testing of an Advanced Thermochemical Conversion Reactor System, PNL-

7245/UC-245, Columbia Maryland, Manufacturing and Technology Conversion International, Inc., for Pacific Northwest Laboratory, Richland, Washington, January.

Solar 2000, (1991), U.S. Department of Energy, Washington, D.C.

Stambler, I. November 1996. "Refinery IGCCs Producing Electric Power, Steam, High Value Products". Gas Turbine World. Vol. 26. No. 6. pp. 16-24.

Tewksbury, Cleyton, Design and Operation of a 50-MW Wood-Fueled Power Plant, Presented at Energy from Biomass and Wastes X, Institute of Gas Technology, 1987.

Tillman, David A. (1996), Cofiring Wood Waste in Utility Boilers: Results of Parametric Testing and Engineering Evaluations, 1996 Joint Power Generation Conference, Vol. 1, ASME, Foster Wheeler Environmental, 1996.

Turnure, J.T.; Winnet, S.; Shackleton, R.;Hohenstein, W.; (1995). "Biomass Electricity: Long-Run Economic Prospects and Climate Policy Implications". Second Biomass Conference of the Americas Proceedings; August 21-24, 1995, Portland, OR. NREL/CP-200-8098. Golden, CO: National Renewable Energy Laboratory; pp. 1418-1427.

Wiant, B.C., Bachovchin, D. M, and Alvin, M.A. August 1995. "Testing Status of the Biomass Gasification Hot Gas Cleanup Demonstration Program." Second Biomass Conference of the Americas Proceedings; August 21-24, 1995, Portland, OR. NREL/CP-200-8098. Golden, CO: National Renewable Energy Laboratory.

Wiltsee, G., Korens, N., Wilhelm, D. (May 1996). "BIOPOWER: Biomass and Waste-Fired Power Plant Performance and Cost Model.” Electric Power Research Institute. EPRI TR-102774 Version 1.01. Palo Alto, CA.

Wiltsee, G.A. (1993). "Strategic Analysis of Biomass and Waste Fuels for Electric Power Generation," Electric Power Research Institute, Palo Alto, CA, TR-102773. 


\section{ENVIRONMENTAL PERFORMANCE}

Two primary issues that could create a tremendous opportunity for biomass are global warming and the implementation of Phase II of Title IV of the Clean Air Act Amendments of 1990 (CAAA). Biomass offers the benefit of reducing $\mathrm{NO}_{x}, \mathrm{SO}_{2}$, and $\mathrm{CO}_{2}$ emissions. The environmental benefits of biomass technologies are among its greatest assets. Global warming is gaining greater salience in the scientific community. There now appears to be a consensus among the world's leading environmental scientists and informed individuals in the energy and environmental communities that there is a discernable human influence on the climate, and that there is a link between the concentration of carbon dioxide (i.e., greenhouse gases) and the increase in global temperatures. Biomass use can play an essential role in reducing greenhouse gases, thus reducing the impact on the atmosphere. Cofiring biomass and fossil fuels and using integrated biomass gasification combined cycle systems can be an effective strategy for electric utilities to reduce their emissions of greenhouse gases.

The use of biomass crops also has the potential to mitigate water pollution. Since many dedicated crops under consideration are perennial, soil disturbance, and thus erosion can be substantially reduced. The need for agricultural chemicals is often lower for dedicated energy crops as well leading to lower stream and river pollution by agrichemical run-off.

\section{Air Pollution}

Biomass power has long been a source of heat and power in the United States and throughout the world. and is unique among renewables because it is a combustion technology that releases air pollutants. This environmental overview reviews air emissions from traditional biomass (wood and agriculture residues) and landfill methane biomass projects, and compares those emissions with conventional fossil-fuel generating plants. Greenhouse gas emissions will be discussed in the life cycle analysis section.

Major emissions of concern from traditional biomass power plants are particulate matter (PM), carbon monoxide $(\mathrm{CO})$, volatile organic compounds $(\mathrm{VOC})$, and nitrogen oxides $\left(\mathrm{NO}_{\mathrm{x}}\right)$. Biomass releases very little sulfur dioxide because of the low amount of sulfur typically found in biomass. Actual amounts and the type of air emissions depend on several factors, including the type of biomass combusted, the furnace design, and operating conditions.

For larger biomass projects, two types of boilers are commonly used. One boiler type is the spreader stoker. Biomass enters the furnace through a fuel chute and is distributed either pneumatically or mechanically across the furnace, where the biomass burns in suspension. At the same time, larger pieces of biomass are spread on a stationary or moving grate and combusted. A second boiler type used is the fluidized bed combustion (FBC) boiler. The fluidized bed is comprised of inert particles through which air is blown so that the fluidized bed behaves as a fluid. The biomass is combusted faster and more completely because of the immediate contact with the hot bed material, and uncontrolled air emissions are correspondingly lower.

Table 6.1 compares air emissions from biomass facilities, using different feedstocks and boilers, with representative coal and natural gas systems. The table illustrates that biomass FBC boilers, as presently permitted, have lower emissions than biomass systems with stoker boilers. Biomass systems using stoker 
boilers emit less $\mathrm{SO}_{2}$ than coal and natural gas units (except for natural gas combined cycle units, which are characterized by extremely low $\mathrm{SO}_{2}$ emissions), and less $\mathrm{NO}_{\mathrm{x}}$ than stoker boilers combusting coal and reciprocating engines burning natural gas. Biomass systems with $\mathrm{FBC}$ boilers are even cleaner, with lower $\mathrm{SO}_{2}$ and $\mathrm{NO}_{\mathrm{x}}$ emissions than coal and natural gas combustion turbines and lower PM-10 emissions than coal systems. When comparing emissions, it is very important to understand that all the power systems reported-both fossil and biomass-meet the air emission standards governing permitting and operation that were in effect when the facilities were constructed, and represent not only differences in fuel, but also differences in emission control systems. Future systems will meet the emissions standards in place at the time of permitting, and choices of system and fuel will largely be governed by costs associated with meeting those standards.

Table 6.1 Direct Air Emissions from Wood Residue Facilities by Boiler Type

\begin{tabular}{|c|c|c|c|c|c|}
\hline & $\mathrm{so}_{\mathrm{x}}$ & $\mathrm{NO}_{\mathrm{X}}$ & CO & $\mathrm{PM}-10^{1}$ & Comments \\
\hline \multicolumn{6}{|c|}{ Biomass Technology } \\
\hline \begin{tabular}{l|} 
Stoker Boiler, \\
Wood Residues $(1,4)$
\end{tabular} & 0.08 & $\begin{array}{c}2.1 \\
\text { (biomass type } \\
\text { not specified) }\end{array}$ & $\begin{array}{c}12.2 \\
\text { (biomass type } \\
\text { not specified) }\end{array}$ & $\begin{array}{c}0.50 \\
\text { (total particulates) } \\
\text { (biomass type } \\
\text { not specified) }\end{array}$ & $\begin{array}{l}\text { Based on } 23 \text { California grate } \\
\text { boilers, except for } \mathrm{SO}_{2} \\
\text { (uncontrolled) }\end{array}$ \\
\hline $\begin{array}{l}\text { Fluidized Bed, } \\
\text { Biomass (4) }\end{array}$ & $\begin{array}{c}0.08 \\
\text { (biomass type } \\
\text { not specified) }\end{array}$ & $\begin{array}{c}0.9 \\
\text { (biomass type } \\
\text { not specified) }\end{array}$ & $\begin{array}{c}0.17 \\
\text { (biomass type } \\
\text { not specified) }\end{array}$ & $\begin{array}{c}0.3 \\
\text { (total particulates) } \\
\text { (biomass type } \\
\text { not specified) }\end{array}$ & $11 \mathrm{FBC}$ boilers in California \\
\hline $\begin{array}{l}\text { Energy Crops } \\
\text { (Poplar) } \\
\text { Gasification } \\
(a, b)\end{array}$ & \begin{tabular}{|c|}
0.05 \\
(suggested value \\
based on SOx numbers \\
for Stoker and FBC, \\
adjusted by a factor of \\
$9,180 / 13,800$ to account \\
for heat rate \\
improvement)
\end{tabular} & $\begin{array}{c}1.10 \text { to } 2.2 \\
(0.66 \text { to } 1.32 \mathrm{w} / \mathrm{SNCR} ; \\
0.22 \text { to } 0.44 \mathrm{w} \text { ith SCR })\end{array}$ & 0.23 & $\begin{array}{c}0.01 \\
\text { (total } \\
\text { particulates) }\end{array}$ & $\begin{array}{c}\text { Combustor flue gas goes } \\
\text { through cyclone and } \\
\text { baghouse. Syngas goes } \\
\text { through scrubber and } \\
\text { baghouse before gas turbine. } \\
\text { No controls on gas turbine. }\end{array}$ \\
\hline \multicolumn{6}{|l|}{ Coal Technology } \\
\hline \begin{tabular}{l|} 
Bituminous Coal, \\
Stoker Boiler (f)
\end{tabular} & $\begin{array}{c}20.2 \\
1 \mathrm{wt} \% \mathrm{~S} \text { coal }\end{array}$ & 5.8 & 2.7 & 0.62 & $\begin{array}{l}\text { PM Control only } \\
\text { (baghouse) }\end{array}$ \\
\hline $\begin{array}{l}\text { Pulverized Coal } \\
\text { Boiler (d) }\end{array}$ & 14.3 & 6.89 & 0.35 & $\begin{array}{c}0.32 \\
\text { (total particulates) }\end{array}$ & $\begin{array}{l}\text { Average US PC boiler } \\
\text { (typically:baghouse, } \\
\text { limestone FGC) }\end{array}$ \\
\hline $\begin{array}{l}\text { Cofiring 15\% Biomass } \\
\text { (d2) }\end{array}$ & 12.2 & 6.17 & 0.35 & $\begin{array}{l}0.32 \text { (total } \\
\text { particulates) }\end{array}$ & $?$ \\
\hline $\begin{array}{l}\text { Fluidized Bed, } \\
\text { Coal }(f)\end{array}$ & $\begin{array}{c}3.7(1 \mathrm{wt} \% \mathrm{~S} \text { coal } \\
\mathrm{Ca} / \mathrm{S}=2.5)\end{array}$ & 2.7 & 9.6 & 0.30 & $\begin{array}{l}\text { Baghouse for PM Control, } \mathrm{Ca} \\
\text { sorbents used for } \mathrm{SO}_{x}\end{array}$ \\
\hline \multicolumn{6}{|c|}{ Natural Gas Technology } \\
\hline $\begin{array}{l}\text { 4-Stroke NG } \\
\text { Reciprocating } \\
\text { Engine }(\mathrm{g})\end{array}$ & 0.006 & $\begin{array}{c}7.96-38.3 \\
\text { (depends on load } \\
\text { and air:fuel ratio) }\end{array}$ & $\begin{array}{c}2.98-35.0 \\
\text { (depends on load } \\
\text { and air:fuel ratio) }\end{array}$ & $\begin{array}{c}0.09-0.18 \\
\text { (depends on load } \\
\text { and air:fuel ratio) }\end{array}$ & $\begin{array}{l}\text { No control except } \\
\text { PCC at high-end of } \\
\text { PM-10 range }\end{array}$ \\
\hline $\begin{array}{l}\text { Natural Gas } \\
\text { Turbine (e) }\end{array}$ & $\begin{array}{c}0.009 \\
(0.0007 \mathrm{wt} \% \mathrm{~S})\end{array}$ & 1.72 & 0.4 & $\begin{array}{c}.09 \\
\text { (total particulates) }\end{array}$ & $\begin{array}{l}\text { Water-steam } \\
\text { injection only }\end{array}$ \\
\hline $\begin{array}{l}\text { Natural Gas } \\
\text { Combined Cycle }(c, e)\end{array}$ & 0.004 & $\begin{array}{c}0.91 \\
(0.21 \mathrm{w} / \mathrm{SCR})\end{array}$ & 0.06 & $\begin{array}{c}0.14 \\
\text { (total particulates) }\end{array}$ & $\begin{array}{l}\text { Water-steam } \\
\text { injection only }\end{array}$ \\
\hline
\end{tabular}

Sources:

a. Spath and Mann (2000), "A Summary of Life Cycle Assessment Studies Conducted on Biomass, Coal, and Natural Gas Systems." NREL

b. Spath and Mann (1997), "Life Cycle Assessment of a Biomass Gasification Combined-Cycle System." NREL.

c. Spath and Mann (2000), "Life Cycle Assessment of a Natural Gas Combined-Cycle Power Generation System."

NREL.

d. Spath, Mann, and Kerr (1999), "Life Cycle Assessment of Coal-Fired Power Production." NREL.

d2. Mann???!5\% wood residue on a heat basis (on Exh3 cofire sheet)

e. AP-42 Chapter 3.1

f. AP-42 Chapter 1.1

g. AP-42 Chapter 3.2

$1 \& 4$ from References

Notes: ${ }^{1} \mathrm{PM} 10$ emission factors are not always available. Total particulates are specified in some cases (includes PM larger than 10 microns). Condensible PM is included in the direct emissions factors for Bituminous Coal Stoker Boiler, Fluidized Bed Coal Boiler, NG Reciprocating Engine, and the NG Turbine. In general, all particulates from 
Additional emissions data for wood combustion systems from the Environmental Protection Agency, $5^{\text {th }}$ Edition of AP-42, Compilation of Air Pollution Emission Factors are given in Appendix 4.

Table 6.2 presents averaged permitted and actual emission levels from 34 operating wood-fired generating plants in California. Of these, 23 are spreader stoker facilities and 11 are FBCs. These facilities were built prior to the new emissions standards. New facilities are subject to the new and much stricter Clean Air Act emissions standards. Air emission standards for the most recently constructed stand-alone biomass plant in the New England region, Pine Tree Power in Westminster, Massachusetts, are included for comparison. This facility was permitted to burn clean construction/demolition wood and has the most restrictive permit conditions of any wood-fired power plant in New England. The facility can meet these requirements using a high-efficiency fluidized bed boiler (low CO and VOC emissions), an SNCR system for NOx reduction, and a mechanical collector and baghouse for particulate control. No $\mathrm{SO}_{2}$ controls are required.

Table 6.2 Air Pollutant Emissions Limits for Biomass Power Plants (Ib/MWh)

\begin{tabular}{|c|c|c|c|c|c|c|c|c|c|}
\hline & \multirow{2}{*}{$\begin{array}{l}\text { Boiler } \\
\text { Type }\end{array}$} & \multicolumn{2}{|c|}{$\mathrm{SO}_{2}$} & \multicolumn{2}{|c|}{ NOx } & \multicolumn{2}{|c|}{$\mathrm{CO}$} & \multicolumn{2}{|c|}{ PM } \\
\hline & & Permitted & Measured & Permitted & Measured & Permitted & Measured & Permitted & Measured \\
\hline \multirow{3}{*}{$\begin{array}{l}\text { Existing California } \\
\text { Biomass Facilities }^{1}\end{array}$} & All & 1.0 & 0.08 & 2.2 & 1.7 & 9.6 & 8.6 & 0.7 & 0.4 \\
\hline & Stokers & 0.8 & 0.08 & 2.6 & 2.1 & 13.6 & 12.2 & 0.8 & 0.5 \\
\hline & FBCs & 1.4 & 0.08 & 1.3 & 0.8 & 1.7 & 0.2 & 0.5 & 0.3 \\
\hline $\begin{array}{c}\text { New } \\
\text { Massachussetts } \\
\text { Biomass Facility }^{2}\end{array}$ & FBC & $\begin{array}{c}0.78 \\
\text { (BACT) }\end{array}$ & $\mathrm{N} / \mathrm{A}$ & $\begin{array}{c}0.74 \\
\text { (LAER) }\end{array}$ & $\mathrm{N} / \mathrm{A}$ & $\begin{array}{c}0.88 \\
\text { (BACT) }\end{array}$ & $\mathrm{N} / \mathrm{A}$ & $\begin{array}{c}0.20 \\
\text { (BACT) }\end{array}$ & N/A \\
\hline
\end{tabular}

${ }^{1}$ [4air] Data averaged for 34 California biomass facilities (23 stokers and 11 FBCs). Based on a heating value for biomass of 8,293 BTU/lb, and an average heat rate of $13,800 \mathrm{BTU} / \mathrm{kWh}$.

2[2air]Permitted emissions levels for new Pine Tree Biomass Pow er Plant in Westminster, MA. BACT=Best Available Control Technology; LAER=Low est Achievable Emissions Rate

A number of states-including Texas, California, and Connecticut-have enacted or are considering type certification standards for distributed generation units less than $50 \mathrm{MW}_{\mathrm{e}}$ to ensure that emissions from small electric generating units to do not exceed BACT standards for central generating stations, and to simplify and reduce the time and cost of permitting such units. The majority of existing biopower plants would be covered by such standards if permitted today.

The Texas air quality standard became effective in 2001 for distributed generation units less than $50 \mathrm{MW}_{\mathrm{e}}$ installed or permitted after June 1,2001, to provide a streamlined permitting method to encourage the use of clean electric generating units. The standard provides a certification method for emissions based on test results from EPA reference methods, California Air Resources Board methods, or equivalent testing to verify certification, and requires re-certification of the unit after 16,000 hours, or three years, of operation. The standard only requires certification of $\mathrm{NO}_{\mathrm{x}}$ under the decision that $\mathrm{CO}$ and $\mathrm{VOC}$ emissions will be controlled if the $\mathrm{NO}_{\mathrm{x}}$ limits are reached. To control $\mathrm{SO}_{\mathrm{x}}$, only gases containing less than 10 grains total sulfur per 100 standard cubic feet are allowed. Systems are required to display the certification on the unit, much like an automobile emissions sticker. Certification permit costs are $\$ 450$ for units larger than $1 \mathrm{MW}_{\mathrm{e}}$, and $\$ 100$ for units smaller than $1 \mathrm{MW}_{\mathrm{e}}$. Units that use combined heat and power may take credit for heat at a rate of $1 \mathrm{MWh}$ for each 3.4 million Btu if the heat recovered is greater than $20 \%$ of the total CHP output. Emissions have been established for ozone attainment (West Texas) and non- 
attainment (East Texas) areas, for units larger and smaller than $10 \mathrm{MW}_{\mathrm{e}}$, for units that operate less than 300 hours per year, and for certain gases that would otherwise be vented to the atmosphere. A summary of emission limits are given in Table 6.3.

Table 6.3: Texas Distributed Generation Certification Standards

\begin{tabular}{|lllll|}
\hline Size & Area & $>300$ hours per year & $<300$ hours per year & $\begin{array}{l}\text { Landfill gas, digester } \\
\text { gas }\end{array}$ \\
$>10 \mathrm{MW}$ & All & $0.14 \mathrm{lb} \mathrm{NO}_{\mathrm{x}} / \mathrm{MWh}$ & $0.38 \mathrm{lb} \mathrm{NO}_{\mathrm{x}} / \mathrm{MWh}$ & $\left.1.77 \mathrm{lb} \mathrm{NO} / \mathrm{MWh}^{\mathrm{a}}\right)$ \\
$<10 \mathrm{MW}$ & East Texas & $0.44 \mathrm{lb} \mathrm{NO}_{\mathrm{x}} / \mathrm{MWh}(\mathrm{b})$ & \\
& & $0.14 \mathrm{lb} \mathrm{NO}_{\mathrm{x}} / \mathrm{MWh}(\mathrm{c})$ & \\
$<10 \mathrm{MW}$ & West Texas & $1.6 \mathrm{lb} \mathrm{NO} / \mathrm{MWh}$ & $21 \mathrm{lb} \mathrm{NO}_{\mathrm{x}} / \mathrm{MWh}$ & \\
\hline
\end{tabular}

(a) must contain less than 1.5 grains of $\mathrm{H}_{2} \mathrm{~S}$ or 30 grains of total sulfur

(b) prior to December 31, 2004

(c) after January 1, 2005

California has issued a draft standard, to become effective January 1, 2003, for any distributed generation system sold, leased, or offered for sale or lease, for use or operation in the State of California. CHP units may take credit for heat recovery if the unit achieves a minimum efficiency of 60 percent (useful energy out/fuel in). Unit emissions must be certified by California Air Resources Board reference methods; and the certification fee is $\$ 500$ (60 day processing period). Units must meet the emission standards for 15,000 hours of operation when operated and maintained according to the manufacturer's instructions; and must be re-certified every 4 years. A summary of the proposed standard is given in Table 6.4.

Table 6.4: Proposed California Distributed Generation Certification Standards.

\begin{tabular}{|lccc|}
\hline Pollutant & & Emission Standard (lb/MWh) & \\
& Power Only & CHP & All Units \\
$\mathrm{NO}_{\mathrm{x}}$ & Jan 2003 - Dec 2006 & Jan 2003 - Dec 2006 & After Jan 1, 2007 \\
$\mathrm{CO}$ & 0.5 & 0.7 & 0.05 \\
VOCs & 6.0 & 6.0 & 0.08 \\
\hline
\end{tabular}

To evaluate the potential of biopower systems, a simple analysis has been performed to compare existing and potential biopower system performance relative to the proposed standards. $\mathrm{NO}_{\mathrm{x}}$ emissions for existing systems are given in Figure $6.1^{1}$ on both a life cycle and point-source plant emission basis. A national average coal station has $\mathrm{NO}_{\mathrm{x}}$ emissions of about $6.75 \mathrm{lb} \mathrm{NO} / \mathrm{MWh}$, a NSPS coal plant emits

${ }^{1}$ Mann, M.K.; Spath, P.L. (2001). Comparison of Environmental Consequences of Power from Biomass, Coal and Natural Gas. Kyritsis, S., et al., eds. ${ }^{\text {st }}$ World Conference on Biomass for Energy and Industry: Proceedings of the Conference held 5-9 June 2000, Sevilla, Spain. London, UK: James \& James Ltd.; Vol. I: pp. 6568; NREL NICH Report No. 31172. 


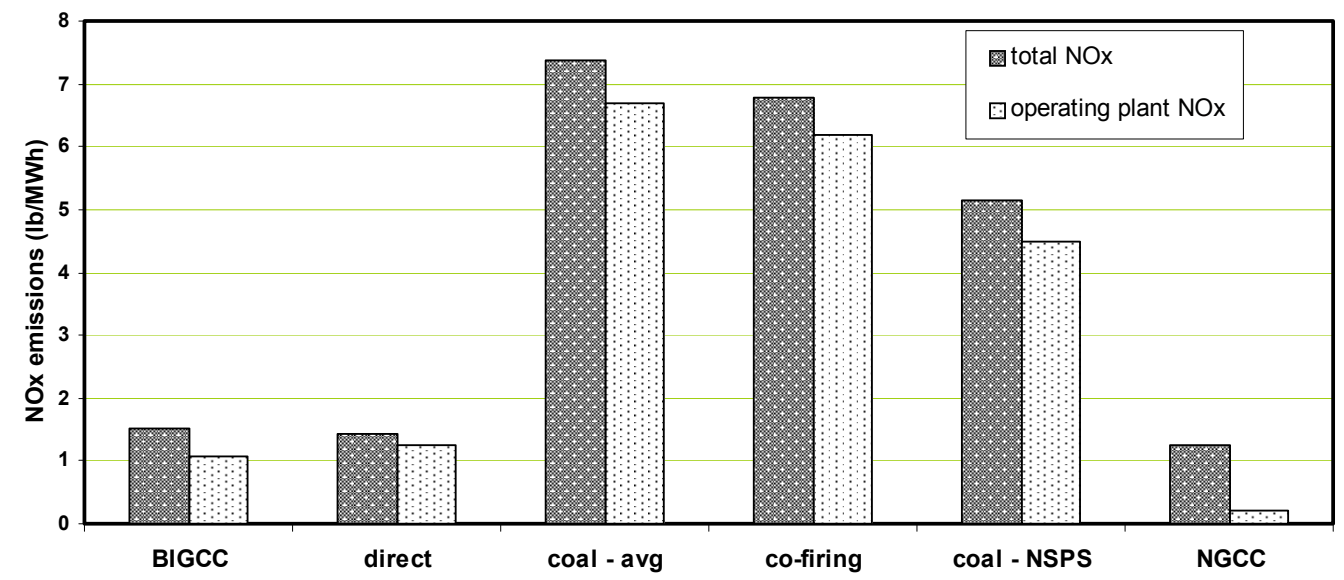

Figure 6.1: NO $_{x}$ Emissions-Life Cycle Total and Plant Operating Emissions

about $4.5 \mathrm{lb} \mathrm{NO} / \mathrm{MWh}$, a natural gas combined cycle plant emits about $0.2 \mathrm{lb} \mathrm{NO} \mathrm{N}_{\mathrm{x}} / \mathrm{MWh}$, and a biopower direct combustion system emits about $1.2 \mathrm{lb} \mathrm{NO}_{\mathrm{x}} / \mathrm{MWh}$.

Figure 6.2 gives a comparison of four existing biopower direct combustion plant emissions relative to the proposed standards for East and West Texas. CHP emissions have also been estimated, assuming that the existing systems could be modified to give a $60 \%$ CHP efficiency. Two out of the four operating biopower plants meet the West Texas standard. All CHP systems meet the West Texas standard, but additional $\mathrm{NO}_{\mathrm{x}}$ control would be required for the systems to meet the East Texas standard.

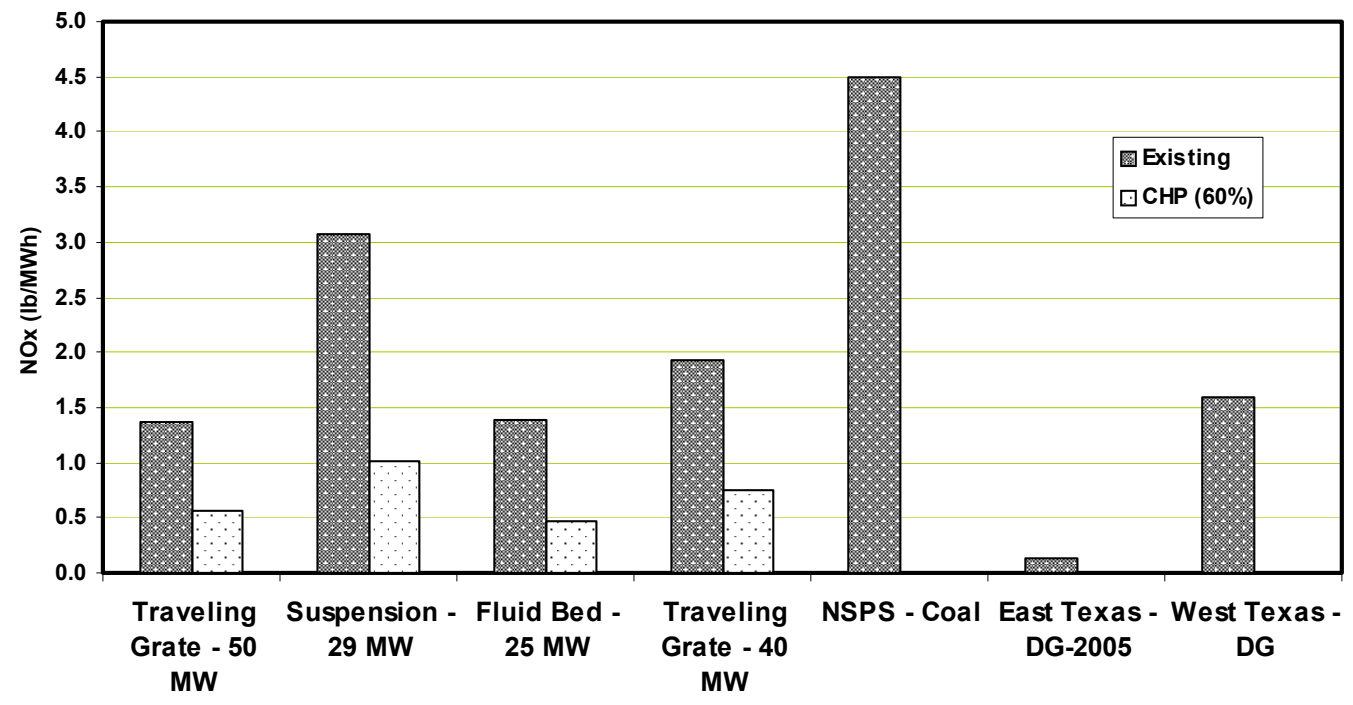

Figure 6.2: Biomass Combustion -Comparison of $\mathrm{NO}_{\mathrm{x}}$ Emissions to 2001 Texas DG Standard 
The potential for a CHP system to meet standards is shown in Figure 6.3. A existing system with flue gas recycle (FGR) has emissions of about $1.4 \mathrm{lb} \mathrm{NO} / \mathrm{MWh}$. Since FGR and selective catalytic reduction (SCR) are additive, SCR is also used, assuming an additional $80 \%$ reduction. This lowers the $\mathrm{NO}_{\mathrm{x}}$ to about $0.25 \mathrm{lb} \mathrm{NO}_{\mathrm{x}} / \mathrm{MWh}$. CHP is then assumed (60\% total efficiency), bringing the level down to $0.12 \mathrm{lb}$ $\mathrm{NO}_{\mathrm{x}} / \mathrm{MWh}$. The existing system meets the West Texas standard, and the CHP system with both FGR and SCR meets the East Texas standard. The system with FGR and SCR meets the 2003 California standard, but additional optimization would be required for the CHP system to meet the 2007 California standard.

Figure 6.3: Biomass Combustion - Potential for $\mathrm{NO}_{\mathrm{x}}$ Reduction

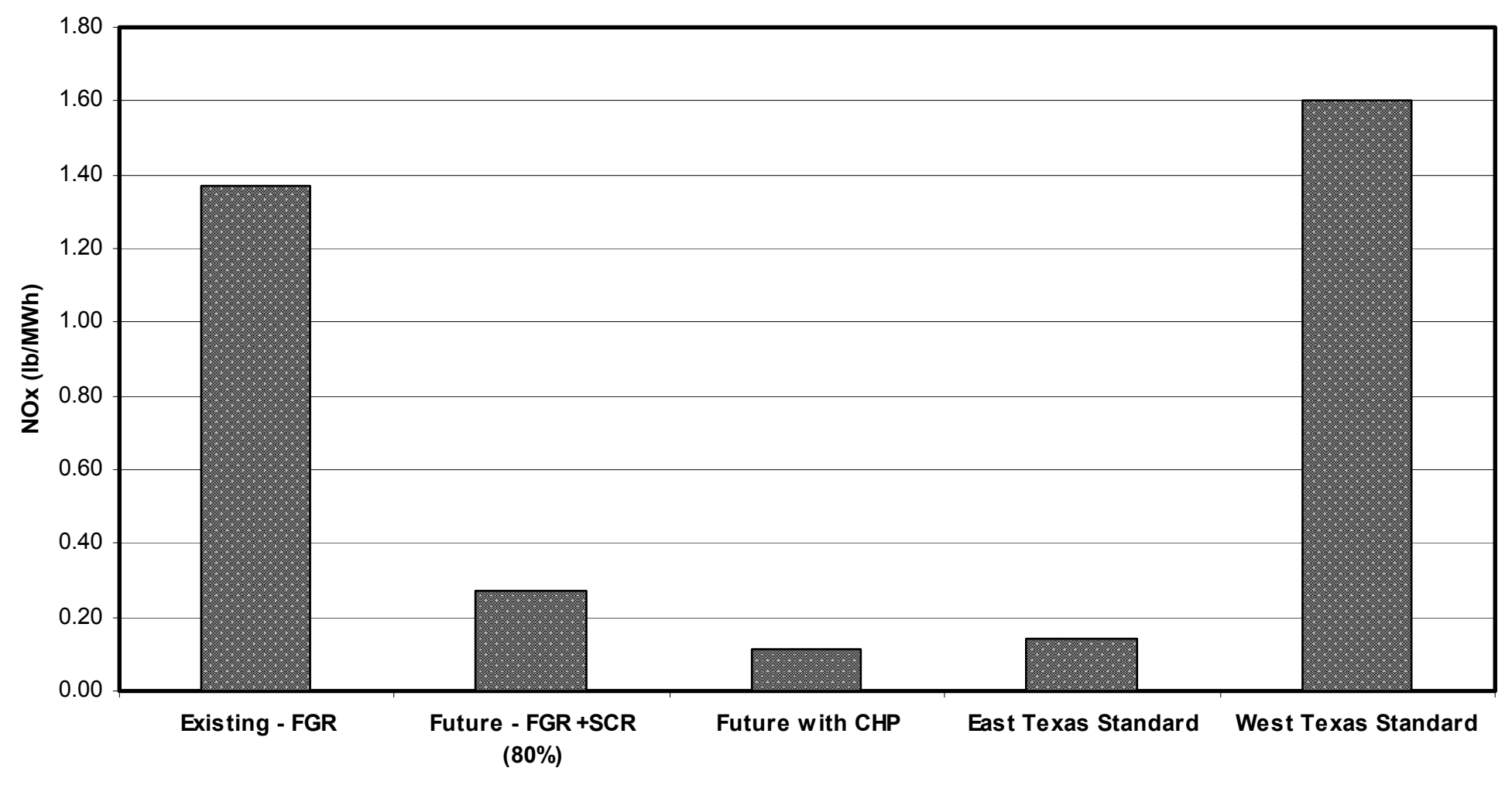

There are about 2,500 active landfills in the United States that receive over 200 million tons of municipal solid waste every year, with 55 to 60 percent from household waste, and 35 to 45 percent as commercial waste. Landfill gas is produced during the bacterial decomposition of this waste. The amount of landfill gas that is generated depends on the composition of waste in the landfill, the age of the landfill, the moisture content in the waste, $\mathrm{pH}$ levels, oxygen availability, and the temperature in the landfill.

Air emissions from landfills consist of roughly 50 percent methane, 48 percent carbon dioxide, small amounts of hydrogen, oxygen and nitrogen, and trace amounts of more than 100 non-methane organic compounds (NMOCs) like ethane, toluene, and benzene. The NMOC emissions include VOCs, hazardous air pollutants (HAPs), and odorous compounds. The VOCs present in NMOC emissions from landfills contribute to the formation of ozone that can reduce or damage growth in vegetables as well as exacerbate respiratory problems in humans. The health effects of HAPs include cancerous and noncancerous illnesses like respiratory irritation and damage of the central nervous system. In 1996, the EPA issued New Source Performance Standards (NSPS) under the Clean Air Act for landfills with a capacity 
of greater than 2.75 million tons that emit more than $50 \mathrm{Mg} /$ year of NMOC emissions. These landfills have to install gas collection and combustion systems capable of controlling 98 percent or more of the NMOC emissions. The landfill gas can either be flared or converted to direct energy use or electrical energy.

Nationwide, there are over 325 landfill gas projects, with about two-thirds generating electricity for sale. The other one-third is for direct use, particularly for heating. Air emissions from landfill gas electric generating projects include $\mathrm{CO}, \mathrm{NO}_{\mathrm{x}}, \mathrm{SO}_{2}$, hydrogen chloride ( $\left.\mathrm{HCI}\right), \mathrm{PM}$, and other combustion products. Representative emissions are given in Table 6.5. PM emissions may also result from fugitive dust created by garbage trucks traveling along paved and unpaved roads. Gas collection systems are typically 60 to 85 percent efficient, so emissions of methane and NMOCs still occur. $\mathrm{SO}_{2}$ emissions are site-specific and depend on the sulfur content of the waste in the landfill, and so are not included in the table.

Table 6.5: Air Emission Rates from Landfill Gas Combustion and Electric Generation (lb/MWh)

\begin{tabular}{|lccc|}
\hline & $\mathrm{NO}_{\mathrm{x}}$ & $\mathrm{CO}$ & $\mathrm{PM}-10$ \\
\hline Flare (Btu Equivalent) & 0.38 & 7.13 & 0.16 \\
Internal Combustion & $2.37-4.73$ & $4.45-8.9$ & $0.45-0.91$ \\
Engine & & & $0.24-0.49$ \\
Gas Turbine & $0.98-1.93$ & $2.55-5.10$ & $0.08-0.16$ \\
Gas Boiler with low- & $0.33-0.66$ & $0.06-0.11$ & \\
NOx burners & & & \\
\hline
\end{tabular}

Landfill gas systems with internal combustion (IC) engines generally have lower emissions than coal with stoker boilers, but higher emissions than most natural gas systems (except with reciprocating engines) and coal with FBC boilers. Landfill systems with gas turbines tend to have lower $\mathrm{NO}_{\mathrm{x}}$ and $\mathrm{CO}$ emissions than coal systems with stoker boilers and natural gas combustion turbines, but higher $\mathrm{NO}_{\mathrm{x}}$ and $\mathrm{CO}$ emissions than natural gas combined cycle systems. Landfill gas systems using gas turbines with low- $\mathrm{NO}_{\mathrm{x}}$ burners have lower $\mathrm{NO}_{\mathrm{x}}$ emissions than most of the generating technologies except natural gas combined cycle plants. All three landfill gas systems have relatively low levels of PM-10 emissions that are comparable to natural gas systems and lower than most coal systems.

Air emissions for landfill gas tend to be higher from facilities using IC engines, which are used at about 75 percent of the landfill gas electric facilities in the country. Because of tighter air emission standards, future landfill gas systems may need to use low- $\mathrm{NO}_{\mathrm{x}}$ engines or gas turbines and may need $\mathrm{CO}$ and $\mathrm{NO}_{\mathrm{x}}$ removal systems as well. Air emissions from landfill gas can be reduced through selective catalytic reduction to reduce $\mathrm{NO}_{x}$ emissions by injecting ammonia into the exhaust stream. Significant fuel pretreatment must be done at landfill gas generators to remove trace contaminants that can ruin the catalyst.

Some concern has been raised about possible dioxin production from landfill gas facilities. However, the EPA believes the potential is small for dioxin emissions from the combustion of landfill gas. Previous EPA analysis found that dioxin emissions from the combustion of landfill gas are comparable to dioxin emissions from oil or coal combustion, and significantly less than dioxin emissions from municipal waste combustion. 


\section{LIFE CYCLE ANALYSES ${ }^{2}$}

The generation of electricity, and the consumption of energy in general, result in consequences to the environment. Using renewable resources and incorporating advanced technologies such as integrated gasification combined cycle (IGCC) may result in less environmental damage, but to what degree, and with what trade-offs? Life cycle assessment studies have been conducted on various power generating options in order to better understand the environmental benefits and drawbacks of each technology. Material and energy balances were used to quantify the emissions, energy use, and resource consumption of each process required for the power plant to operate. These include feedstock procurement (mining coal, extracting natural gas, growing dedicated biomass, collecting residue biomass), transportation, manufacture of equipment and intermediate materials (e.g., fertilizers, limestone), construction of the power plant, decommissioning, and any necessary waste disposal.

The systems chosen are:

- a biomass-fired integrated gasification combined cycle (IGCC) system using a biomass energy crop (hybrid poplar)

- $\quad$ a direct-fired biomass power plant using biomass residue (urban, primarily)

- $\quad$ a pulverized coal boiler with steam cycle, representing the average for coal-fired power plants in the U.S. today

- $\quad$ a system cofiring biomass residue with coal ( $15 \%$ by heat input will be presented here)

- a natural gas combined cycle power plant.

Each study was conducted independently and can therefore stand alone, giving a complete picture of each power generation technology. However, the resulting emissions, resource consumption, and energy requirements of each system can ultimately be compared, revealing the environmental benefits and drawbacks of the renewable and fossil based systems.

\section{System Energy Balance}

The total energy consumed by each system includes the fuel energy consumed plus the energy contained in raw and intermediate materials that are consumed by the systems. Examples of the first type of energy use are the fuel spent in transportation, and fossil fuels consumed by the fossil-based power plants. The second type of energy is the sum of the energy that would be released during combustion of the material (if it is a fuel) and the total energy that is consumed in delivering the material to its point of use.

Examples of this type of energy consumption are the use of natural gas in the manufacture of fertilizers and the use of limestone in flue-gas desulfurization. The combustion energy calculation is applied where non-renewable fuels are used, reflecting the fact that the fuel has a potential energy that is being consumed by the system. The combustion energy of renewable resources, those replenished at a rate equal to or greater than the rate of consumption, is not subtracted from the net energy of the system. This is because, on a life cycle basis, the resource is not being consumed. To determine the net energy balance of each system, the energy used in each process block is subtracted from the energy produced by the power plant. The total system energy consumption by each system is shown in Table 6.6.

${ }^{2}$ Excerpted from Mann, M.K.; Spath, P.L. (2000). A Comparison of the Environmental Consequences of Power from Biomass, Coal, and Natural Gas. First World Conference and Exhibition on Biomass for Energy and Industry. June 5-9, Seville, Spain. 
Table 6.6: Total System Energy Consumption

\begin{tabular}{|lc|}
\hline \multicolumn{1}{|c}{ System } & $\begin{array}{c}\text { Total energy } \\
\text { consumed } \\
(\mathrm{kJ} / \mathrm{kWh})\end{array}$ \\
$\begin{array}{l}\text { Biomass-fired IGCC using hybrid } \\
\text { poplar } \\
\text { Direct-fired biomass power plant } \\
\text { using biomass residue }\end{array}$ & 231 \\
$\begin{array}{l}\text { Average coal } \\
\text { Biomass / coal cofiring (15\% by } \\
\text { heat input) }\end{array}$ & 125 \\
Natural gas IGCC & 10,118 \\
\hline
\end{tabular}

To examine the process operations that consume the largest quantities of energy within each system, two energy measurement parameters were defined. First, the energy delivered to the grid divided by the total fossil-derived energy consumed by each system was calculated. This measure, known as the net energy ratio, is useful for assessing how much energy is generated for each unit of fossil fuel consumed. The other measure, the external energy ratio, is defined to be the energy delivered to the grid divided by the total non-feedstock energy to the power plant. That is, the energy contained in the coal and natural gas used at the fossil-based power plants is excluded. The external energy ratio assesses how much energy is generated for each unit of upstream energy consumed. Because the energy in the biomass is considered to be both generated and consumed within the boundaries of the system, the net energy ratio and external energy ratio will be the same for the biomass-only cases (biomass-fired IGCC and direct-fired biomass). In calculating the external energy ratio, we are essentially treating the coal and natural gas fed to the fossil power plants as renewable fuels, so that upstream energy consumption can be compared. Figure 6.4 shows the energy results for each case studied.

As expected, the biomass-only plants consume less energy overall, since the consumption of nonrenewable coal and natural gas at the fossil plants results in net energy balances of less than one. The direct-fired biomass residue case delivers the most amount of electricity per unit of energy consumed. This is because the energy used to provide a usable residue biomass to the plant is fairly low. Despite its higher plant efficiency, the biomass IGCC plant has a lower net energy balance than the direct-fired plant because a significant amount of energy was required to grow the biomass as a dedicated crop. Resource limitations, however, may necessitate the use of energy crops in the future. Cofiring biomass with coal slightly increases the energy ratios over those for the coal-only case, even though the plant efficiency was derated by 0.9 percentage points.

In calculating the external energy ratios, the feedstocks to the power plants were excluded, essentially treating all feedstocks as renewable. Because of the perception that biomass fuels are of lower quality than fossil fuels, it was expected that the external energy ratios for the fossil-based systems would be substantially higher than those of the biomass-based systems. The opposite is true, however, due to the large amount of energy that is consumed in upstream operations in the fossil-based systems. 


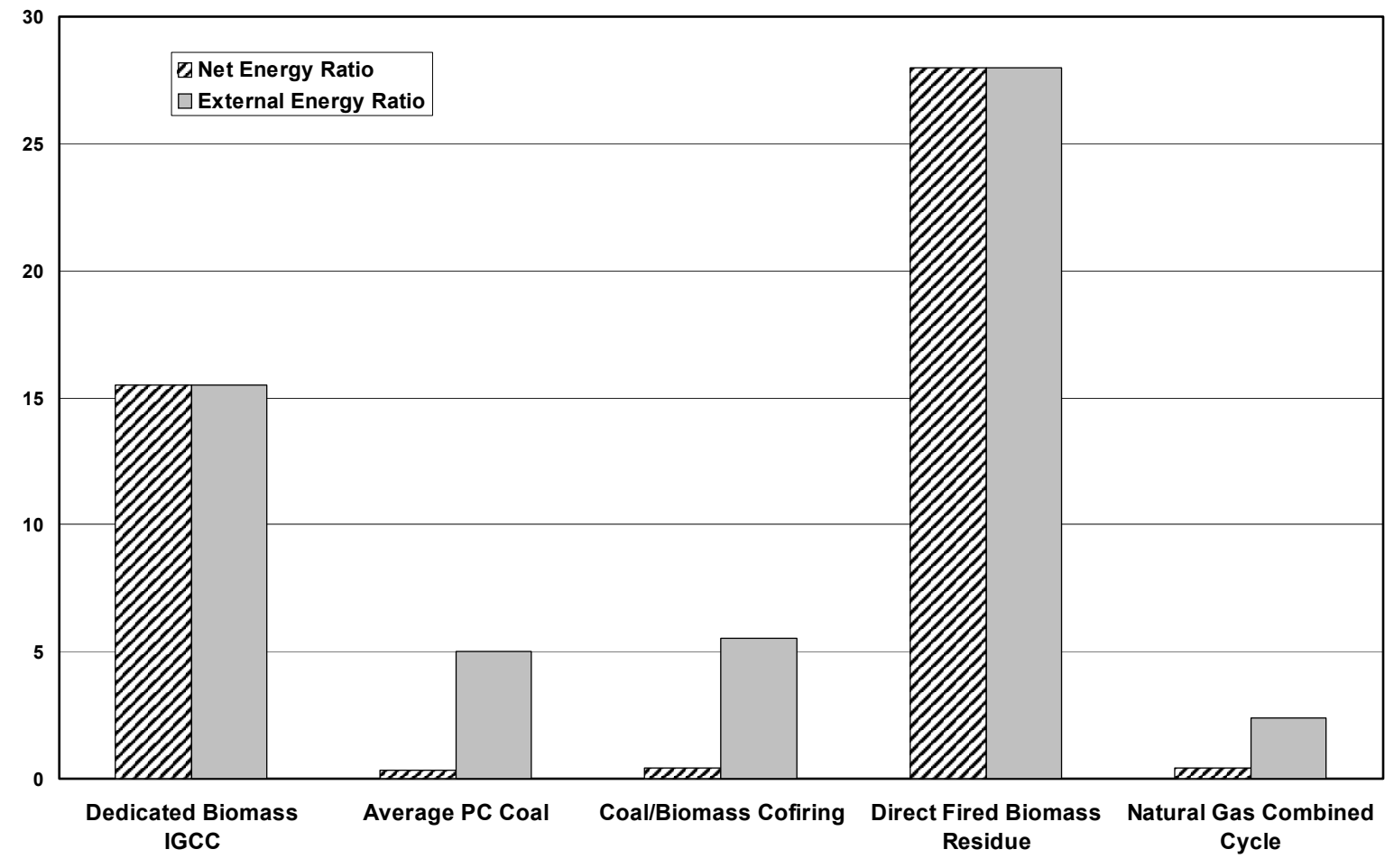

Figure 6.4: Life Cycle Energy Balance

The total non-feedstock energy consumed by the systems is shown in Table 6.7 . In the coal case, $35 \%$ of this energy is consumed in operations relating to flue-gas cleanup, including limestone procurement. Mining the coal consumes $25 \%$ of this energy, while transporting the coal is responsible for $32 \%$. Greater than $97 \%$ of the upstream energy consumption related to the natural gas IGCC system is due to natural gas extraction and pipeline transport steps, including fugitive losses. Although upstream processes in the biomass systems also consume energy, shorter transportation distances and the fact that flue-gas desulfurization is not required, reduce the total energy burden.

Table 6.7: Non-feedstock Energy Consumption

\begin{tabular}{|lc|}
\hline \multicolumn{1}{|c|}{ System } & $\begin{array}{c}\text { Non-feedstock } \\
\text { energy consumed } \\
(\mathrm{kJ} / \mathrm{kWh})\end{array}$ \\
$\begin{array}{l}\text { Biomass-fired IGCC using hybrid } \\
\text { poplar }\end{array}$ & 231 \\
$\begin{array}{l}\text { Direct-fired biomass power plant } \\
\text { using biomass residue }\end{array}$ & 125 \\
$\begin{array}{l}\text { Average coal } \\
\text { Biomass / coal cofiring }(15 \% \text { by heat } \\
\text { input })\end{array}$ & 702 \\
Natural gas IGCC & 614 \\
\hline
\end{tabular}




\section{Global Warming Potential}

Figure 6.5 shows the net emissions of greenhouse gases, using the 100 -year values from the Intergovernmental Panel on Climate Change. $\mathrm{CO}_{2}, \mathrm{CH}_{4}$, and $\mathrm{N}_{2} \mathrm{O}$ were quantified for these studies. The biomass IGCC system has a much lower GWP than the fossil systems because of the absorption of $\mathrm{CO}_{2}$ during the biomass growth cycle. The direct-fired biomass system has a highly negative rate of greenhouse gas emissions because of the avoided methane generation associated with biomass decomposition that would have occurred had the residue not been used at the power plant.

Figure 6.5: Net Life Cycle Greenhouse Gas Emissions

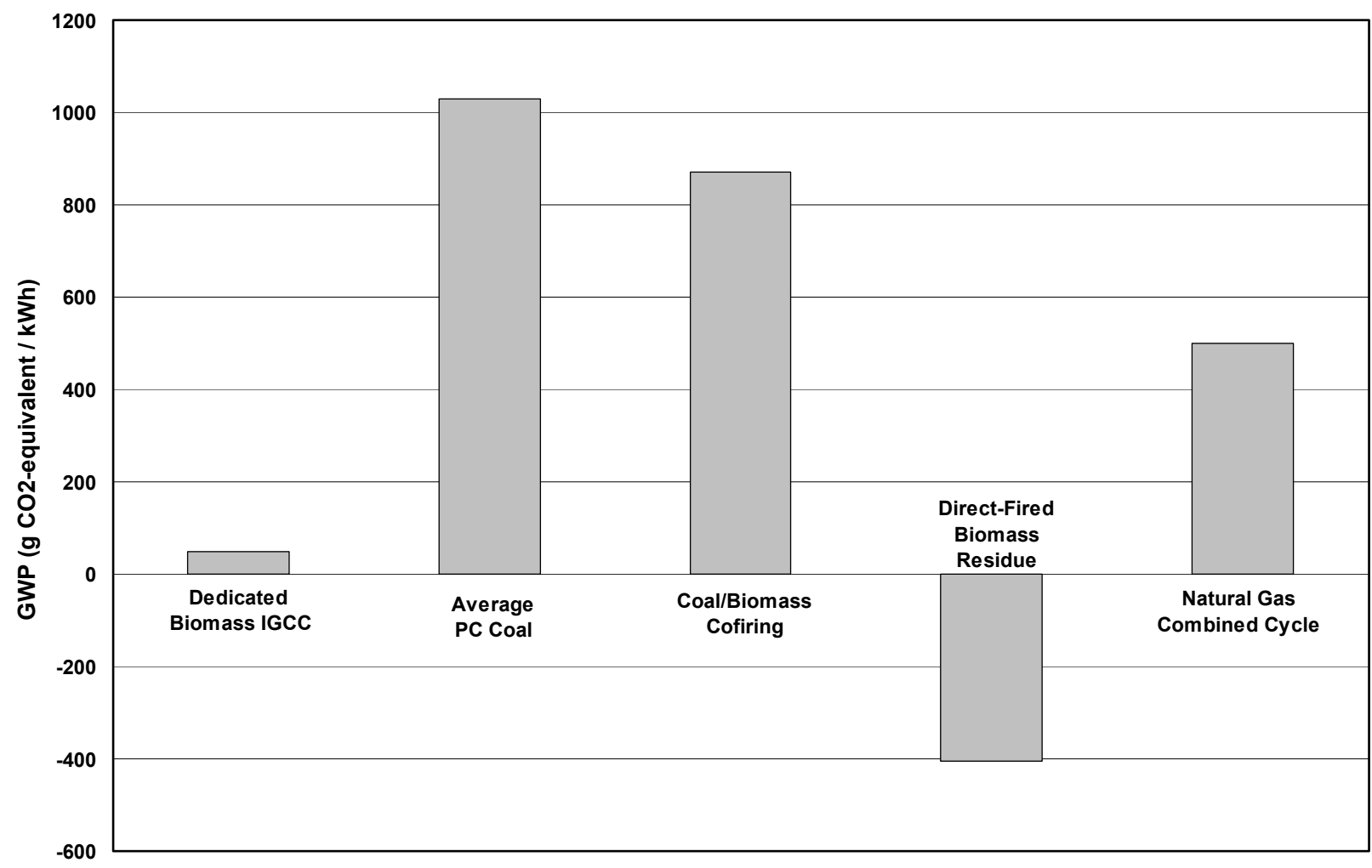

Based on current disposal practices, it was assumed that $46 \%$ of the residue biomass used in the directfired and cofiring cases would have been sent to a landfill and that the remainder would end up as mulch and other low-value products. Decomposition studies reported in the literature were used to determine that approximately $9 \%$ of the carbon in the biomass residue would end up as $\mathrm{CH}_{4}$ were it not used at the power plant, while $61 \%$ would end up as $\mathrm{CO}_{2}$. The remaining carbon is resistant to decomposition in the landfill, either due to inadequate growth conditions for the microbes or because of the protective nature of the lignin compounds.

Sensitivity analyses demonstrated that even moderate amounts of soil carbon sequestration $(1,900$ $\mathrm{kg} / \mathrm{ha} /$ seven-year rotation) would result in the biomass IGCC system having a zero-net greenhouse gas balance. Sequestration amounts greater than this would result in a negative release of greenhouse gases, and a system that removes carbon from the atmosphere overall. The base case presented here assumes that there will be no net change in soil carbon, as actual gains and losses will be very site specific. 
The natural gas combined cycle has the lowest GWP of all fossil systems because of its higher efficiency, despite natural gas losses that increase net $\mathrm{CH}_{4}$ emissions. Cofiring biomass with coal at $15 \%$ by heat input reduces the GWP of the average coal-fired power plant by $18 \%$.

\section{Air Emissions}

Emissions of particulates, $\mathrm{SO}_{\mathrm{x}}, \mathrm{NO}_{\mathrm{x}}, \mathrm{CH}_{4}, \mathrm{CO}$, and $\mathrm{NMHCs}$ are shown in Figure 6.6. Methane emissions are high for the natural gas case due to natural gas losses during extraction and delivery. The direct-fired biomass and coal/biomass cofiring cases have negative methane emissions, due to avoided decomposition processes (landfilling and mulching). CO and NMHCs are higher for the biomass case because of upstream diesel combustion during biomass growth and preparation. Cofiring reduces the coal system air emissions by approximately the rate of cofiring, with the exception of particulates, which are generated during biomass chipping.

Figure 6.6: Other Air Emissions

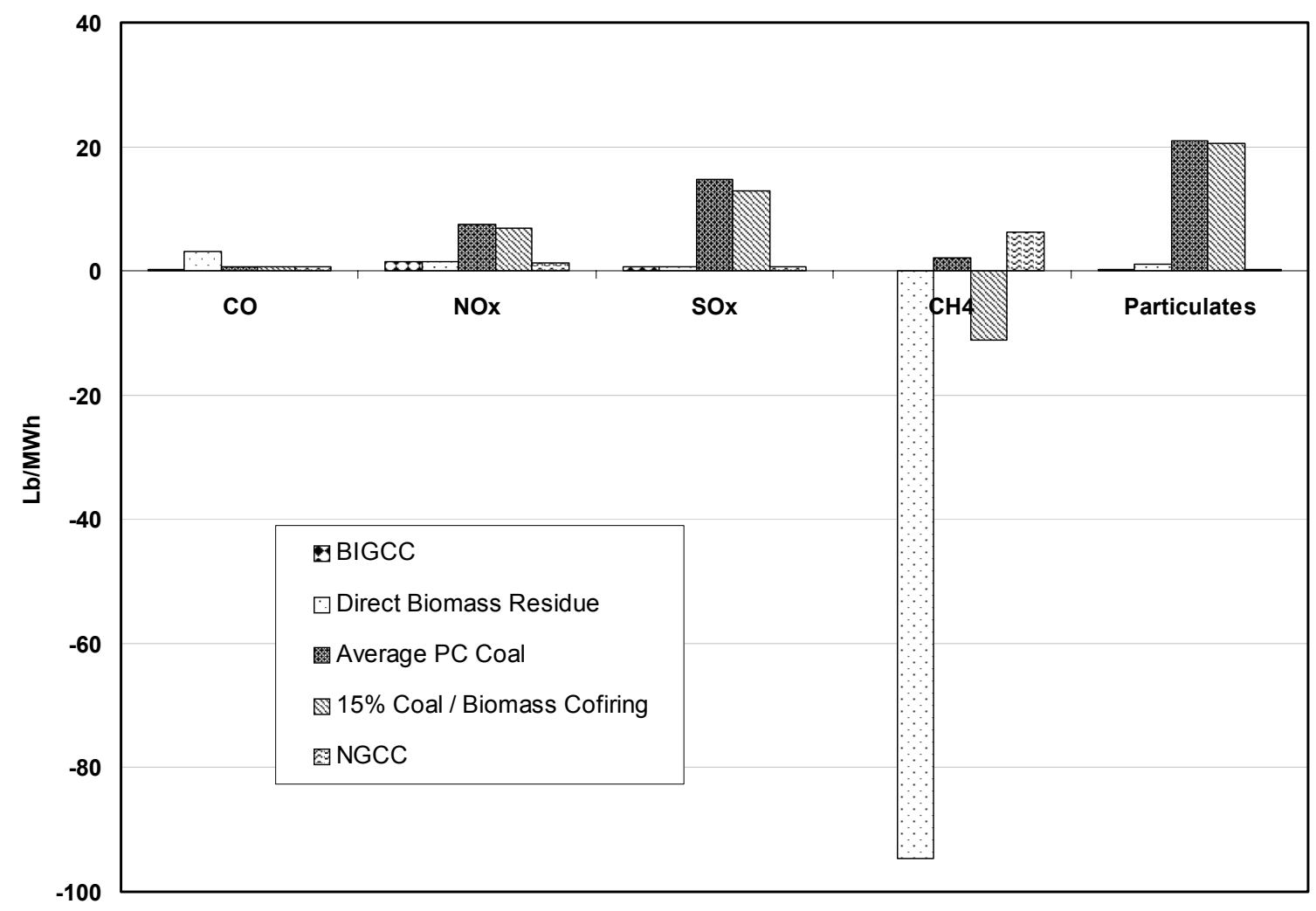

\section{Resource Consumption}

Figure 6.7 shows the total amount of non-renewable resources consumed by the systems. Limestone is used in significant quantities by the coal-fired power plants for flue-gas desulfurization. The natural gas combined cycle plant consumes almost negligible quantities of resources, with the exception of the feedstock itself. The natural gas consumed in this case includes a $1.4 \%$ loss to the atmosphere during extraction and delivery. 


\section{Figure 6.7 Resource Consumption}

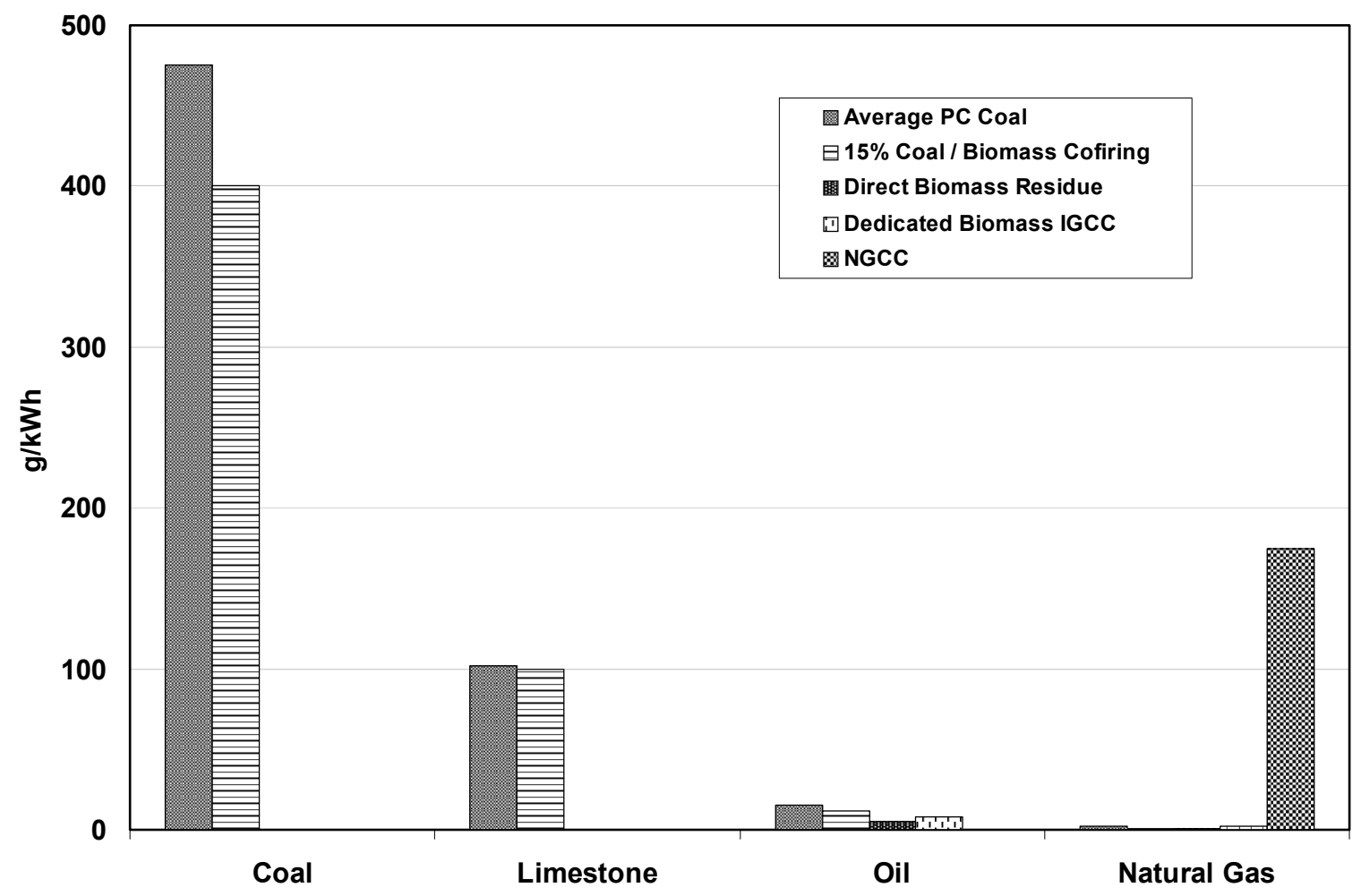

\section{Summary}

Completing several life cycle assessment studies has allowed us to determine where biomass power systems reduce the environmental burden associated with power generation. The key comparative results can be summarized as follows:

- The GWP of generating electricity using a dedicated energy crop in an IGCC system is $4.7 \%$ of that of an average U.S. coal power system.

- $\quad$ Cofiring residue biomass at $15 \%$ by heat input reduces the greenhouse gas emissions and net energy consumption of the average coal system by $18 \%$ and $12 \%$, respectively.

- The life cycle energy balances of the coal and natural gas systems are significantly lower than those of the biomass systems because of the consumption of non-renewable resources.

- Not counting the coal and natural gas consumed at the power plants in these systems, the net energy balance is still lower than that of the biomass systems because of the energy used in processes related to flue gas clean-up, transportation, and natural gas extraction and coal mining.

- The biomass systems produce very low levels of particulates, $\mathrm{NO}_{\mathrm{x}}$, and $\mathrm{SO}_{\mathrm{x}}$ compared to the fossil systems.

- $\quad$ System methane emissions are negative when residue biomass is used because of avoided decomposition emissions.

- The biomass systems consume very small quantities of natural resources compared to the fossil systems.

- $\quad$ Other than natural gas, the natural gas IGCC consumes almost no resources. 
These results demonstrate quite clearly that, overall, biomass power provides significant environmental benefits over conventional fossil-based power systems. In particular, biomass systems can significantly reduce the amount of greenhouse gases that are produced per $\mathrm{kWh}$ of electricity generated. Additionally, because the biomass systems use renewable energy instead of non-renewable fossil fuels, they consume very small quantities of natural resources and have a positive net energy balance. Cofiring biomass with coal offers us an opportunity to reduce the environmental burdens associated with the coal-fired power systems that currently generate over half of the electricity in the United States. Finally, by reducing $\mathrm{NO}_{\mathrm{x}}$, $\mathrm{SO}_{\mathrm{x}}$, and particulates, biomass power can improve local air quality. 


\section{POLICY}

U.S. government policies are used to advance energy strategies such as energy security and environmental quality. In the case of renewable energy, and bioenergy in particular, a variety of policies have been implemented - research, development, and demonstration of new technologies, financial incentives, and regulatory mandates - to advance the use of renewables in the energy marketplace and thus realize the benefits of renewable energy. Many of the benefits of renewable energy are not captured in the traditional marketplace economics. Government policies are a means of converting non-economic benefits to an economic basis, often referred to as "internalizing externalities." This may be accomplished by supporting the research, development, and demonstration of new technologies that are not funded by industry because of projected high costs or long development time lines. To facilitate the introduction and market penetration of renewable technologies, the government may establish financial incentives such as tax credits for new technology or additional taxes on existing technology to make the product economically competitive. The government may also mandate the use of renewable energy or products through regulatory actions that override market economics. A Renewable Portfolio Standard that requires a given percentage of renewable generation of electricity is an example of regulatory policy. This chapter briefly reviews the pertinent Federal government policies.

\section{Research, Development and Demonstration/Deployment ${ }^{1}$}

Biomass research, development, and demonstration/deployment (RD\&D) power, heat, fuels, and chemicals has been the subject of United States government programs since the early 1970s. In 1972, the Research Applied to National Needs (RANN) Directorate of the National Science Foundation (NSF) held several workshops to define the Fuels from Biomass Program (Ward 1976). In parallel, the Department of Interior had several activities funding urban wastes and industry residues uses, including energy (Phillips 1998).

To frame biomass RD\&D in the context of the 1970s, the Environmental Protection Agency was formed at the end of 1970:

As concern with the condition of our physical environment has intensified, it has become increasingly clear that we need to know more about the total environment--land, water, and air. It also has become increasingly clear that only by reorganizing our Federal efforts can we develop that knowledge, and effectively ensure the protection, development and enhancement of the total environment itself (President Nixon on the establishment of the Agency).

At that time, the United States had nearly 200 million inhabitants in 60 million households. Schools had no computers. Each person generated more than $1.5 \mathrm{~kg}$ of MSW per day in the United States. Paper companies recycled less than $20 \%$ of their fiber. Each person used about $350 \mathrm{GJ} \mathrm{y}^{-1}$; and each dollar of the US GDP required $18 \mathrm{MJ}$ of energy. Vehicles had an average fuel economy of less than $15.7 \mathrm{~L}$ per 100 $\mathrm{km}$ (15 miles/gallon), and the disposable income used to purchase motor fuels was about $4 \%$.

Households spent half of that amount to purchase electricity. A trillion vehicle miles were traveled in the United States in that year (NSTC 1995).

\footnotetext{
${ }^{1}$ Excerpted from Chum, H.C. and R.P. Overend (2002?) "Biomass and Bioenergy in the United States," Advances in Solar Energy, Volume 15
} 
The oil embargo and related crises of the 1970s brought urgency to solve energy and security issues. A series of changes in government structure gave energy higher importance and consolidated activities that were previously conducted by a number of agencies. The NSF's RANN research activities were transferred to the Federal Energy Administration. In Fiscal Year 1974, a comprehensive 5-year plan, "Fuels from Biomass Energy Program," was developed as part of the Project Independence Blueprint. The early vision, Figure 7.1, presented by Martin Wolf at a Congressional hearing on bioconversion, guided much of the subsequent developments (Wolf 1974). In 1975, biomass energy activities were transferred to the Energy Research and Development Authority (ERDA). The Fuels from Biomass program at ERDA was funded at $\$ 600,000$ in 1975 . Urban waste activities were transferred from the Department of Interior and funded at the level of $\$ 400,000$. The total funding for these activities corresponds to $\$ 3$ million in constant $1999 \$$ (we will mainly use year $1999 \$$ and $2000 \$$ to express the expenditures in constant dollars, through a calculation using the GDP deflator).

Figure 7.1: The Bioenergy "Vision" in 1974

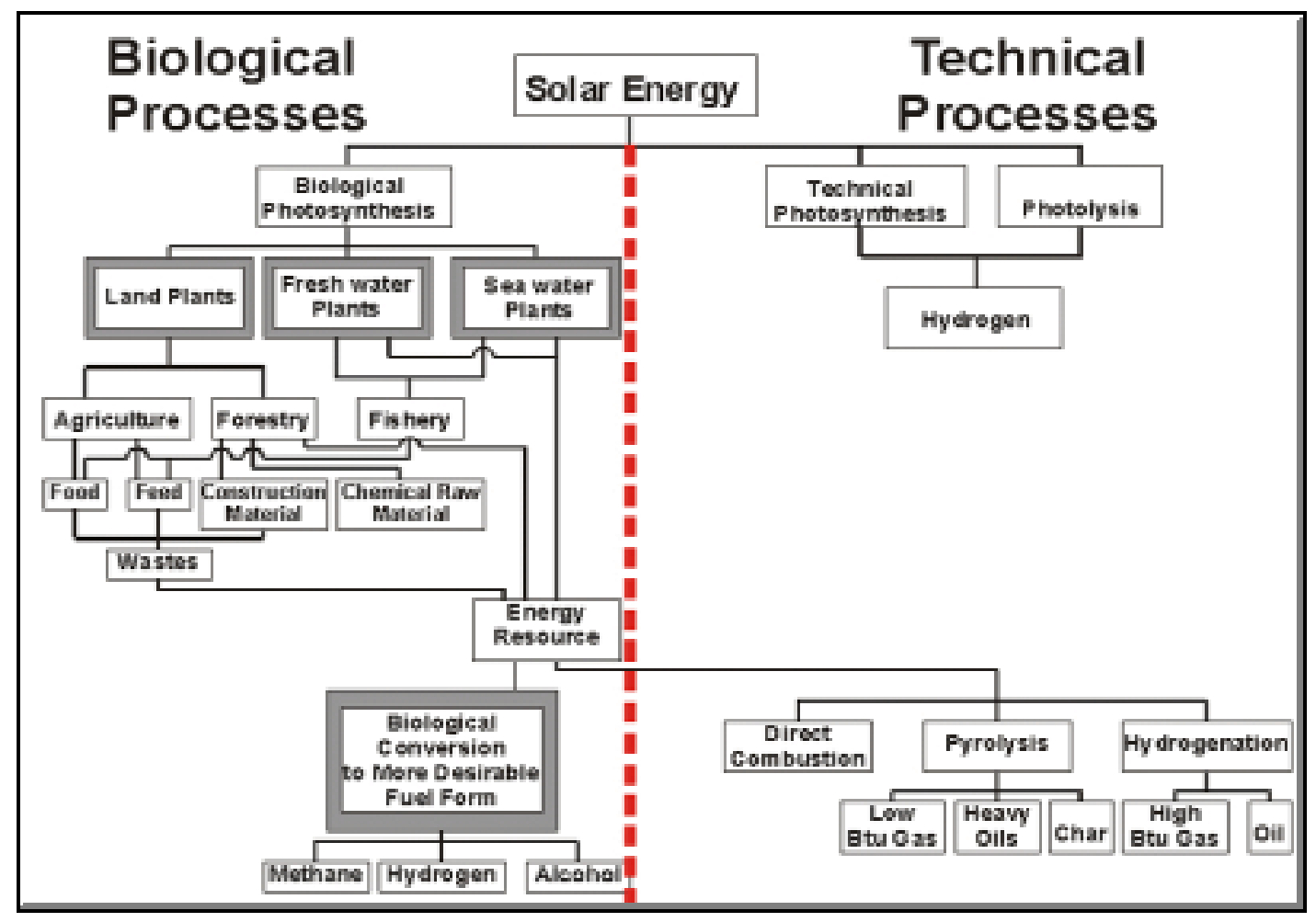

By 1977, all energy RD\&D activities were consolidated in a new cabinet, the U.S. Department of Energy (USDOE). This department had then, and has now, multiple missions, including energy, energy security, defense-related activities such as nuclear weapons development and production, their safety and security, and advancement of the related science and technology (USDOE 2001).

Biomass and bioenergy funding from the USDOE can be framed in the context of the overall energy RD\&D appropriations since 1978. A comparison of the major energy producing expenditures is shown in Figure 7.2, where funding for each of the technologies is in the order: nuclear $>>$ coal $>$ renewables $>>$ oil, gas, and shale. Renewable RD\&D investments over this period have been one-quarter to one-third of those in the nuclear area. Within the renewable energy technologies Figure 7.3, biomass and biofuels represent $12 \%$ of the overall investment (1978-2000) or $\$ 1.2$ billion (2000\$). Additional biomass 
investments are found in the industrial activities funded under energy efficiency such as pulp and paper, agriculture, alternative feedstocks to chemicals, etc., as shown in Figure 7.4; energy efficiency activities in transportation, buildings, industry, and the Federal Energy Management Program (FEMP) are also included. For comparison, Figure 7.5 shows related investments in major fossil energy and component areas.

Figure 7.2: United States Appropriations for Energy R\&D 1978 - 1998

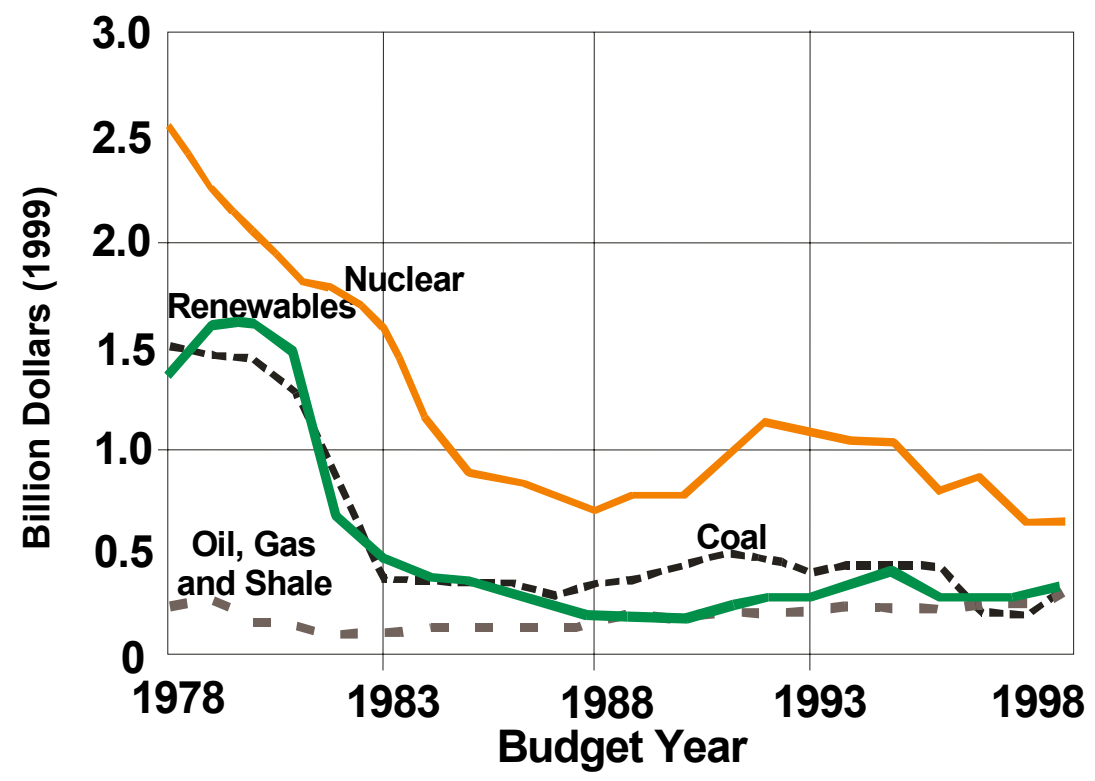

Figure 7.3: United States Appropriations for Renewable Energy R\&D 1978 - 1998

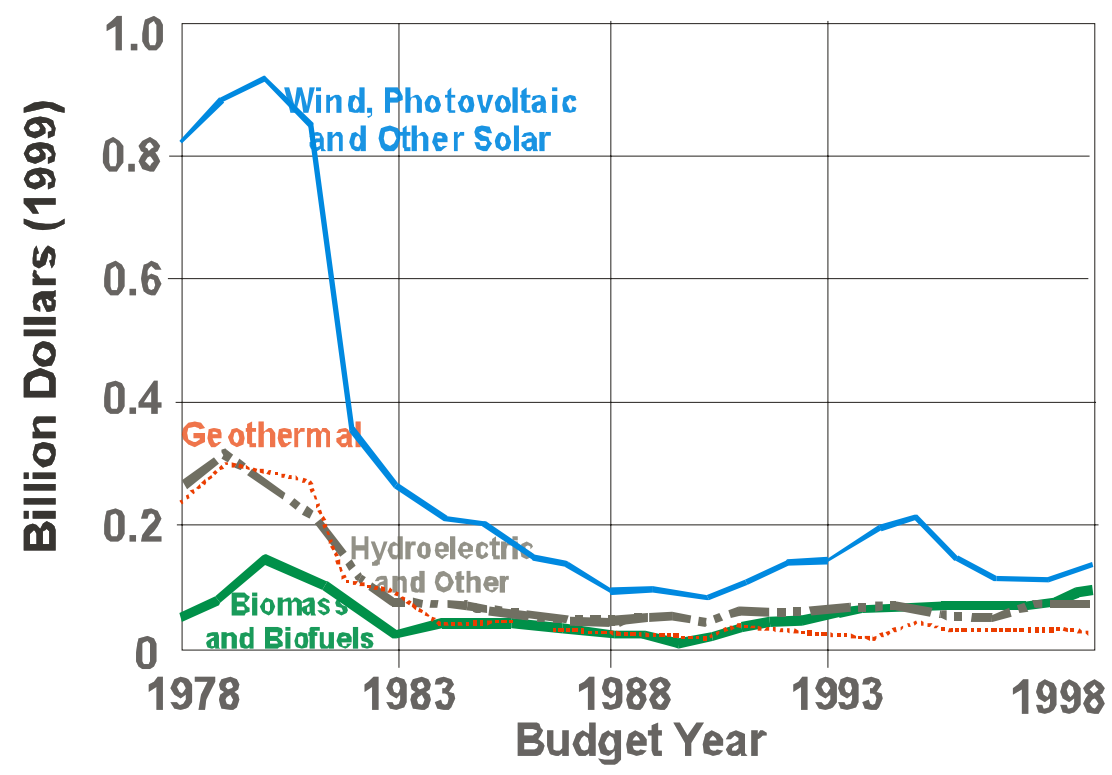


Figure 7.4: United States Appropriations for Energy Efficiency R\&D 1978 - 1998

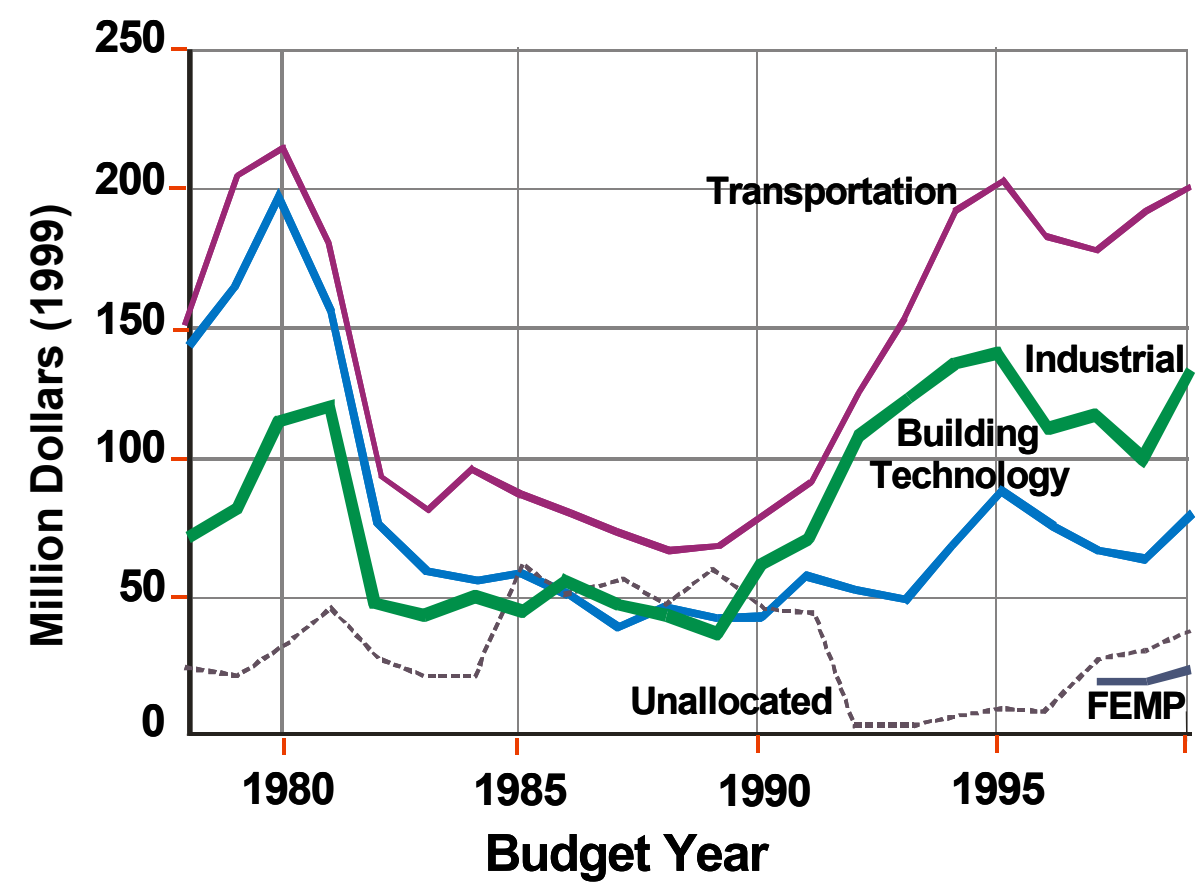

Figure 7.5: United States Appropriations for Fossil Energy R\&D 1978 - 1998

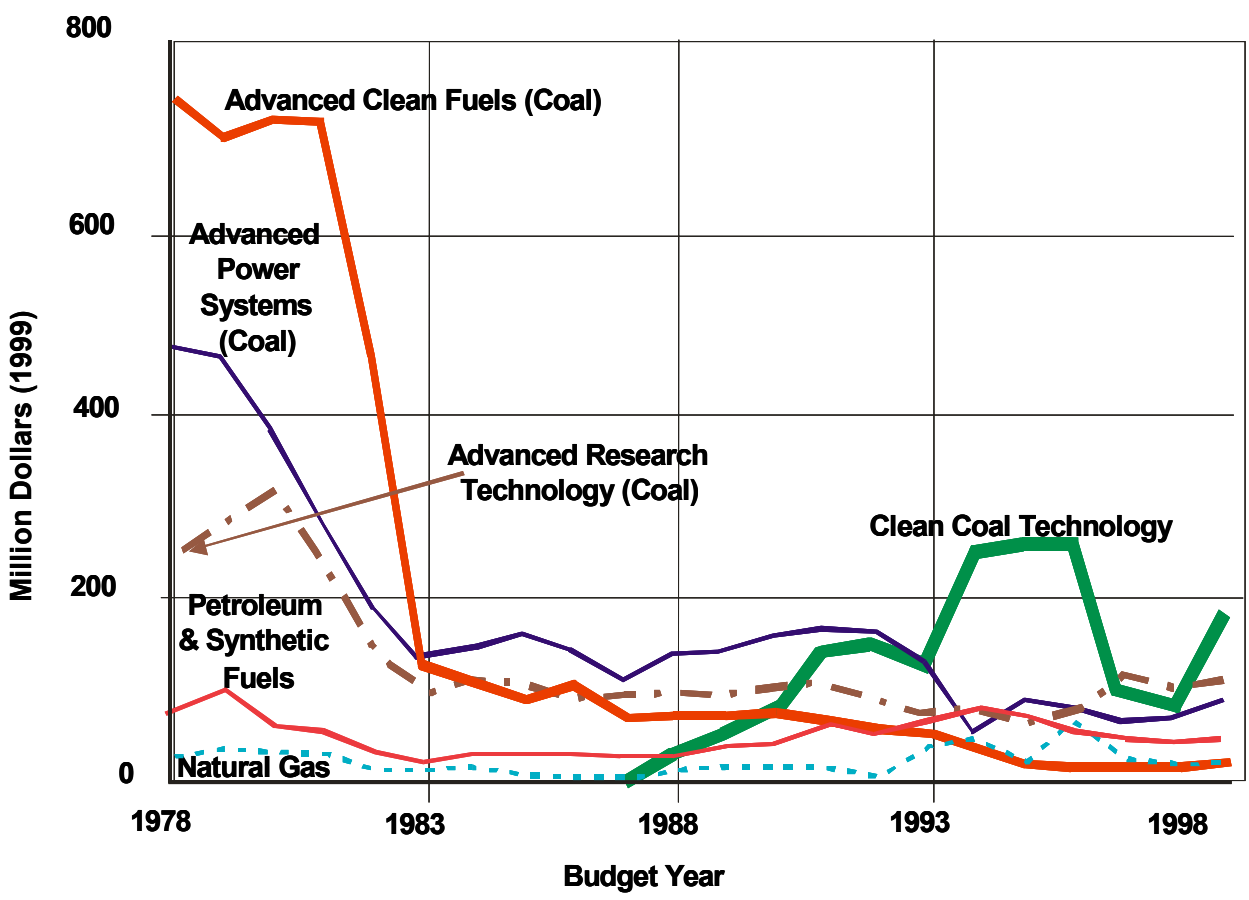


The total investment in this period for all biomass and bioenergy expenditures, including urban waste energy and management and related energy efficiency activities, is $\$ 1.4-1.5$ billion (2000\$), or 14\%-15\% of total Federal energy RD\&D expenditures. Funding for non-RD\&D activities is not included (EIA 1999; EIA 2000).

Government actions to increase biomass use for energy varied significantly over the past 25 years. Many of these actions responded to crude oil price signals, as shown in Figure 7.6 in constant 2000 \$. In 19771983, the goal was primarily to reduce the dependence of the United States on energy imports - mainly oil. The programs focused on the development of alternative fuels and activities included RD\&D from exploratory to pioneer plants for a wide range of technology options. Significant outreach activities helped increase the energy self-sufficiency of the existing biomass industry and speed the replacement of some oil applications with biomass, e.g., home heating.

Figure 7.6: Crude Oil Prices 1970 - 2000 in 2000\$

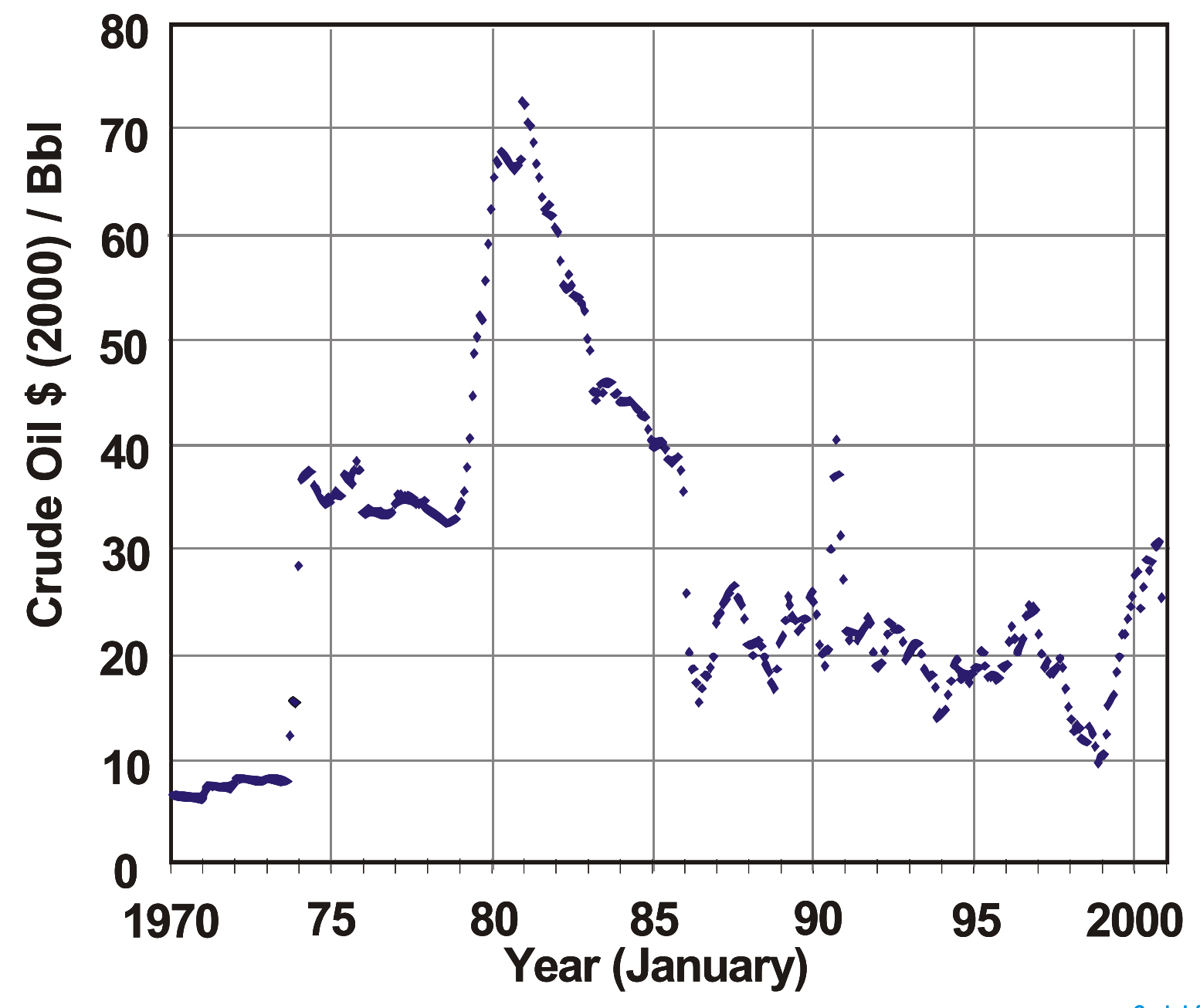

During 1977-1983, a technology-driven RD\&D approach responded to the wide diversity of biomass resources and product possibilities, including a range of gaseous, liquid, and solid fuels, power, heat, value added products, and the use of many different biomass sources. The biomass resources included agricultural and forestry residues, urban wastes, and dedicated feedstocks to be produced on land or 
water. Freshwater and seawater plants were considered for their biomass as well as for the direct production of hydrogen fuel from sunlight and water. Deployment was fostered in many ways, including studies facilitating the construction of commercial plants to produce alternative fuels - mainly ethanol. A few of the late 1970 s technologies were advanced sufficiently to become commercially viable. Direct combustion improvements were implemented in areas such as the forest products industry, pulp and paper mills, and home heating equipment.

In the period 1983-1990, there was a marked change in the approach of the Federal government towards energy supply. Supply and demand imbalances were to be resolved by market forces and supporting federal government policies, many of which were also applied at state and local levels. This alignment amplified federal actions and afforded significant penetration of several renewable technologies and, in particular, biomass combustion and ethanol from corn starch. RD\&D continued to develop technologies to expand supply and reduce demand through increased efficiency RD\&D. The priority of government funding was to conduct long-term high-risk R\&D. Companies could not be expected to carry out such R\&D because the benefits were not immediate nor could the benefits be captured by individual firms. The focus on the production of liquid fuels and energy from municipal waste was maintained, though other ways to recover resources and safely manage solid waste were investigated.

The 1990s saw the U.S. federal government increase renewable energy and energy efficiency RD\&D as a priority. Cost-shared RD\&D was conducted through a wide range of public-private partnerships in defined sectors - power, transportation fuels, forest products, and agriculture. Government sponsored some outreach activities and the development of selected pioneer plants for new biomass technologies. The overall approach combined market forces with technology development. The focus was specific products - electricity, ethanol from lignocellulosic biomass, biodiesel, specific model terrestrial feedstocks, and efforts to make energy and value-added products from biomass. In addition, RD\&D in the forest products and agricultures sectors was reconfigured. Industry associations in these sectors developed Agenda 2020 visions and technology roadmaps to guide the selection of DOE efforts in this area (Agenda 2020, Agriculture Vision 2020 Anon 1998 and 1999).

A baseline (essentially a single snapshot) inventory of the overall government funding for bioenergy and biobased products for the United States federal government was prepared for fiscal year 1998 (Chum, Elam et al. 2000). In that year the U.S. federal government invested $\$ 253$ million in RD\&D activities, including investments in basic research at the DOE Office of Science and at the Ntional Science Foundation. Of the $\$ 253$ million, $\$ 153$ million were devoted to bioenergy. Approximately $90 \%$ of the total bioenergy and biobased products amount, nearly \$230 million (2000\$), was appropriated through DOE and USDA programs. Other agencies - the NSF, EPA, and the Department of Commerce (Advanced Technology Program) - funded specific activities in support of these areas.

In fiscal year 2001, the government investment in RD\&D at DOE and USDA was \$239 million. The total R\&D investment level by these two departments was similar to the previous numbers, but there were major changes in emphasis and scope. These totals do not include R\&D investments at the NSF on the Plant Genome Research Program. The NSF plant genome activities began in 1998, and a portion of the \$25 million annual budget is certainly applicable to biomass activities. The NSF also funds bioprocessing, metabolic engineering, separations technologies, fermentation and enzyme-catalyzed systems, chemistry, materials, and engineering programs, which include biobased products and bioenergy. In fiscal year 2001, the EPA invested $\$ 7$ million in biomass-related activities, according to a report to Congress on Biomass Research and Development Act of 2000 (USDA/USDOE 2001).

Throughout these 25 years, funding for specific bioenergy areas was discontinued while focusing on specific products. Market and business considerations, funding availability, policy changes (e.g., deregulation of the electricity sector), and Congressional directions on specific projects to fund all played 
a role in the process of selecting areas to be maintained or discontinued. For example, the efforts in highpressure liquefaction to produce oil replacements did not reach product quality or cost effectiveness goals and was terminated in 1983. Macroalgae sometimes known as giant kelp were explored in several concepts but they were not cost effective in light of the declining oil price trend of that period. Similarly, during the "lean funding years" of the mid-to late-1980s, when the United States was in the process of balancing its budget, discretionary spending was significantly curtailed and much of the R\&D in thermochemical fuels was discontinued in favor of ethanol from lignocellulosic biomass, which became, respectively, the fuel and feedstock of choice. All thermochemical fuels activities including methanol, other transportation fuels, or thermal depolymerization concepts that could have led to multiple products (1988-1989) were discontinued. By 1993, investigations on microalgae accumulating large fractions of their body mass as lipids were also discontinued primarily because of difficulties reaching cost effectiveness. Finally, towards the mid-1990s, the programs on wastes-to-energy or products from a wide range of "wastes" (municipal, urban, industrial, and agricultural) were also discontinued.

\section{Incentives $^{2}$}

The major Federal legislation on financial incentives for renewable energy and renewable transportation fuels has been structured as tax credits and production incentive payments. See Tables 7.1 and 7.2 for a summary of major Federal provisions that affect renewable energy and renewable-based transportation fuels, respectively. For renewable energy, tax credits for purchases of renewable energy equipment were aimed at both the residential and business sectors. Accelerated depreciation of renewable energy equipment and production incentives were aimed at investors. From 1978 through 1998, similar types of tax credits have been in existence. Over time, the various laws have usually expanded the technologies covered, increased the credit amount, or extended the time period.

Two new types of financial incentives were introduced as part of the Energy Policy Act of 1992 (EPACT) - a production tax credit (PTC) and a renewable energy production incentive (REPI). The PTC is a 1.5 cents-per- kilowatthour $(\mathrm{kWh})$ payment, payable for 10 years, to private investors as well as to investor-owned electric utilities for electricity from wind and closed-loop biomass facilities. The PTC is also known as the Section 45 tax credit, and was modified in 1999 to include chicken litter as well as closed-loop biomass. Closed-loop biomass is defined as biomass grown and harvested specifically for energy purposes. As far as is known today, no organization has applied for the PTC for closed-loop biomass. The REPI provides a 1.5 cents-per-kWh incentive, subject to annual congressional appropriations for generation from biomass (except municipal solid waste), geothermal (except dry steam), wind and solar from tax-exempt publicly owned utilities, local and county governments, and rural cooperatives.

For renewable transportation fuels, tax credits and tax exemptions are used to promote the use of renewable fuels, with the goal of displacing petroleum use in the transportation sector. There are four Federal tax subsidies for the production and use of alcohol transportation fuels: (1) a 5.4-cents-per-gallon excise tax exemption, (2) a 54-cents-per-gallon blender's tax credit, (3) a 10-cents-per-gallon small ethanol production tax credit, and (4) the alternative fuels production tax.

However, only the partial exemption from motor fuels excise tax is used to any extent. It is important to note that there are important financial incentive issues in the form of tax equity regarding all of the

\footnotetext{
${ }^{2}$ Excerpted from: Gielecki, M. Mayes, F. and L. Prete "Incentives, Mandates, and Government Programs for Promoting Renewable Energy," USDOE Energy Information Agency, http://www.eia.doe.gov/cneaf/solar.renewables/rea issues/incent.html, 4/18/2002
} 
"alternate transportation fuels." However, only the alcohol fuels are renewable, so this discussion is confined to those. The primary incentive is the ethanol excise tax exemption.

Table 7.1: Time Line - Major Tax Provisions Affecting Renewable Energy

\begin{tabular}{|c|c|}
\hline 1978 & $\begin{array}{l}\text { Energy Tax Act of } 1978 \text { (ETA) (P.L.95-618) } \\
\text { Residential energy (income) tax credits for solar and wind energy equipment expenditures: } 30 \\
\text { percent of the first } \$ 2,000 \text { and } 20 \text { percent of the next } \$ 8,000 \text {. } \\
\text { Business energy tax credit: } 10 \text { percent for investments in solar, wind, geothermal, and ocean } \\
\text { thermal technologies; (in addition to standard } 10 \text { percent investment tax credit available on all } \\
\text { types of equipment, except for property which also served as structural components, such as some } \\
\text { types of solar collectors, e.g., roof panels). In sum, investors were eligible to receive income tax } \\
\text { credits of up to } 25 \text { percent of the cost of the technology. } \\
\text { Percentage depletion for geothermal deposits: depletion allowance rate of } 22 \text { percent for 1978- } \\
1980 \text { and } 15 \text { percent after } 1983 \text {. }\end{array}$ \\
\hline 1980 & $\begin{array}{l}\text { Crude Oil Windfall Profits Tax Act of } 1980 \text { (WPT) (P.L.96-223) } \\
\text { Increased the ETA residential energy tax credits for solar, wind, and geothermal technologies from } \\
30 \text { percent to } 40 \text { percent of the first } \$ 10,000 \text { in expenditures. } \\
\text { Increased the ETA business energy tax credit for solar, wind, geothermal, and ocean thermal } \\
\text { technologies from } 10 \text { percent to } 15 \text { percent, and extended the credits from December } 1982 \text { to } \\
\text { December } 1985 . \\
\text { Expanded and liberalized the tax credit for equipment that either converted biomass into a } \\
\text { synthetic fuel, burned the synthetic fuel, or used the biomass as a fuel. } \\
\text { Allowed tax-exempt interest on industrial development bonds for the development of solid waste } \\
\text { to energy (WTE) producing facilities, for hydroelectric facilities, and for facilities for producing } \\
\text { renewable energy. }\end{array}$ \\
\hline 1981 & $\begin{array}{l}\text { Economic Recovery Tax Act of } 1981 \text { (ERTA) (P.L.97-34) } \\
\text { Allowed accelerated depreciation of capital (five years for most renewable energy-related } \\
\text { equipment), known as the Accelerated Cost Recovery System (ACRS); public utility property was } \\
\text { not eligible. } \\
\text { Provided for a } 25 \text { percent tax credit against the income tax for incremental expenditures on } \\
\text { research and development (R\&D). }\end{array}$ \\
\hline 1982 & $\begin{array}{l}\text { Tax Equity and Fiscal Responsibility Act of } 1982 \text { (TEFRA) (P.L.97-248) } \\
\text { Canceled further accelerations in ACRS mandated by ERTA, and provided for a basis adjustment } \\
\text { provision which reduced the cost basis for purposes of ACRS by the full amount of any regular tax } \\
\text { credits, energy tax credit, rehabilitation tax credit. }\end{array}$ \\
\hline $\begin{array}{l}1982- \\
1985\end{array}$ & $\begin{array}{l}\text { Termination of Energy Tax Credits } \\
\text { In December 1982, the } 1978 \text { ETA energy tax credits terminated for the following categories of } \\
\text { non-renewable energy property: alternative energy property such as synfuels equipment and } \\
\text { recycling equipment; equipment for producing gas from geopressurized brine; shale oil equipment; } \\
\text { and cogeneration equipment. The remaining energy tax credits, extended by the WPT, terminated } \\
\text { on December 31, 1985. }\end{array}$ \\
\hline
\end{tabular}




\begin{tabular}{|c|c|}
\hline 1986 & $\begin{array}{l}\text { Tax Reform Act of } 1986 \text { (P.L.99-514) } \\
\text { Repealed the standard } 10 \text { percent investment tax credit. } \\
\text { Eliminated the tax-free status of municipal solid waste (MSW) powerplants (WTE) financed with } \\
\text { industrial development bonds, reduced accelerated depreciation, and eliminated the } 10 \text { percent tax } \\
\text { credit (P.L.96-223). } \\
\text { Extended the WPT business energy tax credit for solar property through } 1988 \text { at the rates of } 15 \\
\text { percent for } 1986,12 \text { percent for } 1987 \text {, and } 10 \text { percent for } 1988 \text {; for geothermal property through } \\
1988 \text { at the rates of } 15 \text { percent for } 1986 \text {, and } 10 \text { percent for } 1987 \text { and } 1988 \text {; for ocean thermal } \\
\text { property through } 1988 \text { at the rate of } 15 \text { percent; and for biomass property through } 1987 \text { at the rates } \\
\text { of } 15 \text { percent for } 1986 \text {, and } 10 \text { percent for } 1987 \text {. (The business energy tax credit for wind systems } \\
\text { was not extended and, consequently, expired on December } 31 \text {, 1985.) } \\
\text { Public utility property became eligible for accelerated depreciation. }\end{array}$ \\
\hline 1992 & $\begin{array}{l}\text { Energy Policy Act of } 1992 \text { (EPACT) (P.L.102-486) } \\
\text { Established a permanent } 10 \text { percent business energy tax credit for investments in solar and } \\
\text { geothermal equipment. } \\
\text { Established a 10-year, } 1.5 \text { cents per kilowatthour (kWh) production tax credit (PTC) for privately } \\
\text { owned as well as investor-owned wind projects and biomass plants using dedicated crops (closed- } \\
\text { loop) brought on-line between } 1994 \text { and 1993, respectively, and June } 30,1999 . \\
\text { Instituted the Renewable Energy Production Incentive (REPI), which provides } 1.5 \text { cents per kWh } \\
\text { incentive, subject to annual congressional appropriations (section 1212), for generation from } \\
\text { biomass (except municipal solid waste), geothermal (except dry steam), wind and solar from tax } \\
\text { exempt publicly owned utilities and rural cooperatives. } \\
\text { Indefinitely extended the } 10 \text { percent business energy tax credit for solar and geothermal projects. }\end{array}$ \\
\hline 1999 & $\begin{array}{l}\text { Tax Relief Extension Act of } 1999 \text { (P.L. 106-170) } \\
\text { Extends and modifies the production tax credit (PTC in EPACT) for electricity produced by wind } \\
\text { and closed-loop biomass facilities. The tax credit is expanded to include poultry waste facilities, } \\
\text { including those that are government-owned . All three types of facilities are qualified if placed in } \\
\text { service before January 1, 2002. Poultry waste facilities must have been in service after } 1999 \text {. } \\
\text { A nonrefundable tax credit of } 20 \text { percent is available for incremental research expenses paid or } \\
\text { incurred in a trade or business. }\end{array}$ \\
\hline & $\begin{array}{l}\text { sidential energy credit provided a credit (offset) against tax due for a portion of taxpayer } \\
\text { for energy conservation and renewable energy sources. The general business credit is a limited } \\
\text { le credit (offset) against income tax that is claimed after all other non-refundable credits. }\end{array}$ \\
\hline
\end{tabular}


Table 7.2. Timeline - Major Tax Provisions Affecting Renewable Transportation Fuels

\begin{tabular}{|c|c|}
\hline 1978 & $\begin{array}{l}\text { Energy Tax Act of } 1978 \text { (ETA) (P.L.95-618) } \\
\text { Excise tax exemption through } 1984 \text { for alcohol fuels (methanol and ethanol): exemption of } 4 \\
\text { cents per gallon (the full value of the excise tax at that time) of the Federal excise tax on } \\
\text { "gasohol" (gasoline or other motor fuels that were at least } 10 \text { percent alcohol (methanol and } \\
\text { ethanol)) }\end{array}$ \\
\hline 1980 & $\begin{array}{l}\text { Crude Oil Windfall Profits Tax Act of } 1980 \text { (WPT) (P.L.96-223) } \\
\text { Extended the gasohol excise tax exemption from October 1, 1984, to December 31, } 1992 . \\
\text { Introduced the alternative fuels production tax credit. The credit of } \$ 3 \text { per barrel equivalent is } \\
\text { indexed to inflation using } 1979 \text { as the base year, and is applicable only if the real price of oil is } \\
\text { bellow } \$ 27.50 \text { per barrel. The credit is available for fuel produced and sold from facilities placed } \\
\text { in service between } 1979 \text { and } 1990 \text {. The fuel must be sold before } 2001 \text {. } \\
\text { Introduced the alcohol fuel blenders' tax credit; available to the blender in the case of blended } \\
\text { fuels and to the user or retail seller in the case of straight alcohol fuels. This credit of } 40 \text { cents per } \\
\text { gallon for alcohol of at least } 190 \text { proof and } 45 \text { cents per gallon for alcohol of at least } 150 \text { proof } \\
\text { but less that } 190 \text { proof was available through December } 31,1992 \text {. } \\
\text { Extended the ETA gasohol excise tax exemption through 1992. } \\
\text { Tax-exempt interest on industrial development bonds for the development of alcohol fuels } \\
\text { produced from biomass, solid waste to energy producing facilities, for hydroelectric facilities, and } \\
\text { for facilities for producing renewable energy. }\end{array}$ \\
\hline 1982 & $\begin{array}{l}\text { Surface Transportation Assistance Act (STA) (P.L. 97-424) } \\
\text { Raised the gasoline excise tax from } 4 \text { cents per gallon to } 9 \text { cents per gallon, and increased the } \\
\text { ETA gasohol excise tax exemption from } 4 \text { cents per gallon to } 5 \text { cents per gallon. Provided a full } \\
\text { excise tax exemption of } 9 \text { cents per gallon for "neat" alcohol fuels (fuels having an } 85 \text { percent or } \\
\text { higher alcohol content). }\end{array}$ \\
\hline 1984 & $\begin{array}{l}\text { Deficit Reduction Act of } 1984 \text { (P.L.98-369) } \\
\text { The STA excise tax exemption for gasohol was raised from } 5 \text { cents per gallon to } 6 \text { cents per } \\
\text { gallon. } \\
\text { Provided a new exemption of } 4.5 \text { cents per gallon for alcohol fuels derived from natural gas. } \\
\text { The alcohol fuels "blenders" credit was increased from } 40 \text { cents to } 60 \text { cents per gallon of blend } \\
\text { for } 190 \text { proof alcohol. } \\
\text { The duty on alcohol imported for use as a fuel was increased from } 50 \text { cents to } 60 \text { cents per gallon }\end{array}$ \\
\hline 1986 & $\begin{array}{l}\text { Tax Reform Act of } 1986 \text { (P.L.99-514) } \\
\text { Reduced the tax exemption for "neat" alcohol fuels (at least } 85 \text { percent alcohol) from } 9 \text { cents to } 6 \\
\text { cents per gallon. } \\
\text { Permitted alcohol imported from certain Caribbean countries to enter free of the } 60 \text { cents per } \\
\text { gallon duty. } \\
\text { Repealed the tax-exempt financing provision for alcohol-producing facilities. }\end{array}$ \\
\hline
\end{tabular}




\begin{tabular}{|l|l|}
\hline 1990 & $\begin{array}{l}\text { Omnibus Budget Reconciliation Act of } 1990 \text { (P.L. 101-508) } \\
\text { Allows ethanol producers a } 10 \text { cent per gallon tax credit for up to } 15 \text { million gallons of ethanol } \\
\text { produced annually. } \\
\text { Reduced the STA gasohol excise tax exemption to } 5.4 \text { cents per gallon. }\end{array}$ \\
\hline 1992 & $\begin{array}{l}\text { Energy Policy Act of } 1992 \text { (EPACT) (P.L. 102-486) } \\
\text { Provides: (1) a tax credit (variable by gross vehicle weight) for dedicated alcohol-fueled vehicles; } \\
\text { (2) a limited tax credit for alcohol dual-fueled vehicles; and (3) a tax deduction for alcohol fuel } \\
\text { dispensing equipment. }\end{array}$ \\
\hline $\begin{array}{l}\text { Energy Conservation Reauthorization Act of 1998 (ECRA) (P.L. 105-388) } \\
\text { Amended EPACT to include a credit program for biodiesel use by establishing Biodiesel Fuel } \\
\text { Use Credits. An EPACT-covered fleet can receive one credit for each 450 gallons of neat (100 } \\
\text { percent) biodiesel purchased for use in vehicles weighing in excess of 8500 lbs (gross vehicle } \\
\text { weight (GVW)). One credit is equivalent to one alternative fueled vehicle (AFV) acquisition. To } \\
\text { qualify for the credit, the biodiesel must be used in biodiesel blends containing at least } 20 \text { percent } \\
\text { biodiesel (B20) by volume. If B20 is used, 2,250 gallons must be purchased to receive one credit. } \\
\text { Transportation Equity Act for the 21 st Century (TEA-21) (P.L. 105-178) } \\
\text { Maintains, through 2000, the 5.4 cent per gallon (of gasoline) excise tax exemption for fuel } \\
\text { ethanol set by the Omnibus Budget Reconciliation Act of 1990 (P.L. 101-508). Extends the } \\
\text { benefits through September 30, 2007, and December 31, 2007, but cuts the ethanol excise tax } \\
\text { exemption to 5.3, 5.2, and 5.1 cents for 2001-2002, 2003-2004, and 2005-2007, respectively, and } \\
\text { the income tax credits by equivalent amounts. The exemption is eliminated entirely in } 2008 .\end{array}$ \\
\hline 1998
\end{tabular}

\section{Regulatory}

The Public Utility Regulatory Policies Act of 1978 (PURPA) was the most significant section of the National Energy Act in fostering the development of facilities to generate electricity from renewable energy sources. However, with the electric power industry challenging its legality and implementation issues, the broad application of PURPA did not occur until after the legality of PURPA was upheld in 1981. PURPA opened the door to competition in the U.S. electricity supply market by requiring utilities to buy electricity from qualifying facilities (QFs). QFs are defined as nonutility facilities that produce electric power using cogeneration technology, or power plants no greater than 80 megawatts of capacity that use renewable energy sources. There is no size restriction for cogeneration plants; however, at least 5 percent of the energy output from a qualifying cogeneration facility must be dedicated to "useful" thermal applications.

Under PURPA, utilities are required to purchase electricity from QFs at the utilities' "avoided cost." The Federal government, in formulating regulations, often delegates implementation to the States. This occurred with PURPA, as the Federal Energy Regulatory Commission (FERC) delegated the authority for the determination of avoided cost to the States. In several States including California, avoided cost purchase contracts were very favorable to non-utility generators. For example, between 1982 and 1988, Standard Offer 4 (SO4) contracts written in California allowed QFs to sell renewable energy under 15-to30 year terms. The contract guarantees fixed payment rates (based on forecasted short-run avoided costs) for up to 10 years if the QF has signed a contract for at least 20 years. After the $10^{\text {th }}$ year, energy prices moved to the short-run avoided cost of the purchasing utility. The 10 -year provisions were tied to 
forecasts of increases in oil and gas prices, and were the basis for the fixed payments for the first ten years of the contracts. The forecasts were much higher than prices actually turned out to be. Therefore, a price and revenue drop occurred in the eleventh year when the fixed contract energy prices converted to variable prices (based on short-term avoided cost), greatly lessening the economic viability of affected projects.

This assessment of the effectiveness of PURPA is actually an assessment of PURPA in combination with various tax incentives in place between 1978 and 1998. Under PURPA, qualifying facilities (QF) not only sold electricity to electric utilities at the utility's avoided cost rates-these facilities were also granted tax benefits described in, which lowered their overall costs. PURPA's QF status applied to existing as well as new projects. Together, by year end 1998, existing and new projects totaled 12,658 megawatts of QF renewable capacity (Table 3$)$. Of this, two-thirds (8,219 megawatts) of QF capacity was biomass. Some of these biomass QFs, however, were not "new" facilities, but rather had gone into commercial operation prior to PURPA. PURPA enabled these facilities to connect to the grid, if they chose to become QFs, and sell any generation beyond their own use at avoided cost rates.

\begin{tabular}{|l|r|r|}
\hline \multicolumn{1}{|c|}{ Table 7.3: Nonutility Qualifying Facilities Using Renewable Resources as of December 31, 1998 } \\
\hline \multicolumn{1}{|c|}{ Fuel Source } & $\begin{array}{c}\text { Nameplate Capacity } \\
\text { (megawatts) }\end{array}$ & $\begin{array}{c}\text { Gross Generation } \\
\text { (thousand megawatthours) }\end{array}$ \\
\hline \hline Biomass & 8,219 & 45,032 \\
\hline Geothermal & 1,449 & 9,882 \\
\hline Hydroelectric ${ }^{\text {a }}$ & 1,263 & 5,756 \\
\hline Wind & 1,373 & 2,568 \\
\hline Solar Thermal & 340 & 876 \\
\hline Photovoltaic & 14 & 11 \\
\hline Total Renewable QF & 12,658 & 64,126 \\
\hline Total QF, All Sources & 60,384 & 327,977 \\
\hline Total Nonutility, All Sources & 98,085 & 421,364 \\
\hline \hline $\begin{array}{l}{ }^{2} \text { Conventional; excludes pumped storage. } \\
\text { Notes: Totals may not equal sum of components due to independent rounding. }\end{array}$ \\
Source: Form ElA-860B, "Annual Electric Generator Report - Nonutility \\
\hline
\end{tabular}

Two of the criteria for evaluating the effectiveness of incentives and mandates such as PURPA are renewable capacity and generation growth. The EIA began collecting data from nonutility companies in 1989 (Table 4), 11 years after the passage of PURPA. However, between 1989 and 1998, renewable capacity increased by 11.9 percent. At the national level, non-hydroelectric renewable generating capacity rose by 4,426 MW; the increase in hydroelectric capacity was 5,703 MW. Renewable generation rose by 22 percent (Table 5). Most of the increase in electricity generation from renewable energy is in the utility hydropower sector, including net imports. Nearly all of the increase in biomass, geothermal, solar, and wind generation occurred between 1989 and 1993. Non-hydro renewable generation, excluding imports, actually declined by more than 5 percent between 1993 and 1998, due primarily to California replacing Standard Offer 4 contract "avoided cost" provisions with competitive bidding mechanisms, and declining production at The Geysers geothermal plant. Also, in 1992, New York amended its Six-Cent Rule, which established a 6-cents-per-kilowatt hour floor on avoided costs for projects less than $80 \mathrm{MW}$ in size, such that it was not applicable to any future power purchase agreements. 


\begin{tabular}{|c|c|c|c|c|c|c|c|c|c|c|}
\hline Source & 1989 & 1990 & 1991 & 1992 & 1993 & 1994 & 1995 & 1996 & 1997 & 1998 \\
\hline Hydroelectric $^{\mathrm{a}}$ & 74,587 & 73,964 & 76,179 & 74,773 & 77,405 & 78,042 & 78,563 & 76,437 & 79,788 & 79,573 \\
\hline Geothermal & 2,603 & 669 | & & & & & 2,968 & & & 2,917 \\
\hline Biomass & 7,840 & 8,796 & 9,627 & 9,701 & 10,045 & 10,465 & 10,280 & $\mid 10,557$ & 10,535 & 10,266 \\
\hline Solar/PV & & & & & & & 333 & 333 & 334 & 365 \\
\hline Wind & 1,697 & 1,911 & 1,975 & 1,823 & 1,813 & 1,745 & 1,731 & 1,678 & 1,579 & 1,698 \\
\hline $\begin{array}{l}\text { Total } \\
\text { Renewables }\end{array}$ & 86,990 & 87,679 & 90,736 & 89,547 & 92,582 & 93,591 & 93,874 & 91,897 & 95,090 & 94,819 \\
\hline $\begin{array}{l}\text { Non } \\
\text { Renewables }\end{array}$ & 637,275 & 647,241 & 649,741 & 657,016 & 662,373 & 670,423 & 675,643 & 683,975 & 683,412 & 681,065 \\
\hline Total & 724,265 & 734,920 & 740,477 & 746,563 & 754,955 & 764,014 & 769,517 & 775,872 & 778,502 & 775,884 \\
\hline \multicolumn{11}{|c|}{$\begin{array}{l}\text { aConventional; excludes pumped storage. } \\
\text { Notes: Biomass capability does not include capability of plants where the Btu of the biomass consumed } \\
\text { represents less than } 50 \text { percent of the Btu consumed from all energy sources. Totals may not equal sum } \\
\text { of components due to independent rounding. } \\
\text { Sources: Energy Information Administration, Form EIA-860A, "Annual Electric Generator Report - } \\
\text { Utility" and predecessor forms, and estimated data using Form EIA-860B, "Annual Electric Generator } \\
\text { Report - Nonutility," and predecessor form. }\end{array}$} \\
\hline
\end{tabular}

\begin{tabular}{|c|c|c|c|c|c|c|c|c|c|c|}
\hline \multicolumn{11}{|c|}{$\begin{array}{l}\text { Table 7.5: Electricity Generation From Renewable Energy by Energy Source, 1989-1998 } \\
\text { (Thousand Kilowatthours) }\end{array}$} \\
\hline Source & 1989 & 1990 & 1991 & 1992 & 1993 & 1994 & 1995 & 1996 & 1997 & 1998 \\
\hline \multicolumn{11}{|c|}{ Nonutility Sector (Gross Generation) } \\
\hline Biomass & $36,350,275$ & $42,499,581$ & $48,259,818$ & $53,606,891$ & $55,745,781$ & $57,391,594$ & $57,513,666$ & $57,937,058$ & $55,144,102$ & $53,744,724$ \\
\hline Geothermal & $5,416,495$ & $7,235,113$ & $8,013,969$ & $8,577,891$ & $9,748,634$ & $10,122,228$ & $9,911,659$ & $10,197,514$ & $9,382,646$ & $9,881,958$ \\
\hline Hydroelectric & $7,124,418$ & $8,152,891$ & $8,180,198$ & $9,446,439$ & $11,510,786$ & $13,226,934$ & $14,773,801$ & $16,555,389$ & $17,902,653$ & $14,632,521$ \\
\hline Solar & 488,527 & $|663,387|$ & 779,206 & 746,277 & 896,796 & 823,973 & 824,193 & 902,830 & 892,892 & 886,553 \\
\hline Wind & $1,832,537$ & $2,250,846$ & $2,605,505$ & $2,916,379$ & $3,052,416$ & $3,481,616$ & $3,185,006$ & $3,399,642$ & $3.248,140$ & $3,015,497$ \\
\hline Total & $51,212,252$ & $60,801,818$ & $67,838,696$ & $75,293,877$ & $80,954,413$ & $85,046,345$ & $86,208,325$ & $88,992,433$ & $86,569,433$ & $82,161,253$ \\
\hline \multicolumn{11}{|c|}{ Electric Utility Sector (Net Generation) } \\
\hline Biomass & $1,959,864$ & $2,064,331$ & $2,038,229$ & $2,088,109$ & $1,986,535$ & $1,985,463$ & $1,647,247$ & $1,912,472$ & $1,983,532$ & $2,024,377$ \\
\hline Geothermal & $9,341,677$ & $8,581,228$ & $8,087,055$ & $8,103,809$ & $7,570,999$ & $6,940,637$ & $4,744,804$ & $5,233,927$ & $5,469,110$ & $5,176,280$ \\
\hline Hydroelectric & $265,063,067$ & $283,433,659$ & $280,060,621$ & $243,736,029$ & $269,098,329$ & $247,070,938$ & $296,377,840$ & $331,058,055$ & $341,273,443$ & $308,843,770$ \\
\hline Solar & 2,567 & 2,448 & 3,338 & 3,169 & 3,802 & 3,472 & 3,909 & 3,169 & 3,481 & 2,518 \\
\hline Wind & 479 & 398 & 285 & 308 & 243 & 309 & 11,097 & 10,123 & 5,977 & 2,957 \\
\hline Total & $276,367,654$ & $294,082,064$ & $290,189,528$ & $253,931,424$ & $278,659,908$ & $256,000,819$ & $302,784,897$ & $338,217,746$ & $348,734,543$ & $316,050,902$ \\
\hline \multicolumn{11}{|c|}{ Imports and Exports } \\
\hline $\begin{array}{l}\text { Geothermal } \\
\text { (Imports) }\end{array}$ & 533,261 & 538,313 & 736,980 & 889,864 & 877,058 & $1,172,117$ & 884,950 & 649,514 & 16,493 & 45,145 \\
\hline $\begin{array}{l}\text { Conventional } \\
\text { Hydroelectric } \\
\text { (Imports) }\end{array}$ & $19,148,542$ & $16,302,116$ & $22,318,562$ & $26,948,408$ & $28,558,134$ & $30,478,863$ & $28,823,244$ & $33,359,983$ & $27,990,905$ & $26,031,784$ \\
\hline $\begin{array}{l}\text { Conventional } \\
\text { Hydroelectric } \\
\text { (Exports) }\end{array}$ & $5,464,824$ & $7,543,487$ & $3,138,562$ & $3,254,289$ & $3,938,973$ & $2,806,712$ & $3,059,261$ & $2,336,340$ & $6,790,778$ & $6,158,582$ \\
\hline $\begin{array}{l}\text { Total Net } \\
\text { Imports }\end{array}$ & $14,216,980$ & $9,296,942$ & |19,916,921 & $24,583,983$ & $25,496,219$ & $28,844,268$ & $26,648,933$ & $31,673,157$ & $21,216,620$ & $19,918,347$ \\
\hline $\begin{array}{l}\text { Total } \\
\text { Renewable } \\
\text { Electricity } \\
\text { Generation }\end{array}$ & $341,796,886$ & $\mid 364,180,824$ & $377,945,145$ & $353,809,284$ & $385,110,540$ & $369,891,432$ & $415,642,155$ & $458,883,336$ & $456,520,167$ & $418,129,367$ \\
\hline $\begin{array}{l}\text { Note: Total } \\
\text { Sources: } \mathbf{N} \\
\text { Sector - 1998 } \\
\text { Energy Inforn } \\
\text { Generator Re } \\
\text { DC). }\end{array}$ & $\begin{array}{l}\text { 8: Energy Infor } \\
\text { nation Adminis } \\
\text { eport - Utility." }\end{array}$ & $\begin{array}{l}\text { rmation Admin } \\
\text { stration, Form } \\
\text { Imports and }\end{array}$ & $\begin{array}{l}\text { iistration, Forn } \\
\text { EIA-860, "Anr } \\
\text { Exports: Ener }\end{array}$ & $\begin{array}{l}\text { m EIA-860B, " } \\
\text { nual Electric G } \\
\text { rgy Information }\end{array}$ & $\begin{array}{l}\text { Annual Electri } \\
\text { eenerator Rep } \\
\text { n Administrati }\end{array}$ & $\begin{array}{l}\text { c Generator R } \\
\text { ort." Electric } \\
\text { on, Renewable }\end{array}$ & $\begin{array}{l}\text { Ueport - Nonutil } \\
\text { Utility Sector- Energy Annu }\end{array}$ & $\begin{array}{l}\text { lity Power Prod } \\
\text { lility." Electric } \\
\text { - 1998: Form E } \\
\text { ual, DOE/EIA-C }\end{array}$ & $\begin{array}{l}\text { ducer Report." } \\
\text { Utility Sector } \\
\text { EIA-860A "Ann } \\
-0603(95-99)(V\end{array}$ & $\begin{array}{l}\text { Nonutility } \\
-1989-1997 \text { : } \\
\text { nual Electric } \\
\text { Washington, }\end{array}$ \\
\hline
\end{tabular}


Data on renewable capacity in California were available for years prior to 1989 . These data, for 1980 through 1996 (Table 6), more clearly show the growth in renewable capacity owned by nonutilities since the passage of PURPA. Renewable-based nonutility capacity (excluding cogeneration) rose from 187 megawatts in 1980 to 3,777 megawatts (excluding small hydropower and cogeneration plants) in 1996.

Table 7.6: California Nonutility Power Plants Installed Capacity, 1980-1996 (Megawatts)

\begin{tabular}{|c|c|c|c|c|c|c|c|}
\hline Year & Cogeneration $^{a}$ & $\begin{array}{l}\text { Waste-to- } \\
\text { Energy }^{\text {b }}\end{array}$ & Geothermal & $\begin{array}{l}\text { Small } \\
\text { Hydro }\end{array}$ & Solar & Wind & Total \\
\hline 1980 & 227 & 14 & 0 & 0 & 0 & 173 & 414 \\
\hline 1981 & 261 & 14 & 0 & 0 & 0 & 176 & 451 \\
\hline 1982 & 412 & 32 & 0 & 48 & 1 & 176 & 669 \\
\hline 1983 & 658 & 46 & 9 & 59 & 8 & 227 & 1,007 \\
\hline 1984 & 893 & 79 & 96 & 67 & 27 & 496 & 1,658 \\
\hline 1985 & 1,444 & 140 & 178 & 107 & 57 & 1,015 & 2,941 \\
\hline 1986 & 1,788 & 275 & 188 & 144 & 122 & 1,235 & 3,752 \\
\hline 1987 & 3,063 & 396 & 319 & 176 & 155 & 1,366 & 5,475 \\
\hline 1988 & 3,662 & 513 & 587 & 229 & 221 & 1,378 & 6,590 \\
\hline 1989 & 4,942 & 783 & 806 & 298 & 301 & 1,382 & 8,512 \\
\hline 1990 & 5,315 & 878 & 870 & 321 & 381 & 1,647 & 9,412 \\
\hline 1991 & 5,838 & 883 & 813 & 330 & 374 & 1,698 & 9,936 \\
\hline 1992 & 5,684 & 804 & 831 & 371 & 408 & 1,729 & 9,827 \\
\hline 1993 & 5,778 & 845 & 863 & 370 & 373 & 1,797 & 10,026 \\
\hline 1994 & 5,857 & 795 & 863 & 410 & 373 & 1,629 & 9,927 \\
\hline 1995 & 6,280 & 709 & 846 & 349 & 368 & 1,630 & 10,182 \\
\hline 1996 & 6,177 & 823 & 885 & 362 & 360 & 1,709 & 10,316 \\
\hline
\end{tabular}

${ }^{a}$ Includes gas-fired facilities and biomass co-firing and cogeneration.

b Waste-to-Energy includes wood and wood waste, municipal solid waste, landfill gas, and other biomass. However, biomass co-firing and cogeneration capacity is included under cogeneration. Source: California Energy Commission, Draft Final Report, California Historical Energy Statistics, January 1998, Publication Number: P300-98-001.

Notes: Data exlude facilities rated less than 5 megawatts. Some data in this table are inconsistent with national data in Table 4 due to different sources, categories, and coverage. Also, these data represent installed capacity, while the data in Table 4 represent net summer capability.

Most of the growth had occurred by 1990 . Between 1990 and 1993, California nonutility renewable capacity (excluding small hydropower and cogeneration plants) increased just 3\% to 3,878 megawatts, and between 1993 and 1995, capacity actually dropped to 3,553 megawatts; generation followed a similar pattern. The principal reasons for this decline were the lower PURPA "avoided costs" when the long-term energy payment provisions of the contracts (usually 10-years), mostly signed in the early 1980s, expired. Natural gas prices in nominal dollars paid by electric utilities in California declines from a high of $\$ 6.77$ per million Btu in 1982 to between $\$ 2.50$ to $\$ 3.00$ in 1986 through 1993. By 1995, the price declined further to $\$ 2.22$. 
This, along with the repeal of the standard investment tax credits in 1986, caused some wind, biomass, and solar facilities to reduce output or cease operation. Also, there was a substantial slowdown in the construction of new capacity. This slowdown transpired despite substantial decreases in short-run average costs of renewables because the operating costs were not reduced enough to be competitive in the market conditions of the mid-to-late 1990s.

Another criterion in evaluating the effectiveness of PURPA, in addition to expansion of renewable energy capacity and generation, is the cost competitiveness of the renewable facilities in the market. Utility wholesale power purchases from other utilities, which are more often made on a mutually agreeable economic basis between utilities and may be regarded as reflecting "wholesale" prices, averaged 3.53 cents per $\mathrm{kWh}$ nationwide in 1995. Although EIA has not attempted to estimate the cost of PURPA directly, it has examined the prices that utilities paid in 1995 to purchase power from nonutilities and, in particular, PURPA QF nonutilities using renewable resources. The average price utilities paid all nonutilities was 6.31 cents per $\mathrm{kWh}$ nationwide, considerably higher than the average wholesale price. Higher still was the price utilities paid nonutilities for renewable-based electricity. Utilities paid an average of 9.05 cents per kWh for nearly 42,800 million kWh of power from renewable QFs in 1995, compared with just 5.17 cents per $\mathrm{kWh}$ for 3,300 million $\mathrm{kWh}$ of power from non-QF renewables. This difference was even more extreme in California, where the renewable $\mathrm{QF} /$ non-QF purchased power costs were 12.79 and 3.33 cents per $\mathrm{kWh}$, respectively. All non-QF purchases of renewable energy, however, were from hydropower facilities, the lowest cost renewable resource-and the lowest cost of all electricity resources. In analyzing these data, the reader should bear in mind that by 1995 , many of the original PURPA power purchase contracts between utilities and nonutilities had expired. Therefore, the data reflect a mixture of the original avoided cost contracts and newer contracts.

Renewable-based generation costs would obviously have compared much more favorably with other generation costs during 2000, when California experienced severe electricity and natural gas shortages. Natural gas prices--the primary basis for determining alternative generation cost--rose sharply during 2000. Through September, the average cost of gas delivered to electric utilities in California increased to $\$ 4.32$ per million Btu as compared to \$2.68 for deliveries through September 1999 . 
Appendix 1

Biomass Feedstock Availability in the United States 


\section{Biomass Feedstock Availability in the United States: 1999 State Level}

\section{Analysis}

Marie E. Walsh $^{\mathrm{a}}$, Robert L. Perlack ${ }^{\mathrm{a}}$, Anthony Turhollow ${ }^{\mathrm{a}}$, Daniel de la Torre Ugarte ${ }^{\mathrm{b}}$, Denny A. Becker $^{\mathrm{c}}$, Robin L. Graham ${ }^{\mathrm{a}}$, Stephen E. Slinsky ${ }^{\mathrm{b}}$, and Daryll E. Ray ${ }^{\mathrm{b}}$

${ }^{a}$ Oak Ridge National Laboratory, Oak Ridge, TN 37831-6205

${ }^{b}$ University of Tennessee, Knoxville, TN 37901-1071

${ }^{\mathrm{c} S}$ cience Applications International Corporation, Oak Ridge, TN 37830

April 30, 1999, Updated January, 2000

\section{Introduction}

Interest in using biomass feedstocks to produce power, liquid fuels, and chemicals in the U.S. is increasing. Central to determining the potential for these industries to develop is an understanding of the location, quantities, and prices of biomass resources. This paper describes the methodology used to estimate biomass quantities and prices for each state in the continental U.S. An Excel ${ }^{\mathrm{TM}}$ spreadsheet contains estimates of biomass quantities potentially available in five categories: mill wastes, urban wastes, forest residues, agricultural residues and energy crops. Availabilities are sorted by anticipated delivered price. A presentation that explains how this information was used to support the goal of increasing biobased products and bioenergy 3 times by 2010 expressed in Executive Order 13134 of August 12, 1999 is also available.

\section{Biomass Feedstock Availability}

For the purpose of this analysis, biomass feedstocks are classified into five general categories: forest residues, mill residues, agricultural residues, urban wood wastes, and dedicated energy crops. Forestry is a major industry in the United States encompassing nearly 559 million acres in publicly and privately held forest lands in the continental U.S. (USDA, 1997). Nearly 16 million cubic feet of roundwood are harvested and processed annually to produce sawlogs, paper, veneers, composites and other fiber products (USDA, 1998a). The extensive forest acreage and roundwood harvest generate logging residues and provide the potential to harvest non-merchantable wood for energy. Processing of the wood into fiber products creates substantial quantities of mill residues that could potentially be used for energy. Agriculture is another major industry in the United States. Approximately 337 million acres of cropland are currently in agricultural production (USDA, 1997). Following the harvest of many of the traditional agricultural crops, residues (crop stalks) are left in the field. A portion of these residues could potentially be collected and used for energy. Alternatively, crop acres could be used to grow dedicated energy crops. A final category of biomass feedstocks includes urban wood wastes. These wastes include yard trimmings and other wood materials that are generally disposed of in municipal solid waste (MSW) and construction/demolition (C/D) landfills. Following is a description of the potential availability of these biomass feedstocks in the United States.

\section{A. Forest Residues}

Forest wood residues can be grouped into the following categories--logging residues; rough, rotten, and salvable dead wood; excess saplings; and small pole trees $\frac{(1)}{}$. The forest wood residue supplies that could potentially be available for energy use in the U.S. are estimated using an updated version of a model originally developed by McQuillan et al. (1984). The McQuillan model estimates the total quantities of forest wood residues that can be recovered by first classifying the total forest inventory by the above wood categories (for both softwood and 
hardwood), and by volume, haul distances, and equipment operability constraints. This total inventory is then revised downward to reflect the quantities that can be recovered in each class due to constraints on equipment retrieval efficiencies, road access to a site, and impact of site slope on harvest equipment choice $\frac{(2)}{\text {. }}$.

The costs of obtaining the recoverable forest wood residues are estimated for each category. Prices include collection, harvesting, chipping, loading, hauling, and unloading costs, a stumpage fee, and a return for profit and risk. Prices are in 1995 dollars. For the purposes of this analysis, we have included only logging residues and rough, rotten, and salvable dead wood quantities. The potential annual forest waste residues available by state for three price scenarios are presented in Table 1. Quantities are cumulative quantities at each price (i.e., quantities at $\$ 50 / \mathrm{dt}$ include all quantities available at $\$ 40 / \mathrm{dt}$ plus quantities available between $\$ 40$ and $\$ 50 / \mathrm{dt})$.

Polewood, which represent the growing stock of merchantable trees, has not been included in the analysis due to the fact that it could potentially be left to grow and used for higher value fiber products. It is doubtful that these trees will be harvested for energy use. However, if harvested, they could add another 17 million dry tons at less than \$30/dt delivered; 37.7 million dry tons at less than $\$ 40$ delivered; and 65 million dry tons at less than $\$ 50 / \mathrm{dt}$ delivered. For a more detailed explanation of the methodology used to estimate the forest wood residue quantities and prices, see Walsh et al, 1998.

Table 1: Estimated Annual Cumulative Forest Residues Quantities (dry tons), by Delivered Price and State

\begin{tabular}{|l|l|l|l|}
\hline & $\begin{array}{l}<\$ 30 / \text { dry ton } \\
\text { delivered }\end{array}$ & $\begin{array}{l}<\$ 40 / \text { dry ton } \\
\text { delivered }\end{array}$ & $\begin{array}{l}<\$ 50 / \text { dry ton } \\
\text { delivered }\end{array}$ \\
\hline Alabama & 1009000 & 1475000 & 1899000 \\
\hline Arizona & 134000 & 200000 & 261400 \\
\hline Arkansas & 928000 & 1352000 & 1737800 \\
\hline California & 1231000 & 1819000 & 2364400 \\
\hline Colorado & 373000 & 554000 & 720300 \\
\hline Connecticut & 109000 & 159000 & 204100 \\
\hline Delaware & 26000 & 37000 & 48400 \\
\hline Florida & 515000 & 755000 & 9757000 \\
\hline Georgia & 1041000 & 1525000 & 1967800 \\
\hline Idaho & 605000 & 902000 & 1179500 \\
\hline Illinois & 228000 & 330000 & 423300 \\
\hline Indiana & 253000 & 367000 & 470100 \\
\hline Iowa & 72000 & 105000 & 135000 \\
\hline
\end{tabular}




\begin{tabular}{|l|l|l|l|}
\hline Kansas & 47000 & 68000 & 88100 \\
\hline Kentucky & 475000 & 690000 & 883500 \\
\hline Louisiana & 872000 & 1275000 & 1641800 \\
\hline Maine & 806000 & 1182000 & 1529100 \\
\hline Maryland & 189000 & 273000 & 351200 \\
\hline Massachusetts & 196000 & 284000 & 366200 \\
\hline Michigan & 710000 & 1034000 & 1327900 \\
\hline Minnesota & 468000 & 682000 & 874900 \\
\hline Mississippi & 946000 & 1380000 & 1774600 \\
\hline Missouri & 505000 & 733000 & 938700 \\
\hline Montana & 676000 & 1007000 & 1316700 \\
\hline Nebraska & 19000 & 27000 & 34400 \\
\hline Nevada & 8000 & 11000 & 14400 \\
\hline New Hampshire & 299000 & 438000 & 564400 \\
\hline New Jersey & 70000 & 102000 & 130700 \\
\hline New Mexico & 125000 & 185000 & 241900 \\
\hline New York & 933000 & 1360000 & 1746400 \\
\hline North Carolina & 1068000 & 1557000 & 2004900 \\
\hline North Dakota & 11000 & 17000 & 21700 \\
\hline Ohio & 232000 & 335000 & 430100 \\
\hline Oklahoma & 156000 & 228000 & 292200 \\
\hline Oregon & 1299000 & 1928000 & 2515900 \\
\hline Pennsylvania & 948000 & 1377000 & 1763000 \\
\hline Rhode Island & 20000 & 27000 & 35900 \\
\hline South Carolina & 613000 & 898000 & 1158400 \\
\hline South Dakota & 33000 & 49000 & 64300 \\
\hline Tennessee & 930000 & 1351000 & 1732600 \\
\hline Texas & 557000 & 814000 & 1050700 \\
\hline & & & \\
\hline
\end{tabular}




\begin{tabular}{|l|l|l|l|}
\hline Utah & 90000 & 133000 & 173000 \\
\hline Vermont & 265000 & 386000 & 497200 \\
\hline Virginia & 959000 & 1397000 & 1793600 \\
\hline Washington & 1230000 & 1825000 & 2379600 \\
\hline West Virginia & 727000 & 1056000 & 1352500 \\
\hline Wisconsin & 609000 & 886000 & 1138400 \\
\hline Wyoming & 132000 & 196000 & 256100 \\
\hline \multicolumn{4}{|l|}{} \\
\hline U.S. Total & 23747000 & 34771000 & 44871800 \\
\hline
\end{tabular}

\section{B. Primary Mill Residues}

The quantities of mill residues generated at primary wood mills (i.e., mills producing lumber, pulp, veneers, other composite wood fiber materials) in the U.S. are obtained from the data compiled by the USDA Forest Service for the 1997 Resource Policy Act (RPA) Assessment (USDA, 1998a). Mill residues are classified by type and include bark; coarse residues (chunks and slabs); and fine residues (shavings and sawdust). Data is available for quantities of residues generated by residue type and on uses of residues by residue type and use category (i.e., not used, fuel, pulp, composite wood materials, etc.). Data is available at the county, state, subregion, and regional level. In cases where a county has fewer than three mills, data from multiple counties are combined to maintain the confidentiality of the data provided by individual mills. Data represent short run average quantities.

Because primary mill residues are clean, concentrated at one source, and relatively homogeneous, nearly 98 percent of all residues generated in the United States are currently used as fuel or to produce other fiber products. Of the 24.2 million dry tons of bark produced in the U.S., 2.2 percent is not used while 79.4 percent is used for fuel and 18 percent is used for such things as mulch, bedding, and charcoal. Only about 1.4 percent of the 38.7 million dry tons of coarse residues are not used. The remainder are used to produce pulp or composite wood products such as particle board, wafer board, and oriented strand board (78 percent) and about 13 percent are used for fuel. Of the 27.5 million dry tons of fine wood residues, approximately 55.6 percent are used for fuel, 23 percent are used to produce pulp or composite wood products, 18.7 percent are used for bedding, mulch and other such uses, and about 2.6 percent are unused. The residues, while currently used, could potentially be available for energy use if utilities could pay a higher price for the residues than their value in their current uses. Data regarding the value of these residues in their current uses are difficult to obtain. Much of the residues used for fuel are used on site by the residue generator in low efficiency boiler systems to produce heat and steam. Conversations with those in the industry and other anecdotal evidence suggests that these residues could be purchased for $\$ 15-25 /$ dry ton for use in higher efficiency fuel systems. Similar anecdotal evidence suggests that residues used to produce fiber products (pulp, composite wood materials) sell for about \$30-40/dry ton. For the purposes of this analysis, we assume that the residues not currently used could potentially be available for energy uses at delivered prices of less than $\$ 20 /$ dry ton (assuming transportation distances of less than 50 miles). For similar 
transportation distances, we assume that residues currently used for fuel could be available at less than $\$ 30 /$ dry ton delivered and residues currently used for pulp, composite wood materials, mulch, bedding, and other such uses could potentially be available at delivered prices of less than $\$ 50 /$ dry ton. Table 2 presents the cumulative annual quantities of mill residues by delivered price for each state. 


\begin{tabular}{|c|c|c|c|}
\hline \multicolumn{4}{|c|}{$\begin{array}{c}\text { Table 2: Estimated Annual Cumulative Mill Residue Quantities } \\
\text { Delivered Price and State }\end{array}$} \\
\hline & $<\$ 20 /$ dry ton delivered & $<\$ 30 /$ dry ton delivered & $<\$ 50 /$ dry ton delivered \\
\hline Alabama & 17000 & 4581000 & 7802000 \\
\hline Arizona & 0 & 75000 & 251000 \\
\hline Arkansas & 2000 & 2497000 & 4705000 \\
\hline California & 8000 & 2294000 & 4823000 \\
\hline Colorado & 86000 & 121000 & 180000 \\
\hline Connecticut & 0 & 40000 & 91000 \\
\hline Delaware & 0 & 4000 & 16000 \\
\hline Florida & 4000 & 1412000 & 2678000 \\
\hline Georgia & 72000 & 3913000 & 7969000 \\
\hline Idaho & 69000 & 1629000 & 4400000 \\
\hline Illinois & 19000 & 117000 & 282000 \\
\hline Indiana & 31000 & 213000 & 699000 \\
\hline Iowa & 2000 & 46000 & 158000 \\
\hline Kansas & 1000 & 9000 & 20000 \\
\hline Kentucky & 109000 & 421000 & 1940000 \\
\hline Louisiana & 64000 & 1943000 & 3245000 \\
\hline Maine & 43000 & 209000 & 504000 \\
\hline Maryland & 0 & 13000 & 166000 \\
\hline Massachusetts & 0 & 44000 & 135000 \\
\hline Michigan & 10000 & 932000 & 1564000 \\
\hline Minnesota & 71000 & 916000 & 1121000 \\
\hline Mississippi & 128000 & 3178000 & 6029000 \\
\hline Missouri & 162000 & 315000 & 1196000 \\
\hline Montana & 17000 & 659000 & 2173000 \\
\hline
\end{tabular}




\begin{tabular}{|l|l|l|l|}
\hline Nebraska & 12000 & 21000 & 69000 \\
\hline Nevada & 0 & 0 & 0 \\
\hline $\begin{array}{l}\text { New } \\
\text { Hampshire }\end{array}$ & 23000 & 439000 & 1109000 \\
\hline New Jersey & 0 & 8000 & 21000 \\
\hline New Mexico & 25000 & 61000 & 125000 \\
\hline New York & 28000 & 495000 & 1274000 \\
\hline North Carolina & 33000 & 2060000 & 5028000 \\
\hline North Dakota & 0 & 3000 & 4000 \\
\hline Ohio & 0 & 0 & 0 \\
\hline Oklahoma & 0 & 318000 & 698000 \\
\hline Oregon & 10000 & 1738000 & 6834000 \\
\hline Pennsylvania & 172000 & 591000 & 1628000 \\
\hline Rhode Island & 0 & 11000 & 25000 \\
\hline South Carolina & 4000 & 1706000 & 3382000 \\
\hline South Dakota & 8000 & 46000 & 124000 \\
\hline Tennessee & 202000 & 1325000 & 2018000 \\
\hline Texas & 18000 & 1649000 & 4043000 \\
\hline Utah & 20000 & 67000 & 102000 \\
\hline Vermont & 0 & 59000 & 124000 \\
\hline Virginia & 80000 & 1234000 & 2860000 \\
\hline Washington & 5000 & 2262000 & 5689000 \\
\hline West Virginia & 136000 & 459000 & 192000 \\
\hline Wisconsin & 42000 & 1202000 & 255000 \\
\hline Wyoming & 47000 & 124000 & \\
\hline & 1780000 & & \\
\hline U.S. Total & & & 91459000 \\
\hline
\end{tabular}




\section{Agricultural Residues}

Agriculture is a major activity in the United States. Among the most important crops in terms of average total acres planted from 1995 to 1997 are corn (77 million acres), wheat (72 million acres), soybeans ( 65 million acres), hay (60.5 million acres), cotton (15 million acres), grain sorghum (10 million acres), barley ( 7 million acres), oats ( 5 million acres), rice ( 3 million acres), and rye (1.5 million acres) (USDA, 1998b). After harvest, a portion of the stalks could potentially be collected for energy use. The analysis in this paper is limited to corn stover and wheat straw. Large acreage is dedicated to soybean production, but in general, residue production is relatively small and tends to deteriorate rapidly in the field, limiting the usefulness of soybean as an energy feedstock. However, additional residue quantities could be available from this source that have not been included in this analysis. Similarly, additional residue quantities could be available if barley, oats, rice, and rye production were included. Production of some of these crops (rice in particular) tends to be concentrated in a relatively small geographic area, and thus these crops could be an important local source of resources. Another potential source in the southern U.S. is cotton. A recent study (NEOS, 1998) suggests that approximately 500,000 dry tons of cotton gin trash is currently produced in the United States and this material is generally given away to farmers for use as a soil amendment. Another 171,000 dry tons of textile mill residues are produced, but much of this material is used to make other textiles and sells for prices in excess of $\$ 100 /$ dry ton. These quantities are not included in this analysis.

The quantities of corn stover and wheat straw residues that can be available in each state are estimated by first calculating the total quantities of residues produced and then calculating the total quantities that can be collected after taking into consideration quantities that must be left to maintain soil quality (i.e., maintain organic matter and prevent erosion). Residue quantities generated are estimated using grain yields, total grain production, and a ratio of residue quantity to grain yield,,$\underline{(3)}$ The net quantities of residue per acre that are available for collection are estimated by subtracting from the total residue quantity generated, the quantities of residues that must remain to maintain quality (Lightle, 1997). Quantities that must remain differ by crop type, soil type, typical weather conditions, and the tillage system used. A state average was used for this analysis. In general, about 30 to 40 percent of the residues can be collected.

The estimated prices of corn stover and wheat straw include the cost of collecting the residues, the premium paid to farmers to encourage participation, and transportation costs.

The cost of collecting the agricultural residues are estimated using an engineering approach. For each harvest operation, an equipment complement is defined. Using typical engineering specifications, the time per acre required to complete each operation and the cost per hour of using each piece of equipment is calculated (ASAE, 1995; NADA, 1995; USDA, 1996; Doanes, 1995). For corn stover, the analysis assumes $1 \mathrm{x}$ mow, $1 \mathrm{x}$ rake, $1 \mathrm{x}$ bale with a large round baler, and pickup, transport, and unloading of the bales at the side of the field where they are stored until transport to the user facility. The same operations are assumed for wheat straw minus the mowing. The operations assumed are conservative--mowing is often eliminated and the raking operation is also eliminated in some circumstances. The method used to estimate collection costs is consistent with that used by USDA to estimate the costs of producing agricultural crops (USDA, 1996).

An additional cost of $\$ 20 /$ dry ton is added to account for the premium paid to farmers and the transportation cost from the site of production to the user facility. Currently, several companies purchase corn stover and/or wheat straw to produce bedding, insulating materials, particle board, paper, and chemicals (Gogerty, 1996). These firms typically pay $\$ 10$ to $\$ 15 /$ dry ton to farmers to compensate for any lost nutrient or environmental benefits that result from harvesting residues. The 
premium paid to farmers depends, in part, on transportation distance with farmers whose fields are at greater distances from the user facility receiving lower premiums. Studies have estimated that the cost of transporting giant round bales of switchgrass are $\$ 5$ to $\$ 10$ per dry ton for haul distances of less than 50 miles (Bhat et al, 1992; Graham et al, 1996; Noon et al, 1996). Agricultural residue bales are of similar size, weight, and density as switchgrass bales, and a similar transportation cost is assumed. This cost is similar to the reported transportation costs of facilities that utilize agricultural residues (Schechinger, 1997). Prices are in 1995\$. For a more detailed explanation of the methodology used to estimate agricultural residue quantities and prices, see Walsh et al, 1998. The estimated annual cumulated agricultural residues quantities, by delivered price and state are contained in Table 3. Table 3 also contains by state, the percent of the total available residues that are corn stover. 


\begin{tabular}{|c|c|c|c|c|c|c|}
\hline \multicolumn{5}{|c|}{$\begin{array}{c}\text { Table 3: Estimated Annual Cumulative Agricultural Residue } \\
\text { Delivered Price and State }\end{array}$} & \multicolumn{2}{|c|}{ Quantities (dry tons), by } \\
\hline & \multicolumn{2}{|c|}{$<\$ 30 /$ dry ton delivered } & \multicolumn{2}{|c|}{$<\$ 40 /$ dry ton delivered } & \multicolumn{2}{|c|}{$<\$ 50 /$ dry ton delivered } \\
\hline & Quantity & $\%$ Corn & Quantity & $\%$ Corn & Quantity & $\%$ Corn \\
\hline Alabama & 0 & 0 & 0 & 0 & 19267 & 0 \\
\hline Arizona & 0 & 0 & 221864 & 24 & 221864 & 24 \\
\hline Arkansas & 0 & 0 & 859361 & 0 & 984495 & 13 \\
\hline California & 0 & 0 & 1478283 & 40 & 1478283 & 40 \\
\hline Colorado & 0 & 0 & 2523820 & 90 & 2523820 & 90 \\
\hline Connecticut & 0 & 0 & 0 & 0 & 0 & 0 \\
\hline Delaware & 0 & 0 & 88077 & 0 & 300736 & 0 \\
\hline Florida & 0 & 0 & 14824 & 0 & 14824 & 0 \\
\hline Georgia & 0 & 0 & 344423 & 0 & 779871 & 56 \\
\hline Idaho & 0 & 0 & 1248120 & 10 & 1248120 & 10 \\
\hline Illinois & 0 & 0 & 24270757 & 94 & 24270757 & 94 \\
\hline Indiana & 0 & 0 & 11883845 & 94 & 11883845 & 94 \\
\hline Iowa & 0 & 0 & 23911214 & 99 & 23911214 & 99 \\
\hline Kansas & 0 & 0 & 8570003 & 48 & 8570003 & 48 \\
\hline Kentucky & 0 & 0 & 471819 & 0 & 2280603 & 49 \\
\hline Louisiana & 0 & 0 & 80930 & 0 & 380557 & 79 \\
\hline Maine & 0 & 0 & 0 & 0 & 0 & 0 \\
\hline Maryland & 0 & 0 & 272468 & 0 & 802298 & 66 \\
\hline Massachusetts & 0 & 0 & 0 & 0 & 0 & 6 \\
\hline Michigan & 0 & 0 & 680783 & 0 & 4265671 & 84 \\
\hline Minnesota & 0 & 0 & 11935896 & 88 & 11935896 & 88 \\
\hline Mississippi & 0 & 0 & 0 & 0 & 37877 & 0 \\
\hline Missouri & 0 & 0 & 1204353 & 0 & 4081358 & 70 \\
\hline Montana & 0 & 0 & 406592 & 9 & 406592 & 9 \\
\hline
\end{tabular}




\begin{tabular}{|l|l|l|l|l|l|l|}
\hline Nebraska & 0 & 0 & 16326915 & 98 & 16326915 & 98 \\
\hline Nevada & 0 & 0 & 15350 & 0 & 15350 & 0 \\
\hline $\begin{array}{l}\text { New } \\
\text { Hampshire }\end{array}$ & 0 & 0 & 0 & 0 & 0 & 0 \\
\hline New Jersey & 0 & 0 & 32723 & 0 & 32723 & 0 \\
\hline New Mexico & 0 & 0 & 476529 & 55 & 476529 & 55 \\
\hline New York & 0 & 0 & 129515 & 0 & 129515 & 0 \\
\hline North Carolina & 0 & 0 & 473229 & 0 & 1130744 & 58 \\
\hline North Dakota & 0 & 0 & 14015 & 0 & 3715404 & 0 \\
\hline Ohio & 0 & 0 & 7634476 & 82 & 7634476 & 82 \\
\hline Oklahoma & 3214403 & 0 & 3440745 & 7 & 3440745 & 7 \\
\hline Oregon & 0 & 0 & 155855 & 40 & 155855 & 40 \\
\hline Pennsylvania & 0 & 0 & 197689 & 0 & 1031195 & 0 \\
\hline Rhode Island & 0 & 0 & 0 & 0 & 0 & 0 \\
\hline South Carolina & 0 & 0 & 239680 & 0 & 239680 & 0 \\
\hline South Dakota & 0 & 0 & 3686246 & 71 & 2852740 & 71 \\
\hline Tennessee & 0 & 0 & 300849 & 0 & 1004781 & 70 \\
\hline Texas & 0 & 0 & 4497784 & 66 & 4497784 & 66 \\
\hline Utah & 0 & 0 & 216546 & 29 & 216546 & 29 \\
\hline Vermont & 0 & 0 & 0 & 0 & 0 & 0 \\
\hline Virginia & 0 & 0 & 297986 & 0 & 585717 & 21 \\
\hline Washington & 0 & 0 & 1364254 & 30 & 1364254 & 30 \\
\hline West Virginia & 0 & 0 & 12008 & 0 & 51295 & 77 \\
\hline Wisconsin & 0 & 0 & 5179618 & 97 & 5179618 & 97 \\
\hline Wyoming & 0 & 0 & 171585 & 51 & 171585 & 51 \\
\hline & 3214403 & 0 & 135331029 & 81 & 150651402 & 80 \\
\hline U.S. Total & 0 & & & & 0 & \\
\hline
\end{tabular}




\section{Dedicated Energy Crops}

Dedicated energy crops include short rotation woody crops (SRWC) such as hybrid poplar and hybrid willow, and herbaceous crops such as switchgrass (SG). Currently, dedicated energy crops are not produced in the United States, but could be if they could be sold at a price that ensures the producer a profit at least as high as could be earned using the land for alternative uses such as producing traditional agricultural crops. The POLYSYS model is used to estimate the quantities of energy crops that could potentially be produced at various energy crop prices. POLYSYS is an agricultural sector model that includes all major agricultural crops (wheat, corn, soybeans, cotton, rice, grain sorghum, barley, oats, alfalfa, other hay crops); a livestock sector; and food, feed, industrial, and export demand functions. POLYSYS was developed and is maintained by the Agricultural Policy Analysis Center at the University of Tennessee and is used by the USDA Economic Research Service to conduct economic and policy analysis. Under a joint project between USDA and DOE, POLYSYS is being modified to include dedicated energy crops. A workshop consisting of USDA and DOE experts was held in November, 1997 to review the energy crop data being incorporated into the POLYSYS model.

The analysis includes cropland acres that are presently planted to traditional crops, idled, in pasture, or are in the Conservation Reserve Program. Energy crop production is limited to areas climatically suited for their production--states in the Rocky Mountain region and the Western Plains region are excluded. Because the CRP is an environmental program, two management scenarios have been evaluated--one to optimize for biomass yield and one to provide for high wildlife divesity. Energy crop yields vary within and between states, and are based on field trial data and expert opinion. Energy crop production costs are estimated using the same approach that is used by USDA to estimate the cost of producing conventional crops (USDA, 1996). Recommended management practices (planting density, fertilizer and chemical applications, rotation lengths) are assumed. Additionally, switchgrass stands are assumed to remain in production for 10 years before replanting, are harvested annually, and are delivered as large round bales. Hybrid poplars are planted at a $8 \times 10$ foot spacing ( 545 trees/acre) and are harvested in the 10th year of production in the northern U.S., after 8 years of production in the southern U.S., and after 6 years of production in the Pacific Northwest. Poplar harvest is by custom operation and the product is delivered as whole tree wood chips. Hybrid willow varieties are suitable for production in the northern U.S. The analysis assumes 6200 trees/acre, with first harvest in year 4 and subsequent harvests every three years for a total of 7 harvests before replanting is necessary. Willow is delivered as whole tree chips.

The estimated quantities of energy crops are those that could potentially be produced at a profit at least as great as could be earned producing traditional crops on the same acres, given the assumed energy crop yield and production costs, and the 1999 USDA baseline production costs, yields, and traditional crop prices (USDA, 1999b). In the U.S., switchgrass production dominates hybrid poplar and willow production at the equivalent (on an MBTU basis) market prices. The POLYSYS model estimates the farmgate price; an average transportation cost of $\$ 8 / \mathrm{dt}$ is added to determine the delivered price. Prices are in $\$ 1997$. Table 4 presents the estimated annual cumulative quantities of energy crops by state by delivered price. For a more detailed explanation of the methodology used to estimate dedicated energy crop prices and quantities, see Walsh et al, 1998 and de la Torre Ugarte et al, 1999. 


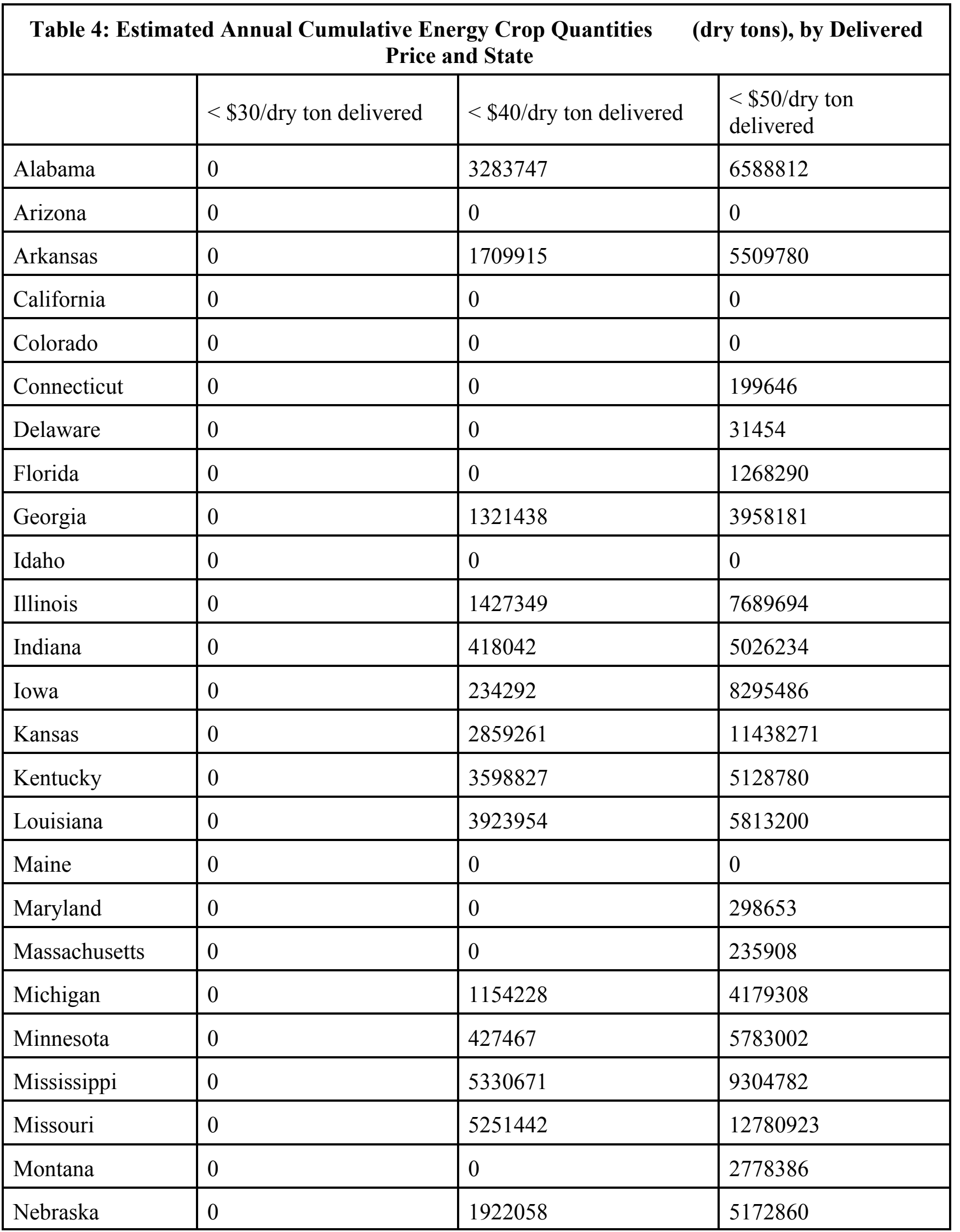




\begin{tabular}{|l|l|l|l|}
\hline Nevada & 0 & 0 & 0 \\
\hline New Hampshire & 0 & 0 & 158757 \\
\hline New Jersey & 0 & 0 & 142902 \\
\hline New Mexico & 0 & 0 & 0 \\
\hline New York & 0 & 0 & 3388035 \\
\hline North Carolina & 0 & 639228 & 1632077 \\
\hline North Dakota & 0 & 1928463 & 16757889 \\
\hline Ohio & 0 & 3808089 & 9657080 \\
\hline Oklahoma & 0 & 3644173 & 8083722 \\
\hline Oregon & 0 & 0 & 0 \\
\hline Pennsylvania & 0 & 0 & 2338243 \\
\hline Rhode Island & 0 & 0 & 4943 \\
\hline South Carolina & 0 & 1338745 & 2438152 \\
\hline South Dakota & 0 & 5613863 & 12757734 \\
\hline Tennessee & 0 & 6616717 & 9350856 \\
\hline Texas & 0 & 4549899 & 9139885 \\
\hline Utah & 0 & 0 & 0 \\
\hline Vermont & 0 & 0 & 333465 \\
\hline Virginia & 0 & 1260668 & 2609867 \\
\hline Washington & 0 & 0 & 0 \\
\hline West Virginia & 0 & 369250 & 1890299 \\
\hline Wisconsin & 0 & 06127422 & \\
\hline Wyoming & 0 & & 067361 \\
\hline & 0 & 0 & 0 \\
\hline U.S. Total & 0 & 0 & \\
\hline
\end{tabular}




\section{E. Urban Wood Wastes}

Urban wood wastes include yard trimmings, site clearing wastes, pallets, wood packaging, and other miscellaneous commercial and household wood wastes that are generally disposed of at municipal solid waste (MSW) landfills and demolition and construction wastes that are generally disposed of in construction/demolition (C/D) landfills. Data regarding quantities of these wood wastes is difficult to find and price information is even rarer. Additionally, definitions differ by states. Some states collect data on total wastes deposited at each MSW and C/D landfill in their states, and in some states, the quantities are further categorized by type (i.e., wood, paper and cardboard, plastics, etc.). However, not all states collect this data. Therefore, the quantities presented are crude estimates based on survey data (Glenn, 1998; Bush et al, 1997; Araman et al, 1997).

For municipal solid wastes (MSW) a survey by Glenn, 1998 is used to estimate total MSW generated by state. These quantities are adjusted slightly to correspond to regional MSW quantities that are land-filled as estimated by a survey conducted by Araman et al, 1997. Using the Araman survey, the total amount of wood contained in land-filled MSW is estimated. According to this survey, about 6 percent of municipal solid waste in the Midwest is wood, with 8 percent of the MSW being wood in the South, 6.6 percent being wood in the Northeast and 7.3 percent being wood in the West. Estimated quantities were in wet tons; they were corrected to dry tons by assuming a 15 percent moisture content by weight.

To estimate construction and demolition wastes (C/D), the Glenn study and the Bush et al, 1997 survey were used. The Glenn study provided the number of C/D landfills by state, and the Bush et al survey provided the average quantity of waste received per C/D landfill by region as well as the regional percent of the waste that was wood. According to the Bush et al survey, C/D landfills in the Midwest receive an average 25,700 tons of waste per year with 46 percent of that quantity being wood. In the South, C/D landfills receive an average 36,500 tons of waste/yr with 39 percent being wood. Northeastern C/D landfills receive an average 13,700 tons of waste/yr with 21 percent being wood and Western C/D landfills receive an average 28,800 tons of waste/yr with 18 percent being wood. Estimated quantities were in wet tons; they were corrected to dry tons by assuming a 15 percent moisture content by weight.

Yard trimmings taken directly to a compost facility rather than land-filled, were estimated from the Glenn study. This estimate was made by multiplying the number of compost facilities in each state by the national average tons of material received by site ( 2750 tons). The total compost material was then corrected for the percent that is yard trimmings (assumed to be 80 percent) and for the quantity that is wood (assumed to be 90 percent). Quantities were corrected to dry tons by assuming a 40 percent moisture by weight.

In an effort to reduce the quantities of waste materials that are land-filled, most states actively encourage the recycling of wastes. Quantities and prices of recycled wood wastes are not readily available. However, the Araman and Bush surveys report limited data on the recycling of wood wastes at MSW and C/D sites. They report that in the South, approximately 36 percent of C/D landfills and 50 percent of MSW landfills operate a wood/yard waste recycling facility and that about 34 percent of the wood at C/D landfills and 39 percent of the wood at MSW landfills is recycled. In the Midwest, about 31 percent of the MSW and 25 percent of the C/D landfills operate wood recycling facilities with 16 percent of the MSW wood and 1 percent of the C/D wood is recycled. In the West, 27 percent of the MSW and C/D landfills operate wood recycling facilities and recycle 25 percent each of their wood. In the Northeast, 39 percent of the MSW and 28 percent of the C/D landfills operate wood recycling facilities and recycle 39 percent of the MSW wood and 28 percent of the $\mathrm{C} / \mathrm{D}$ wastes. 
The surveys do not report the use of total recycled wood, but do report the uses of recycled pallets which represent about 7 percent of the total wood and 4 percent of the recycled wood at C/D landfills and about 24 percent of the total wood and about 13 percent of the recycled wood at MSW landfills. At C/D landfills, about 14 percent of the recycled pallets are re-used as pallets, about 39 percent are used as fuel, and the remainder is used for other purposes such as mulch and composting. About 69 percent of the recyclers reported that they gave away the pallet material. Of those selling the material, the mean sale price was $\$ 11.01 /$ ton and the median sale price was $\$ 10.50 /$ ton. At MSW landfills, about 3 percent of the recycled pallets are re-used as pallets, about 41 percent are used as fuel, and the remainder is used for other purposes such as mulch and composting. About 58 percent of the C/D recyclers reported that they gave away the pallet material. Of those selling the material, the mean sale price was $\$ 13.17 /$ ton and the median sale price was $\$ 10.67 /$ ton. Transportation costs must still be added to the sale price. Given the lack of information regarding prices, we assumed that of the total quantity available, 60 percent could be available at less than $\$ 20 /$ dry ton and that the remaining quantities could be available at less than $\$ 30 /$ dry ton. Table 5 presents the estimated annual cumulative quantities of urban wood wastes by state and price. 
Table 5: Estimated Annual Cumulative Urban Wood Waste Quantities (dry tons), by Delivered Price and State

\begin{tabular}{|c|c|c|c|c|}
\hline & $<\$ 20 /$ dry ton & $<\$ 30 /$ dry ton & $<\$ 40 /$ dry ton & $<\$ 50 /$ dry ton \\
\hline Alabama & 823566 & 1372610 & 1372610 & 1372610 \\
\hline Arizona & 219736 & 366227 & 366227 & 366227 \\
\hline Arkansas & 400364 & 667273 & 667273 & 667273 \\
\hline California & 1579813 & 2633022 & 2633022 & 2633022 \\
\hline Colorado & 94661 & 157769 & 157769 & 157769 \\
\hline Connecticut & 246938 & 411563 & 411563 & 411563 \\
\hline Delaware & 38959 & 64931 & 64931 & 64931 \\
\hline Florida & 2757950 & 4596584 & 4596584 & 4596584 \\
\hline Georgia & 862094 & 1436823 & 1436823 & 1436823 \\
\hline Idaho & 135265 & 338162 & 338162 & 338162 \\
\hline Illinois & 416047 & 693411 & 693411 & 693411 \\
\hline Indiana & 316610 & 527684 & 527684 & 527684 \\
\hline Iowa & 171802 & 286337 & 286337 & 286337 \\
\hline Kansas & 736289 & 1227148 & 1227148 & 1227148 \\
\hline Kentucky & 345699 & 576165 & 576165 & 576165 \\
\hline Louisiana & 452322 & 753870 & 753870 & 753870 \\
\hline Maine & 108358 & 180597 & 180597 & 180597 \\
\hline Maryland & 204643 & 341071 & 341071 & 341071 \\
\hline Massachusetts & 419272 & 698787 & 698787 & 698787 \\
\hline Michigan & 495734 & 826224 & 826224 & 826224 \\
\hline Minnesota & 919517 & 1532529 & 1532529 & 1532529 \\
\hline Mississippi & 470831 & 784719 & 784719 & 784719 \\
\hline Missouri & 315547 & 525911 & 525911 & 525911 \\
\hline Montana & 52060 & 86766 & 86766 & 86766 \\
\hline Nebraska & 102073 & 170121 & 170121 & 170121 \\
\hline
\end{tabular}




\begin{tabular}{|c|c|c|c|c|}
\hline Nevada & 184112 & 306853 & 306853 & 306853 \\
\hline New Hampshire & 110579 & 184298 & 184298 & 184298 \\
\hline New Jersey & 389089 & 648481 & 648481 & 648481 \\
\hline New Mexico & 142896 & 238160 & 238160 & 238160 \\
\hline New York & 1140080 & 1900133 & 1900133 & 1900133 \\
\hline North Carolina & 636035 & 1060056 & 1060056 & 1060056 \\
\hline North Dakota & 326510 & 544184 & 544184 & 544184 \\
\hline Ohio & 744518 & 1240864 & 1240864 & 1240864 \\
\hline Oklahoma & 111173 & 185289 & 185289 & 185289 \\
\hline Oregon & 182532 & 304220 & 304220 & 304220 \\
\hline Pennsylvania & 399963 & 666605 & 666605 & 666605 \\
\hline Rhode Island & 29803 & 49671 & 49671 & 49671 \\
\hline South Carolina & 1289900 & 2149833 & 2149833 & 2149833 \\
\hline South Dakota & 123982 & 206637 & 206637 & 206637 \\
\hline Tennessee & 676029 & 1126715 & 1126715 & 1126715 \\
\hline Texas & 1209449 & 2015749 & 2015749 & 2015749 \\
\hline Utah & 138765 & 231275 & 231275 & 231275 \\
\hline Vermont & 40802 & 68004 & 68004 & 68004 \\
\hline Virginia & 519454 & 865757 & 865757 & 865757 \\
\hline Washington & 292432 & 487387 & 487387 & 487387 \\
\hline West Virginia & 105236 & 175393 & 175393 & 175393 \\
\hline Wisconsin & 383466 & 639110 & 639110 & 639110 \\
\hline Wyoming & 177383 & 295638 & 295638 & 295638 \\
\hline U.S. Total & 22040338 & 36846616 & 36846616 & 36846616 \\
\hline
\end{tabular}




\section{Summary}

Table 6 summarizes the estimated total annual cumulative quantities of biomass resources available by state and delivered price. It is estimated that substantial quantities of biomass (510 million dry tons) could be available annually at prices of less that $\$ 50 / \mathrm{dt}$ delivered. However, several caveats should be noted. There is a great deal of uncertainty surrounding some of the estimates. For example, while there is substantial confidence in the estimated quantities of mill residues available by state, there is a great deal of uncertainty about the estimated prices of these residues. The value of these feedstocks in their current uses is speculative and based solely on anecdotal discussions. Given that the feedstock is already being used--much of it under contract or in-house by the generator of the waste--energy facilities may need to pay a higher price than assumed to obtain the feedstock.

Additionally, both the quantity and price of urban wastes are highly speculative. The analysis is based solely on one national study and regional averages taken from two additional surveys. There is no indication of the quality of the material present (i.e., whether the wood is contaminated with chemicals, etc.). Because of the ways in which the surveys were conducted, there may be double counting of some quantities (i.e., MSW may contain yard trimmings and C/D wastes as well). Additionally, the analysis assumes that the majority of this urban wood is available for a minimal fee, with much of the cost resulting from transportation. Other industries have discovered that once a market is established, these "waste materials" become more valuable and are no longer available at minimal price. This situation could also happen with urban wastes used for energy if a steady customer becomes available. It should also be noted however, that some studies indicate that greater quantities of urban wastes are available, and are available at lower prices, than are assumed in this analysis (Wiltsee, 1998). Given the high level of uncertainty surrounding the quantity and price estimates of urban wastes and mill residues, and the fact that these wastes are estimated to be the least cost feedstocks available, they should be viewed with caution until a more detailed analysis is completed.

The analysis has assumed that substantial quantities of dead forest wood could be harvested. The harvest of deadwood is a particularly dangerous activity and not one relished by most foresters. Additionally, large polewood trees represent the growing stock of trees, that if left for sufficient time, could be harvested for higher value uses. These opportunity costs have not been considered. And, the sustainability of removing these forest resources has not been thoroughly analyzed.

We estimate the price of agricultural residues to be high largely because of the small quantities that can be sustainably removed on a per acre basis. Improvements in the collection/transport technologies and the ability to sustainably collect larger quantities (due to a shift in no-till site preparation practices for example) could increase quantities and decrease prices over time. Also, the inclusion of some of the minor grain crops (i.e., barley, oats, rye, rice) and soybeans could increase the total quantities of agricultural residues available by state. However, further elucidation of quantities that can sustainably be removed might lower available quantities.

Dedicated energy crops (i.e., switchgrass and short rotation wood crops) are not currently produced--the analysis is based on our best estimates of yield, production costs, and profitability of alternative crops that could be produced on the same land. Improving yields and decreasing production costs through improved harvest and transport technologies could increase available quantities at lower costs.

We have assumed a transportation cost of $\$ 8 /$ dry ton for most feedstocks. This cost is based on a typical cost of transporting materials (i.e., switchgrass bales and wood chips) for less than 50 miles (Graham et al, 1996; Bhat et al, 1992; Noon et al, 1996). Finally, the analysis is conducted at a state level and the distribution of biomass resources within the state is not specifically considered. We 
have simply assumed that the feedstock is available within 50 miles of a user facility. This may not be the case which would result either in the cost of the feedstock being higher to a user facility due to increased transportation costs, or the quantities of available feedstock being lower to a user facility if the material is simply too far away from the end-user site to be practical to obtain. Biomass resource assessments are needed at a lower aggregation level than the state. Any facility considering using the analysis need to conduct its own local analysis to verify feedstock quantity and prices. 
Table 6: Estimated Cumulative Biomass Quantities (dry ton/yr), by Delivered Price and State

\begin{tabular}{|c|c|c|c|c|}
\hline & $<\$ 20 /$ dry ton & $<\$ 30 /$ dry ton & $<\$ 40 /$ dry ton & $<\$ 50 /$ dry ton \\
\hline Alabama & 840566 & 6962610 & 10712357 & 17681689 \\
\hline Arizona & 219736 & 575227 & 863091 & 1100491 \\
\hline Arkansas & 402364 & 4092273 & 7085549 & 13604348 \\
\hline California & 1587813 & 6158022 & 8224305 & 11298705 \\
\hline Colorado & 180661 & 651769 & 3356589 & 3581889 \\
\hline Connecticut & 246938 & 560563 & 610563 & 906309 \\
\hline Delaware & 38959 & 94931 & 194008 & 461521 \\
\hline Florida & 2761950 & 6753122 & 6778408 & 9533398 \\
\hline Georgia & 934094 & 6390823 & 8540684 & 16111675 \\
\hline Idaho & 204265 & 2572162 & 4117282 & 7165782 \\
\hline Illinois & 435047 & 1038411 & 26838517 & 33359162 \\
\hline Indiana & 347610 & 993684 & 13409571 & 18606863 \\
\hline Iowa & 173802 & 404337 & 24582843 & 32786037 \\
\hline Kansas & 737289 & 1283148 & 12733412 & 21343522 \\
\hline Kentucky & 454699 & 1472165 & 5757811 & 10809048 \\
\hline Louisiana & 516322 & 3568870 & 7976754 & 11834427 \\
\hline Maine & 151358 & 1195597 & 1571597 & 2213697 \\
\hline Maryland & 204643 & 543071 & 899539 & 1959222 \\
\hline Massachusetts & 419272 & 938787 & 1026787 & 1435895 \\
\hline Michigan & 505734 & 2468224 & 4627235 & 12163103 \\
\hline Minnesota & 990517 & 2916529 & 15493892 & 21247327 \\
\hline Mississippi & 598831 & 4908719 & 10673390 & 17930978 \\
\hline Missouri & 477547 & 1345911 & 8029706 & 19522892 \\
\hline Montana & 69060 & 1421766 & 2159358 & 6761444 \\
\hline Nebraska & 114073 & 210121 & 18467094 & 21773296 \\
\hline
\end{tabular}




\begin{tabular}{|c|c|c|c|c|}
\hline Nevada & 184112 & 314853 & 333203 & 336603 \\
\hline New Hampshire & 133579 & 922298 & 1061298 & 2016455 \\
\hline New Jersey & 389089 & 726481 & 791204 & 975806 \\
\hline New Mexico & 167896 & 424160 & 960689 & 1081589 \\
\hline New York & 1168080 & 3328133 & 3884648 & 8438083 \\
\hline North Carolina & 669035 & 4188056 & 5789513 & 10855777 \\
\hline North Dakota & 326510 & 558184 & 2506662 & 21043177 \\
\hline Ohio & 744518 & 1472864 & 13018429 & 18962520 \\
\hline Oklahoma & 111173 & 3873692 & 7816207 & 12699956 \\
\hline Oregon & 192532 & 3341220 & 4126075 & 9809975 \\
\hline Pennsylvania & 571963 & 2205605 & 2832294 & 7427043 \\
\hline Rhode Island & 29803 & 80671 & 87671 & 115514 \\
\hline South Carolina & 1293900 & 4468833 & 6332258 & 9368065 \\
\hline South Dakota & 131982 & 285637 & 9601746 & 16005411 \\
\hline Tennessee & 878029 & 3381715 & 10720281 & 15232952 \\
\hline Texas & 1227449 & 4221749 & 13526432 & 20747118 \\
\hline Utah & 158765 & 388275 & 647821 & 722821 \\
\hline Vermont & 40802 & 392004 & 513004 & 1022669 \\
\hline Virginia & 599454 & 3058757 & 5055411 & 8714941 \\
\hline Washington & 297432 & 3979387 & 5938641 & 9920241 \\
\hline West Virginia & 241236 & 1361393 & 1971651 & 3736487 \\
\hline Wisconsin & 425466 & 2450110 & 11502364 & 14963398 \\
\hline Wyoming & 224383 & 551638 & 787223 & 1465684 \\
\hline U.S. Total & 23820338 & 105496557 & 314535067 & 510855005 \\
\hline
\end{tabular}




\section{REFERENCES}

1.American Society of Agricultural Engineers, Standards 1995-Standards, Engineering Practices, and Data, 1995.

2.P.A. Araman, R.J. Bush, and V.S. Reddy, Municipal Solid Waste Landfills and Wood

Pallets--What's Happening in the U.S., Pallet Enterprise, March 1997, pp. 50-56.

3.M.B. Bhat, B.C. English, and M. Ojo, Regional Costs of Transporting Biomass Feedstocks, Liquid

Fuels From Renewable Resources, John S. Cundiff (ed.), American Society of Agricultural

Engineers, St. Joseph, MI, December 1992.

4.R.J. Bush, V.S. Reddy, and P.A. Araman, Construction and Demolition Landfills and Wood

Pallets--What's Happening in the U.S., Pallet Enterprise, March 1997, pp. 27-31.

5.D.G. de la Torre Ugarte, S.P. Slinsky, and D.E. Ray, The Economic Impacts of Biomass Crop

Production on the U.S. Agriculture Sector, University of Tennessee Agricultural Policy Analysis

Center, Knoxville, TN, July 1999, Draft Document.

6.Doane's Agricultural Report, Estimated Machinery Operating Costs, 1995, Vol. 58, No. 15-5, April 14, 1995.

7.J. Glenn, The State of Garbage, BioCycle, April 1998, pp. 32-43.

8.R. Gogerty, Crop Leftovers: More Uses, More Value, Resource: Engineering and Technology for a Sustainable World, Vol. 3, No. 7, July 1996.

9.R.L. Graham, W. Liu, H.I. Jager, B.C. English, C.E. Noon, and M.J. Daly, A Regional-Scale GIS-Based Modeling System for Evaluating the Potential Costs and Supplies of Biomass From Biomass Crops, in Proceedings of Bioenergy '96 - The Seventh National Bioenergy Conference, Nashville, TN, September 15-20, 1996, Southeastern Regional Biomass Energy Program, pp. 444-450, 1996.

10.W.G. Heid, Jr., Turning Great Plains Crop Residues and Other Products into Energy, U.S. Department of Agriculture, Economic Research Service, Agricultural Economic Report No. 523, Washington, DC, November 1984.

11.D.T. Lightle, A Soil Conditioning Index for Cropland Management Systems (Draft), U.S. Department of Agriculture, Natural Resources Conservation Service, National Soil Survey Center, April 1997.

12.A. McQuillan, K. Skog, T. Nagle, and R. Loveless, Marginal Cost Supply Curves for Utilizing Forest Waste Wood in the United States, Unpublished Manuscript, University of Montana, Missoula, February 1984.

13.NEOS Corporation, Non-synthetic Cellulosic Textile Feedstock Resource Assessment, Southeastern Regional Biomass Energy Program, Muscle Shoals, AL, July 1998.

14.C.E. Noon, M.J. Daly, R.L. Graham, and F.B. Zahn, Transportation and Site Location Analysis for Regional Integrated Biomass Assessment (RIBA), in Proceedings of Bioenergy '96 - The Seventh National Bioenergy Conference, Nashville, TN, September 15-20, 1996, Southeastern Regional Biomass Energy Program, pp. 487-493, 1996.

15.North American Dealers Association, Official Guide--Tractors and Farm Equipment, 1995. 16.T. Schechinger, Great Lakes Chemical Corporation, personal communication, 1997.

17.U.S. Department of Agricultural, National Agricultural Statistics Service, World Agricultural Outlook Board, USDA Agricultural Baseline Projections to 2009, WAOB-99-1, Washington, DC, February 1999.

18.U.S. Department of Agriculture, Forest Service, Forest Inventory and Analysis Timber Product Output Database Retrieval System, (http://srsfia.usfs.msstate.edu/rpa/tpo), 1998a. 
19.U.S. Department of Agriculture, National Agricultural Statistical Service, Crop Production Summary, Washington, DC, January 1998 b.

20.U.S. Department of Agriculture, Economic Research Service, Agricultural Resources and Environmental Indicators, 1996-1997, Agricultural Handbook No. 712, Washington, DC, July 1997. 21.U.S. Department of Agriculture, Economic Research Service, Economic Indicators of the Farm Sector: Costs of Production--Major Field Crops, 1995, Washington, DC, 1996. 22.M.E. Walsh, R.L. Perlack, D.A. Becker, A. Turhollow, and R.L. Graham, Evolution of the Fuel Ethanol Industry: Feedstock Availability and Price, Oak Ridge National Laboratory, Oak Ridge, TN, April 21, 1998, Draft Document.

23.G. Wiltsee, Urban Wood Waste Resources in 30 US Metropolitan Areas, Appel Consultants, Inc., Valencia, CA, 1998.

1. Logging residues are the unused portion of the growing of stock trees (i.e., commercial species with a diameter breast height (dbh) greater than 5 inches, excluding cull trees) that are cut or killed by logging and left behind. Rough trees are those that do not contain a sawlog (i.e., 50 percent or more of live cull volume) or are not a currently merchantable species. Rotten trees are trees that do not contain a sawlog because of rot (i.e., 50 percent or more of the live cull volume). Salvable dead wood includes downed or standing trees that are considered currently or potentially merchantable. Excess saplings are live trees having a dbh of between 1.0 and 4.9 inches. Small pole trees are trees with a dbh greater than 5 inches, but smaller than saw timber trees. (back to report)

2. Retrieval efficiency accounts for the quantity of the inventory that can actually be recovered due to technology or equipment (assumed to be 40 percent). It is assumed that 50 percent of the resource is accessible without having to construct roads, except for logging residues for which 100 percent of the inventory is assumed accessible. Finally, inventory that lies on slopes greater than 20 percent or where conventional equipment cannot be used are eliminated for cost and environmental reasons. (back to report)

3. The assumed residue factors are-- 1 ton of corn stover for every 1 ton of corn grain produced; 1.7 tons of wheat straw for every 1 ton of winter wheat grain; and 1.3 ton of wheat straw for every 1 ton of spring and duram wheat grain (Heid, 1984). We assume a grain weight of 56 and $60 \mathrm{lb} / \mathrm{bu}$ for corn and wheat grain respectively. Grain moisture factors are assumed to be 1 for corn and .87 for wheat. (back to report)

Publications

List

Last updated: Tuesday, 29-Aug-2000 08:02:14 EDT 
Appendix 2

Chemical Industry Utilities Costs 
Chemicals Industry Manufacturing Costs

Reference:

Department of Energy (1998). "Chemicals Industry Costs," EIA Manufacturing Consumption of Energy 1998, Table N8.3

$\begin{array}{ll}1998 \text { Data } & \text { Dollars per physical unit } \\ \text { NAICS } & \text { Subsector and Industry } \\ \text { Code } & \end{array}$

Code

Total United States

311

Food

311221 Wet Corn Milling

Chemicals

325110 Petrochemicals

325120 Industrial Gases

$325181 \quad$ Alkalies and Chlorine

325188 Other Basic Inorganic Chemicals

325192 Cyclic Crudes and Intermediates

325199 Other Basic Organic Chemicals

325211 Plastics Materials and Resins

325212 Synthetic Rubber

325222 Noncellulosic Organic Fibers

325311 Nitrogeneous Fertilizers

325312 Phosphatic Fertilizers

326

326199 Other Plastics Products

Electricity
Total (kWh)

Electrical Components
$\begin{array}{cc}\text { From Local } & \text { From Other } \\ \text { Utility (kWh) } & \begin{array}{c}\text { Sources } \\ (\mathrm{kWh})\end{array}\end{array}$

Natural Gas

Total (mscf)$$
\text { (kWh) }
$$

$0.051 \quad 0.051$

$0.034 \quad 0.034$

$\begin{array}{ll}0.036 & 0.036 \\ 0.039 & 0.041\end{array}$

$0.033 \quad \mathrm{~W}$

$\begin{array}{ll}0.026 & 0.027 \\ 0.026 & 0.026\end{array}$

$0.026 \quad 0.026$

$0.040 \quad W$

$0.037 \quad 0.039$

$\begin{array}{ll}0.038 & 0.039 \\ 0.041 & 0.041 \\ 0.036 & 0.038\end{array}$

$\begin{array}{ll}0.041 & 0.041 \\ 0.036 & 0.038\end{array}$

$\begin{array}{ll}0.036 & 0.035 \\ 0.037 & 0.037\end{array}$

$\begin{array}{ll}0.037 & 0.037\end{array}$

$0.053 \quad 0.053$

$$
\text { W }
$$$$
\text { W }
$$$$
0.032
$$$$
\text { W }
$$$$
\text { W }
$$

0.032

W

0.028

0.035

0.049
0.030

0.030
0.044

0.000

0.045
Natural Gas Components

From Local From Other

Utility Sources

(mscf)

3.24

2.79
2.61

2.61
2.22

2.13

W

3.01
2.37

2.37
2.58

3.29

W

2.40

2.36

3.80 (mscf)

Steam Total

(million Btu)

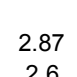

2.6

2.39
2.51

W

2.73

2.95

2.31

2.33

2.41

2.28

2.33

3.23
3.33

2.53
$W$
3.13
2.68
3.49
$W$
4.20
3.67
2.90
3.59
4.06
W
W
W
3.45
W

\section{Steam Components}

From Local From Other Utility (Mbtu) Sources (Mbtu)
2.15

W

3.01

W 


\begin{tabular}{|c|c|c|}
\hline $\begin{array}{l}\text { NAICS } \\
\text { Code }\end{array}$ & & Subsector and Industry \\
\hline Northeast Cens & s Region & \\
\hline 311 & & Food \\
\hline & 311221 & Wet Corn Milling \\
\hline 325 & & Chemicals \\
\hline & 325110 & Petrochemicals \\
\hline & 325120 & Industrial Gases \\
\hline & 325181 & Alkalies and Chlorine \\
\hline & 325188 & Other Basic Inorganic Chemicals \\
\hline & 325192 & Cyclic Crudes and Intermediates \\
\hline & 325199 & Other Basic Organic Chemicals \\
\hline & 325211 & Plastics Materials and Resins \\
\hline & 325212 & Synthetic Rubber \\
\hline & 325222 & Noncellulosic Organic Fibers \\
\hline & 325311 & Nitrogeneous Fertilizers \\
\hline & 325312 & Phosphatic Fertilizers \\
\hline 326 & & Plastics and Rubber Products \\
\hline & 326199 & Other Plastics Products \\
\hline NAICS & & Subsector and Industry \\
\hline Code & & \\
\hline Midwest Censt & Region & \\
\hline 311 & & Food \\
\hline & 311221 & Wet Corn Milling \\
\hline 325 & & Chemicals \\
\hline & 325110 & Petrochemicals \\
\hline & 325120 & Industrial Gases \\
\hline & 325181 & Alkalies and Chlorine \\
\hline & 325188 & Other Basic Inorganic Chemicals \\
\hline & 325192 & Cyclic Crudes and Intermediates \\
\hline & 325199 & Other Basic Organic Chemicals \\
\hline & 325211 & Plastics Materials and Resins \\
\hline & 325212 & Synthetic Rubber \\
\hline & 325222 & Noncellulosic Organic Fibers \\
\hline & 325311 & Nitrogeneous Fertilizers \\
\hline & 325312 & Phosphatic Fertilizers \\
\hline 326 & & Plastics and Rubber Products \\
\hline & 326199 & Other Plastics Products \\
\hline
\end{tabular}

\begin{tabular}{|c|c|c|c|c|c|}
\hline \multirow{2}{*}{$\begin{array}{l}\text { Electricity } \\
\text { Total (kWh) }\end{array}$} & \multicolumn{2}{|c|}{ Electrical Components } & \multirow{2}{*}{$\begin{array}{l}\text { Natural Gas } \\
\text { Total (mscf) }\end{array}$} & \multicolumn{2}{|c|}{ Natural Gas Components } \\
\hline & $\begin{array}{l}\text { From Local } \\
\text { Utility (kWh) }\end{array}$ & $\begin{array}{l}\text { From Other } \\
\text { Sources } \\
\text { (kWh) }\end{array}$ & & $\begin{array}{c}\text { From Local } \\
\text { Utility } \\
\text { (mscf) }\end{array}$ & $\begin{array}{c}\text { From Othe } \\
\text { Sources } \\
\text { (mscf) }\end{array}$ \\
\hline 0.073 & 0.074 & 0.060 & 3.88 & 4.09 & 3.76 \\
\hline w & W & 0.000 & 0.00 & 0.00 & 0.00 \\
\hline 0.052 & 0.054 & 0.037 & 3.67 & 3.75 & 3.58 \\
\hline W & W & 0.000 & w & w & 0.00 \\
\hline 0.040 & 0.038 & W & W & W & 0.00 \\
\hline 0.019 & 0.022 & W & W & W & W \\
\hline 0.059 & 0.059 & W & 3.49 & 3.60 & 3.35 \\
\hline 0.048 & 0.047 & W & 3.45 & W & 3.62 \\
\hline 0.048 & 0.048 & 0 & 3.86 & 4.08 & 3.70 \\
\hline 0.055 & 0.055 & 0 & 3.72 & 4.08 & 3.24 \\
\hline W & W & W & W & 6.22 & W \\
\hline 0.089 & 0.089 & 0.000 & W & W & WW \\
\hline 0.065 & 0.071 & w & 4.25 & W & 3.60 \\
\hline w & W & 0.000 & 0.00 & 0.00 & 0.00 \\
\hline 0.070 & 0.070 & 0.060 & 4.35 & 4.65 & 3.96 \\
\hline 0.067 & 0.068 & 0.050 & 4.90 & 5.25 & 4.48 \\
\hline \multirow[t]{2}{*}{$\begin{array}{l}\text { Electricity } \\
\text { Total (kWh) }\end{array}$} & \multicolumn{2}{|c|}{ Electrical Components } & $\begin{array}{l}\text { Natural Gas } \\
\text { Total (mscf) }\end{array}$ & \multicolumn{2}{|c|}{ Natural Gas Components } \\
\hline & $\begin{array}{l}\text { From Local } \\
\text { Utility (kWh) }\end{array}$ & $\begin{array}{l}\text { From Other } \\
\text { Sources } \\
\text { (kWh) }\end{array}$ & & $\begin{array}{c}\text { From Local } \\
\text { Utility } \\
\text { (mscf) }\end{array}$ & $\begin{array}{c}\text { From Othe } \\
\text { Sources } \\
\text { (mscf) }\end{array}$ \\
\hline 0.046 & 0.046 & 0.055 & 2.87 & 3.02 & 2.78 \\
\hline 0.034 & 0.034 & w & 2.64 & 2.77 & 2.60 \\
\hline 0.035 & 0.035 & 0.037 & 2.73 & 3.26 & 2.56 \\
\hline 0.056 & 0.056 & 0 & 3.43 & W & W \\
\hline 0.034 & 0.034 & W & 2.87 & 2.87 & W \\
\hline 0.032 & 0.032 & 0.000 & 3.23 & W & W \\
\hline W & W & 0.000 & 3.00 & 2.99 & 3.00 \\
\hline 0.036 & 0.036 & 0.000 & 2.98 & 3.03 & W \\
\hline 0.040 & 0.040 & W & 2.92 & 2.80 & 2.99 \\
\hline 0.039 & 0.039 & w & 3.64 & 4.26 & 2.66 \\
\hline 0.046 & 0.042 & W & 2.91 & 3.28 & W \\
\hline 0.000 & 0.000 & 0.000 & 0.00 & 0.00 & 0.00 \\
\hline 0.035 & 0.035 & W & 2.30 & W & 2.28 \\
\hline W & W & 0.000 & W & W & W \\
\hline 0.051 & 0.051 & 0.034 & 3.38 & 3.66 & 3.11 \\
\hline 0.054 & 0.054 & W & 3.59 & 4.06 & 3.12 \\
\hline
\end{tabular}

\begin{tabular}{ccc}
$\begin{array}{c}\text { Steam Total } \\
\text { (million Btu) }\end{array}$ & \multicolumn{2}{c}{ Steam Components } \\
$\begin{array}{c}\text { From Local } \\
\text { Utility (Mbtu) }\end{array}$ & $\begin{array}{c}\text { From Other } \\
\text { Sources } \\
\text { (Mbtu) }\end{array}$ \\
2.60 & 2.47 & 2.99 \\
0.00 & 0.00 & 0.00 \\
4.39 & 3.68 & 4.46 \\
0.00 & 0.00 & 0.00 \\
W & W & W \\
W & 0.00 & W \\
W & 0.00 & W \\
W & 0.00 & W \\
3.05 & W & 3.16 \\
3.98 & W & 3.97 \\
W & 0.00 & W \\
0.00 & 0.00 & 0.00 \\
0.00 & 0.00 & 0.00 \\
0.00 & 0.00 & 0.00 \\
W & W & 0.00 \\
0.00 & 0.00 & 0.00 \\
& & \\
Steam Total & Steam Components \\
(million Btu) & & \\
& From Local & From Other \\
& Utility (Mbtu) & Sources \\
& & (Mbtu)
\end{tabular}

$\begin{array}{ccc}2.97 & 2.89 & \text { W } \\ \text { W } & \text { W } & \text { W } \\ 3.21 & 3.92 & 2.77 \\ 0 & 0 & 0 \\ \text { W } & \text { W } & \text { W } \\ \text { W } & \text { W } & 0.00 \\ 3.43 & W & \text { W } \\ \text { W } & 0.00 & \text { W } \\ 2.34 & 0.00 & 2.34 \\ 2.91 & 4.45 & 2.44 \\ \text { W } & \text { W } & 0.00 \\ 0.00 & 0.00 & 0.00 \\ \text { W } & 0.00 & \text { W } \\ 0.00 & 0.00 & 0.00 \\ \text { W } & \text { W } & 0.00 \\ \text { W } & \text { W } & 0.00\end{array}$




\begin{tabular}{|c|c|c|c|c|c|c|c|c|c|c|c|}
\hline \multirow{2}{*}{$\begin{array}{l}\text { NAICS } \\
\text { Code }\end{array}$} & & \multirow[t]{2}{*}{ Subsector and Industry } & \multirow{2}{*}{$\begin{array}{l}\text { Electricity } \\
\text { Total (kWh) }\end{array}$} & \multicolumn{2}{|c|}{ Electrical Components } & \multirow{2}{*}{$\begin{array}{l}\text { Natural Gas } \\
\text { Total (mscf) }\end{array}$} & \multicolumn{2}{|c|}{ Natural Gas Components } & \multirow{2}{*}{$\begin{array}{l}\text { Steam Total } \\
\text { (million Btu) }\end{array}$} & \multicolumn{2}{|c|}{ Steam Components } \\
\hline & & & & $\begin{array}{l}\text { From Local } \\
\text { Utility (kWh) }\end{array}$ & $\begin{array}{c}\text { From Other } \\
\text { Sources } \\
\text { (kWh) }\end{array}$ & & $\begin{array}{c}\text { From Local } \\
\text { Utility } \\
\text { (mscf) }\end{array}$ & $\begin{array}{l}\text { From Other } \\
\text { Sources } \\
\text { (mscf) }\end{array}$ & & $\begin{array}{l}\text { From Local } \\
\text { Utility (Mbtu) }\end{array}$ & $\begin{array}{c}\text { From Other } \\
\text { Sources } \\
\text { (Mbtu) }\end{array}$ \\
\hline \multicolumn{12}{|c|}{ South Census Region } \\
\hline \multirow[t]{2}{*}{311} & & Food & 0.049 & 0.049 & 0.047 & 3.13 & 3.36 & 2.85 & 2.77 & 2.79 & 2.66 \\
\hline & 311221 & Wet Corn Milling & 0.032 & 0.032 & 0.000 & 2.71 & W & 2.60 & 0.00 & 0.00 & 0.00 \\
\hline \multirow[t]{12}{*}{325} & & Chemicals & 0.034 & 0.035 & 0.030 & 2.35 & 2.38 & 2.34 & 2.99 & 3.22 & 2.80 \\
\hline & 325110 & Petrochemicals & 0.039 & 0.040 & W & 2.42 & 2.22 & 2.50 & 2.68 & W & W \\
\hline & 325120 & Industrial Gases & 0.031 & 0.031 & 0.000 & 1.99 & 1.94 & W & W & W & W \\
\hline & 325181 & Alkalies and Chlorine & 0.028 & 0.028 & W & 2.31 & W & W & W & 0.00 & W \\
\hline & 325188 & Other Basic Inorganic Chemicals & 0.026 & 0.026 & W & 2.80 & 2.90 & 2.76 & W & W & W \\
\hline & 325192 & Cyclic Crudes and Intermediates & 0.040 & 0.040 & 0.000 & 2.35 & 2.23 & 2.87 & W & W & 0.00 \\
\hline & 325199 & Other Basic Organic Chemicals & 0.035 & 0.037 & 0.027 & 2.30 & 2.47 & 2.28 & 2.92 & 3.21 & 2.88 \\
\hline & 325211 & Plastics Materials and Resins & 0.036 & 0.036 & 0.034 & 2.35 & 2.69 & 2.30 & 3.81 & 3.76 & 3.83 \\
\hline & 325212 & Synthetic Rubber & 0.038 & 0.038 & W & 2.36 & 2.65 & 2.33 & 3.59 & W & 3.49 \\
\hline & 325222 & Noncellulosic Organic Fibers & 0.036 & 0.037 & 0.030 & 2.68 & 3.02 & W & W & W & W \\
\hline & 325311 & Nitrogeneous Fertilizers & 0.035 & 0.035 & W & 2.28 & w & 2.29 & W & 0.00 & W \\
\hline & 325312 & Phosphatic Fertilizers & 0.420 & 0.042 & 0.000 & 2.37 & 2.72 & 2.35 & W & 0.00 & W \\
\hline \multirow[t]{2}{*}{326} & & Plastics and Rubber Products & 0.045 & 0.046 & 0.037 & 3.40 & 3.59 & 2.97 & 3.03 & W & 2.74 \\
\hline & 326199 & Other Plastics Products & 0.050 & 0.050 & 0.000 & 4.68 & 5.36 & 2.98 & 0.00 & 0.00 & 0.00 \\
\hline \multirow{2}{*}{$\begin{array}{l}\text { NAICS } \\
\text { Code }\end{array}$} & & Subsector and Industry & Electricity & \multicolumn{2}{|c|}{ Electrical Components } & $\begin{array}{l}\text { Natural Gas } \\
\text { Total (mscf) }\end{array}$ & \multicolumn{2}{|c|}{ Natural Gas Components } & Steam Total & \multicolumn{2}{|c|}{ Steam Components } \\
\hline & & & lotal (kWh) & $\begin{array}{l}\text { From Local } \\
\text { Utility (kWh) }\end{array}$ & $\begin{array}{l}\text { From Other } \\
\text { Sources } \\
\text { (kWh) }\end{array}$ & Iotal (msct) & $\begin{array}{l}\text { From Local } \\
\text { Utility } \\
\text { (mscf) }\end{array}$ & $\begin{array}{l}\text { From Other } \\
\text { Sources } \\
\text { (mscf) }\end{array}$ & & $\begin{array}{l}\text { From Local } \\
\text { Utility (Mbtu) }\end{array}$ & $\begin{array}{c}\text { From Other } \\
\text { Sources } \\
\text { (Mbtu) }\end{array}$ \\
\hline \multicolumn{12}{|c|}{ West Census Region } \\
\hline \multirow{2}{*}{311} & & Food & 0.054 & 0.054 & 0.056 & 2.89 & 3.16 & 2.71 & 1.94 & 2.93 & 1.76 \\
\hline & 311221 & Wet Corn Milling & 0.041 & 0.041 & 0.000 & 2.71 & w & 2.70 & W & W & W \\
\hline \multirow[t]{12}{*}{325} & & Chemicals & 0.039 & 0.038 & 0.048 & 2.62 & 2.99 & 2.53 & 2.59 & W & 2.43 \\
\hline & 325110 & Petrochemicals & 0.000 & 0.000 & 0.000 & 0.00 & 0.00 & 0.00 & 0.00 & 0.00 & 0.00 \\
\hline & 325120 & Industrial Gases & 0.040 & 0.040 & W & 2.59 & W & W & 0.00 & 0.00 & 0.00 \\
\hline & 325181 & Alkalies and Chlorine & 0.023 & 0.023 & 0.000 & W & 0.00 & W & W & W & 0.00 \\
\hline & 325188 & Other Basic Inorganic Chemicals & 0.029 & 0.028 & W & 2.55 & w & 2.56 & W & 0.00 & W \\
\hline & 325192 & Cyclic Crudes and Intermediates & 0.067 & 0.067 & 0.000 & 2.77 & 2.84 & W & 0.00 & 0.00 & 0.00 \\
\hline & 325199 & Other Basic Organic Chemicals & 0.056 & 0.061 & W & 3.28 & $\mathrm{Q}$ & 3.26 & 3.50 & w & w \\
\hline & 325211 & Plastics Materials and Resins & 0.064 & 0.063 & 0.079 & 3.46 & 3.74 & 3.16 & w & 0.00 & W \\
\hline & 325212 & Synthetic Rubber & 0.107 & 0.107 & 0.000 & 6.78 & 6.78 & 0.00 & 0.00 & 0.00 & 0.00 \\
\hline & 325222 & Noncellulosic Organic Fibers & w & W & 0.000 & 0.00 & 0.00 & 0.00 & 0.00 & 0.00 & 0.00 \\
\hline & 325311 & Nitrogeneous Fertilizers & 0.030 & 0.029 & w & W & w & W & W & 0.00 & W \\
\hline & 325312 & Phosphatic Fertilizers & W & W & 0.000 & W & W & W & 0.00 & 0.00 & 0.00 \\
\hline 326 & & Plastics and Rubber Products & 0.061 & 0.061 & Q & 3.71 & 3.83 & 3.02 & W & W & 0.00 \\
\hline
\end{tabular}




\begin{tabular}{|c|c|c|c|c|c|c|c|c|c|c|}
\hline 1998 Data & Dollars per physical unit & & & & & & & & & \\
\hline \multirow{2}{*}{$\begin{array}{l}\text { NAICS } \\
\text { Code }\end{array}$} & \multirow[t]{2}{*}{ Subsector and Industry } & \multirow{2}{*}{$\begin{array}{l}\text { Electricity } \\
\text { Total (kWh) }\end{array}$} & \multicolumn{2}{|c|}{ Electrical Components } & \multirow{2}{*}{$\begin{array}{l}\text { Natural Gas } \\
\text { Total (mscf) }\end{array}$} & \multicolumn{2}{|c|}{ Natural Gas Components } & \multirow{2}{*}{$\begin{array}{l}\text { Steam Total } \\
\text { (million Btu) }\end{array}$} & \multicolumn{2}{|c|}{ Steam Components } \\
\hline & & & $\begin{array}{l}\text { From Local } \\
\text { Utility (kWh) }\end{array}$ & $\begin{array}{c}\text { From Other } \\
\text { Sources } \\
\text { (kWh) }\end{array}$ & & $\begin{array}{c}\text { From Local } \\
\text { Utility } \\
\text { (mscf) }\end{array}$ & $\begin{array}{c}\text { From Other } \\
\text { Sources } \\
\text { (mscf) }\end{array}$ & & $\begin{array}{l}\text { From Local } \\
\text { Utility (Mbtu) }\end{array}$ & $\begin{array}{c}\text { From Other } \\
\text { Sources } \\
\text { (Mbtu) }\end{array}$ \\
\hline 325 & & & & & & & & & & \\
\hline al United States & Chemicals & 0.036 & 0.036 & 0.032 & 2.44 & 2.61 & 2.39 & 3.13 & 3.30 & 3.01 \\
\hline theast Census Region & Chemicals & 0.052 & 0.054 & 0.037 & 3.67 & 3.75 & 3.58 & 4.39 & 3.68 & 4.46 \\
\hline Iwest Census Region & Chemicals & 0.035 & 0.035 & 0.037 & 2.73 & 3.26 & 2.56 & 3.21 & 3.92 & 2.77 \\
\hline th Census Region & Chemicals & 0.034 & 0.035 & 0.030 & 2.35 & 2.38 & 2.34 & 2.99 & 3.22 & 2.80 \\
\hline st Census Region & Chemicals & 0.039 & 0.038 & 0.048 & 2.62 & 2.99 & 2.53 & 2.59 & W & 2.43 \\
\hline
\end{tabular}




\section{Appendix 3}

\section{Properties of Biomass ${ }^{1}$}

March 2002

${ }^{1}$ Updated from Graboski, M. S. and Bain R. L. (1979). "Chapter 3: Properties of Biomass

Relevant to Gasification," in A Survey of Biomass Gasification, Volume II - Principles of Gasification, Solar Energy Research Inst., Golden, CO, SERI/TR-33-239, July 


\section{TABLE OF CONTENTS}

3.1 BULK CHEMICAL ANALYSIS OF BIOMASS $\ldots \ldots \ldots \ldots \ldots \ldots \ldots \ldots$

3.1 .1 Proximate Analyses $\ldots \ldots \ldots \ldots \ldots \ldots \ldots \ldots \ldots \ldots \ldots \ldots \ldots \ldots \ldots \ldots \ldots \ldots$

3.1 .2 Ultimate Analyses . . . . . . . . . . . . . . . . . . . . . . . . 5

3.1 .3 Moisture Content of Fuels $\ldots \ldots \ldots \ldots \ldots \ldots \ldots \ldots \ldots \ldots \ldots \ldots \ldots \ldots$

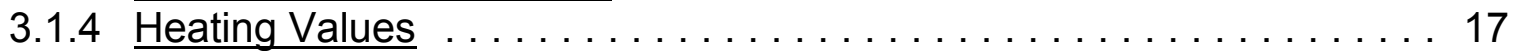

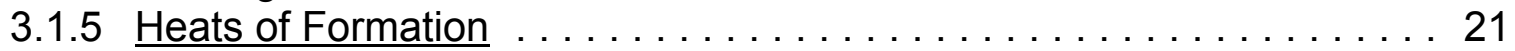

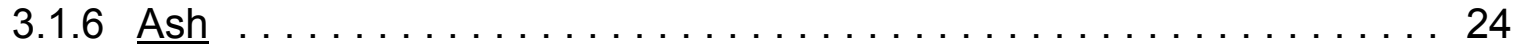

3.2 CHEMICAL COMPOSITION OF WOODS $\ldots \ldots \ldots \ldots \ldots \ldots \ldots \ldots \ldots$

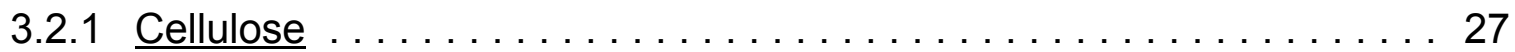

$3.2 .2 \frac{\text { Principal Hemicelluloses }}{3.2 .2 . \ldots \ldots \ldots \ldots \ldots \ldots \ldots \ldots \ldots \ldots} 28$

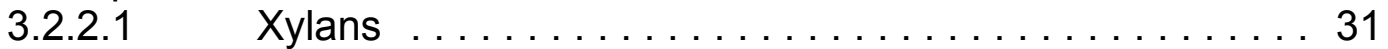

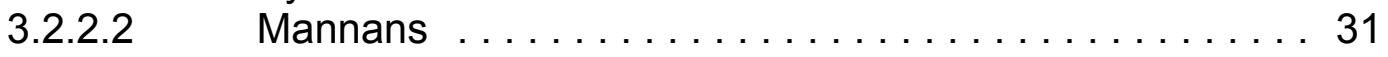

3.2 .3 Cellulose Data for Woods $\ldots \ldots \ldots \ldots \ldots \ldots \ldots \ldots \ldots \ldots \ldots \ldots \ldots \ldots \ldots$

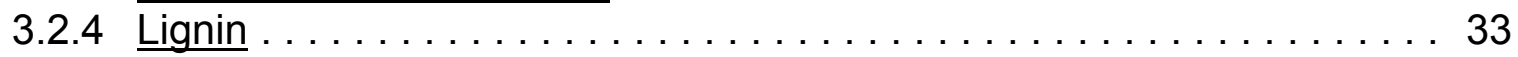

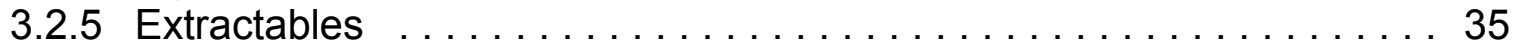

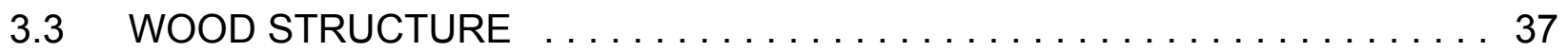

3.3.1 Physical Structure of Softwoods $\ldots \ldots \ldots \ldots \ldots \ldots \ldots \ldots \ldots \ldots$

3.3.2 Physical Structure of Hardwoods $\ldots \ldots \ldots \ldots \ldots \ldots \ldots \ldots \ldots \ldots$

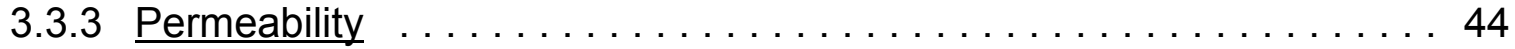

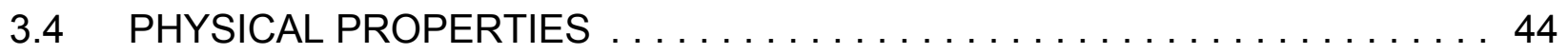

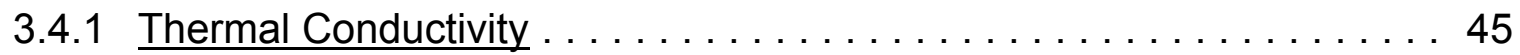

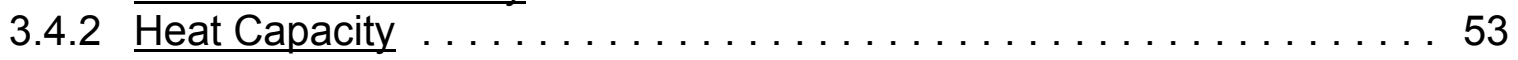

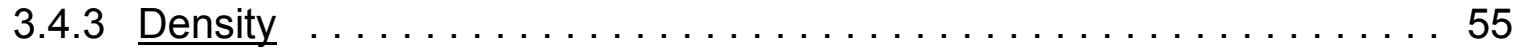

3.4.3.1 Effect of Moisture Content on Density .......... 56

3.4.3.2 Densification .................... 58

3.4.4 Diffusion Coefficients in Biomass Materials $\ldots \ldots \ldots \ldots \ldots \ldots \ldots 8$

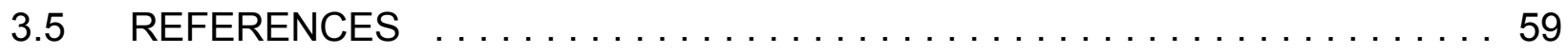




\section{LIST OF FIGURES}

Figure 3-1: Nitrogen Content of Selected Biomass Samples . . . . . . . . . . . . 12

Figure 3-2: Potassium Content of Selected Biomass Samples . . . . . . . . . . . 13

Figure 3-3: Biomass Higher Heating Value . . . . . . . . . . . . . . . 20

Figure 3-4: Heats of Formation of Carbonaceous Fuels $\ldots \ldots \ldots \ldots \ldots \ldots \ldots 23$

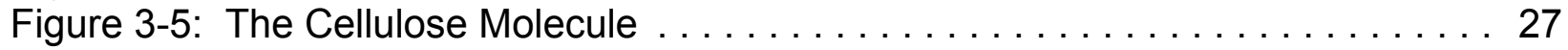

Figure 3-6: Extraction Sequence for Isolation of Softwood Polysaccharides . . . . . 29

Figure 3-7: Structural Interrelationship of Commonly Occurring

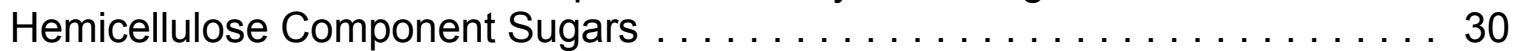

Figure 3-8: Xylan Hemicellulose Structures . . . . . . . . . . . . . . . . 32

Figure 3-9: Several Monomer Units in Lignin . . . . . . . . . . . . . . . . . 34

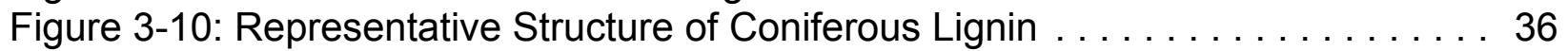

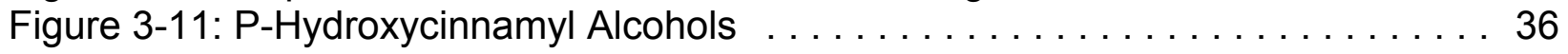

Figure 3-12: Gross Structure of a Typical Southern Pine Softwood . . . . . . . . 40

Figure 3-13: Radial Surfaces of Earlywood

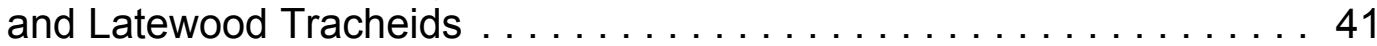

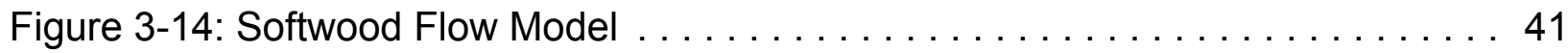

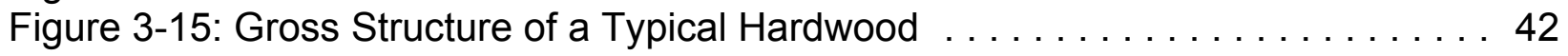

Figure 3-16: Generalized Flow Model for Hardwoods . . . . . . . . . . . . . . 43

Figure 3-17: Thermal Conductivity as a Function of Moisture

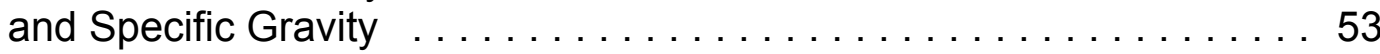




\section{LIST OF TABLES}

Table 3-1: ASTM Standards Methods for Biomass and Coal $\ldots \ldots \ldots \ldots \ldots \ldots$

Table 3-2: Elemental Analyzer Equipment . . . . . . . . . . . . . . . . 3

Table 3-3: Proximate Analysis Data for Selected Solid Fuels and Biomass . . . . . . 4

Table 3-4: Ultimate Analysis Data for Selected Solid Fuels and Biomass Materials . . 6

Table 3-5: Elemental Analysis of Volatiles Liberated by Pyrolysis for

Two Selected Fuels . . . . . . . . . . . . . . . . . . . . . . . . . 14

Table 3-6: Evaluation of Feedstocks for Pyrolysis by Material Balance Calculation . 15

Table 3-7: Ultimate Analysis Data for Selected Pyrolysis Chars . . . . . . . . . . . 16

Table 3-8: Approximate Moisture Contents Of Typical Biomass Fuels . . . . . . . . 17

Table 3-9: Comparison of Experimental and Calculated Higher (Gross) Heating Values

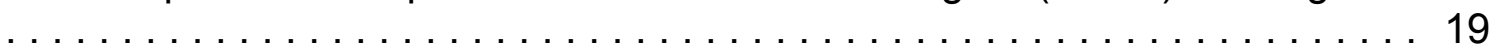

Table 3-10: Heats of Formation for Typical

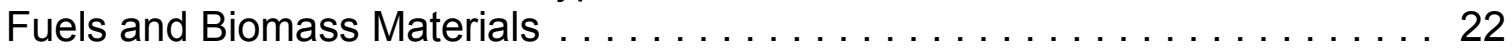

Table 3-11: Ash Composition of Selected Biomass Samples . . . . . . . . . . . . 25

Table 3-12: Chemical Analyses of Representative Woods . . . . . . . . . . . . 26

Table 3-13: Chemical Analyses of Representative Wood Barks . . . . . . . . . . . 27

Table 3-14: Breakdown of Holocellulose Fraction of Woods $\ldots \ldots \ldots \ldots \ldots \ldots 33$

Table 3-15: Elemental Analysis of Wood Lignin . . . . . . . . . . . . . . 33

Table 3-16: Lignin in Miscellaneous Plant Material . . . . . . . . . . . . . . . . 34

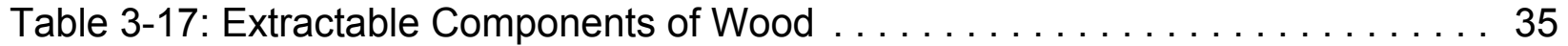

Table 3-18: Extraction Data for Woods . . . . . . . . . . . . . . . . 38

Table 3-19: Typical Permeability Values . . . . . . . . . . . . . . . . . 44

Table 3-20: Thermal Conductivity of Selected Biomass Materials . . . . . . . . . 46

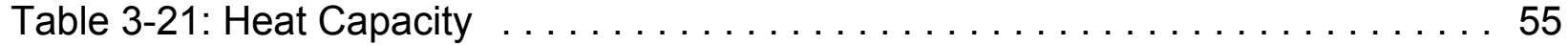

Table 3-22: Apparent Density of Selected Woods $\ldots \ldots \ldots \ldots \ldots \ldots \ldots \ldots . \ldots$ 


\section{PROPERTIES OF BIOMASS RELEVANT TO GASIFICATION}

An understanding of the structure and properties of biomass materials is necessary to evaluate their utility as feedstocks for conversion processes. This section summarizes available information on a variety of such properties including chemical analysis, heats of combustion and formation, physical structure, heat capacities, and transport properties of biomass feedstocks and chars. Much of the information reported is for wood materials; however, where data were available for other forms of biomass such as municipal solid waste and feedlot waste, they were included.

\subsection{BULK CHEMICAL ANALYSIS OF BIOMASS}

In evaluating gasification feedstocks, it is generally useful to have proximate and ultimate analyses, heats of combustion, and sometimes ash analyses. These provide information on volatility of the feedstock, elemental analysis, and heat content. The elemental analysis is particularly important in evaluating the feedstock in terms of potential pollution.

Table 3-1 lists the standard Methods for evaluating carbonaceous feedstocks.

A number of instruments have been developed for determining elemental composition, most often, in biomass conversion, for carbon, hydrogen, nitrogen, sulfur, and oxygen. Chlorine normally is not determined by such analyzers. Most of these systems employ a catalytic combustion or pyrolysis step to decompose the sample to carbon dioxide, water, hydrogen sulfide, and nitrogen, which are then determined quantitatively by as chromatography using flame ionization (FID) or thermal conductivity (TC) detectors. Oxygen is usually determined by catalytic conversion to carbon monoxide over a platinized carbon catalyst followed by GC analysis. A short list of some representative equipment is given in Table 3-2.

\subsubsection{Proximate Analyses}

The proximate analysis classifies the fuel in terms of its moisture $(M)$, volatile matter (VM), ash, and (by difference) fixed carbon content. In the test procedure, the volatile material is driven off in an inert atmosphere at high temperatures $\left(950^{\circ} \mathrm{C}\right)$ using a slow heating rate. The pyrolysis yield is representative of that for slow pyrolysis processes; fast pyrolysis techniques employing very rapid heating rates normally yield more volatile matter. The moisture determined by the proximate method represents physically bound water only; water released by chemical reactions during pyrolysis is classified with the volatiles. The ash content is determined by combustion of the volatile and fixed carbon fractions. The resulting ash fraction is not representative of the original ash, more appropriately termed mineral matter, due to the oxidation process employed in its determination. In the most exact analysis, small corrections to the ash weight are necessary to correct it to a mineral 
Table 3-1: ASTM Standards Methods for Biomass and Coal

\begin{tabular}{|c|c|c|c|c|}
\hline Method & $\begin{array}{l}\text { Biomass } \\
\text { Test No. }\end{array}$ & $\begin{array}{c}\text { Coal } \\
\text { Test No. }\end{array}$ & $\begin{array}{c}\text { Repeatability } \\
\text { (wt\%) }\end{array}$ & $\begin{array}{c}\text { Reproducibility } \\
\text { (wt } \% \text { ) }\end{array}$ \\
\hline \multicolumn{5}{|l|}{ Proximate Analysis } \\
\hline Moisture & E871 & $\begin{array}{l}\text { D2013, } \\
\text { D3173 }\end{array}$ & 0.5 & 1.0 \\
\hline Volatile Matter & $\begin{array}{l}\text { E872, } \\
\text { E897 }\end{array}$ & D3175 & 0.5 & 1.0 \\
\hline Ash & $\begin{array}{l}\text { D1102, } \\
\text { E830 }\end{array}$ & D3174 & 0.6 & 1.3 \\
\hline Fixed Carbon & Difference & Difference & & \\
\hline Ultimate Analysis & & D3176 & & \\
\hline C & E777 & D3176 & 0.5 & 1.6 \\
\hline $\mathrm{H}$ & E777 & D3178 & 0.2 & 0.5 \\
\hline $\mathrm{N}$ & E778 & D3179 & 0.04 & 0.05 \\
\hline$S$ & E775 & $\begin{array}{l}\text { D4239, } \\
\text { D3177 }\end{array}$ & 0.03 & 0.06 \\
\hline $\mathrm{O}$ & Difference & Difference & & \\
\hline Chlorine & E776 & D2361 & 0.03 & 0.11 \\
\hline Gross Heating Value & $\begin{array}{l}\text { E711, } \\
\text { D2015 }\end{array}$ & D2015 & $27-111 \mathrm{Btu} / \mathrm{lb}^{\mathrm{c}}$ & $68-250 \mathrm{Btu} / \mathrm{lb}^{\mathrm{c}}$ \\
\hline \multicolumn{5}{|l|}{ Ash Analysis } \\
\hline Ash in Biomass & E1755 & & $2.7^{\mathrm{d}}$ & $8.9^{d}$ \\
\hline Ash in wood & D1102 & & $0.03\left(6.6^{d}\right)$ & \\
\hline Elemental Ash & $\begin{array}{l}\text { D3682, } \\
\text { D2795 }\end{array}$ & & $\begin{array}{c}5^{\mathrm{d}} \\
\text { See element }\end{array}$ & \\
\hline Fusion temp & D1857 & & $50^{\circ} \mathrm{F}$ & \\
\hline Water soluble alkali & \multicolumn{2}{|c|}{$\begin{array}{l}\text { Soak overnight in } \mathrm{H}_{2} \mathrm{O} \\
@ 90 \mathrm{C} \text {, Analyze by AA }\end{array}$} & & \\
\hline Bulk Density & E873 & & TBD & TBD \\
\hline Fuel size (based on RDF) & E828 & & & \\
\hline
\end{tabular}

${ }^{a}$ within laboratory; ${ }^{b}$ between laboratories; ${ }^{c}$ dependent on magnitude of HHV

$\mathrm{d} \%$ of average 
matter basis. The fixed-carbon content of an as received sample is calculated by material balance. Thus:

$$
\mathrm{FC}=1-\mathrm{M}-\mathrm{ASH}-\mathrm{VM}
$$

The fixed carbon is considered to be a polynuclear aromatic hydrocarbon residue resulting from condensation reactions which occur in the pyrolysis step.

Table 3-2: Elemental Analyzer Equipment

\begin{tabular}{|llll|}
\hline Instrument & Oxidant & Capability & Detection \\
Carlo Erba 1104 & oxygen & $\mathrm{C}, \mathrm{H}, \mathrm{N}, \mathrm{O}$ & FID \& TIC \\
$\begin{array}{l}\text { Chemical Data Systems } \\
\text { (CDS 1200) }\end{array}$ & oxygen & $\mathrm{C}, \mathrm{H}, \mathrm{N}, \mathrm{O}, \mathrm{S}$ and & FID \& TC \\
Hewlett-Packard HP-185 & $\mathrm{MNO}_{2}$ added & C, H, N & \\
Perkin Elmer 240 & oxygen & $\mathrm{C}, \mathrm{H}, \mathrm{N}, \mathrm{O}, \mathrm{S}$ & FID \& TC \\
\hline
\end{tabular}

The most useful basis for reporting proximate analysis is the dry basis. In this instance the compositions are normalized to a moisture-free basis (denoted by *):

$$
\mathrm{VM}^{*}+\mathrm{FC}^{*}+\mathrm{ASH}=1,
$$

and, for example,

$$
\mathrm{VM}^{*}=\mathrm{VM} /(1-\mathrm{M}) .
$$

The moisture is reported as grams of moisture per gram of dry feedstock. Typical proximate analyses for solid fuels are given in Table 3-3, from which it is evident that common biomass materials are more readily devolatilized (pyrolyzed) than lignite and bituminous coals, yielding considerably less fixed-carbon residue. This is due to the much more aromatic structure of the coals which is produced by the geological coalification process. The higher volatile content of biomass materials makes them potentially useful feedstocks for pyrolysis processes. In general, the ash content of biomass materials is considerably lower than for coals. This is due to the fact that the bulk of the coal ash was deposited in coal beds by processes such as siltation and did not come from the parent carbonaceous material. An exception is municipal solid waste, which contains a high mineral content due to nonvolatile trash components such as metals and glass. 
Table 3-3: Proximate Analysis Data for Selected Solid Fuels and Biomass (Dry basis, wt\%)

\begin{tabular}{|c|c|c|c|c|}
\hline & $\begin{array}{r}\text { Volatile } \\
\text { Matter } \\
\text { (VM) }\end{array}$ & $\begin{array}{r}\text { Fixed } \\
\text { Carbon } \\
(F C)\end{array}$ & Ash & Reference \\
\hline \multicolumn{5}{|l|}{ Coals } \\
\hline Pittsburgh seam & 33.9 & 55.8 & 10.3 & Bituminous Coal Research 1974 \\
\hline Wyoming Elkol & 44.4 & 51.4 & 4.2 & \\
\hline Lignite & 43.0 & 46.6 & 10.4 & \\
\hline \multicolumn{5}{|l|}{ Oven Dry Woods } \\
\hline Western hemlock & 84.8 & 15.0 & 0.2 & Howlett and Gamanche 1977 \\
\hline Douglas fir & 86.2 & 13.7 & 0.1 & \\
\hline White fir & 84.4 & 15.1 & 0.5 & \\
\hline Ponderosa pine & 87.0 & 12.8 & 0.2 & \\
\hline Redwood & 83.5 & 16.1 & 0.4 & \\
\hline Cedar & 77.0 & 21.0 & 2.0 & \\
\hline \multicolumn{5}{|l|}{ Oven Dry Barks } \\
\hline Western hemlock & 74.3 & 24.0 & 1.7 & Howlett and Gamance 1977 \\
\hline Douglas fir & 70.6 & 27.2 & 2.2 & \\
\hline White fir & 73.4 & 24.0 & 2.6 & \\
\hline Ponderosa pine & 73.4 & 25.9 & 0.7 & \\
\hline Redwood & 71.3 & 27.9 & 0.8 & \\
\hline Cedar & 86.7 & 13.1 & 0.2 & \\
\hline \multicolumn{5}{|l|}{ Municipal Refuse and Major } \\
\hline \multicolumn{5}{|l|}{ Components } \\
\hline Nat'l Ave. Waste & 65.9 & 9.1 & 25.0 & Klass and Ghosh 1973 \\
\hline Newspaper (9.4\%) & 86.3 & 12.2 & 1.5 & \\
\hline Paper boxes $(23.4 \%)$ & 81.7 & 12.9 & 5.4 & \\
\hline Magazine paper (6.8\%) & 69.2 & 7.3 & 23.4 & \\
\hline Brown paper $(5.6 \%)$ & 89.1 & 9.8 & 1.1 & \\
\hline \multicolumn{5}{|l|}{ Selected Biomass } \\
\hline Almond wood & 77.28 & 15.94 & 6.78 & Miles et. al. 1995 \\
\hline Red oak sawdust & 86.22 & 13.47 & 0.31 & \\
\hline Hybrid poplar & 84.81 & 12.49 & 2.70 & \\
\hline Alfalfa stems & 78.92 & 15.81 & 5.27 & \\
\hline Wheat straw, Denmark & 69.80 & 12.29 & 10.78 & \\
\hline Wheat straw, OR & 81.24 & 17.06 & 4.32 & \\
\hline Rice straw & 65.47 & 15.86 & 18.67 & \\
\hline Willow & 85.23 & 13.82 & 0.95 & \\
\hline Sugar cane bagasse & 85.61 & 11.95 & 2.44 & \\
\hline Switchgrass, MN & 82.94 & 14.37 & 2.69 & \\
\hline Bana Grass & 73.44 & 16.68 & 9.88 & \\
\hline
\end{tabular}




\subsubsection{Ultimate Analyses}

Ultimate analyses generally report $\mathrm{C}, \mathrm{H}, \mathrm{N}, \mathrm{S}$ and $\mathrm{O}$ (by difference) in the solid fuel. Table 3-1 lists the appropriate ASTM tests for these elements while Table 3-2 lists several manufacturers of modern elemental analyzers. Care must be exercised in using ultimate analyses for fuels containing high moisture content because moisture is indicated in the ultimate analysis as additional hydrogen and oxygen.

To avoid confusion and give a good representation of the fuel itself, ultimate analyses should be performed and reported on a dry basis; when this is done all hydrogen determined is truly a constituent of the fuel. For certain biomass materials like municipal solids and animal waste, the determination of chlorine is important because it represents a possible pollutant and corrosive agent in gasification and combustion systems.

Typical ultimate analyses for a variety of feedstocks are presented in Table 3-4.

All biomass materials have carbon contents considerably lower than coals; the atomic carbon to hydrogen ratio is much higher in coals than in biomass materials. For coal, the $\mathrm{H} / \mathrm{C}$ ratio is unity, while for biomass the ratio is typically 1.5 . The bound oxygen content of biomass materials is considerably higher, due to the ether, acid, and alcohol groups in the cellulose, hemicellulose, and lignin fractions of biomass, as will be discussed later in this section. The nitrogen and sulfur contents in coal are considerably higher than those in most biomass. Thus, in direct biomass combustion, pollutants resulting from bound nitrogen and sulfur in the fuel generally are present in small enough quantities to meet EPA standards, although the high chlorine contents that are found in animal wastes can pose a severe pollution problem. The nitrogen content, normalized by heating value, of selected samples from Table 3-4 is given in Figure 3-1. Alkali content of biomass is important also because of its potential impact on slagging and fouling in combustion and gasification systems. A recent study (Miles 1995) found that biomass feeds containing less than $0.5 \mathrm{lb} \mathrm{K}$ per million Btu did not cause fouling and slagging in commercial biomass boilers. The potassium content of selected biomass samples from Table 3-4 is shown in Figure 3-2.

The relative "quality" of the volatile matter can be estimated using the ultimate analysis and simple stoichiometry. If it is assumed that the fixed carbon contains only carbon, then all hydrogen and oxygen plus a portion of the carbon are associated with the volatile materials. Table 3-5 presents a typical calculation for the volatile fraction of lignite and Douglas fir bark. 
Table 3-4: Ultimate Analysis Data for Selected Solid Fuels and Biomass Materials

\begin{tabular}{|c|c|c|c|c|c|c|c|c|c|c|}
\hline Material & $\mathbf{C}$ & $\mathbf{H}$ & $\mathbf{N}$ & $\mathrm{s}$ & 0 & $\mathrm{Cl}$ & Ash & $\begin{array}{r}\text { HHV } \\
\text { Btu/lb }\end{array}$ & $\begin{array}{c}\mathrm{HHV} \\
\mathrm{MJ} / \mathrm{kg}\end{array}$ & Reference \\
\hline Pittsburgh seam coal & 75.5 & 5.0 & 1.2 & 3.1 & 4.9 & -- & 10.3 & 13,650 & 31.68 & Tillman 1978 \\
\hline West Kentucky No. 11 coal & 74.4 & 5.1 & 1.5 & 3.8 & 7.9 & -- & 7.3 & 13,460 & 31.24 & Bituminous Coal Research 1974 \\
\hline Utah coal & 77.9 & 6.0 & 1.5 & 0.6 & 9.9 & -- & 4.1 & 14,170 & 32.89 & Tillman 1978 \\
\hline Wyoming Elkol coal & 71.5 & 5.3 & 1.2 & 0.9 & 16.9 & -- & 4.2 & 12,710 & 29.50 & Bituminous Coal Research 1974 \\
\hline Lignite & 64.0 & 4.2 & 0.9 & 1.3 & 19.2 & -- & 10.4 & 10,712 & 24.86 & Bituminous Coal Reseach 1974 \\
\hline Charcoal & 80.3 & 3.1 & 0.2 & 0.0 & 11.3 & -- & 3.4 & 13,370 & 31.03 & Tillman 1978 \\
\hline Alder, red & 49.55 & 6.06 & 0.13 & 0.07 & 43.78 & & 0.40 & 8,578 & 19.91 & Rossi \\
\hline Alder/fir sawdust & 51.02 & 5.80 & 0.46 & 0.05 & 68.54 & 0.02 & 4.13 & 8,760 & 20.33 & Miles et. al. 1995 \\
\hline Alfalfa Pellets & 44.90 & 5.60 & 2.90 & 0.22 & 37.08 & 0.39 & 9.30 & 7,807 & 18.12 & MN Project \\
\hline Alfalfa Pellets & 45.60 & 5.50 & 2.70 & 0.21 & 36.99 & 0.39 & 9.00 & 7,880 & 18.29 & MN Project \\
\hline Alfalfa seed straw & 46.76 & 5.40 & 1.00 & 0.02 & 40.72 & & 7.25 & 7,949 & 18.45 & Jenkins and Ebeling \\
\hline Almond hulls & 45.79 & 5.36 & 0.96 & 0.01 & 40.60 & & 5.78 & 7,850 & 18.22 & Jenkins and Ebeling \\
\hline Almond prunings & 51.30 & 5.29 & 0.66 & 0.01 & 40.90 & & 1.63 & 8,621 & 20.01 & Jenkins and Ebeling \\
\hline Almond shells & 44.98 & 5.97 & 1.16 & 0.02 & 42.27 & & 4.81 & 8,350 & 19.38 & Jenkins and Ebeling \\
\hline Almond wood & 47.45 & 5.53 & 0.59 & 0.08 & 39.57 & 0.03 & 6.78 & 6,829 & 15.85 & Miles et. al. 1995 \\
\hline Animal waste & 42.7 & 5.5 & 2.4 & 0.3 & 31.3 & & 17.8 & 7,380 & 17.13 & Tillman 1978 \\
\hline Ash, white & 49.70 & 6.90 & & & 43.00 & & 0.30 & 8,940 & 20.75 & Johnson and Auth \\
\hline Bagasse & 39.70 & 5.50 & 0.30 & & 42.30 & & 13.30 & 6,756 & 15.68 & Mudge et al \\
\hline Bagasse & 44.80 & 5.35 & 0.38 & 0.01 & 39.55 & & 11.27 & 7,467 & 17.33 & Jenkins and Ebeling \\
\hline Bagasse & 46.27 & 5.27 & 0.12 & 0.05 & 42.41 & 0.05 & 5.83 & 7,885 & 18.30 & Turn et. al. \\
\hline Bagasse & 48.64 & 5.87 & 0.16 & 0.04 & 42.85 & 0.03 & 2.44 & 8,166 & 18.95 & Miles et. al. 1995 \\
\hline Bagasse & 45.71 & 5.89 & & & 40.37 & & 8.03 & 8,402 & 19.50 & Grover and Anuradha \\
\hline Bana Grass, HI & 45.06 & 5.42 & 0.84 & 0.11 & 38.69 & 0.83 & 9.88 & 7,533 & 17.48 & Miles et. al. 1995 \\
\hline Banagrass & 47.10 & 5.29 & 0.44 & 0.16 & 41.93 & 0.61 & 4.47 & 7,897 & 18.33 & Turn et. al. \\
\hline Bark & 47.27 & 5.20 & 0.40 & 0.05 & 37.68 & 0.03 & 9.37 & 7,721 & 17.92 & Feldman et. al. \\
\hline Bean straw & 42.97 & 5.59 & 0.83 & 0.01 & 44.93 & & 5.93 & 7,523 & 17.46 & Jenkins and Ebeling \\
\hline Beech & 51.6 & 6.3 & 0.0 & 0.0 & 41.5 & & 0.6 & 8,760 & 20.33 & Tillman 1978 \\
\hline Birch and maple mix & 49.86 & 6.12 & 0.10 & 0.09 & 43.45 & 0.03 & 0.36 & 8,453 & 19.62 & Feldman et. al. \\
\hline Birch, white & 49.80 & 6.50 & & & 43.40 & & 0.30 & 8,669 & 20.12 & Johnson and Auth \\
\hline
\end{tabular}




\begin{tabular}{|c|c|c|c|c|c|c|c|c|c|c|}
\hline Material & C & $\mathbf{H}$ & $\mathbf{N}$ & $\mathbf{S}$ & 0 & $\mathrm{Cl}$ & Ash & $\begin{array}{r}\text { HHV } \\
\text { Btu/lb }\end{array}$ & $\begin{array}{l}\mathrm{HHV} \\
\mathrm{MJ} / \mathbf{k g}\end{array}$ & Reference \\
\hline Black locust & 50.73 & 5.71 & 0.57 & 0.01 & 41.93 & & 0.80 & 8,492 & 19.71 & Jenkins and Ebeling \\
\hline Black walnut prunings & 49.80 & 5.82 & 0.22 & 0.01 & 43.25 & & 0.78 & 8,544 & 19.83 & Jenkins and Ebeling \\
\hline Cabernet Sauvignon prunings & 46.59 & 5.85 & 0.83 & 0.04 & 43.90 & & 2.17 & 8,199 & 19.03 & Jenkins and Ebeling \\
\hline Casuarina & 48.50 & 6.04 & 0.31 & 0.00 & 43.32 & & 1.83 & 8,087 & 18.77 & Channiwala \\
\hline Casuarina & 48.61 & 5.83 & 0.59 & 0.02 & 43.36 & & 1.40 & 8,376 & 19.44 & Jenkins and Ebeling \\
\hline Cedar bark & 51.00 & 5.70 & & & 38.20 & & 5.10 & 8,630 & 20.03 & Johnson and Auth \\
\hline Cedar, white & 48.80 & 6.40 & & & 44.40 & & 0.40 & 8,018 & 18.61 & Johnson and Auth \\
\hline Chaparall & 46.90 & 5.08 & 0.54 & 0.03 & 40.17 & & 6.13 & 8,337 & 19.35 & Jenkins and Ebeling \\
\hline Chenin Blanc prunings & 48.02 & 5.89 & 0.86 & 0.07 & 41.93 & & 2.51 & 8,242 & 19.13 & Jenkins and Ebeling \\
\hline Cherry & 48.52 & 5.81 & 0.31 & 0.02 & 42.97 & 0.02 & 1.35 & 8,408 & 19.51 & Feldman et. al. \\
\hline Chinkapin & 49.68 & 5.93 & 0.07 & 0.01 & 44.03 & & 0.30 & 8,337 & 19.35 & Rossi \\
\hline Christmas trees & 51.59 & 5.58 & 0.52 & 0.40 & 36.70 & -- & 5.21 & 9,009 & 20.91 & Miles et. al. 1995 \\
\hline Cocoa hulls & 48.23 & 5.23 & 2.98 & 0.12 & 33.19 & & 8.25 & 8,203 & 19.04 & Jenkins and Ebeling \\
\hline Coconut fiber (coir) & 50.29 & 5.05 & 0.45 & 0.16 & 39.63 & & 3.72 & 8,639 & 20.05 & Channiwala \\
\hline Coconut shells & 50.22 & 5.07 & 0.00 & 0.00 & 43.37 & & 0.71 & 8,832 & 20.50 & Channiwala \\
\hline Corn cobs & 46.58 & 5.87 & 0.47 & 0.11 & 45.46 & & 1.36 & 8,087 & 18.77 & Jenkins and Ebeling \\
\hline Corn stover & 43.65 & 5.56 & 0.61 & 0.01 & 43.31 & & 5.58 & 7,604 & 17.65 & Jenkins and Ebeling \\
\hline Corn Stover & 46.50 & 5.81 & 0.56 & 0.11 & 39.67 & & 7.40 & 8,186 & 19.00 & Gregory et al \\
\hline Corn stover & 46.51 & 5.81 & 0.56 & 0.11 & 39.67 & & 7.00 & 8,782 & 20.38 & Evans et. al. \\
\hline Cotton gin trash & 39.59 & 5.26 & 2.09 & 2.09 & 36.38 & & 17.60 & 7,075 & 16.42 & Jenkins and Ebeling \\
\hline Cotton gin waste & 42.66 & 6.05 & 0.18 & & 49.50 & & 1.61 & 7,531 & 17.48 & Channiwala \\
\hline Cotton stalk & 39.47 & 5.07 & 1.25 & 0.02 & 38.09 & & 17.20 & 6,820 & 15.83 & Channiwala \\
\hline Cotton stalk & 43.64 & 5.81 & 0.00 & 0.00 & 43.87 & & 6.68 & 7,867 & 18.26 & Grover and Anuradha \\
\hline Cypress & 55.00 & 6.50 & & & 38.10 & & 0.40 & 9,892 & 22.96 & Johnson and Auth \\
\hline Demolition wood & 46.30 & 5.39 & 0.57 & 0.12 & 34.50 & 0.05 & 13.12 & 7,916 & 18.37 & Miles et. al. 1995 \\
\hline Douglas fir & 50.64 & 6.18 & 0.06 & 0.02 & 43.00 & & 0.10 & 8,837 & 20.51 & Rossi \\
\hline Douglas fir & 52.3 & 6.3 & 0.1 & 0.0 & 40.5 & & 0.8 & 9,050 & 21.01 & Tillman 1978 \\
\hline Douglas fir bark & 56.2 & 5.9 & 0.0 & 0.0 & 36.7 & & 1.2 & 9,500 & 22.05 & Tillman 1978 \\
\hline Elm & 50.40 & 6.60 & & & 42.30 & & 0.70 & 9,039 & 20.98 & Johnson and Auth \\
\hline Eucalyptus Camaldulensis & 49.00 & 5.87 & 0.30 & 0.01 & 43.97 & & 0.76 & 8,367 & 19.42 & Jenkins and Ebeling \\
\hline Eucalyptus Globulus & 48.18 & 5.92 & 0.39 & 0.01 & 44.18 & & 1.10 & 8,285 & 19.23 & Jenkins and Ebeling \\
\hline Eucalyptus Grandis & 48.33 & 5.89 & 0.15 & 0.01 & 45.13 & & 0.52 & 8,337 & 19.35 & Jenkins and Ebeling \\
\hline
\end{tabular}




\begin{tabular}{|c|c|c|c|c|c|c|c|c|c|c|}
\hline Material & C & $\mathbf{H}$ & $\mathbf{N}$ & $\mathrm{s}$ & 0 & $\mathbf{C l}$ & Ash & $\begin{array}{r}\text { HHV } \\
\text { Btu/lb }\end{array}$ & $\begin{array}{c}\mathrm{HHV} \\
\mathrm{MJ} / \mathrm{kg}\end{array}$ & Reference \\
\hline Fir mill waste & 51.23 & 5.98 & 0.06 & 0.03 & 42.29 & 0.19 & 0.41 & 8,779 & 20.38 & Miles et. al. 1995 \\
\hline Fir, white & 49.00 & 5.98 & 0.05 & 0.01 & 44.75 & & 1.52 & 8,367 & 19.42 & Jenkins and Ebeling \\
\hline Forest residuals & 50.31 & 4.59 & 1.03 & 0.11 & 39.99 & 0.04 & 3.97 & 8,670 & 20.12 & Miles et. al. 1995 \\
\hline Furniture waste & 49.87 & 5.91 & 0.29 & 0.03 & 40.29 & $<0.01$ & 3.61 & 8,658 & 20.10 & Miles et. al. 1995 \\
\hline Grape pomice & 54.94 & 5.83 & 2.09 & 0.21 & 32.08 & & 4.20 & 9,393 & 21.80 & Grover and Anuradha \\
\hline Groundnut shells & 48.59 & 5.64 & 0.58 & 0.00 & 39.49 & & 5.70 & 8,552 & 19.85 & Johnson and Auth \\
\hline Gum & 50.88 & 6.06 & 0.15 & 0.04 & 41.57 & 0.02 & 1.28 & 8,475 & 19.67 & Feldman et. al. \\
\hline Hardwood & 49.73 & 6.06 & 0.24 & 0.04 & 42.87 & 0.11 & 0.95 & 8,430 & 19.57 & Feldman et. al. \\
\hline Hemlock, western & 50.4 & 5.8 & 0.1 & 0.1 & 41.4 & & 2.2 & 8,620 & 20.01 & Tillman 1978 \\
\hline Hickory & 49.7 & 6.5 & 0.0 & 0.0 & 43.1 & & 0.7 & 8,670 & 20.12 & Tillman 1978 \\
\hline Hog fuel & 45.36 & 5.63 & 0.18 & 0.02 & 42.13 & 0.03 & 16.89 & 7,681 & 17.83 & Feldman et. al. \\
\hline Kelp, brown, Soquel Point & 27.80 & 3.77 & 4.63 & 1.05 & 23.69 & & 42.10 & 4,632 & 10.75 & Chynoweth et al \\
\hline Kelp, giant brown, Monterey & 26.60 & 3.74 & 2.55 & 1.09 & 20.22 & & 45.80 & 4,421 & 10.26 & Chynoweth et al \\
\hline Macadamia shells & 54.41 & 4.99 & 0.36 & 0.01 & 39.69 & & 0.40 & 9,052 & 21.01 & Jenkins and Ebeling \\
\hline Madrone & 48.56 & 6.05 & 0.05 & 0.02 & 45.08 & & 0.30 & 8,246 & 19.14 & Rossi \\
\hline Madrone & 48.94 & 6.03 & 0.05 & 0.02 & 41.74 & & 0.20 & 8,406 & 19.51 & Rossi \\
\hline Mango wood & 46.24 & 6.08 & 0.28 & & 44.42 & & 2.98 & 8,259 & 19.17 & Johnson and Auth \\
\hline Manzanita & 48.18 & 5.95 & 0.17 & 0.02 & 44.68 & & 0.82 & 8,315 & 19.30 & Jenkins and Ebeling \\
\hline Maple & 49.54 & 6.11 & 0.10 & 0.02 & 49.54 & & 0.50 & 8,306 & 19.28 & Evans et. al. \\
\hline Maple & 50.6 & 6.0 & 0.3 & 0.0 & 41.7 & & 1.4 & 8,580 & 19.91 & Tillman 1978 \\
\hline Millet straw & 43.71 & 5.85 & 0.01 & 0.00 & 45.16 & & 5.27 & 7,777 & 18.05 & Channiwala \\
\hline Mixed waste paper & 47.99 & 6.63 & 0.14 & 0.07 & 36.84 & & 8.33 & 8,934 & 20.74 & Miles et. al. 1995 \\
\hline Mixed wood & 49.31 & 6.03 & 0.18 & 0.02 & 42.98 & 0.04 & 1.44 & 8,366 & 19.42 & Feldman et. al. \\
\hline Mixed wood ( $90 \%$ red oak) & 48.51 & 6.17 & 0.12 & 0.04 & 44.22 & & 0.94 & 8,210 & 19.06 & Evans et. al. \\
\hline Mixed wood & 48.40 & 6.31 & 0.21 & 0.03 & 44.23 & & 0.82 & 8,228 & 19.10 & Evans et. al. \\
\hline Municipal solid waste & 47.6 & 8.0 & 1.2 & 0.3 & 32.9 & & 12.0 & 8,546 & 19.84 & Saner et. al. 1970 \\
\hline Napier grass & 45.20 & 6.00 & & & 42.30 & & 5.70 & 7,889 & 18.31 & Elliot et al \\
\hline Oak & 49.83 & 5.87 & 0.32 & 0.04 & 41.82 & 0.03 & 2.09 & 8,373 & 19.43 & Feldman et. al. \\
\hline Oak, Alabama woodwaste & 49.5 & 5.7 & 0.2 & 0.0 & 41.3 & -- & 3.3 & 8,266 & 19.19 & Boley and Landers 1969 \\
\hline Oak, Canyon & 47.84 & 5.80 & 0.07 & 0.01 & 45.76 & & 0.50 & 8,178 & 18.98 & Rossi \\
\hline Oak, red & 49.34 & 5.93 & 0.07 & 0.13 & 41.74 & 0.03 & 2.76 & 8,220 & 19.08 & Feldman et. al. \\
\hline Oak, red, sawdust & 49.96 & 5.92 & 0.03 & 0.01 & 43.77 & 0.07 & 0.31 & 8,374 & 19.44 & Miles et. al. 1995 \\
\hline
\end{tabular}




\begin{tabular}{|c|c|c|c|c|c|c|c|c|c|c|}
\hline Material & $\mathbf{C}$ & $\mathbf{H}$ & $\mathbf{N}$ & $\mathbf{S}$ & 0 & $\mathrm{Cl}$ & Ash & $\begin{array}{r}\text { HHV } \\
\text { Btu/lb }\end{array}$ & $\begin{array}{l}\mathrm{HHV} \\
\mathrm{MJ} / \mathrm{kg}\end{array}$ & Reference \\
\hline Oak, tan & 48.67 & 6.03 & 0.06 & 0.04 & 44.99 & & 0.20 & 8,156 & 18.93 & Rossi \\
\hline Oak, tan & 48.34 & 6.12 & 0.03 & 0.03 & 44.99 & & 0.50 & 8,238 & 19.12 & Jenkins and Ebeling \\
\hline Oak, white & 49.48 & 5.38 & 0.35 & 0.01 & 43.13 & & 1.52 & 8,367 & 19.42 & Jenkins and Ebeling \\
\hline Olive pits & 48.81 & 6.23 & 0.36 & 0.01 & 43.48 & & 3.20 & 9,216 & 21.39 & Channiwala \\
\hline Paper & 43.4 & 5.8 & 0.3 & 0.2 & 44.3 & -- & 6.0 & 7,572 & 17.57 & Bowernan 1969 \\
\hline $\begin{array}{l}\text { Peach pits } \\
\text { Peach pits }\end{array}$ & $\begin{array}{l}49.14 \\
53.00\end{array}$ & $\begin{array}{l}6.34 \\
5.90\end{array}$ & $\begin{array}{l}0.48 \\
0.32\end{array}$ & $\begin{array}{l}0.02 \\
0.05\end{array}$ & $\begin{array}{l}43.52 \\
39.14\end{array}$ & & $\begin{array}{l}1.10 \\
1.03\end{array}$ & $\begin{array}{l}8,367 \\
8,970\end{array}$ & $\begin{array}{l}19.42 \\
20.82\end{array}$ & $\begin{array}{l}\text { Rossi } \\
\text { Jenkins and Ebeling }\end{array}$ \\
\hline Peanut hulls & 45.77 & 5.46 & 1.63 & 0.12 & 39.56 & & 5.89 & 8,031 & 18.64 & Jenkins and Ebeling \\
\hline Pine & 51.27 & 6.19 & 0.13 & 0.13 & 42.13 & 0.02 & 0.13 & 8,748 & 20.30 & Feldman et. al. \\
\hline Pine bark & 52.3 & 5.8 & 0.2 & 0.0 & 38.8 & & 2.9 & 8,780 & 20.38 & Tillman 1978 \\
\hline Pine needles & 48.21 & 6.57 & & & 43.72 & & 1.50 & 8,669 & 20.12 & Grover and Anuradha \\
\hline Pine, long leaf, bark & 56.40 & 5.50 & & & 37.40 & & 0.70 & 9,380 & 21.77 & Risser \\
\hline Pine, ponderosa & 49.25 & 5.99 & 0.06 & 0.03 & 44.36 & & 0.29 & 8,470 & 19.66 & Jenkins and Ebeling \\
\hline Pine, slash, bark & 56.20 & 5.40 & & & 37.30 & & 0.70 & 9,380 & 21.77 & Risser \\
\hline Pine, white & 52.60 & 6.10 & & & 41.20 & & 0.10 & 8,919 & 20.70 & Johnson and Auth \\
\hline Pine, yellow & 52.60 & 7.00 & & & 52.60 & & 1.31 & 9,668 & 22.44 & Riser \\
\hline Pine. Loblolly, bark & 56.30 & 5.60 & & & 37.70 & & 0.40 & 9,384 & 21.78 & Risser \\
\hline Pistachio shells & 48.79 & 5.91 & 0.56 & 0.01 & 43.41 & & 1.13 & 8,298 & 19.26 & Jenkins and Ebeling \\
\hline Poplar & 48.45 & 5.85 & 0.47 & 0.01 & 43.69 & & 1.33 & 8,350 & 19.38 & Jenkins and Ebeling \\
\hline Poplar & 51.6 & 6.3 & 0.0 & 0.0 & 41.5 & & 0.6 & 8,920 & 20.70 & Tillman 1978 \\
\hline Poplar - coarse & 50.82 & 5.89 & 0.59 & 0.02 & 41.08 & 0.04 & 1.60 & 8,139 & 18.89 & Miles et. al. 1995 \\
\hline Poplar, hybrid & 50.18 & 6.06 & 0.60 & 0.02 & 40.44 & 0.01 & 2.70 & 8,178 & 18.98 & Miles et. al. 1995 \\
\hline Redwood & 53.5 & 5.9 & 0.1 & 0.0 & 40.3 & & 0.2 & 9,040 & 20.98 & Tillman 1978 \\
\hline Redwood wastewood & 53.4 & 6.0 & 0.1 & 0.1 & 39.9 & & 0.6 & 9,163 & 21.27 & Boley and Landers 1969 \\
\hline RDF - Tacoma, WA & 39.70 & 5.78 & 0.80 & 0.35 & 27.24 & & 26.13 & 6,679 & 15.50 & Miles et. al. 1995 \\
\hline Rice hulls & 38.30 & 4.36 & 0.83 & 0.06 & 35.45 & & 20.60 & 6,415 & 14.89 & Rossi \\
\hline Rice hulls & 38.5 & 5.7 & 0.5 & 0.0 & 39.8 & & 15.5 & 6,610 & 15.34 & Tillman 1978 \\
\hline Rice husk & 38.92 & 5.10 & 2.17 & 0.12 & 37.89 & & 15.80 & 6,751 & 15.67 & Maheshwari \\
\hline Rice husk bran & 39.82 & 5.12 & 0.55 & 0.00 & 36.77 & & 18.64 & 6,588 & 15.29 & Channiwala \\
\hline Rice straw & 39.2 & 5.1 & 0.6 & 0.1 & 35.8 & & 19.2 & 6,540 & 15.18 & Tillman 1978 \\
\hline Rice straw & 41.78 & 4.63 & 0.70 & 0.08 & 36.57 & & 13.42 & 7,014 & 16.28 & Jenkins and Ebeling \\
\hline Sawdust & 51.33 & 6.13 & 0.12 & 0.02 & 41.97 & 0.07 & 0.36 & 8,802 & 20.43 & Feldman et. al. \\
\hline
\end{tabular}




\begin{tabular}{|c|c|c|c|c|c|c|c|c|c|c|}
\hline Material & C & $\mathbf{H}$ & $\mathbf{N}$ & $\bar{S}$ & 0 & $\mathbf{C l}$ & Ash & $\begin{array}{r}\text { HHV } \\
\text { Btu/lb }\end{array}$ & $\begin{array}{c}\mathrm{HHV} \\
\mathrm{MJ} / \mathrm{kg}\end{array}$ & Reference \\
\hline Sawdust pellets & 47.2 & 6.5 & 0.0 & 0.0 & 45.4 & & 1.0 & 8,814 & 20.46 & Wen et. al. 1974 \\
\hline Shredded currency & 42.89 & 5.97 & 1.75 & 0.30 & 43.62 & & 5.47 & 7,867 & 18.26 & Miles et. al. 1995 \\
\hline Softwood & 50.80 & 6.25 & 0.15 & 0.14 & 41.74 & 0.03 & 0.78 & 8,771 & 20.36 & Feldman et. al. \\
\hline Southern oak & 49.94 & 5.30 & 0.16 & 0.00 & 42.77 & 0.02 & 0.81 & 8,500 & 19.73 & Feldman et. al. \\
\hline Spruce & 51.80 & 5.70 & & & 38.30 & & 3.80 & 8,759 & 20.33 & Johnson and Auth \\
\hline Sudan grass & 44.58 & 5.35 & 1.21 & 0.01 & 39.18 & & 8.65 & 7,492 & 17.39 & Jenkins and Ebeling \\
\hline Switchgrass, Columbus, $\mathrm{OH}$ & 46.68 & 5.82 & 0.77 & 0.19 & 37.57 & 0.03 & 8.97 & 7,766 & 18.02 & Miles et. al. 1995 \\
\hline Switchgrass, Dakota Leaf, MN & 47.45 & 5.75 & 0.74 & 0.08 & 42.37 & 0.03 & 3.61 & 8,014 & 18.60 & Miles et. al. 1995 \\
\hline Switchgrass, G Petersen 1 & 48.64 & 5.46 & 0.04 & 0.07 & 42.06 & 0.005 & 3.73 & 8,001 & 18.57 & lowa Project \\
\hline Switchgrass, G Petersen 2 & 47.98 & 5.46 & 0.19 & 0.06 & 41.54 & 0.007 & 4.77 & 7,765 & 18.02 & lowa Project \\
\hline Switchgrass, G Petersen 4 & 48.37 & 5.52 & 0.03 & 0.15 & 43.59 & 0.003 & 2.34 & 8,104 & 18.81 & lowa Project \\
\hline Switchgrass, Joe Cross 1 & 47.11 & 5.39 & 0.23 & 0.06 & 43.19 & 0.007 & 4.02 & 7,934 & 18.41 & lowa Project \\
\hline Switchgrass, Joe Cross 2 & 46.00 & 4.57 & 0.32 & 0.05 & 44.51 & 0.006 & 4.54 & 7,862 & 18.25 & lowa Project \\
\hline Switchgrass, Joe Cross 4 & 48.00 & 5.54 & 0.16 & 0.07 & 42.61 & 0.004 & 3.61 & 8,017 & 18.61 & lowa Project \\
\hline Switchgrass, Krutsinger 1 & 46.91 & 5.38 & 0.38 & 0.07 & 41.61 & 0.017 & 5.64 & 7,890 & 18.31 & lowa Project \\
\hline Switchgrass, Krutsinger 2 & 44.97 & 5.10 & 0.69 & 0.09 & 42.43 & 0.024 & 6.72 & 7,812 & 18.13 & lowa Project \\
\hline Switchgrass, Krutsinger 4 & 48.20 & 5.68 & 0.24 & 0.06 & 42.00 & 0.017 & 3.81 & 7,952 & 18.46 & lowa Project \\
\hline Switchgrass, Lodge Land 1 & 47.71 & 5.43 & 0.38 & 0.04 & 41.53 & 0.007 & 4.91 & 7,953 & 18.46 & lowa Project \\
\hline Switchgrass, Lodge Land 2 & 47.46 & 5.41 & 0.48 & 0.05 & 43.18 & 0.007 & 3.42 & 8,091 & 18.78 & lowa Project \\
\hline Switchgrass, Lodge Land 4 & 47.72 & 5.48 & 0.15 & 0.06 & 43.10 & 0.003 & 3.49 & 8,034 & 18.65 & lowa Project \\
\hline Switchgrass, Schulz 30 & 48.69 & 5.61 & 0.06 & 0.05 & 43.14 & 0.003 & 2.44 & 8,012 & 18.60 & lowa Project \\
\hline Switchgrass, Sellers 1 & 48.69 & 5.50 & 0.34 & 0.06 & 41.28 & 0.004 & 4.14 & 8,021 & 18.62 & lowa Project \\
\hline Switchgrass, Sellers 2 & 48.31 & 5.52 & 0.29 & 0.09 & 42.59 & 0.005 & 3.20 & 8,074 & 18.74 & lowa Project \\
\hline Switchgrass, Sellers 32 & 49.10 & 5.71 & 0.17 & 0.05 & 42.21 & 0.002 & 2.76 & 7,983 & 18.53 & lowa Project \\
\hline Switchgrass, Sellers 4 & 48.72 & 5.54 & 0.16 & 0.05 & 41.70 & 0.008 & 3.83 & 8,052 & 18.69 & lowa Project \\
\hline Switchgrass, Summer, MN & 47.51 & 5.02 & 0.65 & 0.07 & 37.02 & 0.03 & 2.69 & 7,979 & 18.52 & Miles et. al. 1995 \\
\hline Switchgrass, SWG10 & 43.78 & 5.25 & 0.52 & 0.07 & 46.10 & 0.035 & 4.29 & 7,806 & 18.12 & lowa Project \\
\hline Switchgrass, SWG12 & 43.20 & 5.23 & 0.50 & 0.10 & 47.19 & 0.046 & 3.78 & 7,735 & 17.95 & lowa Project \\
\hline Switchgrass, SWG14 & 42.13 & 5.07 & 0.54 & 0.08 & 48.49 & 0.022 & 3.68 & 7,803 & 18.11 & lowa Project \\
\hline Switchgrass, SWG16 & 42.89 & 5.05 & 0.57 & 0.10 & 47.68 & 0.015 & 3.71 & 7,837 & 18.19 & lowa Project \\
\hline Switchgrass, SWG18 & 43.93 & 5.17 & 0.55 & 0.08 & 46.86 & 0.005 & 3.41 & 7,809 & 18.12 & lowa Project \\
\hline Switchgrass, SWG20 & 44.21 & 5.07 & 0.64 & 0.09 & 46.23 & 0.004 & 3.75 & 7,793 & 18.09 & lowa Project \\
\hline
\end{tabular}




\begin{tabular}{|c|c|c|c|c|c|c|c|c|c|c|}
\hline Material & C & $\mathbf{H}$ & $\mathbf{N}$ & s & $\mathbf{O}$ & $\mathrm{Cl}$ & Ash & $\begin{array}{r}\text { HHV } \\
\text { Btu/lb }\end{array}$ & $\begin{array}{l}\mathrm{HHV} \\
\mathrm{MJ} / \mathbf{k g}\end{array}$ & Reference \\
\hline Switchgrass, SWG22 & 44.45 & 5.14 & 0.59 & 0.11 & 46.17 & 0.004 & 3.53 & 7,847 & 18.21 & lowa Project \\
\hline Switchgrass, SWG26 & 44.86 & 5.15 & 0.57 & 0.09 & 46.20 & 0.005 & 3.13 & 7,852 & 18.22 & lowa Project \\
\hline Switchgrass, SWG28 & 44.71 & 5.15 & 0.63 & 0.07 & 45.90 & 0.003 & 3.55 & 7,785 & 18.07 & lowa Project \\
\hline Switchgrass, Van Patten 1 & 48.32 & 5.50 & 0.10 & 0.06 & 42.80 & 0.036 & 3.21 & 8,161 & 18.94 & lowa Project \\
\hline Switchgrass, Van Patten 2 & 48.41 & 5.48 & 0.09 & 0.04 & 42.56 & 0.024 & 3.42 & 8,091 & 18.78 & lowa Project \\
\hline Switchgrass, Van Patten 4 & 46.95 & 5.79 & 0.14 & 0.06 & 44.71 & 0.012 & 2.35 & 8,182 & 18.99 & lowa Project \\
\hline Switchgrass, WG24 & 44.03 & 5.09 & 0.55 & 0.09 & 46.30 & 0.006 & 3.93 & 7,864 & 18.25 & lowa Project \\
\hline Urban wood waste & 48.77 & 5.76 & 0.27 & 0.07 & 39.59 & 0.05 & 2.50 & 8,361 & 19.41 & Miles et. al. 1995 \\
\hline Walnut shells & 49.98 & 5.35 & 0.21 & 0.01 & 43.35 & & 0.56 & 8,695 & 20.18 & Jenkins and Ebeling \\
\hline Walnut, English, prunings & 49.72 & 5.63 & 0.37 & 0.01 & 43.14 & & 1.08 & 8,458 & 19.63 & Jenkins and Ebeling \\
\hline Water hyacinth & 40.30 & 4.60 & 1.51 & & 33.99 & & 19.60 & 6,402 & 14.86 & Klass and Ghosh \\
\hline Water hyacinth & 43.00 & 5.80 & 5.60 & & 29.50 & & 15.30 & 7,747 & 17.98 & Elliot et al \\
\hline Wheat dust & 41.38 & 5.10 & 3.04 & 0.19 & 35.17 & & 13.68 & 6,980 & 16.20 & Jenkins and Ebeling \\
\hline Wheat straw & 43.20 & 5.00 & 0.61 & 0.11 & 39.40 & & 8.90 & 7,199 & 16.71 & Jenkins and Ebeling \\
\hline Willow - SA22 -3 yr & 49.90 & 5.90 & 0.61 & 0.07 & 41.81 & $<0.01$ & 1.71 & 8,424 & 19.55 & Miles et. al. 1995 \\
\hline Willow - SA22 Butt & 48.95 & 6.05 & 0.36 & 0.04 & 43.54 & 0.01 & 1.06 & 8,326 & 19.32 & Miles et. al. 1995 \\
\hline Willow - SA22 Top & 49.42 & 5.89 & 0.96 & 0.12 & 41.27 & $<0.01$ & 2.34 & 8,510 & 19.75 & Miles et. al. 1995 \\
\hline Willow - SA22-1 yr & 49.75 & 6.00 & 0.65 & 0.09 & 42.01 & 0.01 & 1.50 & 8,457 & 19.63 & Miles et. al. 1995 \\
\hline Willow - SH3-1 yr & 48.85 & 6.04 & 0.71 & 0.06 & 42.64 & 0.01 & 1.70 & 8,443 & 19.60 & Miles et. al. 1995 \\
\hline Willow - SP3-1yr & 50.29 & 6.01 & 0.50 & 0.07 & 41.93 & $<0.01$ & 1.20 & 8,691 & 20.17 & Miles et. al. 1995 \\
\hline Willow - SV1-1 yr & 47.94 & 5.84 & 0.63 & 0.06 & 44.43 & $<0.01$ & 1.10 & 8,325 & 19.32 & Miles et. al. 1995 \\
\hline Willow - SV1-3 yr & 49.09 & 5.89 & 0.35 & 0.03 & 46.39 & $<0.01$ & 0.95 & 8,330 & 19.33 & Miles et. al. 1995 \\
\hline Wood - land clearing & 42.32 & 5.02 & 0.33 & 0.06 & 35.77 & 0.02 & 16.50 & 7,408 & 17.19 & Miles et. al. 1995 \\
\hline Wood - yard waste & 41.54 & 4.79 & 0.85 & 0.24 & 32.21 & 0.30 & 20.37 & 7,009 & 16.27 & Miles et. al. 1995 \\
\hline
\end{tabular}


Figure 3-1: Nitrogen Content of Selected Biomass Samples

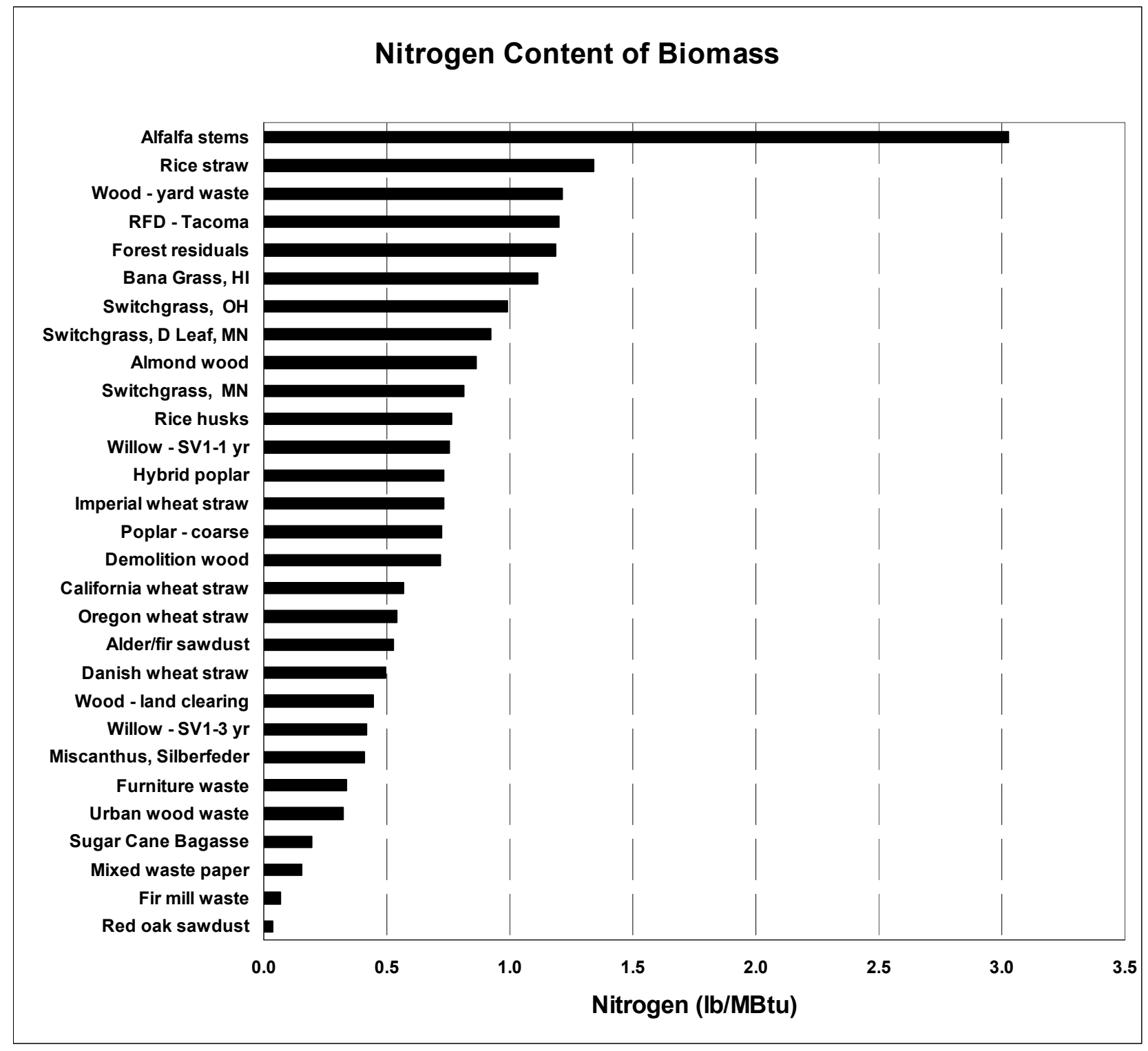




\section{Figure 3-2: Potassium Content of Selected Biomass Samples ${ }^{3}$}

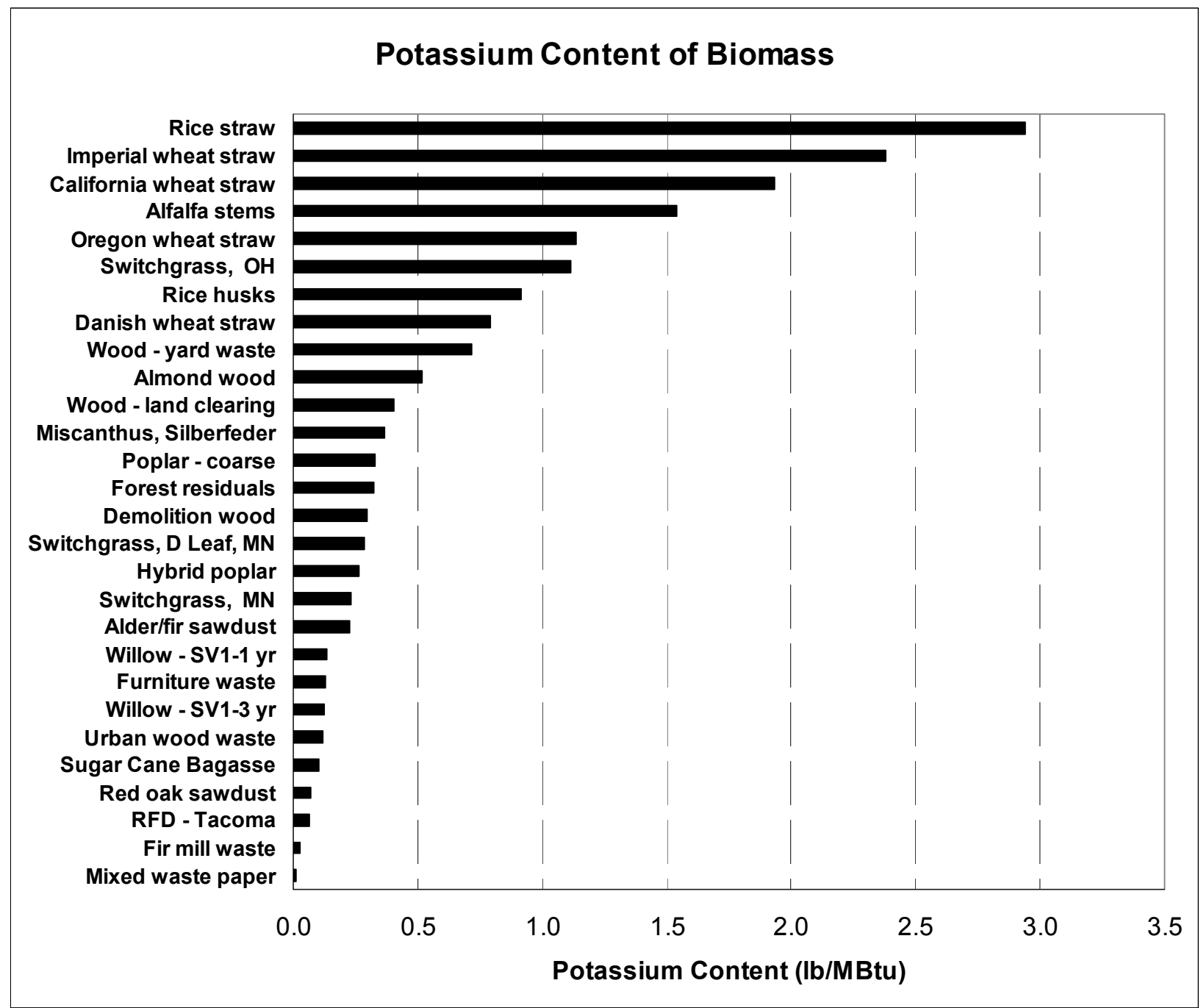


Table 3-5: Elemental Analysis of Volatiles Liberated by Pyrolysis for Two Selected Fuels

\begin{tabular}{|lcccccc|}
\hline Fuel & \multicolumn{3}{c}{ wt\% in volatile, dry basis } & \multicolumn{3}{c|}{ Molar ratio volatile } \\
& $\mathrm{C}$ & $\mathrm{H}$ & $\mathrm{O}$ & $\mathrm{C}$ & $\mathrm{H}$ & $\mathrm{O}$ \\
\hline Lignite & 17.4 & 4.22 & 19.17 & 1 & 2.91 & 0.83 \\
Douglas fir bark & 23.4 & 5.9 & 36.7 & 1 & 3.03 & 1.17 \\
\hline
\end{tabular}

The $\mathrm{C} / \mathrm{H} / \mathrm{O}$ ratios of these volatile fractions are very similar despite the difference in feedstock. In the pyrolysis process, at relatively high temperatures,

$$
\begin{array}{lll} 
& \nearrow & \mathrm{CH}_{4} \\
\text { Volatiles } & \rightarrow & \mathrm{CO}+\mathrm{CO}_{2} \\
& \searrow & \mathrm{H}_{2} \mathrm{O}
\end{array}
$$

If we assume that $\mathrm{CO}$ is produced exclusively we can calculate the product analysis from pyrolysis.

Therefore, assuming:

$$
\begin{aligned}
& \mathrm{C}+4 \mathrm{H} \rightarrow \mathrm{CH}_{4} \\
& 2 \mathrm{H}+\mathrm{O} \rightarrow \mathrm{H}_{2} \\
& \mathrm{C}+\mathrm{O} \rightarrow \mathrm{CO},
\end{aligned}
$$

let $\mathrm{X}$ be the moles of carbon converted to methane, $\mathrm{Y}$ the oxygen converted to water, and $\mathrm{Z}$ the carbon to $\mathrm{CO}$.

The material balance equations yield:

$$
\begin{aligned}
& X=[2+(\mathrm{H} / \mathrm{C})-2(\mathrm{O} / \mathrm{C})] / 6 \\
& Z=1-X \\
& Y=O / C-Z
\end{aligned}
$$


In the calculation for methane it should be pointed out that as long as water-gas shift reaction equilibrium is attained, it makes no difference whether the non-hydrocarbon products are $\mathrm{CO}$ and $\mathrm{H}_{2} \mathrm{O}$ or a mixture of $\mathrm{CO}, \mathrm{CO}_{2}, \mathrm{H}_{2}$, and $\mathrm{H}_{2} \mathrm{O}$.

Table 3-6 presents such an analysis on a dry basis of $100 \mathrm{lb}$ of fuel.

Table 3-6: Evaluation of Feedstocks for Pyrolysis by Material Balance Calculation

\begin{tabular}{|c|c|c|c|c|c|}
\hline \multirow[t]{2}{*}{ Fuel } & \multirow{2}{*}{$\begin{array}{l}\frac{\text { SCF Gas }}{100 \mathrm{lb} \text { dry }} \\
\text { feed }\end{array}$} & \multicolumn{3}{|c|}{ Mole Fractions } & \multirow{2}{*}{$\frac{\mathrm{Lb} \mathrm{C} \text { in } \mathrm{CH}_{4}}{100 \mathrm{lb} \mathrm{C} \text { in feed }}$} \\
\hline & & $\mathrm{CH}_{4}$ & $\mathrm{CO}$ & $\mathrm{H}_{2} \mathrm{O}$ & \\
\hline Lignite & 754 & 0.395 & 0.334 & 0.271 & 14.7 \\
\hline $\begin{array}{l}\text { Douglas fir } \\
\text { bark }\end{array}$ & 1196 & 0.277 & 0.341 & 0.382 & 18.7 \\
\hline
\end{tabular}

The gas derived from lignite is higher in quality than that from the fir bark due to the bark's greater potential to form water. The quantity of gas produced is greater for the fir bark due to the greater quantity of volatiles present. The most important factor is the fraction of carbon converted to methane. The woody material shows a greater potential to form methane on a carbon feed basis, indicating that it is a higher quality feedstock for pyrolysis. This may be attributed to the higher degree of aromaticity exhibited in coals.

Table 3-7 presents ultimate analysis for typical pyrolysis chars derived from biomass feedstocks. Except for the municipal solid waste char, all contain considerable quantities of volatile constituents, including $\mathrm{H}$ and $\mathrm{O}$, due to the low processing temperature.

The $\mathrm{C} / \mathrm{H}$ and $\mathrm{C} / \mathrm{O}$ ratios are greater in all chars than in the fresh feed materials. The high-temperature municipal waste char has been almost completely devolatized, as is evidenced by the low $\mathrm{H}$ and $\mathrm{O}$ contents.

\subsubsection{Moisture Content of Fuels}

Woody fuels and municipal solid waste samples are available with various moisture contents. The moisture is important in determining drying costs and as-received heat contents of the fuels.

Table 3-8 presents approximate ranges of moisture for typical biomass fuels. The effect of moisture on the recoverable heat is dramatic due to the heat requirements for vaporizing the moisture plus superheating the vapor. 
Table 3-7: Ultimate Analysis Data for Selected Pyrolysis Chars

(Dry Basis, Weight Percent)

\begin{tabular}{|c|c|c|c|c|c|c|c|c|c|}
\hline Material & C & $\mathbf{H}$ & $\mathbf{N}$ & S & 0 & Ash & $\begin{array}{l}\text { HHV } \\
\text { Btu/lb }\end{array}$ & $\begin{array}{l}\mathrm{HHV} \\
\mathrm{MJ} / \mathrm{kg}\end{array}$ & Reference \\
\hline Fir bark char & 49.9 & 4.0 & 0.1 & 0.1 & 24.5 & 21.4 & 8,260 & 19.17 & $\begin{array}{l}\text { Pober and } \\
\text { Bauer } 1977\end{array}$ \\
\hline Rice hull char & 36.0 & 2.6 & 0.4 & 0.1 & 11.7 & 49.2 & 6,100 & 14.16 & $\begin{array}{l}\text { Pober and } \\
\text { Bauer } 1977\end{array}$ \\
\hline Grass straw char & 51.0 & 3.7 & 0.5 & 0.8 & 19.7 & 24.3 & 8,300 & 19.26 & $\begin{array}{l}\text { Pober and } \\
\text { Bauer } 1977\end{array}$ \\
\hline $\begin{array}{l}\text { Animal waste } \\
\text { char }^{\mathrm{a}}\end{array}$ & 34.5 & 2.2 & 1.9 & 0.9 & 7.9 & 48.8 & 5,450 & 12.65 & $\begin{array}{l}\text { Pober and } \\
\text { Bauer } 1977\end{array}$ \\
\hline MSW char & 54.9 & 0.8 & 1.1 & 0.2 & 1.8 & 41.2 & 8,020 & 18.61 & $\begin{array}{l}\text { Sanner et a } \\
1970\end{array}$ \\
\hline $\begin{array}{l}\text { Redwood } \\
\text { charcoal } \\
\left(421-549^{\circ} \mathrm{C}\right)\end{array}$ & 75.6 & 3.3 & 0.2 & 0.2 & 18.4 & 2.3 & 12,400 & 28.78 & $\begin{array}{l}\text { Boley and } \\
\text { Landers } \\
1969\end{array}$ \\
\hline $\begin{array}{l}\text { Redwood } \\
\text { charcoal } \\
\left(460-941^{\circ} \mathrm{C}\right)\end{array}$ & 78.8 & 3.5 & 0.2 & 0.2 & 13.2 & 4.1 & 13,100 & 30.41 & $\begin{array}{l}\text { Boley and } \\
\text { Landers } \\
1969\end{array}$ \\
\hline $\begin{array}{l}\text { Oak charcoal } \\
\left(438-641^{\circ} \mathrm{C}\right)\end{array}$ & 67.7 & 2.4 & 0.4 & 0.2 & 14.4 & 14.9 & 10,660 & 24.60 & $\begin{array}{l}\text { Boley and } \\
\text { Landers } \\
1969\end{array}$ \\
\hline $\begin{array}{l}\text { Oak charcoal } \\
\left(571^{\circ} \mathrm{C}\right)\end{array}$ & 64.6 & 2.1 & 0.4 & 0.1 & 15.5 & 17.3 & 9,910 & 23.00 & $\begin{array}{l}\text { Boley and } \\
\text { Landers } \\
1969\end{array}$ \\
\hline
\end{tabular}

${ }^{\mathrm{a} C o n t a i n s} 3.7 \% \mathrm{Cl}$ lumped with oxygen 
Table 3-8: Approximate Moisture Contents Of Typical Biomass Fuels

\begin{tabular}{|lc|}
\hline \multicolumn{1}{|c|}{ Biomass Fuel } & $\begin{array}{c}\text { Moisture Content } \\
\text { (wt \%) }\end{array}$ \\
Bark & $25-75$ \\
Coarse wood residue & $30-60$ \\
Manure, beef cattle & $80-90$ \\
Manure, poultry & $70-80$ \\
Shavings & $16-40$ \\
Sawdust & $25-40$ \\
Sander dust & $2-8$ \\
Municipal refuse & 20 \\
Air dry feedlot waste & 12 \\
Baled switchgrass & $10-15$ \\
\hline
\end{tabular}

\subsubsection{Heating Values}

The heating value of carbon feedstocks is determined by the ASTM method listed in Table 3-1. The experimental method employs an adiabatic bomb calorimeter which measures the enthalpy change between reactants and products at $25^{\circ} \mathrm{C}$. The heating value obtained is termed the higher heating value because the water of combustion is present in the liquid state at the completion of the experimental determination.

The heating value may be reported on two bases. These are the gross or higher heating value and the net or lower heating value. The higher heating value (HHV) represents the heat of combustion relative to liquid water as the product. The lower heating value (LHV) is based on gaseous water. You may also see HHV and LHV referred to as gross calorific value (GCV) and net calorific value (NCV). The difference in the heating value is the latent heat of the water of combustion. Heating values often are reported on both wet and dry fuel bases. The conversion between bases is simple in the case of the higher heating value, involving only normalizing out the moisture (M). This is true because the moisture present in the raw fuel is in the same state before and after combustion.

$$
\mathrm{HHV}^{*}=\mathrm{HHV} /(1-\mathrm{M})
$$

Lower (net) heating values depend on the moisture content in a more complicated 
fashion. Since both the product water and moisture are present as vapor after combustion, a portion of the heat of combustion is used to evaporate the moisture. Therefore, using the latent heat of water, $\lambda=980 \mathrm{Btu} / \mathrm{lb}$,

$$
H_{H V}^{*}=(L H V-M \lambda) /(1-M)
$$

To convert between higher (gross) and lower (net) heating values, the amount of water produced by combustion reactions, but not including moisture, must be known. If this is called $\mathrm{W}, \mathrm{lb}$ water/lb fuel, then the heating values are related by:

$$
H H V=L L V+W \lambda .
$$

All heats reported in this discussion are higher (gross) heating values on a dry basis.

Table 3-4 reports higher heating values on a dry basis for a variety of biomass fuels. Typically, the heating values for coals are much greater than for biomass materials, ranging from $10 \mathrm{MBtu} / \mathrm{lb}$ to $14 \mathrm{MBtu} / \mathrm{lb}(23.2 \mathrm{MJ} / \mathrm{kg}$ to $32.5 \mathrm{MJ} / \mathrm{kg})$ and $5 \mathrm{MBtu} / \mathrm{lb}$ to 9 MBtu/lb (11.6 MJ/kg to $20.9 \mathrm{MJ} / \mathrm{kg})$, respectively. This is principally due to the higher carbon content of the coals. Table 3-7 gives higher heating values for biomass chars. The values are low due to the high ash content of the chars; however, on a dry, ash-free basis, the heating values are similar to those of the coals.

A common method for estimating heating values of solid fuels is the Boie equation (Van Krevelan 1961) which permits the heating value to be estimated from the ultimate analysis. The Boie equation has been used to estimate the HHV of the biomass samples in Table 3-4. The average absolute error of the estimate is $4.70 \%$, with a bias of $3.19 \%$. A second method for estimating heating values is that of Tillman (1978). As shown in Table 3-9, the results for Tillman's equation, which uses only the carbon content, give comparable values. The average error is roughly $2.83 \%$ with a positive bias of $0.83 \%$.

A third method of estimating gross heating values has been developed at IGT (Institute of Gas Technology 1978) using the experimental heating values and ultimate analyses of more than 700 coal samples. When this heating value correlation is used to estimate the higher heating values of fresh biomass materials, the average error is $3.34 \%$ with a negative $1.73 \%$ bias.

A linear least-squares regression has been performed on the biomass data set in Table 3-4 and the resulting regression equation is given in Table 3-9. The average error is $2.02 \%$, with a positive bias of 0.09 . $R^{2}$ for the fit is 0.900 . A graphical representation of the correlation versus data is given in Figure 3.3. While this better represents the data in Table 3-4, it must be noted that the estimate has not been checked for biomass samples outside the given data set. The experimental error in the ASTM heating value is $\pm 100 \mathrm{Btu} / \mathrm{lb}$ while the regression yields an average error for chars and fresh biomass 
of about $\pm 160 \mathrm{Btu} / \mathrm{lb}$. Experimental values should be used in cases where the elemental analysis is much different from materials previously tested.

Table 3-9: Comparison of Experimental and Calculated Higher (Gross) Heating Values

\begin{tabular}{|c|c|c|c|c|}
\hline Name & $\begin{array}{c}\text { Equation } \\
\text { HHV [=] Btu/lb }\end{array}$ & $\begin{array}{c}\text { Absolute } \\
\text { Avg Error } \\
\%\end{array}$ & $\begin{array}{c}\text { Bias } \\
\%\end{array}$ & $\mathbf{R}^{2}$ \\
\hline Boie (1) & $157.4 \mathrm{C}+520.4 \mathrm{H}+28.1 \mathrm{~N}+46.9 \mathrm{~S}-49.7 \mathrm{O}$ & 4.70 & 3.19 & -- \\
\hline Tillman (2) & $188 \mathrm{C}-718$ & 2.83 & 0.83 & -- \\
\hline IGT (3) & $146.58 \mathrm{C}+568.78 \mathrm{H}+29.45 \mathrm{~S}-6.58 \mathrm{~A}-51.53(\mathrm{O}+\mathrm{N})$ & 3.34 & -1.73 & -- \\
\hline Bain (4) & $\begin{array}{l}85.65+137.04 \mathrm{C}+217.55 \mathrm{H}+62.56 \mathrm{~N}+107.73 \mathrm{~S}+ \\
8.04 \mathrm{O}-12.94 \mathrm{~A}(\mathrm{Eq} \mathrm{3-15)}\end{array}$ & 2.02 & 0.09 & 0.900 \\
\hline
\end{tabular}

(1) Van Krevelan, D.W. (1961). Coal; Coal Science and Technology 3, Elsevier Scientific Publishing Company, NY, NY, page 416

(2) Tillman, D.A. (1978). Wood as an Energy Source, Academic Press, NY, NY.

(3) Institute of Gas Technology (1978). "Coal Conversion Systems Technical Data Book," DOE Contract EX-76-C-01-2286, available from NTIS.

(4) This publication

To convert to $\mathrm{MJ} / \mathrm{kg}$ multiply by 0.00232

Nomenclature: All values are in weight percent, dry basis

$$
\begin{aligned}
& A=\text { ash } \\
& C=\text { carbon } \\
& H=\text { hydrogen } \\
& N=\text { nitrogen } \\
& O=\text { oxygen } \\
& S=\text { sulfur }
\end{aligned}
$$

\% Error $=100$ (calc. HHV - Exptl. HHV) / Exptl. HHV

Absolute Average Error $=\sum(\text { absoute error })_{\mathrm{i}} / \mathrm{n}$

Bias $=\sum(\text { Error })_{\mathrm{i}} / \mathrm{n}$

where $\mathrm{n}=175$ 
Figure 3-3: Biomass Higher Heating Value

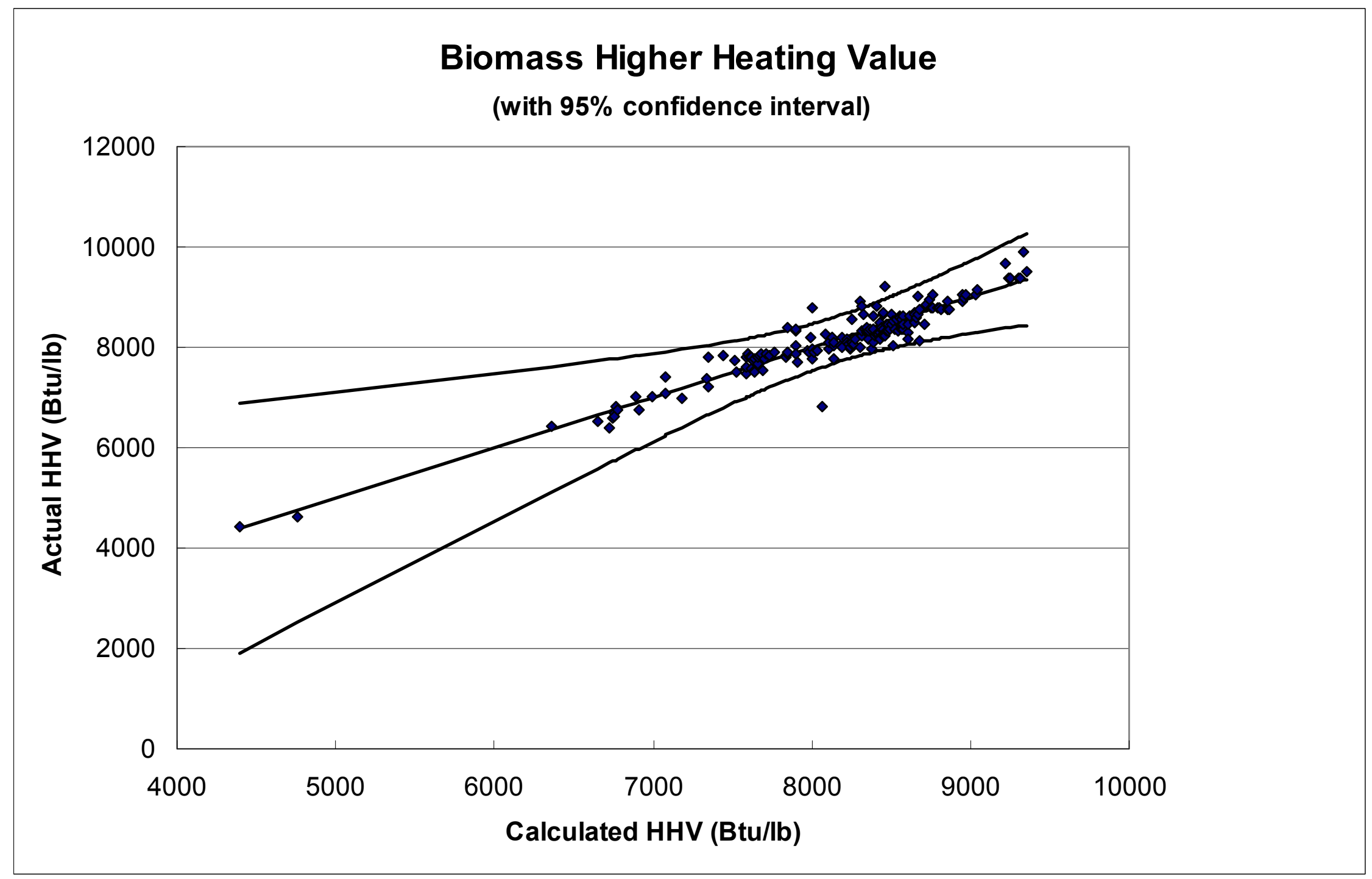




\subsubsection{Heats of Formation}

In thermodynamic calculations, the heat of formation of the feedstocks is required. Heats of formation may be calculated rigorously from the heats of combustion, assuming that the only materials oxidized are $\mathrm{C}, \mathrm{H}, \mathrm{N}$, and $\mathrm{S}$, by posing the following reactions:

$$
\begin{array}{rlr} 
& \rightarrow \mathrm{CO}_{2}, & -94,052 \mathrm{cal} / \mathrm{mole} \\
\text { Fuels }+\mathrm{O}_{2} & \rightarrow \mathrm{H}_{2} \mathrm{O}(\mathrm{L}), \quad-68,317 \mathrm{cal} / \mathrm{mole} \\
& \rightarrow \mathrm{NO}_{2}, \quad+7,960 \mathrm{cal} / \mathrm{mole} \\
& \rightarrow \mathrm{SO}_{2}, & -70,940 \mathrm{cal} / \mathrm{mole}
\end{array}
$$

The heat of formation of the fuel may be calculated as follows, assuming no chemical heat involving ash reactions:

$$
\mathrm{H}_{\mathrm{f}}\left(25^{\circ} \mathrm{C}\right)=\left(\mathrm{HHV}^{*}+0.018 \sum_{\text {Prod }}\left[\mathrm{H}_{\mathrm{fi}} \mathrm{n}_{\mathrm{fi}}\right]\right) /(1-\mathrm{Ash})
$$

in Btu/lb, dry, ash-free basis.

In this equation, $\mathrm{n}_{\mathrm{fi}}$ is the moles of species i formed per $100 \mathrm{lb}$ of dry biomass on combustion ( $\mathrm{i}$ can be $\mathrm{CO}_{2}, \mathrm{H}_{2} \mathrm{O}(\mathrm{L}), \mathrm{NO}_{2}, \mathrm{SO}_{2}$ ) while $\mathrm{H}_{\mathrm{fi}}$ is the heat of formation of $\mathrm{i}$ at $25^{\circ} \mathrm{C}$ in cal $/ \mathrm{mole}$. The factor 0.018 puts the formation enthalpy on a Btu per pound of biomass basis. The HHV is treated as a positive number. The heat of formation is normalized to a dry, ash-free basis for purposes of comparison. Table 3-10 presents heat of formation for a variety of feedstocks. The data show a definite trend in terms of the rank (degree) of aromatization of the materials involved. Biomass is very low in rank since its structure consists of only single aromatic rings (benzene derivatives). Fuels of higher rank - peat, lignite, bituminous, and anthracite coals - have structures containing progressively larger aromatic clusters. Typical bituminous coal structures contain from four to six condensed aromatic rings. The fuel of highest rank is graphite. The coals tend to have low heats of formation which increase in the exothermic sense as the rank decreases. Most woody materials exhibit a constant heat of formation in the range of $-2,200 \mathrm{Btu} / \mathrm{lb}$. Materials such as straw and rice hulls have higher heats of formation, on the order of $-2,700 \mathrm{Btu} / \mathrm{lb}$. The biomass chars generally exhibit heats of formation intermediate between coals and fresh biomass materials. Figure 3-4 shows how the heats of formation depend on the $\mathrm{H} / \mathrm{C}$ ratio of the feedstock. It is evident that the biomass chars, although similar in ultimate analysis to coals do not correlate with the coals in terms of $\mathrm{H} / \mathrm{C}$ ratio. This is probably due to the coal's greater degree of aromatization, which is a result of the coalification process. 


\section{Table 3-10: Heats of Formation for Typical \\ Fuels and Biomass Materials \\ (Basis: Dry, Ash-Free Solid)}

\begin{tabular}{|lrc|}
\hline \multicolumn{1}{|c}{ Material } & Hf $\left.\mathbf{( 7 7 ^ { \circ }} \mathbf{F}\right)$ & H'/C' $^{\prime}$ \\
& (Btu/lb) & \\
\hline Charcoal & & \\
Pittsburgh seam coal & 142 & 0.46 \\
Western Kentucky No. 11 coal & -209 & 0.79 \\
Utah coal & -323 & 0.82 \\
Wyoming Elkol & -540 & 0.92 \\
Lignite & -648 & 0.88 \\
Douglas fir & -1062 & 0.78 \\
Doulas fir bark & -2219 & 1.45 \\
Pine bark & -2081 & 1.26 \\
Western hemlock & -2227 & 1.33 \\
Redwood & -2106 & 1.38 \\
Beech & -2139 & 1.33 \\
Hickory & -2480 & 1.45 \\
Maple & -2344 & 1.57 \\
Poplar & -2203 & 1.43 \\
Rice hulls & -2229 & 1.45 \\
Rice straw & -2747 & 1.78 \\
Sawdust pellets & -2628 & 1.56 \\
Animal waste & -1860 & 1.65 \\
Muncipal solid waste & -2449 & 1.55 \\
Fir bark char & -2112 & 1.51 \\
Muncipal solid waste char & -1580 & 0.96 \\
Grass straw char & -1136 & 0.87 \\
Animal waste char & -1581 & 0.87 \\
Municipal solid waste char & -1536 & 0.76 \\
\hline
\end{tabular}


Figure 3-4: Heats of Formation of Carbonaceous Fuels

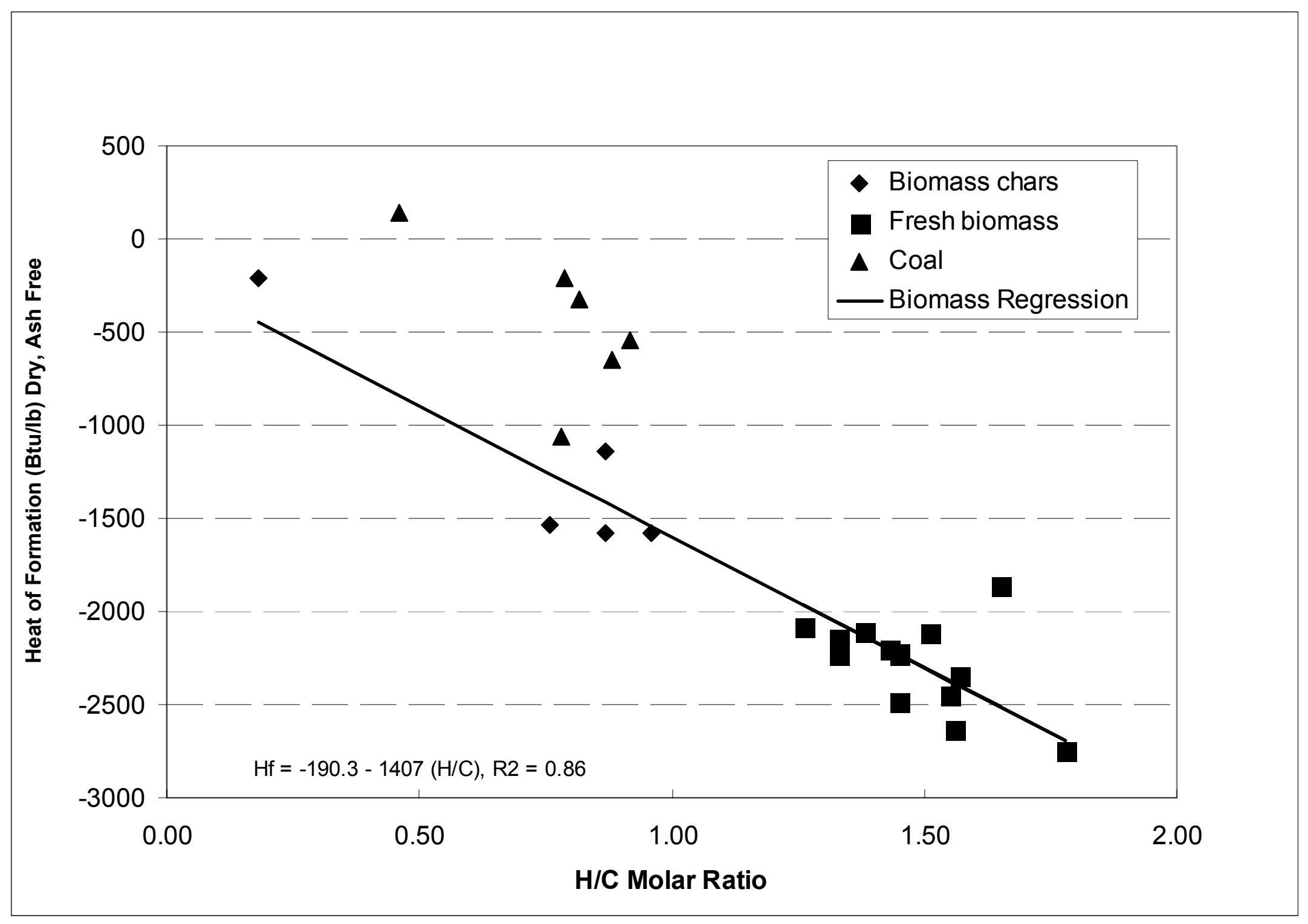


Heats of combustion for biomass materials can be calculated using the heat of formation data based on the following empirical correlation for biomass materials:

$$
H_{f}\left(77^{\circ} F\right)=-190.3-1407 H^{\prime} / C^{\prime}
$$

with $\mathrm{H}^{\prime} / \mathrm{C}^{\prime}$ as mole ratio, Btu/lb, dry ash-free basis.

For natural biomass materials and their chars, the following equation results, based on the ultimate analysis and the pertinent combustion reactions:

$$
H H V^{*}=(141 \mathrm{C}+615 \mathrm{H}-10.2 \mathrm{~N}+39.8 \mathrm{~S})-(1-\mathrm{A} / 100)[(16,769 \mathrm{H} / \mathrm{C})+190]
$$

The $\mathrm{HHV}^{*}$ is the gross heating value on a dry basis, Btu/lb, and the analytical data are expressed in weight percent. This equation cannot be expected to function for manmade materials such as plastics or for non-cellulose-derived materials like leather. For the biomass data set in Table 3-4, the average absolute error is $2.52 \%$ and the bias is $-0.47 \%$.

\subsubsection{Ash}

The ash content of selected biomass samples in given in Table 3-11. Biomass with high annual growth, such as herbaceous materials, annual crops, and woody prunings all have abundant alkali in the ash. Potassium is of primary importance because it volatilizes and reacts during combustion. In addition, biomass rich in both potassium and chlorine can cause large amounts of slagging and fouling during combustion. Biomass ash samples are typically low in sodium content because sodium is toxic to non-halophytic plants. Ash samples high in iron typically indicate presence of nonbiomass materials such as dirt or soil. 
Table 3-11: Ash Composition of Selected Biomass Samples

\begin{tabular}{|c|c|c|c|c|c|c|c|c|c|c|c|c|c|}
\hline \multirow[t]{2}{*}{ Material } & \multirow{2}{*}{$\begin{array}{l}\text { Ash } \\
\text { wt } \%\end{array}$} & \multicolumn{12}{|c|}{ Elemental Composition, wt $\%$} \\
\hline & & $\mathrm{SiO} 2$ & $\mathrm{Al} 2 \mathrm{O} 3$ & $\mathrm{TiO} 2$ & $\mathrm{Fe} 2 \mathrm{O} 3$ & $\mathrm{CaO}$ & $\mathrm{MgO}$ & $\mathrm{Na} 2 \mathrm{O}$ & $\mathrm{K} 2 \mathrm{O}$ & $\mathrm{SO} 3$ & P2O5 & CO2/Other & Undet. \\
\hline Mixed waste paper & 8.33 & 28.10 & 52.56 & 4.29 & 0.81 & 7.49 & 2.36 & 0.53 & 0.16 & 1.70 & 0.20 & & 1.80 \\
\hline Fir mill waste & 0.41 & 15.17 & 3.96 & 0.27 & 6.58 & 11.90 & 4.59 & 23.50 & 7.00 & 2.93 & 2.87 & 18.92 & 2.31 \\
\hline RFD - Tacoma & 26.13 & 33.81 & 12.71 & 1.66 & 5.47 & 23.44 & 5.64 & 1.19 & 0.20 & 2.63 & 0.67 & & 12.58 \\
\hline Red oak sawdust & 0.31 & 20.97 & 2.99 & 0.27 & 2.94 & 10.90 & 4.15 & 1.40 & 22.40 & 2.69 & 1.33 & 14.30 & 15.66 \\
\hline Sugar Cane Bagasse & 2.44 & 46.61 & 17.69 & 2.63 & 14.14 & 4.47 & 3.33 & 0.79 & 4.15 & 2.08 & 2.72 & & 1.39 \\
\hline Urban wood waste & 5.54 & 55.12 & 12.49 & 0.72 & 4.51 & 13.53 & 2.93 & 3.19 & 4.78 & 1.92 & 0.88 & & -0.07 \\
\hline Willow - SV1-3 yr & 0.95 & 8.08 & 1.39 & 0.06 & 0.84 & 45.62 & 1.16 & 2.47 & 13.20 & 1.15 & 10.04 & 13.67 & 2.32 \\
\hline Furniture waste & 3.61 & 57.62 & 12.23 & 0.50 & 5.63 & 13.89 & 3.28 & 2.36 & 3.77 & 1.00 & 0.50 & & -0.78 \\
\hline Willow - SV1-1 yr & 1.10 & 16.76 & 3.01 & 0.07 & 0.85 & 34.83 & 2.46 & 3.05 & 12.20 & 1.70 & 10.36 & 17.58 & -2.87 \\
\hline Alder/fir sawdust & 4.13 & 35.36 & 11.54 & 0.92 & 7.62 & 24.90 & 3.81 & 1.71 & 5.75 & 0.78 & 1.90 & 1.85 & 3.86 \\
\hline Switchgrass, MN & 2.69 & 61.64 & 1.32 & 0.19 & 1.08 & 11.11 & 4.86 & 0.64 & 8.24 & 0.80 & 3.09 & & 7.03 \\
\hline Hybrid poplar & 2.70 & 5.90 & 0.84 & 0.30 & 1.40 & 49.92 & 18.40 & 0.13 & 9.64 & 2.04 & 1.34 & 8.18 & 1.91 \\
\hline Switchgrass, D Leaf, M & 3.61 & 61.23 & 0.57 & 0.37 & 0.79 & 12.06 & 5.42 & 0.43 & 7.63 & 1.11 & 3.56 & & 6.83 \\
\hline \begin{tabular}{|l|l} 
Demolition wood \\
\end{tabular} & 13.12 & 45.91 & 15.55 & 2.09 & 12.02 & 13.51 & 2.55 & 1.13 & 2.14 & 2.45 & 0.94 & & 1.71 \\
\hline Forest residuals & 3.97 & 17.78 & 3.55 & 0.50 & 1.58 & 45.46 & 7.48 & 2.13 & 8.52 & 2.78 & 7.44 & & 2.78 \\
\hline Poplar - coarse & 1.60 & 0.88 & 0.31 & 0.16 & 0.57 & 44.40 & 4.32 & 0.23 & 20.08 & 3.95 & 0.15 & 19.52 & 5.43 \\
\hline Miscanthus, Silberfeder & 3.05 & 61.84 & 0.98 & 0.05 & 1.35 & 9.61 & 2.46 & 0.33 & 11.60 & 2.63 & 4.20 & & 4.95 \\
\hline Wood - land clearing & 16.50 & 65.77 & 14.84 & 0.55 & 5.27 & 5.78 & 1.81 & 2.70 & 2.19 & 0.36 & 0.66 & 0.45 & -0.38 \\
\hline Almond wood & 6.78 & 45.60 & 10.75 & 0.54 & 4.06 & 18.96 & 4.22 & 3.08 & 6.26 & 2.06 & 1.47 & & 3.00 \\
\hline Wood - yard waste & 20.37 & 59.65 & 3.06 & 0.32 & 1.97 & 23.75 & 2.15 & 1.00 & 2.96 & 2.44 & 1.97 & & 0.73 \\
\hline Danish wheat straw & 3.89 & 55.32 & 0.84 & 0.22 & 1.05 & 12.27 & 2.48 & 1.51 & 12.90 & 2.49 & 4.30 & & 6.62 \\
\hline Rice husks & 20.26 & 91.42 & 0.78 & 0.02 & 0.14 & 3.21 & 0.01 & 0.21 & 3.71 & 0.72 & 0.43 & & \\
\hline Switchgrass, OH & 8.97 & 65.18 & 4.51 & 0.24 & 2.03 & 5.60 & 3.00 & 0.58 & 11.60 & 0.44 & 4.50 & & 2.32 \\
\hline Oregon wheat straw & 4.32 & 46.07 & 1.69 & 0.09 & 1.85 & 9.95 & 2.45 & 1.18 & 25.20 & 4.92 & 3.32 & & 3.28 \\
\hline Alfalfa stems & 5.27 & 5.79 & 0.07 & 0.02 & 0.30 & 18.32 & 10.38 & 1.10 & 28.10 & 1.93 & 7.64 & 14.80 & 11.55 \\
\hline California wheat straw & 7.02 & 55.32 & 1.88 & 0.08 & 0.73 & 6.14 & 1.06 & 1.71 & 25.60 & 4.40 & 1.26 & & 1.82 \\
\hline Imperial wheat straw & 9.55 & 37.06 & 2.23 & 0.17 & 0.84 & 4.91 & 2.55 & 9.74 & 21.70 & 4.44 & 2.04 & & 14.32 \\
\hline Rice straw & 18.67 & 74.67 & 1.04 & 0.09 & 0.85 & 3.01 & 1.75 & 0.96 & 12.30 & 1.24 & 1.41 & & 2.68 \\
\hline Bana Grass, $\mathrm{HI}$ & 9.88 & 33.65 & 0.80 & 0.07 & 0.63 & 3.57 & 1.71 & 0.38 & 42.80 & 0.85 & 2.74 & 8.97 & 3.83 \\
\hline
\end{tabular}




\subsection{CHEMICAL COMPOSITION OF WOODS}

In characterizing and correlating reactivity data for pyrolysis and gasification, it is necessary to have some idea of the chemical structure of the reactant material. Woods can be analyzed in terms of fractions of differing reactivity by solvent extraction techniques. This discussion provides some of the relevant information on the structure and composition of these reactive fractions which will be useful in discussions of gasification kinetics and pyrolysis.

Woods can be separated into three fractions: extractables, cell wall components, and ash. The extractables, generally present in amounts of $4 \%$ to $20 \%$, consist of materials derived from the living cell. The cell wall components, representing the bulk of wood, are principally the lignin fraction and the total carbohydrate fraction (cellulose and hemicellulose) termed holocellulose. Lignin, the cementing agent for the cellulose fibers, is a complex polymer of phenylpropane. Cellulose is a polymer formed from $d$ $(+)$-glucose while the hemicellulose polymer is based on other hexose and pentose sugars. In woods, the cell wall fraction generally consists of lignin/cellulose in the ratio 43/57. Residues of the total wood, such as bark and sawdust, have differing compositions.

Table 3-12 presents some analyses of woods on a dry basis while Table 3-13 presents data for typical wood barks.

Table 3-12: Chemical Analyses of Representative Woods ${ }^{\text {a }}$ (wt \% Dry Basis)

\begin{tabular}{|lcccc|}
\hline Sample & Ash & Extractables & Lignin & Holocellulose \\
\hline Softwoods $^{\mathrm{b}}$ & & & & \\
$\quad$ Western white pine & 0.20 & 13.65 & 26.44 & 59.71 \\
$\quad$ Western yellow pine & 0.46 & 15.48 & 26.65 & 57.41 \\
$\quad$ Yellow cedar & 0.43 & 14.39 & 31.32 & 53.86 \\
$\quad$ Incense cedar & 0.34 & 20.37 & 37.68 & 41.60 \\
$\quad$ Redwood & 0.21 & 17.13 & 34.21 & 48.45 \\
Hardwoods & & & & \\
$\quad$ Tanbark oak & 0.83 & 16.29 & 24.85 & 58.03 \\
Mesquite & 0.54 & 23.51 & 30.47 & 45.48 \\
Hickory & 0.69 & 19.65 & 23.44 & 56.22 \\
\hline
\end{tabular}

${ }^{a}$ Encyclopedia of Chem. Tech. (1963), p. 358

bSoftwood refers to conifer woods

cHardwood refers to deciduous woods 
Table 3-13: Chemical Analyses of Representative Wood Barks ${ }^{a}$ (\% Dry Basis)

\begin{tabular}{|lcccc|}
\hline Sample & Ash & Extractables & Lignin & Holocellulose $^{\mathbf{b}}$ \\
\hline Black spruce & 2.1 & 24.78 & 45.84 & 24.78 \\
Fir & 3.1 & 30.37 & 39.16 & 27.37 \\
White birch & 1.5 & 21.6 & 37.8 & 39.1 \\
Yellow birch & 2.9 & 19.9 & 36.5 & 40.7 \\
Beech & 8.3 & 18.3 & 37.0 & 36.4 \\
\hline
\end{tabular}

${ }^{\mathrm{a} F r o m ~ W i s e ~} 1946$

${ }^{\mathrm{b}}$ By difference

In comparing the ultimate analysis data for barks and whole woods in Table 3-4, there is no indication that the chemical makeup of the feedstocks is different. However, from the extractable and cell wall analyses it is evident that the lignin and extractable contents of barks are much greater than those of whole woods. It should be expected that these materials would exhibit different overall reactivities due to their chemical differences.

\subsubsection{Cellulose}

The carbohydrate fraction of plant tissues is composed of cellulose and hemicelluloses, which are moderate to high molecular weight polymers based on simple sugars. Cellulose itself is derived from d-glucose while the hemicelluloses are principally polymers of d-xylose and d-mannose. The hemicellulose composed of pectin generally is present in only very small quantities in woody material but can be a substantially abundant constituent of the inner bark of trees. The cellulose polymer is shown in Fig. 3-5.

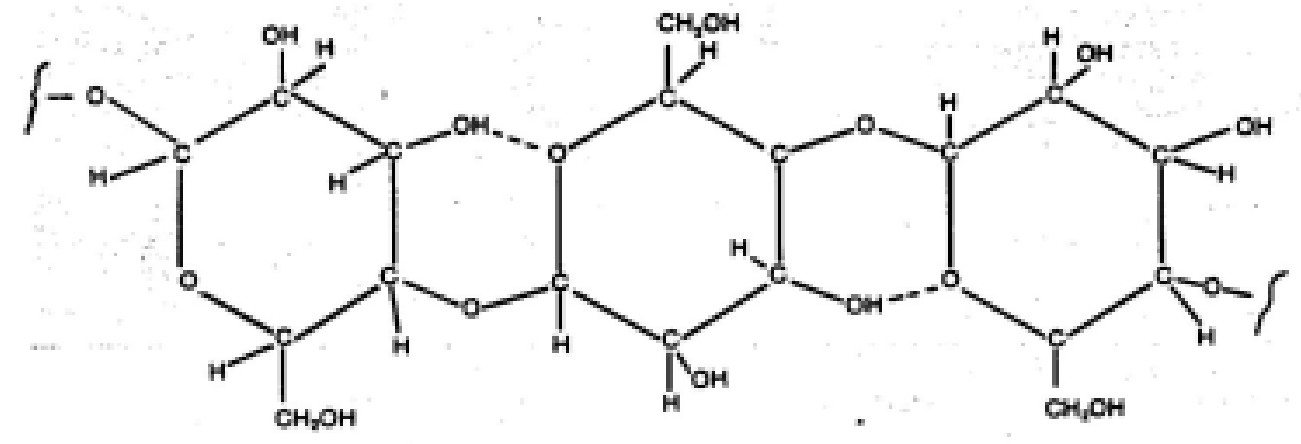

Figure 3-5: The Cellulose Molecule 
Cellulose is composed of d-glucose units $\left(\mathrm{C}_{6} \mathrm{H}_{10} \mathrm{O}_{5}\right)$ bound together by ether-type linkages called glycosidic bonds. Glucose is a hexose, or six carbon sugar. In wood the polymers form thread-like chains of molecular weight greater than 100,000. In cotton, 3000 or more units with a combined molecular weight of 500,000 may be present in chains, yielding an extended length of $15,700 \AA$ and cross section of 4 by 8 $\AA$. These very long, thin molecules can be coiled and twisted but, because of the arrangement of the ether linkage, the chain is stiff and extended. An additional contribution to rigidity results from the hydrogen bonding between a hydroxyl hydrogen and the ring oxygen in the adjacent monomer. The threads are woven amongst each other in a random fashion, termed amorphous cellulose, and also fitted together in a crystalline arrangement. Strong van der Waals forces and hydrogen bonds between threads (termed secondary bonding) give rise to a lamellae structure, The weakest bond in the chain direction is the $\mathrm{C}-\mathrm{O}$ glycosidic bond with an energy of $50 \mathrm{kcal}$. Cellulose fibers are thus very strong.

The dominant physical characteristic of cellulose is its extreme insolubility, which retards not only acid and enzymic hydrolysis but also the removal of lignins and hemicelluloses interspersed through the cellulose structures. The strong secondary bonding is responsible for the insolubility. Cellulose can be dissolved by strong acids such as hydrochloric, sulfuric, and phosphoric.

Pyrolysis of cell wall materials provides a mixture of volatile materials, tars, and char. The proportion of each fraction and its composition depends on the reaction conditions including temperature, pressure, heating rate, and atmospheric composition. Char results from the condensation of aromatic compounds formed from the primary decomposition products. Since aromatics are not present initially, the amount of char formed by condensation reactions is relatively small.

\subsubsection{Principal Hemicelluloses}

Interlaced with cellulose in the cell walls are a number of other polymeric sugars termed hemicelluloses. These are generally differentiated from true cellulose by their solubility in weak alkaline solutions. Figure 3-6 shows a sequence employed by Timell (1967) for isolating softwood polysaccarides. Hemicelluloses are not precursors of cellulose; they are distinctly different compounds that contain acidic and neutral molecules of low and high molecular weight. In contrast to cellulose, which appears to be universal and invariant as the structural polysaccharide of higher land plants, the hemicellulose polysaccharides show a significant variation in composition and structure among species. Several reviews of hemicellulose chemistry have been presented by Polglase (1955), Aspinall (1959), and Whistler and Richards (1970).

Most hemicelluloses contain two to four (and occasionally five to six) simpler sugar residues, d-xylose, d-glucose, d-mannose, d-galactose, 1-arabinose, d-glucuronic acid, and 4-O-methyl-d-glucuronic acid residues constitute the majority of hemicellulose monomers as shown in Fig. 3-7. The structure is similar to that of cellulose except that 


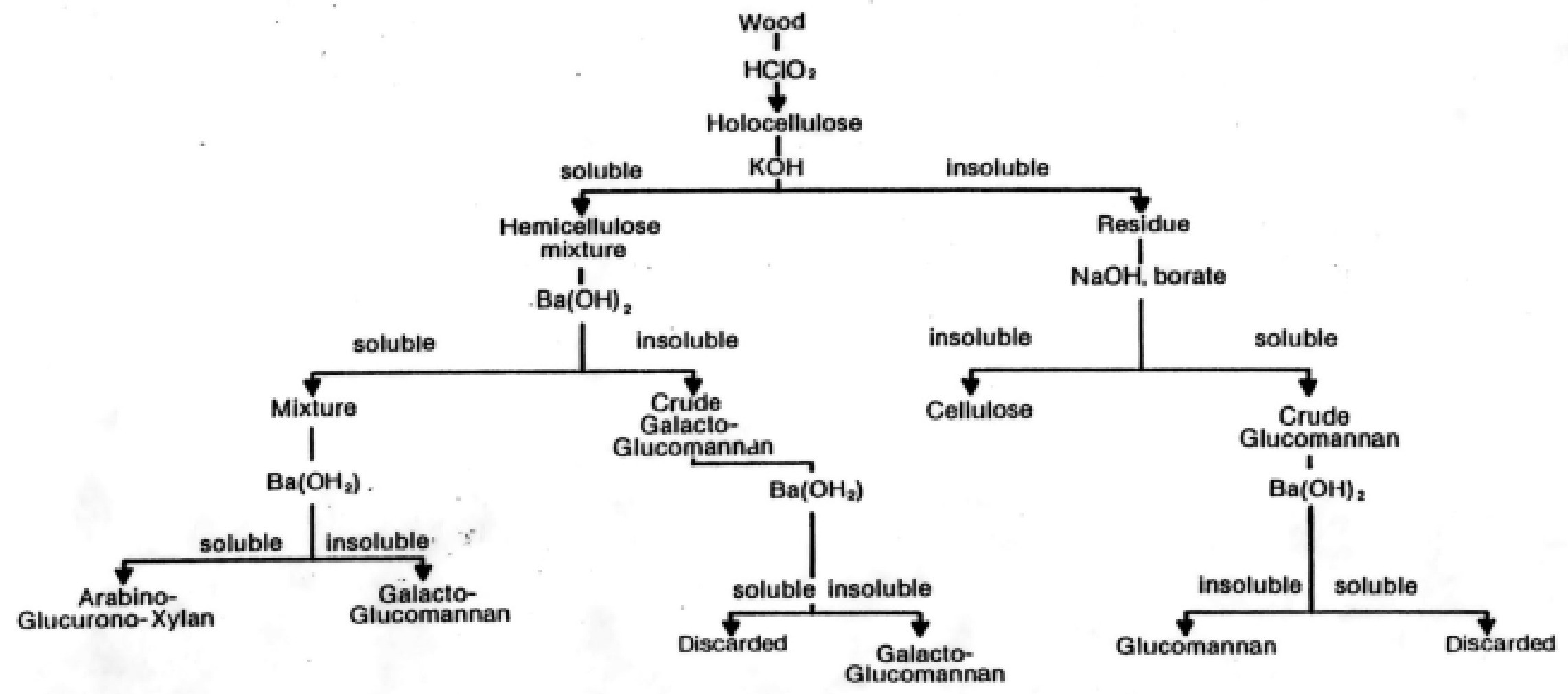

Figure 3-6: Extraction Sequence for Isolation of Softwood Polysaccharides 

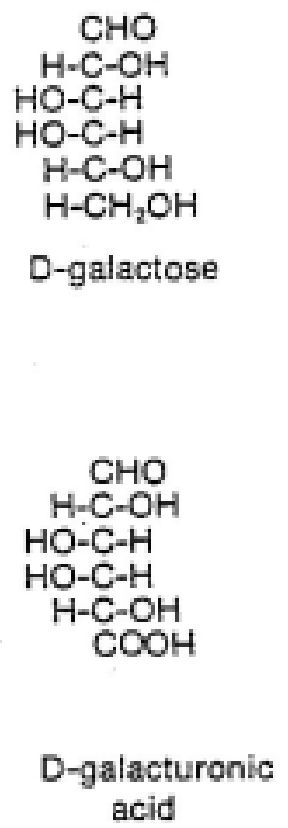

$$
\begin{gathered}
\mathrm{CHO} \\
\mathrm{HO}-\mathrm{C}-\mathrm{H} \\
\mathrm{HO}-\mathrm{C}-\mathrm{H} \\
\mathrm{H}-\mathrm{C}-\mathrm{OH} \\
\mathrm{H}-\mathrm{C}-\mathrm{OH} \\
\mathrm{CH}_{2} \mathrm{OH}
\end{gathered}
$$$$
\text { D-mannose }
$$

$$
\begin{gathered}
\mathrm{CHO} \\
\mathrm{H}-\mathrm{C}-\mathrm{OH} \\
\mathrm{HO}-\mathrm{C}-\mathrm{H} \\
\mathrm{H}-\mathrm{C}-\mathrm{OH} \\
\mathrm{H}-\mathrm{C}-\mathrm{OH} \\
\mathrm{CH}
\end{gathered}
$$

$$
\text { D-glucose }
$$

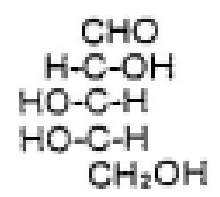

L-arabinose

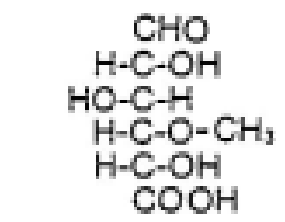

4-0-methylD-giucuronic acid

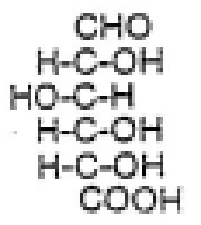

D-glucuronic acid

Figure 3-7: Structural Interrelationship of Commonly Occurring Hemicellulose Component Sugars 
the hemicellulose polymers generally contain 50 units to 200 units and exhibit a branched rather than a linear structure.

These structural characteristics, as well as the number and proportion of different sugar residues present (degree of heteropolymerization), largely determine the observed physical properties of hemicelluloses. The heteropolymerization decreases the ability to form regular, tight-fitting crystalline regions and thus makes hemicellulose more soluble than cellulose. Solubility is also increased due to the branching, which decreases the number of intermolecular hydrogen bonds, and the decreased degree of polymerization compared to cellulose.

\subsubsection{Xylans}

Xylans, the most abundant of the hemicelluloses, are polymers of $d$-xylose $\left(\mathrm{C}_{5} \mathrm{H}_{10} \mathrm{O}\right)$. Xylose is a pentose sugar. The xylan fraction of cellulose is often termed pentosan. They are most abundant in agricultural residues such as grain hulls and corn stalks. Hardwoods (deciduous) and softwoods contain appreciable amounts of xylans. Xylan chains are short, exhibiting molecular weights on the order of 30,000 or less. In addition, some xylans contain carboxylic acid and methyl-ether groups. Typical xylans are shown in Fig. 3-8. The acidic xylans contain d-glucuronic acis or the methylate acid as terminal branch units.

Some of the acid xylans are of low molecular weight. They are known as hemicellulose$B$ and are differentiated from the normal xylans and other neutral hemicelluloses in that they are not precipitated from the alkaline extract by neutralization.

\subsubsection{Mannans}

Mannan-based hemicelluloses include glucomannans, which are built up from linked $d-$ glucose and d-mannose residues in about a 30:70 ratio, and galactoglucomannans, made up of linked d-galactose, d-glucose, and d-mannose in 2:10:30 ratios. In softwoods, mannans are present in substantial amounts while in hardwoods there is generally very little mannan hemicellulose.

\subsubsection{Cellulose Data for Woods}

Table 3-14 presents some data on the cellulose content of woods. The holocellulose fraction of hardwoods is composed principally of cellulose and xylans. The total content of mannans and other hemicelluloses averages only $4.8 \%$ for the four samples. In softwoods, the cellulose fraction is about the same as in hardwoods. However, mannans are present to a much greater extent; the mannans equal or exceed the total xylans in the conifers. Other hemicelluloses are present at $5.4 \%$ on the average for the four samples. 


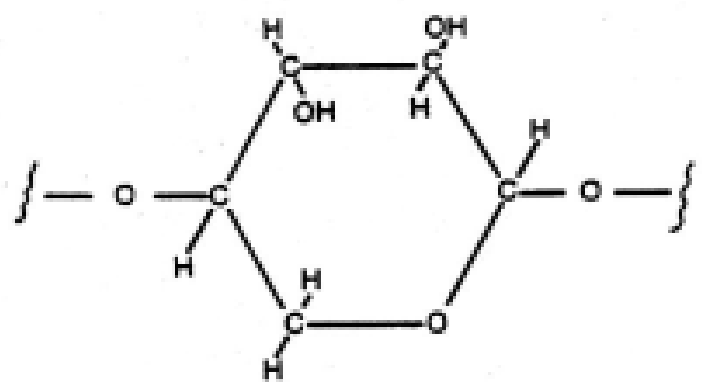

Xylan
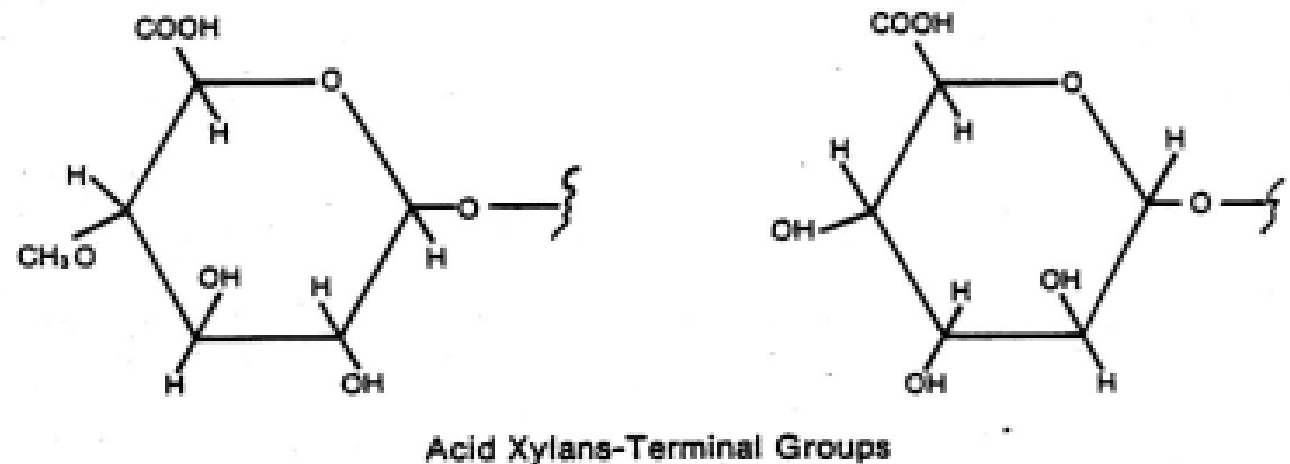

Acid Xylans-Terminal Groups

Figure 3-8: Xylan Hemicellulose Structures 
Table 3-14: Breakdown of Holocellulose Fraction of Woods ${ }^{\text {a }}$

\begin{tabular}{|lccccc|}
\hline & \multicolumn{5}{c|}{ Wt\% in Holocellulose } \\
& Cellulose & Xylans & Acidxylans & Mannans & Others \\
\hline Hardwoods & & & & \\
Trembling Aspen & 71.5 & 20.0 & 4.1 & 2.9 & 1.5 \\
Beech & 64.5 & 23.8 & 6.5 & 2.9 & 2.3 \\
Sugar Maple & 69.8 & 20.0 & 5.9 & 3.1 & 1.2 \\
Southern Red Oak & 59.8 & 28.3 & 6.6 & 2.9 & 2.4 \\
Softwoods & & & & & \\
Eastern hemlock & 69.0 & 6.1 & 5.0 & 17.1 & 2.8 \\
Douglas Fir & 64.6 & 4.2 & 4.2 & 16.0 & 11.0 \\
White spruce & 65.2 & 9.5 & 5.0 & 16.3 & 3.9 \\
Jack Pine & 65.1 & 10.1 & 5.6 & 15.1 & 4.0 \\
\hline
\end{tabular}

${ }^{\mathrm{a} F r o m ~ E n c y c l o p e d i a ~ o f ~ C h e m . ~ T e c h ., ~ 1963, ~ p . ~} 358$.

\subsubsection{Lignin}

The noncarbohydrate component of the cell wall, termed lignin, is a three-dimensional polymer based primarily on the phenylpropane unit. Lignin is deposited in an amorphous state surrounding the cellulose fibers and is bound to the cellulose directly by ether bonds. Its exact structure is not known, although considerable information is available based on its chemical reactivity. In solubility analyses, lignin is defined as the cell wall portion not soluble in $72 \%$ sulfuric acid. Table 3-15 gives typical elemental analyses of wood lignins.

Table 3-15: Elemental Analysis of Wood Lignin

\begin{tabular}{|l|c|c|c|c|c|}
\hline Type & $\mathbf{C ~ ( \% )}$ & $\mathbf{H ~ ( \% )}$ & $\mathbf{O}(\%)$ & $\mathbf{O C H}_{\mathbf{3}}(\mathbf{\%})$ & Molecular Wt. \\
\hline Softwood & 63.8 & 6.3 & 29.9 & 15.8 & 10,000 \\
Hardwood & 59.8 & 6.4 & 33.7 & 21.4 & 5,000 \\
\hline
\end{tabular}

It is assumed, based on much evidence, that the lignins are composed of several monomer groups as shown in Fig. 3-9. These are combined to form the polymer by a variety of linkages involving the aromatic rings and functional groups. The polymer formed contains only single aromatic rings as shown in 3-10 (structural formula). 


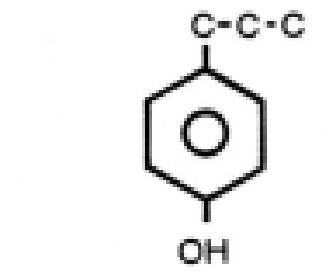

p-hydroxylphenylpropane

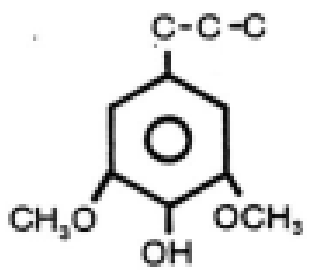

syringylpropane

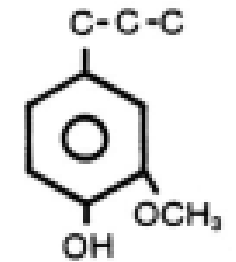

guaiacylpropane

Figure 3-9: Several Monomer Units in Lignin

The representative structure contains the phenylpropane substituted as sinapyl, coniferyl, and p-coumaryl alcohols as shown in Fig. 3-11. Lignification, as discussed by Freudenberg (1965), is thought to occur by dehydration-ploymerization of these alcohol units. Thermal pyrolysis of lignin generally yields a considerable amount of char. It is likely that thermal pyrolysis and lignification follow the same route to yield a condensed polynuclear aromatic structure.

The amount of lignin present varies among materials. Typical amounts for woods and barks are given in Tables 3-12 and 3-13. Table 3-16 gives data for a variety of other biomass materials.

Table 3-16: Lignin in Miscellaneous Plant Material ${ }^{\text {a }}$

\begin{tabular}{|lc|}
\hline Material & Wt \%, Dry Unextracted Material \\
\hline Rice hulls & 40.0 \\
Bagasse & 20.3 \\
Peanut shells & 28.0 \\
Pine needles & 23.9 \\
Wheat straw & 13.9 \\
Corncobs & 13.4 \\
\hline
\end{tabular}

${ }^{a}$ From Encyclopedia of Chem. Tech., 1963, p.361

\subsubsection{Extractables}

The nature and quantity of extractables vary widely among woods. Table 3-17 lists the type of extractables found in a variety of wood materials. The resins and volatile oils 
are fragrant and found most commonly in softwoods. Waxes, fatty acids, pigments, and carbohydrates are commonly found in all woods. Starches account for about $3 \%$ of the total wood. Since the quality and nature of extractables vary, the products after pyrolysis and gasification vary.

\section{Table 3-17: Extractable Components of Wood}

Volatile Oils (removed by steam of ether soluble

Terpenes $\left(\mathrm{C}_{12} \mathrm{H}_{16}\right)$

Sesquiterpene $\left(\mathrm{C}_{15} \mathrm{H}_{24}\right)$ and their oxygenated derivatives

Resins and Fatty Acids (soluble in ether)

Resin acids $\left(\mathrm{C}_{20} \mathrm{H}_{30} \mathrm{O}_{2}\right)$

Fatty acids (oleic, linoleic, palmitic)

Glyceryl esters of fatty acids

Waxes (esters of monohydroxyalcohols and fatty acids)

Physterols (high molecular weight cyclic alcohols)

Pigments (soluble in alcohol)

Flavonols (multi-ring naphthenic and aromatic alcohols, chlorides, ketones acids)

Pyrones (multi-ring naphthenic and aromatic alcohols, chlorides, ketones acids)

Antranols (multi-ring naphthenic and aromatic alcohols, chlorides, ketones acids

Tannins (amorphous polyhydroxylic phenols)

Carbohydrate Components (water soluble)

Starch

Simple sugars

Organic acids 


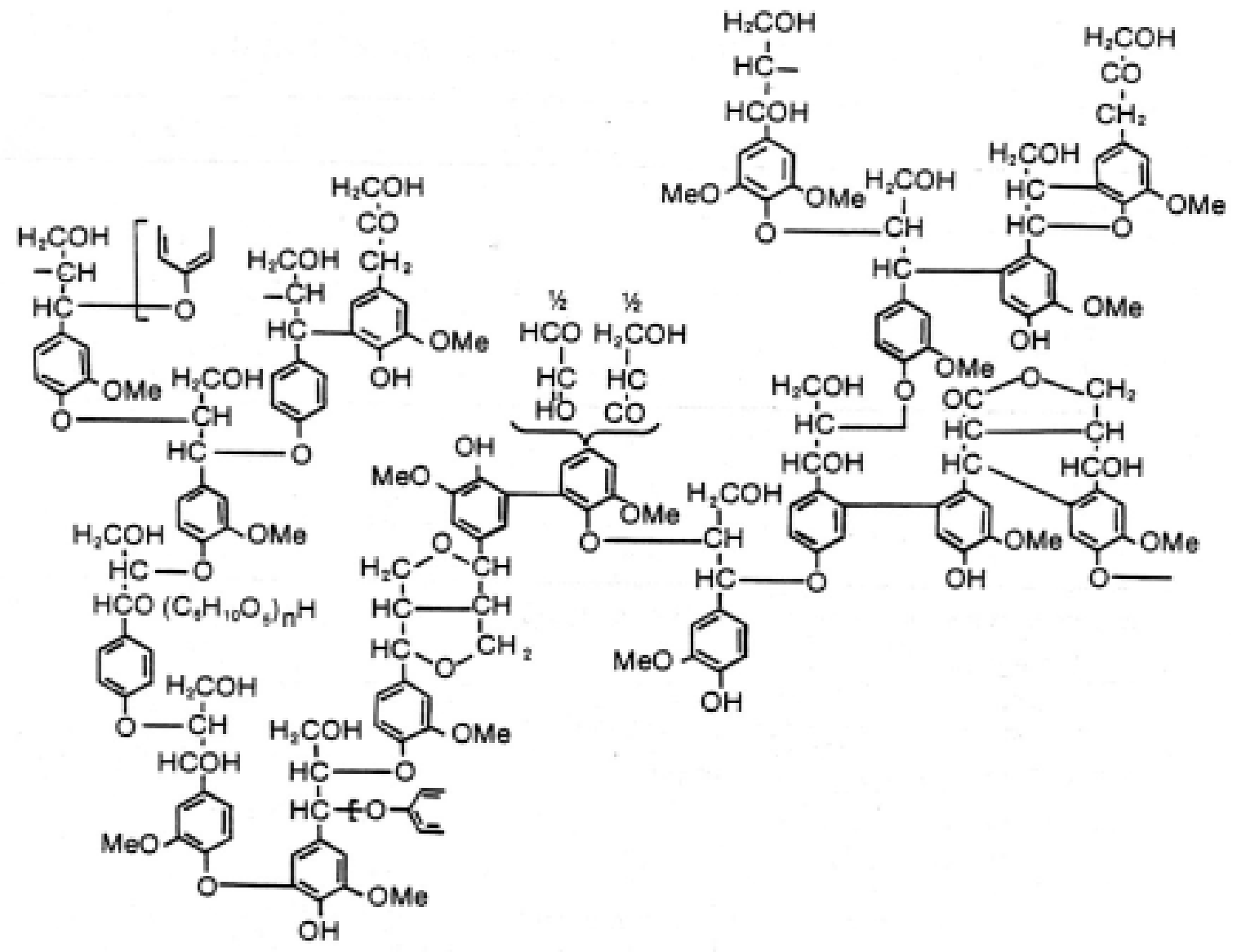

Figure 3-10: Representative Structure of Coniferous Lignin

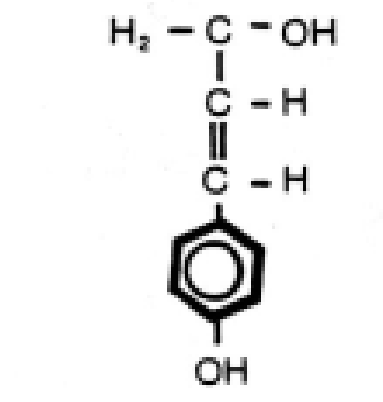

p-coumaryl alcohol

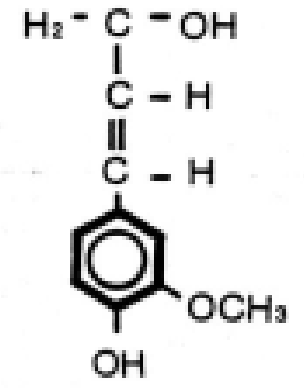

coniferyl alcohol

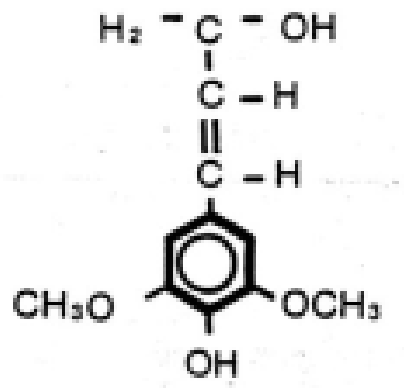

sinapyl alcohol

Figure 3-11: P-Hydroxycinnamyl Alcohols 
Table 3-18 presents some typical extraction data on woods. The bulk of the extractables may be removed by hot water and ether. The ether-soluble portion is usually much greater for the softwoods, showing the higher content of volatile oils and resins. The hot water extraction, which leaches some tannins as well as the carbohydrates, gives yields approximately the same for the soft- and hardwoods.

Table 3-18: Extraction Data for Woods ${ }^{a}$

\begin{tabular}{|c|cc|}
\hline \multirow{2}{*}{ Sample } & \multicolumn{2}{|c|}{ Wt \% of Solubles } \\
\cline { 2 - 3 } Softwoods & Hot Water & Ether \\
\cline { 2 - 3 } Western yellow pine & & \\
Yellow cedar & 5.05 & 8.52 \\
Incense cedar & 3.11 & 2.55 \\
Redwood & 5.38 & 4.31 \\
Western white pine & 9.86 & 1.07 \\
Longleaf pine & 4.49 & 4.26 \\
Douglas fir & 7.15 & 6.32 \\
Western larch & 6.50 & 1.02 \\
White spruce & 12.59 & 0.81 \\
Hardwoods & 2.14 & 1.36 \\
Tanbark oak & & \\
Mesquite & 5.60 & 0.80 \\
Hickory & 15.09 & 2.30 \\
Basswood & 5.57 & 0.63 \\
Yellow birch & 4.07 & 1.96 \\
Sugar Maple & 3.97 & 0.60 \\
Average-Softwoods & 4.36 & 0.25 \\
Average- Hardwoods & 6.25 & 3.36 \\
\hline
\end{tabular}

${ }^{\mathrm{a}}$ From Enclyclopedia of Chem. Tech., 1963, p.358 


\subsection{WOOD STRUCTURE}

Wood is composed of cells of various sizes and shapes. Long pointed cells are known as fibers; hardwood fibers are about $1 \mathrm{~mm}$ in length, while softwood fibers vary in length from about $3 \mathrm{~mm}$ to $8 \mathrm{~mm}$. The mechanical properties of wood depend largely on its density, which, in turn, is largely determined by the thickness of the cell walls.

\subsubsection{Physical Structure of Softwoods}

Figure 3-12 shows a typical softwood structure taken from Siau (1971). In softwoods, the fluid conducting elements are the longitudinal tracheids and ray tracheids. Longitudinal and horizontal resin canals are also present in many species.

Longitudinal tracheids, shown in Fig. 3-13, make up the bulk of the structure of softwoods. These are long, hollow, narrow cells having no openings that are tapered along the radial surfaces for a considerable portion of the lengths where they are in contact with other tracheids. The surfaces of the tracheids are dotted with pits, minute depressions in the plant tissue wall which permit the movement of water and dissolved materials between tracheids. The pit is covered with a semipermeable membrane. Pits are oriented in softwoods as adjacent pairs (pit pairs); fluid flow occurs between tracheids in the direction normal to the principal direction of flow.

The tracheid diameter varies from 15 to $80 \mu \mathrm{m}$ according to species, with a length ranging from 1200 to $7500 \mu \mathrm{m}$. Average values of diameter and length, respectively, are $33 \mu \mathrm{m}$ and $3500 \mu \mathrm{m}$. The inner diameter which is available for flow is typically 20$30 \mu \mathrm{m}$. The effective radius of the pit openings is 0.01 to $4 \mu \mathrm{m}$ due to the restriction created by the membrane. Typically, a tracheid contains 50 pits. In addition to pit pairs allowing longitudinal flow, there are also pit pairs leading from longitudinal tracheids to ray tracheids, permitting radial flow.

The volumetric composition of a typical softwood is as follows:

$\begin{array}{ll}\text { Longitudinal tracheids } & 93 \% \\ \text { Longitudinal resin canals } & 1 \% \\ \text { Ray tracheids } & 6 \%\end{array}$

Since the principal voidage is oriented longitudinally, the magnitude of the permeability in the longitudinal direction is much greater than the radial permeability. Figure 3-14 shows a schematic model for flow through a softwood. 


\subsubsection{Physical Structure of Hardwoods}

The structure of a typical hardwood is shown in Fig. 3-15. The dominant feature of the hardwood structure is the large open vessels or pores. Tracheids and pits are present but contribute significantly more resistance to flow. In a typical hardwood, the following structural composition is present:

$\begin{array}{lr}\text { Vessels } & 55 \% \\ \text { Tracheids } & 26 \% \\ \text { Woods rays } & 18 \% \\ \text { Others } & 1 \%\end{array}$

Vessels are large, with diameters of 20 to $30 \mu \mathrm{m}$. The vessels are short, connected by "perforation plates" which offer very low flow resistance. Thus the vessels behave as long capillaries. Figure 3-16 shows the nature of flow through hardwoods. 


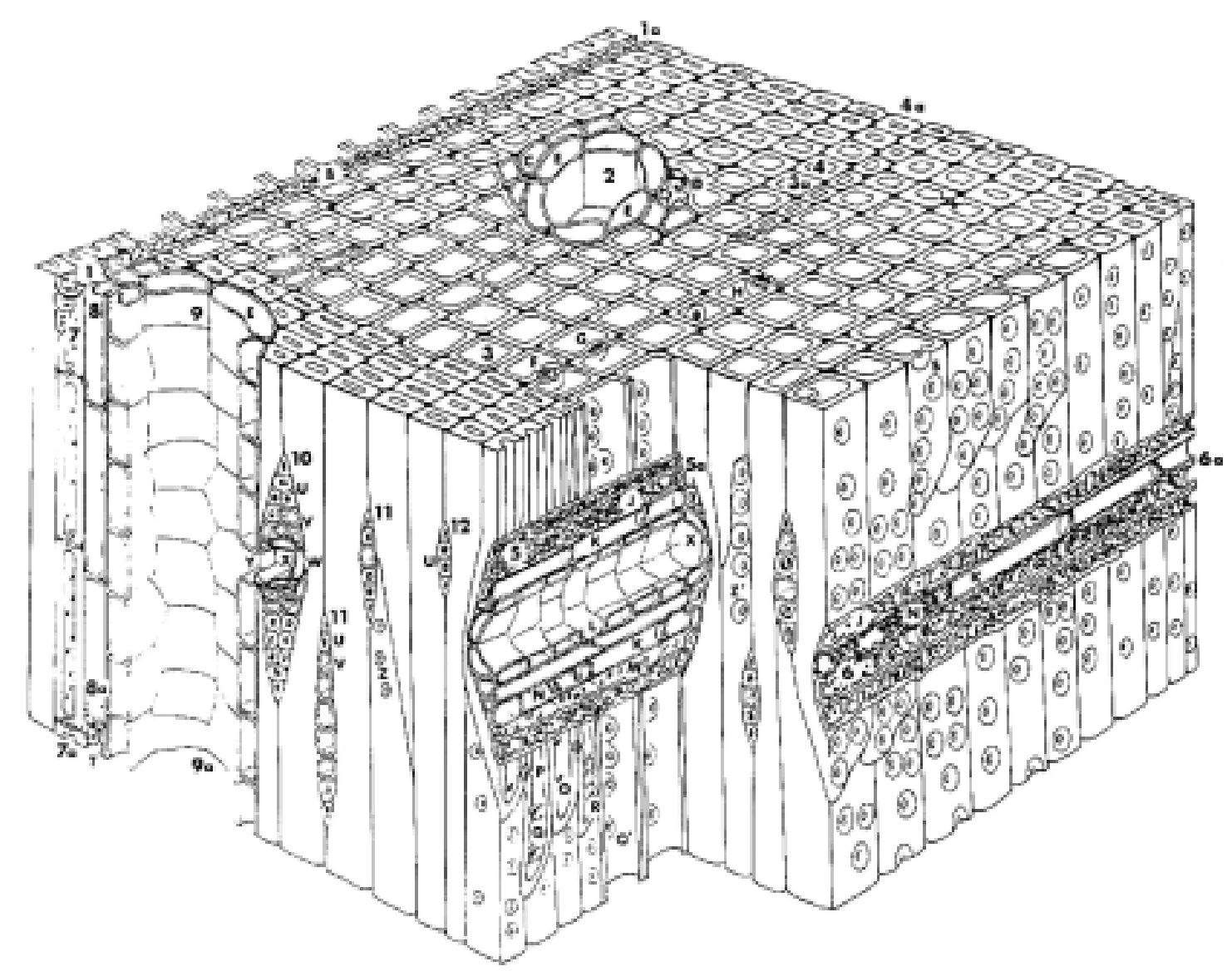

Figure

\section{3-12: Gross Structure of a Typical Southern Pine Softwood}

Transverse view: 1-1a, ray; $\mathrm{B}$, dentate ray tracheid; 2 , resin canal; $\mathrm{C}$, thin-walled longitudinal parenchyma; $\mathrm{D}$, thick-walled longitudinal parenchyma; E, epithelial cells; 3-3a, earlywood tracheids; F, radial bordered pit pair cut through torus and pit apertures; $\mathrm{G}$, pit pair cut below pit apertures; $\mathrm{H}$, tangential pit pair; 4-4a, latewood.

Radial view: 5-5a, sectioned fusiform ray; J, dentate ray tracheid; $K$, thin-walled parenchyma; $L$, epithelial cells; M, unsectioned ray tracheid; N, thick-walled parenchyma; O, latewood radial pit (inner aperture); O', earlywood radial pit (inner aperture); P, tangential bordered pit; Q, callitorid-like thickenings; R, spiral thickenings; $\mathrm{S}$, radial bordered pits (the compound middle lamella has been stripped away removing crassulae and tori); 6-6a, sectioned uniseriate heterogenous ray.

Tangential view: 7-7a, strand tracheids; 8-8a, longitudinal parenchyma (thin-walled); T, thick-walled parenchyma; 9-9a, longitudinal resin canal; Y, opening between horizontal and vertical resin canals; 11, uniseriate homogeneous rays; 12 , uniseriate homogeneous ray; $Z$, small tangential pits in latewood; Z', large tangential pits in earlywood. 

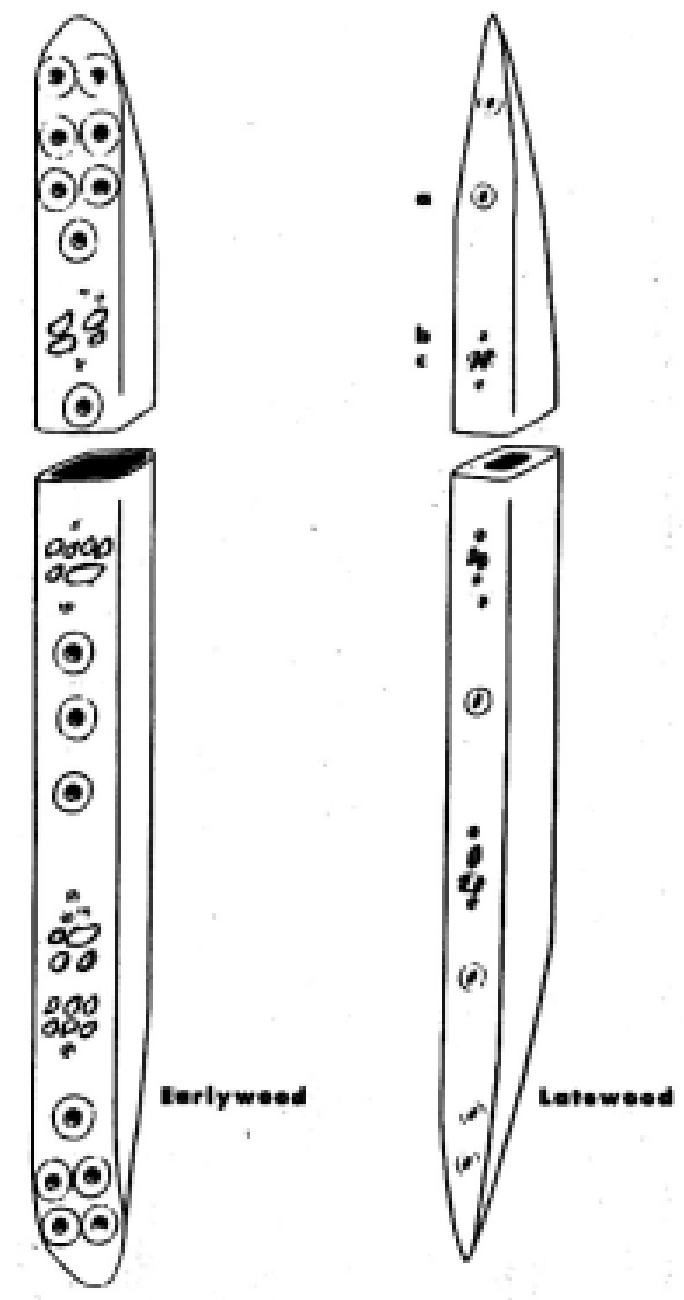

Figure 3-13: Radial Surfaces of Earlywood and Latewood Tracheids

(a) intertracheal bordered pits; (b) bordered pits to

tracheids; (c) pinoid pits to ray parenchyma

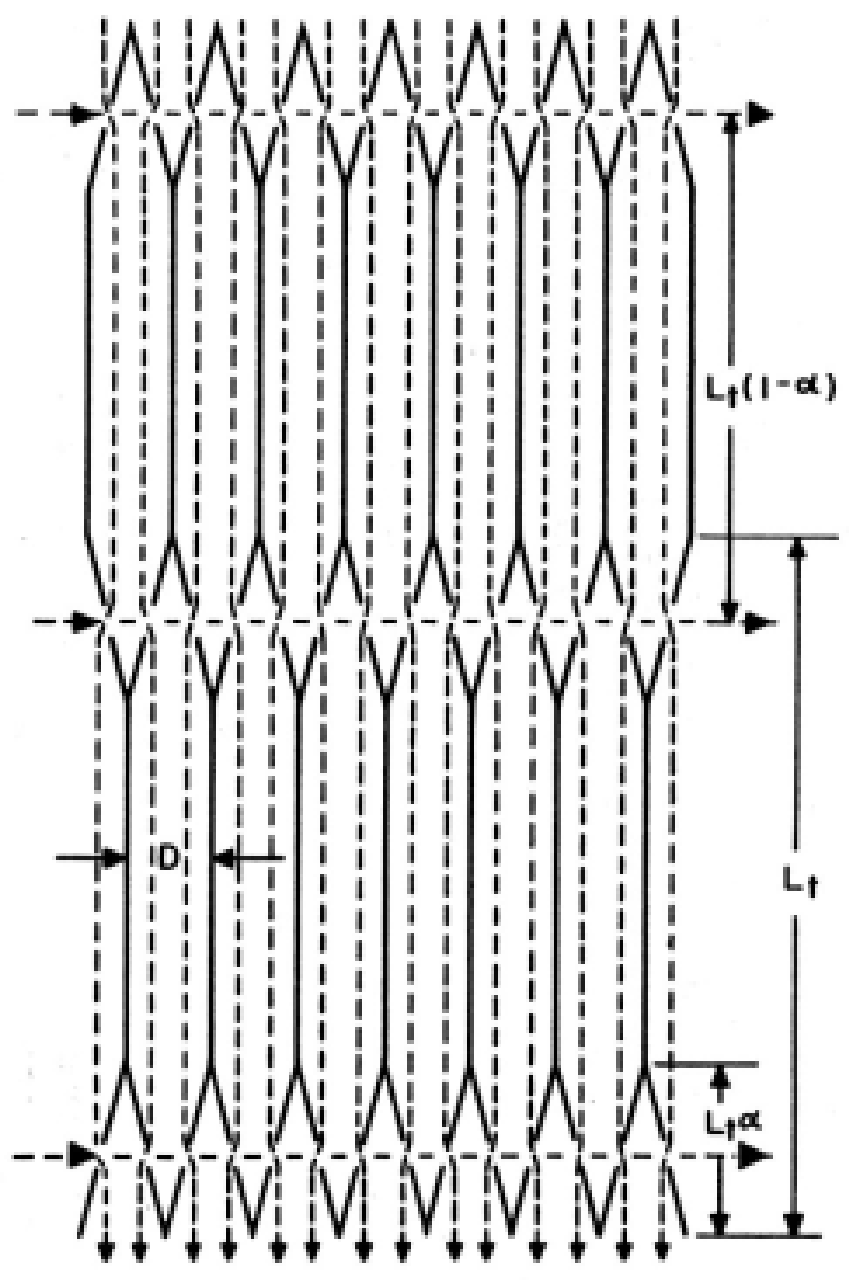

Figure 3-14: Softwood Flow Model

Tangential section showing pits on the radial surfaces Of the tapered ends of the tracheids 


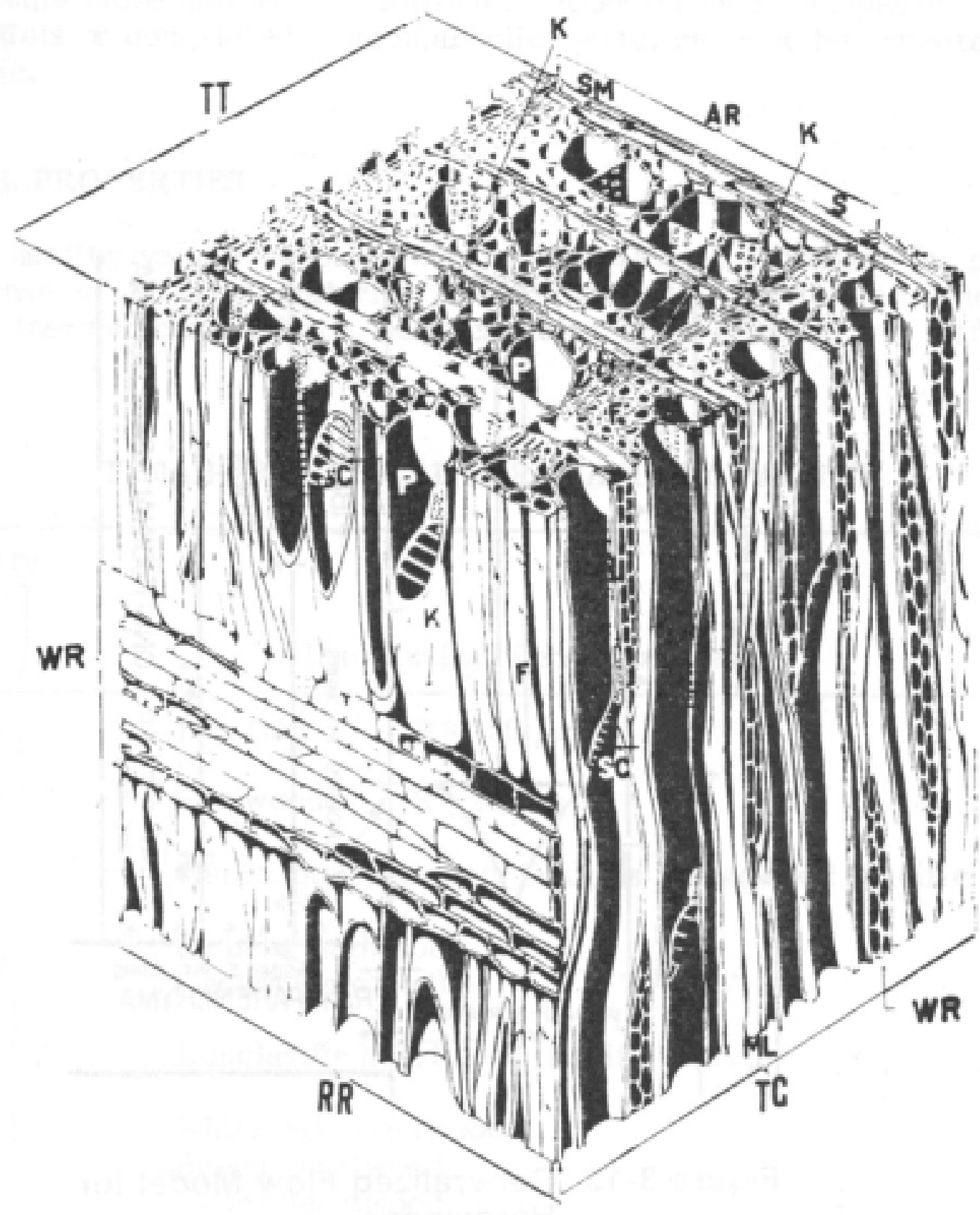

Figure 3-15: Gross Structure of a Typical Hardwood

Plane TT is the cross section, RR is the radial surface, and TG is the tangential surface. The vessels or pores are indicated by $\mathrm{P}$, and the elements are separated by scalariform perforation plates, $\mathrm{SC}$. The fibers, $F$, have small cavities and thick walls. Pits in the walls of the fibers and vessels, $K$, provide for the flow of liquid between the cells, The wood rays are indicated at WR. AR indicates one annual ring. The earlywood (springwood) is designated S, while the latewood (summerwood) is SM. The true middle lamella is located at ML. 


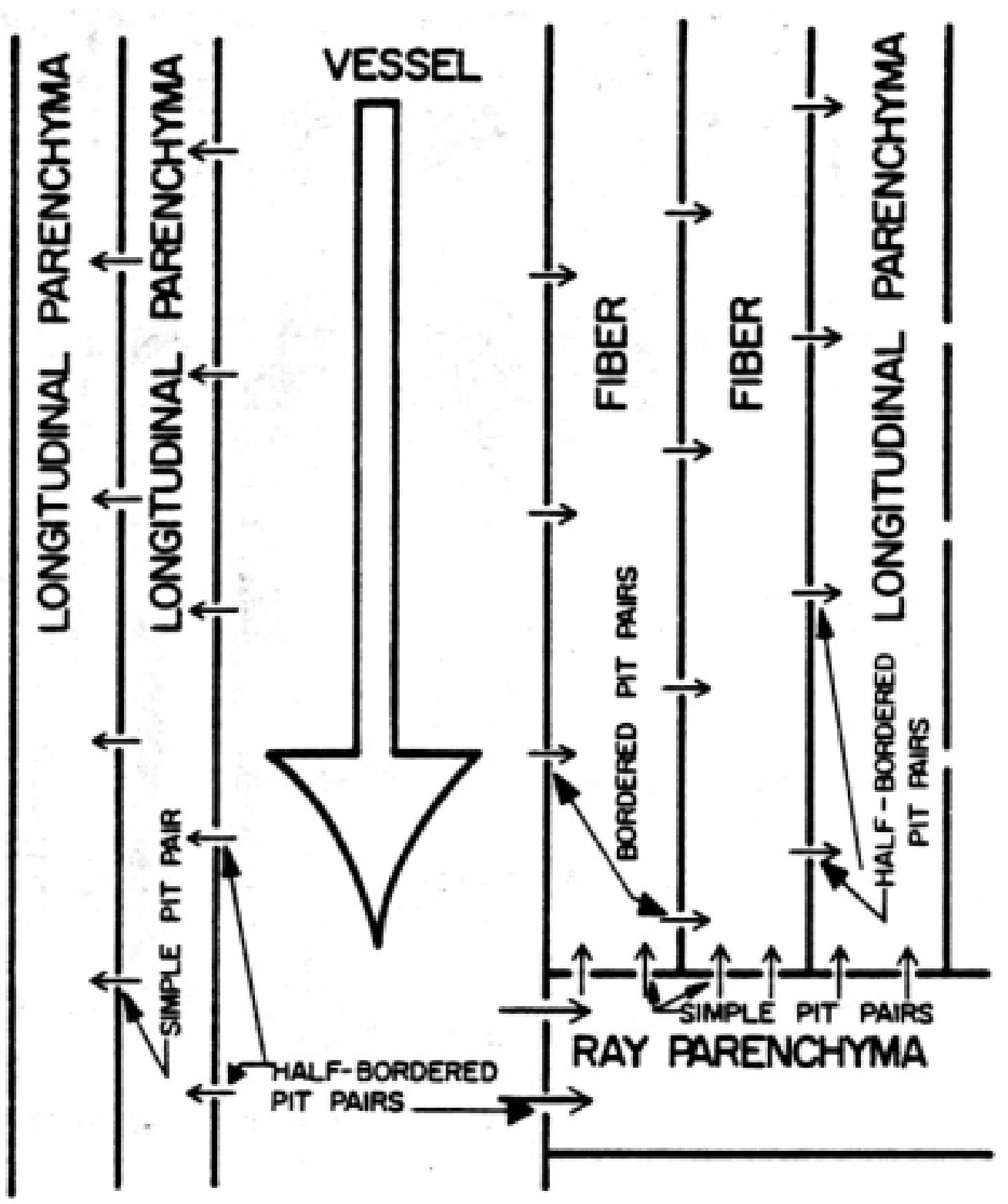

Figure 3-16: Generalized Flow Model for Hardwoods 


\subsubsection{Permeability}

Permeability is important in pyrolysis. During heating, pyrolysis gases and liquids are generated within the particle and must pass through the porous structure to the surroundings. Low permeability may significantly affect the product distribution by increasing the residence time of the primary pyrolysis products in the hot zone, thereby increasing the probability that they will enter into secondary reactions. Pelletized, densified biomass will have a low permeability compared with natural woods. Table 319 shows the range of permeability for various natural woods.

In natural soft- and hardwood structures, it is evident that the porosity is directed principally in the vertical direction in the livewood. Physical properties such as thermal conductivity and diffusivity therefore depend on direction within fresh wood. Such a behavior is termed anisotropic (aeolotropic).

Table 3-19: Typical Permeability Values

\begin{tabular}{|lll|}
\hline $\begin{array}{l}\text { Permeability } \\
\left(\mathbf{c m}^{\mathbf{3}} \text { (air) } \mathbf{c m}^{-1} \mathbf{a t m}^{-1} \text { ) }\right.\end{array}$ & \multicolumn{1}{c|}{ Longitudinal Permeabilities } \\
\hline $10^{4}$ & Red Oak & $\mathrm{R} \approx 150 \mu \mathrm{m}$ \\
$10^{3}$ & Basswood & $\mathrm{R} \approx 20 \mu \mathrm{m}$ \\
$10^{2}$ & Maple, oine sapwood, Douglas fir sapwood (Pacific Coast) \\
$10^{1}$ & Spruces (sapwood), cedars (sapwood) \\
$10^{0}$ & Douglas fir heartwood (Pacific Coast) \\
$10^{-1}$ & White oak heartwood, Beech heartwood, Cedar heartwood \\
& Douglas fir heartwood (intermountain) \\
$10^{-2}$ & & \\
$10^{-3}$ & & Transverse permeabilities. (The \\
$10^{-4}$ & species are in approximately the same \\
\hline
\end{tabular}

\subsection{PHYSICAL PROPERTIES}

In addition to heating value, the other major physical data necessary for predicting the thermal response of biomass materials under pyrolysis, gasification, and combustion processes are thermal conductivity, heat capacity, true density, and diffusion coefficients. 


\subsubsection{Thermal Conductivity}

Thermal conductivity is defined in general terms as a proportionality factor which relates heat flow through a material to a temperature difference across a specified distance in that material. Mathematically, thermal conductivity is defined by Fourier's Law of Heat Conduction, given here for unidimensional heat flux in the $\mathrm{x}$-direction in rectangular coordinates:

$$
q_{x}=-k_{x} \frac{d T}{d x}
$$

Most homogeneous materials are isotropic, and the thermal conductivity varies only with temperature

$$
q=-k \nabla T
$$

However, most naturally occurring biomass materials are anisotropic. For wood, the thermal conductivity is a function of temperature and spatial direction. Modified biomass materials, such as densified wood, probably do not exhibit the same type of anisotropic behavior as the naturally occurring biomass materials. Thermal conductivity should be related to the various materials present in a substance. Thus in biomass thermal conductivity should be a function of the major constituents, including moisture, cellulose, hemicellulose, and lignin.

Table 3-20 compiles available thermal conductivity data for biomass materials. No data are available for compacted biomass feedstocks. In general, no chemical analyses are presented with the data. The bulk of the data are probably effective thermal conductivities of powders rather than of the solids. The conductivities for solid woods, for example, are two to ten times greater than for many of the other biomass materials listed in Table 3-20 (e.g., sawdust and redwood shavings). Most data sources do not specify the state of the materials.

Steinhagen (1977) has summarized thermal conductivity data for several woods over the range $-40^{\circ} \mathrm{C}$ to $+100^{\circ} \mathrm{C}$ as a function of moisture content and has shown that moisture is an important parameter in wood conductivity. Since the moisture content is not known for the bulk of the entries in Table 3-20, the data presented are at best only semi-quantitative.

Completely lacking in the available data are thermal conductivities at higher temperatures. This is primarily because the majority of the data were determined by researchers in the forest products industry interested in the thermal properties of wood and insulating materials for home heating and cooling applications. If thermal conductivity values are to be used in modeling pyrolysis or gasification processes, then new data over the actual range of processing conditions must be developed, including data for densified materials. 
Table 3-20: Thermal Conductivity of Selected Biomass Materials

\begin{tabular}{|c|c|c|c|c|}
\hline Material & $\begin{array}{l}\text { Bulk Density } \\
\quad\left(\mathrm{lb} / \mathrm{ft}^{3}\right)\end{array}$ & $\begin{array}{c}\text { Temperature } \\
\left({ }^{\circ} \mathrm{F}\right)\end{array}$ & $\begin{array}{c}\text { Thermal } \\
\text { Conductivity } \\
\text { (Btu/ft-h-º } F)\end{array}$ & Reference \\
\hline Ashes, wood & -- & $32-212$ & 0.040 & Kern 1950 \\
\hline Cardboard & -- & -- & 0.037 & Kern 1950 \\
\hline \multicolumn{5}{|l|}{ Carbon, porous, with grain } \\
\hline Grade $60 \quad 48 \%$ porosity & $65.5^{\mathrm{a}}$ & Room Temp. & 0.083 & Perry and Chilton 1973 \\
\hline Grade $45 \quad 47 \%$ porosity & 64.9 & Room Temp. & 0.083 & Perry and Chilton 1973 \\
\hline Grade $25 \quad 47 \%$ porosity & & Room Temp. & 0.083 & Perry and Chilton 1973 \\
\hline Carbon Refractory brick - $17 \%$ porosity & & Room Temp. & 1.33 & Perry and Chilton 1973 \\
\hline \multirow[t]{7}{*}{ Celotex, sheet fiber from sugar cane } & 13.2 & -- & 0.028 & Handbook Chem. Phys, 1966 \\
\hline & 14.8 & -- & 0.028 & Handbook Chem. Phys, 1966 \\
\hline & 14.4 & 32 & 0.0253 & McAdams 1954 \\
\hline & 14.4 & 0 & 0.0242 & McAdams 1954 \\
\hline & 14.4 & -100 & 0.0208 & McAdams 1954 \\
\hline & 14.4 & -200 & 0.0175 & McAdams 1954 \\
\hline & 14.4 & -300 & 0.0133 & McAdams 1954 \\
\hline \multicolumn{5}{|l|}{ Charcoal - from maple, beech, birch } \\
\hline Coarse & 13.2 & -- & 0.030 & Handbook Chem. Phys, 1966 \\
\hline 6 mesh & 15.2 & -- & 0.031 & Handbook Chem. Phys, 1966 \\
\hline 20 mesh & 19.2 & -- & 0.032 & Handbook Chem. Phys, 1966 \\
\hline Charcoal flakes & 11.9 & 176 & 0.043 & McAdams 1954 \\
\hline
\end{tabular}




\begin{tabular}{|c|c|c|c|c|}
\hline Material & $\begin{array}{l}\text { Bulk Density } \\
\left(\mathrm{lb} / \mathrm{ft}^{3}\right)\end{array}$ & $\begin{array}{c}\text { Temperature } \\
\left({ }^{\circ} \mathrm{F}\right)\end{array}$ & $\begin{array}{c}\text { Thermal } \\
\text { Conductivity } \\
\left.\text { (Btu/ft-h- }{ }^{\circ} \mathrm{F}\right)\end{array}$ & Reference \\
\hline & 15 & 176 & 0.051 & McAdams 1954 \\
\hline & -- & 0 to 100 & 0.0133 & Handbook Chem. Phys, 1966 \\
\hline \multicolumn{5}{|l|}{ Cork, regranulated } \\
\hline Fine particles & 9.4 & -- & 0.025 & Handbook Chem. Phys, 1966 \\
\hline 1/16-in. Particles & 8.1 & -- & 0.026 & Handbook Chem. Phys, 1966 \\
\hline \multirow[t]{9}{*}{ Corkboard } & 5.4 & -- & 0.021 & Handbook Chem. Phys, 1966 \\
\hline & 7.0 & -- & 0.022 & Handbook Chem. Phys, 1966 \\
\hline & 10.6 & -- & 0.025 & Handbook Chem. Phys, 1966 \\
\hline & 14.0 & -- & 0.028 & Handbook Chem. Phys, 1966 \\
\hline & 6.9 & 32 & 0.0205 & McAdams 1954 \\
\hline & 6.9 & 0 & 0.0200 & McAdams 1954 \\
\hline & 6.9 & -100 & 0.0183 & McAdams 1954 \\
\hline & 6.9 & -200 & 0.0142 & McAdams 1954 \\
\hline & 6.9 & -300 & 0.0100 & McAdams 1954 \\
\hline \multirow[t]{3}{*}{ Cork, pulverized } & 10.0 & 32 & 0.035 & McAdams 1954 \\
\hline & 10.0 & 100 & 0.039 & McAdams 1954 \\
\hline & 10.0 & 200 & 0.032 & McAdams 1954 \\
\hline \multirow[t]{4}{*}{ Cotton } & 5.0 & 200 & 0.037 & McAdams 1954 \\
\hline & 5.0 & 100 & 0.035 & McAdams 1954 \\
\hline & 5.0 & 32 & 0.0325 & McAdams 1954 \\
\hline & 5.0 & -100 & 0.0276 & McAdams 1954 \\
\hline
\end{tabular}




\begin{tabular}{|c|c|c|c|c|}
\hline Material & $\begin{array}{l}\text { Bulk Density } \\
\left(\mathrm{lb} / \mathrm{ft}^{3}\right)\end{array}$ & $\begin{array}{c}\text { Temperature } \\
\left({ }^{\circ} \mathrm{F}\right)\end{array}$ & $\begin{array}{c}\text { Thermal } \\
\text { Conductivity } \\
\text { (Btu/ft-h-'-F) }\end{array}$ & Reference \\
\hline & 5.0 & -200 & 0.0235 & McAdams 1954 \\
\hline Cotton & 5.0 & -300 & 0.0198 & McAdams 1954 \\
\hline Graphite - 2 3/4" Dia., $3 / 4$ " Thick, $30 \%$ porosity & $98.6^{\mathrm{a}}$ & -- & 7.33 & Handbook Chem. Phys, 1966 \\
\hline Porous, Grade $6052 \%$ porosity & $65.5^{\mathrm{a}}$ & -- & 4.17 & Handbook Chem. Phys, 1966 \\
\hline Porous, Grade $4553 \%$ porosity & $64.9^{a}$ & -- & 3.75 & Handbook Chem. Phys, 1966 \\
\hline Porous, Grade $2553 \%$ porosity & $64.3^{\mathrm{a}}$ & -- & 3.33 & Handbook Chem. Phys, 1966 \\
\hline Paper & -- & -- & 0.075 & McAdams 1954 \\
\hline Paper or pulp, macerated & 2.5-3.5 & -- & 0.0121 & Lewis 1968 \\
\hline Sawdust, various & 12.0 & -- & 0.034 & Handbook Chem. Phys, 1966 \\
\hline Redwood & 10.9 & -- & 0.035 & Handbook Chem. Phys, 1966 \\
\hline (and shavings) & $8-15$ & -- & 0.0375 & Handbook Chem. Phys, 1966 \\
\hline \multicolumn{5}{|l|}{ Sawdust (soft pine and oak) } \\
\hline \multirow[t]{9}{*}{$10-40$ mesh } & -- & -295 & 0.016 & Chow 1948 \\
\hline & -- & -180 & 0.0195 & Chow 1948 \\
\hline & & -105 & 0.0235 & Chow 1948 \\
\hline & & -55 & 0.0265 & Chow 1948 \\
\hline & & -20 & 0.0295 & Chow 1948 \\
\hline & & 5 & 0.0325 & Chow 1948 \\
\hline & & 30 & 0.0355 & Chow 1948 \\
\hline & & 35 & 0.0385 & Chow 1948 \\
\hline & & 62 & 0.040 & Chow 1948 \\
\hline
\end{tabular}




\begin{tabular}{|c|c|c|c|c|}
\hline Material & $\begin{array}{l}\text { Bulk Density } \\
\quad\left(\mathrm{lb} / \mathrm{ft}^{3}\right)\end{array}$ & $\begin{array}{c}\text { Temperature } \\
\left({ }^{\circ} \mathrm{F}\right)\end{array}$ & $\begin{array}{c}\text { Thermal } \\
\text { Conductivity } \\
\text { (Btu/ft-h-'-F) }\end{array}$ & Reference \\
\hline \multicolumn{5}{|c|}{${ }^{a}$ Apparent density, defined in Section 3.4.3 } \\
\hline \multirow[t]{8}{*}{ Shredded redwood bark } & 4.0 & 32 & 0.0290 & McAdams 1954 \\
\hline & 4.0 & -100 & 0.0235 & McAdams 1954 \\
\hline & 4.0 & -200 & 0.0196 & McAdams 1954 \\
\hline & 4.0 & -300 & 0.0155 & McAdams 1954 \\
\hline & -- & -50 & 0.0168 & Rowley et al. 1945 \\
\hline & -- & -25 & 0.0180 & Rowley et al. 1945 \\
\hline & -- & 25 & 0.0203 & Rowley et al. 1945 \\
\hline & -- & 75 & 0.0226 & Rowley et al. 1945 \\
\hline \multirow[t]{2}{*}{ Sheet insulite, from wood pulp } & 16.2 & -- & 0.028 & Handbook Chem. Phys, 1966 \\
\hline & 16.9 & -- & 0.028 & Handbook Chem. Phys, 1966 \\
\hline \multirow[t]{4}{*}{ Wood fiber, mat } & 1.7 & -50 & 0.016 & Rowley et al. 1945 \\
\hline & 1.7 & 0 & 0.018 & Rowley et al. 1945 \\
\hline & 1.7 & 50 & 0.020 & Rowley et al. 1945 \\
\hline & 1.7 & 100 & 0.023 & Rowley et al. 1945 \\
\hline \multirow[t]{4}{*}{ Wood fiber, blanket } & 3.5 & -50 & 0.016 & Rowley et al. 1945 \\
\hline & 3.5 & 0 & 0.018 & Rowley et al. 1945 \\
\hline & 3.5 & 50 & 0.020 & Rowley et al. 1945 \\
\hline & 3.5 & 100 & 0.022 & Rowley et al. 1945 \\
\hline \multirow[t]{2}{*}{ Wood fiber, excelsier } & 1.64 & -50 & 0.019 & Rowley et al. 1945 \\
\hline & 1.64 & 0 & 0.022 & Rowley et al. 1945 \\
\hline
\end{tabular}




\begin{tabular}{|c|c|c|c|c|}
\hline Material & $\begin{array}{l}\text { Bulk Density } \\
\quad\left(\mathrm{lb} / \mathrm{ft}^{3}\right)\end{array}$ & $\begin{array}{c}\text { Temperature } \\
\left({ }^{\circ} \mathrm{F}\right)\end{array}$ & $\begin{array}{c}\text { Thermal } \\
\text { Conductivity } \\
\text { (Btu/ft-h-'-F) }\end{array}$ & Reference \\
\hline & 1.64 & 50 & 0.022 & Rowley et al. 1945 \\
\hline Wood fiber, excelsier & 1.64 & 100 & 0.024 & Rowley et al. 1945 \\
\hline \multicolumn{5}{|l|}{ Solid woods } \\
\hline \multirow[t]{8}{*}{ Balsa } & $8-12$ & -300 & 0.0151 & Gray et al. 1960 \\
\hline & $8-12$ & -285 & 0.0150 & Gray et al. 1960 \\
\hline & $8-12$ & -260 & 0.0167 & Gray et al. 1960 \\
\hline & $8-12$ & -207 & 0.0183 & Gray et al. 1960 \\
\hline & $8-12$ & -190 & 0.0192 & Gray et al. 1960 \\
\hline & $8-12$ & -160 & 0.0233 & Gray et al. 1960 \\
\hline & $8-12$ & -130 & 0.0233 & Gray et al. 1960 \\
\hline & $8-12$ & -95 & 0.0232 & Gray et al. 1960 \\
\hline \multirow[t]{3}{*}{ Balsa, across grain } & 7.3 & -- & 0.028 & Handbook Chem. Phys, 1966 \\
\hline & 8.8 & -- & 0.032 & Handbook Chem. Phys, 1966 \\
\hline & 20 & -- & 0.048 & Handbook Chem. Phys, 1966 \\
\hline Cypress, across grain & 29 & -- & 0.056 & Handbook Chem. Phys, 1966 \\
\hline Mahogany, across grain & 34 & -- & 0.075 & Handbook Chem. Phys, 1966 \\
\hline Maple, across grain & 44.7 & 122 & 0.11 & McAdams 1954 \\
\hline Fir & 26 & 75 & 0.063 & Chapman 1974 \\
\hline Oak & $30-38$ & 86 & 0.096 & Chapman 1974 \\
\hline Yellow pine & 40 & 75 & 0.065 & Chapman 1974 \\
\hline White pine & 27 & 86 & 0.087 & Chapman 1974 \\
\hline
\end{tabular}




\begin{tabular}{|c|c|c|c|c|}
\hline Material & $\begin{array}{l}\text { Bulk Density } \\
\left(\text { (lb/ft } \mathrm{ft}^{3}\right)\end{array}$ & $\begin{array}{c}\text { Temperature } \\
\left({ }^{\circ} \mathrm{F}\right)\end{array}$ & $\begin{array}{c}\text { Thermal } \\
\text { Conductivity } \\
\left.\text { (Btu/ft-h- }{ }^{\circ} \mathrm{F}\right)\end{array}$ & Reference \\
\hline \multirow[t]{2}{*}{ Pine, white, across grain } & 34 & 59 & 0.087 & McAdams 1954 \\
\hline & 32 & -- & 0.032 & Handbook Chem. Phys, 1966 \\
\hline Pine, Virginia, across grain & 34 & -- & 0.082 & Handbook Chem. Phys, 1966 \\
\hline \multirow[t]{4}{*}{ Pine board, $1 \frac{1}{4}$ " thick } & -- & -50 & 0.0515 & Gray et al. 1960 \\
\hline & -- & 0 & 0.054 & Gray et al. 1960 \\
\hline & -- & 50 & 0.0575 & Gray et al. 1960 \\
\hline & -- & 100 & 0.059 & Gray et al. 1960 \\
\hline Pine, with grain & 34.4 & 59 & 0.20 & McAdams 1954 \\
\hline Oak, across grain & 51.5 & 59 & 0.12 & McAdams 1954 \\
\hline
\end{tabular}

Equations have been developed for wood, expressing thermal conductivity as a function of of moisture and specific gravity for combined heat flow in the radial and tangential directions (McLean 1941). The expression was derived at ambient temperatures. 
For moisture contents less than $40 \%$ the thermal conductivity is expressed as

$$
k=S(0.116+0.00233 M)+0.01375
$$

and for moisture contents greater than $40 \%$

$$
k=S(0.116+0.00317 M)+0.01375
$$

where $\quad S=$ apparent specific gravity, as defined in Section 3.4.3

$\mathrm{M}=$ Percent moisture content, oven dry basis, or

$$
M=100(W-D) / D,
$$

where $\quad W=$ Original weight

$\mathrm{D}=$ Dry weight after oven drying

A plot of thermal conductivity as a function of moisture content and specific gravity using equation 3-25 is given in Figure 3-17.

Figure 3-17: Thermal Conductivity as a Function of Moisture and Specific Gravity (MacLean 1941)

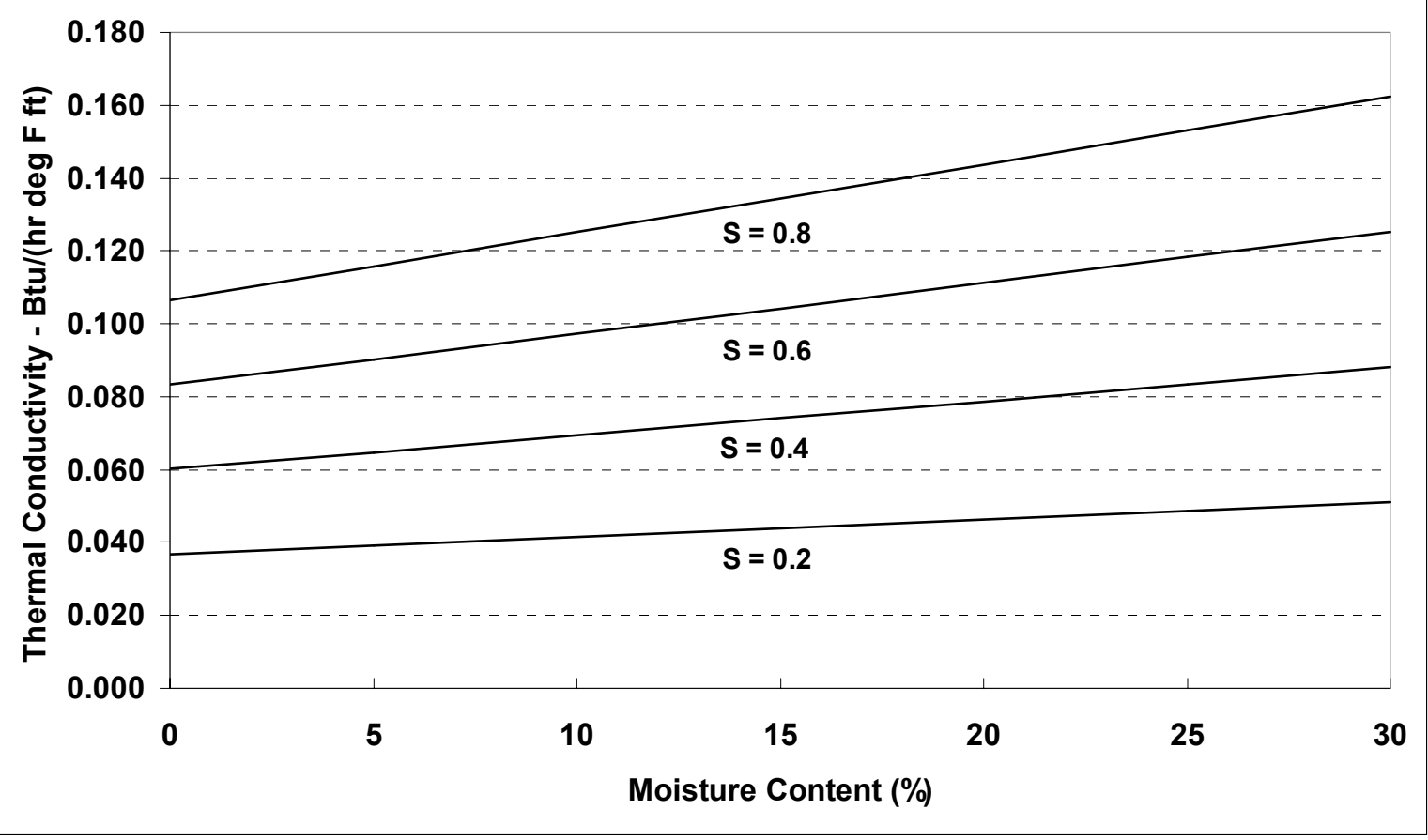




\subsubsection{Heat Capacity}

Heat capacity, as normally reported, is defined in terms of the enthalpy content of a material and represents the relative ability of a material to store energy. Enthalpy is a function of temperature and pressure.

$$
H=H(T, P)
$$

and

$$
d H=(\partial H / \partial T)_{P} d T+(\partial H / \partial P)_{T} d P
$$

For solids and liquids $\partial \mathrm{H} / \partial \mathrm{P}$ is very small and

$$
d H=(\partial h / \partial T)_{P} d T
$$

By definition the temperature dependency term $(\partial \mathrm{H} / \partial \mathrm{P})_{\mathrm{p}}$ is called heat capacity at constant pressure, $C_{p}$, and is reported on a per unit weight basis. The resulting equation for the enthalpy change is as follows:

$$
\Delta \mathrm{H}=\int_{\mathrm{T}_{\mathrm{O}}}^{\mathrm{T}} \mathrm{C}_{\mathrm{P}} \mathrm{dT}
$$

This equation is normally used for materials of constant mass and no phase transitions. For example, if water is driven out of wood the apparent heat capacity may change very rapidly with temperature; the same is true for other phase transitions. Generally, if phase transitions are incorporated the enthalpy change will be:

$$
\Delta H=\int_{T_{0}}^{T_{P}} C^{\alpha}{ }_{P} d T+\Delta H_{\text {PHASE CHANGE }}+\int_{T_{P}}^{T} C^{\beta}{ }_{P} d T
$$

where

$$
\begin{aligned}
\mathrm{C}_{\mathrm{P}}^{\mathrm{a}}, \mathrm{C}^{\beta}{ }_{\mathrm{P}} & =\text { heat capacities of phases } 1 \text { and } 2 \\
\mathrm{~T}_{\mathrm{P}} & =\text { temperature at which phase change occurs }
\end{aligned}
$$

The heat capacity is a function of the composition and temperature but not the density of the material as long as compacting does not alter the chemical structure.

The data on heat capacity are limited. Some typical values are given in Table 3-21. No characterization data are reported for the samples. 
Several $C_{p}$ equations have been developed to predict the heat capacities of wood at temperatures to $100^{\circ} \mathrm{C}$. As an example of specific heat equations for woods, Beall (1968) shows the equation in which moisture is an important parameter in estimating the heat capacity:

$$
C_{p}=0.259+\left(9.75 \times 10^{-4}\right) \mathrm{M}+6.05 \times 20^{-4} \mathrm{~T}_{1}+1.3 \times 10^{-5} \mathrm{M} \mathrm{T}_{1},
$$

where

$$
M=\% \text { moisture, up to } 27 \% \text {. }
$$

Table 3-21: Heat Capacity

\begin{tabular}{|l|c|c|l|}
\hline \multicolumn{1}{|c|}{ Material } & $\begin{array}{c}\text { Temperature } \\
\left({ }^{\circ} \mathrm{F}\right)\end{array}$ & $\begin{array}{c}\text { Heat capacity } \\
\left(\mathbf{B t u ~ l b}^{-1}{ }^{\circ} \mathbf{F}^{-1}\right)\end{array}$ & Reference \\
\hline Carbon & $78-168$ & 0.168 & Perry 1973 \\
& $103-1640$ & 0.314 & Perry 1973 \\
Charcoal & $132-2640$ & 0.387 & Perry 1973 \\
Cellulose & 50 & 0.16 & Perry 1973 \\
Oak & -- & 0.32 & Perry 1973 \\
Fir & -- & 0.57 & Perry 1973 \\
Yellow pine & 75 & 0.65 & Chapman 1974 \\
Cork & 75 & 0.67 & Chapman 1974 \\
\hline
\end{tabular}

Other methods are available and generally are for the same temperature range.

As with thermal conductivity, no references were readily available for heat capacity of biomass materials for the temperature range of thermal processing conditions needed for pyrolysis or gasification; new data are needed for applicable temperature ranges.

\subsubsection{Density}

The density of the material is important in considering energy contents of fuels on a volumetric basis, such as for transporting, solids handling, and sizing reaction vessels. There are three ways of reporting solid material density: bulk density, apparent particle 
density, and skeletal density. These density values differ in the way in which the material volume is calculated. The bulk density volume basis includes the actual volume of the solid, the pore volume, and the void volume between solid particles. Apparent particle density includes solid volume and pore volume. Skeletal density, or true density, includes only solid volume. The three values are related as follows:

$$
\begin{aligned}
& \rho_{a}=\rho_{s}\left(1-\epsilon_{p}\right) \\
& \rho_{b}=\rho_{a}\left(1-\epsilon_{b}\right),
\end{aligned}
$$

where

$$
\begin{aligned}
& \rho_{s}=\text { skeletal density, weight/volume } \\
& \rho_{a}=\text { apparent density, weight/volume } \\
& \rho_{b}=\text { bulk density, weight/volume } \\
& \epsilon_{p}=\text { particle porosity }=\quad \frac{\text { Volume of pores }}{\text { Volume of pores and volume of solid }} \\
& \epsilon_{b}=\text { bed porosity }=\quad \frac{\text { Volume of external voids }}{\text { Volume of external voids and volume of particles }}
\end{aligned}
$$

Densification of biomass is accomplished by reducing the particle porosity $\epsilon_{\mathrm{p}}$.

The density of biomass depends on the nature of the material, its moisture content, and degree of densification. Raw, over-dry biomass (with $7 \%$ to $8 \%$ moisture) has an apparent density of about $40 \mathrm{lb} / \mathrm{ft}^{3}$ (hardwoods) and $28 \mathrm{lb} / \mathrm{ft}^{3}$ (softwoods). The density of woods with high moisture contents can be as high as $60 \mathrm{lb} / \mathrm{ft}^{3}$. Densification produces particles with apparent bone dry densities of $55 \mathrm{lb} / \mathrm{ft}^{3}$ to $75 \mathrm{lb} / \mathrm{ft}^{3}$. The skeletal density of over dry biomass has been reported to be $91 \mathrm{lb} / \mathrm{ft}^{3}$ (Siau 1971). Bulk densities of a number of biomass materials are given in Table 3-20. Apparent densities of a number of biomass materials are given in Table 3-22.

\subsubsection{Effect of Moisture Content on Density}

The apparent density of wood and biomass depends on the moisture content. The dry and wet biomass apparent densities are related as follows from the moisture content obtained from the proximate analysis of the raw feedstock:

$$
\rho_{a}(D)=(1-M) \rho_{a}(R),
$$

where

$$
\begin{aligned}
\rho_{a}(D) & =\text { apparent density of dry biomass } \\
\rho_{a}(R) & =\text { apparent density of raw biomass, and } \\
M & =\text { proximate moisture }
\end{aligned}
$$


For a typical raw biomass with $50 \%$ moisture and apparent dry density of $30 \mathrm{lb} / \mathrm{ft}^{3}$, the raw biomass sample has a density of $60 \mathrm{lb} / \mathrm{ft}^{3}$. 
Table 3-22: Apparent Density of Selected Woods

(Jenkins, 1989)

\begin{tabular}{|l|c|c|}
\hline \multicolumn{1}{|c|}{ Wood Type } & Specific Gravity & $\begin{array}{c}\text { Density } \\
\left(\mathbf{I b}_{\mathbf{f t}} \mathbf{f t}^{\mathbf{3}}\right.\end{array}$ \\
\hline Almond & 0.78 & 48.67 \\
Alder (red) & 0.38 & 23.71 \\
Ash (white) & 0.54 & 33.70 \\
Aspen & 0.36 & 22.46 \\
Bald cypress & 0.43 & 26.83 \\
Beech & 0.57 & 35.57 \\
Birch, yellow & 0.55 & 34.32 \\
Cedar, incense & 0.35 & 21.84 \\
Cottonwood & 0.37 & 23.09 \\
Elm, American & 0.46 & 28.70 \\
Fir, balsam & 0.32 & 19.97 \\
Hemlock, mountain & 0.42 & 26.21 \\
Hickory, pecan & 0.61 & 38.06 \\
Maple, sugar & 0.57 & 35.57 \\
Oak, northern red & 0.56 & 34.94 \\
Oak, white & 0.60 & 37.44 \\
Pine, jack & 0.40 & 24.96 \\
\multicolumn{1}{|c|}{ lodgepole } & 0.39 & 24.34 \\
\multicolumn{1}{|c|}{ ponderosa } & 0.39 & 24.34 \\
Poplar, balsam & 0.34 & 21.22 \\
Redwood, old growth & 0.30 & 18.72 \\
Spruce, black & 0.39 & 24.34 \\
Tanoak & 0.38 & 23.71 \\
Yellow poplar & 0.58 & 36.19 \\
\hline
\end{tabular}




\subsubsection{Densification}

Densification by compaction reduces the internal voidage of the biomass material and reshapes the particles so that the bulk density is increased. The bulk density of green wood chips is typically $20 \mathrm{lb} / \mathrm{ft}^{3}$, while the apparent density is on the order of $60 \mathrm{lb} / \mathrm{ft}^{3}$. The typical external void fraction, $\epsilon_{\mathrm{b}}$, for chips is therefore about 0.67 . The high voidage is due to the shape of the particles. Reshaping the particles to cylinders typically reduces the void fraction $\epsilon b$ to about 0.5 and thus raises the bulk density to about 30 $\mathrm{lb} / \mathrm{ft}^{3}$. Thus the weight per unit volume is increased $50 \%$ by reshaping, and more material can be transported in the same carrier volume.

Densification of biomass by decreasing the particle porosity further improves handling. For raw, dry biomass of apparent density of $30 \mathrm{lb} / \mathrm{ft}^{3}$, the particle porosity, $\epsilon_{\mathrm{p}}$, is typically 0.67 assuming $91 \mathrm{lb} / \mathrm{ft}^{3}$ for the skeletal density. For densified samples, with reported apparent bone dry densities of $55 \mathrm{lb} / \mathrm{ft}^{3}$ to $75 \mathrm{lb} / \mathrm{ft}^{3}$, the particle porosity has decreased to 0.4 to 0.18 . Thus in densification a large fraction of the internal voidage is removed.

\subsubsection{Diffusion Coefficients in Biomass Materials}

No data are readily available in the literature on gas diffusion coefficients in either natural or pelleted biomass materials or in the pyrolysis chars. 


\subsection{REFERENCES}

Aspinall, G. O. 1959. Advances in Carbohydrate Chemistry. Vol 14: p. 429.

Beall, F. C. 1968. Specific Heat of Wood - Further Research Required to Obtain Meaningful Data. Madison, WI: Forest Products Laboratory; U.S. Forest Service Research Note FPL-0184.

Bituminous Coal Research, Inc. 1974. Gas Generator Research and Development, Phase II. Process and Equipment Development. OCR-20-F; PB-125530/3GI.

Boley, C. C.; Landers, W. S. 1969. Entrainment Drying and Carbonization of Wood Waste. Washington, D.C.: Bureau of Mines; Report of Investigations 7282.

Bowerman, F. R. 1969. Introductory chapter to Principles and Practices of Incineration. Corey, R. C., editor. New York: John Wiley and Sons.

Channiwala, S. A. 1992. "On Biomass Gasification Process and Technology Development," Ph.D. Thesis, Indian Inst. Of Technology, Bombay, India.

Chapman, A. J. 1974. Heat Transfer. Third Edition. New York: McMillan Publishing Co.

Chow, C. S. 1948. "Thermal Conductivity of Some Insulating Materials at Low Temperatures." Proceedings Physics Society. Vol. 6: p. 206.

Chynoweth, D. P., Klass, D. L. and Ghosh, S. 1978. "Biomethanation of Giant Brown KelpMacrocystis Pyferia," In Energy from Biomass and Wastes, Inst. Of Gas Technology, Chicago, IL, p 229-252.

Encyclopedia of Chemical Technology. Kirk, R. E. and Othmer, D. F., editors. 1963. New York: Wiley Interscience.

Freudenberg. 1965. "Lignin: Its Constituents and Formation From p-Hydroxycinnamyl Alcohols." Science. Vol. 148: p. 30.

Gray, V. H.; Gelder, T. F.; Cochran, R. P.; Goodykoontz, J. H. 1960. Bonded and Sealed External Insulations for Liquid Hydrogen Fueled Rocket Tanks During Atmospheric Flight. AD 244287; Div. 14; p. 51.

Grover, P. D. and Anuradha, G. 1988. "Thermochemical Characterization of Biomass for Gasification," Report on Physico-chemical Parameters of Biomass Residues, IT - Dehli.

Handbook of Chemistry and Physics, $47^{\text {th }}$ Ed. 1966. Cleveland, $\mathrm{OH}$ : Chemical Rubber Company.

Howlett, K.; Gamache, A. 1977. Forest and Mill Residues as potential Sources of Biomass. Vol. VI. Final Report. McLean, VA: The MITRE Corporation/Metrek Division; ERDA Contract No. E(49-18) 2081; MTR 7347.

Institute of Gas Technology. 1978. Coal Conversion Systems Technical Data Book. DOE 
Contract EX-76-C-01-2286. Available from NTIS, Springfield, VA.

Jenkins, B. M. 1980. “Downdraft Gasification Characteristics of Major California Residue Derived Fuels," Ph.D. Thesis, Univ. of California Davis.

Jenkins, B. M. 1989. "Physical Properties of Biomass," in Biomass Handbook, eds. Kitani, O. and C. W. Hall, Gordon and Breach, NY,NY, 860 - 891.

Jenkins, B. M. and Ebeling, J. M. 1985. "Correlation of Physical and Chemical Properties of Tereestrial Biomass with Conversion," Symposium, Energy From Biomass and Waste IX, Inst. Of Gas Technology, Chicago, IL, p271.

Johnson, J. A. and Auth, G. H. 1951. Fuels and Combustion Handbook, McGraw-Hill, NY, NY.

Jones, D. M. 1964. Advances in Carbohydrate Chemistry. Vol. 19: p. 219.

Kern, D. Q. 1950. Process Heat Transfer. New York: McGraw Hill Book Company

Klass D. L.; Ghosh, S. 1973. "Fuel Gas From Organic Wastes.” Chemical Technology. p. 689.

Lewis, W. C. 1968. Thermal Insulation from Wood for Buildings: Effects of Moisture and Its Control. Madison, WI: Forest Products Laboratory; Forest Service; U.S. Dept. of Agriculture.

MacLean, J. D. 1941. "Thermal Conductivity of Wood," Trans. Am. Soc. Heating and Ventilation, 47, 323-354.

McAdams, W. H. 1954. Heat Transmission. New York: McGraw Hill Book Company.

Miles, T. R., Miles, T. R. Jr., Baxter, L. L., Bryers, R. W., Jenkins, B. M., and Oden, L. L. 1996. "Alkali Deposits Found in Biomass Power Plants; A Preliminary Investigation of Their Extent and Nature," NREL /TP-433-8142, National Renewable Energy Laboratory, Golden, CO.

Mudge, L. K., Mitchell, D. H., Baker, E. G., Robertus, R. J., and Brown, M. D. 1982. "Steam Gasification of Wood in the Presence of Catalysts," Proc. $14^{\text {th }}$ Biomass Thermochemical Conversion Contractor's Meting, p 9-31.

Perry, R. H.; Chilton, C. H. (editors). 1973. Chemical Engineer's Handbook, $5^{\text {th }}$ Ed., New York: McGraw Hill Book Company.

Pober, K. W.; Bauer, H. F. 1977. "The Nature of Pyrolytic Oil From Municipal Solid Waste." Fuels From Waste. Anderson, L. L. and Tillman, D. A., editors. New York: Academic Press. Pp.73-86.

Polglase, W. J. 1955. Advances in Carbohydrate Chemistry. Vol. 10: p. 283

Risser, P. G. 1981. "Agricultural and Forestry Residues," in Biomass Conversion Processes for Energy and Fuels," Ed. Soffer, S. S. and Zaborsky, O. R., Plennum Press, N.Y., NY, p 25-56d. 
Rowley, F. B.; Jordan, R. C.; Lander, R. M. 1945. "Thermal Conductivity of Insulating Materials at Low Mean Temperatures." Refrigeration Engineering. Vol. 50: pp. 541-544.

Rowley, F. B.; Jordan, R. C.; Lander, R. M. 1947. "Low Mean Temperature Thermal Conductivity Studies," Refrigeration Engineering. Vol. 53: pp. 35-39.

Sanner, W. S.; Ortuglio, C.; Walters, J. G.; Wolfson, D. E. 1970. Conversion of Municipal and Industrial Refuse Into Useful Materials by Pyrolysis. U.S. Bureau of Mines; Aug.; RI 7428.

Shafizadeh, F.; McGinnis, G. D. 1971. "Chemical Composition and Thermal Analysis of Cottonwood." Carbohydrate Research. Vol. 16: p. 273.

Siau, J. F. 1971. Flow in Wood. Syracuse, NY: Syracuse University Press.

Spiers, H. M. 1962. Technical Data on Fuel. Sixth Edition. New York: Wiley; p. 291.

Steinhagen, H. P. 1977. Thermal Conductive Properties of Wood, Green or Dry, From -40 to + 100 C: Literature Review. Madison, WI: Forest Products Laboratory; U.S. Forest Service, Dept. of Agriculture.

Tillman, D. A. 1978. Wood as an Energy Resource. New York: Academic Press.

Timell, T. E. 1967. Wood Science Technology. Vol. 1: p. 45.

Van Krevelan, D.W. 1961. Coal; Coal Science and Technology 3, Elsevier Scientific Publishing Company, NY, NY, page 416

Wen, C. Y.; Bailie, R. C.; Lin, C. Y.; O’Brien, W. S. 1974. "Production of Low Btu Gas Involving Coal Pyrolysis and Gasification." Advances in Chemistry Series. Vol. 131. Washington, D.D.: American Chemical Society.

Whistler, R. L.; Richards, E. L. 1970. Chapter 37 in The Carbohydrates. Pigman, W. and Horton, D., editors. New York: Academic Press.

Wise, L. E. 1946. Wood Chemistry. American Chemistry Society Monograph Series No. 97. 
Appendix 4

Wood Residue Combustion in Boilers 


\subsection{Wood Residue Combustion In Boilers}

\subsubsection{General ${ }^{1-6}$}

The burning of wood residue in boilers is mostly confined to those industries where it is available as a byproduct. It is burned both to obtain heat energy and to alleviate possible solid residue disposal problems. In boilers, wood residue is normally burned in the form of hogged wood, bark, sawdust, shavings, chips, mill rejects, sanderdust, or wood trim. Heating values for this residue range from about 4,500 British thermal units/pound (Btu/lb) of fuel on a wet, as-fired basis, to about 8,000 $\mathrm{Btu} / \mathrm{lb}$ for dry wood. The moisture content of as-fired wood is typically near 50 weight percent for the pulp, paper and lumber industries and is typically 10 to 15 percent for the furniture industry. However, moisture contents may vary from 5 to 75 weight percent depending on the residue type and storage operations. Generally, bark is the major type of residue burned in pulp mills; either a mixture of wood and bark residue or wood residue alone is burned most frequently in the lumber, furniture, and plywood industries.

\subsubsection{Firing Practices $5,7,8$}

Various boiler firing configurations are used for burning wood residue. One common type of boiler used in smaller operations is the Dutch oven. This unit is widely used because it can burn fuels with very high moisture content. Fuel is fed into the oven through an opening in the top of a refractory-lined furnace. The fuel accumulates in a cone-shaped pile on a flat or sloping grate. Combustion is accomplished in two stages: (1) drying and gasification, and (2) combustion of gaseous products. The first stage takes place in the primary furnace, which is separated from the secondary furnace chamber by a bridge wall. Combustion is completed in the secondary chamber before gases enter the boiler section. The large mass of refractory helps to stabilize combustion rates but also causes a slow response to fluctuating steam demand.

In another boiler type, the fuel cell oven, fuel is dropped onto suspended fixed grates and is fired in a pile. Unlike the Dutch oven, the refractory-lined fuel cell also uses combustion air preheating and positioning of secondary and tertiary air injection ports to improve boiler efficiency. Because of their overall design and operating similarities, however, fuel cell and Dutch oven boilers have many comparable emission characteristics.

The firing method most commonly employed for wood-fired boilers with a steam generation rate larger than $100,000 \mathrm{lb} / \mathrm{hr}$ is the spreader stoker. In this boiler type, wood enters the furnace through a fuel chute and is spread either pneumatically or mechanically across the furnace, where small pieces of the fuel burn while in suspension. Simultaneously, larger pieces of fuel are spread in a thin, even bed on a stationary or moving grate. The burning is accomplished in three stages in a single chamber: (1) moisture evaporation; (2) distillation and burning of volatile matter; and (3) burning of fixed carbon. This type of boiler has a fast response to load changes, has improved combustion control, and can be operated with multiple fuels. Natural gas, oil, and/or coal, are often fired in spreader stoker boilers as auxiliary fuels. The fossil fuels are fired to maintain constant steam production when the wood residue moisture content or mass rate fluctuates and/or to provide more steam than can be generated from the residue supply alone. Although spreader stokers are the most common stokers among larger wood-fired boilers, overfeed and underfeed stokers are also utilized for smaller units. 
Another boiler type sometimes used for wood combustion is the suspension-fired boiler. This boiler differs from a spreader stoker in that small-sized fuel (normally less than $2 \mathrm{~mm}$ and normally low moisture) is blown into the boiler and combusted by supporting it in air rather than on fixed grates. Rapid changes in combustion rate and, therefore, steam generation rate are possible because the finely divided fuel particles burn very quickly.

A later innovation in wood firing is the fluidized bed combustion (FBC) boiler. A fluidized bed consists of inert particles through which air is blown so that the bed behaves as a fluid. Wood residue enters in the space above the bed and burns both in suspension and in the bed. Because of the large thermal mass represented by the hot inert bed particles, fluidized beds can handle fuels with moisture contents up to near 70 percent (total basis). Fluidized beds can also handle dirty fuels (up to 30 percent inert material). Wood fuel is pyrolyzed faster in a fluidized bed than on a grate due to its immediate contact with hot bed material. As a result, combustion is rapid and results in nearly complete combustion of the organic matter, thereby minimizing the emissions of unburned organic compounds.

\subsubsection{Emissions And Controls ${ }^{7-12}$}

The major emission of concern from wood boilers is particulate matter (PM). These emissions depend primarily on the composition of the residue fuel burned, and the particle control device. Oxides of nitrogen $\left(\mathrm{NO}_{\mathrm{x}}\right)$ may also be emitted in significant quantities when certain types of wood residue are combusted or when operating conditions are poor.

\subsubsection{Criteria Pollutants}

The composition of wood residue and the characteristics of the resulting emissions depend largely on the industry from which the wood residue originates. Pulping operations, for example, produce great quantities of bark that may contain more than 70 weight percent moisture, sand, and other non-combustibles. As a result, bark boilers in pulp mills may emit considerable amounts of particulate matter to the atmosphere unless they are controlled. On the other hand, some operations, such as furniture manufacturing, generate a clean, dry wood residue ( 2 to 20 weight percent moisture) which produces relatively low particulate emission levels when properly burned. Still other operations, such as sawmills, burn a varying mixture of bark and wood residue that results in PM emissions somewhere between these two extremes. Additionally, $\mathrm{NO}_{\mathrm{x}}$ emissions from wet bark and wood boilers are typically lower (approximately one-half) in comparison to $\mathrm{NO}_{\mathrm{x}}$ emissions from dry wood-fired boilers.

Furnace operating conditions are particularly important when firing wood residue. For example, because of the high moisture content that may be present in wood residue, a larger than usual area of refractory surface is often necessary to dry the fuel before combustion. In addition, sufficient secondary air must be supplied over the fuel bed to burn the volatiles that account for most of the combustible material in the residue. When proper drying conditions do not exist, or when secondary combustion is incomplete, the combustion temperature is lowered, and increased PM, CO, and organic compound emissions may result from any boiler type. Significant variations in fuel moisture content can cause short-term emissions to fluctuate.

\subsubsection{Greenhouse Gases ${ }^{13-18}$ \\ Carbon dioxide $\left(\mathrm{CO}_{2}\right)$, methane $\left(\mathrm{CH}_{4}\right)$, and nitrous oxide $\left(\mathrm{N}_{2} \mathrm{O}\right)$ emissions are all produced} during wood residue combustion. Nearly all of the fuel carbon (99 percent) in wood residue is converted to $\mathrm{CO}_{2}$ during the combustion process. This conversion is relatively independent of firing configuration. Although the formation of $\mathrm{CO}$ acts to reduce $\mathrm{CO}_{2}$ emissions, the amount of $\mathrm{CO}$ produced is insignificant compared to the amount of $\mathrm{CO}_{2}$ produced. The majority of the fuel carbon not converted to $\mathrm{CO}_{2}$, due to incomplete combustion, is entrained in the bottom ash. $\mathrm{CO}_{2}$ emitted from this source is generally not 
counted as greenhouse gas emissions because it is considered part of the short-term $\mathrm{CO}_{2}$ cycle of the biosphere.

Formation of $\mathrm{N}_{2} \mathrm{O}$ during the combustion process is governed by a complex series of reactions and its formation is dependent upon many factors. Formation of $\mathrm{N}_{2} \mathrm{O}$ is minimized when combustion temperatures are kept high (above $1475^{\circ} \mathrm{F}$ ) and excess air is kept to a minimum (less than 1 percent).

Methane emissions are highest during periods of low-temperature combustion or incomplete combustion, such as the start-up or shut-down cycle for boilers. Typically, conditions that favor formation of $\mathrm{N}_{2} \mathrm{O}$ also favor emissions of $\mathrm{CH}_{4}$.

\subsubsection{Controls}

Currently, the four most common control devices used to reduce PM emissions from wood-fired boilers are mechanical collectors, wet scrubbers, electrostatic precipitators (ESPs), and fabric filters. The use of multitube cyclone (or multiclone) mechanical collectors provides particulate control for many wood-fired boilers. Often, two multiclones are used in series, allowing the first collector to remove the bulk of the dust and the second to remove smaller particles. The efficiency of this arrangement varies from 25 to 65 percent. The most widely used wet scrubbers for wood-fired boilers are venturi scrubbers. With gas-side pressure drops exceeding 15 inches of water, particulate collection efficiencies of 85 percent or greater have been reported for venturi scrubbers operating on wood-fired boilers.

ESPs are employed when collection efficiencies above 90 percent are required. When applied to wood-fired boilers, ESPs are often used downstream of mechanical collector precleaners which remove larger-sized particles. Collection efficiencies of 90 to 99 percent for PM have been observed for ESPs operating on wood-fired boilers.

A variation of the ESP is the electrostatic gravel bed filter. In this device, PM in flue gases is removed by impaction with gravel media inside a packed bed; collection is augmented by an electrically charged grid within the bed. Particulate collection efficiencies are typically over 80 percent.

Fabric filters (i. e., baghouses) have had limited applications to wood-fired boilers. The principal drawback to fabric filtration, as perceived by potential users, is a fire danger arising from the collection of combustible carbonaceous fly ash. Steps can be taken to reduce this hazard, including the installation of a mechanical collector upstream of the fabric filter to remove large burning particles of fly ash (i. e., "sparklers"). Despite complications, fabric filters are generally preferred for boilers firing salt-laden wood. This fuel produces fine particulates with a high salt content having a quenching effect, thereby reducing fire hazards. Particle collection efficiencies are typically $80 \%$ or higher.

For stoker and FBC boilers, overfire air ports may be used to lower $\mathrm{NO}_{\mathrm{x}}$ emissions by staging the combustion process. In those areas of the $\mathrm{U}$. S. where $\mathrm{NO}_{\mathrm{x}}$ emissions must be reduced to their lowest levels, the application of selective noncatalytic reduction (SNCR) to residue wood-fired boilers has been accomplished; the application of selective catalytic reduction (SCR) is being contemplated. Both systems are postcombustion $\mathrm{NO}_{\mathrm{x}}$ reduction techniques in which ammonia (or urea) is injected into the flue gas to selectively reduce $\mathrm{NO}_{\mathrm{x}}$ to nitrogen and water. In one application of SNCR to an industrial wood-fired boiler, $\mathrm{NO}_{\mathrm{x}}$ reduction efficiencies varied between 35 and 75 percent as the ammonia-to- $\mathrm{NO}_{\mathrm{x}}$ ratio increased from 0.4 to 3.2 .

Emission factors and emission factor ratings for wood residue boilers are summarized in Tables 1.6-1, 1.6-2, 1.6-3, 1.6-4. The factors are presented on an energy basis (pound of pollutant per million Btu of heat input). Factors for wet wood represent facilities that burn wood residue with a 
moisture content of 20 percent or greater. Factors for dry wood represent wood residue with less than 20 percent moisture content. Cumulative particle size distribution data and associated emission factors are presented in Table 1.6-5. Uncontrolled and controlled size-specific emission factors are plotted in Figure 1.6-1.

\subsubsection{Updates Since the Fifth Edition}

The Fifth Edition was released in January 1995. Revisions to this section since that date are summarized below. For further detail, consult the background report for this section. This and other documents can be found on the CHIEF Web Site at http://www.epa.gov/ttn/chief/, or by calling the Info CHIEF Help Desk at (919)541-1000.

Supplement A, February 1996

- $\quad$ Significant figures were added to some PM and PM-10 emission factors.

- In the table with $\mathrm{NO}_{\mathrm{x}}$ and $\mathrm{CO}$ emission factors, text was added in the footnotes to clarify meaning.

Supplement B, October 1996

- $\quad \mathrm{SO}_{x}, \mathrm{CH}_{4}, \mathrm{~N}_{2} \mathrm{O}, \mathrm{CO}_{2}$, speciated organics, and trace elements emission factors were corrected.

- $\quad$ Several HAP emission factors were updated.

Supplement D, February 1998

- Table 1.6-1, the PM-10 and one PM emission factors were revised to present two significant figures and the PM-10 emission factor for wood-fired boilers with mechanical collectors without flyash reinjection was revised to $2.6 \mathrm{lb} /$ ton to reflect that these values are based on wood with 50\% moisture. A typographical error in the wet scrubber emission factor for PM-10 was corrected.

- Table 1.6-2, the $\mathrm{SO}_{\mathrm{x}}$ emission factors for all boiler categories were revised to $0.075 \mathrm{lb} /$ ton to reflect that these factors are based on wood with $50 \%$ moisture.

- $\quad$ Tables 1.6-4 and 1.6-5 were re-titled to reflect that the speciated organic and trace element analysis presented in these tables are compiled from wood-fired boilers equipped with a variety of PM control technologies.

Supplement D, August 1998

- $\quad$ Table 1.6-4, the emission factor for trichlorotrifluoroethane was removed. The phenol emission factor was corrected to $1.47 \mathrm{E}-04$; the phenanthrene factor was corrected to 5.02E-05; the chrysene factor was corrected to 4.52E-07; and, the polychlorinated dibenzo-p-furans factor was corrected to $2.9 \mathrm{E}-08$. 
Supplement E, February 1999

- In the footnotes of tables 1.6-1, 2, 3, 4, 5, 6, 7, some text was removed that described how to adjust the factors when burning wood with moisture and thermal content significantly different from $50 \%$ or $4500 \mathrm{Btu} / \mathrm{lb}$, respectively. The EPA is revising Section 1.6 and, in the interim, consistent with EPA's recommendations regarding proper use of AP-42, the EPA encourages users of the wood combustion emission factors to account for the specific assumptions included in the factors and to convert the factors to a thermal content basis (i.e., lb/MMBtu) to estimate emissions when burning wood that differs significantly from $4500 \mathrm{Btu} / \mathrm{lb}$ or $50 \%$ moisture.

Supplement G, July 2001

- $\quad$ All emission factors were revised and new factors were added. In some cases separate factors were developed for wet wood (greater than or equal to 20 percent moisture content) and dry wood (less than 20 percent moisture).

- $\quad$ Separate PM and NOx emission factors are provided for dry wood combustion.

- $\quad$ All emission factors have been converted to units of lb/MMBtu.

- $\quad$ PM emission factors are specified by fuel type and control device type but not by boiler type.

- $\quad \mathrm{NOx}, \mathrm{SOx}$ and $\mathrm{CO}$ emission factors are specified by fuel type and not by boiler type.

- $\quad$ Additional toxic emission factors have been added.

- $\quad$ The general quality rating for PM factors are higher than before.

- $\quad$ TOC and $\mathrm{CO} 2$ emission factors are specified by all wood types and not by boiler type.

- $\quad$ New Source Classification Codes (SCC) were assigned for dry wood.

March 2002

The VOC and TOC emission factors in Table 1.6-3 were calculated incorrectly. This has been corrected. The correct factors are 0.013 and 0.039 , respectively. 
Table 1.6-1. EMISSION FACTORS FOR PM FROM WOOD RESIDUE COMBUSTION ${ }^{\mathrm{a}}$

\begin{tabular}{|c|c|c|c|c|c|c|c|}
\hline \multirow[b]{2}{*}{ Fuel } & \multirow[b]{2}{*}{ PM Control Device } & \multicolumn{2}{|c|}{ Filterable PM } & \multicolumn{2}{|c|}{ Filterable PM- $10^{\mathrm{b}}$} & \multicolumn{2}{|c|}{ Filterable PM-2.5 } \\
\hline & & $\begin{array}{c}\text { Emission } \\
\text { Factor } \\
\text { (lb/MMbtu) } \\
\end{array}$ & $\begin{array}{l}\text { EMISSION } \\
\text { FACTOR } \\
\text { RATING } \\
\end{array}$ & $\begin{array}{l}\text { Emission } \\
\text { Factor } \\
\text { (lb/MMbtu) } \\
\end{array}$ & $\begin{array}{l}\text { EMISSION } \\
\text { FACTOR } \\
\text { RATING } \\
\end{array}$ & $\begin{array}{l}\text { Emission } \\
\text { Factor } \\
\text { (lb/MMbtu) } \\
\end{array}$ & $\begin{array}{c}\text { EMISSION } \\
\text { FACTOR } \\
\text { RATING } \\
\end{array}$ \\
\hline Bark/Bark and Wet Wood & No Control ${ }^{\mathrm{c}}$ & $0.56^{\mathrm{d}}$ & $\mathrm{C}$ & $0.50^{\mathrm{e}}$ & $\mathrm{D}$ & $0.43^{\mathrm{e}}$ & $\mathrm{D}$ \\
\hline Dry Wood & No Control $^{c}$ & $0.40^{\mathrm{f}}$ & A & $0.36^{\mathrm{e}}$ & $\mathrm{D}$ & $0.31^{\mathrm{e}}$ & $\mathrm{D}$ \\
\hline Wet Wood & No Control $^{\mathrm{c}}$ & $0.33^{\mathrm{g}}$ & A & $0.29^{\mathrm{e}}$ & $\mathrm{D}$ & $0.25^{\mathrm{e}}$ & $\mathrm{D}$ \\
\hline Bark & Mechanical Collector & $0.54^{\mathrm{h}}$ & $\mathrm{D}$ & $0.49^{\mathrm{e}}$ & $\mathrm{D}$ & $0.29^{\mathrm{e}}$ & $\mathrm{D}$ \\
\hline Bark and Wet Wood & Mechanical Collector & $0.35^{\mathrm{i}}$ & $\mathrm{C}$ & $0.32^{\mathrm{e}}$ & $\mathrm{D}$ & $0.19^{\mathrm{e}}$ & $\mathrm{D}$ \\
\hline Dry Wood & Mechanical Collector & $0.30^{\mathrm{j}}$ & A & $0.27^{\mathrm{e}}$ & $\mathrm{D}$ & $0.16^{\mathrm{e}}$ & $\mathrm{D}$ \\
\hline Wet Wood & Mechanical Collector & $0.22^{\mathrm{k}}$ & $\mathrm{A}$ & $0.20^{\mathrm{e}}$ & $\mathrm{D}$ & $0.12^{\mathrm{e}}$ & $\mathrm{D}$ \\
\hline All Fuels ${ }^{\mathrm{m}}$ & Electrolyzed Gravel Bed & $0.1^{\mathrm{m}}$ & $\mathrm{D}$ & $0.074^{\mathrm{e}}$ & $\mathrm{D}$ & $0.065^{\mathrm{e}}$ & $\mathrm{D}$ \\
\hline All Fuels ${ }^{\mathrm{m}}$ & Wet Scrubber & $0.066^{\mathrm{n}}$ & A & $0.065^{\mathrm{e}}$ & $\mathrm{D}$ & $0.065^{\mathrm{e}}$ & $\mathrm{D}$ \\
\hline All Fuels ${ }^{\mathrm{m}}$ & Fabric Filter & $0.1^{\circ}$ & $\mathrm{C}$ & $0.074^{\mathrm{e}}$ & $\mathrm{D}$ & $0.065^{\mathrm{e}}$ & \\
\hline All Fuels ${ }^{\mathrm{m}}$ & Electrostatic Precipitator & $0.054^{\mathrm{p}}$ & $\mathrm{B}$ & $0.04^{\mathrm{e}}$ & $\mathrm{D}$ & $0.035^{\mathrm{e}}$ & \\
\hline & & $\frac{\text { Condensible }}{\underline{\mathrm{PM}}}$ & & & & & \\
\hline All Fuels ${ }^{\mathrm{m}}$ & All Controls/No Controls & $0.017^{\mathrm{q}}$ & A & & & & \\
\hline
\end{tabular}


Table 1.6-1. (cont.)

a Units of $\mathrm{lb}$ of pollutant/million Btu (MMBtu) of heat input. To convert from lb/MMBtu to lb/ton, multiply by (HHV * 2000), where HHV is the higher heating value of the fuel, MMBtu/lb. CPM = Condensible Particulate Matter. These factors apply to Source Classification Codes (SCC) 1-0X-009-YY, where $\mathrm{X}=1$ for utilities, 2 for industrial, and 3 for commercial/institutional, and where $\mathrm{Y}=01$ for bark-fired boiler, 02 for bark and wet wood-fired boiler, 03 for wet wood-fired boiler, and 08 for dry wood-fired boiler.

b $\quad \mathrm{PM}-10=$ particulate matter less than or equal to 10 microns in aerodynamic diameter. PM-2.5 = particulate matter less than or equal to 2.5 microns in aerodynamic diameter. Filterable PM $=$ PM captured and measured on the filter in an EPA Method 5 (or equivalent) sampling train. Condensible PM = PM captured and measured in an EPA Method 202 (or equivalent) sampling train.

c Factor represents boilers with no controls, Breslove separators, Breslove separators with reinjection, and mechanical collectors with reinjection. Mechanical collectors include cyclones and multiclones.

d References 19-21, 88 .

Cumulative mass \% provided in Table 1.6-6 for Bark and Wet Wood-fired boilers multiplied by the Filterable PM factor.

References 22-32, 88 .

References 26, 33-36, 88 .

References 37, 38, 88.

References 26, 39-41, 88.

References 26, 27, 34, 42-54, 88.

Reference 55-57, 88.

All fuels = Bark, Bark and Wet Wood, Dry Wood, and Wet Wood.

References 27, 58, 88.

References 26, 59-66, 88.

References 26, 67-70, 88 .

References 26, 71-74, 88

References 19-21, 25, 28, 29, 31, 32, 36-41, 46, 51, 53-60, 62 - 65, 67-69, 72-75, 88. 
Table 1.6-2. EMISSION FACTORS FOR $\mathrm{NO}_{x}, \mathrm{SO}_{2}$, AND CO FROM WOOD RESIDUE COMBUSTION ${ }^{\mathrm{a}}$

\begin{tabular}{|c|c|c|c|c|c|c|}
\hline \multirow[b]{2}{*}{ Source Category $^{\mathrm{c}}$} & \multicolumn{2}{|c|}{$\mathrm{NO}_{X}{ }^{\mathrm{b}}$} & \multicolumn{2}{|c|}{$\mathrm{SO}_{2}{ }^{\mathrm{b}}$} & \multicolumn{2}{|c|}{$\mathrm{CO}^{\mathrm{b}}$} \\
\hline & $\begin{array}{c}\text { Emission } \\
\text { Factor } \\
\text { (lb/MMbtu) }\end{array}$ & $\begin{array}{c}\text { EMISSION } \\
\text { FACTOR } \\
\text { RATING }\end{array}$ & $\begin{array}{c}\text { Emission } \\
\text { Factor } \\
\text { (lb/MMBtu) }\end{array}$ & $\begin{array}{c}\text { EMISSION } \\
\text { FACTOR } \\
\text { RATING } \\
\end{array}$ & $\begin{array}{c}\text { Emission } \\
\text { Factor } \\
\text { (lb/MMbtu) }\end{array}$ & $\begin{array}{c}\text { EMISSION } \\
\text { FACTOR } \\
\text { RATING }\end{array}$ \\
\hline Bark/bark and wet wood/wet wood-fired boiler & $0.22^{\mathrm{d}}$ & A & $0.025^{\mathrm{e}}$ & A & $0.60^{\mathrm{f}, \mathrm{g}, \mathrm{i}, \mathrm{j}}$ & A \\
\hline Dry wood-fired boilers & $0.49^{\mathrm{h}}$ & $\mathrm{C}$ & $0.025^{\mathrm{e}}$ & A & $0.60^{\mathrm{f}, \mathrm{g}, \mathrm{i}, \mathrm{j}}$ & A \\
\hline
\end{tabular}

${ }^{a}$ Units of $\mathrm{lb}$ of pollutant/million Btu (MMBtu) of heat input. To convert from lb/MMBtu to lb/ton, multiply by (HHV * 2000), where HHV is the higher heating value of the fuel, MMBtu/lb. To convert lb/MMBtu to $\mathrm{kg} / \mathrm{J}$, multiply by $4.3 \mathrm{E}-10 . \mathrm{NO}_{\mathrm{x}}=\mathrm{Nitrogen}$ oxides, $\mathrm{SO}_{2}=\mathrm{Sulfur}$ dioxide, $\mathrm{CO}=$ Carbon monoxide.

${ }^{\mathrm{b}}$ Factors represent boilers with no controls or with particulate matter controls.

c These factors apply to Source Classification Codes (SCC) 1-0X-009-YY, where X $=1$ for utilities, 2 for industrial, and 3 for commercial/institutional, and where $\mathrm{Y}=01$ for bark-fired boiler, 02 for bark and wet wood-fired boiler, 03 for wet wood-fired boiler, and 08 for dry wood-fired boiler.

d References 19, 33, 34, 39, 40, 41, 55, 62-64, 67, 70, 72, 78, 79, 88-89.

e References 26, 45, 50, 72, 88-89.

References 26, 59, 88-89.

g References 19, 26, 39-41, 60-64, 67, 68, 70, 75, 79, 88-89.

h References 30, 34, 45, 50, 80, 81, 88-89.

i References 26, 30, 45-51, 80-82, 88-89.

j Emission factor is for stokers and dutch ovens/fuel cells. References 26, 34, 36, 55, 60, 65, 71, 72, 75. CO Factor for fluidized bed combustors is $\mathbf{0 . 1 7} \mathbf{~ l b} / \mathbf{M M b t u}$. References 26, 72, 88-89. 
Table 1.6-3. EMISSION FACTORS FOR SPECIATED ORGANIC COMPOUNDS, TOC, VOC, NITROUS OXIDE, AND CARBON DIOXIDE FROM WOOD RESIDUE COMBUSTION ${ }^{\mathrm{a}}$

\begin{tabular}{|c|c|c|}
\hline Organic Compound & $\begin{array}{c}\text { Average Emission Factor } \\
(\mathrm{lb} / \mathrm{MMBtu})\end{array}$ & EMISSION FACTOR RATING \\
\hline Acenaphthene & $9.1 \mathrm{E}-07^{\mathrm{c}}$ & $\mathrm{B}$ \\
\hline Acenaphthylene & 5.0 E-06 ${ }^{d}$ & A \\
\hline Acetaldehyde & $8.3{\mathrm{E}-04^{\mathrm{e}}}$ & A \\
\hline Acetone & $1.9 \mathrm{E}-04^{\mathrm{f}}$ & $\mathrm{D}$ \\
\hline Acetophenone & 3.2 E-09g & $\mathrm{D}$ \\
\hline Acrolein & 4.0 E-03 ${ }^{h}$ & $\mathrm{C}$ \\
\hline Anthracene & 3.0 E-06 & A \\
\hline Benzaldehyde & $<8.5{\mathrm{E}-07^{\mathrm{j}}}$ & $\mathrm{D}$ \\
\hline Benzene & $4.2{\mathrm{E}-03^{\mathrm{k}}}$ & A \\
\hline Benzo(a)anthracene & $6.5 \mathrm{E}-08^{1}$ & $\mathrm{~B}$ \\
\hline Benzo(a)pyrene & $2.6 \mathrm{E}^{-06^{\mathrm{m}}}$ & A \\
\hline Benzo(b)fluoranthene & $1.0 \mathrm{E}-07^{1}$ & $\mathrm{~B}$ \\
\hline Benzo(e)pyrene & $2.6 \mathrm{E}-09^{\mathrm{f}}$ & $\mathrm{D}$ \\
\hline Benzo(g,h,i)perylene & 9.3 E-08 ${ }^{n}$ & $\mathrm{~B}$ \\
\hline Benzo(j,k)fluoranthene & $1.6 \mathrm{E}-07^{\circ}$ & $\mathrm{D}$ \\
\hline Benzo(k)fluoranthene & 3.6 E-08 & $\mathrm{B}$ \\
\hline Benzoic acid & 4.7 E-08 ${ }^{q}$ & $\mathrm{D}$ \\
\hline bis(2-Ethylhexyl)phthalate & 4.7 E-08 & $\mathrm{D}$ \\
\hline Bromomethane & $1.5 E-05^{f}$ & $\mathrm{D}$ \\
\hline 2-Butanone (MEK) & 5.4 E-06 & $\mathrm{D}$ \\
\hline Carbazole & $1.8 \mathrm{E}-06^{\mathrm{f}}$ & $\mathrm{D}$ \\
\hline Carbon tetrachloride & $4.5{\mathrm{E}-05^{\mathrm{r}}}$ & $\mathrm{D}$ \\
\hline Chlorine & $7.9 \mathrm{E}-04^{\mathrm{s}}$ & $\mathrm{D}$ \\
\hline Chlorobenzene & $3.3{\mathrm{E}-05^{\mathrm{f}}}$ & $\mathrm{D}$ \\
\hline Chloroform & $2.8{\mathrm{E}-05^{\mathrm{f}}}$ & $\mathrm{D}$ \\
\hline Chloromethane & $2.3 E-05^{f}$ & $\mathrm{D}$ \\
\hline 2-Chloronaphthalene & 2.4 E-09 ${ }^{f}$ & $\mathrm{D}$ \\
\hline 2-Chlorophenol & 2.4 E-08 & $\mathrm{C}$ \\
\hline Chrysene & $3.8 \mathrm{E}-08^{\mathrm{c}}$ & $\mathrm{B}$ \\
\hline Crotonaldehyde & $9.9{\mathrm{E}-06^{\mathrm{j}}}$ & $\mathrm{D}$ \\
\hline Decachlorobiphenyl & $2.7 \mathrm{E}-10^{\mathrm{r}}$ & $\mathrm{D}$ \\
\hline Dibenzo(a,h)anthracene & 9.1 E-09 & $\mathrm{B}$ \\
\hline 1,2-Dibromoethene & $5.5{\mathrm{E}-05^{\mathrm{f}}}$ & $\mathrm{D}$ \\
\hline Dichlorobiphenyl & $7.4 \mathrm{E}-10^{\mathrm{r}}$ & $\mathrm{C}$ \\
\hline 1,2-Dichloroethane & $2.9 \mathrm{E}^{-05^{\mathrm{r}}}$ & $\mathrm{D}$ \\
\hline Dichloromethane & $2.9 \mathrm{E}-04^{v}$ & $\mathrm{D}$ \\
\hline 1,2-Dichloropropane & $3.3{\mathrm{E}-05^{\mathrm{f}}}$ & $\mathrm{D}$ \\
\hline 2,4-Dinitrophenol & $1.8 \mathrm{E}-07^{\mathrm{w}}$ & $\mathrm{C}$ \\
\hline Ethylbenzene & $3.1 \mathrm{E}-05^{\mathrm{f}}$ & $\mathrm{D}$ \\
\hline Fluoranthene & $1.6 \mathrm{E}-06^{\mathrm{x}}$ & B \\
\hline Fluorene & 3.4 E-06 & A \\
\hline Formaldehyde & $4.4{\mathrm{E}-03^{\mathrm{y}}}$ & A \\
\hline Heptachlorobiphenyl & $6.6 \mathrm{E}-11^{\mathrm{r}}$ & $\mathrm{D}$ \\
\hline
\end{tabular}


Table 1.6-3. (cont.)

\begin{tabular}{|c|c|c|}
\hline Organic Compound & $\begin{array}{c}\text { Average Emission Factor }{ }^{\mathrm{b}} \\
(\mathrm{lb} / \mathrm{MMBtu})\end{array}$ & EMISSION FACTOR RATING \\
\hline Hexachlorobiphenyl & $5.5 \mathrm{E}-10^{\mathrm{r}}$ & $\mathrm{D}$ \\
\hline Hexanal & $7.0 \mathrm{E}-06^{\mathrm{x}}$ & D \\
\hline Heptachlorodibenzo-p-dioxins & 2.0 E-09 ${ }^{\mathrm{aa}}$ & $\mathrm{C}$ \\
\hline Heptachlorodibenzo-p-furans & $2.4 \mathrm{E}-10^{\mathrm{aa}}$ & $\mathrm{C}$ \\
\hline Hexachlorodibenzo-p-dioxins & $1.6 \mathrm{E}-06^{\mathrm{aa}}$ & $\mathrm{C}$ \\
\hline Hexachlorodibenzo-p-furans & $2.8 \mathrm{E}-10^{\mathrm{aa}}$ & $\mathrm{C}$ \\
\hline Hydrogen chloride & $1.9 \mathrm{E}-02^{\mathrm{j}}$ & $\mathrm{C}$ \\
\hline Indeno( $1,2,3, \mathrm{c}, \mathrm{d})$ pyrene & $8.7 E-08^{1}$ & $\mathrm{~B}$ \\
\hline Isobutyraldehyde & $1.2 \mathrm{E}-05^{x}$ & $\mathrm{D}$ \\
\hline Methane & $2.1{\mathrm{E}-02^{\mathrm{f}}}$ & $\mathrm{C}$ \\
\hline 2-Methylnaphthalene & $1.6 \mathrm{E}-07^{\mathrm{z}}$ & $\mathrm{D}$ \\
\hline Monochlorobiphenyl & $2.2 \mathrm{E}-10^{\mathrm{r}}$ & $\mathrm{D}$ \\
\hline Naphthalene & $9.7 \mathrm{E}-05^{\mathrm{ab}}$ & A \\
\hline 2-Nitrophenol & $2.4 \mathrm{E}-07^{\mathrm{w}}$ & $\mathrm{C}$ \\
\hline 4-Nitrophenol & $1.1 \mathrm{E}-07^{\mathrm{w}}$ & $\mathrm{C}$ \\
\hline Octachlorodibenzo-p-dioxins & $6.6 \mathrm{E}-08^{\mathrm{aa}}$ & B \\
\hline Octachlorodibenzo-p-furans & $8.8 \mathrm{E}-11^{\text {aa }}$ & $\mathrm{C}$ \\
\hline Pentachlorodibenzo-p-dioxins & $1.5 \mathrm{E}-09^{\mathrm{aa}}$ & B \\
\hline Pentachlorodibenzo-p-furans & $4.2 \mathrm{E}-10^{\mathrm{aa}}$ & $\mathrm{C}$ \\
\hline Pentachlorobiphenyl & $1.2 \mathrm{E}-09^{\mathrm{r}}$ & $\mathrm{D}$ \\
\hline Pentachlorophenol & $5.1 \mathrm{E}-08^{\mathrm{ac}}$ & $\mathrm{C}$ \\
\hline Perylene & $5.2 \mathrm{E}-10^{\mathrm{f}}$ & $\mathrm{D}$ \\
\hline Phenanthrene & 7.0 E-06 ${ }^{\text {ad }}$ & B \\
\hline Phenol & $5.1 \mathrm{E}-05^{\mathrm{ae}}$ & $\mathrm{C}$ \\
\hline Propanal & $3.2 \mathrm{E}-06^{\mathrm{z}}$ & $\mathrm{D}$ \\
\hline Propionaldehyde & $6.1 \mathrm{E}-05^{\mathrm{f}}$ & $\mathrm{D}$ \\
\hline Pyrene & 3.7 E-06 ${ }^{\text {af }}$ & A \\
\hline Styrene & $1.9 E-03^{f}$ & $\mathrm{D}$ \\
\hline 2,3,7,8-Tetrachlorodibenzo-p-dioxins & $8.6 \mathrm{E}-12^{\mathrm{aa}}$ & $\mathrm{C}$ \\
\hline Tetrachlorodibenzo-p-dioxins & $4.7 \mathrm{E}-10^{\mathrm{ag}}$ & $\mathrm{C}$ \\
\hline 2,3,7,8-Tetrachlorodibenzo-p-furans & $9.0 \mathrm{E}-11^{\text {aa }}$ & $\mathrm{C}$ \\
\hline Tetrachlorodibenzo-p-furans & $7.5 \mathrm{E}-10^{\mathrm{aa}}$ & $\mathrm{C}$ \\
\hline Tetrachlorobiphenyl & $2.5 \mathrm{E}-09^{\mathrm{r}}$ & $\mathrm{D}$ \\
\hline Tetrachloroethene & $3.8{\mathrm{E}-05^{\mathrm{t}}}$ & $\mathrm{D}$ \\
\hline o-Tolualdehyde & $7.2{\mathrm{E}-06^{\mathrm{j}}}$ & $\mathrm{D}$ \\
\hline p-Tolualdehyde & $1.1{\mathrm{E}-05^{\mathrm{x}}}$ & $\mathrm{D}$ \\
\hline Toluene & $9.2 \mathrm{E}-04^{\mathrm{v}}$ & $\mathrm{C}$ \\
\hline Trichlorobiphenyl & $2.6 \mathrm{E}-09^{\mathrm{r}}$ & $\mathrm{C}$ \\
\hline 1,1,1-Trichloroethane & $3.1 \mathrm{E}-05^{\mathrm{t}}$ & $\mathrm{D}$ \\
\hline Trichloroethene & $3.0 \mathrm{E}-05^{\mathrm{t}}$ & $\mathrm{D}$ \\
\hline Trichlorofluoromethane & $4.1 \mathrm{E}-05$ & $\mathrm{D}$ \\
\hline 2,4,6-Trichlorophenol & $<2.2 \mathrm{E}-08^{\mathrm{ak}}$ & $\mathrm{C}$ \\
\hline
\end{tabular}


Table 1.6-3. (cont.)

\begin{tabular}{|c|c|c|}
\hline Organic Compound & $\begin{array}{c}\text { Average Emission Factor } \\
(\mathrm{lb} / \mathrm{MMBtu})\end{array}$ & EMISSION FACTOR RATING \\
\hline Vinyl Chloride & $1.8 \mathrm{E}-05^{\mathrm{r}}$ & $\mathrm{D}$ \\
\hline o-Xylene & $2.5{\mathrm{E}-05^{\mathrm{v}}}^{-}$ & $\mathrm{D}$ \\
\hline Total organic compounds (TOC) & $0.039^{\text {ai }}$ & $\mathrm{D}$ \\
\hline Volatile organic compounds (VOC) & $0.013^{\text {aj }}$ & $\mathrm{D}$ \\
\hline Nitrous Oxide $\left(\mathrm{N}_{2} \mathrm{O}\right)$ & $0.013^{\mathrm{ak}}$ & $\mathrm{D}$ \\
\hline Carbon Dioxide $\left(\mathrm{CO}_{2}\right)$ & $195^{\text {al }}$ & A \\
\hline
\end{tabular}

Units of $\mathrm{lb}$ of pollutant/million Btu (MMBtu) of heat input. To convert from lb/MMBtu to lb/ton, multiply by (HHV * 2000), where HHV is the higher heating value of the fuel, MMBtu/lb. To convert lb/MMBtu to $\mathrm{kg} / \mathrm{J}$, multiply by 4.3E-10. These factors apply to Source Classification Codes (SCC) 1-0X-009-YY, where X $=1$ for utilities, 2 for industrial, and 3 for commercial/institutional, and where $\mathrm{Y}=01$ for bark-fired boiler, 02 for bark and wet wood-fired boiler, 03 for wet wood-fired boiler, and 08 for dry wood-fired boiler.

b Factors are for boilers with no controls or with particulate matter controls.

c References 26, 34, 36, 59, 60, 65, 71-73, 75 .

d References 26, 33, 34, 36, 59, 60, 65, 71-73, 75 .

e References, 26, 35, 36, 46, 50, 59, 60, 65, 71-75.

f Reference 26.

g Reference 33.

h Reference 26, 50, 83.

References 26, 34, 36, 59, 60, 65, 71-73, 75.

References 26, 50.

References 26, 35, 36, 46, 59, 60, 65, 70, 71-75.

References 26, 36, 59, 60, 65, 70-75.

m References 26, 33, 36, 59, 60, 65, 70-73, 75.

n References 26, 33, 36, 59, 60, 65, 71-73, 75.

- Reference 34.

p References 26, 36, 60, 65, 71-75.

q References 26, 33.

r References 26.

s Reference 83.

t References 26, 72.

u References 35, 60, 65, 71, 72.

$\checkmark$ References 26, 72.

w References 35, 60, 65, 71, 72.

$x \quad$ References 26, 33, 34, 59, 60, 65, 71-75.

y References 26, 28, 35, 36, 46 - 51, 59, 60, 65, 70, 71-75, 79, 81, 82.

z Reference 50.

aa Reference 26, 45.

ab References 26, 33, 34, 36, 59, 60, 65, 71-75, 83.

ac References 26, 35, 60, 65, 71, 72 .

ad References 26, 33, 34, 36, 59, 60, 65, 71 - 73 .

ae References 26, 33, 34, 35, 60, 65, 70, 71, 72 .

af References 26, 33, 34, 36, 59, 60, 65, $71-73,83$.

ag References 26, 45.

ah References 26, 35, 60, 65, 71 .

ai $\mathrm{TOC}=$ total organic compounds. Factor is the sum of all factors in table except nitrous oxide and carbon dioxide.

aj VOC volatile organic compounds. Factor is the sum of all factors in table except hydrogen chloride, chlorine, formaldehyde, tetrachloroethene, 1,1,1,-trichloroethane, dichloromethane, acetone, nitrous oxide, methane, and carbon dioxide.

ak Reference 83.

al References 19 - 26, 33 - 49, 51- 57, 77, 79 - 82, 84 - 86. 
Table 1.6-4. EMISSION FACTORS FOR TRACE ELEMENTS

FROM WOOD RESIDUE COMBUSTION ${ }^{\mathrm{a}}$

\begin{tabular}{|c|c|c|}
\hline Trace Element & Average Emission Factor (lb/MMBtu) ${ }^{\mathrm{b}}$ & EMISSION FACTOR RATING \\
\hline Antimony & $7.9 \mathrm{E}-06^{\mathrm{c}}$ & $\mathrm{C}$ \\
\hline Arsenic & $2.2 \mathrm{E}-05^{\mathrm{d}}$ & A \\
\hline Barium & $1.7 \mathrm{E}-04^{\mathrm{c}}$ & $\mathrm{C}$ \\
\hline Beryllium & $1.1 \mathrm{E}-06^{\mathrm{e}}$ & $\mathrm{B}$ \\
\hline Cadmium & $4.1 E-06^{f}$ & A \\
\hline Chromium, total & 2.1 E-05 & A \\
\hline Chromium, hexavalent & 3.5 E-06 $^{\text {h }}$ & $\mathrm{C}$ \\
\hline Cobalt & $6.5 \mathrm{E}-06^{\mathrm{i}}$ & $\mathrm{C}$ \\
\hline Copper & $4.9 \mathrm{E}-05^{\mathrm{g}}$ & A \\
\hline Iron & $9.9{\mathrm{E}-04^{\mathrm{k}}}$ & $\mathrm{C}$ \\
\hline Lead & $4.8{\mathrm{E}-05^{1}}^{2}$ & A \\
\hline Manganese & $1.6{\mathrm{E}-03^{\mathrm{d}}}$ & A \\
\hline Mercury & $3.5 \mathrm{E}-06^{\mathrm{m}}$ & A \\
\hline Molybdenum & $2.1 \mathrm{E}-06^{\mathrm{c}}$ & $\mathrm{D}$ \\
\hline Nickel & $3.3 \mathrm{E}-05^{\mathrm{n}}$ & A \\
\hline Phosphorus & $2.7 \mathrm{E}-05^{\mathrm{c}}$ & $\mathrm{D}$ \\
\hline Potassium & $3.9 \mathrm{E}-02^{\mathrm{c}}$ & $\mathrm{D}$ \\
\hline Selenium & $2.8 \mathrm{E}-06^{\circ}$ & A \\
\hline Silver & $1.7 \mathbf{E}-03^{p}$ & D \\
\hline Sodium & $3.6 \mathrm{E}-04^{\mathrm{c}}$ & $\mathrm{D}$ \\
\hline Strontium & $1.0 \mathrm{E}-05^{\mathrm{c}}$ & $\mathrm{D}$ \\
\hline Tin & $2.3 \mathrm{E}-05^{\mathrm{c}}$ & D \\
\hline Titanium & $2.0 \mathrm{E}-05^{\mathrm{c}}$ & D \\
\hline Vanadium & $9.8 \mathrm{E}-07^{\mathfrak{c}}$ & D \\
\hline Yttrium & $3.0 \mathrm{E}-07^{\mathrm{c}}$ & D \\
\hline Zinc & $4.2 \mathrm{E}-04^{\circ}$ & $\mathrm{A}$ \\
\hline
\end{tabular}

a Units of $\mathrm{lb}$ of pollutant/million Btu (MMBtu) of heat input. To convert from lb/MMBtu to lb/ton, multiply by (HHV * 2000), where HHV is the higher heating value of the fuel, MMBtu/lb. To convert lb/MMBtu to $\mathrm{kg} / \mathrm{J}$, multiply by 4.3E-10. These factors apply to Source Classification Codes (SCC) 1-0X-009-YY, where X $=1$ for utilities, 2 for industrial, and 3 for commercial/institutional, and where $\mathrm{Y}=01$ for bark-fired boiler, 02 for bark and wet wood-fired boiler, 03 for wet wood-fired boiler, and 08 for dry wood-fired boiler.

b Factors are for boilers with no controls or with particulate matter controls.

c Reference 26.

d References 26, 33, 36, 46, 59, 60, 65, 71-73, 75, 81 .

e References 26, 35, 36, 46, 59, 60, 65, 71-73, 75 .

f References 26, 35, 36, 42, 46, 59, 60, 65, 71-73, 75, 81.

g References 26, 34, 35, 36, 42, 59, 60, 65, 71-73, 75, 81.

h References 26, 36, 46, 59, 60, 71, 72, 73, 75.

References 26, 34, 83.

References 26, 33-36, 46, 59, 60, 65, 71-73, 75, 81.

k References 26, 71, 72, 81.

1 References 26, 33-36, 46, 59, 60, 65, 71-73, 75.

m References 26, 35, 36, 46, 59, 60, 65, 71-73, 75, 81.

n References 26, 33 - 36, 46, 59, 60, 65, 71-73, 75, 81.

- References 26, 33, 35, 46, 59, 60, 65, 71-73, 75, 81.

p Reference 34. 
Table 1.6-5. CUMULATIVE PARTICLE SIZE DISTRIBUTION AND SIZE-SPECIFIC EMISSION FACTORS FOR WOOD/BARK-FIRED BOILERS ${ }^{\mathrm{a}}$

EMISSION FACTOR RATING: E

\begin{tabular}{|c|c|c|c|c|c|}
\hline \multirow[b]{3}{*}{$\begin{array}{l}\text { Particle Size } \\
\quad(\mu \mathrm{m})\end{array}$} & \multicolumn{5}{|c|}{ Cumulative Mass $\% \leq$ Stated Size } \\
\hline & \multirow[b]{2}{*}{ Uncontrolled $^{\mathrm{c}}$} & \multicolumn{4}{|c|}{ Controlled } \\
\hline & & $\begin{array}{l}\text { Multiple } \\
\text { Cyclone }^{\mathrm{d}}\end{array}$ & $\begin{array}{l}\text { Multiple } \\
\text { Cyclone }^{\mathrm{e}}\end{array}$ & Scrubber ${ }^{\mathrm{f}}$ & $\begin{array}{c}\text { Dry Electrostatic } \\
\text { Granular Filter (DEGF) }\end{array}$ \\
\hline 15 & 94 & 96 & 35 & 98 & 77 \\
\hline 10 & 90 & 91 & 32 & 98 & 74 \\
\hline 6 & 86 & 80 & 27 & 98 & 69 \\
\hline 1.00 & 67 & 24 & 6 & 95 & 58 \\
\hline 0.625 & ND & 16 & 3 & ND & 51 \\
\hline Total & 100 & 100 & 100 & 100 & 100 \\
\hline
\end{tabular}

Reference 89.

${ }^{\mathrm{b}}$ Expressed as aerodynamic equivalent diameter.

c From data on underfeed stokers. May also be used as size distribution for wood-fired boilers.

${ }^{\mathrm{d}}$ From data on spreader stokers with flyash reinjection.

e From data on spreader stokers without flyash reinjection.

${ }^{f}$ From data on Dutch ovens. Assumed control efficiency is $94 \%$. 


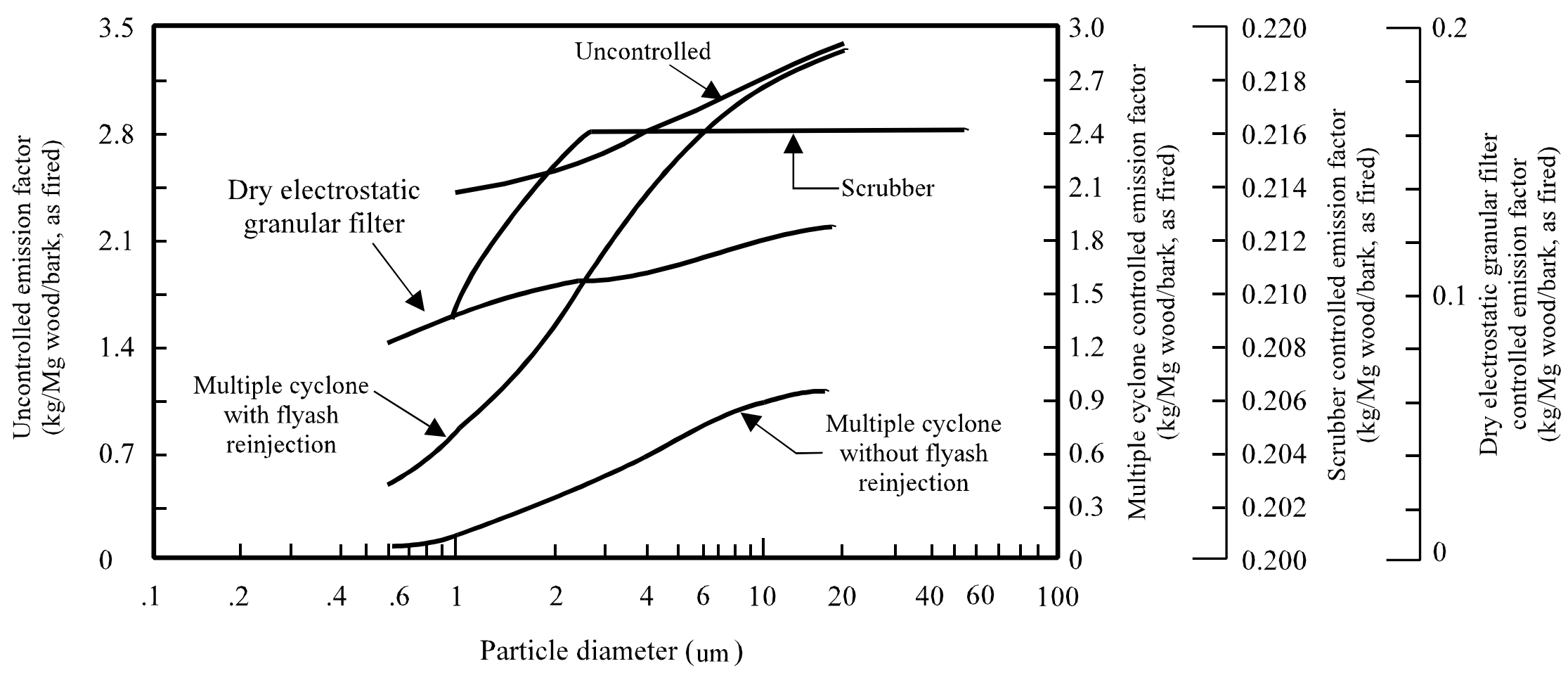

Figure 1.6-1. Cumulative size-specific particulate matter emission factors for wood/bark-fired boilers. 


\section{References For Section 1.6}

1. Emission Factor Documentation For AP-42 Section 1.6 - Wood Waste Combustion In Boilers, Technical Support Division, Office of Air Quality Planning and Standards, U. S. Environmental Protection Agency, Research Triangle Park, NC, April 1993.

2. $\quad$ Steam, 38th Edition, Babcock and Wilcox, New York, NY, 1972.

3. Atmospheric Emissions From The Pulp And Paper Manufacturing Industry, EPA-450/1-73-002, U. S. Environmental Protection Agency, Research Triangle Park, NC, September 1973.

4. C-E Bark Burning Boilers, C-E Industrial Boiler Operations, Combustion Engineering, Inc., Windsor, CT, 1973.

5. Nonfossil Fuel Fired Industrial Boilers - Background Information, EPA-450/3-82-007, U. S. Environmental Protection Agency, Research Triangle Park, NC, March 1982.

6. Industrial Combustion Coordinated Rulemaking Database, Version 5.1. Process data. U.S. Environmental Protection Agency, 1998.

7. Control Of Particulate Emissions From Wood-Fired Boilers, EPA 340/1-77-026, U. S. Environmental Protection Agency, Washington, DC, 1977.

8. Background Information Document For Industrial Boilers, EPA 450/3-82-006a, U. S. Environmental Protection Agency, Research Triangle Park, NC, March 1982.

9. $\quad$ E. F. Aul, Jr. and K. W. Barnett, "Emission Control Technologies For Wood-Fired Boilers", Presented at the Wood Energy Conference, Raleigh, NC, October 1984.

10. G. Moilanen, et al., "Noncatalytic Ammonia Injection For $\mathrm{NO}_{\mathrm{x}}$ Reduction on a Residue Wood Fired Boiler", Presented at the 80th Annual Meeting of the Air Pollution Control Association, New York, NY, June 1987.

11. "Information On The Sulfur Content Of Bark And Its Contribution $\mathrm{To}^{\mathrm{SO}} \mathrm{E}_{2}$ Emissions When Burned As A Fuel", H. Oglesby and R. Blosser, Journal Of The Air Pollution Control Agency, 30(7):769-772, July 1980.

12. Written communication from G. Murray, California Forestry Association, Sacramento, CA to E. Aul, Edward Aul \& Associates, Inc., Chapel Hill, NC, Transmittal of Wood Fired Boiler Emission Test, April, 24, 1992.

13. L. P. Nelson, L. M. Russell, and J. J. Watson, "Global Combustion Sources of Nitrous Oxide Emissions", Research Project 2333-4 Interim Report, Radian Corporation, Sacramento, CA, 1991.

14. Rebecca L. Peer, Eric P. Epner, and Richard S. Billings, Characterization Of Nitrous Oxide Emission Sources, EPA Contract No. 68-D1-0031, Research Triangle Park, NC, 1995. 
15. Steven D. Piccot, Jennifer A. Buzun, and H. Christopher Frey, Emissions And Cost Estimates For Globally Significant Anthropogenic Combustion Sources $\mathrm{Of} \mathrm{NO}_{x}, \mathrm{~N}_{2} \mathrm{O}, \mathrm{CH}_{4}, \mathrm{CO}$, And $\mathrm{CO}_{2}$, EPA Contract No. 68-02-4288, Research Triangle Park, NC, 1990.

16. G. Marland, and R. M. Rotty, Carbon Dioxide Emissions From Fossil Fuels: A Procedure For Estimation And Results For 1951-1981, DOE/NBB-0036 TR-003, Carbon Dioxide Research Division, Office of Energy Research, U.S. Department of Energy, Oak Ridge, TN, 1983.

17. Sector-Specific Issues And Reporting Methodologies Supporting The General Guidelines For The Voluntary Reporting Of Greenhouse Gases Under Section 1605(b) Of The Energy Policy Act Of 1992, Volume 2 of 3, U.S. Department of Energy, DOE/PO-0028, 1994.

18. R. A. Kester, Nitrogen Oxide Emissions From A Pilot Plant Spreader Stoker Bark Fired Boiler, Department of Civil Engineering, University of Washington, Seattle, WA, December 1979.

19. Stack Emission Test Report on Hogged Wood Fired Boilers 1,2 and 3 at Snow Mountain Pine of Oregon, LTD, Burns, Oregon. Horizon Engineering. May 4-5, 1993.

20. Air Emissions Test, on the Wood-Fired Boilers No. 4 and 6 at Nicolet Hardwood Corp., Laona, Wisconsin. Environmental Technology \& Engineering. June 10-11, 1990.

21. Boiler Emission Test at Nicolet Hardwood Corp., Laona, Wisconsin. Badger Laboratories \& Engineering. June 25, 1992.

22. Particulate Emissions Test. Boiler Number 1. Thomasville Furniture Industries, Inc. West Jefferson, North Carolina. PACE, Inc. April 16, 1991.

23. No title. Tests performed at Thomasville Furniture Industries Plant C, Thomasville, NC., by Entropy Environmentalists on May 25, 1978.

24. No title. Tests performed at Thomasville Furniture Industries, Winston Salem, NC., by Entropy Environmentalists on April 23/24, 1980.

25. Report to A.A. Laun Furniture Co., Kiel, Wisconsin, for Particulate \& Formaldehyde Emissions Testing, Wood-Fired Boiler. Environmental Technology \& Engineering Corp. March 30, 1995.

26. Industrial Combustion Coordinated Rulemaking (ICCR) Emissions Test database, Version 5.0. Emissions data. U.S. Environmental Protection Agency, Research Triangle Park, NC. 1998.

27. Information Submitted to EPA by Laura Herbert and Steve Maynard, North Carolina Department of Environment and Natural Resources. January 26, 1999.

28. Boiler Emission Test at Banks Hardwood, Menomonie, Wisconsin. Badger Laboratories \& Engineering. May 25, 1994.

29. Brown County Cabinet Company Boiler Emission Test at Green Bay, WI. Badger Laboratories \& Engineering. November 6, 1996.

30. Results of the November 16, 1993 State Air Emission Tests of the Cleaver Brooks Boiler at the Eggers Industries Plant Located in Two Rivers, Wisconsin. Interpoll Laboratories, Inc. February $1,1994$. 
31. Results of the April 20, 1995 Particulate Emission Compliance Test on the Wood-Fired Boiler at the Dresser Lumber \& Tie Plant, Haywood, Wisconsin. Interpoll Laboratories. April 20, 1995.

32. Boiler Emission Test at America Excelsior Company, Marinette, Wisconsin. Badger Laboratories \& Engineering. December 20, 1994.

33. Hazardous Air Emissions Potential From A Wood-Fired Furnace (and attachments). A.J. Hubbard, Wisconsin Department of Natural Resources. Madison, WI. July 1991.

34. Environmental Assessment of a Wood-Residue-Fired Industrial Watertube Boiler. Acurex Corporation. November 1982.

35. Source Emission Testing of the Wood-fired Boiler at Big Valley Lumber Company, Bieber, California. Galson Technical Services, Inc. February, 1991.

36. Source Emission Testing of the CE Wood-Fired Boiler at Roseburg Forest Products (TAC Site \#3). Performed for the Timber Association of California. Galston Technical Services. January, 1991.

37. Boiler Emission Test at Nagel Lumber Company, Land O'Lakes, Wisconsin. Badger Laboratories \& Engineering. July 2, 1996.

38. Boiler Emission Test at Nagel Lumber Company, Land O'Lakes, Wisconsin. Badger Laboratories \& Engineering. April 19, 1996.

39. Stack Emission Test Report on Hogged Wood Fired Boiler \# 5 at Snow Mountain Pine of Oregon, LTD, Burns, Oregon. Horizon Engineering. December 1, 1992.

40. Source Emission Evaluation on Hogged Fuel Boiler \# 2 at International Paper Company, Gardiner, Oregon. AMTEST Air Quality, Inc. November 12, 1993.

41. Source Emission Evaluation on Boiler \# 1 Outlet and Boiler \# 2 Outlet at Bohemia Inc., Gardiner, Oregon. AMTEST Air Quality, INC. May 15-16 1990.

42. Stationary Source Sampling Report for Lexington Furniture Industries Plant Number 10, Hildebran, North Carolina. ABCO Boiler Stack. Trigon Engineering Consultants, Inc. December, 1993.

43. Stationary Source Sampling Report. Lexington Furniture Industries Plant Number 11, Mocksville, North Carolina. Entropy Environmentalists. August 15 and 16, 1991.

44. Stationary Source Sampling Report for Lexington Furniture Industries, Spruce Pine, North Carolina. Trigon Engineering Consultants, Inc. December, 1995.

45. Stationary Source Sampling Report. ERG Reference No. 0539. Emissions Testing For: Carbon Monoxide; Dioxins; Furans; Nitrogen Oxides; Particulate (PM-10); Sulfur Dioxide; Total Hydrocarbons. Environmental Technical Group, Inc. May 19, 1998. 
46. Source Emission Testing of the Wood-Fired Boiler "C" Exhaust at Bohemia, Inc. Rocklin, California. Performed for the Timber Association of California. Galston Technical Services. December, 1990.

47. Results of the July 7, 1993 Air Emission Compliance Testing on the Wood-fired Boiler at the Ashley Furniture Facility, Arcadia, Wisconsin. Interpoll Laboratories, Inc. August 16, 1993.

48. Results of the April 14, 1994 Air Emission Compliance Testing on the Wood-fired Boiler at the Ashley Furniture Facility, Arcadia, Wisconsin. Interpoll Laboratories, Inc. May 11, 1994.

49. Results of the October 27, 1994 Air Emission Compliance Testing of the Boiler at the Endeavor Hardwoods Facility, Lyndon Station, Wisconsin. Interpoll Laboratories, Inc. November 16, 1994.

50. Source Test Report. Source Emission Testing of the Wood-fired Boiler at Ethan Allen, Inc.Mayville Division. Mayville, New York. Galson Corporation. May 13, 1994.

51. Results of the October 27, 1994 Air Emission Compliance Test of the Boiler at the Endevor Hardwoods Facility, Lyndon Station, Wisconsin. Interpoll Laboratories. October 27, 1994.

52. Results of the November 10, 1994 Air Emission Compliance Testing on the Wood-Fired Boiler at the Ashley Furniture Facility, Arcadia, Wisconsin. Interpoll Laboratories, Inc. December 2, 1994.

53. Report to Laminated Products, Inc. Kenosha, Wisconsin for Particulate Emissions Testing Wood-Fired Boiler, May 31, 1994. Environmental Technology \& Engineering Corp. July 7 , 1994.

54. Report to Laminated Products, Inc. Kenosha, Wisconsin for Particulate Emissions Testing Wood-Fired Boiler, September 2, 1994. Environmental Technology \& Engineering Corp. September 19, 1994.

55. Source Emission Evaluation on Wellons Boiler Exhaust Stack at WTD Industries-Trask River Lumber Company, Tillamook, Oregon. AMTEST Air Quality, INC. August 30, 1995.

56. Wood Fired Boiler Emission Test at Marion Plywood Corp., Marion, Wisconsin. Badger Laboratories \& Engineering. September 2 \& 3, 1992.

57. Wood Fired Boiler Emission Test at Marion Plywood Corp., Marion, Wisconsin. Badger Laboratories \& Engineering. August 11, 1992.

58. Results of the January 18, 1990 Particulate Emission Compliance Test on the Konus Common Stack at the Louisiana Pacific Corporation Facility, Hayward, Wisconsin. Pace Laboratories, Inc. January 18, 1990.

59. Source Emission Testing of the Wood-Fired Boiler \#3 Exhaust at Georgia Pacific, Fort Bragg, California. Performed for the Timber Association of California. Galston Technical Services. February, 1991. 
60. Source Emission Testing of the Wood-Fired Boiler \#5 Exhaust at Roseburg Forest Products, Anderson, California. Performed for the Timber Association of California. Galston Technical Services. February, 1991.

61. Emission Test Report on the Hogged Fuel Fired Boiler at Tillamook Lumber Company, Tillamook, Oregon. Horizon Engineering. December 20, 1994.

62. Emission Test Report on Wood Residue Boiler at Timber Products, Medford, Oregon. BWR Associates, Inc. July 22, 1993.

63. Emission Test Report on Wood Residue Boiler at Timber Products, Medford, Oregon. BWR Associates, Inc. November 18, 1993.

64. Emission Test Report on Wood Waste Boiler at Timber Products, Medford, Oregon. BWR Associates, Inc. March 26, 1991.

65. Source Emission Testing of the Wood-fired Boiler At Catalyst Hudson, Inc., Anderson, California. Galson Technical Services, Inc. February, 1991.

66. Results of the May 18, 1988 Particulate and Carbon Monoxide Emission Compliance Test on the No.1 Boiler at the Norenco Cogeneration Facility, Ladysmith, Wisconsin. Interpoll Laboratories. May 19, 1988.

67. Emission Test Report on Wood Waste Boilers at Stone Forest Industries, White City, Oregon. BWR Associates, Inc. December 21, 1992.

68. Results of the February 1, 1994 Air Emission Compliance Test on the GEKA Common Stack at the Louisiana Pacific Waferboard Plant, Tomahawk, Wisconsin. Interpoll Laboratories, Inc. February 1, 1994.

69. Report to Laminated Products, Inc. Kenosha, Wisconsin for Particulate Emissions Testing Wood-Fired Boiler, July 7, 1995. Environmental Technology \& Engineering Corp. July 17, 1995.

70. Results of the August 17-19, 1993 Air Emission Compliance Test at the Louisiana Pacific Waferboard Plant, Tomahawk, Wisconsin. Interpoll Laboratories, Inc. August 17-19, 1993.

71. Source Emission Testing of the Wood-Fired Boiler Exhaust at Sierra Pacific, Burney, California. Performed for the Timber Association of California. Galston Technical Services. February, 1991.

72. Source Emission Testing of the Wood-Fired Boiler \#1 Exhaust Stack at Wheelabrator Shasta Energy Company (TAC Site 9), Anderson, California. Performed for the Timber Association of California. Galston Technical Services. January, 1991.

73. Source Emission Testing of the Wood-Fired Boiler " $C$ " Exhaust at Pacific Timber, Soctia, California. Performed for the Timber Association of California. Galston Technical Services. February, 1991. 
74. Source Emission Testing of the Wood-Fired Boiler at Yanke Energy, North Fork, California.

Performed for the Timber Association of California. Galston Technical Services. January, 1991.

75. Source Emission Testing of the Wood-Fired Boiler Exhaust at Miller Redwood Company, Crescent City, California. Performed for the Timber Association of California. Galston Technical Services. February, 1991.

76. Nitrogen Oxide Emissions from a Pilot Plant Spreader Stoker Bark Fired Boiler. R.A. Kester, Department of Civil Engineering. University of Washington, Seattle, WA. December, 1979.

77. Stack Emission Test Report on Hogged Wood Fired Boiler Plant at Champion International Corporation, Roseburg, Oregon. Horizon Engineering. August 19, 1991.

78. American Furniture Manufacturers Association Test Report. Determination of Nitrogen Oxide and Carbon Monoxide Emissions. September 22, 23, and 24, 1998. Air Monitoring Specialists. September, 1998.

79. Results of the April 20 \& 21,1993 Air Emission Tests on the Cleaver Brooks and Kidwell Wood-Fired Boilers at the Eggers Industries Plant in Two Rivers, Wisconsin. Interpoll Laboratories, Inc. May 25, 1993.

80. Report to Eggers Industries, Inc., Two Rivers, Wisconsin for Stack Emission Test, West Plant Wood-Fired Boiler. Environmental Technology And Engineering Corporation. August 5, 1997.

81. Test Report Prepared for American Furniture Manufacturing Association. Air Monitoring Specialists, Inc. December, 1996.

82. Emission Test Program on the Wood-Fired Boiler at Goodman Forest Industries, Ltd. Goodman, Wisconsin. Air Environmental. Inc. December 14, 1995.

83. Emission Factor Documentation for AP-42 Section 1.6- Wood Waste Combustion in Boilers. Technical Support Division, Office of Air Quality Planning and Standards. U.S. Environmental Protection agency. Research Triangle Part, NC. April, 1993.

84. Report to Eggers Industries, Inc., Two Rivers, Wisconsin for Stack Emission Test, West Plant Wood-Fired Boiler. Environmental Technology And Engineering Corporation. February 27, 1996.

85. Lamico, Inc., Emission test at 474 Mariod Road, Oshkosh, WI, October 5 \& 6, 1989. Badger Laboratories \& Engineering Co., Inc. November 1, 1989.

86. Cleaver-Brooks Boiler Stack Particulate Emission Testing on November 8, 1994. Environmental Services of America, Inc. December 7, 1994.

87. Inhalable Particulate Source Category Report for External Combustion Sources, EPA Contract No. 68-02-3156, Acurex Corporation, Mountain View, CA, January 1985.

88. Oregon Department of Environmental Quality Database, Process data. State of Oregon, 2001.

89. Wood Products in The Waste Stream - Characterization and Combustion Emissions, U.S. Environmental Protection Agency, Control Technology Center, October 1996. 


\section{REPORT DOCUMENTATION PAGE}

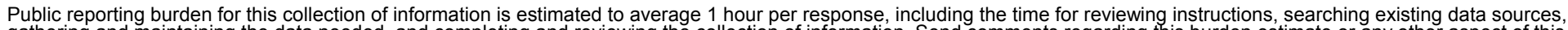
gathering and maintaining the data needed, and completing and reviewing the collection Davis Highway, Suite 1204, Arlington, VA 22202-4302, and to the Office of Management and Budget, Paperwork Reduction Project (0704-0188), Washington, DC 20503.
1. AGENCY USE ONLY (Leave blank)
2. REPORT DATE
March 2003
3. REPORT TYPE AND DATES COVERED
Technical Paper

\section{TITLE AND SUBTITLE}

Biopower Technical Assessment: State of the Industry and the Technology

5. FUNDING NUMBERS

6. $\operatorname{AUTHOR}(\mathrm{S})$

R.L. Bain, W.A. Amos, M. Downing, R.L. Perlack

7. PERFORMING ORGANIZATION NAME(S) AND ADDRESS(ES)

National Renewable Energy Laboratory

8. PERFORMING ORGANIZATION

1617 Cole Blvd.

Golden, CO 80401-3393

BBB3.6110

(Golden, c0 80401-3393

9. SPONSORING/MONITORING AGENCY NAME(S) AND ADDRESS(ES)

10. SPONSORING/MONITORING AGENCY REPORT NUMBER

11. SUPPLEMENTARY NOTES
12a. DISTRIBUTION/AVAILABILITY STATEMENT
National Technical Information Service
U.S. Department of Commerce
5285 Port Royal Road
Springfield, VA 22161

13. ABSTRACT (Maximum 200 words)

This report provides an assessment of the state of the biopower industry and the technology for producing electricity and heat from biomass.

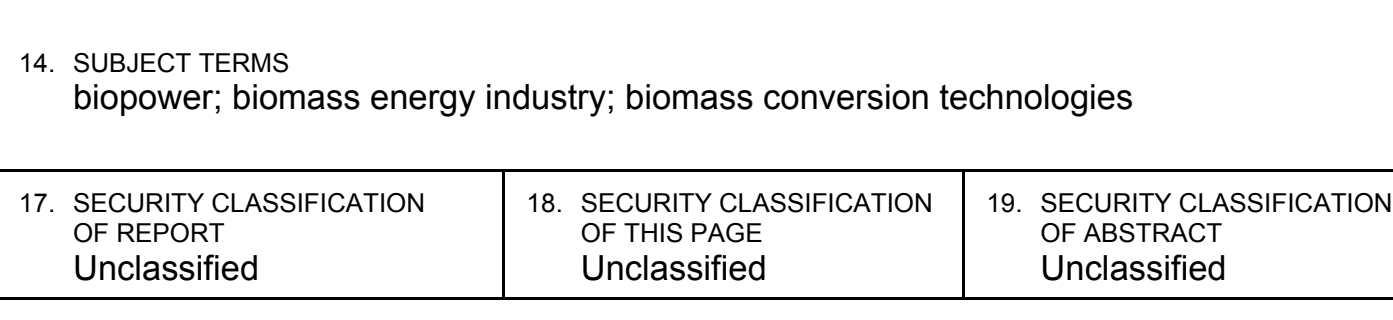

NSN 7540-01-280-5500 12b. DISTRIBUTION CODE

15. NUMBER OF PAGES

16. PRICE CODE

20. LIMITATION OF ABSTRACT

UL 